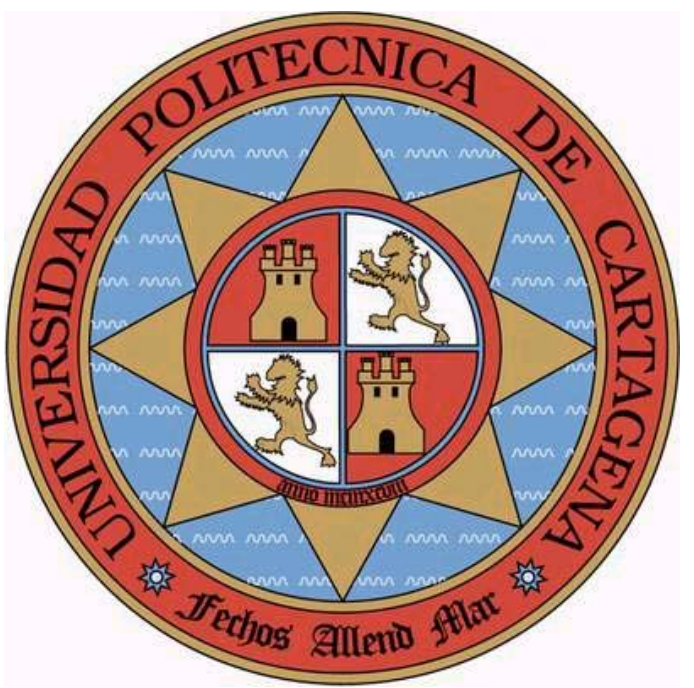

UNIVERSIDAD POLITÉCNICA DE CARTAGENA DEPARTAMENTO DE INGENIERÍA QUÍMICA Y AMBIENTAL

\title{
MODELOS PREDICTIVOS DE LA CONCENTRACIÓN POLÍNICA EN LA ATMÓSFERA DE CARTAGENA (1993-1999)
}


A Nerea que me soporta todos los días, y que tanto ha hecho por mí. 


\section{AGRADECIMIENTOS}

Aunque parezca increíble he de confesar que es esta la parte que me resulta más difícil, entre otras cosas, porque es la última ya estoy muy cansado, y por otro lado, porque son muchas las personas que han contribuido de una forma directa o indirecta a que este trabajo vaya llegando al final. Por ello, de antemano pido disculpas a aquellas personas que no mencione con el detalle que debería o que incluso no cite, puesto que ello es resultado de la confianza, olvido, cansancio, etc. De todas formas, quisiera expresar mi gratitud a las siguientes personas e instituciones:

- En primer lugar, y de forma conjunta, puesto que me resulta a veces diferenciar y establecer un orden, a los Doctores Dña. Stella Moreno Grau y D. Joaquín Moreno Clavel, puesto que no sólo me han ayudado y han puesto toda la dedicación necesaria para que haya podido finalizar este trabajo, sino que también han contribuido a que actualmente forme parte del grupo de trabajo que han constituido con mucho esfuerzo y empeño, y que ambos lideran actualmente. También quisiera aprovechar la ocasión, para pedirles perdón por esas veces que uno se desespera, se pone nervioso, se agobia, etc. Así que espero que lo entiendan y decirles de nuevo, que muchas gracias.

- En segundo lugar, al Departamento de Ingeniería Química y Ambiental, del que me siento muy orgulloso de formar parte en la actualidad, y especialmente a D. José Antonio Cascales y D. Enrique Solano, por facilitarme en todo momento el trabajo.

- A la Fundación Séneca, por la financiación de una beca predoctoral de Formación del Personal Investigador, lo que supuso desde octubre de 1996 a diciembre de 1999, mi soporte económico para subsistir y hacer frente a este trabajo.

- A Javier por su inestimable ayuda en los recuentos polínicos, por soportar mis reiteradas quejas y por su disposición en todo momento a todas las tareas con las que me he enfrentado. 
- A Belén y Sele, por su ayuda en los recuentos polínicos, así como en múltiples tareas como traducciones, problemas informáticos, librarme de otras tareas, etc.

- A Loren, por sus consejos, anécdotas, por tantas tardes que hemos pasado juntos contándonos las penas, aunque estoy completamente seguro que nunca llegaremos a ver los "modelos" desde la misma perspectiva.

- A todos los miembros del grupo de Investigación, D. Joaquín Serrano, D. Lorenzo Vergara Juárez, D. Andrés Pérez, D. José Molina, ...., puesto que han contribuido directa o indirectamente con su conocimiento, consejos, humor, etc., a que el camino a recorrer haya sido más corto y agradable.

- A la Doctora Suárez Cervera, nuestra maestra en Aerobiología y amiga.

- Al Doctor D. Antonio García Sánchez, por responder a los cientos de dudas estadísticas que nos han ido surgiendo a lo largo de este trabajo.

- A los profesores del Departamento de Matemática Aplicada y Estadística, y especialmente a Dña. Pilar Sanmartín, Antonio Guillamón y Mathieu Kessler, por el rigor y atención con la que han respondido a cuantas preguntas les hemos formulado.

- Al Servicio de Medio Ambiente del Excmo. Ayuntamiento de Cartagena, que toma las muestras aerobiológicas y por el suministro de los datos meteorológicos utilizados, así como por su amabilidad y lo resolutivos que han estado.

- Al profesor Peter Scheff, por su gran ayuda prestada en numerosas cuestiones estadísticas y sobre todo por su colaboración en el desarrollo de los modelos ARIMA.

- Al Personal de la Biblioteca de la UPCT, por la eficacia y rapidez que siempre han mostrado, ante alguna petición o duda bibliográfica. 
- Al personal de Reprografía, especialmente a Isabel y Pedro, por su gran ayuda y rapidez en el servicio.

- Y en último lugar, pero no por ello menos importante, a mis padres, a mis hermanas, a mis sobrinos, a Salva, a Noa,...., por todo lo que han supuesto y suponen para mí. 
ÍNDICE 


\section{ÍNDICE}

PÁGINAS

ÍNDICE............................................................ 1

1.-INTRODUCCIÓN...................................................... 11

2.-OBJETIVOS...................................................... 19

3.-ANTECEDENTES BIBLIOGRÁFICOS....................................... 23

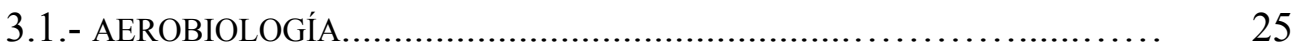

3.1.1. INTRODUCCIÓN.......................................... 25

3.1.2. APLICACIONES AEROBIOLÓGICAS EN MEDICINA................ 29

3.1.3. APLICACIONES AEROBIOLÓGICAS EN AGRICULTURA.......... $\quad 30$

3.1.4. APLICACIONES AEROBIOLÓGICAS EN EL BIODETERIORO..... 31

3.1.5. APLICACIONES AEROBIOLÓGICAS EN BIOGEOGRAFÍA Y

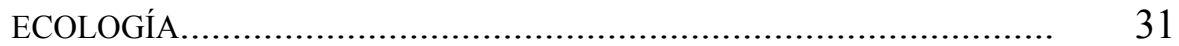

3.2. CARACTERÍSTICAS GENERALES DEL GRANO DE POLEN................ 32

3.2.1.PRINCIPALES CARACTERÍSTICAS MORFOLÓGICAS DEL GRANO DE POLEN....................................................... 34

3.3.CALENDARIOS POLÍNICOS....................................... 35

3.4. MODELIZACIÓN AMBIENTAL ........................................ 38

3.4.1.INTRODUCCIÓN................................................... 38

3.4.2.LA MODELIZACIÓN COMO HERRAMIENTA DE GESTIÓN

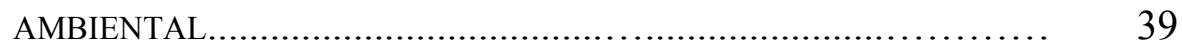

3.4.3. GENERALIDADES SOBRE MODELOS............................. 43

3.4.4.ELEMENTOS EN LA MODELIZACIÓN.............................. 46

3.4.5. PASOS EN EL PROCESO DE MODELIZACIÓN........................ 47

3.4.6. ETAPAS EN LA CONSTRUCCIÓN DE UN MODELO................... 48

3.4.7. PROBLEMAS DE LOS MODELOS DE CALIDAD DEL AIRE......... 51

3.4.8. CLASIFICACIÓN Y TIPOS DE MODELOS............................ 52

3.4.9. MODELIZACIÓN EN AEROBIOLOGÍA.................................... 59

3.5. METEOROLOGÍA Y NIVELES DE INMISIÓN........................................ 71

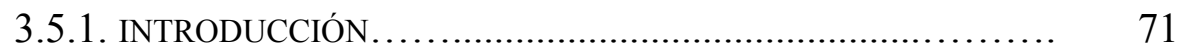

3.5.2. COMPOSICIÓN DE LA ATMÓSFERA................................... 72

3.5.3. LA ATMÓSFERA TERRESTRE............................................. 74

3.5.4. RADIACIÓN SOLAR............................................ 78 
3.5.5. VARIACIONES ESTACIONALES

3.5.6. MOVIMIENTO ATMOSFÉRICO HORIZONTAL......................... 84

3.5.7. MOVIMIENTO VERTICAL EN LA ATMÓSFERA...................... 88

3.5.8. TRANSPORTE Y DISPERSIÓN DE CONTAMINANTES EN LA ATMÓSFERA

3.5.8.1. INVERSIONES POR RADIACIÓN

3.5.8.2. INVERSIONES POR SUBSIDENCIA. 93

3.5.8.3. BRISAS 94

3.5.8.4. EFECTOS TOPOGRÁFICOS MENORES

3.6. LIBERACIÓN, TRANSPORTE, DISPERSIÓN Y DEPOSICIÓN DE POLEN EN LA ATMÓSFERA.

96

3.6.1. PRODUCCIÓN DE POLEN.

96

3.6.2. LIBERACIÓN DE POLEN.

100

3.6.3. TRANSPORTE ATMOSFÉRICO...

100

3.6.4. DEPOSICIÓN DE POLEN EN LA ATMÓSFERA Y MUESTREO.

101

3.7. FACTORES QUE INFLUYEN EN EL TRANSPORTE Y DISPERSIÓN DE LA FRACCIÓN BIÓTICA DEL AEROSOL ATMOSFÉRICO.

104

3.7.1. FENOLÓGICOS.

104

3.7.2. VEGETACIÓN.

105

3.7.3. TEMPERATURA

105

3.7.4. PRECIPITACIONES

107

3.7.5. HUMEDAD RELATIVA

109

3.7.6. RADIACIÓN SOLAR. 109

3.7.7. VIENTO.

110

3.7.8. SITUACIONES CLIMATOLÓGICAS 110

3.7.9. SITUACIÓN DEL CAPTADOR.

3.8. CLASIFICACIÓN DE SITUACIONES METEOROLÓGICAS TIPO MEDIANTE DE CLUSTERS.

3.8.1. INTRODUCCIÓN.

3.8.2. APLICACCIONES DE LA CLASIFICACIÓN CLIMATOLÓGICA EN LOS ESTUDIOS AMBIENTALES.

3.8.3.MEDIDAS DE PROXIMIDAD PARA AGRUPAR LOS DATOS 
METEOROLÓGICOS

3.8.4. CLASIFICACIÓN DE LOS MÉTODOS DE ANÁLISIS DE CLUSTER

3.8.4.1. MÉTODOS JERÁRQUICOS

3.8.4.2. MÉTODOS NO JERÁRQUICOS

124

3.8.5. PROCEDIMIENTO DE CLASIFICACIÓN.

125

3.8.6. ANÁLISIS DE COMPONENTES PRINCIPALES

126

4. MATERIALES Y MÉTODOS.

131

4.1. DATOS AEROBIOLÓGICOS.

133

4.1.1. MÉTODO DE CAPTACIÓN.

4.1.2. PRINCIPIO DE CAPTACIÓN..

4.1.3. IDENTIFICACIÓN DE PÓLENES.

4.2. DATOS METEOROLÓGICOS.

4.2.1. FUENTES DE DATOS METEOROLÓGICOS

4.2.2. MÉTODOS INSTRUMENTALES DE MEDIDA EN CONTINUO DE PARÁMETROS METEOROLÓGICOS.

136

4.2.2.1. ANEMOCINAMÓMETRO

136

4.2.2.2. SENSOR CONVERTIDOR DE TEMPERATURA Y HUMEDAD RELATIVA

4.2.2.3. BAROTRANSMISOR PASCAL

4.2.2.4. SENSOR DE RADIACIÓN SOLAR GLOBAL.

4.3. CONSTRUCCIÓN DE LAS BASES DE DATOS.

4.3.1. BASE DE DATOS AEROBIOLÓGICA.

4.3.2. BASE DE DATOS METEOROLÓGICA 1993-1994.

4.3.3. BASE DE DATOS METEOROLÓGICA 1995-1999.

4.3.4. BASE DE DATOS METEOROLÓGICA Y AEROBIOLÓGICA 1993-1999.

4.4. TRATAMIENTO ESTADÍSTICO DE LOS DATOS

4.4.1. ESTUdio ESTADístico DE METEOROLOGÍA Y PÓLENES.

4.5. CLASIFICACIÓN DE LAS SITUACIONES CLIMATOLÓGICAS PARA LA CIUDAD DE CARTAGENA.

4.5.1. METODOLOGÍA. 
4.5.2. CLASIFICACIÓN EN CLUSTERS DE LOS AÑOS 19951997.

4.6. MODELOS DE REGRESIÓN LINEAL MÚLTIPLE Y DE REGRESIÓN LOGÍSTICA

4.7. MODELOS ARIMA

5.1. CONCENTRACIONES POLÍNICAS DE LA CIUDAD DE CARTAGENA DURANTE LOS AÑOS 1993-1999

5.1.1. PÓLENES TOTALES.

5.1.2. CONCENTRACIONES POLÍNICAS DE CHENOPODIACEAEAMARANTHACEAE DURANTE 1993-1999

5.1.3. EVOLUCIÓN DE LAS CONCENTRACIONES POLÍNICAS TOTALES Y DE CHENOPODIACEAE-AMARANTHACEAE DURANTE LOS AÑOS 1993-1999

5.2. METEOROLOGÍA DE LA CIUDAD DE CARTAGENA DURANTE LOS AÑOS 1993-1999.

5.3. METEOROLOGÍA Y PÓLENES

5.3.1. VARIABLES METEOROLÓGICAS Y CONCENTRACIONES POLÍNICAS TOTALES

5.3.1.1. PRESIÓN Y CONCENTRACIÓN POLÍNICA TOTAL DIARIA ESTANDARIZADA.

5.3.1.2. VELOCIDAD DEL VIENTO Y CONCENTRACIÓN POLÍNICA TOTAL DIARIA ESTANDARIZADA.

5.3.1.3. DIRECCIÓN DEL VIENTO Y CONCENTRACIÓN POLÍNICA TOTAL DIARIA ESTANDARIZADA.

5.3.1.4.PRECIPITACIONES Y CONCENTRACIÓN POLÍNICA TOTAL DIARIA ESTANDARIZADA

5.3.2. VARIABLES METEOROLÓGICAS Y CONCENTRACIONES POLÍNICAS DE CHENOPODIACEAE-AMARANTHACEAE

5.3.2.1. PRESIÓN Y CONCENTRACIÓN POLÍNICA DE CHENOPODIACEAE-AMARANTHACEAE (2 $2^{\mathrm{a}}$ FLORACIÓN)...

5.3.2.2. VELOCIDAD DEL VIENTO Y CONCENTRACIÓN POLÍNICA DE CHENOPODIACEAE-AMARANTHACEAE $\left(2^{\mathrm{a}}\right.$ 
FLORACIÓN)

5.3.2.3. DIRECCIÓN DEL VIENTO Y CONCENTRACIÓN POLÍNICA DE CHENOPODIACEAE-AMARANTHACEAE $\left(2^{\mathrm{a}}\right.$ FLORACIÓN)

5.3.2.4. PRECIPITACIONES Y CONCENTRACIÓN POLÍNICA DE CHENOPODIACEAE-AMARANTHACEAE $\left(2^{\mathrm{a}}\right.$ FLORACIÓN)

5.4. RESULTADOS DE LA IDENTIFICACIÓN DE LOS FLUJOS DE VIENTO DOMINANTES EN LA CIUDAD DE CARTAGENA

5.5. RESULTADOS DE CLASIFICAR LOS FLUJOS DE VIENTO DOMINANTES EN LA CIUDAD DE CARTAGENA PARA LOS AÑOS 1995-1997 EN 5 GRUPOS

5.6. MODELOS DE REGRESIÓN LINEAL MÚLTIPLE

5.6.1. PÓLENES TOTALES.

5.6.1.1 CORRELACIONES BIVARIADAS ENTRE LA CONCENTRACIÓN POLÍNICA TOTAL DIARIA ESTANDARIZADA Y LAS VARIABLES UTILIZADAS...

5.6.1.2. MODELOS DE REGRESIÓN LINEAL MÚLTIPLE PARA LA CONCENTRACIÓN POLÍNICA TOTAL DIARIA ESTANDARIZADA 1995-1998

5.6.1.3. DESARROLlo DE MODELOS PREDICTIVOS DE REGRESIÓN LINEAL MÚLTIPLE PARA LOS CONGLOMERADOS QUE DEFINEN LOS FLUJOS DE VIENTO.

5.6.1.4. VALIDACIÓN DEL MODELO DE REGRESIÓN LINEAL MÚLTIPLE PARA LA CONCENTRACIÓN POLÍNICA TOTAL DIARIA ESTANDARIZADA 1995-1998

5.6.1.5 VALIDACIÓN DE LOS MODELOS DE REGRESIÓN LINEAL MÚLTIPLE PARA LA CONCENTRACIÓN POLÍNICA TOTAL DIARIA ESTANDARIZADA PARA CADA CLUSTER IDENTIFICADO

5.6.2. CONCENTRACIONES POLÍNICAS DE CHENOPODIACEAEAMARANTHACEAE 
CONCENTRACIONES POLÍNICAS DE CHENOPODIACEAEAMARANTHACEAE Y EL RESTO DE VARIABLES.....

5.6.2.2. MODELOS PREDICTIVOS DE REGRESIÓN LINEAL MÚLTIPLE PARA LA CONCENTRACIÓN POLÍNICA ESTANDARIZADA DE CHENOPODIACEAEAMARANTHACEAE (1995-1998).

5.6.2.3. DESARROLLO DE MODELOS DE REGRESIÓN LINEAL MÚLTIPLE PARA LA SEGUNDA FLORACIÓN DE LA CONCENTRACIÓN POLÍNICA ESTANDARIZADA DE CHENOPODIACEAE-AMARANTHACREAE PARA LOS CONGLOMERADOS QUE DEFINEN LOS FLUJOS DE VIENTO.

5.6.2.4. VALIDACIÓN DEL MODELO DE REGRESIÓN LINEAL MÚLTIPLE PARA LA SEGUNDA FLORACIÓN DE LAS CONCENTRACIONES POLÍNICAS DE CHENOPODIACEAE-AMARANTHACEAE CON LOS DATOS DEL AÑO 1999.

5.7. MODELOS DE REGRESIÓN LOGÍSTICA

5.7.1. MODELOS DE REGRESIÓN LOGÍSTICA PARA LA CONCENTRACIÓN POLÍNICA TOTAL ESTANDARIZADA (52 SEMANAS), DE 1995 A 1998.

5.7.2. VALIDACIÓN DEL MODELO DE REGRESIÓN LOGÍSTICA CON LOS DATOS DEL AÑO 1999.

5.8. MODELIZACIÓN DE LA CONCENTRACIÓN POLÍNICA MEDIA SEMANAL DE 1994 A 1999 MEDIANTE ANÁLISIS DE SERIES TEMPORALES DE BOXJENKINS (MODELOS ARIMA)

5.8.1. PREDICCIÓN Y VALIDACIÓN DEL MODELO ARIMA PARA EL AÑO 2000

6. DISCUSIÓN.

6.1. CONCENTRACIONES POLÍNICAS DE LA CIUDAD DE CARTAGENA DURANTE LOS AÑOS 1993-1999.

6.2. METEOROLOGÍA DE LA CIUDAD DE CARTAGENA DURANTE LOS AÑOS 1993-1999. 
6.3. METEOROLOGÍA Y PÓLENES.

6.3.1. VARIABLES METEOROLÓGICAS Y CONCENTRACIONES POLÍNICAS TOTALES..

362

6.3.2. VARIABLES METEOROLÓGICAS Y CONCENTRACIONES POLÍNICAS DE CHENOPODIACEAE-AMARANTHACEAE.

368

6.4. IDENTIFICACIÓN DE LOS FLUJOS DE VIENTO DOMINANTES EN LA CIUDAD DE CARTAGENA

6.5. IDENTIFICACIÓN DE LOS FLUJOS DE VIENTO DOMINANTES EN LA CIUDAD DE CARTAGENA PARA LOS AÑOS 1995-1997....

378

6.6. MODELOS PREDICTIVOS: MODELOS DE REGRESIÓN MÚLTIPLE.

380

6.7. MODELOS DE REGRESIÓN LOGÍSTICA

388

6.8. MODELOS ARIMA PARA LAS CONCENTRACIONES POLÍNICAS MEDIAS SEMANALES 1993 A 1998.

7. CONCLUSIONES. 401

8.- BIBLIOGRAFÍA.

409 


\section{Capítulo 1 INTRODUCCIÓN}




\section{CAPÍTULO 1. INTRODUCCIÓN}

La importante relación que la presencia de polen y esporas en el aire tiene con la salud del hombre, ha hecho que en todo el mundo crezca el número de grupos de investigación dedicados a esta disciplina. Sin embargo, sus implicaciones socioeconómicas a todos los niveles, deberían llevar a que el estudio minucioso de la fracción biótica del aerosol atmosférico fuese considerado uno de los parámetros básicos a controlar en las redes de control de la contaminación atmosférica.

Aun cuando este control se efectúa, por la naturaleza de las determinaciones realizadas, los niveles de polen y esporas se conocen con posterioridad, es decir, podemos saber las concentraciones alcanzadas en los días anteriores, por ello, numerosos grupos de investigación trabajan en dos vertientes.

La primera, la puesta a punto de métodos automatizados de medida, que permita conocer los datos en tiempo real. La segunda, la que proponemos abordar con este proyecto de investigación, el desarrollo de modelos predictivos, que permitan conocer la evolución en las concentraciones de pólenes con anterioridad, en función de determinados parámetros y variables de estado seleccionados.

Los modelos utilizados en la gestión ambiental se manifiestan como necesarios, si se considera que la previsión y cuantificación del impacto ambiental atmosférico, sólo es posible con un análisis detallado, cuando se ha conseguido de una manera suficientemente representativa la modelización de las características básicas de los medios emisor, difusor y receptor en su interrelación temporal y espacial (Jørgensen, 1991).

La necesidad de abordar la problemática de la contaminación de origen biológico a través de los resultados obtenidos con los modelos de diverso tipo, se presenta como una herramienta primordial e insustituible frente a otros sistemas, desde el momento en que los resultados obtenidos pueden ser empleados con antelación al inicio de los problemas principales que éstos desencadenan en los receptores finales (Raynor y Hayes, 1970; Bringfelt, 1980; Norris-Hill, 1995; Galán et al., 1995). 
Si bien es cierto, que de entrada estamos asumiendo que cualquier simulación matemática de un fenómeno tan complejo como es la liberación, transporte y deposición de los granos de polen no es nunca exacta, no es menos cierto, que los resultados de un modelo son el instrumento más válido en la decisión de la planificación y en la adopción de medidas preventivas, ya que con ellos se pueden identificar el momento más crítico, la zona más desfavorable, etc. (Zannetti, 1993).

La aplicación de un modelo atmosférico tiene como objeto la integración de todos aquellos elementos que inciden de alguna forma en la calidad del aire final, como son los condicionantes atmosféricos, la localización de las fuentes productoras de polen y densidad de las mismas, situación de los receptores finales, influencia de la topografía, orografía, etc., a fin de tomar las medidas correctoras más viables desde el punto de vista económico y técnico (Burleigh et al., 1979).

Los modelos atmosféricos en general, constituyen un instrumento de gran utilidad y en muchas ocasiones se presentan como prioritarios en los programas de actuación, cuando se requiere abordar entre otros, los siguientes problemas: evaluaciones de impacto ambiental originada por una determinada masa vegetal, predicciones de contaminación potencial, programas de prevención, planificación urbana e industrial (escala regional, local y nacional), diseño de redes de calidad del aire, etc. (Zannetti, 1993).

La fiabilidad de un modelo está directamente relacionada con el banco de datos que se posea, siendo fundamental que la información meteorológica en la que está sustentada el modelo, proceda de series suficientemente extensas y detalladas, para los distintos parámetros climáticos susceptibles de utilizar en el modelo (Milford y Russell, 1993).

Con la construcción de estos modelos, se trata de disponer de una herramienta que permita reproducir la realidad. El modelo, puesto que nunca contendrá todos los rasgos del sistema que queremos reproducir, sí será necesario que contenga los rasgos característicos, que se consideren esenciales para la descripción y resolución de la dinámica de los granos de polen en la atmósfera.

El desarrollo de estos modelos predictivos, va a ser abordado desde varios puntos de vista, modelos de regresión múltiple, de regresión logística y modelos de 
series temporales (ARIMA). Los modelos estadísticos más frecuentes, se elaboran mediante estudios de correlación y de regresión entre los diferentes parámetros implicados. Por otro lado, tenemos los modelos numéricos, que se basan en la resolución de la ecuación de dispersión, siendo necesario para ello tener datos de la fuente y datos meteorológicos, que no abordaremos por carecer de datos precisos de producción de polen a nivel de fuente. La falta de un adecuado conocimiento de las leyes que gobiernan los procesos naturales, y la imposibilidad consecuente de plasmarlas en ecuaciones, supone un freno importante al desarrollo de la modelización numérica, y ha sido señalada como la razón del auge de los métodos estadísticos de modelización (Kolehmainen et al., 2001).

Los modelos en el campo de la contaminación atmosférica, han sido desarrollados como una potente herramienta para predecir el impacto de las emisiones de contaminantes sobre la calidad del aire y sobre el clima. Además, pueden utilizarse para estudiar la exposición de las personas a estos contaminantes presentes en el aire y para decidir la estrategia de control más idónea desde el punto de vista tecnológico y económico (Milford y Russell, 1993).

Para abordar la construcción de estos modelos predictivos, proponemos el estudio conjunto de una base de datos meteorológica y una base de datos aeropalinológica, de las que para ambas, y para el caso concreto de la ciudad de Cartagena disponemos de datos diarios desde el año 1993 hasta 1999.

En primer lugar, se procederá a la construcción de las dos bases de datos en un soporte informático adecuado, que permita con posterioridad su utilización, bien en nuestro caso o en otros estudios de la zona que precise este tipo de datos.

En una primera etapa se pretende estudiar la influencia de los distintos parámetros meteorológicos en los registros polínicos diarios. Finalmente, con estas dos bases de datos se pretende construir modelos predictivos de los tipos antes mencionados.

Con el proyecto de investigación presentado tratamos en último término de desarrollar herramientas de trabajo que permitan predecir las concentraciones de pólenes aerovagantes con anterioridad en el tiempo, de tal manera que se puedan ejercer las acciones preventivas correspondientes. 
Como pasos previos al desarrollo de los modelos se han abordado una serie de objetivos que en sí mismos tienen un interés científico claro, ya que:

- Se dispondrá de bases de datos actualizadas y fiables que pueden ser utilizadas para otras finalidades.

- Al definir los flujos de viento característicos de la zona y su relación con los datos aerobiológicos, ofertaremos una información de gran valor para otros estudios en la zona.

- El análisis de los datos nos permitirá definir los periodos e intensidad de la floración, datos que pueden ser utilizados para prever la repercusión clínica sobre individuos sensibles, la polinización de determinadas especies, etc.

Finalmente, los beneficios globales del proyecto presentado revertirán a la sociedad, ya que es un objetivo planteado, poner a disposición de las autoridades pertinentes los datos y modelos desarrollados para que sean utilizados por éstas como herramienta de gestión. 


\section{Capítulo 2 OBJETIVOS}




\section{CAPÍTULO 2. OBJETIVOS}

Los objetivos iniciales marcados para el desarrollo de este proyecto de investigación, han sido los siguientes:

1.- Construir y actualizar en un soporte informático adecuado las bases de datos meteorológica y aeropalinológica de la ciudad de Cartagena para los años 1993-1999, generando las variables necesarias para los fines del presente estudio.

2.- Descripción de las características meteorológicas para el periodo 1993-1999.

3.- Caracterización de los parámetros meteorológicos que influyen en mayor medida en el contenido de polen en el aerosol atmosférico de la zona.

4.- Determinar con los datos meteorológicos disponibles para cada estación meteorológica (Ayuntamiento, ETASA, Escombreras y Lo Campano), los flujos del viento para la ciudad de Cartagena y estudiar la relación de éstos con el contenido polínico en la atmósfera.

5.- Desarrollar la construcción de modelos predictivos estadísticos, para estudiar el mecanismo de dispersión del polen en la atmósfera de la ciudad de Cartagena: modelos lineales de regresión múltiple, de regresión logística y ARIMA.

6.- Poner a disposición de las autoridades los modelos desarrollados, para alcanzar la finalidad preventiva de este estudio, posibilitando su uso como herramienta de gestión. 


\section{Capítulo 3 ANTECEDENTES}




\section{ANTECEDENTES BIBLIOGRÁFICOS}

Una vez definidos los objetivos de este estudio y antes de abordar su desarrollo, se va a hacer una revisión sobre los conceptos utilizados a lo largo de la memoria, empezando por centrar la disciplina en la que se engloba este estudio, la aerobiología y sus aplicaciones, las características generales del grano de polen y el uso de calendarios polínicos como herramienta que permite definir el contenido en pólenes aerovagantes en una determinada localización. Pasaremos en ese momento a repasar los fundamentos de la modelización ambiental, entrando a analizar la modelización en aerobiología, para ver seguidamente la relación existente entre meteorología y niveles de inmisión, este recorrido nos llevará a plantearnos la fuente de emisión de los pólenes y los mecanismos que están implicados en las concentraciones polínicas a nivel de receptor, estudiando también los factores que influyen en el transporte y dispersión del bioaerosol, cerrando este capítulo con los métodos de clasificación de situaciones meteorológicas basados en el análisis de cluster.

\subsection{AEROBIOLOGÍA.}

\subsubsection{INTRODUCCIÓN.}

El término Aerobiología es conocido desde 1930, entendiéndola como una disciplina científica que se ocupa del estudio de los organismos presentes en el aire, tanto de ambientes interiores como exteriores. En su definición original, su estudio se restringía únicamente al estudio de partículas biológicas presentes en el aire (Gregory, 1973).

Pero contaminantes, tanto de origen natural como antropogénico, también pueden afectar a la viabilidad de los organismos presentes en la atmósfera, 
incluyéndose por esta razón gases y partículas, cuando sus efectos biológicos son demostrados (Edmonds, 1979).

Los gases más conocidos que afectan de forma adversa a los microorganismos presentes en el aire son el dióxido de azufre, óxidos de nitrógeno, monóxido de carbono y ozono. La materia particulada considerada como importante en Aerobiología incluye humos, polvo, núcleos de condensación, pesticidas y las formas biológicas (virus, bacterias, fragmentos de hongos y esporas, algas, protozoos, pólenes, pequeñas semillas de plantas, insectos y otra microfauna) (Edmonds, 1979).

Según Spieksma (1992), la Aerobiología en sentido estricto, es la ciencia que se ocupa del estudio del transporte de partículas biológicas de origen animal o vegetal a través del aire. Este proceso incluiría el estudio de tres fases claramente diferenciadas: la liberación o lanzamiento desde sus fuentes o substratos; la permanencia en el aire y transporte a través del mismo y la deposición final. Desde el momento que existe la posibilidad de resuspensión de estas partículas, se debería incluir el estudio de los efectos que aparecen después del depósito.

Hirst (1994), define la Aerobiología en los estatutos de la Federación Británica de Aerobiología, como una disciplina científica enfocada al transporte atmosférico de material biológicamente significativo.

Comtois (2000), define de una forma muy simple la aerobiología, como el estudio cuantitativo de los microorganismos presentes en el aire, indicando que por definición los datos obtenidos son numéricos.

Las partículas grandes, que en general, se dispersan en el aire tienen un tamaño comprendido entre 10 y 100 micras, por lo que no todos los granos de polen se dispersan en el aire. Por ello, en principio se pensaba que eran sólo los pólenes procedentes de las plantas anemófilas los que se dispersaban, por tener éstos un menor tamaño, pero posteriormente se demostró la aerovagancia y alergenicidad de numerosas plantas entomófilas (Lewis, 1979). 
La tabla 3.1, muestra el tipo de partículas de interés en Aerobiología y su diámetro. La mayoría de las partículas biológicas, están comprendidas en el rango de 0,5 a $100 \mu \mathrm{m}$, aunque el rango de interés total está entre $0,0001 \mu \mathrm{m}$ en humos, hasta centímetros en el caso de insectos. Existe en general un predominio de partículas no biológicas, aunque los posibles efectos de éstas, demuestran su posible impacto (Edmonds, 1979).

El polen y las esporas que están presentes en la atmósfera son partículas vivas dispersas en el aire, de función reproductora. Así, los granos de polen constituyen el gametofito masculino en las plantas superiores, mientras que las esporas de los hongos son formas haploides o diploides de propagación y resistencia (Suárez-Cervera y Márquez-Pereira, 1990).

Debido a su dispersión anemófila entran en contacto no sólo con su receptor, por lo que interaccionan con otros seres vivos, así como con los materiales, edificios, obras de arte, etc. Desde esta perspectiva diversos campos de aplicación se abren en su estudio: Medicina, Agricultura, Biodeterioro, Biogeografía y Ecología, etc.

Las implicaciones socio-económicas de la aerobiología son diversas y de gran importancia y repercusión, entre ellas podemos destacar las que tienen lugar en los siguientes campos. 
Tabla 3.1. Tipos y tamaños de la materia particulada de interés en Aerobiología presente en el aire.

Tipo de partículas

Diámetro $(\mu \mathrm{m})$

Humos

$0,001-0,1$

Núcleos de condensación

$0,1-20$

Polvo

$0,1-\mathrm{cm}$

Virus

$0,015-0,45$

Bacterias

$0,3-10$

Algas

$0,5-\mathrm{cm}$

Esporas de hongos

$1-100$

Fragmentos de líquenes

$1-\mathrm{cm}$

Protozoos

$2-\mathrm{cm}$

Esporas de musgos

6-30

Esporas de helechos

20-60

Pólenes

$10-100$

Fragmentos de plantas, pequeñas semillas, insectos, arañas, etc. $>100$ 


\subsubsection{APLICACIONES AEROBIOLÓGICAS EN MEDICINA.}

La aerobiología tiene una contribución muy importante a este campo, al ser los granos de polen, esporas de hongos, polvo, humos, microbios, etc., presentes en el aire, los responsables de numerosas enfermedades y reacciones alérgicas, que tienen una importancia vital para la humanidad, tanto por el aspecto puramente sanitario, como por las repercusiones socio-económicas que todo ello conlleva (absentismo laboral, preparación de tratamientos profilácticos, etc.) (Cole et al., 1993; Suárez-Cervera, 1996; Levetin et al., 1997; Belchí-Hernández, 1998).

Por otro lado, la presencia de partículas no biológicas y gases en la atmósfera, puede agravar los efectos de las enfermedades ocasionadas por los distintos agentes alergénicos (Edmonds, 1979; Schäppi et al., 1996; D’Amato et al., 2000).

Las esporas y los pólenes aerovagantes tienen una importancia especial en su relación con el hombre al ser la causa de sensibilizaciones. Según datos publicados por la Asociación Española de Alergia e Inmunología Clínica, subjetivamente al $22 \%$ de la población española y objetivamente al $15 \%$ de la población padece alergias, de las cuales un $30 \%$ corresponden a pólenes y se cifra en torno a un $10 \%$ el de individuos sensibilizados a esporas de hongos (Libro Blanco, 1986; Alergológica, 1995).

Por consiguiente, el conocimiento a priori de las concentraciones polínicas de los tipos más representativos de una zona, resulta fundamental para predecir el comienzo de manifestaciones clínicas en pacientes sensibles, aunque son muchos factores los involucrados en la determinación de estos síntomas (Larese et al., 1992). 


\subsubsection{APLICACIONES AEROBIOLÓGICAS EN AGRICULTURA.}

En la práctica agronómica, la productividad de determinadas especies anemófilas está asociada a la adecuada dispersión de los granos de polen, el conocimiento de su concentración y la relación existente entre ésta y la producción, permite planificar de modo adecuado determinadas prácticas agrícolas, aclareo de frutos, programas de recolección, mejoras en los canales de comercialización, adaptación de la oferta y la demanda, previsión de cosechas (Cour y Villemour, 1985; González-Minero et al., 1998; Cristofolini y Gottardini, 2000; Muñoz et al., 2000).

El estudio de forma continua de las esporas responsables de las principales patologías de las plantas cultivadas, resulta esencial para la planificación de las medidas preventivas a adoptar, con vistas a la ejecución de un sistema de control integrado en la agricultura, que es lo que se está imponiendo en los últimos años, con objeto de reducir los impactos ambientales ocasionados por los tratamientos fitosanitarios.

Los hongos son los responsables de numerosas patologías de las plantas, bien por una infección directa de los mismos, o bien porque actúan como vehículos transmisores de determinados virus. El estudio paralelo de la concentración de esporas en la atmósfera y de las enfermedades en las plantas, tanto en periodo pre como post recolección, permitiría poner en marcha programas de prevención que mejorarían los rendimientos y los beneficios económicos (Edmonds, 1979; Snowdon, 1990a y b).

En los últimos años también está adquiriendo una especial importancia la higiene ocupacional, y de ahí la preocupación por conocer las concentraciones de contaminantes tanto de origen biótico como abiótico dentro del ambiente de trabajo. Dentro de esta aplicación de la aerobiologia, es en los trabajadores de la agricultura donde adquiere una relevancia vital, al estar éstos expuestos a importantes niveles de microorganismos que pueden producir enfermedades (Dutkiewicz et al., 2000). 
Otra posible aplicación es el estudio de la calidad de las mieles, conocido como melisopalinología, en base a la caracterización polínica previa que se haya podido hacer de una zona, con vistas a la denominación de origen de esa miel (Sáenz y Gómez, 2000).

\subsubsection{APLICACIONES AEROBIOLÓGICAS EN EL BIODETERIORO.}

Los materiales se encuentran sometidos a la acción de los componentes del aire, estando directamente relacionada la conservación de éstos a la composición del ambiente, así como con las condiciones físico-químicas que pueden favorecer el crecimiento de ciertos microorganismos perjudiciales.

Un aspecto de gran importancia es la acción de los microorganismos sobre los materiales, en lo que se conoce con el nombre de biodeterioro, que puede dar lugar en algunos casos a pérdidas irreparables, como en el caso de monumentos y obras de arte, y que obligan, en muchas ocasiones, a tomar medidas drásticas tales como la imposibilidad de visitar ciertos monumentos, imponer restricciones a las visitas, etc. (Monte y Ferrari, 1993; Ariño y Sáiz-Jiménez, 1996).

\subsubsection{APLICACIONES AEROBIOLÓGICAS EN BIOGEOGRAFÍA Y ECOLOGÍA.}

La Aerobiología es pieza fundamental para recoger información de tipo biogeográfico y ecológico, y por consiguiente, para llevar a cabo programas de conservación y protección ambiental. La biogeografía por sí sola recoge información sobre la distribución de los seres vivos y especies inicialmente invasoras, pero la aerobiología es mucho más eficiente a la hora de detectar cambios en ciertas zonas marginales, además, puede ser utilizada como un 
poderoso indicador de cambios medio ambientales y para conocer la extensión de determinadas especies de especial interés (Roure y Belmonte, 1988).

La evolución de las concentraciones polínicas a lo largo del tiempo permite poner de manifiesto variaciones en las distribuciones de las comunidades vegetales, determinando los efectos que sobre la ecología y el medio ambiente ocasionan la presión de las actuaciones del hombre, los cambios climatológicos globales y determinados fenómenos naturales tales como los incendios forestales.

Stephen (1998), en el suroeste de América del Norte, pone de manifiesto las implicaciones biogeográficas de la Aerobiología, con la colonización de un terreno por un alga de aguas frías en el Norte de Santa Fe (Nuevo México) procedente de un reservorio situado $42 \mathrm{~km}$ al suroeste de donde estaba ubicado el muestreador, dejando patente que la habilidad que posee este alga para dispersarse y sobrevivir en condiciones adversas, le proporciona una capacidad biogeográfica de propagarse rápidamente y colonizar nuevos terrenos con independencia de otros vectores de dispersión.

Por otro lado, la Aerobiología también puede resultar muy interesante, para detectar cambios climáticos como pueden ser el calentamiento global, que a su vez pueden verse reflejados en importantes cambios sobre los ecosistemas naturales, variaciones en los registros polínicos, etc. (Emberlin, 1994).

\subsection{CARACTERÍSTICAS GENERALES DEL GRANO DE POLEN.}

Los pólenes aerovagantes, en general, constituyen una pequeña porción variable en relación con todas las partículas presentes en el aire. El grano de polen constituye el gametofito masculino tanto en angiospermas como gimnospermas (Suárez-Cervera y Márquez-Pereira, 1990).

En tamaño, el diámetro de los granos de polen varía desde unas $5 \mu \mathrm{m}$ hasta más de $200 \mu \mathrm{m}$. Sólo un 10\% de las especies conocidas son anemófilas, es decir, 
sus granos son dispersados por acción del viento. Las restantes son polinizadas por acción de los insectos (entomófilas), pájaros, murciélagos, (zoófilas). También se conocen algunas especies que presentan una forma anfifila de polinización, como en el género Zygophyllum (Castells, 2000). Sólo los pólenes anemófilos son los que presentan un mayor interés para la aerobiología y sus distintas aplicaciones, por lo que son los que se incluyen en el estudio del aerosol atmosférico (Rantio-Lehtimäki, 1995).

Las principales características de las especies polinizadas por acción del viento pueden resumirse, como señala Faegri e Iversen (1989) en:

a) Producción de grandes cantidades de polen con una superficie exterior con irregularidades (Castells, 2000).

b) Los estambres son largos, saliendo en forma de filamentos largos, bien expuestos y a veces pegados o formando grupos.

c) El polen generalmente es liberado con mayor facilidad cuando el ambiente es caliente y seco.

d) Tienen los estigmas largos y bien expuestos para favorecer la recepción del polen.

e) El color, aroma y néctar es frecuente que esté totalmente ausente en las flores.

Es interesante señalar el aumento de especies anemófilas con la latitud y altitud, así el número de especies anemófilas es relativamente bajo en ambientes tropicales y alto en los bosques boreales (Regal, 1982).

El grano de polen maduro no es sólo una célula, sino que presenta básicamente tres elementos que se pueden distinguir (Suárez-Cervera y MárquezPereira, 1990):

- La célula vegetativa, gametofítica, en cuyo interior hay dos células germinales que en el momento de la germinación fecundan al ovario. 
- La intina, que es la capa que separa a la célula vegetativa del exterior, y que está compuesta básicamente por celulosa y hemicelulosa.

- La exina, que es la capa más externa, dura y resistente. En esta capa se pueden distinguir a su vez el téctum y ornamentaciones y las columelas o báculos. La estructura de esta capa no es uniforme, presentando en la superficie una serie de protusiones y hendiduras regulares, llamadas poros y colpos. Las características morfológicas de ésta, junto con las de las aperturas, son las que nos sirven para identificar los distintos granos de polen.

\subsubsection{PRINCIPALES CARACTERÍSTICAS MORFOLÓGICAS DEL GRANO DE POLEN.}

Las características morfológicas que presenta el grano de polen, resultan esenciales para la clasificación e identificación de éstos, y se hacen notables avances en la caracterización estructural de los granos de polen (Thanikaimoni, 1986; Suárez-Cervera et al.,1995 a y b; Suárez-Cervera et al., 2000). Las principales características son: la forma en que se presentan las unidades, simetría y polaridad, forma del grano de polen, tamaño, aperturas y constitución de la pared (Lewis et al., 1983; Faegri e Iversen, 1989; Suárez-Cervera y MárquezPereira, 1990; Díaz de la Guardia y Blanca, 1994; Suárez-Cervera, 1996).

La mayoría de los granos de polen se presentan en forma individual, lo que se llaman mónadas, aunque también es posible encontrarlos como granos compuestos con varias unidades, como es el caso de tétradas o poliadas.

En cuanto a la simetría y polaridad, nos encontramos con el eje polar que une los dos polos (distal y proximal) y el eje ecuatorial, perpendicular al anterior, resultando ser éstos fundamentales para determinar las dimensiones de un grano de polen (Suárez-Cervera y Márquez-Pereira, 1990). 
La forma del grano de polen es otra característica que resulta esencial para la diferenciación, hablando básicamente de forma esférica (cuando el eje polar es igual que el eje ecuatorial); elipsoidal-oblato (el eje ecuatorial es mayor que el polar) y elipsoidal-prolato (el eje ecuatorial es menor que el polar).

Otra característica fundamental, son las aperturas que presenta el grano de polen, que van a ser por donde va a salir el tubo polínico en el momento de producirse la germinación. Básicamente se distinguen dos tipos de aperturas: poros (orificios generalmente redondeados) y colpos (aperturas en forma alargada). Hay pólenes que pueden presentar ambos tipos de aperturas, llamándose colporados. La estructura del grano de polen es tal que le pemite aumentar o disminuir su tamaño, fenómeno conocido con el nombre de harmometangia, característica que va a resultar ser muy importante en el transporte y dispersión de los granos de polen. (Blackmore y Barnes, 1986; Suárez-Cervera y Márquez-Pereira, 1990).

La otra característica importante, es la constitución de la pared, como se ha mencionado anteriormente. Es importante destacar que la exina o capa más externa del grano de polen, que es resistente a los ácidos y que se puede subdividir a su vez desde dentro hacia fuera en la nexina y la sexina. Es la morfología de esta última capa la que va a resultar esencial en la identificación de los distintos tipos polínicos, pudiendo encontrar una extructura compacta, tectada, semitectada o alveolar (Seoana-Camba y Suárez-Cervera, 1986; Suárez-Cervera y MárquezPereira, 1990).

\subsection{CALENDARIOS POLÍNICOS.}

La comprensión de la dinámica de los contaminantes de origen biótico en la atmósfera se ha hecho durante mucho tiempo a través del estudio de los datos registrados en periodos anteriores, sobre todo en países del oeste de Europa, donde se cuenta con series bastantes completas y con datos de muchas estaciones 
de muestreo (Suárez-Cervera y Seoane-Camba, 1983; Fernández González, 1990; Belmonte y Roure, 1991; González-Minero et al., 1993; Spieksma, 1994; Belmonte et al., 1995a, b y c; Díaz de la Guardia et al., 1995; Domínguez-Vilches et al., 1995; Ong et al., 1995; Alba, 1996; Herrero et al.,1996 a y b; Aira et al., 1998; Alcázar et al., 1998; Bermejo et al., 1998; Cariñanos et al., 1998; Díaz de la Guardia y Alba, 1998; Galán; 1998; Galán et al., 1998; Iglesias et al., 1998; Elvira-Rendueles et al., 2000).

Las razones que han llevado a realizar este tipo de estudios, se deben fundamentalmente a la relación de estas partículas presentes en el aire con los problemas de polinosis que presentan algunas personas.

No obstante, uno de los primeros fines perseguidos por la Aerobiología, y en concreto con el análisis de los datos de polen, es plasmar los resultados obtenidos en forma de diagramas, más comúnmente llamados calendarios polínicos o fúngicos, introducidos por Von Post en 1916 (Faegri e Iversen, 1989). El objetivo de estos calendarios polínicos es visualizar y simplificar la caracterización de la atmósfera local, detectar cambios en la flora local, etc.

La importancia de los calendarios queda reflejada en la relación que presenta la Aerobiología con la medicina, la agricultura, higiene ocupacional, etc., constituyendo un elemento indispensable para la construcción de bases de datos aeropalinológicas, que a su vez son necesarias para el desarrollo de modelos predictivos.

Como señala Emberlin (1994), los principales objetivos perseguidos con las medidas de las concentraciones polínicas son:

a) Determinar el patrón general de los distintos tipos polínicos y su presencia estacional (calendarios polínicos).

b) Tener una idea de las cantidades polínicas diarias que producen problemas de polinosis en las personas alérgicas (diagnosis). 
c) Hacer predicciones de futuras concentraciones polínicas a corto o medio plazo para programar tratamientos profilácticos.

d) Estudiar de año en año las tendencias y fluctuaciones en relación con los problemas de alergias y registrar los posibles cambios ambientales como desforestación, contaminación del suelo y aire, etc.

Estos calendarios tienen una gran importancia en los distintos campos relacionados con la Aerobiología, básicamente medicina y agricultura, aunque presentan serias limitaciones como son el requerimiento de amplias series temporales de datos para obtener calendarios fiables, requieren la participación de personal especializado para la identificación y cuantificación y es mucho el tiempo invertido en esta labor.

Por todo ello, el desarrollo de modelos predictivos en el campo de la aerobiología constituye una herramienta fundamental de aplicación en cualquiera de los campos de interés de esta disciplina. La modelización de sistemas constituye en todos los campos de la ciencia una pieza fundamental para su desarrollo (Jørgensen, 1991).

Cuando se dispone de un modelo adecuado se obtiene valiosa información tanto del funcionamiento y dinámica interna del sistema modelizado, como de la previsible evolución de éste y de los efectos que sobre el sistema tienen determinadas acciones.

Además, con un modelo se pueden simular determinadas situaciones, obteniendo los resultados en cortos periodos de tiempo y de esta manera seleccionar las mejores acciones introduciendo consideraciones de diferente tipo, por ello se utilizan ampliamente en la gestión medioambiental. Así dentro de las actuaciones de la Comisión Europea, el Comité de Gestión de la Acción COST 615 (1997) ha inventariado un total de 61 modelos de dispersión en ambientes urbanos. 


\subsection{MODELIZACIÓN AMBIENTAL.}

\subsubsection{INTRODUCCIÓN.}

La modelización juega un papel decisivo en la toma de decisiones diarias y más concretamente en las decisiones de aspectos relacionados con el medio ambiente (Jørgensen, 2000). En este trabajo, Jørgensen (2000), analiza los trabajos relacionados con la modelización ambiental publicados en los últimos años, destacando que en los últimos tres años el 23\% de los trabajos publicados hacen referencia a algún problema terrestre, el número de trabajos relacionados con problemas acuáticos es de un $17 \%$ y un $24 \%$ han tratado aspectos teóricos, (17\% métodos y técnicas de modelización; 4\% utilización de modelos para representar el comportamiento de ecosistemas y 3\% basados en la comprensión termodinámica de estos ecosistemas).

Podemos definir la modelización ambiental como la habilidad para simular o reproducir por métodos matemáticos, bien numéricamente o estadísticamente, fenómenos ambientales. Los modelos en general, han avanzado mucho en los últimos años, tanto en complejidad como en tamaño, hecho que se deriva del auge que se viene experimentando en el campo de las computadoras (Zannetti, 1993), aunque se está produciendo un avance importante en los últimos años en la modelización estadística frente a la modelización numérica o determinística (Kolehmainen et al., 2001).

Los modelos matemáticos se pueden considerar como un laboratorio numérico, que sirve a los investigadores para verificar determinadas hipótesis, desarrollar ciertos experimentos, y representar algunos escenarios, con objeto de predecir con la mayor precisión posible algunos fenómenos que tienen lugar en la realidad (Zannetti, 1993).

Así, si la contaminación ambiental en general, es un gran problema para toda la sociedad, difícil de resolver, la modelización matemática no puede ser la solución a este problema, sino que puede considerarse como una herramienta muy 
valiosa e indispensable para realizar algunos análisis ambientales que nos puedan ayudar a la toma de decisiones.

Por tanto debe considerarse como tal y no como la panacea o una estrategia directa del control de la contaminación ambiental. De hecho, el coste efectivo óptimo de la adopción de una estrategia de control adecuada, vendrá determinado por una rigurosa aplicación de la simulación mediante un buen modelo y la optimización de las técnicas de control.

Por tanto, la modelización ambiental debe ser entendida sólo como una herramienta práctica y objetiva que nos puede ayudar a responder las cuestiones que nos planteamos del tipo “Qué......si...?” No obstante, no debemos caer en el error de creer que la/s respuestas de nuestros modelos son un fiel reflejo de la realidad, sino que debemos ser conscientes que si la construcción y calibración del modelo ha sido la correcta, las respuestas obtenidas serán tanto más parecidas a las que se obtendrían en la realidad, aunque siempre se estará sujeto a posibles perturbaciones que se puedan producir en el futuro (Milford y Russell, 1993).

\subsubsection{LA MODELIZACIÓN COMO HERRAMIENTA DE GESTIÓN AMBIENTAL.}

La urbanización, el desarrollo tecnológico, el incremento de superficie destinada a cultivo, etc., han tenido un impacto creciente sobre el medio ambiente en los últimos años. Los contaminantes se liberan en los ecosistemas, donde pueden causar crecimiento más rápido de algas o bacterias, el daño de especies o la alteración de la estructura ecológica. Pero, un ecosistema es tan extremadamente complejo que es difícil poder predecir con cierta exactitud los efectos que sobre el medio ambiente producirá una emisión determinada.

Es aquí donde el modelo entra en juego. Con el conocimiento que se dispone del medio, es posible extraer las características de los ecosistemas que 
están involucradas en los problemas de contaminación considerados, para formular las bases del modelo matemático.

Así, el conocer el futuro con cierta antelación es uno de los mayores deseos perseguidos por el hombre a lo largo de toda la historia. La justificación de este hecho ha sido puesta de manifiesto con el desarrollo de modelos relacionados con la salud humana, aprendizaje, económicos, meteorológicos, medio ambientales, etc. (DeLurgio, 1998).

Históricamente, podemos comprobar cómo el hombre ha recurrido a usar la predicción con diferentes finalidades, generalmente con un enfoque bastante personal, algunos de estos métodos no científicos, se encuentran hoy día en decadencia, astrología, cartomancia, quiromanica, etc., pero han sido utilizados para predecir el futuro.

En detrimento de los métodos subjetivos y no cuantitativos en los últimos años se han desarrollado, de manera importante, modelos predictivos en distintos campos, que tienen una finalidad más social y ello ha hecho que se avance mucho en el conocimiento de la teoría y práctica de estos modelos que pueden aplicarse a una amplia variedad de fenómenos que varían en el tiempo.

Una predicción consiste en una estimación probabilística o descripción de un futuro valor o condición. Por ello, se recomienda que toda predicción vaya acompañada de una buena planificación y control, así como que los resultados de la predicción vengan acompañados de una media, un rango y una estimación probabilística de ese rango (DeLurgio, 1998). En este sentido, son abundantes los trabajos en aerobiología en los que no se han efectuado estudios estadísticos de los datos, por lo que las conclusiones obtenidas a partir de ellos no tienen la significación adecuada (Comtois et al., 2000).

El desarrollo de la modelización como herramienta de la gestión medio ambiental se ha producido fundamentalmente en los últimos años, como consecuencia de los siguientes factores (Jørgensen, 1999): 
- El desarrollo de tecnologías informáticas más potentes y rápidas, que nos permiten resolver sistemas matemáticos complejos, que antes éramos incapaces de hacer.

- El conocimiento de los problemas de contaminación que ha llevado a desechar la idea de una descarga cero, pero que hace factible el desarrollo de sistemas adecuados de control. Sistemas de control en los que la disponibilidad limitada de recursos económicos hace necesaria una seria consideración sobre el impacto de la contaminación en los receptores.

- Nuestro conocimiento sobre el ambiente y los problemas ecológicos, ha aumentado significativamente.

Los problemas de contaminación del aire, incluyen tanto contaminantes de origen abiótico (metales pesados, partículas en suspensión, óxidos de nitrógeno, ozono, etc.) como contaminantes de origen biótico (polen, esporas, bacterias, insectos, ácaros, terpenos, etc.). En algunos casos, el origen de algunos de estos contaminantes lo encontramos en el incremento de la población, industrialización, intensificación de la producción, sensibilización, etc. Los modelos de la calidad del aire, constituyen la base para comprender la dinámica de estos contaminantes en la atmósfera, y haciendo uso del conocimiento humano, establecer las estrategias más apropiadas a cada caso para efectuar el control más efectivo desde el punto de vista técnico y económico de la contaminación.

El objetivo fundamental de estos modelos es establecer el posible impacto de una determinada fuente considerada potencialmente como contaminante sobre un área determinada (local, regional, etc.). La mayoría de los modelos matemáticos desarrollados, tratan de relacionar las fuentes contaminantes con las concentraciones de contaminantes registradas.

Los modelos, sirven, en definitiva, para integrar nuestro conocimiento de la física y química del proceso, con la dinámica de los contaminantes, examinar 
sistemas complejos, revelar las propiedades del sistema, revelar los vacíos del conocimiento, comprobar las hipótesis científicas y poder así desarrollar estrategias encaminadas a conseguir o mantener una determinada calidad ambiental (Moreno-Grau et al., 1996).

Esto es, la acción de cualquier contaminante puede alterar los sistemas. Por ello, los resultados obtenidos con nuestro modelo, pueden ser utilizados por las autoridades competentes para seleccionar la tecnología más adecuada, para la solución de los problemas específicos o para el establecimiento de una legislación de reducción o eliminación de emisiones, etc. En nuestro caso, las medidas adoptadas deben ir encaminadas a informar a la población sensible, realizar ciertas prácticas agronómicas preventivas, etc.

Para ello, el primer paso consiste en la caracterización de las emisiones. El segundo paso consistiría en establecer la influencia de la química y la meteorología en la transformación y transporte de contaminantes. La salida del modelo va a venir dada fundamentalmente como concentración de contaminante, flujo y en algunos casos en la estimación de la exposición.

Con estos resultados, se pueden estimar los impactos sobre la salud humana y sobre el medio ambiente en general, para pasar a continuación a adoptar la estrategia más conveniente. Además, el modelo permite la posibilidad de una vez adoptada una estrategia, hacer correr el modelo nuevamente, modificando las acciones hasta que los niveles de calidad del aire estén dentro de los límites aceptados.

Por tanto, los modelos, entendidos como una visión simplificada de la realidad, se han utilizado desde hace muchas décadas, tanto como herramienta científica como de gestión (Jørgensen, 1999). 


\subsubsection{GENERALIDADES SOBRE MODELOS.}

Un modelo matemático es una representación objetiva, en términos lógicos y matemáticos de un determinado fenómeno, basado en nuestro conocimiento teórico del proceso que hemos empleado para la construcción de dicho modelo. Cualquier modelo matemático, debe describir las principales características del sistema en términos matemáticos, mediante ecuaciones que liguen los diferentes parámetros implicados en el proceso que queremos reproducir.

Por tanto, un buen modelo, ha de recoger los parámetros que mejor definen el sistema y que son esenciales en el contexto del problema o experimento planteado, aunque no todos los detalles del sistema real que pretende representar, ya que esto supondría el sistema en sí mismo y complicaría todo el proceso excesivamente (Jørgensen, 1991; Bayo, 1998).

Otra definición de modelo matemático es la dada por Jørgensen (1991): "Conjunto de expresiones de los elementos de un problema en términos físicos o matemáticos". No obstante, se debe entender la modelización como una nueva rama de la ciencia, pero no como la solución a todos los problemas que los investigadores no son capaces de resolver de otra manera.

Según Sinclair (1991), un modelo matemático es una comprensión abstracta de la idea de un proceso y requiere la representación de:

- La realidad física del proceso (modelo físico abstracto o conceptual).

- Las ecuaciones o expresiones matemáticas del proceso (modelo cinético, térmico, de difusión, etc.).

Cuando combinamos el conocimiento o modelo físico abstracto de un proceso y las expresiones matemáticas correspondientes, se tiene un modelo matemático que puede servir para los siguientes fines (Jørgensen, 1991): 
- A partir de la construcción del modelo: ayuda al pensamiento y/o organización del conocimiento.

- Por el uso del modelo: para la organización de datos, realizar experimentos hipotéticos, cuantificación de conceptos, estudios de sensibilidad, determinación de parámetros, etc.

Para la elaboración de un modelo se requerirán el conjunto de relaciones que ligan las variables de interés en el sistema que estamos estudiando. Este conjunto de relaciones puede estar en forma de ecuaciones, gráficas, tablas o incluso como un conjunto no expresado de relaciones causa/efecto.

Para la construcción del modelo matemático, en general, hay que construir una serie de ecuaciones para cada región control (región del espacio que es objeto de nuestro estudio):

- Ecuaciones de balance.

- Ecuaciones de velocidad: de transferencia de masa a través de los límites de la región de control y/o de generación o consumo dentro de la región de control.

- Ecuaciones termodinámicas.

La mayoría de los procesos que son objeto de la modelización, son complejos y difíciles de representar. Además, mucha de las veces nos vamos a encontrar con un comportamiento no lineal, componentes estocásticos (aleatorios), lazos de retroalimentación, etc, que van a complicar la construcción de los modelos.

Muchas veces, puede que tengamos un conocimiento significativo a nivel cualitativo del proceso que queremos representar, pero en cambio nuestro conocimiento cuantitativo es insignificante. Por lo tanto, en este caso la posibilidad de expresar un proceso como un conjunto de ecuaciones matemáticas 
detalladas no existe, o las ecuaciones resultantes serán demasiado complicadas para resolverlas sin simplificaciones (Steyaert, 1993). Por todo ello, muchas veces el que un modelo sea mejor que otro, es consecuencia de que el fenómeno que estamos tratando de representar es más fácil de escribir en ese lenguaje matemático que aquel otro fenómeno.

Por ello, los modelos no se deben considerar nunca como una herramienta objetiva y directa para la toma de decisiones, sino que los resultados obtenidos deben ser interpretados y adaptados de la mejor forma posible a las necesidades que en cada caso demanda la sociedad. La figura 3.1. recoge la representación esquemática de cómo funcionaría un modelo de calidad del aire.

Figura 3.1. Representación esquemática de un modelo de calidad del aire.

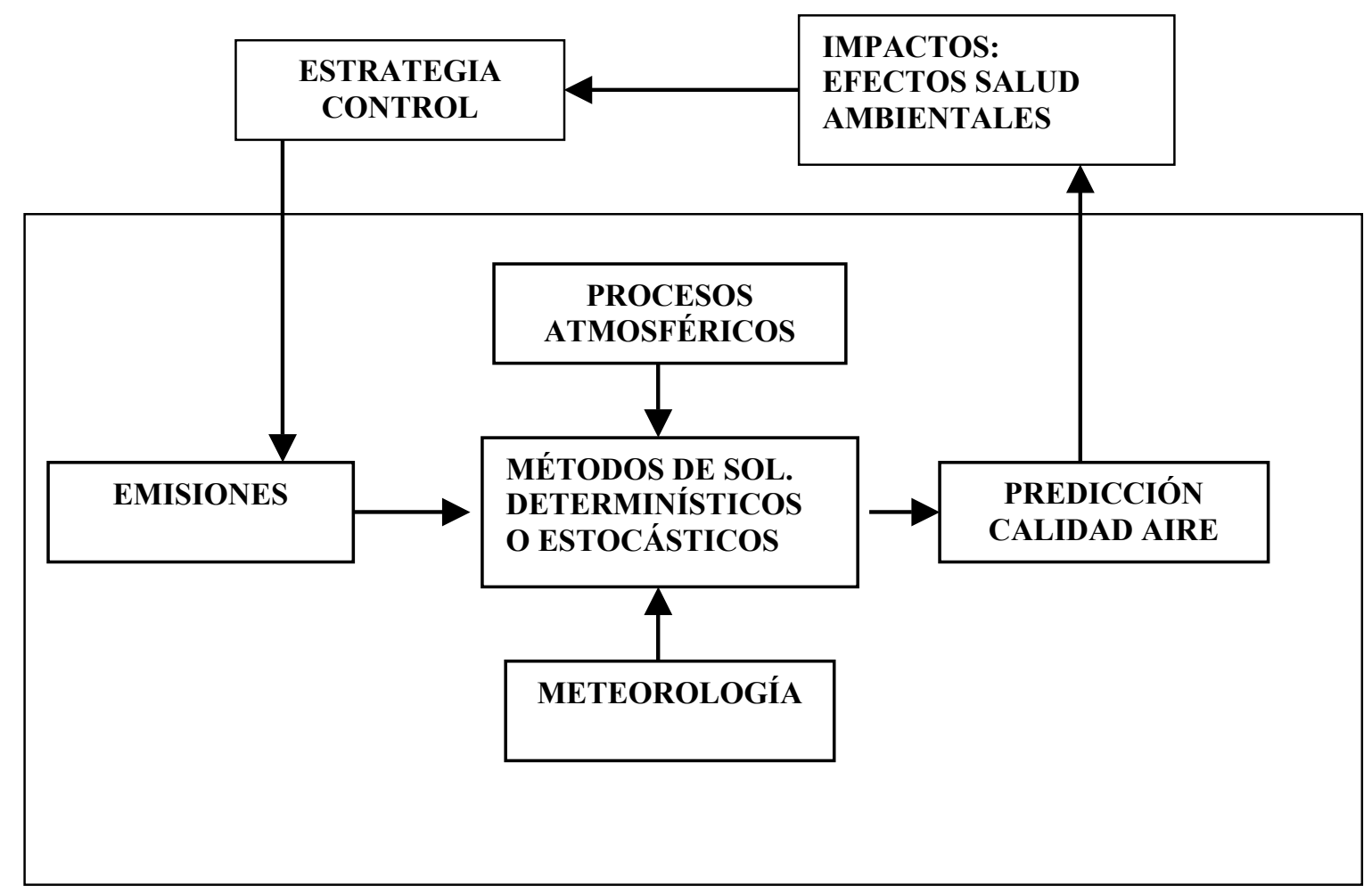


El empleo de modelos como herramienta científica no es una tarea exclusiva en medio ambiente, pues otras disciplinas emplean la misma técnica, cuando problemas y sistemas complejos están bajo investigación. La idea subyacente en el uso de modelos como herramientas científicas, puede describirse como el desarrollo interactivo de un esquema. Cada vez que podamos concluir que tanto el modelo como la hipótesis es correcta, podremos añadir una nueva pieza al esquema global del proceso, y por tanto esto supondrá en definitiva, un mejor entendimiento de la naturaleza del sistema analizado.

\subsubsection{ELEMENTOS EN LA MODELIZACIÓN.}

Según Jørgensen (1991), un modelo matemático relacionado con el medio ambiente, tiene cinco componentes en su formulación:

1.- Funciones fijas o variables externas. Se trata de funciones o variables de naturaleza externa que influyen en el estado del sistema. En un contexto de gestión, se variaría alguna de estas funciones fijas, para ver cómo influiría esto en el estado del ecosistema. El modelo se emplearía para predecir lo que ocurriría en el ecosistema, cuando las funciones fijas sean variadas con el tiempo.

Las funciones fijas bajo nuestro control, se denominan a menudo funciones de control. Otras funciones fijas de interés en modelos medio ambientales pueden ser las variables climáticas, que en este caso se trataría de funciones fijas no controlables.

2.- Variables de estado. Describen el estado del sistema. La selección de las variables del estado es fundamental para la estructura del modelo. Cuando el modelo se usa en un contexto de gestión, los valores de las variables de estado predichas por cambio en las funciones fijas, pueden ser consideradas como los resultados del modelo, porque el modelo contendrá relaciones entre las funciones fijas y las variables de estado. 
3.- Ecuaciones matemáticas. Se usan para representar los procesos biológicos, químicos y físicos. Describen la relación entre las funciones fijas y las variables de estado. El mismo tipo de proceso puede encontrarse en muchos contextos medio ambientales diferentes, lo que implica que la misma ecuación puede emplearse en modelos diferentes. Esto no implica, sin embargo, que un mismo proceso sea siempre formulado por la misma ecuación.

4.- Parámetros. Son coeficientes en la representación matemática de los procesos. Pueden considerarse constantes para un ecosistema específico o parte de un ecosistema.

5.- Constantes universales. Tales como la constante de los gases y los pesos atómicos, que también se emplean en la mayoría de los modelos.

\subsubsection{PASOS EN EL PROCESO DE MODELIZACIÓN.}

Todo proceso de modelización matemática requiere que se definan tres pasos significativos: calibración, verificación y validación (Jørgensen, 1991).

a) Calibración: Es un intento de encontrar la mejor concordancia entre los datos observados y los obtenidos con el modelo, mediante el ajuste de algunos parámetros seleccionados.

Debe llevarse a cabo mediante prueba y error, o con el empleo de software desarrollado para encontrar los parámetros que den la mayor coincidencia entre los valores observados y los obtenidos con el modelo. En algunos modelos estáticos y en algunos modelos sencillos, que contengan unos pocos parámetros bien definidos o medidos directamente, puede no requerirse la calibración.

b) Verificación. Es una prueba de la lógica interna del modelo. La verificación es en gran parte una comprobación subjetiva del comportamiento del modelo. 
Generalmente la verificación se realizará durante el empleo del modelo, antes de la fase de calibración, anteriormente mencionada.

c) Validación. Consiste en un test objetivo en el que se comprueba cómo los datos obtenidos con el modelo se adecuan a los datos observados. La selección de posibles test objetivos dependerá de los propósitos del modelo, aunque a menudo se emplean las desviaciones estándar entre las predicciones del modelo y las observaciones, y una comparación de los valores máximo y mínimos observados y los predichos.

\subsubsection{ETAPAS EN LA CONSTRUCCIÓN DE UN MODELO.}

De acuerdo con Jørgensen (1990, 1991, 1999), antes de iniciar el desarrollo de un modelo, es siempre necesario definir el problema y el sistema que quiere estudiar. Esta es la única forma en que pueden emplazarse correctamente los datos, evitando que la investigación se disperse en actividades irrelevantes. Para este primer paso será necesario acotar el sistema mediante parámetros de espacio, tiempo y subsistemas. Limitar el problema en espacio y tiempo es normalmente sencillo, y consecuentemente mucho más explícito, que la identificación de los distintos subsistemas que hayan de incorporarse al modelo.

Es difícil, al menos cuando comienza a desarrollarse un modelo, determinar el número óptimo de subsistemas que han de incluirse en el mismo para alcanzar un nivel aceptable de precisión según el objetivo esperado. Cuanto más complejo sea un modelo, mayor número de parámetros contendrá, aumentando también así su nivel de incertidumbre. Muchos parámetros habrán de ser calculados en nuevos experimentos de laboratorio o estimados mediante calibración, lo que siempre va unido a nuevos errores, que se irán arrastrando a lo largo de todo el proceso y que contribuirán con ello a la incertidumbre.

Una vez que hayamos decidido cual va a ser la complejidad del modelo, al menos en un primer intento, deberemos intentar desarrollar un diagrama 
conceptual del mismo, que nos dará información de qué variables de estado, funciones de control y procesos se requieren. De forma ideal, debiera determinarse el número y tipo de datos necesarios para el modelo a partir de un diagrama conceptual, aunque en la realidad, lo que ocurre es que la mayoría de los modelos han sido desarrollados después de tener recogidos los datos, limitando así los objetivos y resultados del mismo.

El siguiente paso es la formulación del proceso en términos de ecuaciones matemáticas. Muchos procesos pueden ser descritos por más de una ecuación, y puede ser de gran importancia para los resultados elegir la correcta según el caso de estudio.

Una vez que se dispone de las ecuaciones matemáticas, puede llevarse a cabo una verificación del modelo. Se trata de una prueba de la lógica interna del mismo, a través de la cual se observa si reacciona tal y como se esperaba, si es estable a largo plazo, si sigue la ley de la conservación de la materia, etc. Este paso es, en gran medida, una comprobación subjetiva del comportamiento del modelo, que se realiza mientras se pone en funcionamiento el sistema, antes de la fase de calibración.

El análisis de sensibilidad sigue a la verificación. A través de este estudio, el científico puede tener una idea de los componentes más sensibles del sistema, tanto de los parámetros como de las funciones fijas, submodelos o variables de estado.

A continuación, se llevará a cabo la calibración del modelo. Se trata de un intento de encontrar la mejor concordancia entre los datos observados y los obtenidos con el modelo, mediante el ajuste de algunos parámetros seleccionados. Debe llevarse a cabo mediante pruebas de ensayo y error, o con el empleo de sofwares específicos desarrollados para encontrar los parámetros que den la mejor coincidencia entre los valores observados y los obtenidos con el modelo. En algunos modelos estáticos y en algunos modelos sencillos, que contengan unos pocos parámetros bien definidos o medidos directamente, puede no requerirse este 
paso, aunque, en general, puede decirse que la calibración es necesaria en el desarrollo de modelos medio ambientales, debido a que:

1.- Muchos de los parámetros empleados no son conocidos en su valor exacto. A veces, incluso, tendremos que hacer uso de métodos de estimación de parámetros cuando no se encuentre algún valor deseado.

2.- Todos los modelos biológicos son simplificaciones de la naturaleza, que incluyen los procesos y componentes más importantes pero no todos los detalles. En cierta medida, puede que algunos componentes no considerados en el desarrollo del modelo puedan emplearse en la calibración.

Por ello, el científico, debe observar el comportamiento del modelo cuando varía uno o dos parámetros a la vez, observando sobre todo la respuesta de las variables de estado más importantes. En algunos casos, es posible separar el modelo en submodelos, para poder calibrarlos de manera independiente. Este método de calibración, aunque esté basado en una técnica sistemática, no deja de ser un procedimiento de ensayo y error.

Una vez calibrado el modelo, el siguiente paso es su validación. Se trata de una prueba objetiva en la que el científico comprueba el funcionamiento del modelo, empleando un conjunto independiente de datos. Es importante destacar que la validación sólo confirma el comportamiento del modelo bajo el rango de condiciones representadas por los datos disponibles. Por ello, es preferible validar empleando datos conseguidos en un período distinto de los usados para la calibración previa. 


\subsubsection{PROBLEMAS DE LOS MODELOS DE CALIDAD DEL AIRE.}

Hay dos grandes problemas inherentes en los modelos de la calidad del aire, uno es la incertidumbre en las predicciones y otro es el pobre control experimental para su validación (Zannetti, 1993). Los puntos críticos en el desarrollo de modelos numéricos de calidad del aire son los datos de las emisiones, el conocer las clases de estabilidad y las características de las inversiones de temperatura, así como los relacionados con los campos de viento (Cirillo et al., 1990).

La incertidumbre en las predicciones se debe fundamentalmente a cuatro aspectos que afectan al modelo:

a) La calidad de los datos de entrada en el modelo (datos de emisión y datos meteorológicos).

b) Mayor o menor capacidad del algoritmo utilizado para representar el fenómeno tal y como tiene lugar en la naturaleza.

c) Fenómenos estocásticos inherentes a la dinámica atmosférica.

d) Discordancia entre los valores medidos con los predichos por el modelo.

Los valores de los distintos parámetros meteorológicos y observaciones de la calidad del aire son fenómenos estocásticos, desde el momento que cada valor particular depende de una función de distribución de una serie de valores, todos ellos igualmente probables. Esta propiedad estocástica de los datos de partida, hace que estemos asumiendo desde el principio una cierta incertidumbre en la predicción del sistema.

El segundo gran problema que presentan estos modelos es el pobre control de los datos para la validación de estos modelos. Puesto que el propósito de un modelo de calidad del aire es introducirle ciertos cambios en la calidad del aire, 
con objeto de poder adoptar distintas estrategias encaminadas en cada caso al control de la forma más racional posible. Con el empleo de estos modelos, la validez de las estrategias adoptadas tiene que ser comprobada a posteriori.

En general, los modelos de calidad del aire, pueden estar basados en análisis empíricos de los datos de contaminación o pueden estar basados en una serie de principios físicos y/o meteorológicos que sirven de base para el desarrollo de estos algoritmos.

\subsubsection{CLASIFICACIÓN Y TIPOS DE MODELOS.}

Los modelos usados en el análisis de la calidad del aire, los podemos clasificar atendiendo a varios criterios. Atendiendo al criterio de la metodología utilizada para la resolución de las ecuaciones que conforman el modelo, podemos clasificarlos en dos grandes grupos: modelos deterministas y modelos aleatorios.

Dentro de los modelos deterministas a su vez, podemos distinguir entre modelos analíticos y modelos numéricos, basándonos en la metodología utilizada para la resolución de las distintas ecuaciones que conforman el modelo. Como modelos aleatorios, tendríamos los modelos estadísticos, que se fundamentan en los principios de la estadística para la construcción y resolución de las ecuaciones que los conforman. Así, Zaneti (1993), habla de modelos empíricos o estadísticos y modelos analíticos o determinísticos, como queda reflejado en la figura 3.2.

Otra posible clasificación, quizás más apropiada para estudiar la fracción biótica del aerosol atmosférico, es atender a la forma de plantear el problema, pudiendo distinguir entre modelos de fuente y modelos de receptor. En los últimos años, se ha intentado desarrollar modelos bajo el epígrafe de "modelo receptor híbrido", que trata de aprovechar los puntos de vista de ambos, para abordar el problema de la modelización de algunos sistemas biológicos (Currie, 1992). 
Figura 3.2. Esquema que recoge los diferentes tipos de modelos matemáticos, junto con las entradas y salidas.

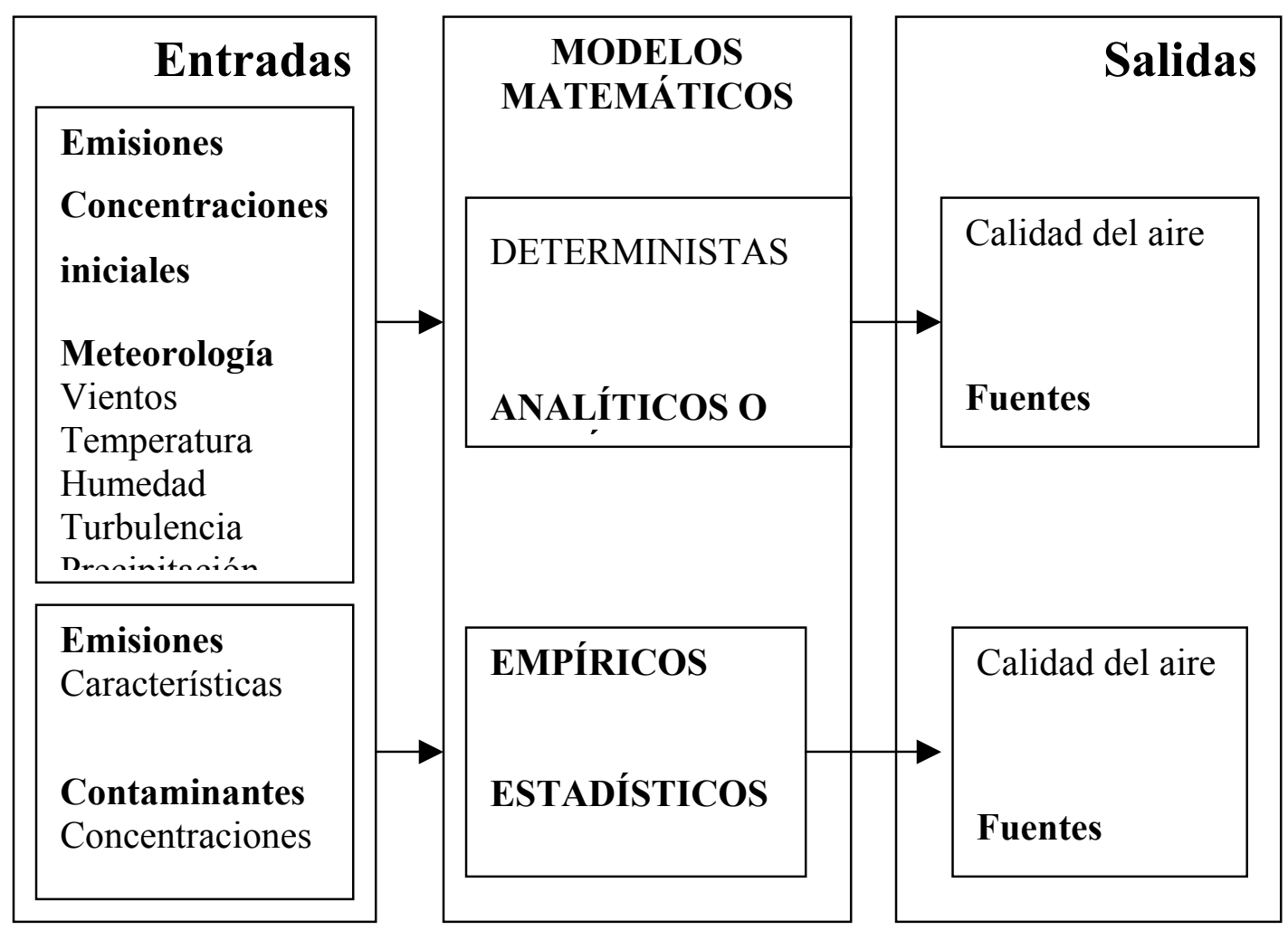

La capacidad de pronosticar las concentraciones de ciertos contaminantes en áreas concretas es esencial para alcanzar y mantener las normas de calidad del aire. Por ello, es necesario desarrollar modelos de dispersión que permitan conocer las concentraciones a nivel del suelo y simular el proceso atmosférico.

Los modelos de fuente, relacionan los distintos parámetros meteorológicos con los niveles de contaminación del aire, simulando con todo ello los procesos de transporte y dispersión de los contaminantes, para pronosticar las inmisiones en una red espacial y temporal. En la figura 3.3. se presenta de forma esquemática el funcionamiento de un modelo de fuente (Burleigh et al., 1979).

En este tipo de modelos, tenemos como datos de entrada en el modelo, las condiciones meteorológicas y la emisión total de las distintas fuentes 
contaminantes. Como datos de salida, se tendrán las predicciones de las concentraciones de contaminantes y su variación en el espacio y en el tiempo.

Los distintos procesos físicos y/o químicos que transforman las emisiones de las fuentes contaminantes en las concentraciones finalmente observadas en los puntos de muestreo, son representados a través de los distintos algoritmos matemáticos que conforman el modelo.

Figura 3.3. Funcionamiento de un modelo de fuente.

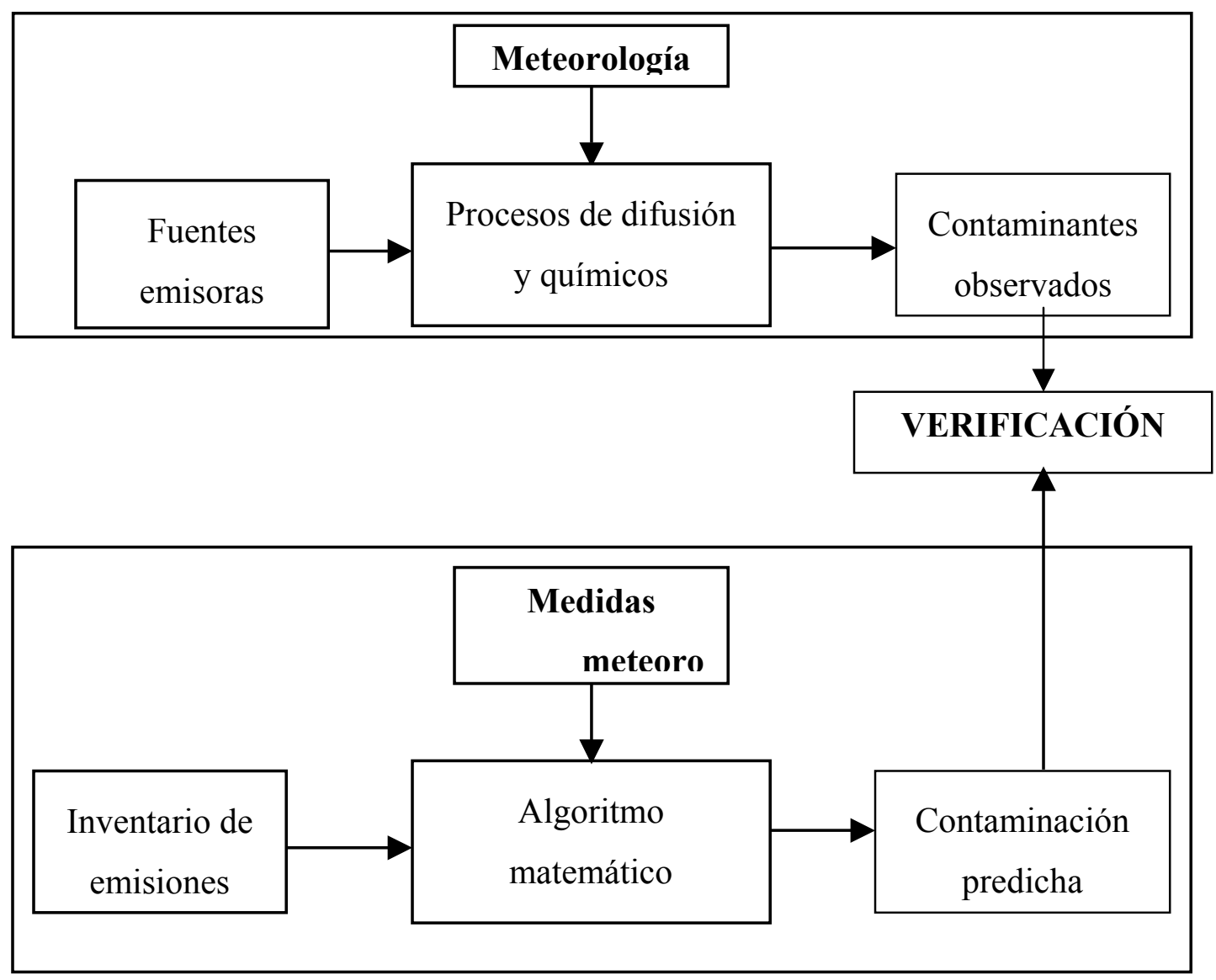

Estos modelos pueden ser aplicados a todos los materiales susceptibles de ser transportados en la atmósfera, por lo que podrían ser aplicados en la modelización de sistemas aerobiológicos. 
En función del área considerada para el estudio, se pueden clasificar a su vez en macroscálicos, mesoscálicos y microscálicos. También se pueden clasificar en función de la metodología utilizada para la resolución, en analíticos, numéricos y estadísticos.

Los modelos analíticos llegan finalmente a una solución analítica de las ecuaciones planteadas, tras hacer previamente grandes simplificaciones. Están basados en los trabajos de Pasquill, Turner (1994). En general, no tendrán en cuenta las reacciones químicas, más allá de las reacciones de primer orden. Se sustentan en emisiones en estado estacionario, por lo que no se pueden aplicar para emisiones discontinuas, como es el caso de los sistemas aerobiológicos. No tienen en cuenta la variación del viento sobre la zona bajo estudio.

Los modelos numéricos se basan en la resolución de la ecuación de difusión turbulenta. Este tipo de modelos eliminan las limitaciones de los modelos gaussianos. Se pueden utilizar para aire de entornos urbanos y para poluciones de amplia gama de transporte, y son fácilmente adaptables a terrenos complicados. También son válidos para contaminantes que pueden reaccionar y generar otros contaminantes secundarios. Tienen importantes requerimientos en cuanto a tiempo y capacidad de las computadoras con las que se trabaja. Por otro lado, requieren una gran cantidad de datos de entrada y elevados requerimientos de cálculo.

A su vez, atendiendo a la forma de solucionar el problema, podemos distinguir en:

\section{Modelos Eulerianos}

El transporte de contaminantes inertes puede ser simulado con la ayuda de modelos que resuelven la ecuación de difusión atmosférica y la ecuación de conservación de la masa. Estos modelos suelen estar embutidos en modelos de pronóstico meteorológico. Modelos de este tipo avanzados, incluyen submodelos para la descripción de la turbulencia. Emplean un sistema de coordenas fijas. 
Estos modelos resuelven las ecuaciones en los puntos de una malla tridimensional en cada intervalo de tiempo.

\section{Modelos Langragianos}

Consisten en el seguimiento de un elemento fluido, usando un cierto número de partículas ficticias para simular la dinámica del movimiento del fluido. El movimiento de estas partículas puede ser determinístico o semialeatorio (técnicas de Montecarlo). Utilizan un sistema móvil de coordenadas y se emplean mucho en modelos de lluvia ácida.

Por otro lado, los modelos estadísticos establecen las ecuaciones predictivas que se ajustan a los datos experimentales mediante análisis de regresión múltiple, en los que, normalmente se incluyen las variables que dominan el proceso, seleccionadas tras un estudio previo de correlación entre las mismas, seleccionando aquellas que resultan ser más relevantes para las concentraciones que se pretenden predecir.

Otra forma de plantear el problema es empezar con las concentraciones observadas en el receptor e intentar definir la contribución de las diferentes fuentes contaminantes a los niveles de calidad del aire.

El concepto de modelo receptor en su sentido más estricto ha sido mal empleado en los últimos años por algunos investigadores para referirse a la modelización en ciencias biológicas, como muy bien señala Currie (1992).

En los modelos de receptor a partir de los datos de inmisión, y conociendo las características de las fuentes, así como algunas características de la dispersión, se estiman las contribuciones de las distintas fuentes potencialmente contaminantes. Podemos distinguir a su vez distintos tipos, en función del principio utilizado para definir la contribución de cada fuente.

Así, Watson (1979), hace referencia a varios tipos de modelos de receptor con entidad propia: 
- De balance químico de materia: Con este planteamiento, conociendo la composición de las emisiones de cada fuente y los niveles de inmisión, se establece un balance de materia para cada especie medida, para estimar la contribución de cada fuente a los niveles de contaminación registrados.

- Factores de enriquecimiento: Es una doble normalización, en la que se utiliza la ratio que hay entre un elemento y un elemento de referencia en dos medios, que generalmente se utiliza para definir si se trata de un contaminante con un origen natural o antropogénico (Alloway, 1995).

- Análisis factorial: Método multivariable reductivo, que permite describir la información relevante contenida en las observaciones en un pequeño número de factores, que explican un alto porcentaje de la varianza del conjunto. En esta aplicación cada factor se asimilará a una fuente (Bisquerra, 1989; Hopke, 1992).

- Correlaciones de series temporales: Las concentraciones ambientales son medidas como una función del tiempo. Aquellas que muestran las mismas fluctuaciones se asocian con una fuente común. La regresión lineal de una concentración con otra proporciona información sobre las relaciones de concentración en la fuente.

La estimación se hace en base a patrones de comportamiento anteriores, relaciones existentes o predicciones subjetivas. Así, algunos autores basándose en estas formas de estimación, clasifican los métodos predictivos en univariados (usan patrones ya existentes); multivariados (utilizan las relaciones existentes entre variables múltiples) y cualitativos (utilizan métodos y decisiones subjetivas) (DeLurgio, 1998).

Los métodos univariados también se conocen como métodos de series temporales, utilizan el pasado, es decir, el comportamiento interno de los datos en una serie, para predecir nuevos valores. Estos métodos incluyen el suavizado, el suavizado exponencial, la descomposición, el análisis de series de Fourier, 
modelos ARIMA, tendencia lineal y modelos no lineales de crecimiento, etc. (DeLurgio, 1998).

Una serie temporal es un conjunto de observaciones tomadas en un lugar específico, asociada a la evolución en el tiempo de alguna variable en particular. Las series temporales se dan en gran variedad de fenómenos naturales y originados por el hombre y la contaminación del aire constituye un buen ejemplo de serie temporal ambiental (Salcedo et al., 1999).

La metodología que normalmente se utiliza para la estimación de los parámetros ambientales está basada en la estadística descriptiva clásica, pero los valores obtenidos están muy limitados, debido a la gran variabilidad asociada a los datos de calidad del aire y la baja relación señal-ruido de las medidas disponibles. El análisis de series temporales puede ser una buena aproximación para esquivar estos problemas, permitiendo la identificación de comportamientos determinísticos ocultos y por lo tanto, contribuyendo a un mejor entendimiento de las relaciones causa efecto en los problemas ambientales (Salcedo et al., 1999).

Los modelos multivariables de predicción, también llamados métodos causales, hacen las prediciones del futuro por la modelización de las relaciones existentes entre una serie con otras. La variable que se pretende conocer es lo que se llama variable dependiente o predicha y las otras variables son las variables independientes o predictoras. Los métodos multivariables incluyen la regresión simple y múltiple, análisis multivariable de series temporales, etc. (DeLurgio, 1998).

La aplicación del análisis factorial o del análisis de cluster a una matriz de correlación inicial formada por los datos ambientales permite identificar ciertas "funciones naturales" que se identifican como fuentes, en los modelos de receptor, o pueden ser utilizadas para la identificación de situaciones meteorológicas tipo (Kalkstein et al., 1986). 
En los estudios de contaminación atmosférica se visualizan algunos resultados como series temporales, pero la distribución de la contaminación en la atmósfera tiene un componente espacial muy importante. El análisis espacial de los datos de calidad del aire, incluyendo los aerobiológicos, es no sólo un intento fundamental, que puede ayudar a comprender el comportamiento de las partículas en el aire sino que es esencial para definir y optimizar las redes de control ambiental (Comtois, 1999).

\subsubsection{MODELIZACIÓN EN AEROBIOLOGÍA.}

Las concentraciones diarias de polen varían ampliamente sobre todo como consecuencia de los propios ritmos de floración de las plantas, así como de las condiciones meteorológicas (Hyde y Adams, 1960), por lo que la modelización de los sistemas aerobiológicos es bastante más complicada que en otros casos donde las condiciones de la fuente emisora y meteorológicas son más fáciles de predecir.

Di-Giovanni et al. (1989), dicen que para modelizar el movimiento de partículas en la atmósfera se puede utilizar dos tipos de modelos: modelos físicos o modelos orientados a la fuente, que han sido muy utilizados con fines científicos y predictivos; y modelos empíricos o modelos orientados al receptor.

Varios autores han desarrollado de forma sistemática, métodos para predecir las concentraciones polínicas con cierta antelación (Raynor y Hayes, 1970; Bringfelt, 1979; Bringfelt et al., 1982), pero estos modelos no han sido pensados para aplicar en la práctica, puesto que están basados en una recogida polínica que ha ocurrido con anterioridad, desarrollando modelos que no validan ni son usados para realizar predicciones. Se fundamentan en el análisis de amplias series temporales, con objeto de poder identificar un patrón típico de comportamiento. Todos ellos tienen en común el considerar que el comportamiento que ha tenido lugar en el pasado se va a repetir en el futuro.

Algunos investigadores introducen técnicas novedosas, tratando de predecir las concentraciones polínicas diarias a partir de estimar la severidad 
potencial de la estación polínica, como es el trabajo desarrollado para la predicción de la concentración diaria de Poaceae (Norris-Hill, 1995), aspecto éste muy importante, debido a las importantes variaciones de los recuentos de un año a otro, a diferencia de algunos otros tipos arbóreos.

Otros autores (Raynor y Hayes, 1970), consideran que hay básicamente dos métodos para predecir las concentraciones atmosféricas de cualquier contaminante en un lugar específico. Así hablan de modelos de fuente y modelos de receptor.

Años más tarde, de nuevo Norris-Hill (1995), comenta que para abordar la modelización de la concentración de polen en la atmósfera, se pueden adoptar dos soluciones válidas: modelos de fuente y modelos de receptor. Considera que son los modelos más apropiados para aquellos casos en los que la fuente no es fácil de ubicar, como ocurre en la mayoría de los casos, cuando se habla de contaminantes de origen biótico.

No obstante, cualquier modelo predictivo requiere un análisis detallado de los distintos factores que gobiernan todo el proceso, así como una comprensión relativa de estos factores para las diferentes circunstancias que se pueden presentar (Galán et al., 1995).

Los modelos orientados a la fuente, utilizan fórmulas matemáticas de difusión, para calcular las concentraciones a cierta distancia de la fuente o para definir la liberación de esta. Ejemplos de este tipo de modelos, son el modelo Gaussiano, el paso de función (Step-Function), los modelos curvilíneos y los modelos de caja.

Todos estos modelos tienen como aspecto en común, el que hacen una serie de simplificaciones sobre la dispersión de los contaminantes en el ambiente, que deben ser realizadas antes de poder aplicarlo. Todos estos modelos están basados en conocer o estimar ratios de emisión de polen, asumiendo que el aire responsable del transporte y dispersión pasa sobre una superficie lisa $\mathrm{y}$ 
considerando que la fuente emisora está perfectamente localizada en un punto muy concreto.

Para poder trabajar con modelos de fuente es necesario conocer las emisiones o poder estimar la contribución de las distintas fuentes individuales, o de todas aquellas regiones de las que el polen podría llegar hasta el lugar en donde se quiere realizar la predicción. En este caso, las concentraciones son calculadas tras la aplicación de una ecuación matemática de difusión y adicionando las distintas fuentes individuales.

Este método requiere una buena estimación de las distintas variables meteorológicas más relevantes, así como un buen conocimiento de las fuentes productoras. Así, en un estudio de la dispersión y deposición de los granos de pólenes de fuentes naturales (Raynor y Hayes, 1970), demostraron que las características de la fuente productora y meteorológicas, son aspectos más relevantes en la predicción que las propias características físicas de cada tipo polínico.

Di-Giovanni y Beckett (1990), para modelizar la cuantificación de la dispersión del polen en una atmósfera turbulenta, mediante el empleo de un método continuo, recurren a la resolución de una ecuación diferencial que gobierna los fenómenos de convección y dispersión en la dirección predominante del viento. Esta ecuación está sujeta a las condiciones de la capa en donde tienen lugar estos fenómenos. No obstante, ponen de manifiesto algunas limitaciones de esta ecuación, como son el utilizar una constante para la velocidad de deposición y la descripción que hace de los fenómenos de sedimentación, indicando que al considerar una velocidad de sedimentación constante, se comenten errores importantes cuando se aplica a espacios bien abiertos, mientras que para bosques o áreas más densas o de difícil circulación del viento, los errores son menores.

Son bastantes los casos en los que se han empleado modelos de fuente basados en la dispersión de gases, para modelizar la dispersión de partículas en la atmósfera. El más sencillo de todos ellos, es el que se basa en una descripción 
estadística para la dispersión gaseosa, aunque este no es el más adecuado para las partículas de origen biótico, como muy bien señala McCartney y Fitt (1985). Por ello, él desarrolla un modelo que aunque trata el problema como un proceso de difusión, introduce una serie de modificaciones que tienen en cuenta los procesos de sedimentación y deposición de estas partículas.

Giostra et al. (1991), desarrollaron en Italia un modelo para predecir los niveles de inmisión y el transporte de polen en la capa de mezcla. Este modelo asumía que las características del terreno como de la fuente productora son homogéneos en una distancia de $10 \mathrm{~km}$. Este modelo para hacerlo funcionar, precisaba de una estimación de la producción de polen, así como de la temperatura y otros parámetros atmosféricos análogos.

Por tanto, este tipo de modelos aplicados a pólenes y esporas, proporcionan unos resultados bastante deficientes, puesto que interviene el viento a su libre elección en la/s trayectorias a seguir. Este comportamiento impredecible del viento, es lo que no recogen nada bien este tipo de modelos.

Como puede derivarse de las distintas consideraciones que hacen estos modelos, es muy difícil encontrar estas condiciones en la realidad, por lo que estos modelos son frecuentemente utilizados cuando se quiere estimar la producción de polen de un área muy bien definida o cuando se trata de una fuente puntual. Fundamentalmente, estos modelos se han utilizado para modelizar la dispersión de polen y esporas de determinadas áreas de cultivo muy bien definidas (McCartney, 1994).

Otro modelo de este tipo, es el desarrollado en Japón (Kawashima y Takahashi, 1995), para simular los procesos de emisión y dispersión de polen procedente de Cryptomeria japonica, con el objetivo de calcular la distribución mesoscálica de éste, a partir de mapas de vegetación y una completa y densa red meteorológica. 
En definitiva, hemos de decir que son modelos que dan resultados muy valiosos para aquellos casos en los que la fuente productora o emisora de contaminantes es fácil de ubicar, como puede ocurrir en el caso de contaminantes de origen industrial, pero para contaminantes que tienen un origen biológico es mucho más difícil su aplicación.

Por ello, Norris-Hill (1995) señala que ninguna de las características que presenta la ciudad de Londres es apropiada para la aplicación de un modelo de fuente, ya que es muy difícil conocer las ratios de emisión de polen así como los procesos de liberación, en los que juegan un papel fundamental la meteorología y los ritmos biológicos.

Además de todos estos aspectos, como muy bien señala Oke (1973), en la simulación de estos modelos interviene la topografía, así en algunas ciudades se pueden generar turbulencias que pueden influir en la dispersión de las partículas.

Como consecuencia de las deficiencias que presentan este tipo de modelos, en los últimos años se ha introducido los modelos de "Markov" para modelizar la dispersión de partículas en la atmósfera. Estos modelos parecen tener el potencial necesario para reproducir el complejo comportamiento del viento en determinadas zonas (MaCartney, 1986).

Otra alternativa para predecir la concentración polínica, es la utilización de modelos orientados al receptor. En este tipo de modelos se pretende conocer las concentraciones a nivel del receptor, sin incluir para su desarrollo datos de las emisiones. Hay que resaltar en primer lugar, que como muy bien señala Currie (1992), en los últimos años y de forma errónea se utiliza el concepto de modelo de receptor para la modelización estadística en el contexto de la ciencias biológicas, cuando en realidad están realizándose modelos de fuente, ya que predicen concentraciones a nivel de receptor, mientras que como ya hemos explicado anteriormente, los modelos de receptor intentan definir contribuciones de diferentes fuentes. 
Dentro del campo de la modelización en aerobiología y en este grupo se engloban la totalidad de los modelos estadísticos que hasta el momento se han desarrollado para la predicción de la contaminación de origen biológico. El criterio adoptado para ello, es que para su desarrollo no se precisa prácticamente de características de la fuente productora, como señala Norris-Hill (1995).

Estos modelos tratan de predecir las concentraciones, sin tener conocimiento de las características de la fuente ni cálculos de transporte y difusión. Es una manera de abordar el problema, en la que la predicción se hace a partir de conocer la relación que existe entre las concentraciones registradas con anterioridad y otras variables que pueden ser medidas o predichas (Raynor y Hayes, 1970; Norris-Hill, 1995).

Dentro de los modelos orientados al receptor, o modelización estadística en Aerobiología, el problema se puede abordar mediante el empleo del análisis de regresión múltiple o regresión logística, en función de los datos que se tengan de partida.

La regresión múltiple estudia las relaciones entre una variable dependiente y un conjunto de variables independientes. Un aspecto importante en el análisis de regresión múltiple es la selección de las variables en el estudio, con el fin de incluir todas aquellas variables relevantes en el estudio y dejar fuera a aquellas que no lo son. Para ello, uno de los primeros pasos es el cálculo de la matriz de correlación (Bisquerra, 1989), que permite definir las variables relacionadas con la variable dependiente. Además, los paquetes informáticos disponen de la opción paso a paso a la hora de desarrollar el modelo de regresión múltiple, lo que permite llegar a un modelo en el que todas las variables incluidas incumplen el criterio de salida y todas las variables excluidas incumplen el de entrada (Ferranz Aranaz, 2001)

Muchos autores han desarrollado con anterioridad modelos predictivos, usando para ello el análisis de regresión múltiple (Davies y Smith, 1973). Algunos, han desarrollado procedimientos para la construcción de modelos de 
predicción de concentraciones polínicas, utilizando para ello el análisis de extensas series temporales. En Estocolmo, utilizaron las condiciones meteorológicas para desarrollar modelos estadísticos que permitieran predecir las concentraciones polínicas con anterioridad (Bringfelt et al., 1982).

Por otro lado, como han puesto de manifiesto algunos investigadores, cuando los contenidos polínicos diarios están relacionados entre sí, parece bastante razonable utilizar algunas técnicas de modelización de series temporales en este campo (Moseholm et al., 1987).

Años más tarde (Galán et al., 1995), utilizan modelos basados en la regresión múltiple, utilizando como variable dependiente los registros polínicos y como variables independientes las características meteorológicas, para realizar un estudio comparativo de los contenidos polínicos de la ciudad de Londres y Córdoba, entre el año 1987 y 1991.

Norris-Hill (1995), desarrolla modelos para predecir la concentración diaria de Poaceae, utilizando para ello una ecuación polinómica de tercer grado y las distintas variables meteorológicas acumuladas. En concreto, como variables predictoras del modelo considera la temperatura media acumulada, lluvia diaria, humedad relativa y temperatura máxima.

Otros autores, para el desarrollo de estos modelos, sólo tienen en cuenta los datos de concentración y meteorológicos registrados en el periodo pre-pico, con lo que se mejora bastante el resultado finalmente obtenido. Así, Recio et al (1996), desarrollan modelos predictivos de regresión lineal y múltiple para Olea europaea L. en la ciudad de Málaga.

Fue a partir de los años 60, cuando se generalizó el empleo de modelos logísticos en los estudios epidemiológicos, para analizar el efecto individual y puntual dentro de un conjunto de variables, implicadas en el riesgo de aparición de una determinada enfermedad (Bayo, 1998), que en nuestro caso serían los síntomas que manifiestan las personas alérgicas al polen. 
La regresión logística, resulta útil en aquellos casos en los que se quiere predecir la presencia o ausencia de una determinada característica o resultado según los valores de un conjunto de variables de predicción o independientes, que pueden ser cuantitativas o cualitativas (Ferránz-Aranaz, 2001). Es por tanto similar a la regresión lineal, pero se ajusta a modelos donde la variable dependiente es dicotómica. Los coeficientes que nos proporcionan estos modelos pueden utilizarse para estimar la conveniencia o no de introducir una variable como independiente dentro del modelo.

Por otro lado, las variables independientes pueden ser numéricas o categóricas, lo que en algunos casos como dirección del viento, rango de velocidad, presiones, etc., puede resultar más fácil de reflejar en el modelo, que en el caso de los modelos de regresión múltiple.

En definitiva, un modelo de regresión logística nos permite establecer asociaciones estadísticas entre las variables independientes o predictivas y la variable dependiente o de salida, pudiendo describirse el efecto que tiene una cierta variable independiente en la respuesta, según la presencia o ausencia de la misma. Además, puede determinarse la importancia de cada variable incluida en el modelo y averiguar cual o cuales son las variables que realmente contribuyen a la respuesta, cuantificando así mismo su contribución (Domínguez-Rojas et al., 1993).

Así, entre los modelos de regresión logística que podemos encontrar en la bibliografía destacar en primer lugar el de Domínguez-Rojas et al. (1993), que estudian la influencia que tienen una serie de variables sobre la caída dental.

Años más tarde, Gil et al. (1996), realizan un estudio de características similares con objeto de determinar la relación existente entre el contenido de plomo en el diente y una serie de variables, relacionadas con la salud bucodental.

Bayo (1998), desarrolla modelos de regresión logística para estudiar el contenido en metales pesados en dientes de leche en niños introduciendo como 
variables independientes una serie de variables socioeconómicas, relacionadas con el entorno familiar del sujeto en estudio.

Pearce y Ferrier (2000), usan modelos de regresión logística para predecir la distribución de algunas especies como herramienta en la planificación de la conservación de la fauna y flora regional de New South Wales (Australia).

Las series temporales estudian la variación de los fenómenos a través del tiempo. En síntesis, consisten en secuencias de medidas hechas a intervalos regulares de tiempo. Dentro del análisis de series temporales se han desarrollado dos metodologías fundamentales, el análisis espectral y los modelos autorregresivos integrados de medias móviles (ARIMA) de Box y Jenkins (Bisquerra, 1989). Estos autores desarrollaron un esquema de clasificación para una gran familia de modelos de series temporales (Koutsoyiannis, 2000). El esquema de clasificación distingue entre modelos autorregresivos de orden $\mathrm{p}$ $(A R(p))$, modelos de media móvil de orden q (MA(q)), modelos combinados de ambos ARMA $(p, q)$ y modelos de procesos no estacionarios, con una componente I (integrado) de orden d (Bisquerra, 1989 y DeLurgio, 1998). Cuando las series incluyen oscilaciones cíclicas o variaciones estacionales, que se superponen a una tendencia, se utilizan modelos ARIMA (p,d,q) (P,D,Q), en los que el primer paréntesis hace referencia a la tendencia y el segundo a las variaciones estacionales (Bisquerra, 1989; DeLurgio, 1998).

El proceso de desarrollo de un modelo ARIMA es un proceso exploratorio, en el que se consideran los modelos más útiles, a partir de los cuales se proponen un número de modelos lo más reducido posible. Esta identificación podría ser modificada a través del proceso iterativo. Se estiman los parámetros de cada modelo tentativo y se diagnostica el ajuste de cada modelo a los datos. Si se encuentran desajustes, se repite el proceso iterativo de identificación, estimación de parámetros y diagnóstico del modelo (Bisquerra, 1989; DeLurgio, 1998; Ferrán Aranaz, 2001). 
El análisis de series temporales tiene muchas aplicaciones, así se encuentran gran número de trabajos en los que se aplican modelos ARIMA en estudios en Economía (McGough y Tsolacos, 1994; Foster y Franz, 1995; Tse, 1997; Kaiser y Maravall, 1999; Östermark, 2000; Spedding y Chan, 2000), también para definir el impacto de determinados programas legislativos (Krimmel y Mele, 1998), para extraer reglas de los sistemas flexibles de producción (Ip et al.,1999), en el desarrollo de modelos de simulación y modelos predictivos en hidrología (Koutsoyiannis, 2000), en estudios de contaminación atmosférica (Hogrefe et al., 1998; Hies et al., 2000; Scheff, 2000; Sebald et al., 2000), en criminología, física, geología, botánica, epidemiología, etc. (DeLurgio, 1998).

Algunos autores han puesto de manifiesto la bondad del ajuste mediante una $\chi^{2}$ entre la temperatura y la dispersión de polen (O'Rourke,1988). Otros autores, han utilizado la regresión de Poisson para predecir las concentraciones polínicas de plantas herbáceas utilizando los datos meteorológicos, puesto que consideran que es muy apropiada por las características heterogéneas de la varianza que presentan las concentraciones polínicas, y porque constituye el modelo estadístico apropiado para trabajar con datos que toman siempre valores enteros, como es este caso (Stark et al., 1997).

Mediante la regresión de los datos transformados por el logaritmo natural, determinan qué variables tienen una mayor importancia en los contenidos polínicos, utilizando como variable dependiente los contenidos de polen y como independientes las distintas variables ambientales, incluyendo variables categóricas relacionadas con las precipitaciones y con las temperaturas de la noche. Con todo ello, se predice el contenido polínico del día siguiente (Stark et al.,1997).

Debido a la gran variabilidad que presentan los datos de floración de una misma especie de unos años a otros, son muchos los modelos desarrollados en los últimos años que pretenden predecir el inicio, la severidad y el final de la estación 
polínica, puesto que el fin perseguido es proteger a las personas sensibles a estos pólenes.

Se puede afirmar que el periodo de polinosis comienza cuando el aire contiene un determinado número de granos de polen por metro cúbico. Y si bien, no se conoce muy bien esa relación, se puede asumir perfectamente, que prediciendo el inicio de la estación polínica, se pueden tomar algunas medidas preventivas para paliar los efectos de polinosis.

Para determinar la mejor fecha para iniciar los tratamientos clínicos en aquellas personas alérgicas, Driessen et al. (1990) en Holanda, desarrollaron un modelo para predecir el inicio de la estación polínica de plantas herbáceas.

En Dinamarca, Andersen (1991), estudia las fechas de inicio de la floración durante un largo periodo, para determinar los requerimientos de horas de frío de cada especie, y elaborar modelos predictivos del inicio de la estación.

En Melbourne (Australia) desarrollaron un modelo de regresión lineal con once años de datos, para predecir el comienzo de la estación polínica (Ong et al, 1995). Dahl et al. (1996), en Gothenburg (Suecia), presentaron un modelo para predecir la magnitud de la floración de Betula y la dispersión de éste para controlar la polinosis a este tipo polínico, así como planificar los tratamientos clínicos.

Dentro de este tipo de modelos, algunos investigadores como Emberlin et al. (1993), han desarrollado modelos empíricos usando la técnica estadística de regresión múltiple, en los que utilizando los datos meteorológicos y los registros polínicos de veinte años en la ciudad de Londres, tratan de predecir el inicio, duración y severidad de la estación polínica. Con este tipo de modelos, se puede predecir al inicio de cada año, las principales características de la estación polínica, basándose en las características meteorológicas de los meses anteriores y la meteorología de un periodo de tiempo bastante largo. 
En Bilbao, Antépara et al. (1995), elaboran un modelo mediante el empleo de la regresión polinómica, y observan que la temperatura media acumulada por encima de $9^{\circ} \mathrm{C}$ juega un papel importante en el inicio de la polinización, mientras que son la temperatura media acumulada y la lluvia caída la inicio y durante la polinización los parámetros que resultan decisivos en la duración del periodo de polinosis.

Uno de los objetivos perseguidos por la Aerobiología es poder predecir las concentraciones polínicas con cierta antelación, pero hasta hace poco tiempo esto se reducía al estudio año tras año de las tendencias y fluctuaciones de las cantidades de polen, con el objetivo de establecer patrones de comportamiento que puedan servir para prevenir sobre todo los problemas de alergias en aquellos pacientes sensibles, así podemos citar los trabajos de Reiss y Kostic (1976) en New Jersey (U.S.A.) ó Goldberg et al. (1988), en Dinamarca.

Así, en relación con este tipo de estudios, algunos investigadores han analizado y comparado las concentraciones polínicas registradas durante un elevado número de años, como el estudio realizado considerando cinco estaciones de muestreo en Europa con series que oscilan entre los 18 y 30 años (Spieksma, 1995); o el realizado por Jäger et al. (1996), en cuatro ciudades europeas, con objeto de comparar el inicio de la floración, cuando se alcanza el contenido máximo y cuando finaliza la estación polínica para algunos tipos polínicos.

En California, Fairley y Batchelder (1986), analizan los picos de polen de roble alcanzado registrados durante 9 años, para identificar la relación existente entre producción y meteorología, así como la relación entre la producción y la distribución local de esta especie. 


\subsection{METEOROLOGÍA Y NIVELES DE INMISIÓN.}

\subsubsection{INTRODUCCIÓN.}

Resulta primordial conocer los principios básicos de la atmósfera, puesto que éstos son la base sobre la que se producen y desarrollan los fenómenos y mecanismos meteorológicos. Para el desarrollo del presente capítulo se han consultado los textos que a continuación se citan, por considerarse básicos y cuyo contenido explica muy bien los distintos aspectos meteorológicos (Wark y Warner, 1990; Masters, 1991; Estrela y Millán, 1994; De Nevers, 1998; Seinfeld y Pandis, 1998; Kiely, 1999; Reible, 1999).

Todos los contaminantes del aire, ya sean de origen natural o antropogénico, emitidos por fuentes puntuales o difusas, son transportados, dispersados o concentrados por las condiciones meteorológicas y topográficas locales.

El ciclo de estancia de los contaminantes en la atmósfera, se inicia con la emisión de los contaminantes, seguido por el transporte y difusión de éstos en la atmósfera. El ciclo se completa, cuando éstos se depositan sobre la vegetación, el ganado, las superficies del suelo y del agua, otras superficies o cuando alcanzan finalmente a un receptor sensible, ocasionándole una serie de problemas, cuando son arrastrados de la superficie por acción del agua de escorrentía superficial, o cuando se escapan al espacio. En algunos casos, los contaminantes pueden volver nuevamente a la atmósfera, por la acción del viento (Wark y Warner, 1990).

En lugares muy concretos, como consecuencia de las condiciones meteorológicas y topográficas, se puede producir una acumulación de estos contaminantes, que pueden acelerar el deterioro de ciertas superficies, afectar gravemente a la salud pública, así como a la vegetación de la zona.

En las áreas urbanas, los contaminantes emitidos por numerosas fuentes puntuales, así como de fuentes difusas, se dispersan sobre toda el área geográfica, de forma desigual, dependiendo sobre todo de los vientos existentes, la presencia 
de edificios altos, etc. Si no se deben de superar ciertos valores para algunos de estos contaminantes, será necesario elegir alguna estrategia para establecer las contribuciones de las diferentes fuentes individuales (Wark y Warner, 1990).

Para ello, es necesario conocer los patrones de transporte y dispersión para el área en estudio, basándonos en algunas herramientas actualmente disponibles, como es el caso de la modelización. El resultado del transporte y dispersión de los contaminantes en la atmósfera es la disminución de la concentración de contaminantes en las proximidades de la fuente emisora, respecto de la que había en el momento de iniciarse la emisión.

La dispersión de un contaminante en la atmósfera es el resultado de tres mecanismos dominantes: a) el movimiento medio general del aire que transporta el contaminante en la dirección del viento; b) las fluctuaciones de la velocidad de éste, que se traduce en la dispersión del contaminante en todas las direcciones y c) la difusión de masa debido a los gradientes de concentración (Milford et al., 1993).

Además, las condiciones particulares de cada contaminante, tales como tamaño, forma, peso, afectan a la tasa a la que las partículas de contaminantes no gaseosos, se depositan en la superficie o son mantenidas en suspensión, como es el caso de los granos de los distintos tipos polínicos.

\subsubsection{COMPOSICIÓN DE LA ATMÓSFERA.}

Es fundamental conocer los distintos componentes de la atmósfera, para pasar a continuación a conocer las propiedades físicas y químicas de ésta, así como comprender la importancia y el papel que tiene cada uno de ellos.

La atmósfera está compuesta por una mezcla invisible de gases que rodean la tierra. Los componentes más importantes son el nitrógeno, oxígeno, dióxido de carbono y el vapor de agua, siendo éstas sus composiciones: 78\% de nitrógeno, 
$21 \%$ de oxígeno y $1 \%$ de argón, así como por vapor de agua y otras pequeñas cantidades de otros gases

El nitrógeno es el gas más abundante, y cabe destacar sobre todo su efecto fertilizante, cuando disuelto en el agua de lluvia, aporta nitrógeno a los suelos. El oxígeno, en cambio es muy activo químicamente, y tiene un papel primordial en la biosfera, siendo la fotosíntesis la principal fuente de su formación. El dióxido de carbono está presente en la atmósfera en muy pequeñas concentraciones $(0,03 \%)$.

El vapor de agua, aunque algunos autores consideran que éste no forma parte ni del aire puro ni del seco, sí que tiene una gran importancia en la meteorología. Está presente en la atmósfera en concentraciones hasta del 4\% en volumen. Es el único gas de la atmósfera que puede cambiar de estado, pasar de líquido a sólido, bajo diferentes condiciones de temperatura y presión.

El aire, está formado por moléculas, y por tanto ocupa un espacio y tiene un peso determinado. Sin embargo, el espacio que ocupa o el peso que tiene la atmósfera no es fijo, sino que puede variar.

El aire no ocupa un espacio fijo, porque sus moléculas tienen una gran libertad de movimiento. Además de esta movilidad, las moléculas de aire pueden estar más o menos unidas, es decir, el aire puede estar más o menos comprimido. Cuando las moléculas de aire están muy unidas, cuando está muy comprimido, el aire es denso. Esta densidad del aire, varía en función de la cantidad de moléculas que hay en el mismo espacio, y la proximidad de éstas.

De esta manera, si el número de moléculas se mantiene constante, el aire más denso será el que tiene las moléculas más unidas entre sí. De este modo, el aire en compresión tiene mayor densidad que el aire en expansión. En definitiva, debido a que en el mismo espacio tenemos más moléculas, podemos decir que el aire comprimido es más denso y de este modo más pesado que el aire expandido o en expansión. 
Una vez conocido el concepto de densidad del aire, podemos hablar de presión, como la fuerza ejercida en este caso por el peso del aire. De manera, que el aire en la atmósfera se comprime o expande como respuesta a las diferentes presiones externas. El propio peso del aire hace que en los niveles bajos el aire se comprima y tenga una gran densidad. Esto explica que a pesar de la extensión de varios kilómetros de la atmósfera, la mitad del total de su peso se ejerce por debajo de los 5500 metros (Estrela y Millán, 1994).

A medida que se asciende en la atmósfera el aire se vuelve menos denso y ligero que el aire de capas inferiores. Puede decirse, que en general, la presión disminuye con la altura.

\subsubsection{LA ATMÓSFERA TERRESTRE.}

La atmósfera se divide en varias capas en las que la temperatura y algunas de sus propiedades varían con la altura. Haremos más hincapié en la capa inferior, la troposfera, que es la más importante para analizar los fenómenos meteorológicos que intervienen en el transporte y dispersión del polen.

Desde el punto de vista de la composición gaseosa, nos encontramos con la homosfera y la heterosfera.

La homosfera es la capa que se extiende hasta una altura de $80 \mathrm{Km}$ desde la superficie terrestre, y se caracteriza porque los principales constituyentes gaseosos del aire permanecen prácticamente constantes. Está dividida a su vez en tres capas, la troposfera (la inferior), la estratosfera y la mesosfera.

La heterosfera es la región que se extiende por encima de la homosfera. En esta región tiene lugar la separación de los gases por difusión, tendiendo a concentrarse los más ligeros en las capas superiores. Las concentraciones de oxígeno molecular disminuyen, mientras que con la altura aumenta la concentración de oxígeno atómico. A grandes alturas el hidrógeno y el helio son 
los principales constituyentes. Está constituida a su vez por la temosfera y la exosfera.

La atmósfera no presenta un comportamiento térmico uniforme con la altura, sino que hay niveles en los que existe una disminución de la temperatura con la altura (como ocurre en la troposfera y en la mesosfera), y otros en los que aumenta.

Así, la atmósfera se divide en varias capas atendiendo a la variación de la temperatura y de sus propiedades con la altura. Así, podemos diferenciar las siguientes capas (Estrela y Millán, 1994):

Troposfera. Es la capa en contacto directo con la tierra, y la que más nos interesa por los fenómenos que en ella van a tener lugar. El espesor medio de esta capa es de unos $12 \mathrm{~km}$. Además, el $80 \%$ de la masa atmosférica está en la troposfera, casi la totalidad de las partículas sólidas y del agua. Se caracteriza principalmente por una disminución de la temperatura con la altura a razón de $0,65^{\circ} \mathrm{C}$ por cada 100 metros de altura, porque en ella tienen lugar movimientos turbulentos, tanto verticales como horizontales y porque tiene una composición química constante. La presión disminuye con la altura desde el entorno de 760 $\mathrm{mm}$ de $\mathrm{Hg}$ a nivel del mar y $250 \mathrm{~mm}$ en sus niveles superiores.

El vapor de agua es uno de los componentes que mayor implicación tiene para la meteorología. Su importancia estriba en primer lugar en que está en el origen de la nubosidad y de los hidrometeoros, y en segundo lugar en que tiene la capacidad de absorber radiación de onda larga. El vapor de agua pasa a la atmósfera desde la superficie de la tierra a través de la evaporación de las masas de agua o bien por la transpiración de las plantas. Las tres cuartas partes del vapor de agua están por debajo de los $4 \mathrm{~km}$ de altitud, siendo muy pequeña su concentración por encima de esta altura.

Se denomina tropopausa al límite superior de la troposfera. En ella se detiene bruscamente el descenso de la temperatura con la altura. La altura de la 
tropopausa varía considerablemente, siendo superior en aire cálido que en aire frío.

Estratosfera. Situada sobre la troposfera, debe su nombre a que durante bastante tiempo se consideró que en esta zona de la atmósfera no se producían fenómenos de turbulencias verticales y que, consecuentemente, las masas de aire constituían estratos de composición muy estable.

Hoy se conoce que en la zona existe un grado de agitación que le confieren cierta homogeneidad en su composición. La estratosfera se caracteriza por su extrema sequedad y por la uniformidad de su temperatura, produciéndose un aumento de la temperatura con la altitud, llegándose a alcanzar aproximadamente $\operatorname{los}-2^{\circ} \mathrm{C}$ en la estratopausa. Este aumento de la temperatura es consecuencia de la absorción de radiación ultravioleta procedente del sol por parte del oxígeno y el ozono. Su presión atmosférica es del orden de $25 \mathrm{~mm}$ y de 12 $\mathrm{mm}$ de $\mathrm{Hg}$ en sus zonas medias inferior y superior, respectivamente (Cacho y Sainz, 1989).

Mesosfera. Por encima de los $50 \mathrm{~km}$, la temperatura vuelve a descender hasta alcanzar a una altura de $80 \mathrm{~km}$ un mínimo de aproximadamente $-92^{\circ} \mathrm{C}$ (figura 3.5). La mesosfera es la capa de la atmósfera menos conocida, pues sólo se ha investigado por medio de cohetes, ya que ocupa una altura superior a la que alcanzan los globos sonda y baja respecto a las zonas que se estudian con satélites artificiales.

En la mesosfera los gases están muy enrarecidos, la presión atmosférica es del orden de $0,005 \mathrm{~mm}$ de $\mathrm{Hg}$ y la concentración de ozono se reduce hasta niveles de fracción molar del orden de $10^{-9}$. La radiación que incide en ella incluye junto a los rayos infrarrojos visibles y ultravioleta, los rayos $\mathrm{X}$ y gamma $\mathrm{y}$, en consecuencia, se inician algunos procesos de fotoionización.

Termosfera. En esta capa se produce una inversión del gradiente térmico atmosférico con un nuevo aumento de la temperatura con la altura, de tal modo 
que a una altura $500 \mathrm{~km}$, conocida como termopausa se alcanzan temperaturas de hasta $1200^{\circ} \mathrm{C}$, con cambios de varios centenares de grados entre el día y la noche.

Esta capa que recibe casi toda la radiación solar, y las moléculas, átomos e iones que la integran, absorben una gran parte del espectro ultravioleta lo que determina las elevadas temperaturas reinantes. Por ello, debido a su gran actividad de cambios químicos que ocurren entre sus componentes también se la conoce como quimiosfera.

Exosfera. Se sitúa por encima de los $500 \mathrm{~km}$ y hasta alturas imprecisas, y se trata de una zona en la que la materia está muy enrarecida y consiguientemente la probabilidad de que se produzcan choques eficaces entre los fotones de la radiación incidente y sus componentes es muy limitada.

Los componentes de esta zona son principalmente hidrógeno, oxígeno ión positivo, helio ión positivo, protones y electrones que, aunque sometidos al campo magnético terrestre, también escapan hacia el espacio exterior. Al parecer esta pérdida de materia se compensa con la entrada en el campo gravitatorio terrestre de micrometeoritos y protones que aportan el espacio exterior y el llamado viento solar.

Magnetosfera. Recibe este nombre la región del espacio situada más allá de los $1000 \mathrm{~km}$, en la que se considera que las partículas están electrizadas y continúan sometidas a la atracción del campo magnético terrestre. Su límite superior o magnetopausa se estima que está situado a unos $95.000 \mathrm{~km}$ de la tierra, zona en la que las partículas están ya más sometidas a la atracción de los campos magnéticos solar e interplanetario.

\subsubsection{RADIACIÓN SOLAR.}

El sol es la principal fuente de energía para la mayor parte de los procesos que tienen lugar en nuestro planeta. La energía solar es generada por procesos de fusión nuclear que tienen lugar en el interior del sol, como resultado de la 
conversión del hidrógeno en helio. Como fuente de energía, el interior de la tierra no tiene casi importancia frente a la del sol. En cualquier caso, si la tierra no se calentara no podrían combinarse temperatura y presión para crear cambios en las condiciones atmosféricas.

Debido a que los cambios atmosféricos dependen en gran medida, directa o indirectamente, de la energía que nos llega desde el sol, es importante resaltar los procesos que intervienen en el calentamiento de la atmósfera.

La energía que se genera en el interior del sol pasa a su superficie, desde donde es radiada al espacio. Es sol está constituido por diversos gases a elevadas temperaturas, muy comprimidos y en varios estados de ionización.

El sol a su vez, está constituido por diversas capas. Se conoce como fotosfera al área más luminosa. En ella se pueden diferenciar unas regiones oscuras (frías) que se conocen como manchas solares, y unas áreas brillantes (cálidas) que son los flóculos.

La cromosfera, es la capa formada por gases de hidrógeno y helio a baja presión. En ella se observan fuertes explosiones conocidas como protuberancias. Por encima de ésta se sitúa la corona o capa exterior del sol, constituida por gases muy tenues que se extienden hacia el espacio. El aumento en la actividad del sol se detecta en la cromosfera, que es donde tienen lugar gigantescas explosiones, que expulsan al espacio material solar junto a una mayor emisión de radiación electromagnética.

En cuanto a la naturaleza de la radiación solar, el 99\% de la radiación electromagnética emitida por el sol, se encuentra dentro de la longitud de onda comprendida entre 0,15 y 4 micras. La distribución espectral de esta energía es del $9 \%$ en ultravioleta (dura), $45 \%$ en el visible (corta) y $46 \%$ en el infrarrojo (larga).

Los estudios realizados, indican que la radiación solar no varía de forma apreciable, razón por la que se define como constante solar a la cantidad de 
radiación solar (de todas las longitudes de ondas), que incide por unidad de tiempo y superficie sobre la tierra, cuando ésta se encuentra a la distancia media del sol. Esta constante, tiene un valor aproximado a $1338 \mathrm{Wm}^{-2}$.

La radiación solar que penetra hasta la superficie de la tierra es menor que la incidente en el límite superior de la atmósfera, debido a la presencia de ésta. Lo importante, es resaltar que una cierta cantidad de energía se pierde por absorción y dispersión, al atravesar cualquier medio, que en este caso es la atmósfera terrestre. Esa energía absorbida depende de la intensidad de radiación, de la cantidad de materia atravesada y de la capacidad que esta materia o medio tenga para absorber la radiación. En la atmósfera, la cantidad de energía que se absorbe es mucho mayor a latitudes altas, puesto que el espesor de la atmósfera es aquí mayor.

A su vez, cada uno de los componentes de la atmósfera, absorben una parte de la energía. Así, en la parte superior de la atmósfera el ozono y oxígeno, absorben una pequeña parte de la radiación solar que se recibe, en torno al $2 \%$. Otros componentes de la atmósfera, como el vapor de agua, dióxido de carbono, partículas, etc., también absorben parte de la radiación.

La radiación procedente del sol, también se ve atenuada por el fenómeno de la dispersión cuando atraviesa la atmósfera. Sin embargo, en este caso, únicamente se produce un cambio en la dirección de propagación con otros efectos sobre la transferencia de energía.

Por otro lado, la tierra también emite energía que, al igual que ocurre con la que proviene del sol, es transferida al espacio y por tanto a la atmósfera en forma de ondas electromagnéticas. El sol, con una temperatura efectiva de unos $5800{ }^{\circ} \mathrm{K}$, irradia como un cuerpo negro, y la mayor parte de esta radiación se sitúa entre las longitudes de onda de 0,15 y 4,0 micras (con un máximo en torno a 0,5), es decir, onda corta.

La temperatura de la tierra y su atmósfera se encuentra dentro del rango de los 200-300 ${ }^{\circ} \mathrm{K}$. Como la temperatura de emisión es mucho menor que la del sol, 
ésta se produce dentro de un rango de longitud de onda mayor, que está localizado dentro del infrarrojo (entre 4 y 100 micras), es decir, onda larga.

Por tanto, la radiación que emite la tierra (como sistema tierra-atmósfera), comprende la radiación de la superficie terrestre (que emite la tierra) y la radiación atmosférica (que llega a la tierra procedente del sol a través de la atmósfera).

La radiación emitida por el sol puede ser en parte absorbida y reflejada por la superficie de la tierra. La radiación que es reflejada por la superficie terrestre no produce calor a la tierra. Puede decirse, que no toda la radiación emitida por el sol llega a la tierra, porque parte puede ser absorbida por el nivel superior de la atmósfera, parte puede ser reflejada por la nubes, con lo que se pierde en el espacio y porque parte de la que alcanza la superficie terrestre puede ser reflejada por ésta.

En resumen, la radiación de onda corta del sol no es absorbida por la atmósfera (que principalmente absorbe radiación de onda larga), sino por la tierra. La radiación emitida por la tierra es principalmente de onda larga. Dado que la atmósfera absorbe radiación de onda larga, ésta puede calentar las capas inferiores de la atmósfera. Así, la radiación de onda corta que proviene del sol es absorbida por la tierra, y la radiación de onda larga que emite la tierra es absorbida por la atmósfera.

Parece evidente por tanto, que la atmósfera no se caliente directamente, sino de forma indirecta por el sol. Es el sol el que caliente la tierra, que devuelve calor a la atmósfera. Las capas inferiores de la atmósfera se calientan principalmente por la radiación emitida por la tierra.

Las nubes, al igual que los gases atmosféricos, tienen diferente capacidad de absorción cuando se trata de radiación emitida por el sol (onda corta) que cuando es radiación emitida por la tierra (onda larga), de esta forma, las nubes 
juegan un papel fundamental en la determinación del balance radiactivo del planeta.

A partir de todo lo comentado anteriormente, se llega a la conclusión de que existe un balance entre la entrada de radiación procedente del sol y la radiación que se emite desde la tierra, como se refleja en la figura 3.4. Si esto no tuviese lugar, la tierra se iría enfriando o calentando progresivamente. La cantidad de la energía recibida del sol que devolvemos al espacio reflejada, bien por la nubes, por la atmósfera o por la superficie de la tierra se denomina albedo planetario, es una constante en tiempos geológicos y en la actualidad es de aproximadamente el 34\% (Wark y Warner, 1990).

Figura 3.4. Balance entre la entrada de radiación procedente del sol y la que se emite desde la tierra.

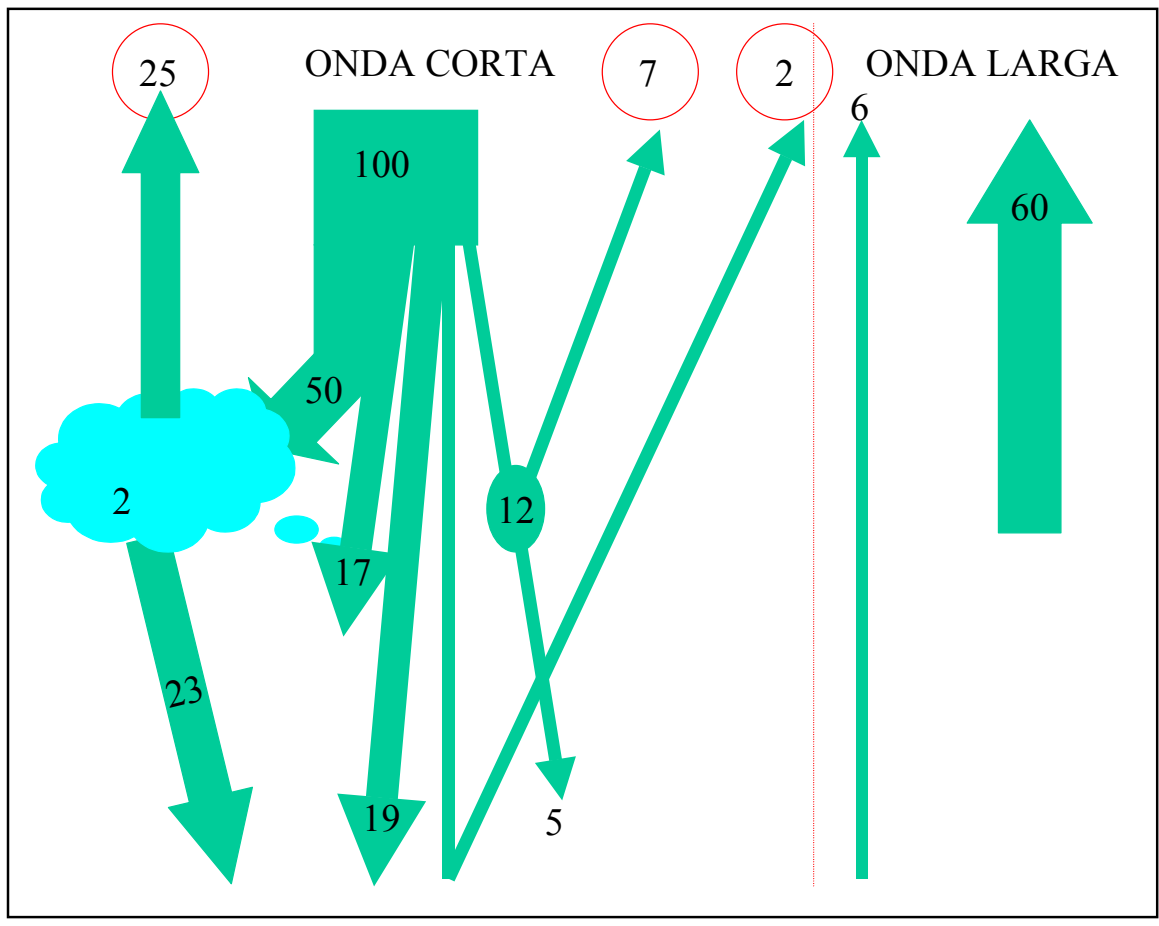

Los procesos físicos y químicos que tienen lugar en la atmósfera están íntimamente relacionados. La temperatura depende de la composición química y 
las reacciones químicas, así como las velocidades a las que se producen, dependen de la temperatura (Wayne, 1991). Los factores que intervienen en la estructura térmica de la atmósfera son muy variados e interactúan de forma compleja entre sí. La energía que calienta la atmósfera terrestre, y la pone en movimiento es suministrada por la radiación solar comprendida entre las bandas del U.V. (de mayor frecuencia) y la infrarroja (de menor frecuencia) dentro del espectro electromagnético. De la cantidad de radiación que llega al límite superior de la atmósfera alrededor del 9\% corresponde al U.V., el 45\% al visible y el 46\% al IR, suponiendo en conjunto unos 1338 w/m² (Iribarne y Godson,1981 y Font Tullot, 1991). La figura 3.5. recoge de modo esquemático una visión global de estas propiedades de la atmósfera.

La cantidad de energía que recibe el planeta acaba por ser devuelta al espacio. La radiación solar que incide y penetra en la atmósfera se ve sometida a una serie de procesos de absorción, difusión y reflexión, que dan lugar a que la energía que es devuelta al espacio lo haga en igual cantidad pero con distintas longitudes de onda. Mientras que la radiación solar es intensa y de onda corta la terrestre es débil y de onda larga.

\subsubsection{VARIACIONES ESTACIONALES.}

Es importante conocer la variación estacional en relación con el calentamiento de la tierra por el sol.

La sucesión del día y la noche, es debida a que la tierra da vueltas en torno a su eje de rotación. De la misma forma que rota sobre su eje, la tierra también gira alrededor del sol. La tierra se mueve alrededor del sol en una órbita elíptica y tarda un año en dar una vuelta completa. El plano en el que la tierra se inscribe en su giro alrededor del sol, se denomina plano de la eclíptica, dado que gira describiendo una elipse y no una circunferencia, en la que el sol ocupa uno de los focos. La distancia entre los centros del sol y la tierra varía, siendo menor en el 
perihelio, que se registra en enero (la tierra está más próxima al sol) y mayor seis meses después, en el afelio, que es cuando la tierra está a más distancia del sol.

Figura 3.5. Esquema de la atmósfera en el que se recogen las capas en las que se divide, la variación de la temperatura con la altitud, la composición y la penetración de la radiación solar hasta distintas alturas.

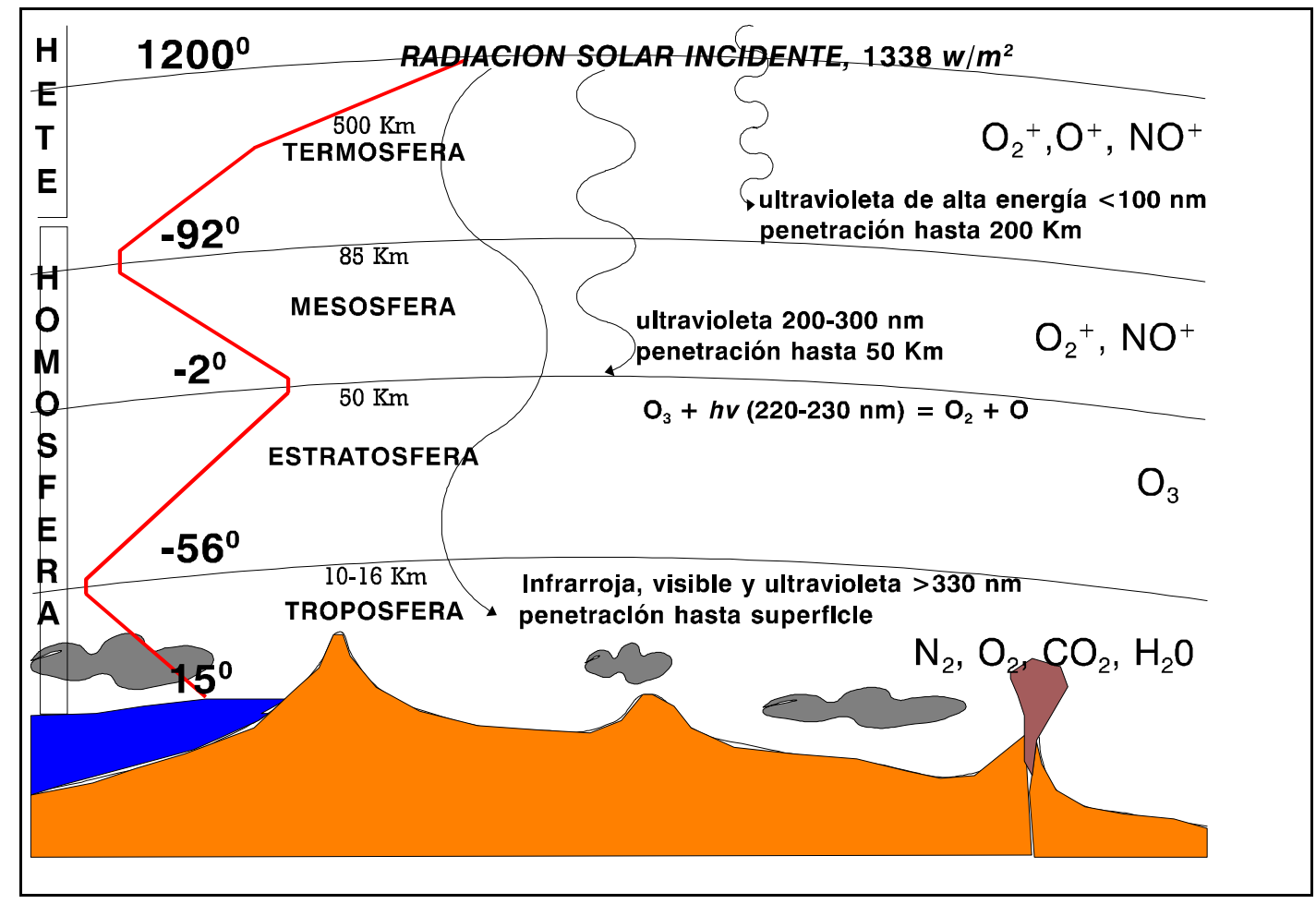

El eje de rotación de la tierra está inclinado con relación al plano de la eclíptica, con el que forma un ángulo de $66^{\circ} 33^{\prime}$. Así, el plano del ecuador con el de la eclíptica forma un ángulo de $23^{\circ} 27^{\prime}$ estableciendo la latitud de los trópicos de cáncer y de capricornio.

Las consecuencias geográficas de la inclinación del eje de rotación terrestre son de gran trascendencia, ya que eso explica la desigual duración de días 
y noches; junto al movimiento de traslación, la aparición de las estaciones astronómicas y las diferencias térmicas entre zonas de la superficie terrestre.

\subsubsection{MOVIMIENTO ATMOSFÉRICO HORIZONTAL.}

El movimiento horizontal de la atmósfera (la componente horizontal de los vientos) es provocado en su mayor parte por un calentamiento diferencial de las masas de aire, y es modificado por el efecto de la rotación de la tierra (fuerza de coriolis) y por la influencia del terreno y el mar.

La diferencia de temperatura entre las atmósferas en los polos y en el ecuador, y entre la atmósfera sobre los continentes y sobre los océanos, es causa de los movimientos a gran escala del aire. Si la tierra no girara, el aire tendería a fluir directamente de las regiones de alta presión a las regiones de baja presión, las que en el plano horizontal significa usualmente de un área fría a un área caliente. Pero es la rotación de la tierra, lo que altera esta situación, como consecuencia de la fuerza de Coriolis.

Esta fuerza explica la aparente deflexión de una porción de aire en movimiento, hacia la derecha en el hemisferio norte, en relación con la superficie, cuando el observador mira en la dirección del movimiento de la porción. Esta fuerza es una función de la velocidad de la porción de aire, así como de la latitud y de la velocidad angular de rotación de la tierra. Es máxima en los polos terrestres y mínima en el ecuador.

Si a esta fuerza vectorial se le añade la fuerza de gradiente de presión, el vector resultante de velocidad forma cierto ángulo con las isobaras. Como la fuerza de gradiente de presión debe ser perpendicular a las isobaras, la fuerza de Coriolis debe ser paralela a la de presión, pero en dirección opuesta, hacia la región de alta presión. Además, la velocidad el viento y la fuerza de Coriolis actúan en ángulo recto una con la otra. De aquí resulta, que el viento tiene que 
soplar paralelamente a las isobaras. Además, la fuerza de Coriolis debe actuar a la derecha de la velocidad del viento en el hemisferio norte. Por tanto, el viento tendrá que soplar de tal manera que la región de baja presión quede a la izquierda de la dirección del movimiento, según el observador mire hacia abajo en dirección a la superficie terrestre.

Los meteorólogos llaman a este viento ideal o conceptual el viento geostrófico, y se aproxima a las condiciones existentes a unos cientos o más metros por encima de la superficie del suelo. Otro tipo de viento al que se hace referencia en meteorología, es el viento gradiente, que está asociado a las isobaras curvas y en este caso hay que tener en cuenta la aceleración centrípeta.

Los vientos geostróficos y de gradiente constituyen conceptos de interés práctico en ausencia de una fuerza significativa de fricción. No obstante, el movimiento del aire cerca de la superficie de la tierra está retrasado por los efectos de fricción de la rugosidad superficial. La región vertical entre la superficie de la tierra y los niveles superiores de la atmósfera donde resulta válido el concepto de viento gradiente se llama capa límite planetaria. La magnitud del retraso de la velocidad del viento con la altura y el espesor de la capa límite son funciones de la rugosidad superficial del terreno, así como del gradiente de temperatura en la atmósfera inferior.

El efecto de esta fuerza de fricción, cuando se suma a las fuerzas de presión y de Coriolis, es hacer girar ligeramente el movimiento del aire hacia la derecha del viento gradiente. En efecto el viento gira en un ligero ángulo hacia la región de baja presión. La fuerza de fricción reduce directamente la velocidad del viento en la capa límite, con lo que reduce la fuerza de Coriolis.

La fuerza de presión permanece, no obstante, igual, de manera que ya no está equilibrada por la fuerza de Coriolis como sucede con el viento geostrófico. El resultado de este desequilibrio es que la dirección del viento corta ahora las isobaras en dirección a la región de baja presión, y ya no es paralela a las isobaras. 
La velocidad del viento ahora es menor que la velocidad del viento geostrófico, si todas las otras condiciones permanecen iguales.

El flujo en las inmediaciones de un centro de alta presión debe pasar en una dirección a favor de las agujas del reloj y con un flujo neto hacia fuera. Si se efectúa un análisis tridimensional más completo del flujo del aire cerca de un centro de presión, se halla que el flujo se dirige hacia abajo así como hacia fuera. Como resultado de ello, el aire se debe introducir desde arriba del centro y dirigirlo hacia abajo a fin de mantener el flujo hacia fuera. Este flujo descendente se llama asentamiento y constituye un posible inhibidor de la dispersión de los contaminantes en la atmósfera. Por tanto, el flujo cercano a un centro de baja presión tiene una dirección contraria a las manecillas del reloj. En este caso el flujo se dirige hacia arriba y hacia dentro. Por tanto, los contaminantes en la parte inferior de la atmósfera serán arrastrados hacia arriba y, por lo general, se dispersarán sobre una amplia área.

El desplazamiento angular del viento en la capa límite planetaria tiene una importante repercusión sobre el patrón de dispersión de los contaminantes. Como la fuerza de retraso por fricción varía con la altura sobre el suelo, la cantidad de desplazamiento angular varía también con la altura. La fuerza de fricción en la capa límite tiene un máximo cerca de la superficie de la tierra y cae esencialmente a cero en la parte superior de la capa límite, donde predomina el viento geostrófico o el gradiente. Por tanto, el ángulo de desplazamiento de la dirección del viento debido a la fricción varía desde un valor máximo cerca de la superficie terrestre hasta cero en la parte superior de la capa límite.

El flujo de calor solar que recibe la superficie de la tierra en el ecuador es mayor que el de los polos. Como respuesta a esta diferencia en el calentamiento, la atmósfera se mueve, y al hacerlo, lleva calor de los trópicos hacia los polos.

Para la tierra se podría suponer que el aire caliente estaría subiendo en el ecuador y hundiéndose en los polos, de modo que se tendría un flujo del ecuador hacia los polos a grandes altitudes, y de los polos hacia el ecuador en la superficie. 
Sin embargo, debido a que la atmósfera es bastante delgada en relación con su ancho, ese flujo es mecánicamente inestable y se rompe en subceldas.

En el hemisferio norte tiene lugar un flujo de sur a norte a gran altitud y uno de norte a sur en la superficie, en las celdas tropical y polar, con los flujos dirigidos en direcciones opuestas, en la celda templada. En el globo, existen siete fronteras entre celdas, una en el ecuador, dos en cada hemisferio y dos en los polos. En la frontera en el ecuador y las dos entre las celdas polares y templadas, el aire está subiendo; en las fronteras entre las celdas tropicales y templadas y en los polos, el aire se está hundiendo.

Es importante resaltar que el aire ascendente, se enfría y produce lluvia, mientras que el aire descendente se calienta y se vuelve relativamente seco. Esto se traduce en que en las fronteras ascendentes (ecuador y templadas-polares) son regiones de precipitación pluvial superior a la promedio; de manera que la mayor parte de los bosques tropicales del mundo están ubicados cerca de la zona ecuatorial ascendente y los grandes bosques de la zona templada se encuentran cerca de las zonas ascendentes templadas-polares.

Las fronteras descendentes (los polos y las fronteras tropicales-templadas) son regiones de precipitación pluvial inferior a la promedio; y de hecho la mayor parte de los desiertos del mundo están ubicados cerca de las zonas descendentes templadas-tropicales. Los polos también tienen poca precipitación; son desiertos fríos, en donde la pequeña cantidad de precipitación se mantiene como hielo y nieve, debido a que existen una evaporación o fusión despreciables.

En el hemisferio norte, el movimiento del viento contrario a las agujas del reloj se llama un ciclón, mientras que el movimiento en el sentido de las agujas del reloj, alrededor de un centro de presión se llama un anticiclón. 


\subsubsection{MOVIMIENTO VERTICAL EN LA ATMÓSFERA.}

En la atmósfera, cualquier porción de aire que sea menos densa que el aire que la rodea se elevará por la acción de un empuje vertical, y cualquier porción que sea más densa que el aire que la rodea se hundirá por acción de un empuje vertical negativo. La mayor parte de los movimientos en la atmósfera son causados por cambios en la densidad del aire (De Nevers, 1998).

Una de las características más importantes de la atmósfera es su estabilidad, esto es, su tendencia a resistir el movimiento vertical, o suprimir la turbulencia existente. Esta tendencia influye sobre la capacidad de la atmósfera de dispersar los contaminantes que se emiten en ella, procedentes de fuentes naturales o producidos por el hombre. Cuando un pequeño volumen de aire se desplaza hacia arriba dentro de la atmósfera, encontrará una presión menor y experimentará una expansión a una temperatura menor.

Usualmente, la expansión es lo suficientemente rápida como para que se pueda suponer que no tiene lugar ninguna transferencia de calor entre dicho volumen de aire y la atmósfera que lo rodea.

Es importante señalar el cambio de la densidad del aire con la temperatura y la humedad. Así, la densidad de cualquier parte de la atmósfera se expresa casi con exactitud por la ley de los gases perfectos. No obstante, la mayor parte de los movimientos verticales que tienen lugar en la atmósfera son provocados por cambios en la temperatura en lugar de por cambios en la humedad, pues se requiere un aumento de alrededor de un $40 \%$ de humedad relativa para producir el mismo efecto que un aumento de $1^{\circ} \mathrm{C}$ en la temperatura.

Otro aspecto a tener en cuenta es el cambio de la densidad del aire con la presión, que se rige por la ecuación básica de la estática de fluídos o ecuación barométrica. 


\subsubsection{TRANSPORTE Y DISPERSIÓN DE CONTAMINANTES EN LA ATMÓSFERA.}

La dispersión de contaminantes en la atmósfera depende fundamentalmente de los flujos horizontales y verticales. Igualmente, la variación de la temperatura con la altitud es un parámetro fundamental para comprender los fenómenos de dispersión en el seno de la troposfera. Cuando la disminución de la temperatura con la altura es menor que la que corresponde al sistema adiabático, la atmósfera es estable, impidiendo la dispersión y dilución de los contaminantes. Por contra, cuando la variación de temperatura es mayor, la atmósfera es inestable, lo que favorece el ascenso de masas de aire, y por lo tanto la dispersión y dilución, mejorando la calidad del aire (Masters, 1991).

Las inversiones de temperatura representan el caso extremo de estabilidad atmosférica. Hay diversas causas para que se produzcan las inversiones térmicas pero dos de ellas tienen una importancia especial desde el punto de vista de la calidad del aire.

La primera, inversiones por radiación, debidas al enfriamiento de la superficie de la tierra, principalmente en las noches claras del invierno. La superficie de la tierra se enfría durante la noche, radiando energía hacia el espacio. En las noches nubladas la radiación de la tierra tiende a ser absorbida por el vapor de agua en la atmósfera y parte de ésta es irradiada hacia la tierra. En las noches claras, estrelladas, sin embargo, la superficie de la tierra radia energía al espacio, por lo que la tierra se enfría más rápidamente. Conforme la tierra se enfría también lo hace el aire directamente en contacto con ella, más rápidamente que las capas de aire más alejadas de la tierra, produciéndose por lo tanto una inversión. Las inversiones por radiación se inician al anochecer y conforme la noche progresa la inversión se extiende a mayores altitudes, llegando a alcanzar unos cientos de metros antes de que amanezca y el sol caliente de nuevo la tierra, llegando a romper la inversión. 
Las inversiones por radiación ocurren cerca del suelo, más frecuentemente en invierno que en verano, y duran unas cuantas horas al día. Se inician al ponerse el sol, coincidiendo con horas puntas de tráfico (6 de la tarde) atrapando cerca de la tierra las emisiones de los vehículos. Sin luz solar no tienen lugar reacciones fotoquímicas, por lo que se traduce en una acumulación de monóxido de carbono, óxidos de nitrógeno e hidrocarburos. Por la mañana al calentar el sol la superficie de la tierra, la inversión empieza a romperse, se calientan las capas más cercanas al suelo, por lo que los contaminantes atrapados en la inversión son repentinamente arrojados sobre la tierra en un fenómeno conocido como fumigación, que es la causa de una breve pero intensa punta de contaminación a nivel del suelo.

La segunda, inversiones de subsidencia, como resultado del calentamiento por compresión de las masas de aire que descienden en zonas de altas presiones. Las inversiones de subsidencia se mantienen durante meses, ocurren a altitudes elevadas, desde unos cientos de metros hasta varios miles, y son más comunes en verano que en invierno, prolongándose en el tiempo mientras persiste la situación anticiclónica (Morán, 1984 y Masters, 1991).

Las inversiones de subsidencia están asociadas con los sistemas de altas presiones, anticiclones. El aire en medio de las zonas de altas presiones es descendente, mientras que en los extremos es ascendente, en la zona superior del anticiclón el aire se mueve desde los extremos hacia el centro, cerca de la tierra se mueve hacia afuera desde el centro. Esto causa una intensa circulación vertical. Como el aire en el centro del sistema cae, experimenta altas presiones y se comprime y calienta, estando más caliente que las capas situadas por debajo de él. La capa en la que se produce la inversión inicialmente es ancha, pero conforme progresa se va estrechando llegando a tener un espesor de $100 \mathrm{~m}$. (Morán, $1984 \mathrm{y}$ Masters, 1991).

Mientras el aire subsidente se calienta es más susceptible de captar vapor de agua mientras desciende, sin fuentes de nueva mezcla, la humedad relativa cae, 
y hay pocas oportunidades para que se formen nubes. El resultado es días claros y noches despejadas. Durante el día se darán mejores condiciones de mezcla, durante la noche la superficie de la tierra se enfría rápidamente, produciéndose una inversión por radiación por debajo de la inversión por subsidencia (Wark y Warner, 1990).

Los fenómenos de dispersión de contaminantes en la atmósfera van a ser fuertemente dependientes de los flujos horizontales (vientos) y de los verticales. La variación de la temperatura con la altitud es un parámetro fundamental para comprender los fenómenos de dispersión en el seno de la troposfera. Para algunos perfiles de temperatura la atmósfera es estable, impidiendo la dispersión y dilución de los contaminantes. Para otros perfiles de temperatura la atmósfera es inestable, viéndose favorecido el ascenso de masas de aire, y por lo tanto se favorece la dispersión y dilución, mejorando la calidad del aire (Masters, 1991), la figura 3.6, recoge un esquela de la variación de la temperatura con la altitud y situaciones de estabilidad en la atmósfera.

Las inversiones de temperatura representan el caso extremo de estabilidad atmosférica. Hay diversas causas para que se produzcan las inversiones térmicas pero dos de ellas tienen una importancia especial desde el punto de vista de la calidad del aire.

La primera, inversiones por radiación, están causadas por el enfriamiento de la superficie de la tierra, principalmente en las noches claras del invierno. La segunda, inversiones de subsidencia, son el resultado del calentamiento por compresión de las masas de aire que descienden en zonas de altas presiones. Por la ubicación de la zona del estudio, es importante resaltar también el establecimiento de las brisas tierra-mar y viceversa.

La superficie de la tierra se enfría durante la noche, radiando energía hacia el espacio. En las noches nubladas la radiación de la tierra tiende a ser absorbida por el vapor de agua en la atmósfera y parte de ésta es reradiada hacia la tierra. En las noches claras, estrelladas, sin embargo, la superficie de la tierra radia energía 
al espacio, por lo que la tierra se enfría más rápidamente. Conforme la tierra se enfría también lo hace el aire directamente en contacto con ella, más rápidamente que las capas de aire más alejadas de la tierra, produciéndose por lo tanto una inversión. Las inversiones por radiación se inician al anochecer y conforme la noche progresa la inversión se extiende a mayores altitudes, llegando a alcanzar unos cientos de metros antes de que amanezca y el sol caliente de nuevo la tierra, llegando a romper la inversión.

Figura 3.6. Esquema de la variación de la temperatura con la altitud y situaciones de estabilidad en la atmósfera.

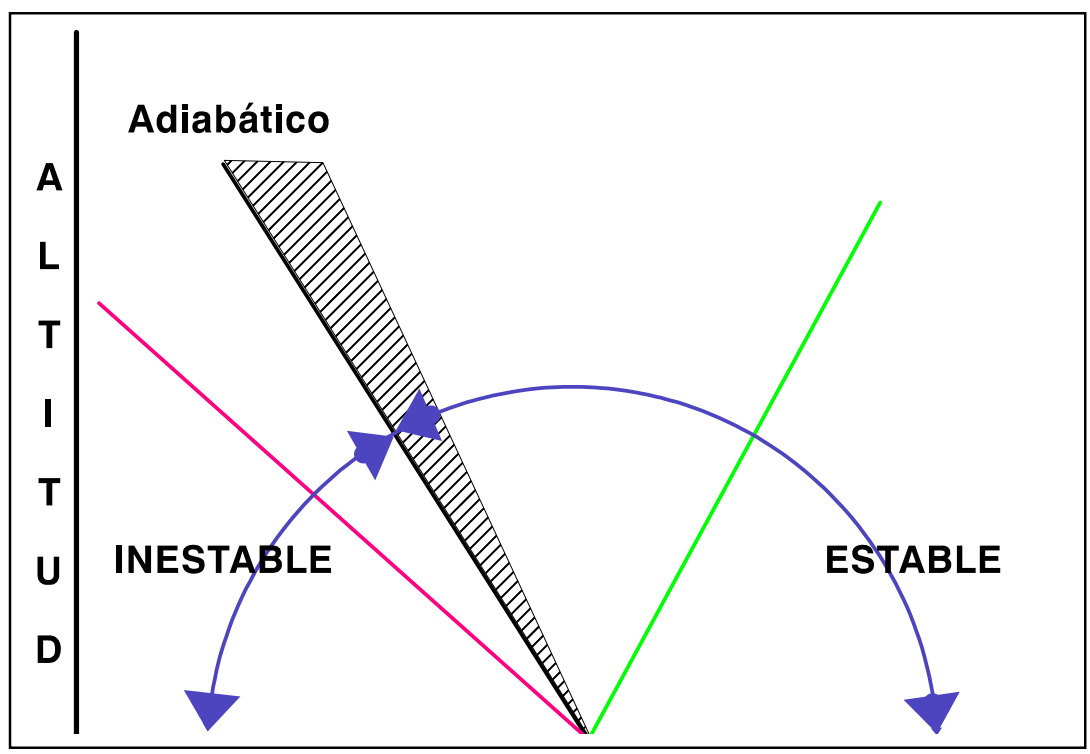

\subsubsection{Inversiones por radiación.}

Las inversiones por radiación ocurren cerca del suelo, más frecuentemente en invierno que en verano, y duran unas cuantas horas al día. Se inician al ponerse el sol, coincidiendo con horas puntas de tráfico (6 de la tarde) atrapando cerca de la tierra las emisiones de los vehículos. Sin luz solar no tienen lugar reacciones fotoquímicas, por lo que se traduce en una acumulación de monóxido de carbono, óxidos de nitrógeno e hidrocarburos. Por la mañana al calentar el sol la superficie 
de la tierra la inversión empieza a romperse, se calientan las capas más cercanas al suelo, por lo que los contaminantes atrapados en la inversión son repentinamente arrojados sobre la tierra en un fenómeno conocido como fumigación, que es la causa de una breve pero intensa punta de contaminación a nivel del suelo.

\subsubsection{Inversiones de subsidencia.}

Las inversiones de subsidencia se mantienen durante meses, ocurren a altitudes elevadas, desde unos cientos de metros hasta varios miles, y son más comunes en verano que en invierno, prolongándose en el tiempo mientras persiste la situación anticiclónica (Morán,1984 y Masters, 1991).

Las inversiones de subsidencia están asociadas con los sistemas de altas presiones, anticiclones. El aire en medio de las zonas de altas presiones es descendente, mientras que en los extremos es ascendente, en la zona superior del anticiclón el aire se mueve desde los extremos hacia el centro, cerca de la tierra se mueve hacia afuera desde el centro.

Esto causa una intensa circulación vertical. Como el aire en el centro del sistema cae, experimenta altas presiones y se comprime y calienta, estando más caliente que las capas situadas por debajo de él. La capa en la que se produce la inversión inicialmente es ancha, pero conforme progresa se va estrechando llegando a tener un espesor de 100 m (Morán, 1984 y Masters, 1991). 


\subsubsection{Brisas.}

En zonas próximas a masas de agua importantes, puede ocurrir un fenómeno característico que recibe el nombre de brisa y que puede complicar el patrón de comportamiento del viento, dificultando en algunos casos la dispersión de los contaminantes en la atmósfera (Wark y Warner, 1990).

Las diferencias en la tasa de calentamiento entre el suelo y el agua, se traduce en una marcada diferencia de temperatura a media mañana entre el aire situado encima de la masa de agua y el situado sobre el suelo. La expansión del aire ascendente más cálido, produce un movimiento general horizontal del aire desde la masa de agua hacia la tierra, para ocupar el hueco dejado por aire que ha ascendido, y teniendo lugar en este caso la brisa mar-tierra.

Después de la puesta del sol, el aire sobre el suelo se enfría más deprisa que el situado sobre el agua y se hace más denso. Por tanto, el aire caliente sobre la masa de agua tenderá a ascender y se producirá un movimiento horizontal del aire desde el suelo hasta el agua, para ocupar nuevamente el hueco dejado por el aire más caliente, teniendo lugar así la denominada brisa tierra-mar.

Por ello, en algunas ciudades como Cartagena, próxima al mar y con una complicada y característica topografía, en presencia de algún tipo de inversión y brisa, puede traducirse a una acumulación paulatina de los contaminantes en un volumen de aire limitado durante varios días, pudiendo alcanzar para algunos contaminantes valores muy por encima de lo que establece la normativa vigente.

\subsubsection{Efectos topográficos menores.}

Por su importancia en el comportamiento de los vientos en la ciudad de Cartagena, comentaremos brevemente los efectos topográficos menores: Efecto de barrera, Chimenea y efecto Valle. El primero de ellos, efecto de barrera, consiste en que las masas de aire que chocan contra un macizo montañoso, tienen que 
variar su rumbo estableciéndose como dirección preferente la de la orientación del conjunto de montañas. El efecto chimenea, se produce en las discontinuidades que presentan estos macizos montañosos, pudiendo el viento penetrar en la dirección en la que fluía a través de las mismas, pero con un considerable aumento en su velocidad. El tercer efecto topográfico citado, el efecto valle, hace referencia que el flujo del viento tendrá que adoptar la dirección de los valles en su paso entre dos montañas, aumentando también su velocidad, debido al encajonamiento que experimenta.

Estos efectos topográficos menores, permiten también entender la importancia que los obstáculos al flujo representan en la dispersión de la contaminación, produciendo impactos por barreras topográficas, encajonamiento de masas de aire en determinadas calles, variaciones en la dirección de viento por la presencia de edificios, aparición de turbulencias, etc. Una buena descripción de estos fenómenos se encuentra en Estrela y Millán (1994) y Wark y Warner (1990) 


\subsection{LIBERACIÓN, TRANSPORTE, DISPERSIÓN Y DEPOSICIÓN DE POLEN EN LA ATMÓSFERA.}

\subsubsection{PRODUCCIÓN DE POLEN.}

La cantidad de polen producida por las plantas individualmente, así como por las comunidades de éstas, no es una cantidad constante, sino que depende fundamentalmente de factores individuales específicos y de parámetros ecológicos, relacionados especialmente con los cambios climáticos.

Las distintas estrategias de polinización que pueden llevar a cabo las plantas, van a incidir de forma decisiva en el número final de granos de polen depositados para análisis y, por consiguiente, en la distribución posterior de éstos (Faegri e Iversen, 1989).

El factor esencial de la polinización, lo constituye la liberación y el transporte de polen desde la antera hasta el estigma. La manera de producirse este transporte y la adaptación de las distintas plantas a esto, es fundamental para el análisis de los datos de polen. Este transporte tiene lugar de diferentes maneras, que pueden resumirse en dos grupos: plantas polinizadas por acción del viento (anemófilas) y plantas polinizadas por acción de diversos animales, principalmente insectos (entomófilas).

La cantidad de polen producida por las plantas anemófilas, es una cantidad relativamente precisa, incluso a lo largo de todo su ciclo de vida. El momento de la liberación del polen, así como la cantidad total de polen producido, son resultado de factores genéticos y de la adaptación de las plantas al medio (Akers et al.,1979). Esto hace que la polinización depende tanto de las capacidades biológicas de las plantas, como de las condiciones del medio en el que ésta se desarrolla.

Las plantas anemófilas producen importantes cantidades de polen que es liberado en el aire y esparcido por los alrededores con lo que se conoce como 
"lluvia de polen". El grano de polen de estas especies es seco y se presenta en granos individualmente separados, con objeto de producir el máximo número de granos y asegurar una buena y regular distribución sobre una amplia área. Además, otra importante característica es que la floración frecuentemente tiene lugar antes de que se desarrolle el follaje, para facilitar así la liberación y dispersión de los granos de polen (Faegri e Iversen, 1989).

Dentro de las especies anemófilas, la producción de polen varía ampliamente para las distintas especies. Además, varía ampliamente de una estación polínica a otra. Si consideramos los valores de polen depositado como una medida válida de la producción de polen, entonces la cantidad de polen depositada durante un cierto periodo de tiempo en distintos lugares, podría servir para analizar la varianza de la producción de polen. Algunos estudios de este tipo, realizados en algunas ciudades como Cardif, Wales, Tucson y Arizona, han puesto de manifiesto que desviaciones standard del 80\% respecto de la media (rango 29\%-161\%) son normales (Solomon y Hayes, 1972).

El problema de la distribución espacial de las plantas, es solventado por el momento preciso de la producción y emisión de polen. Para ello, va a tener lugar un incremento en el número de granos de polen producidos en un punto y, por consiguiente, un aumento de la concentración instantánea, cuando el polen es emitido desde las flores.

La estacionalidad de la polinización por acción del viento, puede ser dividida en tres grupos distintos: los árboles y arbustos de las zonas templadas que emiten polen durante la primavera y comienzo de la actividad vegetativa, las plantas herbáceas anuales y perennes que emiten polen durante el final del verano y al final de su estación de crecimiento y el resto de plantas herbáceas que emiten el polen a lo largo de su estación de crecimiento. Estos tres grupos son los representativos del calendario polínico de cualquier región templada, donde prevalece la polinización por acción del viento, aunque varía de unas zonas a otras (Elvira-Rendueles et al., 2000). 
Los dos primeros grupos presentan mecanismos muy distintos en cuanto a su adaptación a la reproducción. En cambio, el tercer grupo es más bien un grupo artificial, resultado de nuestra incapacidad para distinguir el polen al nivel de las especies, que por problema de las plantas a distinguir la estacionalidad (Akers, et al. 1979).

La concentración de polen en el aire durante la estación polínica, varía de un día a otro y de unas horas a otras, como consecuencia de la dependencia de la cantidad de polen producida por las plantas, de la liberación de éste, de las condiciones de dispersión de la atmósfera y de las condiciones de humedad del aire que contiene ese polen (Moseholm et al., 1987; Rantio-Lehtimäki et al., 1991; Trigo et al., 1996; Comtois, 1997).

El desarrollo del grano de polen dentro de la antera, es un proceso que probablemente depende de la temperatura durante un determinado número de días. El intervalo entre la mitosis del grano de polen y la liberación de éste, es de unos cinco días para varias especies. Antes de la liberación del grano de polen, este sufre un proceso de maduración variable, durante el cual, se produce una acumulación de proteínas e hidratos de carbono (Moseholm et al., 1987).

La primera parte de los procesos y fenómenos que constituyen los problemas y posibilidades del análisis del polen, comienzan con el análisis del polen. Las diferentes formas de polinización influyen y deciden el número de granos de polen que finalmente son depositados para su análisis y su distribución.

El aspecto más importante en la polinización, es el transporte del polen desde las anteras hasta el estigma. Las distintas formas del transporte de los granos de polen y la adaptación de las plantas a éstas es fundamental para la evaluación de los datos (Comtois, 2000).

La mayoría de familias de plantas herbáceas son polinizadas por acción del viento, es decir, una vez abiertas las anteras y cuando las condiciones meteorológicas reinantes son favorables. La floración, incluye la extensión de los 
filamentos y dehiscencia de las anteras, inducida probablemente por un incremento de la temperatura y una disminución de la humedad relativa. El polen no es liberado inmediatamente, sino que es emitido en forma de paquetes de muchos granos de polen, que por acción del viento y de la turbulencia de la atmósfera es depositado en las hojas cercanas y tallos, desde donde será transportado por acción del viento (Ogden et al., 1974).

Como la velocidad de sedimentación es pequeña comparada con las velocidades típicas de las masas de aire, la dispersión del polen liberado de las plantas puede determinarse básicamente sobre la base de la estabilidad de la atmósfera y la velocidad del viento. Durante ciertas épocas del año se presentan estas condiciones que favorecen la dispersión y transporte del polen a largas distancias de su origen (Moseholm, et al.1987).

El análisis del flujo de granos de polen es realmente complejo por la topografía y por la intervención de muchas fuentes de diferentes escalas geográficas. Y aunque lo que verdaderamente interesa conocer en el análisis polínico son las consecuencias y no tanto las causas, por lo que generalmente se aplica el modelo de caja o caja negra, es importante en ciertas condiciones separar las diferentes fuentes que contribuyen a los contenidos polínicos registrados, pues puede ser muy útil para estudiar cambios climáticos, sucesiones de plantas, etc. (Comtois, 1982).

Así desde un punto de vista aeropalinológico, el transporte de polen a grandes distancias es utilizado a veces para identificar el origen de masas de aire, especialmente en zonas muy contaminadas como en el norte de América (Comtois y Schemenauer,1991). En la zona de la costa este de Canadá, en la que se pone de manifiesto que existen diferencias estadísticas significativas en los contenidos polínicos registrados según sea el origen de las masas de aire, sobre todo para bajas concentraciones (Comtois, 1997). 


\subsubsection{LIBERACIÓN DE POLEN.}

La liberación de los granos de polen desde las anteras, es un proceso pasivo y que depende de una serie de agentes como la lluvia, viento, humedad ambiental, presión atmosférica, etc.

Valores típicos de producción de polen para árboles, puede ser del orden de $10^{12}-10^{14}$ granos de polen $/ \mathrm{Km}^{2}$ y año (Akers et al., 1979). La producción varía de un individuo a otro, de un lugar a otro, entre años, especies, etc. Además, muchas especies arbóreas, no comienzan a producir polen hasta que han alcanzado una cierta edad, como en Pinus sylvestris, que necesitan de 40-45 años.

El proceso de liberación, tiene lugar usualmente durante la primavera, para las especies arbóreas de la región templada, variando a su vez con la situación geográfica, climatología durante el periodo previo, así como de las condiciones durante el periodo de liberación de éste. Además, se ha observado que algunas especies producen grandes cantidades de polen cada dos o tres años (Andersen, 1974). Las gramíneas hacia finales de primavera y principios del verano, mientras que algunas plantas herbáceas lo hacen al final del verano y en otoño.

\subsubsection{TRANSPORTE ATMOSFÉRICO.}

La dispersión de cada tipo polínico es una característica propia y sólo mediante la inferencia estadística se pueden predecir los resultados medios, puesto que los cambios se deben a condiciones externas inusuales.

Los principales factores que influyen en el transporte aéreo han sido mencionados previamente por varios autores, aunque casi todos ellos coinciden en que éstos son la fuerza de la gravedad, el viento y la turbulencia (Gregory, 1973; Faegri e Iversen, 1989; Fornaciari et al., 1992; González Minero et al., 1997; Galán et al., 2000). 
La gravedad, es generalmente descrita por la ley de Stokes, para partículas uniformes, esféricas e individuales, aunque estas particularidades rara vez se presentan en el caso de los granos de polen.

En cuanto al viento, los distintos flujos, no van a tener lugar de forma laminar. Estos van a transcurrir de forma irregular, así como en forma de calmas debido a la turbulencia de las distintas capas. La turbulencia a su vez, es el resultado de combinar efectos mecánicos y térmicos.

La turbulencia originada por efectos mecánicos, se debe a los obstáculos que el viento va a encontrar a su paso, así como a la variación de la velocidad de éste con la altura, como consecuencia de la disminución de la fuerza de rozamiento. La turbulencia térmica es causada por el perfil de temperatura que presenta la atmósfera verticalmente, que se traducen finalmente en un aumento de la turbulencia vertical (Di-Giovanni et al., 1989).

\subsubsection{DEPOSICIÓN DE POLEN EN LA ATMÓSFERA Y MUESTREO.}

Para comprender todo el proceso desde la producción hasta la deposición de los granos de polen, es necesario disponer de información detallada durante la estancia de los granos de polen en la atmósfera, entre liberación y deposición. El proceso de muestreo en el aire, no es nada fácil, y de hecho, muchos han sido los aparatos utilizados hasta el momento con el objetivo de obtener una medida cuantitativa de la composición, aunque muy pocos investigadores han proporcionado información para solucionar los problemas que se plantean en el análisis del polen (Faegri e Iversen, 1989).

Desde un punto de vista teórico, uno puede muestrear tres diferentes cantidades: 
a) La cantidad de polen contenido en un volumen de aire, es decir, cantidad de granos en un volumen estático de aire.

b) El polen que es transportado en el aire, (número de granos de polen que atraviesan una sección transversal por unidad de tiempo).

c) Polen del aire que es depositado, (número de granos de polen que se han depositado sobre una superficie horizontal en un intervalo de tiempo dado).

Todas estas cantidades están relacionadas, pero no hay una relación lineal constante entre ellas, sino que la velocidad del viento, la turbulencia, lluvia, características de la superficie, etc., cambian la relación a lo largo del tiempo.

La deposición de polen es proporcional a la concentración cerca de la superficie y es generalmente debida a una combinación de mecanismos como son: impactación, sedimentación, tipo de estabilidad atmosférica, deposición turbulenta, lluvia de lavado y de la deposición electrostática y térmica (Gregory, 1973).

Para realizar el muestreo, el método más apropiado sería aquel que fuera capaz de separar un volumen de aire conocido y calcular la cantidad de granos de polen contenido en éste. Pero esto presenta serias dificultades a la hora de llevarlo a la práctica.

Son varios los métodos disponibles en la actualidad para la captación de pólenes aerovagantes (Edmonds, 1979):

a) Métodos gravitacionales, que se apoyan en la fuerza de la gravedad para la recogida de éstos.

b) De impactación estáticos o rotatorios, que se basan en la captación de los pólenes cuando son empujados por acción del viento (Andersen, 1985). 
c) Volumétricos o de succión, que se fundamentan en la aspiración de aire al interior de un aparato que impacta sobre una cinta cubierta de vaselina y que a su vez va girando con una cierta velocidad (Hirst, 1952).

d) De filtración (Suárez-Cervera y Seoane-Camba, 1983).

Un método bastante aceptado, aunque de fiabilidad variable en función del diseño del equipo, por los problemas de eficiencia en la captura, es el que se basa en contar directamente los granos de polen adheridos a una superficie impregnada con una sustancia adhesiva. El método Hirst (Hirst, 1952), que se basa en este principio, es el que más se utiliza en investigación aerobiológica. Este presenta un mecanismo bastante fiable, fácil de usar, y además presenta la gran ventaja de que presenta una alta resolución temporal, proporcionando una imagen hora a hora del contenido polínico en el ambiente.

Con elevadas velocidades del viento, las concentraciones registradas por este método se ven incrementadas, recogiendo así el concepto dinámico de este método, el transporte de polen, en comparación con otros métodos estáticos. El aspecto del transporte, es recogido por este muestreador mediante la utilización de un tambor rotatorio en dirección perpendicular al flujo del aire. Por consiguiente es un método bastante apropiado para el muestreo aerobiológico, puesto que contenido y transporte, son los dos aspectos más importantes en los estudios de polinización y alergias. 


\subsection{FACTORES QUE INFLUYEN EN EL TRANSPORTE Y DISPERSIÓN DE LA FRACCIÓN BIÓTICA DEL AEROSOL ATMOSFÉRICO.}

Son muchos los trabajos encontrados en Aerobiología, en lo que se pone de manifiesto la relación que existe entre los distintos parámetros meteorológicos y las concentraciones polínicas que finalmente son recogidas en la atmósfera, aunque muchos de ellos han sido referidos a una zona climáticas homogénea o bastante similar (Davies y Smith, 1973; Ogden et al., 1974; Bringfelt, 1979; Smart, et al., 1979;Moseholm et al., 1987; Galán et al., 1995; Norris-Hill, 1995; Recio et al., 1996; Díaz de La Guardia et al., 1998; Moreno-Grau et al., 1998; Galán et al., 2000).

Los distintos factores que influyen en el transporte y dispersión de la fracción biótica del aerosol atmosférico, los podemos resumir a continuación.

\subsubsection{FENOLÓGICOS.}

No todas las plantas florecen al mismo tiempo, algunas tienen una floración anual, en otras su floración es muy breve, pero explosiva y en otras puede que estén floreciendo durante todo el año, por lo que la emisión de polen no será continuada.

Moseholm et al.(1987), ponen de manifiesto que en la liberación, dispersión y deposición de los granos de polen, intervienen numerosos factores, mencionando entre ellos los relacionados con el día de la estación polínica y hora del mismo.

Las diferencias encontradas en la floración de las distintas especies, nos permiten establecer, a grandes rasgos, unas estaciones fenológicas, que corresponden con la presencia en la atmósfera de determinados granos de polen y que suele quedar reflejado con bastante precisión en los calendarios polínicos, de ahí la importancia de que éstos sean lo más completos posible. No obstante, hay 
que destacar que estas floraciones están sujetas a variaciones climáticas anuales.

\subsubsection{VEGETACIÓN.}

Es necesario conocer la flora local, tanto autóctono como la introducida, ya que esto nos permitirá en cada momento, la identificación de los granos de polen que puedan estar presentes en la atmósfera, aunque también es posible encontrar algunos granos de pólenes de algunas especies que estén ubicadas a una distancia bastante considerable del captador (Cabezudo et al., 1997).

Estos dos factores anteriormente mencionados, están más bien relacionados con las características climatológicas y de la flora de la zona bajo estudio. A continuación, se enumeran los principales factores climatológicos, que juegan un importante papel en el transporte y dispersión.

\subsubsection{TEMPERATURA.}

La temperatura, tiene una gran influencia sobre la floración, polinización (antesis) y, en definitiva, sobre la concentración polínica final.

La influencia de la temperatura sobre la antesis, así como sobre la cantidad total de polen producido por la planta, ha sido puesto de manifiesto por numerosos autores:

Así, Davies y Smith (1973), señalan que temperaturas relativamente elevadas y ambientes secos, durante el periodo en el que el polen se está formando en las anteras, resultan ser decisivos durante la estación polínica, traduciéndose en un incremento de las concentraciones registradas. Estos mismo autores, demuestran como la temperatura media diaria acumulada por encima de $6^{\circ} \mathrm{C}$ desde el uno de marzo de cada año, juega un papel decisivo en el inicio de la estación polínica de Poacea en Londres. 
Ogden et al. (1974), manifiestan que el desarrollo del grano de polen es un proceso dependiente de la temperatura, y que éste tiene lugar durante un periodo de tiempo muy limitado, señalando incluso, que el tiempo transcurrido entre la mitosis del grano de polen y la liberación de éste, es del orden de cinco días, para la mayoría de las especies.

Otros autores, han estudiado la influencia de la temperatura en los contenidos polínicos registrados (Davies y Smith, 1973; Emberlin et al. 1993; Galán et al. 1995), llegando todos ellos a la conclusión que tiene una doble influencia; de una parte es decisivo en cuanto al momento en que se presenta la estación polínica y por otro lado, en la cantidad de polen que se va a liberar.

Así en algunos estudios (Comtois y Mandrioli, 1997), se ha puesto de manifiesto como las temperaturas registradas en el verano y otoño anterior, juegan un papel importante en la concentración polínica de la primavera siguiente. Por otro lado, como señala González-Minero et al. (1997), en algunas especies como el olivo, la temperatura acumulada durante los meses de febrero y marzo juega un papel primordial en el inicio de la estación polínica, una vez que los árboles ya han superado el periodo de dormancia.

De ahí, que para la construcción de algunos modelos estadísticos predictivos, algunos autores para predecir el contenido polínico, severidad de la estación o inicio, consideren los registros térmicos en algún periodo previo a la floración, considerando en algunos casos concretos temperaturas medias acumuladas por encima de un cierto valor (Sutra, 1992).

En general, el aumento de temperatura que se produce en primavera, favorece la floración de numerosas especies vegetales. Además, el grano de polen posee una propiedad denominada harmometangia, que consiste en el cambio de forma que experimenta el grano de polen para adaptarse a las condiciones de mayor o menor humedad del ambiente en donde se encuentra (Blackmore y Barnes, 1986). 
Así, en ambientes de temperaturas elevadas y bajas humedades relativas, el grano de polen pierde volumen, favoreciéndose su permanencia en suspensión (disminuye su diámetro aerodinámico equivalente), mientras que por el contrario, con altas humedades relativas y bajas temperaturas, el grano de polen se hidrata, aumenta su volumen y por tanto aumenta su tendencia a la sedimentación.

Además, la temperatura va a jugar un papel decisivo en las concentraciones del aerosol atmosférico, puesto que es la principal responsable de las inversiones térmicas que se puedan originar, ya sean en superficie o en altura.

\subsubsection{PRECIPITACIONES.}

Son varios los autores que han investigado la influencia de las precipitaciones sobre las concentraciones polínicas, y han concluido que se trata de una relación simple y negativa, ya que las lluvias que tienen lugar durante el periodo de floración, van a suponer un lavado de la atmósfera y dificultan la liberación de polen desde las plantas (McDonald, 1980).

No obstante, Norris-Hill y Emberlin (1993), encuentran para la zona centro del norte de Londres, en la que se presentan ciertas situaciones de altas concentraciones de polen durante periodos de lluvia, resultados diferentes. Encontraron que en general, los contenidos de polen en la atmósfera disminuyen con la lluvia, aunque en determinados casos observaron que se registraban importantes concentraciones polínicas después de haberse iniciado la lluvia, en concreto durante once ocasiones a lo largo de cuatro años de estudio, lo que les llevó a pensar que durante estos acontecimientos, estaban teniendo lugar otros procesos que debían ser importantes en los procesos de dispersión del polen. Al final demostraron que esos incrementos en la concentración estaban asociados a tormentas convectivas, en las que a su vez había que estudiar el origen del polen que transportan. 
Es importante destacar la influencia que pueden tener las lluvias registradas durante el periodo previo a la floración, sobre todo en el caso de especies herbáceas. Así, Trigo et al. (1996), indican una influencia positiva de las lluvias registradas en el periodo pre-floración, aumentando así las concentraciones polínicas en los años más lluviosos.

El efecto de la lluvia, puede ser muy variado, por lo que hemos de considerarlo desde tres puntos de vista: floración, polinización y sobre la concentración polínica.

Las lluvias, durante el periodo de floración, pueden producir un bloqueo de la misma, o ejercer una acción de lavado de la atmósfera, con la consecuente disminución de concentración polínica. También parece ser que las lluvias durante la época de polinización, producen un retraso en la dehiscencia de las anteras.

Un aspecto muy importante a tener en cuenta, dentro de las lluvias, es su duración y régimen. Así, una lluvia ligera y prolongada limpia más la atmósfera que una lluvia intensa, en forma de tempestad. El efecto de lavado progresivo de la atmósfera ha sido ya puesto de manifiesto, después de observar que con las primeras gotas caídas aumentaba la cantidad polínica recogida, descendiendo de forma logarítmica a medida que las precipitaciones perduraban (Suárez-Cervera y Seoane-Camba, 1983).

A la hora a la que se produzca la lluvia, también va a influir, puesto que si llueve a las horas en las que la liberación es mayor (Norris-Hill y Emberlin, 1993), éste no se liberará o no se mantendrá en suspensión.

En cuanto a las esporas, se ha observado, que la caída de precipitaciones de forma ligera favorece la formación y liberación de esporas de cladosporium y alternaria (Levetin, 1995). 


\subsubsection{HUMEDAD RELATIVA.}

En general, la humedad relativa va a tener un efecto contrario al de la temperatura. Sus efectos, se van a centrar fundamentalmente en la dehiscencia de las anteras, en la maduración del grano de polen y de su concentración en el aire.

La humedad se condensa en forma de agua, sobre la superficie de los granos de polen, favoreciendo su sedimentación y por lo tanto, provocando un descenso en la concentración polínica (Herrero y Fraile, 1997; Elvira-Rendueles, 2001).

Para los hongos, la humedad es un factor determinante en su crecimiento, situándose sobre un valor de $65 \%$ el valor óptimo para su desarrollo.

\subsubsection{RADIACIÓN SOLAR.}

En general, para las especies de floración primaveral se encuentra una correlación positiva entre la radiación solar y la concentración polínica, algo lógico, puesto que la radiación solar produce una deshidratación de las anteras y su consecuente dehiscencia (Moseholm et al., 1987).

Las plantas herbáceas prefieren las horas de mayor insolación en las que se registran las mayores temperaturas, para liberar los pólenes, encontrándose por ello, a las horas centrales del día los picos máximos de Urticaceae, Chenopodiaceae-Amaranthaceae, etc. (Trigo et al., 1996).

La formación y liberación de esporas son favorecidas por altos niveles de insolación, posibilitando procesos de deshidratación que determinan el desarrollo de mecanismo especializados de dispersión de esporas en la atmósfera. 


\subsubsection{VIENTO.}

La velocidad y dirección del viento van a jugar un papel fundamental en el transporte de pólenes y esporas, de tal manera que la capacidad de transporte es una función directa de la velocidad del viento, y la dirección jugará un papel predominante en la procedencia de las masas de aire que inciden en una determinada zona.

En cuanto a la velocidad, el efecto puede ser de limpieza de la atmósfera cuando la fuente productora de polen o esporas está próxima al captador, mientras que cuando la fuente productora está lejos con respecto al captador, mayores velocidades pueden traducirse en una mayor concentración polínica en el captador (Moreno-Grau, et al. 1998).

Es necesaria una velocidad mínima del viento, para que pueda iniciarse el proceso de liberación de los granos de polen, del orden de 3-4 m/s, así como también es importante las característica y ubicación de la fuente, para poder explicar este fenómeno (Akers et al., 1979).

Así, Smart et al. (1979), para evaluar el efecto del viento en la liberación y transporte del polen, compara los contenidos polínicos para las distintas direcciones del viento a dos horas del día, a las 9 de la mañana y a las 3 de la tarde, representando los distintos contenidos polínicos en una rosa de concentración.

\subsubsection{SITUACIONES CLIMATOLÓGICAS.}

La presencia de anticiclones, favorecen la aparición de situaciones de estabilidad atmosférica, mientras que las situaciones de bajas presiones por lo general, producen turbulencias que mejoran la mezcla entre las masas de aire. 
Así, Emberlin y Norris-Hill (1995), proponen estudiar el origen del polen transportado por masas de aire durante periodos de lluvia, que contribuyen a que se registren importantes concentraciones polínicas.

Uno de los principales elementos a incluir en la evaluación del impacto ambiental ocasionado por los contaminantes atmosféricos es el conocimiento de las características climatológicas de la circulación de las masas de aire sobre el área de emisión. Así, una clasificación del campo de vientos nos puede permitir describir los patrones de circulación sobre una determinada área, su frecuencia de aparición, y en definitiva, asociar cada situación a escala local con una de las clases previamente identificadas.

De ahí, la importancia de utilizar algunas técnicas para la identificación de situación sinópticas tipo de una determinada zona (análisis de cluster, análisis del factor, redes difuso-neuronales, etc.).

Son muchos los autores que han utilizado el análisis de cluster para examinar la relación existente entre los patrones de transporte atmosférico a escala sinóptica y las concentraciones de algunos contaminantes en un lugar determinado (Kalkstein et al., 1987; Davis y Kalkstein, 1990; Dorling et al., 1992; Eder et al., 1994; Dorling y Davis, 1995; Brankov et al., 1998; Desiato, 1997)

Otra forma de abordar el problema, es mediante el empleo de modelos para el análisis de trayectorias. Kleeman y Cass (1999), utilizan un modelo de este tipo para identificar las distintas fuentes individuales que contribuyen a la calidad del aire. Así, en el trabajo de Cabezudo et al. (1997), ya mencionado, se identifica polen de marihuana en la ciudad de Málaga, mediante el análisis de masas de aire que pueden tener un origen en el norte de Africa. 


\subsubsection{SITUACIÓN DEL CAPTADOR.}

Es muy importante la zona en la que esté colocado el captador así como la altura, según se trate de especies arbóreas o herbáceas. Cuando lo que más nos interesa son especies arbóreas, es importante que el captador esté ubicado a cierta altura 3-4 metros del suelo, mientras que cuando lo que nos interesan son las especies herbáceas, éste ha de estar más cercano al suelo.

Alcázar et al. (1998), estudian la variación de la concentración de Urticaceae con la utilización de captadores a diferentes alturas, concluyendo que son principalmente los parámetros meteorológicos los que tienen más influencia. Así cuando la atmósfera es más turbulenta las diferencias son mínimas, mientras que cuando las condiciones son secas y con calmas, las diferencias son más significativas.

Por otro lado, es imprescindible que el captador esté ubicado de tal forma que no existan obstáculos al flujo de vientos en cualquiera de las direcciones posibles, con objeto de poder analizar y llegar a conclusiones correctas.

Comtois et al. (2000), estudian el contenido polínico de la baja atmósfera en León mediante un globo sonda, observando que hasta $200 \mathrm{~m}$ son los fenómenos de mezcla los que gobiernan el proceso de transporte de polen, mientras que en capas más altas $(400 \mathrm{~m})$ la temperatura resulta ser esencial en el contenido polínico registrado y, sólo en altitudes mayores la velocidad del viento tiene alguna influencia. 


\subsection{CLASIFICACIÓN DE SITUACIONES METEOROLÓGICAS TIPO MEDIANTE ANÁLISIS DE CONGLOMERADOS.}

\subsubsection{INTRODUCCIÓN.}

El hombre desde siempre ha tratado de agrupar las observaciones de diversa índole en distintas categorías. Los objetos, las personas, los sucesos, ocurridos en un espacio (físico y temporal), son demasiados numerosos para procesarlos como entidades únicas. Por ello, utiliza la clasificación o identificación para facilitar esta tarea.

La clasificación o identificación, consiste en asignar una observación a un lugar apropiado o al que tiene mayor probabilidad de pertenecer, dentro de un conjunto establecido de categorías, o bien, el acto de formación de las categorías por primera vez (Hernández, 1998).

Desde un punto de vista estadístico, la clasificación es un conjunto de técnicas multivariantes, denominadas genérica e indistintamente Clasificación, Identificación, Análisis cluster, Taxonomía, Agrupamiento, etc., que ante una muestra de entidades (objetos, individuos, variables, etc.), tratan de reorganizarlas en clases, tipos, grupos o cluster, entre ellos lo más homogéneos posibles y a su vez que resulten ser heterogéneos entre sí (Balling, 1984).

Hernández (1998), señala que en la realización de una clasificación deben coexistir tres pretensiones: objetividad, estabilidad y poder predictivo. La objetividad o alcance de conclusiones similares por los distintos investigadores que utilizan la técnica, estabilidad o el hecho de que nuevos datos no la alteren profundamente y el poder predictivo para nuevas entidades.

Si bien es larga la historia de la literatura sobre clasificación, no es menos extensa la lista de las Ciencias que han hecho uso de los métodos de clasificación: Ciencias Sociales y de Comportamiento, Ciencias de la Salud, Geología, Ingeniería, Ciencias de la Información, Política, etc. (Bizquerra, 1989).

Así, por ejemplo esta técnica se ha utilizado en biología para clasificar animales, plantas, etc. Como han reflejado importantes investigadores en algunas ocasiones, la 
clasificación es un proceso fundamental dentro de la ciencia, ya que muchas veces nos vemos en la necesidad de que determinados fenómenos sean agrupados y ordenados, para que puedan ser entendidos.

Aunque muchas veces se pueda decir muy poco o nada de la estructura de los clusters o conglomerados finales, en la mayoría de los casos en los que se pretende obtener una clasificación de las entidades, se puede adelantar algo sobre los cluster inaceptables en función de sus características y la información que a priori se tenga de las entidades a clasificar.

El nombre de "análisis de conglomerados" o "análisis Cluster", se utiliza para definir una serie de técnicas, fundamentalmente algoritmos, que tienen por objeto la búsqueda de grupos similares de individuos, datos o de variables, que se van a ir agrupando en grupos.

En nuestro caso, dada una serie de estaciones meteorológicas de medida, en donde en cada una de ellas se miden una serie de parámetros meteorológicos a lo largo del día, se pretende utilizar el análisis de conglomerados, para tratar de clasificar esos datos horarios (días) en grupos lo más homogéneos posibles.

De manera que, dentro del mismo grupo queden englobados aquellos días que presenten un comportamiento lo más similar posible, y al mismo tiempo resulten grupos bastante diferentes (Balling, 1984).

Tanto el análisis de conglomerados como el análisis discriminante sirven para clasificar a individuos en categorías. La única diferencia entre ellos estriba en que en el análisis discriminante los grupos, clases o categorías han de ser conocidos a priori, cosa que no ocurre en nuestro caso.

Hernández (1998), señala que un proceso de clasificación, es un conjunto de etapas y que pueden ser establecidas, de forma general en:

1.- Elección de las entidades (objetos, variables, individuos, etc.) que se van a clasificar.

2.- Elección de las características que permiten la definición de las entidades y sobre las que se basará la clasificación final. Hay que seleccionar las variables más relevantes para identificar a los distintos grupos. 
3.- Contrastación de la ausencia de estructura de conglomerados entre las entidades.

4.- Elección de una medida que defina la proximidad entre entidades.

5.- Selección de un método de clasificación.

6.- Interpretación de los resultados resultantes.

Por tanto, antes de proceder al inicio de un análisis de conglomerados, debemos de tomar tres decisiones:

- Seleccionar las variables que consideremos más relevantes para la obtención de los grupos finales.

- Elegir la medida de proximidad entre los individuos.

- Elegir el criterio para agrupar a los individuos en conglomerados.

En cuanto a la primera decisión, hemos de decir que hay que seleccionar correctamente las variables que realmente resulten relevantes para identificar a los distintos grupos que pretendemos establecer.

En cuanto a la segunda decisión, hay que estar familiarizado con este tipo de medidas, básicamente similitudes y distancias, ya que los conglomerados que se formen lo hacen basándose en las proximidades entre variables o individuos.

Finalmente, hay que elegir el criterio de agrupación, y para ello nos conviene conocer como mínimo los principales métodos de análisis de conglomerados.

\subsubsection{APLICACIONES DE LA CLASIFICACIÓN CLIMATOLÓGI-CA EN LOS ESTUDIOS AMBIENTALES.}

La contaminación atmosférica, ya sea de origen biótico o abiótico, y la meteorología, están íntimamente relacionadas. Son muchos los trabajos que han puesto de manifiesto que sobre todo el transporte y difusión de algunos contaminantes en el aire, están relacionados con algunos parámetros meteorológicos, tales como la temperatura y humedad de las masas de aire que van a dispersar esos contaminantes, 
presencia o no de lluvias, características de los vientos dominantes, etc. (Balling, 1984; Kalkstein y Corrigan, 1986; Ibarra et al. 1993; Eder et al., 1994).

Por lo visto anteriormente, parece que la climatología sinóptica constituye una herramienta muy valiosa para evaluar la influencia del clima en una amplia serie de problemas medioambientales, (Kalkstein et al. 1987), asociados al desarrollo industrial, urbanístico y agrario de nuestros días.

Entre los objetivos de la climatología sinóptica, podemos citar principalmente la identificación de masas de aire homogéneas, así como de situaciones meteorológicas tipo en una determinada zona, con objeto de dar una mejor explicación del comportamiento o de los niveles registrados para algunos contaminantes en ciertos puntos (Kalkstein y Corrigan, 1986).

Una vez identificadas las distintas situaciones tipo, el siguiente paso consistiría en analizarlas con respecto a sus propiedades meteorológicas e intentar relacionarlas con las características generales de circulación a escala global (Davis y Kalkstein, 1990).

Así, Kalkstein y Corrigan (1986), utilizando este esquema de trabajo, desarrollaron una clasificación sinóptica para Wilmington (Delaware), donde cada día quedaba englobado en una clase sinóptica, para después analizar las variaciones en la concentración de $\mathrm{SO}_{2}$ desde 1974 hasta 1978, observando que las concentraciones más altas se asociaban claramente con una clase sinóptica.

Otro trabajo de características similares es el desarrollado por Davis y Kalkstein (1990), en el que utilizando la misma técnica, clasificaron en distintas situaciones sinópticas una amplia zona, para poder explicar más fácilmente los cambios en las concentraciones de ciertos contaminantes en nueve ciudades de los Estados Unidos.

En principio, cabe esperar que cada una de estas situaciones tipo va a llevar asociada un campo de concentraciones variable para los distintos contaminantes, siendo estas variaciones, dentro de cada situación tipo, mucho más pequeñas que las correspondientes a las de las condiciones de las fuentes emisoras, puesto que en los niveles de concentración registrados van a influir numerosas variables, como pueden ser los distintos regímenes de emisión, día de la semana, época del año, ubicación de las 
fuentes emisoras, implantación o abandono de ciertas tierras de cultivo, etc.(Ibarra et al.1993).

En el caso concreto de algunos contaminantes secundarios, que son el resultado de una serie de reacciones fotoquímicas, en las que también influyen los niveles de otros compuestos, la frecuencia e intensidad con que se producen las reacciones fotoquímicas, depende en gran medida de las condiciones meteorológicas reinantes durante un corto periodo de tiempo. De hecho, son numerosos los estudios que han puesto de manifiesto la dependencia de las concentraciones de ozono con determinadas condiciones meteorológicas que se presentan en un determinado periodo (Millán et al. 1986; Pryor et al. 1995).

Aunque varios autores han reflejado en sus trabajos la dependencia de los niveles de algunos contaminantes con la meteorología, la mayoría de las veces, lo han hecho utilizando un criterio un tanto subjetivo como pueden ser el análisis de los patrones de circulación general o tipos de masas de aire (Kelly et al. 1982; Comrie y Yarnd, 1992; Kassomenos et al. 1995), o bien, analizando los datos meteorológicos e interpretarlos conjuntamente con patrones dispersivos (Kalabokas y Bartzis, 1998; Melas et al. 1998).

Otros autores analizan pormenorizadamente los datos meteorológicos correspondientes a una determinada zona y clasifican e interpretan los patrones dispersivos característicos para el área bajo estudio, como es el caso del Bajo Nervión (Millán et al. 1986; Alonso et al. 1989), mediante el análisis diario de cada periodo de medidas de acuerdo con el comportamiento y la evolución de las masas de aire en la zona. Estableciendo la relación entre los tipos de información disponible y los efectos locales observados, de los que se desprende que para el área estudiada existe una discrepancia casi sistemática entre las condiciones meteorológicas sinópticas y las locales.

Otros autores (Albizuri et al. 1989), aplican la misma metodología para definir seis situaciones tipo en la ciudad de Cartagena, dos bajo vientos del suroeste, dos bajo vientos del noreste y las otros dos para los flujos locales de brisas tierra mar y viceversa.

De ahí que en otros estudios,(Kalkstein et al. 1987; Davis y Kalkstein 1990; McQueen et al. 1994; Pryor et al. 1995; Zelenka, 1997; Brankov et al. 1998), se haya 
utilizado una herramienta mucho más objetiva como es la técnica de análisis multivariante, denominada análisis de conglomerados en dos pasos, para reducir la varianza inexplicada por otros esquemas de clasificación, y al mismo tiempo obtener grupos que recojan a las situaciones que tengan un comportamiento meteorológico similar.

\subsubsection{MEDIDAS DE PROXIMIDAD PARA AGRUPAR LOS DATOS METEOROLÓGICOS.}

La manera habitual de obtener un valor de la proximidad entre las entidades que se desea agrupar o clasificar, es empezar por la formación de la matriz de datos $\mathrm{M}$ de orden $\mathrm{N}$ x p, donde $\mathrm{N}$ es el número de entidades a clasificar $\mathrm{y} \mathrm{p}$, el número de características o variables que se han observado sobre las $\mathrm{N}$ entidades.

A partir de esta matriz $\mathrm{M}$, se debe construir otra matriz $\mathrm{S}$, de orden $\mathrm{N} \times \mathrm{N}$, donde cada $\mathrm{S}_{\mathrm{ij}}$ corresponde a la proximidad entre las entidades i y j, expresándola con un valor numérico parecido, semejanza o similitud entre las dos entidades. También, se puede construir otra matriz D, exactamente igual que la anterior, pero que recoja la desemejanza o disimilitud entre las dos entidades (Hernández, 1998),

Existen muchas formas de medir la semejanza o disimilitud entre dos entidades, ya se correspondan éstas con objetos, variables o grupos. Sin embargo, la definición más extendida es la de una medida de desemejanza denominada distancia métrica. Esta definición representa las entidades como puntos en un espacio de coordenadas tales que las proximidades observadas corresponden a las distancias métricas entre ellas: a menor distancia más proximidad entre las entidades, y a mayor distancia, más diferencia entre las entidades. Hay una gran variedad de medidas de similitud que pueden ser utilizadas para agrupar variables, casos, etc. (Hernández, 1998). 


\subsubsection{CLASIFICACIÓN DE LOS MÉTODOS DE ANÁLISIS DE CONGLOMERADOS.}

Se distinguen dos grandes categorías de análisis de conglomerados (Bizquerra, 1989):

- 1.- Métodos jerárquicos

- 2.- Métodos no jerárquicos

\subsubsection{Métodos jerárquicos.}

Estos métodos permiten la construcción de un árbol de clasificación, denominado dendograma, el cual nos permite visualizar los resultados. Estos métodos a su vez pueden dividirse en aglomerativos y disociativos.

Los métodos aglomerativos, también llamados ascendentes, comienzan el análisis con tantos grupos como casos o individuos haya. A partir de estas unidades iniciales, se van formando grupos de forma ascendente, englobando cada vez a un mayor número de individuos. Al final del proceso todos los casos estarían englobados dentro de un mismo conglomerado (Bizquerra, 1989).

Los métodos disociativos, también llamados descendentes o divisivos, constituyen el proceso inverso al anterior. Empiezan con un conglomerado que engloba a todos los individuos o casos, y a partir de éste gran grupo inicial, se van formando grupos cada vez más pequeños. Al final del proceso, tenemos tantos grupos como individuos teníamos inicialmente (Bizquerra, 1989).

Con independencia del proceso de agrupamiento, hay muchos métodos o criterios de agrupamiento para ir formando esos conglomerados. Todos los criterios se basan en una matriz de distancias o similitudes.

Entre los métodos más comúnmente utilizados tenemos los siguientes (Bizquerra, 1989): 
- Vecino más próximo. Consiste en ir agrupando a los individuos o casos que tienen menos distancia o mayor similitud.

- Vecino más lejano, toma como criterio de agrupación la distancia entre los puntos más alejados.

- Promedio entre grupos. Se define la distancia entre dos conglomerados como el promedio de las distancias entre todos los pares de individuos en los cuales un miembro del par pertenece a cada uno de los clusters formados anteriormente.

- Promedio dentro del grupo. Se combinan los grupos de tal forma que la distancia promedio entre todos los casos en el cluster resultante sea lo más pequeña posible.

- Método del centroide. Calcula la proximidad entre dos clusters como la distancia entre sus medidas para todas las variables.

- Método de Ward. Calcula la media de todas las variables de cada cluster. Luego calcula la distancia euclídea al cuadrado entre cada individuo y la media de su grupo.

En climatología sinóptica, son tres los métodos que normalmente se utilizan para agrupar los datos climáticos en grupos de forma que la similitud de cada grupo sea mínima y entre grupos sea máxima, esto podríamos decir que es el objetivo de cualquier método que se utiliza en el análisis de conglomerados (Kalstein et al. 1987).

Obviamente, la elección del método de conglomerados a utilizar, es función de los objetivos específicos de cada estudio. Así, la elección de un método u otro puede tener importantes implicaciones en la homogeneidad de los grupos que finalmente se obtengan (Kalkstein et al. 1987).

Es importante tener en cuenta las características que presentan los datos meteorológicos para la elección de método más idóneo, puestos que estos están muy relacionados entre sí. Así, Kalkstein et al. (1987), hacen un estudio comparativo de tres de los métodos de análisis de conglomerados más comúnmente utilizados en la 
clasificación de datos meteorológicos: el método de Ward; average-linkage y el método del centroide.

En el método de Ward, es el más utilizado como técnica de análisis de conglomerados jerárquica en clasificación climática (Willmott y Vernon, 1980; Kalkstein y Corrigan, 1986). En cada paso del algoritmo, la suma de cuadrados dentro del conglomerado (W) es minimizada. La similitud entre dos cluster es la suma de cuadrados entre los dos clusters, teniendo en cuenta todas las variables.

Hay que resaltar dos aspectos importantes que recoge este método. Primero, como el objetivo es minimizar la suma de cuadrados dentro del conglomerado, la distancia al cuadrado de conglomerado es muy importante. Por otro lado, el número de observaciones juega un papel fundamental, de manera que si la distancia de una observación a dos clusters ya existentes es igual, esta observación será agrupada dentro del cluster que presente un menor número de observaciones.

Así, podemos decir que este método da prioridad a combinar las observaciones en los clusters que presentan un menor número de observaciones, resultando finalmente clusters de similar tamaño. Esta característica podría ser totalmente negativa, cuando estamos trabajando en una clasificación de datos meteorológicos, pues con este método se podrían enmascarar días que en principio serían fácilmente identificables y que pueden ser muy interesantes de distinguir.

El método del centroide trata de buscar cluster que tengan la menor distancia entre centroides (Bizquerra, 1989). La similitud es entonces definida como la distancia euclídea al cuadrado de medias de dos clusters. Aunque el algoritmo empleado parece sencillo, presenta serios inconvenientes, como el agrupamiento en cadena y, que va aumentando progresivamente.

Los problemas que plantea este método de análisis de conglomerados jerárquico, son denominados “chaining” y "sowballing” (Lankford y Semple, 1973).

El problema de "chaining" consiste en que el algoritmo da prioridad a unir en un mismo cluster, aquellos casos que se encuentran situados en una dirección predominante del espacio, quedando englobados en un cluster casos que estarían mejor clasificados en otro grupo. El segundo problema de "snowballing", consiste en el crecimiento progresivo de ese cluster que agrupa a los casos que se sitúan en una dirección predominante. 
Esto sugiere, que este método produce clusters de gran tamaño, que crecen a expensas de otros más pequeños. Esto desencadena finalmente en un cluster gigante y otros pequeños clusters con pocas observaciones cada uno de ellos. El resultado final es distinto al método de Ward, pero tampoco resulta ser interesante para la clasificación de datos meteorológicos.

El otro método, average-linkage, combina características de los dos métodos vistos anteriormente, por un lado compara la distancia euclídea al cuadrado entre pares de observaciones (una observación de cada cluster).Todos los posibles pares son evaluados y la distancia euclídea media al cuadrado determina la similitud. Este método tiene la capacidad de minimizar la varianza dentro del cluster y maximizar la varianza entre clusters (Kalkstein et al. 1987).

Como hemos dicho anteriormente, este método trata de minimizar la varianza dentro de cada grupo establecido y maximizarla entre los distintos grupos, lo cual es esencial para identificar grupos que presenten unas características meteorológicas homogéneas.

Así, el estadístico empleado en este método, consta de dos partes: Una que hace referencia a la varianza del cluster 1 y del cluster 2 , y una segunda que recoge la distancia al cuadrado entre los centroides de los dos clusters.

Este método por tanto, trabaja con varianzas mayores que la simple suma de cuadrados como hace el método de Ward. Al utilizar varianzas mayores, se reduce la influencia del tamaño del cluster en la unión de conglomerados.

El resultado de aplicar este método es finalmente una situación de equilibrio entre los dos anteriores, es decir, una situación intermedia entre tener un gran cluster con muchas observaciones como en el caso del centroide y tener clusters de muy similar tamaño como en el caso del método de Ward.

Por tanto, de todo lo anterior se deduce que el método más recomendable de utilizar para la clasificación de datos meteorológicos, es el método de average linkage, promedio entre grupos y como medida de proximidad la distancia euclídea al cuadrado (Davis y Kalkstein, 1987).

Para el caso de los métodos disociativos, todo lo expuesto para los métodos aglomerativos es también válido aquí. 


\subsubsection{Métodos no jerárquicos.}

Los métodos no jerárquicos, también llamados partitivos o de optimización, tienen por objeto realizar una sola partición de los individuos en K grupos. Esto implica, que nosotros tenemos que especificar "a priori", el número de grupos que queremos que sean formados. La asignación de individuos a los grupos se hace mediante algún proceso que optimice el criterio de selección (Bizquerra, 1989).

A su vez, dentro de los métodos jerárquicos se distinguen cuatro tipos: reasignación, búsqueda de la densidad, directos y reducción de dimensiones (Bizquerra, 1989).

Los métodos de reasignación permiten que, un individuo asignado a un grupo en un determinado paso del proceso, sea reasignado a otro grupo en un paso posterior si esto optimiza el criterio de selección. El proceso termina cuando no quedan individuos cuya asignación permita optimizar el resultado que se ha conseguido. Algunos de los algoritmos más conocidos dentro de estos métodos son el método $K$-means, quick cluster analysis (Ferran-Aranaz, 2001). No obstante, es el método K-means el más utilizado para la clasificación de datos meteorológicos (Davis y Kalkstein, 1987).

En el método $K$-means, el investigador tiene que establecer el número de grupos homogéneos de individuos que deben formarse. Con este método vamos a dividir el conjunto inicial de individuos, observaciones, etc., en conglomerados, de tal forma que al final del proceso cada caso pertenece al cluster, cuyo centro está más cercano a él. La distancia euclídea al cuadrado es la medida utilizada para establecer la proximidad entre cada caso y el centro de su respectivo cluster. El centro del cluster, viene dado por la media de los individuos que forman cada variable (Ferranz-Aranaz, 2001).

\subsubsection{PROCEDIMIENTO DE CLASIFICACIÓN.}

El objetivo perseguido en el análisis de conglomerados, es clasificar en una serie de grupos homogéneos, aquellos días que meteorológicamente podíamos decir que son similares, puesto que cabe pensar que ellos van a llevar asociados comportamientos distintos frente a los procesos de transporte y dispersión de los distintos contaminantes, según las condiciones meteorológicas reinantes en ese momento. 
Para ello, hemos de tener presente, que hay que definir cada día empleado en el estudio con aquellas variables que nos interesen, y por otro lado, cada día debe estar perfectamente definido a lo largo de la evolución horaria, lo cual nos va a llevar a considerar los valores de esos parámetros seleccionados a distintas horas del día.

Una vez que han sido seleccionadas las variables meteorológicas que se van a tener en cuenta en el estudio y se ha comprobado la validación de los datos, se tiene que proceder a la aplicación de la técnica clustering en dos pasos propiamente dicha, aunque antes hay que aplicar una técnica estadística multivariable, con objeto de eliminar la colinealidad existente entre los distintos parámetros que se van a considerar en el estudio (PCA), puesto que se tratan de datos que van a estar altamente correlacionados.

\subsubsection{ANÁLISIS DE COMPONENTES PRINCIPALES.}

El análisis de componentes principales es un método pionero dentro del análisis multivariante, que se engloba dentro del análisis factorial. Es un método de extracción de factores. Consiste en una técnica de reducción de la información disponible y de la que se dispone de diversas observaciones. Es una técnica estadística que nos va a permitir transformar un conjunto de variables intercorrelacionadas en otro conjunto de variables no correlacionadas, denominadas factores. Los factores son combinación lineal de las variables originales (Bizquerra, 1989).

Con el método de análisis de componentes principales, el primer componente que se extrae es el que resume lo mejor posible la información contenida en la matriz de datos original. Es decir, el que contribuye mejor a explicar la varianza total. El segundo componente, sería el que resume mejor la información restante, es decir, el que aporta un máximo de la varianza residual resultante, siendo independiente del primero.

La secuencia la podríamos hacer continuar hasta extraer tantos factores como variables iniciales, con lo que explicariamos toda la varianza.

La diferencia con el análisis factorial, estriba en que aquí sale en primer lugar el factor que es más importante (que es capaz de explicar un mayor porcentaje de la varianza total), mientras que en el análisis factorial todos los factores son igual de importantes. 
En primer lugar aparecen los estadísticos iniciales, donde hay tantos factores como variables iniciales. Los valores propios (eigenvalues) de cada variable, pueden interpretarse como un porcentaje de la variabilidad total explicada por el factor. Los porcentajes de cada factor y los porcentajes acumulados también aparecen. Es posible extraer tantos componentes principales como variables originales haya. Aunque esto no tendría sentido, puesto que lo que nos interesa es precisamente tener un mínimo número de factores que nos expliquen un máximo de la variabilidad total (Bizquerra, 1989).

El análisis factorial y el análisis de componentes principales están muy relacionados. Algunos autores consideran al segundo como una etapa del primero. Otros lo consideran como técnicas diferentes. No obstante, resulta que dos técnicas distintas, pueden utilizar el mismo algoritmo, cuando en el análisis factorial los factores se extraen por el método de componentes principales. En realidad, los resultados no son significativamente distintos. Entre las posibles causas de que se confundan los dos métodos se encuentran las siguientes: a) el punto de partida habitual de ambos métodos es una matriz de correlaciones, b) uno de los métodos que permite la obtención de factores en el análisis factorial se denomina componentes principales; c) la inclusión del análisis de componentes principales dentro del análisis factorial en la mayoría de los paquetes estadísticos.

En realidad, cuando se trabaja con bases de datos meteorológicas, muchas veces con un mismo parámetro meteorológico medido en distintas estaciones, etc., y en definitiva, todo ello se traduce en trabajar con una matriz de datos en la que la que algunas de las variables están correlacionadas entre sí, con lo cual nos va a interesar eliminar esa colinealidad existente, puesto que en definitiva contienen una información parecida. Hay que eliminar ese exceso de información, y tenemos variables que nos están aportando una misma información, al aplicar la técnica de conglomerados para la clasificación, eso va hacer que esa información aportada por varias variables tenga un peso superior a otra aportada por una sola variable, con lo que sería más determinante en la formación de los grupos.

Para evitar este problema, así como para reducir las dimensiones de la matriz con la que se trabaja, se aplica el método de componentes principales. 
En cuanto al número de componentes a retener en cada caso, es variable en función del criterio que se considere. Así, hay autores que consideran que un componente puede ser considerado significativo, cuando el eigenvalue es igual o mayor que la unidad, puesto que se considera que al menos contiene tanta información como una de las variables originales. Otros autores, para la elección del número de componentes principales, recurren a una serie de test (Catell's scree test) y gráficos.

En cualquier caso, la mayor parte de los autores coinciden en señalar que el número de factores a considerar debe ser tal, que al menos, se explique un importante porcentaje de la varianza de la matriz de datos inicial, del orden del 70-80\% (varianza total acumulada).

Una vez elegidos el número de componentes que explican un porcentaje importante de la varianza total, el siguiente paso es proceder al cálculo de las puntuaciones factoriales (factor scores) de cada observación. El cálculo de las puntuaciones factoriales, se realiza a partir de la matriz factorial rotada y se base en el modelo de regresión múltiple. Es importante resaltar, que estas puntuaciones factoriales, y más concretamente las estandarizadas, son las que se utilizan a continuación para el análisis de conglomerados.

La estandarización de las puntuaciones factoriales, se hace puesto que las variables iniciales pueden presentar unidades de medias variables. Así, nos podemos encontrar con variables que presenten límites de variación muy grandes con respecto a otras, de manera que tendrían un mayor peso a la hora del análisis del cluster y es ese el motivo que hace que se proceda a la tipificación de las puntuaciones factoriales, antes de abordar el análisis de conglomerados propiamente dicho.

Una vez calculados los scores de cada uno de los componentes seleccionados, el siguiente problema que se nos plantea es la determinación del número de conglomerados que debemos seleccionar. Uno de los estadísticos más apropiados para este fin es la correlación múltiple al cuadrado o $\mathrm{R}^{2}$, definida como la proporción de varianza explicada por el número de conglomerados elegidos. Debemos tener en cuenta, que si cada dato inicial u observación fuera considerado como un cluster individual, entonces $\mathrm{R}^{2}$ sería igual a 1 . Por el contrario, si todos los puntos fueran agrupados en un solo cluster, entonces $\mathrm{R}^{2}$ sería igual a 0 . 
El objetivo es encontrar un punto durante el proceso aglomerativo del cluster, en donde $\mathrm{R}^{2}$ descienda más bruscamente que en cualquier otro punto anterior. Generalmente, $\mathrm{R}^{2}$ desciende más rápidamente cuando el número de conglomerados se aproxima a uno conforme el procedimiento está forzando unir conglomerados que son bastantes distintos. Además, este descenso en la proporción de varianza explicada no ocurre de manera uniforme. El mayor descenso ocurre, cuando dos conglomerados distintos son forzados a unirse, y ello resulta esencial para terminar el procedimiento clustering, justamente antes de ese descenso brusco. 


\section{CAPÍtulo 4 MATERIALES Y MétodoS}




\section{CAPÍTULO 4. MATERIALES Y MÉTODOS}

\subsection{DATOS AEROBIOLÓGICOS.}

Los datos aerobiológicos utilizados en el presente estudio han sido obtenidos por nuestro grupo de trabajo siguiendo la metodología propuesta por la Red Española de Aerobiología (Domínguez, 1995) para los puntos de la red integrados en la Red Europea de Aeroalergeneos.

\subsubsection{MÉTODO DE CAPTACIÓN.}

El método de captación de pólenes utilizado es el Hirst de tipo volumétrico, que es similar al utilizado para el muestreo de otras fracciones del aerosol atmosférico. Este método permite expresar los resultados de forma cuantitativa con relación a una unidad de volumen.

Se trata de un método idóneo para el muestreo de pólenes aerovagantes, y todos los resultados son expresados como número de pólenes presentes en un metro cúbico de aire muestreado.

\subsubsection{PRINCIPIO DE IMPACTACIÓN.}

Se ha utilizado el método volumétrico de Hirst, que se basa en el impacto de un determinado volumen de aire sobre una superficie captadora, que a su vez se va desplazando lentamente, siendo la corriente de aire activa generada por una bomba colocada debajo del colector.

En este caso se ha utilizado un captador tipo Hirst (Hirst, 1952), modelo VPPS 2000 de la casa Lanzoni, con un volumen de aspiración de 10 litros por minuto. El equipo dispone de un tambor rotatorio con una cinta de celofán recubierta de silicona adhesiva que gira a una velocidad de $2 \mathrm{~mm} / \mathrm{hora}$, y sobre la que impacta el aire 
muestreado, quedando adheridas a la cinta las partículas cuyo rango esté comprendido entre las 2 y $200 \mu \mathrm{m}$.

A continuación esta cinta es cortada en el laboratorio en secciones de $48 \mathrm{~mm}$, que corresponden a las 24 horas de cada día. Posteriormente, esta cinta de $48 \mathrm{~mm}$ es montada con glicerogelatina sobre portaobjetos que son llevados a microscopio para identificación y contaje.

\subsubsection{IDENTIFICACIÓN DE PÓLENES.}

El portaobjetos con la cinta se examina en un microscopio modelo Olympus BH2, provista de óptica d-plan acromática. Se realizan cuatro barridos longitudinales con el objetivo de inmersión 50x y ocular 10x, ayudados por el objetivo 100x para la identificación completa de los distintos taxones.

Los pólenes son identificados basándonos en sus características morfológicas, utilizando la ayuda de claves, atlas y palinoteca de referencia (Lewis et al., 1983; Faegri e Iversen, 1989; Grant Smith, 1990; Suárez-Cervera y Márquez-Pereira, 1990; Moore et al., 1991).

Las principales características que se han tenido en cuenta para su identificación y diferenciación microscópica son: polaridad y simetría, unidades, aperturas, forma, tamaños y arquitectura de la pared. 


\subsection{DATOS METEOROLÓGICOS.}

Los datos meteorológicos utilizados para este estudio han sido suministrados por el Servicio de Medio Ambiente del Excmo. Ayuntamiento de Cartagena y son obtenidos en las distintas estaciones de medida que componen la red meteorológica del Ayuntamiento de Cartagena desde el año 1993 hasta el año 1999. Los datos de precipitación han sido suministrados por el instituto Nacional de Meteorología, de la estación Cartagena-Ciudad.

\subsubsection{FUENTES DE DATOS METEOROLÓGICOS.}

Las distintas estaciones de medida, así como los parámetros registrados en cada una de ellas se muestran en la tabla 4.1.

TABLA 4.1. Estaciones meteorológicas de la Red de Vigilancia de la Contaminación atmosférica del Ayuntamiento de Cartagena y parámetros que registran.

\begin{tabular}{|l|c|c|c|c|c|c||}
\hline \multicolumn{1}{||l}{ TORRES METEOROLÓGICAS } \\
\hline PARÁMETROS & D.V. & V.V. & T & HR & PRB & R.S. \\
\hline 1.-AYUNTAMIENTO & $\mathrm{X}$ & $\mathrm{X}$ & $\mathrm{X}$ & $\mathrm{X}$ & $\mathrm{X}$ & $\mathrm{X}$ \\
\hline 2.-ESCOMBRERAS & $\mathrm{X}$ & $\mathrm{X}$ & $\mathrm{X}$ & & & \\
\hline 3.-LO CAMPANO & $\mathrm{X}$ & $\mathrm{X}$ & $\mathrm{X}$ & & & \\
\hline 4.-ETASA & $\mathrm{X}$ & $\mathrm{X}$ & $\mathrm{X}$ & $\mathrm{X}$ & & \\
\hline
\end{tabular}

( D.V. = Dirección del viento; V.V.= Velocidad del viento; $\mathrm{T}=$ Temperatura ${ }^{\circ} \mathrm{C} ; \mathrm{HR}=$ Humedad relativa; PRB $=$ Presión atmosférica; R.S. = Radiación solar)

Los datos meteorológicos correspondientes a los años 1993 y 1994, han sido suministrados en soporte papel y como medias diarias para los distintos parámetros. Los datos correspondientes al periodo comprendido entre 1995 y 1999, ambos inclusive, han 
sido suministrados en ficheros informáticos con extensión DBF, correspondientes al programa comercial Dbase. Se trata de datos semihorarios para cada uno de los parámetros registrados en cada una de las torres anteriormente señaladas. Cada registro viene acompañado de un código que hace referencia a la validación del dato.

Cada fichero original para una torre meteorológica que contuviera todos los registros de un año, supondría un total de 17520 datos por parámetro meteorológico, lo que proporciona una idea de la potencia informática requerida para su tratamiento y almacenamiento.

Los datos de lluvia diaria caída en el periodo 1993-1999 han sido comprados al Instituto Nacional de Meteorología y corresponden a la torre meteorológica denominada Cartagena-Ciudad.

\subsubsection{MÉTODOS INSTRUMENTALES DE MEDIDA EN CONTINUO DE PARÁMETROS METEOROLÓGICOS.}

\subsubsection{1. - ANEMOCINAMÓMETRO.}

Es el sensor encargado de medir los valores de velocidad y dirección del viento. El equipo está integrado por dos módulos separados: un sensor de velocidad de viento y un sensor de dirección. Pueden utilizarse de manera independiente, aunque no obstante, pueden disponerse sobre una cruceta metálica, de modo que formen un conjunto de medida integrado de velocidad y dirección.

El equipo de medida de velocidad y dirección del viento Euro II ha sido concebido para su aplicación en zonas donde la intensidad del viento es moderada y la temperatura puede variar entre $-30 \mathrm{y}+60^{\circ} \mathrm{C}$. En la tabla 4.2. se recogen las características técnica de los equipos. 
Tabla 4.2. Anemocinamómetro VELETA EURO II. Características técnicas.

\begin{tabular}{||l|l|}
\hline \multicolumn{2}{|l|}{ SENSOR DE DIRECCIÓN DEL VIENTO } \\
\hline Tipo & Codificador óptico absoluto \\
\hline Resolución & 8 bits. $1,4^{\circ}$ \\
\hline Respuesta mínima & 0,6 nudos. A $90^{\circ}$ \\
\hline Peso & 700 grs. \\
\hline Sensor de velocidad del viento & $\begin{array}{l}\text { Generador } \\
\text { optoelectrónicamente }\end{array}$ \\
\hline Tipo & Impulsos $0-1000$ Hz. \\
\hline Salida & 0,6 nudos \\
\hline Respuesta mínima & $0,6-90$ nudos \\
\hline Margen de medida & 130 nudos \\
\hline Respuesta máxima & $-30-+60{ }^{\circ} \mathrm{C}$ \\
\hline Temperatura funcional & 50 W. Regulada termostáticamente \\
\hline Calefacción & 15 V./ 35 mA. \\
\hline Alimentación & 450 grs. \\
\hline Peso & \\
\hline
\end{tabular}




\subsubsection{SENSOR CONVERTIDOR DE TEMPERATURA Y HUMEDAD RELATIVA.}

Se trata concretamente de un sensor/convertidor celsius PHRT020. Este aparato es capaz de proporcionar los datos de temperatura y humedad relativa a la vez, puesto que la sección de humedad relativa, está basada en un captador de tipo capacitivo, y la capacidad de la sonda es proporcional al \% de HR, efecto que se aprovecha para la evaluación de este parámetro. La tabla 4.3. recoge las características técnicas de los equipos.

Tabla 4.3. Sensor convertidor CELSIUS PHRT020. Características técnicas

\begin{tabular}{|c|c|}
\hline \multicolumn{2}{|c|}{ SENSOR DE TEMPERATURA } \\
\hline Rango & $-30-+50^{\circ} \mathrm{C}$ \\
\hline Precisión & $\pm 0,2^{\circ} \mathrm{C}$ entre $-30-+50^{\circ} \mathrm{C}$ \\
\hline Constante de tiempo & 10 s. a $25^{\circ} \mathrm{C}$ \\
\hline Salida & $4-20 \mathrm{~mA}$ \\
\hline \multicolumn{2}{|c|}{ Sensor de humedad relativa } \\
\hline Rango & $0-100 \% \mathrm{HR}$ \\
\hline Temperatura utilización & $-30-+50^{\circ} \mathrm{C}$ \\
\hline Precisión a $25^{\circ} \mathrm{C}$ & $\pm 1 \%$ \\
\hline Histéresis & $(10-95-10 \%)-<0,5 \%$ HR \\
\hline Constante de tiempo & $<10 \mathrm{~s}$ \\
\hline Tiempo de vida medio & 15 años \\
\hline Protección saturación & Filtro espuma de teflón \\
\hline Salida & $4-20 \mathrm{~mA}$ \\
\hline
\end{tabular}




\subsubsection{BArotransmisor Pascal.}

Es éste el aparato que se utiliza para la medida de la presión atmosférica, y que presenta con respecto a los sensores, que basaban su funcionamiento en el principio de la cubeta de Torricelli, la ventaja de poder presentar la medida a distancia.

El barotransmisor Pascal, concretamente el PGC020 es un barómetro de estado sólido, basado en el principio de bandas extensiométricas. Al deformarse la placa sobre la que van impresas las resistencias, se provoca una variación de tensión mecánica en ellas, y por lo tanto, una variación de su valor resistivo. La tabla 4.4. recoge las características técnicas del equipo.

Tabla 4.4. Barotransmisor Pascal PGC020. Características técnicas

\begin{tabular}{||l|l||}
\hline \multicolumn{2}{|l||}{ SENSOR DE PRESIÓN ATMOSFÉRICA } \\
\hline Rango & $950-1050 \mathrm{mba}$. \\
\hline Salida eléctrica & $0-20 \mathrm{~mA}$. \\
\hline Precisión & $\pm 0,3 \mathrm{mba}$. \\
\hline Temperatura utilización & $0-+35^{\circ} \mathrm{C}$ \\
\hline Alimentación & $200 \mathrm{~V} . \mathrm{AC}$ \\
\hline Consumo & $<50 \mathrm{~mA}$. \\
\hline Peso & $950 \mathrm{~g}$. \\
\hline
\end{tabular}

\subsubsection{SENSOR DE RADIACIÓN SOLAR GLOBAL.}

Este sensor (piranómetro de estrella), es capaz de medir la radiación global que vamos a llamar G. Esta radiación global G, se compone a su vez, de la radiación solar $\mathrm{S}$ y de la radiación difusa del cielo $\mathrm{D}$. 
Si el aparato se coloca hacia abajo, mediría la radiación reflejada de onda corta. La superficie sensible a la radiación del emisor, se compone de 16 plaquitas de cobre lacadas en blanco y negro. El principio de funcionamiento es el siguiente, tras el paso de los rayos por una cúpula de cristal, calientan las plaquitas de cobre blancas y negras, y debido al color de cada una de ellas, las de color negro se calientan más que las blancas. Esta diferencia de temperatura es captada por una columna térmica, produciendo una tensión térmica, siendo una medida de radiación. La tabla 4.5. recoge las características técnicas del equipo.

Tabla 4.5. Piranómetro de estrella Dirmhirm. Características técnicas

\begin{tabular}{||l|l||}
\hline \multicolumn{2}{||l||}{ SENSOR DE RADIACIÓN SOLAR } \\
\hline Capacidad de medida & $1300 \mathrm{~W} \mathrm{~m}^{-2}$ \\
\hline Salida & $1,14 \mathrm{mV} / 100 \mathrm{~W} \mathrm{~m}^{-2}$ \\
\hline Campo espectral & 0,3 a $3 \mu \mathrm{m}$ \\
\hline
\end{tabular}

\subsection{CONSTRUCCIÓN DE LAS BASES DE DATOS.}

Los datos de las lecturas de las muestras aerobiológicas son introducidos en una hoja de cálculo diseñada en Excel, en donde se obtienen a partir de los recuentos los resultados expresados en granos de polen $/ \mathrm{m}^{3}$ y día, para cada tipo polínico identificado y el total, en formato xls.

\subsubsection{BASE DE DATOS AEROBIOLÓGICA.}

A partir del fichero anterior, se ha construido un nuevo fichero en SPSS para windows, formato sav, para cada año incluido en el estudio (1993-1999), que contiene como filas, los registros correspondientes a cada día y como columnas el año, semana, mes, así como las concentraciones polínicas totales y las correspondientes a los taxones identificados en la atmósfera de Cartagena (Moreno-Grau et al., 1998; ElviraRendueles, 2001). 


\subsubsection{BASE DE DATOS METEOROLÓGICA 1993-1994.}

Los datos correspondientes al periodo 1993-1994, suministrados en papel para cada torre meteorológica, han sido pasados a soporte informático, utilizando el paquete informático Dbase, formato dbf, teniendo como filas los distintos días del año, y como columnas cada uno de los parámetros meteorológicos registrados en cada una. Los valores almacenados corresponden al valor medio diario de cada parámero, salvo para la lluvia y la radiación solar que son los valores acumulados diarios.

A partir de cada fichero dbf se ha creado un nuevo fichero en SPSS, extensión $\mathrm{SAV}$, en el que se han generado dos nuevas columnas denominadas rumbo y rango. La variable rumbo se ha calculado tras dividir los $360^{\circ}$ sexagesimales en 12 rumbos iguales (Norte, NNE, ENE, Este, ESE, SSE, Sur, SSW, WSW, Oeste, WNW y NNW), y clasificar cada valor de la dirección media diaria en el rumbo correspondiente.

La variable rango se ha calculado tras clasificar los valores de velocidad media diaria del viento en 4 rangos (Rango $1=0-4,9 \mathrm{~km} / \mathrm{h}$; rango $2=5-10,9 \mathrm{~km} / \mathrm{h}$; rango $4 \geq$ $15 \mathrm{~km} / \mathrm{h})$.

\subsubsection{BASE DE DATOS METEOROLÓGICA 1995-1999.}

Los datos correspondientes al periodo 1995-1999, suministrados en soporte informático para cada torre meteorológica, han sido depurados y almacenados como ficheros con extensión dbf, teniendo como filas los 48 datos semihorarios de cada día del año, y como columnas cada uno de los parámetros meteorológicos registrados en cada una. Los valores almacenados corresponden al valor medio semihorario de cada parámetro.

Como en el caso anterior, y siguiendo la misma metodología, ya en formato sav, se han obtenidos dos nuevas columnas denominadas rumbo y rango. También se han calculado nuevas variables como son la temperatura mínima diaria, temperatura máxima diaria, humedad relativa máxima, humedad relativa mínima, presión atmosférica máxima, presión atmosférica mínima, todas ellas con el objetivo de ser usadas en los modelos predictivos y crear, posteriormente, variables pierna que puedan quedar incluidas en algún modelo de los que se pretende desarrollar. 
A partir de estos ficheros que contienen datos semihorarios se ha calculado otro fichero que contiene como filas los distintos días del año y como columnas las distintas variables, pero en este caso los valores medios diarios, salvo para la radiación solar y la precipitación que se ha trabajado con el valor acumulado diario, y para la dirección del viento que se ha categorizado en rumbos y posteriormente se ha seleccionado la moda como valor representativo del día, cuando dos rumbos han presentado la misma frecuencia, el valor seleccionado ha tenido en cuenta la velocidad del viento.

Además, a este último fichero, se le han añadido una nueva variable denominada rangosmi. Para ello, se ha realizado una inspección de los 48 valores de frecuencias de los valores de rangos de velocidad del viento, asignando a cada día en las variable rangosmi, el valor que correspondía al rango que presentaba un mayor valor de frecuencia.

\subsubsection{BASE DE DATOS METEOROLÓGICA Y AEROBIOLÓGICA 1993-1999.}

A partir de los ficheros anuales de la base de datos meteorológica $y$ aerobiológica, se han fundido éstos, teniendo como filas los distintos días de cada año y como columnas las distintas variables meteorológicas, así como las concentraciones polínicas de los taxones anteriormente mencionados.

Para las concentraciones polínicas de cada taxón y para los totales, se ha procedido a estandarizar los valores diarios, para asegurarnos de la homogeneidad de la varianza de las concentraciones polínicas y eliminar así las variaciones que por diversos factores existen de un año a otro (Emberlin et al., 1993), y poder trabajar con datos de distintos años. La fórmula utilizada para estandarizar los datos es la siguiente (Moseholm et al., 1987):

$$
n_{p}=\ln \left[\frac{p_{r} \times 1000}{p_{y}}+1\right]
$$

Donde:

$$
\mathrm{n}_{\mathrm{p}}=\text { concentración polínica estandarizada }
$$


$\mathrm{p}_{\mathrm{r}}=$ concentración polínica diaria

$\mathrm{p}_{\mathrm{y}}=$ concentración polínica total anual/floración

\subsection{TRATAMIENTO ESTADÍSTICO DE LOS DATOS.}

Para el tratamiento estadístico de los datos se han utilizado los paquetes estadísticos SPSS para Windows Versión 10.0 y SYSTAT para Windows Versión 10.0.

Inicialmente se ha hecho una descripción estadística de las concentraciones polínicas totales registradas durante los años 1993-1999, con el fin de conocer las principales características de las distintas floraciones, así como un estudio de la distribución de las concentraciones polínicas totales.

Se ha efectuado una representación conjunta de las concentraciones polínicas totales y las concentraciones de Chenopodiaceae-Amaranthaceae, para el periodo 19931999, en la que se pretende justificar que las concentraciones polínicas registradas a partir de septiembre, coinciden prácticamente en su totalidad con la segunda floración de quenopodiáceas.

Se ha realizado una descripción estadística de los distintos parámetros meteorológicos que influyen en las concentraciones polínicas registradas (Norris-Hill, 1995), para cada uno de los años de muestreo, así como para el conjunto de los años. Asimismo, se ha efectuado una descripción de la evolución horaria para cada uno de estos parámetros.

También se ha efectuado una descripción del comportamiento del viento durante el periodo del estudio en la torre meteorológica más cercana al captador, confeccionando rosas de vientos en la que se representan las frecuencias en cada dirección, así como tablas de frecuencias de las velocidades del viento por rangos. 


\subsubsection{ESTUDIO ESTADÍSTICO DE METEOROLOGÍA Y PÓLENES.}

Se han calculado los coeficientes de correlación lineal de Pearson y la prueba de significación bilateral entre los distintos parámetros meteorológicos y las concentraciones polínicas totales y de Chenopodiaceae-Amaranthaceae.

Dada la importancia que numerosos autores apuntan que tienen ciertos parámetros meteorológicos en las concentraciones de polen registradas en un determinado punto y momento (McDonald, 1980; Bringfelt et al., 1982; FernándezGonzález et al., 1993; Antépara et al., 1995; Galán et al., 1995; Herrero y Fraile, 1997; Stark et al., 1997; Trigo et al., 1997; Díaz de la Guardia et al., 1998; Moreno-Grau et al., 1998; Muñoz Rodríguez et al., 2000; Sabariego et al., 2001), se ha realizado un análisis de la varianza (ANOVA) de las concentraciones polínicas totales y de Chenopodiaceae-Amaranthaceae para los distintos parámetros meteorológicos, para ver si hay diferencias o no estadísticamente significativas (Hopke, 1992) y conocer la influencia de cada uno.

Se han confeccionado rosas de concentraciones para las distintas direcciones, para facilitar la comprensión de las direcciones que producen mayores o menores concentraciones, así como la ubicación de las masas vegetales con respecto al captador.

\subsection{CLASIFICACIÓN DE LAS SITUACIONES METEOROLÓGICAS TIPO EN LA CIUDAD DE CARTAGENA}

Las medidas de los distintos parámetros son registradas en continuo, aunque finalmente se almacenan los valores semihorarios para cada uno de ellos. Para la realización del presente estudio, y teniendo en cuenta que el objetivo fundamental era la identificación de los flujos predominantes, se han utilizado algunos de los datos semihorarios diarios del vector viento (velocidad y dirección), para tal clasificación, en las cuatro estaciones de medida, por considerar que por las complejas características topográficas de la ciudad, así como por la influencia de éste, en el transporte y dispersión de los contaminantes era fundamental considerar este parámetro, así como recoger su comportamiento en distintos puntos de la ciudad, para que los resultados obtenidos, sean un fiel reflejo de la dinámica de los distintos flujos del viento. 
Por otro lado y ante el desconocimiento de la frecuencia con que se presentan estos flujos, se optó por elegir los datos del vector viento que reflejaran la evolución horaria de éste a lo largo del día, pero al mismo tiempo la información tampoco debía ser excesiva, para facilitar así la separación de los distintos comportamientos que tienen lugar.

Por ello, se eligieron los datos de velocidad y dirección del viento a las 01, 07, 13 y 19 horas de cada día, en cada una de las estaciones (Ayuntamiento, Lo Campano, Etasa y Escombreras), por considerar que con estos datos se podría disponer de la información básica acerca del comportamiento del viento a lo largo de un día. De esta manera quedaban recogidos los valores del viento a primeras horas del día, horas centrales del día, atardecer y por la noche, para poder de esta manera identificar los comportamientos característicos de las masas de aire en una zona próxima al mar, como es la brisa mar-tierra y viceversa.

El siguiente paso fue proyectar los vectores viento de las distintas estaciones, sobre los ejes de coordenadas $\mathrm{X}$ e $\mathrm{Y}$, para obtener así las componentes $\mathrm{V}_{\mathrm{x}} \mathrm{y} \mathrm{V}_{\mathrm{y}}$, en lugar de trabajar con los valores de dirección y velocidad. De esta manera, se tenían como variables las dos componentes transformadas para cada una de las estaciones (8 variables), y como casos, los valores de éstas registrados a las cuatro horas del día consideradas, y esto para cada uno de los días del año 1996 que fueron utilizados para identificar el número de situaciones más adecuado (1464 casos).

\subsubsection{METODOLOGÍA.}

Para el tratamiento estadístico de todos los datos incluidos en este estudio se ha utilizado el paquete informático SPSS versión 10.0 para Windows.

Al considerar como variables las componentes del viento ya transformadas en componentes $\mathrm{X}$ e $\mathrm{Y}$, de las distintas estaciones, y con objeto de eliminar la colinealidad existente entre ellas, sobre este fichero se ha realizado un análisis factorial, en donde el método empleado para la extracción de factores ha sido el de los componentes principales (Roscoe et al., 1982).

El criterio de extracción de factores ha sido gráfico, a partir del gráfico de 
sedimentación seleccionando los componentes anteriores al punto de inflexión en dicha gráfica (Bisquerra, 1989). A partir de la matriz factorial se han calculado las puntuaciones factoriales de todos los individuos (filas iniciales) para cada factor extraído, y se han guardado como columnas, que no se han tipificado, por considerar que no era necesario al trabajar sólo con datos de viento, y las nuevas columnas han constituido las variables para un análisis de cluster en dos pasos.

En primer lugar se ha efectuado un análisis de cluster jerárquico, por el método de vinculación promedio intra-grupos (average linkage), que nos ha servido para identificar el número final de clusters a retener. A continuación, se ha realizado un análisis de cluster no-jerárquico, por el método de K-medias, fijando en este caso el número de clusters que se desean establecer y que han sido definidos en el paso anterior.

A continuación, se ha tabulado el número de casos pertenecientes a cada cluster, y se ha efectuado para cada cluster un análisis de la varianza para el resto de parámetros meteorológicos. Se ha efectuado también para cada cluster, la evolución horaria de los datos meteorológicos y se ha representado en forma de rosa de los vientos las direcciones de éstos para cada cluster, en cada una de las estaciones de medida.

\subsubsection{CLASIFICACIÓN EN CLUSTERS DE LOS AÑOS 1995-1997.}

Una vez identificado el número de cluster por el procedimiento anterior con los datos de dirección y velocidad del viento del año 1996 en las cuatro estaciones de medida, se han elegido los centros finales de los conglomerados finalmente obtenidos para utilizarlos de nuevo en la clasificación del resto de días.

A continuación se ha procedido a clasificar los datos de velocidad y dirección del viento, correspondientes a los años 1995-1997, utilizando el método de análisis de cluster no-jerárquico de K-medias, en el que se definieron el número de clusters que se debían establecer, y en el que como centros iniciales de los conglomerados se eligieron los centros finales que se obtuvieron en el paso anterior, forzando de esta forma al algoritmo de clasificación a incluir todos los casos en esos grupos que previamente habían sido validados. 
A continuación y una vez que teníamos a cada día englobado en un determinado cluster que presentaba unas características determinadas, se procedió nuevamente a analizar las frecuencias de aparición de los distintos clusters durante un mismo día, de forma que aunque un día quedase englobado en un cluster principal, también podía tener en menor medida participaciones de otros, creando de esta forma nuevas variables que indicaban el porcentaje de aparición de cada cluster durante un mismo día.

Para los años 1998 y 1999 se ha realizado el mismo tratamiento, pero únicamente para los datos del vector viento en la torre meteorológica del Ayuntamiento, por carecer de datos para algunas estaciones durante estos años, se ha optado por presentar sólo los resultados obtenidos hasta el año 1997. No obstante se ha utilizado la clasificación obtenida para los años 1998 y 1999 en el Ayuntamiento, que no difiere de la anterior, para completar el tratamiento estadístico, así como para la construcción de los modelos predictivos.

\subsection{MODELOS DE REGRESIÓN MÚLTIPLE Y MODELOS DE REGRESIÓN LOGÍSTICA.}

Se han desarrollado dos tipos de modelos estadísticos para definir ecuaciones predictivas que nos permitan definir las concentraciones polínicas a partir de algunas variables que se han manejado en este estudio.

El primer tipo de modelos, los de regresión múltiple, permite predecir los valores de una variable dependiente en función de diferentes variables independientes, donde todas ellas han de ser numéricas. Para el desarrollo de este tipo de modelos se ha utilizado el paquete estadístico SPSS para Windows, Versión 10.0., con la opción "hacia atrás" del método de selección de variables, utilizando como criterio de salida de cada variable del modelo que $F$ sea inferior a 0,10 (Vinacua, 1997).

Inicialmente se han desarrollado modelos para predecir las concentraciones polínicas totales estandarizadas y las concentraciones polínicas correspondientes a la segunda floración de Chenopodiaceae-Amaranthaceae.

Con los modelos de regresión lineal se pretende predecir el valor de la variable dependiente en función de la combinación lineal de una serie de variables 
independientes. Como uno de los aspectos más importantes en el análisis de regresión múltiple es la selección de las variables a incluir en el estudio, se empezó la construcción de los mismos mediante la matriz de correlaciones, para definir que variables se encuentran intercorrelacionadas tanto con la variable dependiente como entre ellas (Bisquerra, 1989).

Los datos utilizados para el estudio de regresión lineal múltiple corresponden a los valores de pólenes estandarizados de los años 1995 a 1998, no se han utilizado los datos de los años 1993 y 1994, ya que los parámetros meteorológicos no han permitido realizar la clasificación de flujos de viento por el método de análisis de cluster, ni definir las variables para las que se han estudiado los comportamientos semihorarios, siempre relacionadas con el campo de vientos en la zona. Los datos del año 1999 se han sacado de este análisis para ser posteriormente utilizados en la validación de los modelos propuestos.

A la hora de seleccionar el modelo, se utilizó el método de paso hacia delante, proceso que se inicia sin ninguna variable independiente en la ecuación, y en cada paso se introduce o elimina una variable, proceso que finaliza cuando ninguna de las variables de la ecuación o fuera de ella satisfaga los criterios de salida o entrada, respectivamente. De modo complementario, se han obtenido los ANOVA de los modelos de regresión múltiple construidos en el proceso, un p-valor asociado al estadístico $\mathrm{F}$ menor de 0,05 significará que se rechaza la hipótesis nula de que la pendiente del plano de regresión es igual a cero. Para comparar la contribución de las distintas variables al modelo de regresión se han analizado los p-valores asociados a los coeficientes de los modelos, ya que cuando su valor sea menor de 0,05 (condición introducida en el método) indicarán que la contribución de cada una de la variables es significativamente distinta de cero, cuando el p-valor asociado a la constante también sea menor a 0,05 se concluirá que el plano de regresión no pasa por el origen (FerránAranaz, 2001).

Con el fin de mejorar los coeficientes de determinación de las ecuaciones de regresión, se crearon variables de retardo de las concentraciones polínicas y de las variables meteorológicas, también se crearon variables categóricas de algunos de los parámetros meteorológicos, que fueron sucesivamente introducidas en los modelos de regresión lineal múltiple. Este procedimiento se siguió tanto para los pólenes totales, 
con los datos de las primeras 30 semanas de cada año, como para la segunda floración del tipo Chenopodiaceae-Amaranthaceae.

Una vez seleccionado un modelo determinado, se ha procedido a su validación además de estudiando el gráfico P-P normal de los residuos tipificados del modelo, por comparación con los datos del año 1999. Así se predijeron los valores de las concentraciones polínicas a partir de la ecuación de regresión lineal múltiple seleccionada, determinando los coeficientes de correlación y determinación entre los valores predichos y los reales, y efectuando los contrastes de diferencias de varianzas y de medias entre las dos variables. También se analizó el gráfico de dispersión entre los valores predichos y reales.

El segundo tipo de modelos que se han desarrollado, de regresión logística, estiman la probabilidad de que ocurra un determinado suceso, en nuestro caso particular, estiman la probabilidad de que la concentración polínica estandarizada esté por debajo o encima de un determinado valor y además permiten trabajar con variables numéricas y categóricas.

Para la construcción de estos modelos también se empleó el paquete estadístico SPSS para Windows Versión 10.0, utilizando el método Adelante "Wald", que introduce las distintas variables en pasos sucesivos, introduciendo en cada paso aquella que, habiendo quedado fuera en el paso anterior, presente un p-valor asociado menor de 0,05. Del conjunto de variables que cumplen esta condición, el programa introduce aquella que presenta un mayor estadístico Score (puntuación), que se corresponde con la que incumple en mayor medida la hipótesis nula de que el coeficiente para la misma en el modelo sea igual a cero.

Para las variables que ya han sido introducidas en el modelo, su permanencia depende del estadístico de Wald, de forma que si se incumple el criterio de salida de un nivel de significación para dicho estadístico de 0,05 , la variable será eliminada del modelo.

El desarrollo de los modelos de regresión logística, se ha realizado para las concentraciones polínicas totales estandarizadas. En una primera fase, las concentraciones totales estandarizadas, han sido codificadas para obtener una variable dicotómica, dividiendo la población en dos subpoblaciones. Por no existir actualmente 
un cierto consenso en cuanto a la concentración polínica que ocasionaría problemas importantes en los pacientes alérgicos se ha optado por dividir en estas dos subpoblaciones: (1) concentraciones polínicas menores o iguales a la media aritmética de las concentraciones polínicas estandarizadas y (2) concentraciones polínicas por encima este valor.

Para el conjunto de variables que se consideraron categóricas o no numéricas se recodificaron para transformarlas, obteniendo así como variables categóricas las siguientes: semana del año, mes, rumbos, cluster, rangomi, estación (primavera, verano, otoño e invierno), presión (altas, medias y bajas), llueveon (presencia o ausencia de lluvias) y rslogis (radiación solar media acumulada por encima o por debajo de la media anual). El resto de variables que se utilizaron eran numéricas.

Una vez seleccionado el modelo más idóneo, se procedió a la validación de éste con los datos correspondientes al año 1999. Para ello, en una primera etapa se procedió a calcular de nuevo los coeficientes del modelo con los datos del año 1999 y a continuación, se calcularon las probabilidades de los distintos días, de pertenecer a un grupo u otro, y finalmente, se comprobó la bondad del modelo para la predicción realizada en base al número de aciertos obtenidos.

\section{7.-MODELOS DE SERIES TEMPORALES (ARIMA).}

Para la elaboración de los modelos de series temporales se ha utilizado el paquete estadístico SYSTAT 10.0 para Windows, siguiendo un procedimiento iterativo, en el que se plantean distintos modelos y se estudia su adecuación a la serie de partida. La serie temporal empleada ha sido la concentración media semanal de los pólenes totales, partiendo de la primera semana de enero de 1994 hasta la última de diciembre de 1999, eliminando los datos de 1993, ya que comenzaban en marzo.

En cuanto a la metodología aplicada al análisis de la serie, en primer lugar, se definió la periodicidad de la serie, comienzo en 1994, periodicidad 52 semanas, primer dato 1, inspeccionando a continuación el gráfico de secuencia de la serie y los estadísticos descriptivos, efectuando también los gráficos de autocorrelación y autocorrelación parcial de la serie inicial, en función de los resultados obtenidos se 
procedió a realizar una primera diferenciación de orden 1, y se probaron diferentes modelos que fueron rechazados dado el mal comportamiento de los mismos, por ello se realizó una nueva diferenciación de orden 52, construyendo nuevos modelos ARIMA, hasta obtener un modelo que tenía el comportamiento más adecuado, diagnosticando este extremo mediante los gráficos de autocorrelación y autocorrelación parcial de los residuales y con el comportamiento de las predicciones.

Se procedio a continuación a sobreajustar los órdenes del modelo elegido, comprobando que no se mejoraba la predicción, por lo que se procedió a estimar los parámetros del modelo y a establecer la ecuación para el modelo, se efectuaron a partir de este momento predicciones, que se contrastaron con los datos reales de las medias semanales del polen total del año 2000.

Para validar estas predicciones se efectuaron los gráficos de dispersión entre los valores reales y los predichos, se calcularon los coeficientes de correlación y de determinación entre ambas variables y se realizaron los contrastes de diferencias de varianzas y de medias. También se analizó el gráfico de secuencia de los datos reales y los datos predichos. 


\section{Capítulo 5 RESULTADOS}




\section{CAPÍTULO 5. RESULTADOS}

En el presente capítulo se presentan los resultados de los diferentes tratamientos de los datos realizados para el desarrollo de modelos predictivos aplicados a los datos aerobiológicos y meteorológicos para la ciudad de Cartagena en el periodo comprendido entre 1993 y 1999, que a su vez está estructurado en los siguientes apartados:

a) Resultados de las principales características de las concentraciones polínicas totales y de Chenopodiaceae-Amaranthaceae.

b) Resumen de la meteorología de la ciudad de Cartagena durante este periodo, haciendo especial hincapié en el comportamiento del vector viento.

c) A continuación se muestran los resultados obtenidos del estudio conjunto meteorología-pólenes, en los que aparecen los distintos análisis de la varianza de las concentraciones polínicas por variables meteorológicas, así como las correlaciones lineales.

d) Resultados de la clasificación de los flujos de viento para la Ciudad de Cartagena, mediante análisis de cluster en dos pasos.

e) Resumen de los mejores modelos predictivos obtenidos: modelos de regresión múltiple, modelos de regresión logística y modelos de series temporales (ARIMA). 


\subsection{CONCENTRACIONES POLÍNICAS DE LA CIUDAD DE CARTAGENA DURANTE LOS AÑOS 1993-1999.}

\subsubsection{PÓLENES TOTALES.}

Inicialmente se ha efectuado una breve descripción estadística de los parámetros que se han considerado más relevantes para el presente estudio, tablas 5.1. y 5.2. Con objeto de que los resultados sean más manejables, algunos de éstos se han recogido de modo gráfico, así en la figura 5.1. se recoge la secuencia de las concentraciones polínicas totales registradas en la atmósfera de Cartagena desde marzo de 1993 hasta diciembre de 1999. En la figura 5.2. se presenta la secuencia con los valores de la media móvil de 7 días de las concentraciones polínicas totales para el mismo periodo de tiempo.

La tabla 5.2. recoge las medias mensual y anual de los pólenes totales para cada uno de los años estudiados y el conjunto de ellos. En la figura 5.3a. se presenta la distribución de frecuencias de los datos de los pólenes totales en el periodo 1993-1999, y en la figura 5.3b. los gráficos P-P de la distribución de los pólenes totales estandarizados frente a las distribuciones de contraste Gamma y Normal, los datos de concentración polínica se han estandarizado tal y como se ha descrito en el capítulo de materiales y métodos.

En la figura 5.4. se presentan las secuencias de la evolución anual de las concentraciones polínicas máximas semanales y el máximo semanal de la media diaria del periodo estudiado. 
Tabla 5.1a. Características de las concentraciones polínicas totales (granos $/ \mathrm{m}^{3} \mathrm{de}$ aire), durante los años 1993-1999.

\begin{tabular}{|l|c|c|c|}
\hline Año & $\begin{array}{c}\text { Fecha } \\
\text { máximo }\end{array}$ & $\begin{array}{c}\text { Cantidad } \\
\text { máxima }\end{array}$ & Total anual \\
\hline 1993 & 28-Mayo & 635 & 21.584 \\
\hline 1994 & 17-Mayo & 417 & 15.016 \\
\hline 1995 & 12-Mayo & 479 & 16.885 \\
\hline 1996 & 28-Mayo & 423 & 11.326 \\
\hline 1997 & 6-Mayo & 659 & 11.746 \\
\hline 1998 & 9-Marzo & 767 & 13.391 \\
\hline 1999 & 23-Febrero & 595 & 11.370 \\
\hline
\end{tabular}

Tabla 5.1b. Características de las concentraciones polínicas totales de algunos tipos polínicos presentes en el bioaerosol de la ciudad de Cartagena (granos $/ \mathrm{m}^{3}$ de aire).

\begin{tabular}{|l|l|l|l|l|}
\hline & \multicolumn{1}{|c|}{ Urticaceae } & \multicolumn{1}{|c|}{ Oleaceae } & Cupressaceae & \multicolumn{1}{c|}{ Pinaceae } \\
\hline 1993 & 8.271 & 2.161 & 818 & 1.447 \\
\hline 1994 & 4.337 & 1.929 & 2.403 & 424 \\
\hline 1995 & 4.540 & 1.622 & 2.516 & 684 \\
\hline 1996 & 3.016 & 736 & 1.850 & 390 \\
\hline 1997 & 2.545 & 2.393 & 2.038 & 280 \\
\hline 1998 & 2.615 & 669 & 3.852 & 1.671 \\
\hline 1999 & 1.908 & 1.832 & 3.739 & 316 \\
\hline $1993-1999$ & 3.890 & 1.620 & 2.459 & 745 \\
\hline
\end{tabular}


Figura 5.1. Evolución de la concentración polínica total diaria (granos $/ \mathrm{m}^{3}$ de aire), durante los años 1993-1999.

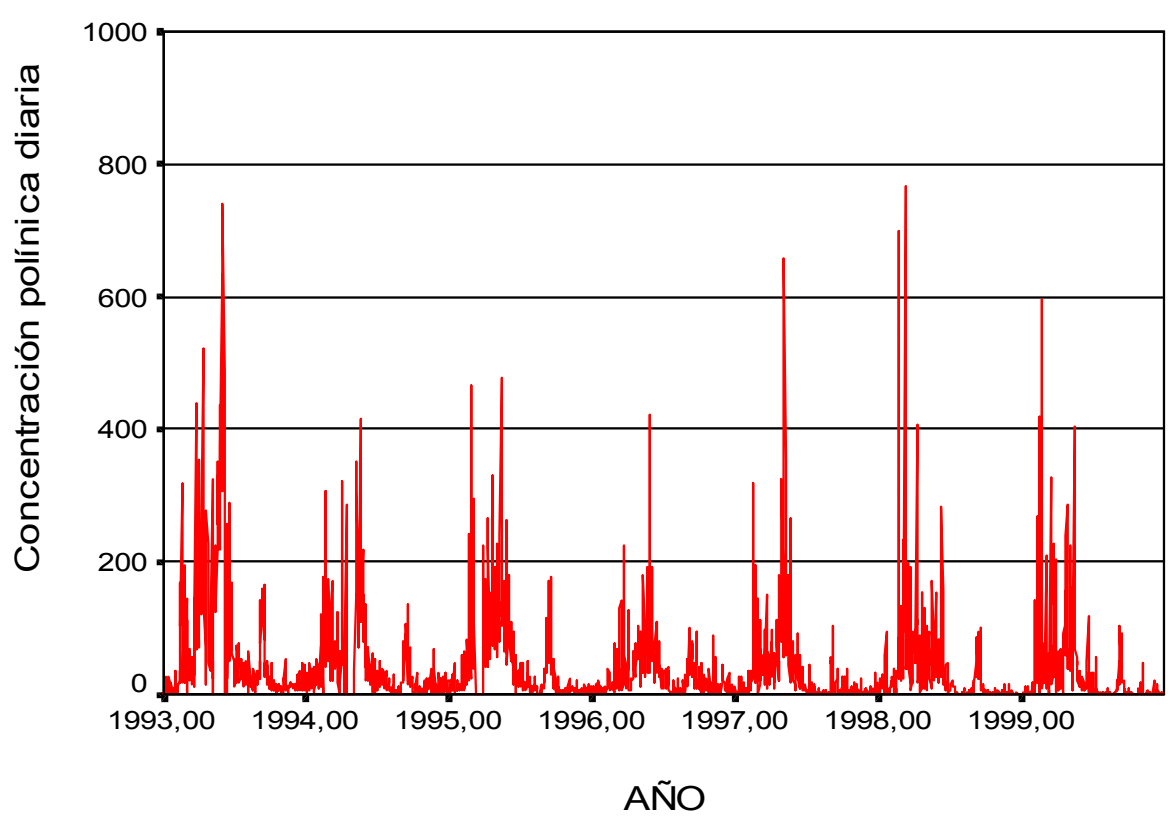

Figura 5.2. Media móvil de 7 días de la evolución de la concentración polínica total diaria (granos/m³ de aire), durante los años 1993-1999.

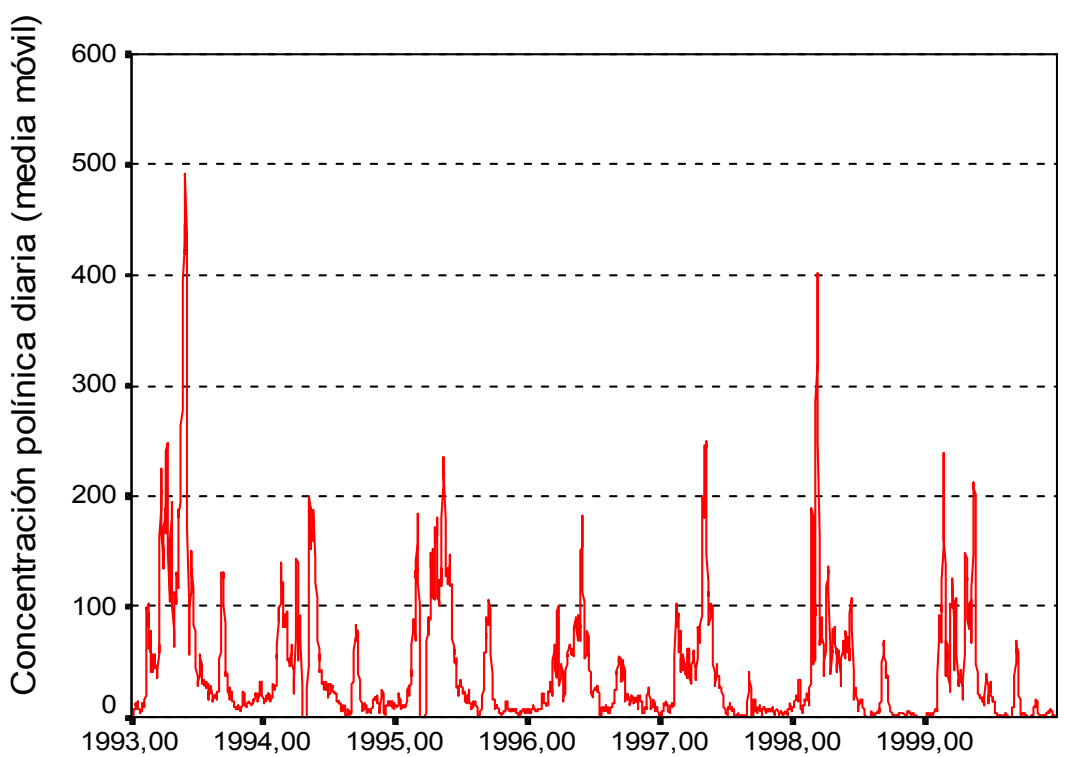

AÑOS 
Tabla 5.2. Media mensual y anual de los pólenes totales para los años 1993-1999 y para el conjunto de los años.

\begin{tabular}{|c|c|c|c|c|c|c|c|c|c|c|c|c|c|}
\hline & Ene. & Feb. & Mar. & Abr. & May. & Jun. & Jul. & Ago. & Sept. & Oct. & Nov. & Dic. & Año \\
\hline 1993 & - & - & 164.6 & 164.9 & 241.3 & 81.48 & 35.16 & 20.55 & 66.63 & 11.94 & 14.17 & 18.97 & 76.14 \\
\hline 1994 & 20.07 & 88.63 & 56.97 & 115.3 & 147.4 & 34.07 & 31.03 & 7.05 & 46.63 & 7.77 & 15.18 & 12.11 & 45.78 \\
\hline 1995 & 10.60 & 68.79 & 124.5 & 125.7 & 154.3 & 60.89 & 16.94 & 12.58 & 60.20 & 5.38 & 7.84 & 4.35 & 50.71 \\
\hline 1996 & 6.55 & 16.34 & 47.10 & 47.07 & 92.39 & 58.77 & 15.26 & 10.55 & 40.53 & 15.39 & 14.70 & 8.83 & 31.12 \\
\hline 1997 & 6.85 & 53.86 & 45.87 & 93.20 & 122.8 & 25.73 & 5.74 & 1.84 & 20.43 & 6.26 & 5.10 & 5.82 & 32.90 \\
\hline 1998 & 15.24 & 61.07 & 138.1 & 80.63 & 53.87 & 51.50 & 3.67 & 4.24 & 33.53 & 2.10 & 3.47 & 0.56 & 39.39 \\
\hline 1999 & 3.35 & 91.71 & 73.03 & 61.50 & 93.23 & 18.48 & 5.22 & 1.35 & 25.50 & 2.10 & 4.55 & 3.53 & 32.49 \\
\hline Total & 10.91 & 62.97 & 84.56 & 97.43 & 130.6 & 57.76 & 16.78 & 8.56 & 42.86 & 7.43 & 9.66 & 8.12 & 45.03 \\
\hline
\end{tabular}

Figura 5.3a. Distribución de frecuencias de las concentraciones polínicas totales para los años 1993-1999.

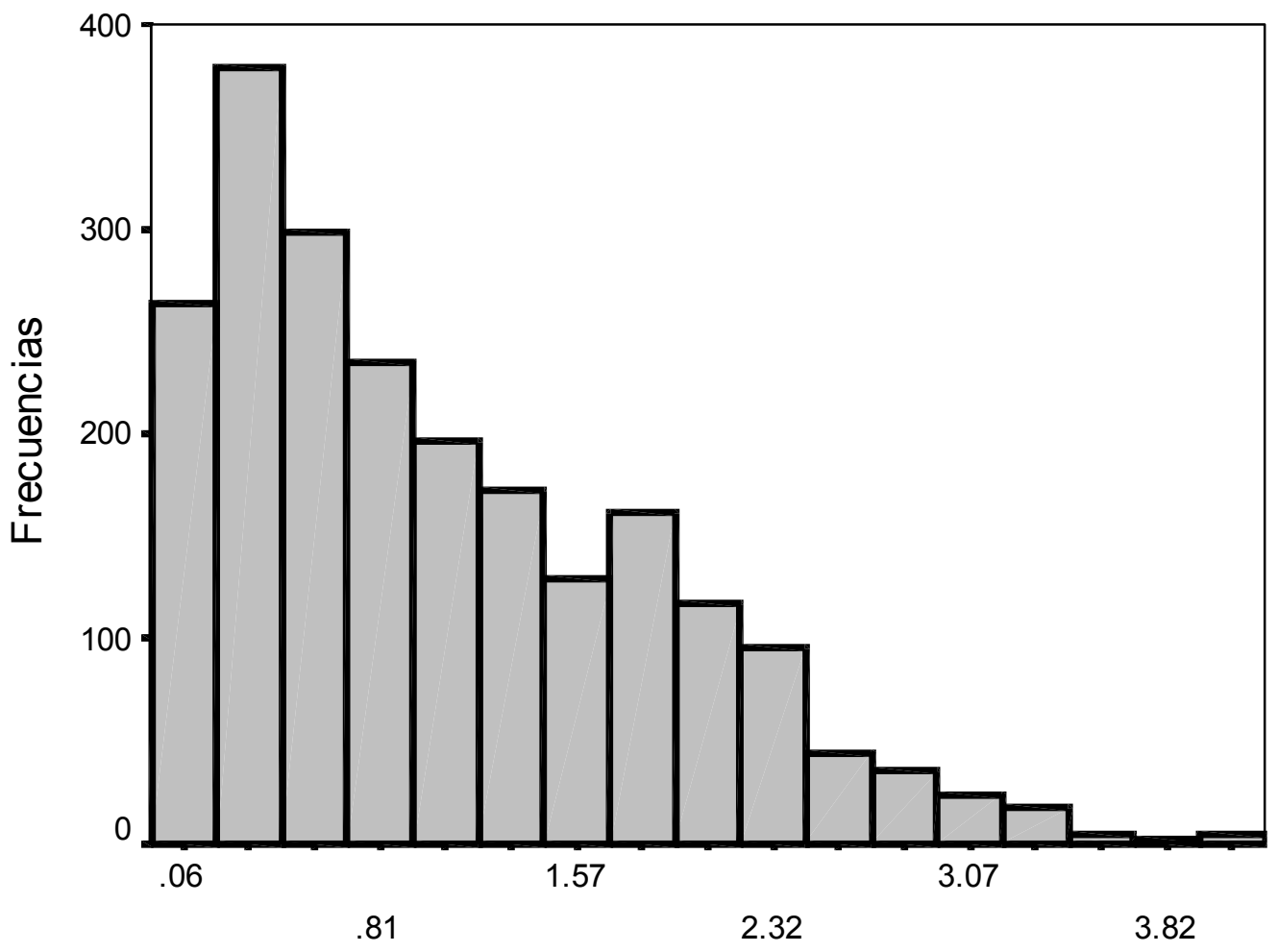

POLENST 
Figura 5.3b. Gráfico P-P de la distribución Gamma y Normal para los pólenes totales (1993-1999).
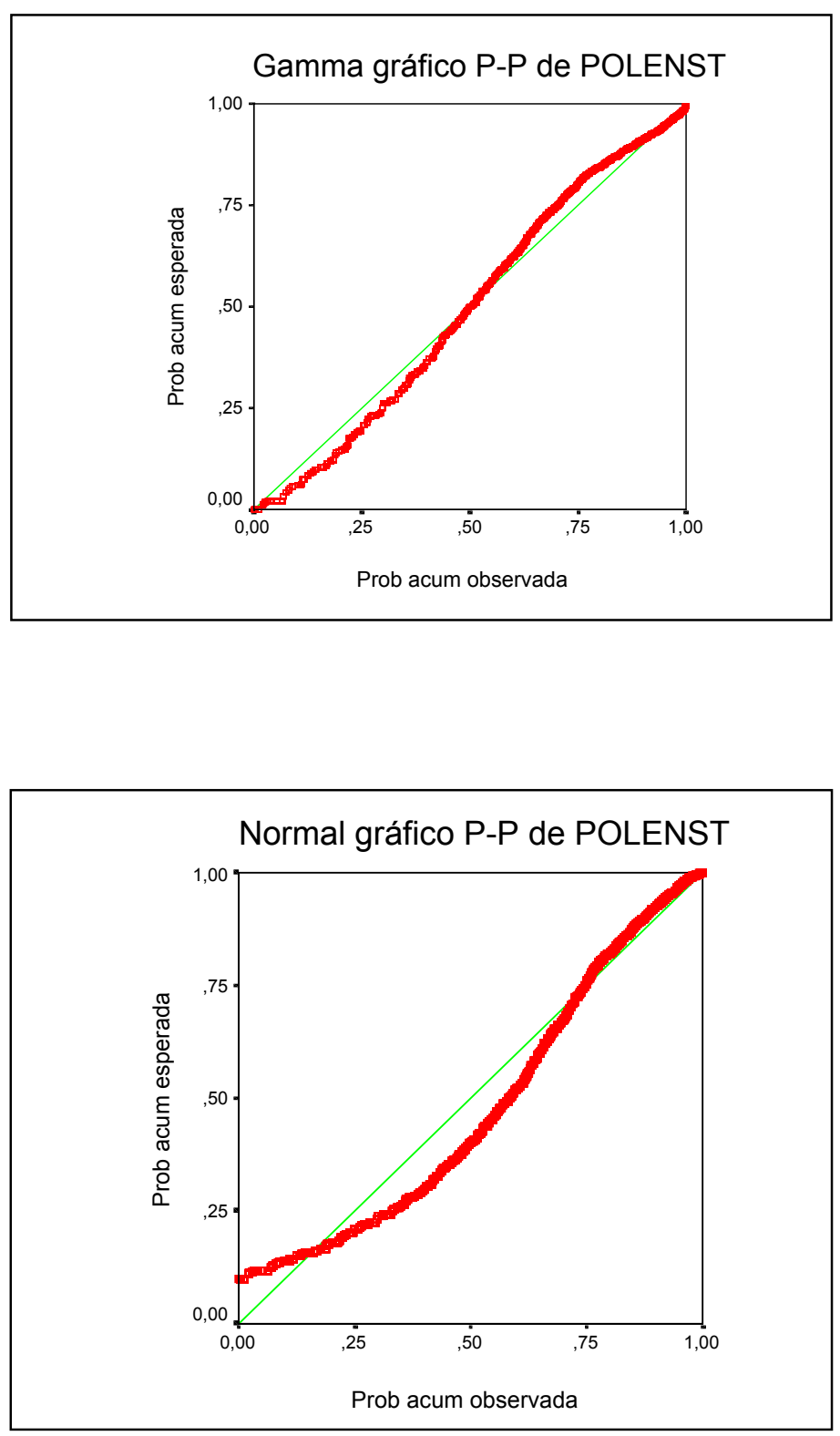
Figura 5.4. Evolución anual de las concentraciones polínicas máximas semanales para los años 1993-1999.
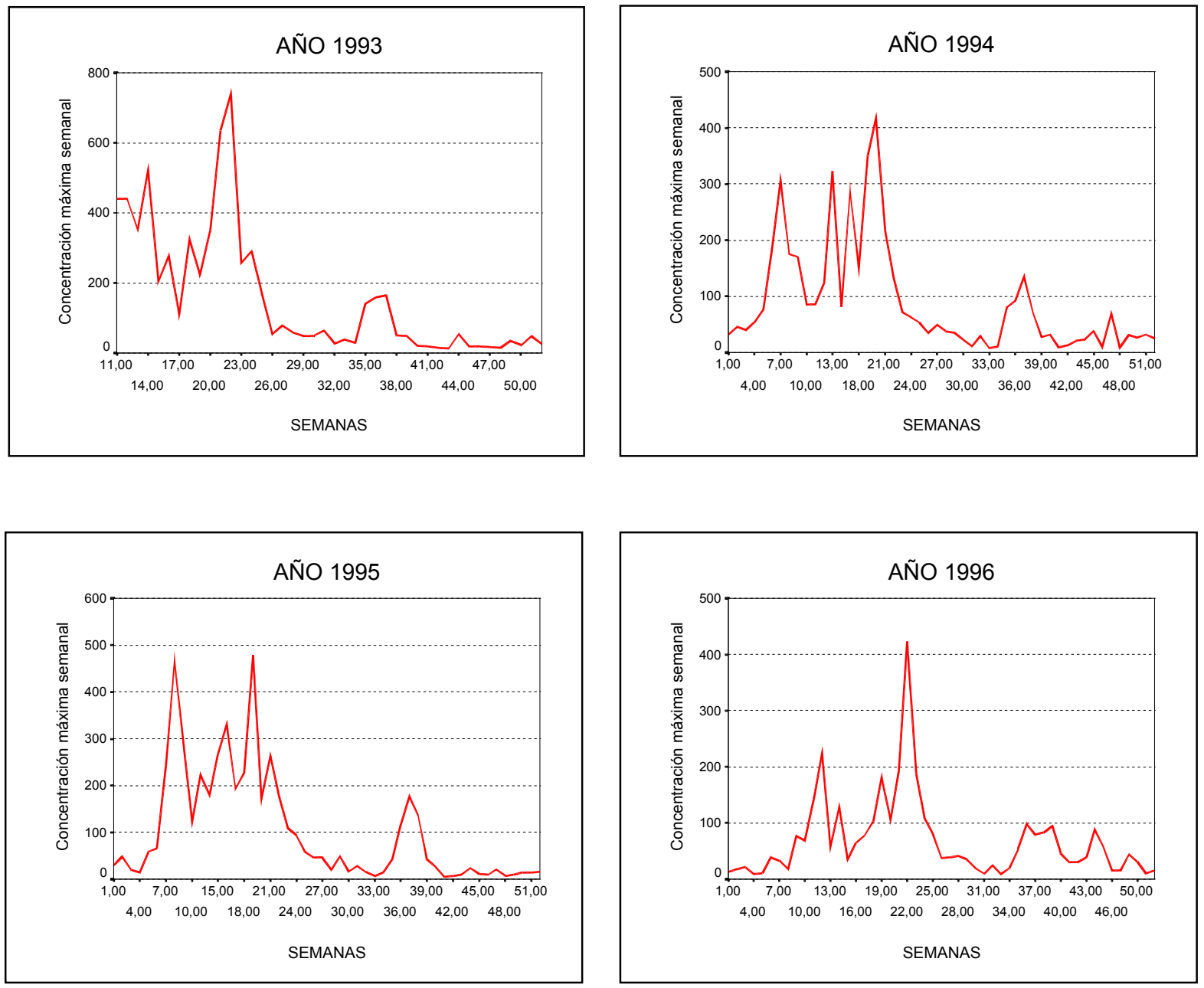
Figura 5.4 Continuación. Evolución anual de las concentraciones polínicas máximas semanales para los años 1993-1999.
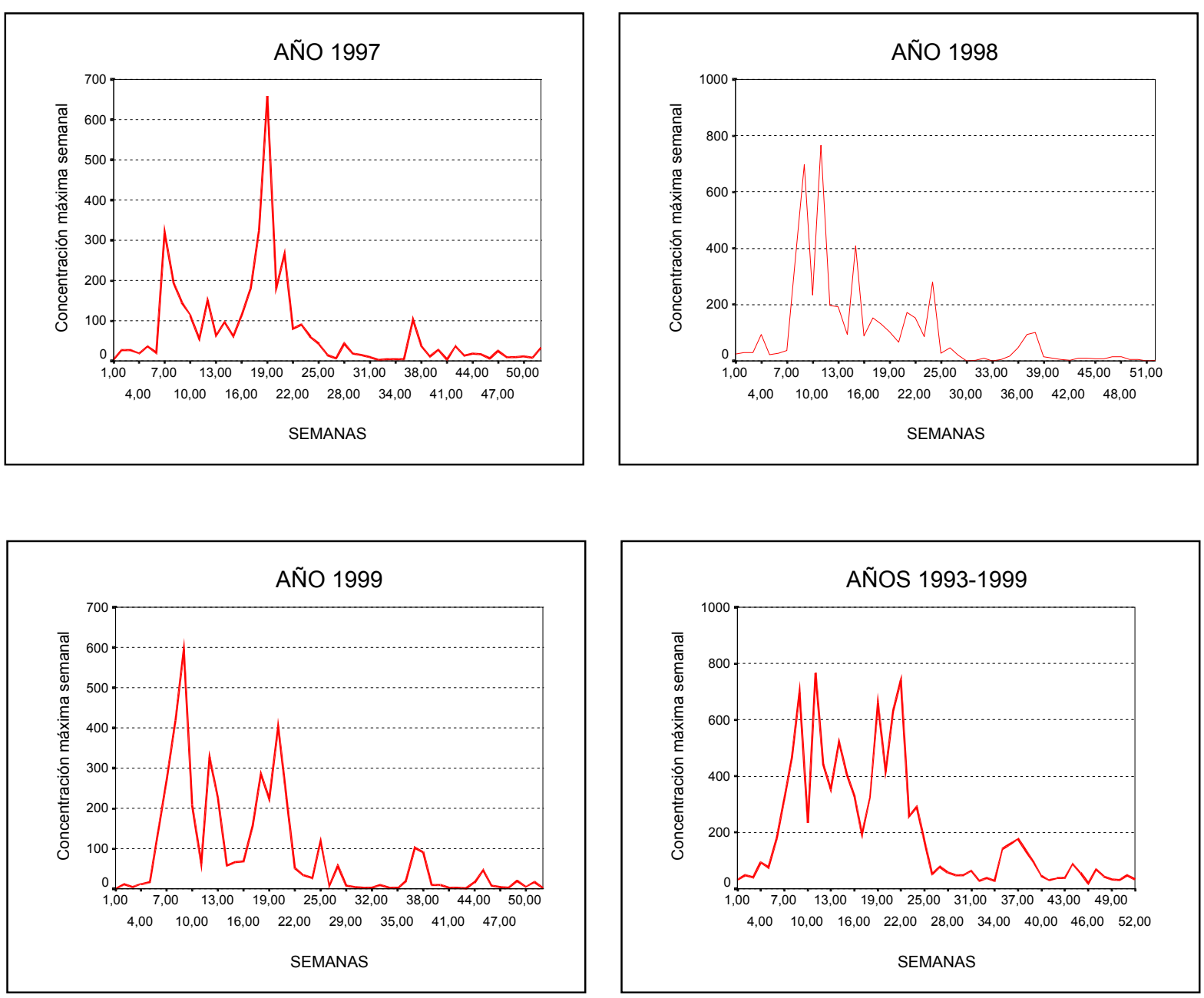


\subsubsection{CONCENTRACIONES POLÍNICAS DE CHENOPODIACEAE- AMARANTHACEAE DURANTE 1993-1999.}

En las tablas 5.3. y 5.4. se recogen las características de las floraciones de Chenopodiaceae-Amaranthaceae en los años 1993 a 1999 y las medias mensuales de cada uno de los años y del periodo total. En la figura 5.5. aparecen las secuencias de los valores máximos semanales para este tipo polínico en cada uno de los años, y el valor máximo semanal de la media del periodo estudiado.

Tabla 5.3. Características de las floraciones de Chenopodiaceae-Amaranthaceae, durante los años 1993-1999, en la que se presentan semana de inicio de la $1^{\mathrm{a}}$ y $2^{\mathrm{a}}$ floración, semana final de cada floración, fecha de máxima concentración y total anual acumulado en granos $/ \mathrm{m}^{3}$ de aire.

\begin{tabular}{|l|c|c|c|c|c|}
\hline Año & Inicio floración & Final floración & Fecha máximo & Cantidad máxima & Total anual \\
\hline 1993 & $11-31$ & $24-42$ & 14 Sept. & 155 & 4.099 \\
\hline 1994 & $11-32$ & $24-41$ & 17 Sept. & 128 & 2.112 \\
\hline 1995 & $10-31$ & $28-40$ & 17 Sept. & 171 & 2.860 \\
\hline 1996 & $15-31$ & $29-43$ & 3 Sept. & 95 & 2.044 \\
\hline 1997 & $10-34$ & $24-41$ & 6 Sept. & 103 & 1.234 \\
\hline 1998 & $12-33$ & $25-41$ & 19 Sept. & 99 & 1.527 \\
\hline 1999 & $12-33$ & $26-40$ & 9 Sept. & 103 & 1.182 \\
\hline
\end{tabular}

Tabla 5.4. Concentraciones medias mensuales de Chenopodiaceae-Amaranthaceae para cada uno de los años 1993-1999, media anual y media para el conjunto del periodo.

\begin{tabular}{|l|c|c|c|c|c|c|c|c|c|c|c|c|c|}
\hline & Ene. & Feb. & Mar. & Abr. & May. & Jun. & Jul. & Ago. & Sept. & Oct. & Nov. & Dic. & Año \\
\hline 1993 & - & - & 1.33 & 8.67 & 40.50 & 12.85 & 6.03 & 7.10 & 55.40 & 3.71 & 0.70 & 0.84 & 14.52 \\
\hline 1994 & 1.22 & 0.56 & 1.00 & 8.77 & 9.96 & 4.50 & 3.22 & 2.95 & 42.30 & 1.87 & 1.03 & 0.01 & 6.54 \\
\hline 1995 & 0.71 & 1.46 & 1.90 & 7.37 & 15.77 & 6.57 & 3.39 & 6.87 & 53.23 & 1.20 & 0.87 & 0.01 & 8.71 \\
\hline 1996 & 0.16 & 0.24 & 0.52 & 6.10 & 7.87 & 3.60 & 1.70 & 6.06 & 35.87 & 3.97 & 1.27 & 0.50 & 5.81 \\
\hline 1997 & 0.42 & 0.75 & 1.32 & 7.80 & 12.03 & 1.57 & 0.74 & 0.71 & 19.68 & 0.74 & 0.20 & 0.01 & 3.47 \\
\hline 1998 & 1.18 & 0.44 & 1.29 & 6.20 & 4.84 & 2.11 & 0.90 & 2.69 & 31.07 & 1.00 & 0.30 & 0.54 & 5.02 \\
\hline 1999 & 0.15 & 0.25 & 1.03 & 5.96 & 5.45 & 0.57 & 0.56 & 0.95 & 25.10 & 0.46 & 0.00 & 0.00 & 4.51 \\
\hline Total & 0.68 & 0.62 & 1.10 & 7.16 & 13.69 & 4.42 & 2.62 & 4.04 & 38.23 & 1.87 & 0.73 & 0.33 & 6.81 \\
\hline
\end{tabular}


Figura 5.5. Evolución de las concentraciones polínicas máximas semanales de Chenopodiaceae-Amaranthaceae para los años 1993-1999.
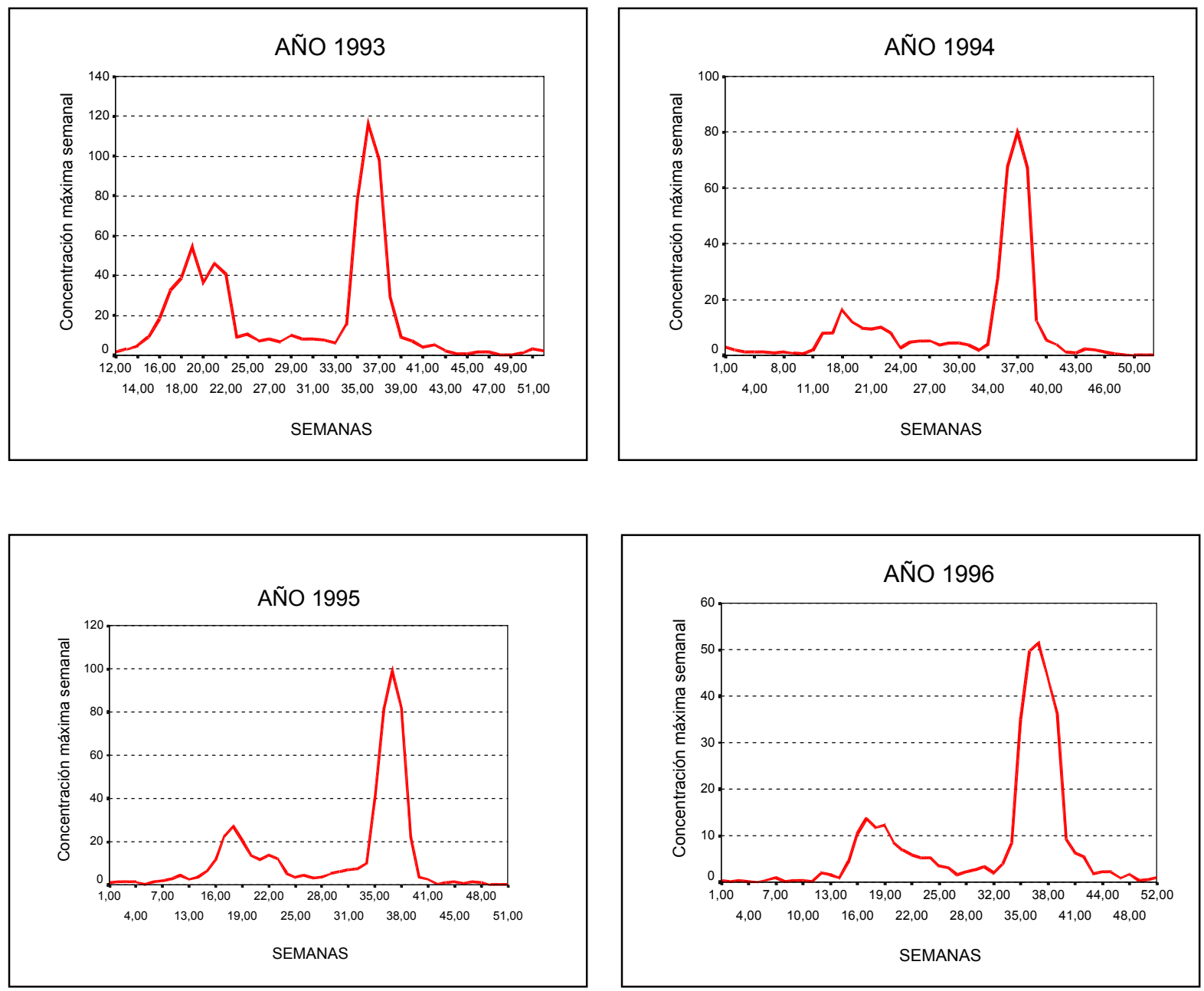
Figura 5.5 Continuación. Evolución de las concentraciones polínicas máximas semanales de Chenopodiaceae-Amaranthaceae para los años 1993-1999.
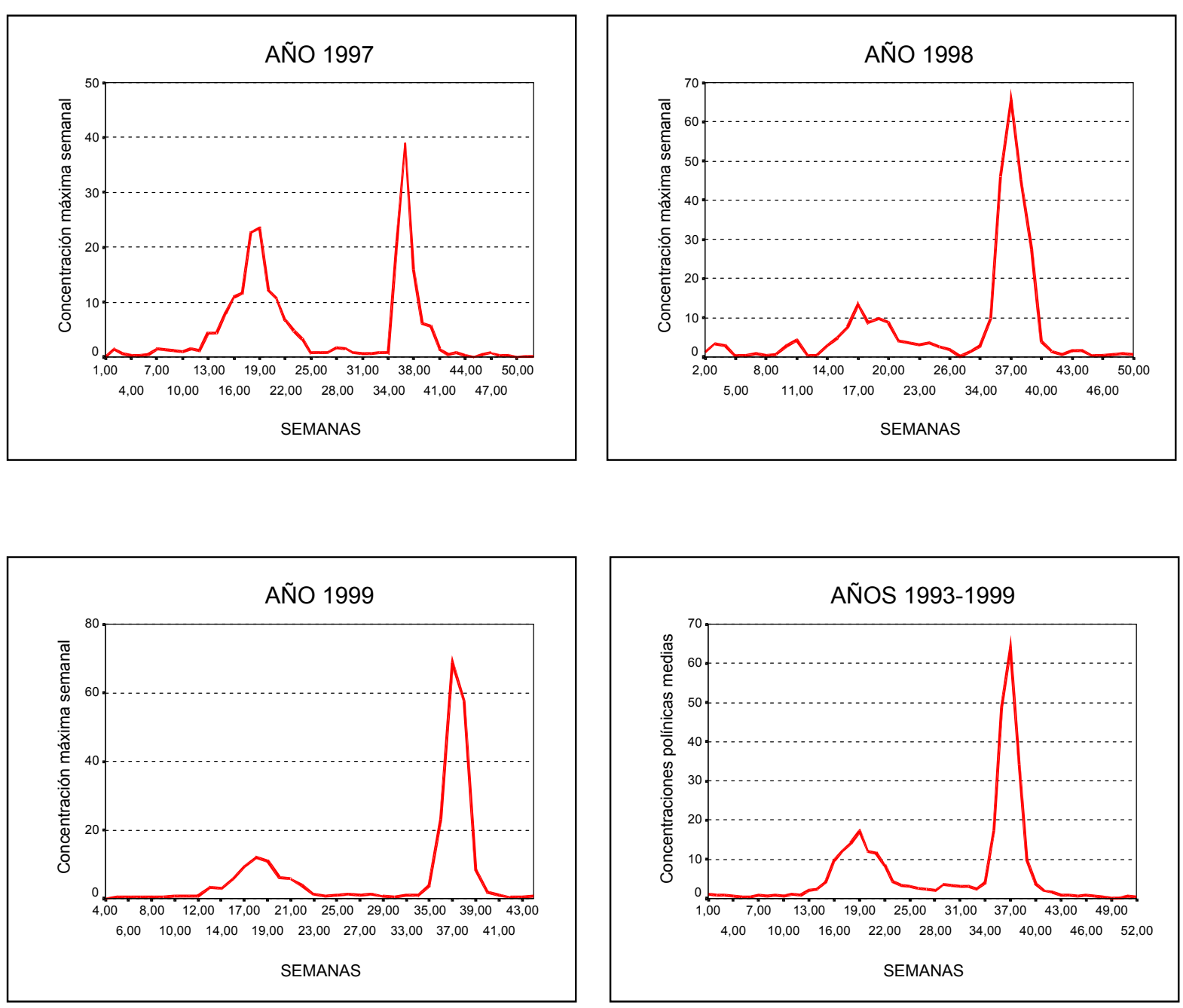


\subsubsection{EVOLUCIÓN DE LAS CONCENTRACIONES POLÍNICAS TOTALES Y DE CHENOPODIACEAE-AMARANTHACEAE DURANTE LOS AÑOS 1993-1999.}

En la figura 5.6. se muestran las evoluciones de las concentraciones medias diarias de los pólenes totales y de Chenopodiaceae-Amaranthaceae durante los años 1993-1999.

Figura 5.6. Evolución de la concentración media diaria para los pólenes totales (línea roja) y para Chenopodiaceae-Amaranthaceae (línea verde), durante los años 1993-1999.

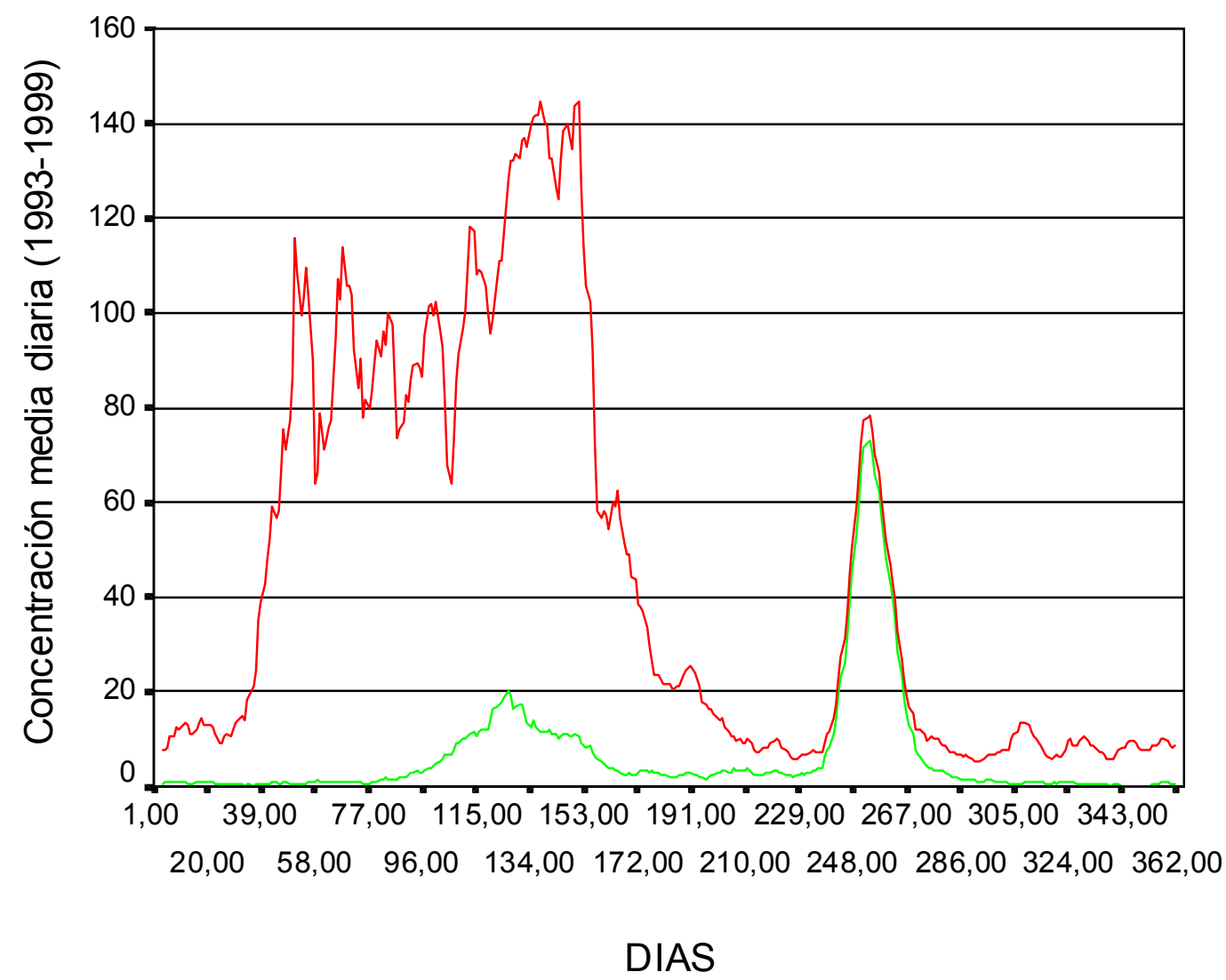




\subsection{METEOROLOGÍA DE LA CIUDAD DE CARTAGENA DURANTE LOS AÑOS 1993-1999.}

A continuación se presentan en tablas y en modo gráfico las principales características de los distintos parámetros meteorológicos registrados en la estación meteorológica del Ayuntamiento de Cartagena durante los años incluidos en este estudio.

En la figura 5.7. se presenta la evolución de la temperatura media mensual para los años 1993 a 1999 y para el conjunto de los años en la torre meteorológica del Ayuntamiento. En la tabla 5.5., se recoge el valor de la temperatura media mensual y anual, para cada año y para el conjunto. En la figura 5.8., se muestra la evolución horaria de la media e intervalo de confianza al $95 \%$ de la temperatura media para cada año y para el conjunto de los años. En las figuras 5.9. y 5.10. se recoge la evolución mensual de la media e intervalo de confianza al 95\% de la temperatura mínima y máxima respectivamente, para cada año y para el conjunto de los años. Las tablas 5.6. a 5.9., recogen la media mensual y anual de las temperaturas mínimas absolutas, la temperatura mínima absoluta para cada mes y año, la media mensual y anual de las temperaturas máximas absolutas y la temperatura mensual y anual de las máximas absolutas, respectivamente.

En la figura 5.11. se presenta la evolución de la humedad relativa media mensual para los años 1993 a 1999 y para el conjunto de los años en la torre meteorológica del Ayuntamiento. En la tabla 5.10., se recoge el valor de la humedad relativa media mensual y anual, para cada año y para el conjunto. En la figura 5.12., se muestra la evolución horaria de la media e intervalo de confianza al 95\% de la humedad relativa media para cada año y para el conjunto de los años.

En la figura 5.13. se presenta la evolución de la presión barométrica media mensual para los años 1993 a 1999 y para el conjunto de los años en la torre meteorológica del Ayuntamiento. En la tabla 5.11., se recoge el valor de la presión barométrica media mensual y anual, para cada año y para el conjunto. En 
la figura 5.14., se muestra la evolución horaria de la media e intervalo de confianza al $95 \%$ de la presión barométrica media para cada año y para el conjunto de los años.

En la figura 5.15. se presenta la evolución de la radiación solar media acumulada mensual para los años 1993 a 1999 y para el conjunto de los años en la torre meteorológica del Ayuntamiento. En la tabla 5.12., se recoge el valor de la radiación solar acumulada media mensual y anual, para cada año y para el conjunto. En la figura 5.16a., se muestra la evolución horaria de la media e intervalo de confianza al $95 \%$ de la radiación solar media para cada año y para el conjunto de los años. En la figura 5.16b., se muestra la evolución horaria de la media e intervalo de confianza al 95\% de la velocidad media del viento para cada año y para el conjunto de los años

En la figura 5.17. se presenta la evolución de la lluvia mensual acumulada para los años 1993 a 1999 y para el conjunto de los años en la torre meteorológica Cartagena-Ciudad. En la tabla 5.13., se recoge el valor de la precipitación acumulada mensual y anual, para cada año y para el conjunto. En la tabla 5.14., se recogen los valores de precipitación media mensual y anual para el periodo de 30 años (1951-1990), en la estación Cartagena-Puerto.

En las figuras 5.18. a 5.30.(numeración par), se recogen las rosas de los vientos y tablas de frecuencias de las direcciones del viento en la torre meteorológica del Ayuntamiento, para los años 1993 a 1998. Las figuras 5.19. a 5.31. (numeración impar), muestran las frecuencias de los vientos por rangos de velocidad y las tablas en modo numérico con los datos empleados de los años 1993 a 1998.

La figura 5.32. muestra las frecuencias de los vientos para las distintas direcciones en la torre meteorológica del Ayuntamiento, para el conjunto de años 1995 a 1999. 
La figura 5.33., recoge las frecuencias de los vientos por velocidades para los años 1995 a 1999, mediante el análisis de las frecuencias semihorarias diarias del viento (RANGOSMI).

La figura 5.34., recoge las frecuencias de los vientos por velocidades para los años 1995 a 1999, mediante el análisis de los valores medios diarios de velocidad del viento (RANGOS). 
Figura 5.7. Resumen de las temperaturas medias mensuales $\left({ }^{\circ} \mathrm{C}\right)$ para los años 1993-1999, en la torre meteorológica Ayuntamiento.
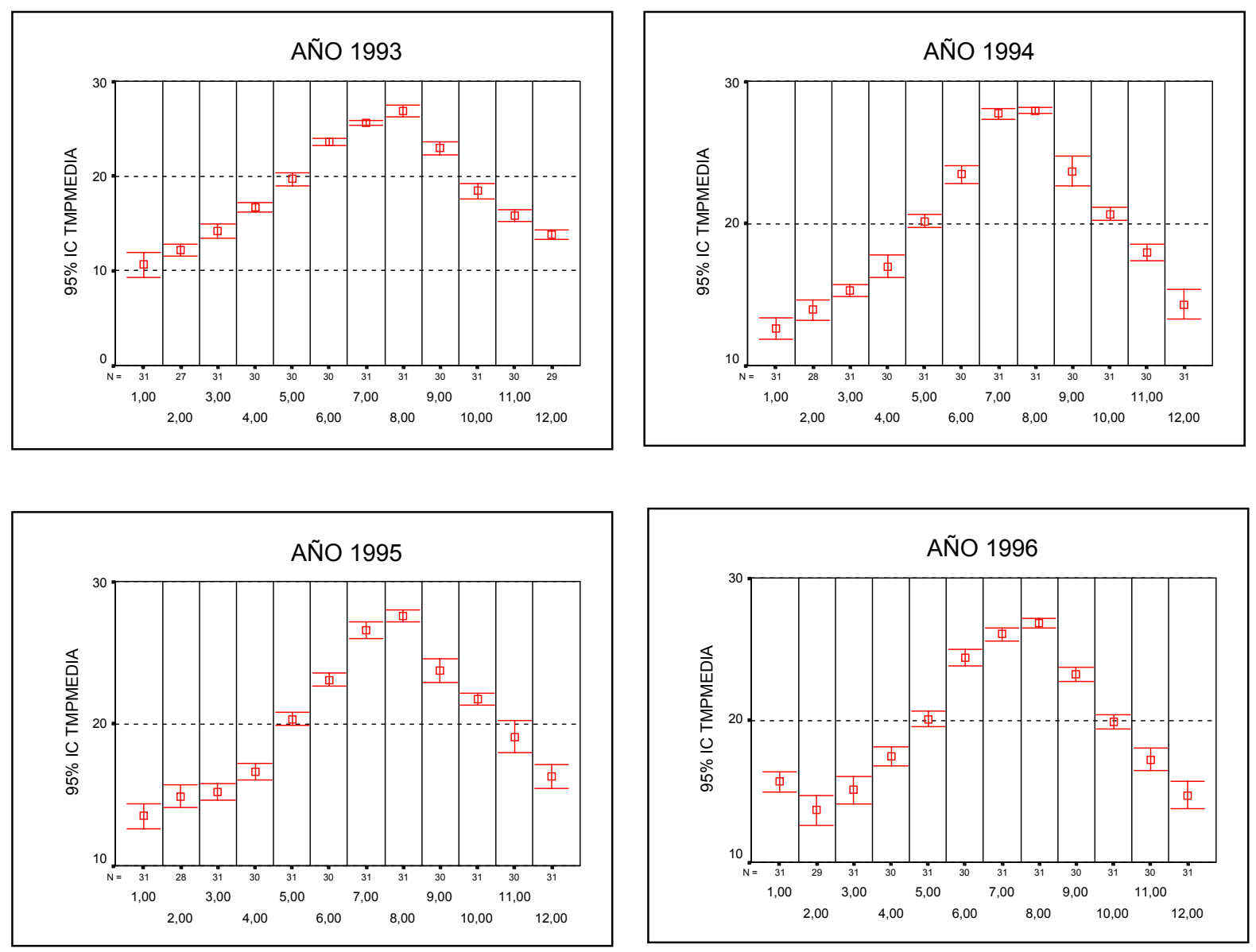
Figura 5.7 Continuación. Resumen de las temperaturas medias mensuales $\left({ }^{\circ} \mathrm{C}\right)$ para los años 1993-1999, en la torre meteorológica Ayuntamiento.
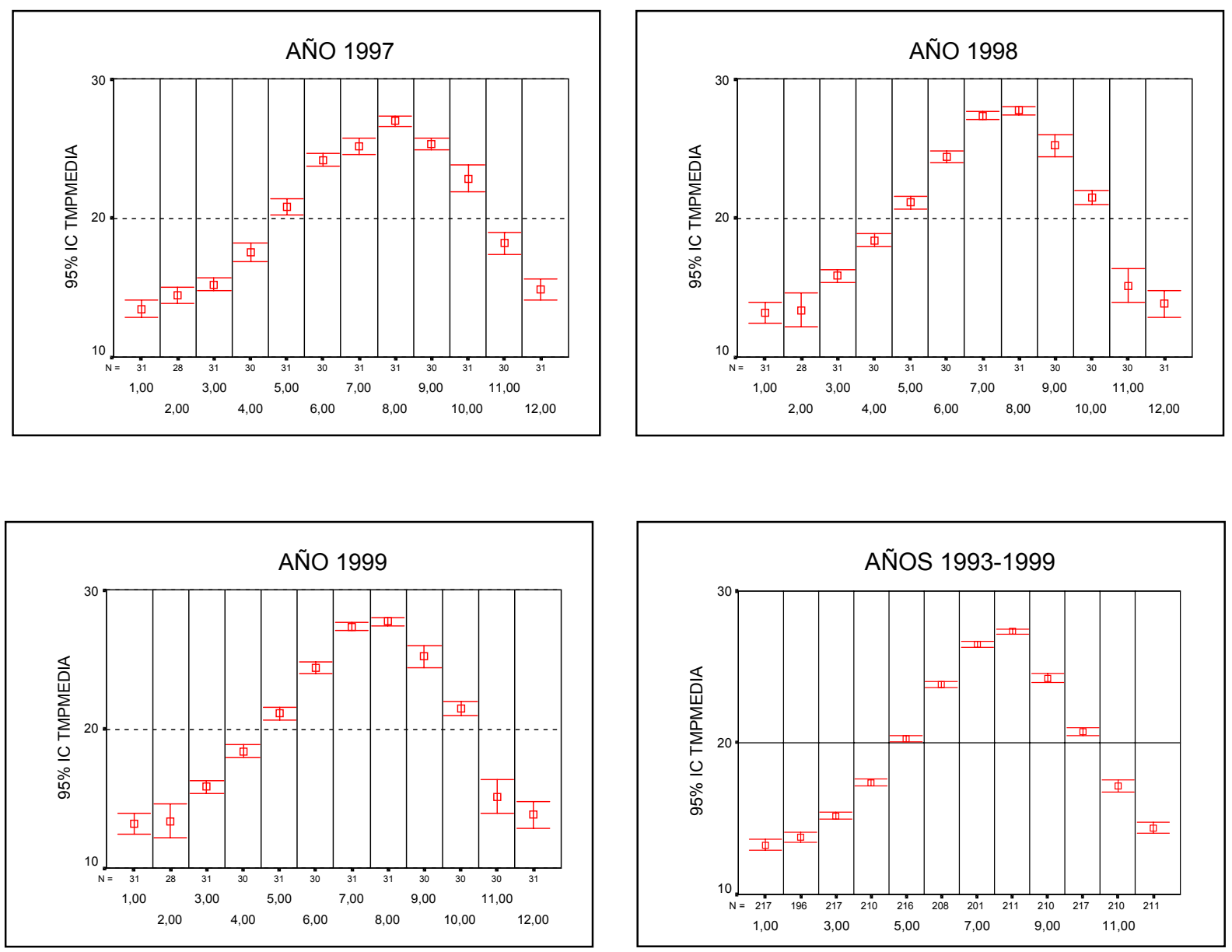
Tabla 5.5. Temperatura media mensual y anual $\left({ }^{\circ} \mathrm{C}\right)$ para los años 1993-1999 y para el conjunto de los años.

\begin{tabular}{|l|l|l|l|l|l|l|l|l|l|l|l|l|l|}
\hline Año & Ene. & Feb. & Mar. & Abr. & May. & Jun. & Jul. & Ago. & Sept. & Oct. & Nov. & Dic. & Anual \\
\hline $\mathbf{1 9 9 3}$ & 10.64 & 12.18 & 14.19 & 16.70 & 19.70 & 23.63 & 25.58 & 26.84 & 22.93 & 18.42 & 15.77 & 13.83 & 18.44 \\
\hline $\mathbf{1 9 9 4}$ & 12.60 & 13.92 & 15.26 & 16.98 & 20.16 & 23.46 & 27.70 & 27.95 & 23.67 & 20.66 & 17.97 & 14.30 & 19.59 \\
\hline $\mathbf{1 9 9 5}$ & 13.50 & 14.88 & 15.19 & 16.62 & 20.32 & 23.08 & 26.56 & 27.58 & 23.75 & 21.70 & 19.08 & 16.28 & 19.91 \\
\hline $\mathbf{1 9 9 6}$ & 15.67 & 13.65 & 15.07 & 17.47 & 20.07 & 24.39 & 26.03 & 26.86 & 23.22 & 19.87 & 17.24 & 14.72 & 19.54 \\
\hline $\mathbf{1 9 9 7}$ & 13.44 & 14.43 & 15.20 & 17.54 & 20.79 & 24.17 & 25.15 & 26.95 & 25.31 & 22.84 & 18.16 & 14.85 & 19.93 \\
\hline $\mathbf{1 9 9 8}$ & 13.80 & 14.00 & 15.63 & 17.82 & 19.78 & 23.79 & 27.49 & 27.49 & 25.67 & 20.12 & 16.69 & 12.76 & 19.16 \\
\hline $\mathbf{1 9 9 9}$ & 13.19 & 13.37 & 15.84 & 18.38 & 21.12 & 24.43 & 27.34 & 27.71 & 25.20 & 21.48 & 15.13 & 13.82 & 19.79 \\
\hline $\mathbf{9 3 - 9 9}$ & 13.26 & 13.78 & 15.20 & 17.36 & 20.28 & 23.85 & 26.47 & 27.33 & 24.25 & 20.73 & 17.15 & 14.40 & 19.49 \\
\hline
\end{tabular}


Figura 5.8. Evolución horaria de la media e intervalo de confianza al $95 \%$ de la temperatura media $\left({ }^{\circ} \mathrm{C}\right)$ para cada año y para el conjunto de años 1995 1999 en la torre meteorológica Ayuntamiento.
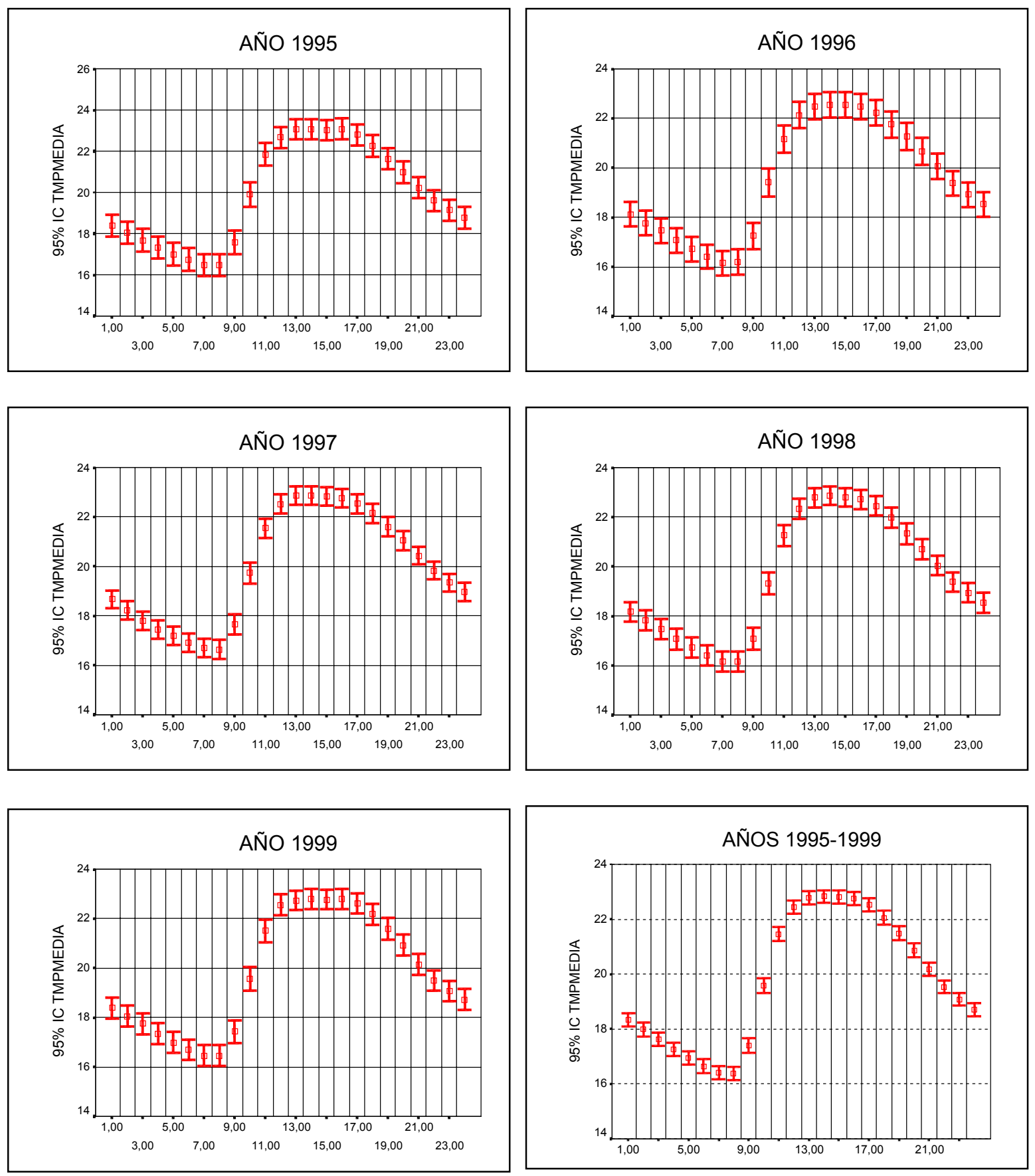
Figura 5.9. Evolución mensual de la media e intervalo de confianza al $95 \%$ de la temperatura mínima $\left({ }^{\circ} \mathrm{C}\right)$ para cada año y para el conjunto de años 1995 1999, en la torre meteorológica Ayuntamiento.
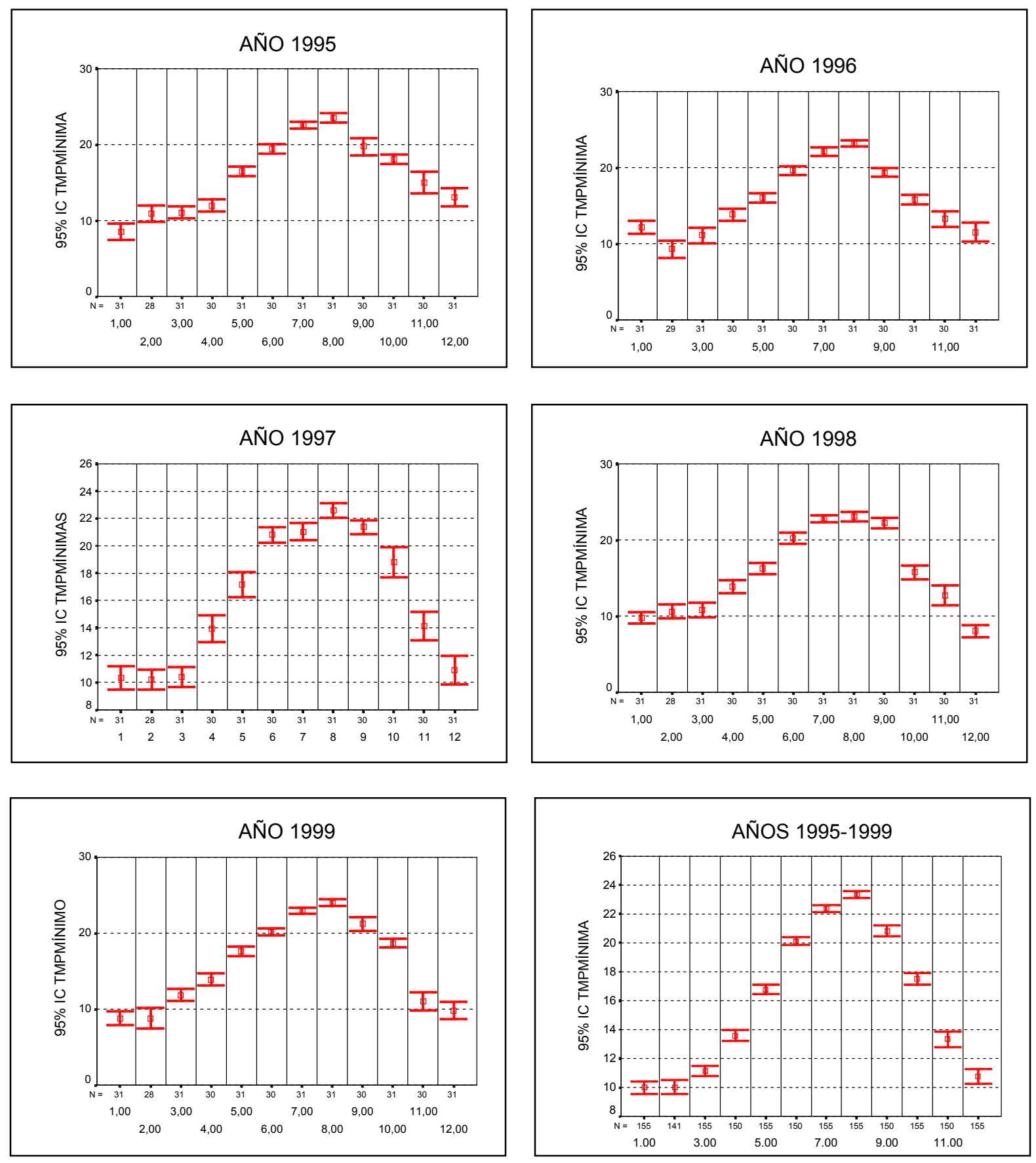
Figura 5.10. Evolución mensual de la media e intervalo de confianza al 95\% de la temperatura máxima $\left({ }^{\circ} \mathrm{C}\right)$ para cada año y para el conjunto de años 1995 1999, en la torre meteorológica Ayuntamiento.
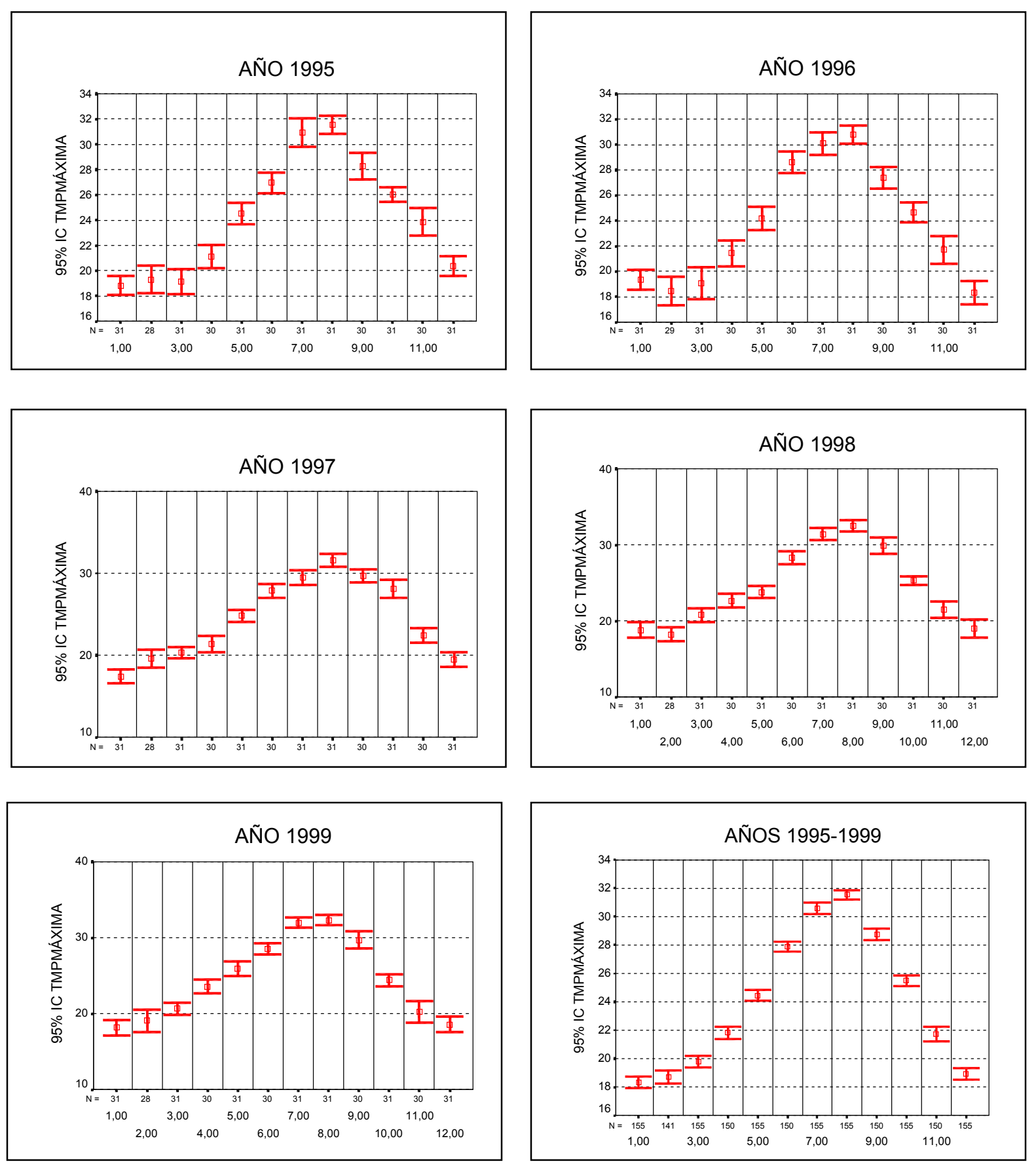
Tabla 5.6. Temperatura media mensual y anual de las mínimas absolutas diarias $\left({ }^{\circ} \mathrm{C}\right)$ para los años 1993-1999.

\begin{tabular}{|l|c|c|c|c|c|c|c|c|c|c|c|c|c|}
\hline Año & Ene. & Feb. & Mar. & Abr. & May. & Jun. & Jul. & Ago. & Sept. & Oct. & Nov. & Dic. & Anual \\
\hline $\mathbf{1 9 9 5}$ & 8.55 & 10.95 & 11.06 & 11.98 & 16.47 & 19.45 & 22.58 & 23.53 & 19.72 & 18.10 & 15.0 & 13.10 & 15.91 \\
\hline $\mathbf{1 9 9 6}$ & 12.18 & 9.30 & 11.08 & 13.82 & 16.05 & 19.62 & 22.11 & 23.18 & 19.37 & 15.77 & 13.25 & 11.53 & 15.62 \\
\hline $\mathbf{1 9 9 7}$ & 10.35 & 10.21 & 10.42 & 13.93 & 17.13 & 20.80 & 21.03 & 22.61 & 21.37 & 18.81 & 14.10 & 10.90 & 16.00 \\
\hline $\mathbf{1 9 9 8}$ & 9.74 & 10.61 & 10.81 & 13.87 & 16.26 & 20.27 & 22.81 & 23.06 & 22.23 & 15.74 & 12.77 & 8.03 & 15.54 \\
\hline $\mathbf{1 9 9 9}$ & 8.81 & 8.78 & 11.87 & 13.90 & 17.63 & 20.13 & 22.93 & 24.00 & 21.20 & 18.68 & 11.07 & 9.81 & 15.78 \\
\hline
\end{tabular}

Tabla 5.7. Temperatura mínima absoluta mensual y anual $\left({ }^{\circ} \mathrm{C}\right)$ para los años 1993-1999.

\begin{tabular}{|l|c|c|c|c|c|c|c|c|c|c|c|c|c|}
\hline Año & Ene. & Feb. & Mar. & Abr. & May. & Jun. & Jul. & Ago. & Sept. & Oct. & Nov. & Dic. & Anual \\
\hline $\mathbf{1 9 9 5}$ & 3.0 & 6.0 & 8.0 & 7.0 & 13.5 & 15.0 & 20.0 & 20.0 & 15.0 & 15.0 & 8.0 & 8.0 & 3.0 \\
\hline $\mathbf{1 9 9 6}$ & 7.0 & 3.0 & 6.0 & 8.5 & 13.0 & 16.0 & 18.5 & 21.0 & 16.5 & 13.0 & 8.0 & 4.0 & 3.0 \\
\hline $\mathbf{1 9 9 7}$ & 5.0 & 7.0 & 8.0 & 10.0 & 12.0 & 17.0 & 18.0 & 19.0 & 19.0 & 12.0 & 8.0 & 6.0 & 5.0 \\
\hline $\mathbf{1 9 9 8}$ & 6.0 & 7.0 & 7.0 & 8.0 & 12.0 & 17.0 & 20.0 & 19.0 & 18.0 & 10.0 & 7.0 & 4.0 & 4.0 \\
\hline $\mathbf{1 9 9 9}$ & 5.0 & 3.0 & 8.0 & 10.0 & 15.0 & 18.0 & 21.0 & 21.0 & 17.0 & 15.0 & 5.0 & 4.6 & 3.0 \\
\hline
\end{tabular}


Tabla 5.8. Temperatura media mensual de las máximas absolutas diarias y anual $\left({ }^{\circ} \mathrm{C}\right)$ para los años 1993-1999.

\begin{tabular}{|l|l|l|l|l|l|l|l|l|l|l|l|l|l|}
\hline Año & Ene. & Feb. & Mar. & Abr. & May. & Jun. & Jul. & Ago. & Sept. & Oct. & Nov. & Dic. & Anual \\
\hline $\mathbf{1 9 9 5}$ & 18.82 & 19.30 & 19.13 & 21.13 & 24.53 & 26.97 & 30.92 & 31.54 & 28.25 & 26.03 & 23.87 & 20.35 & 24.27 \\
\hline $\mathbf{1 9 9 6}$ & 19.32 & 18.43 & 19.06 & 21.43 & 24.18 & 28.62 & 30.10 & 30.81 & 27.38 & 24.64 & 21.70 & 18.31 & 23.69 \\
\hline $\mathbf{1 9 9 7}$ & 17.39 & 19.57 & 20.29 & 21.37 & 24.84 & 27.87 & 29.45 & 31.55 & 29.73 & 28.10 & 22.43 & 19.48 & 24.37 \\
\hline $\mathbf{1 9 9 8}$ & 18.81 & 18.21 & 20.74 & 22.67 & 23.77 & 28.30 & 31.42 & 32.48 & 29.83 & 25.29 & 21.50 & 18.97 & 24.37 \\
\hline $\mathbf{1 9 9 9}$ & 18.13 & 19.03 & 20.64 & 23.57 & 25.90 & 28.53 & 31.97 & 32.32 & 29.70 & 24.42 & 20.20 & 18.57 & 24.45 \\
\hline
\end{tabular}

Tabla 5.9. Temperaturas máximas absolutas mensuales y anual $\left({ }^{\circ} \mathrm{C}\right)$ para los años 1993-1999.

\begin{tabular}{|l|l|l|l|l|l|l|l|l|l|l|l|l|l|}
\hline Año & Ene. & Feb. & Mar. & Abr. & May. & Jun. & Jul. & Ago. & Sept. & Oct. & Nov. & Dic. & Anual \\
\hline $\mathbf{1 9 9 5}$ & 22.0 & 24.0 & 27.0 & 27.0 & 29.5 & 32.0 & 37.0 & 36.0 & 34.0 & 29.5 & 30.0 & 23.5 & 37.0 \\
\hline $\mathbf{1 9 9 6}$ & 26.0 & 24.5 & 27.0 & 28.0 & 31.0 & 32.0 & 37.5 & 34.5 & 33.5 & 28.5 & 26.0 & 24.5 & 37.5 \\
\hline $\mathbf{1 9 9 7}$ & 21.0 & 25.0 & 24.0 & 27.0 & 30.0 & 35.0 & 34.0 & 37.0 & 37.0 & 36.0 & 27.0 & 24.0 & 37.0 \\
\hline $\mathbf{1 9 9 8}$ & 24.0 & 22.0 & 28.0 & 28.0 & 28.0 & 32.0 & 36.0 & 37.0 & 37.0 & 30.0 & 28.0 & 27.0 & 37.0 \\
\hline $\mathbf{1 9 9 9}$ & 24.0 & 27.0 & 27.0 & 28.0 & 32.0 & 33.0 & 37.0 & 35.0 & 34.0 & 31.0 & 28.0 & 22.8 & 37.0 \\
\hline
\end{tabular}


Figura 5.11. Resumen de la humedad relativa media mensual para los años 19931999, y para el conjunto en la torre meteorológica Ayuntamiento en \%.
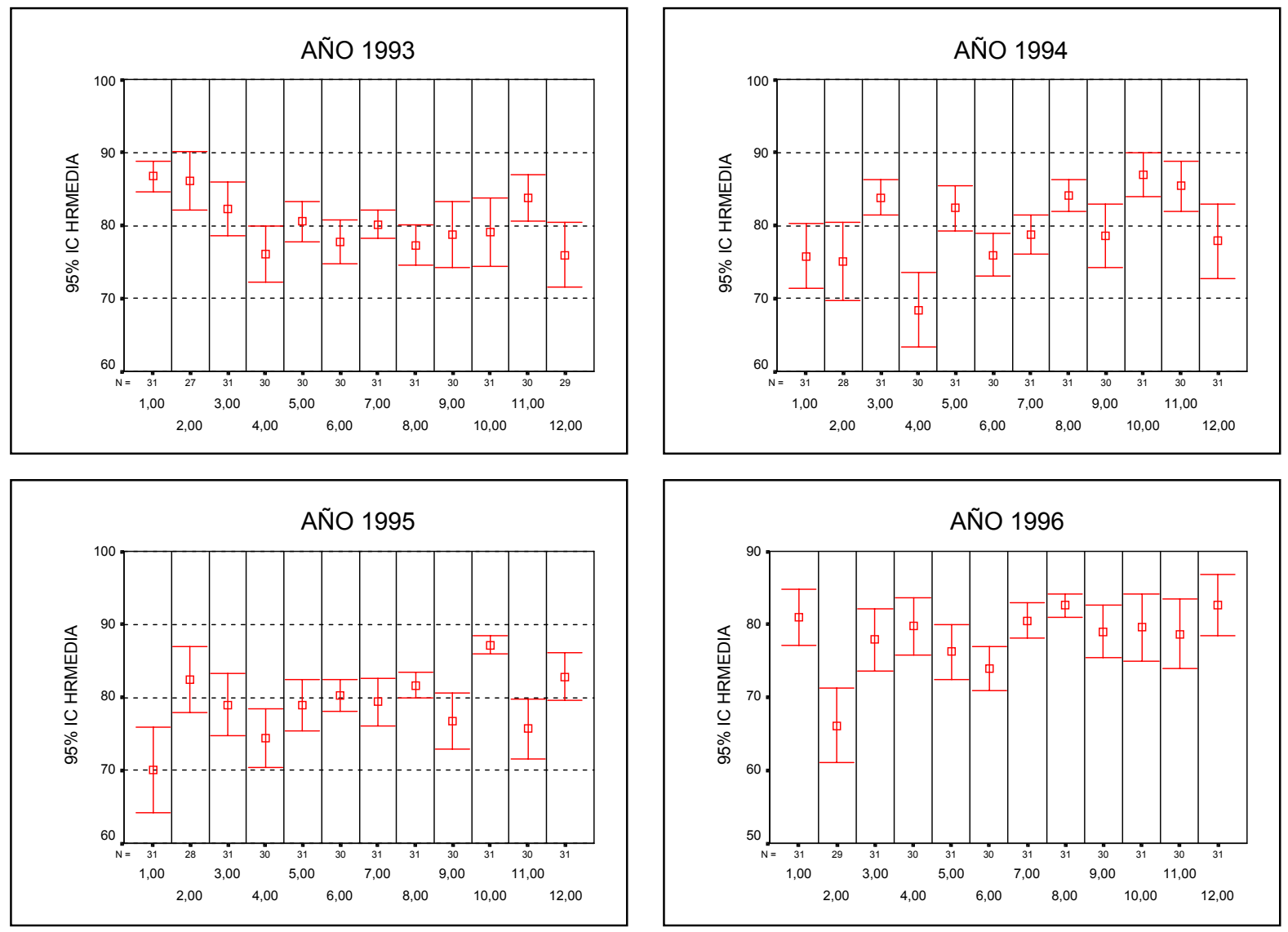
Figura 5.11 Continuación. Resumen de la humedad relativa media mensual para los años 1993-1999, y para el conjunto en la torre meteorológica Ayuntamiento en \%.
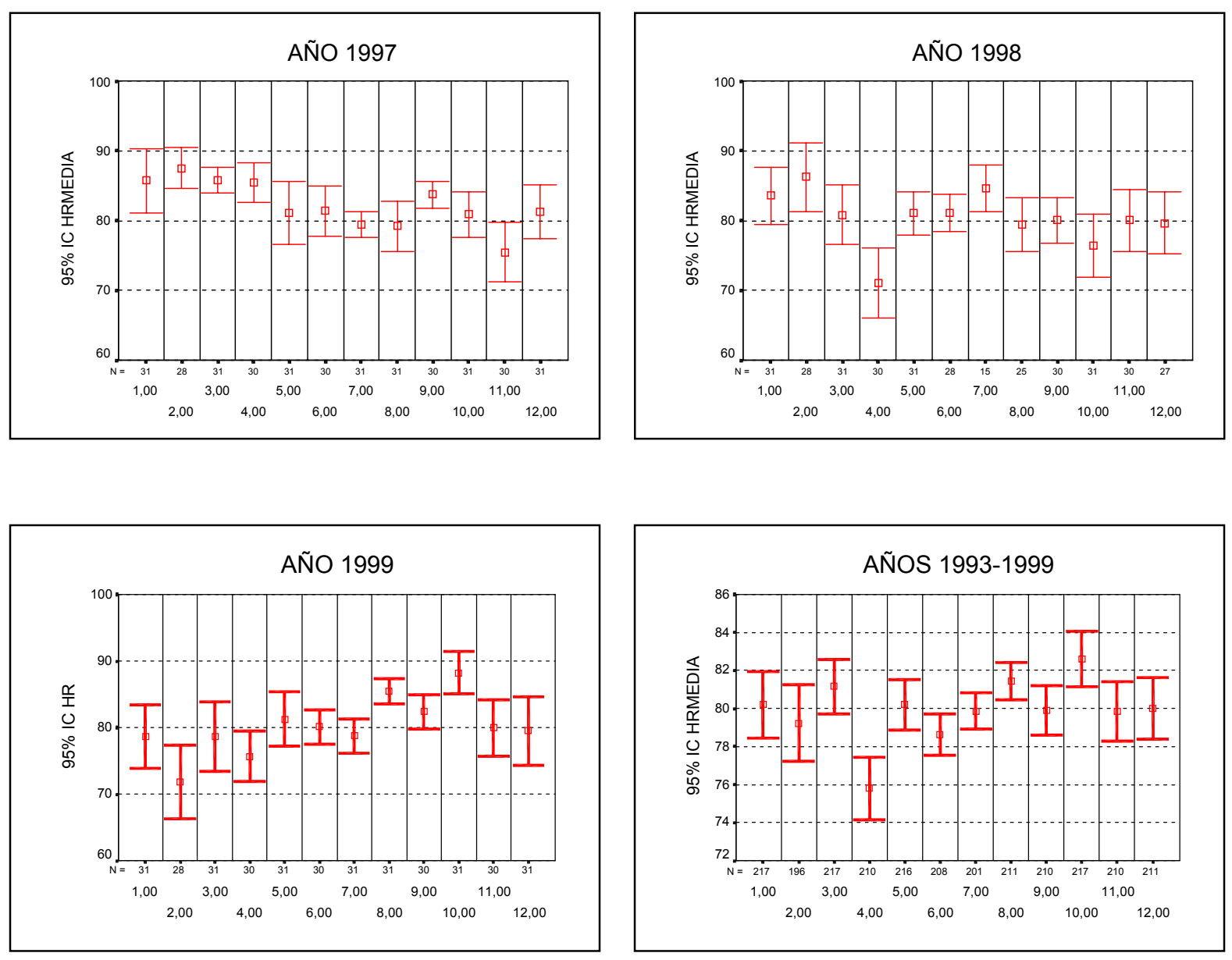
Tabla 5.10. Humedad relativa media mensual y anual para los años 1993-1999 y para el conjunto de los años en $\%$.

\begin{tabular}{|l|l|l|l|l|l|l|l|l|l|l|l|l|l|}
\hline Año & Ene. & Feb. & Mar. & Abr. & May. & Jun. & Jul. & Ago. & Sept. & Oct. & Nov. & Dic. & Anual \\
\hline $\mathbf{1 9 9 3}$ & 86.71 & 86.07 & 82.23 & 76.00 & 80.53 & 77.73 & 80.16 & 77.29 & 78.80 & 79.13 & 83.73 & 75.93 & 80.33 \\
\hline $\mathbf{1 9 9 4}$ & 75.79 & 75.02 & 83.78 & 68.43 & 82.35 & 75.96 & 78.80 & 84.09 & 78.58 & 86.97 & 85.40 & 77.89 & 79.48 \\
\hline $\mathbf{1 9 9 5}$ & 69.98 & 82.50 & 78.95 & 74.39 & 78.91 & 80.32 & 79.34 & 81.65 & 76.76 & 87.15 & 75.68 & 82.82 & 79.03 \\
\hline $\mathbf{1 9 9 6}$ & 80.97 & 66.09 & 77.91 & 79.78 & 76.23 & 73.94 & 80.54 & 82.55 & 78.99 & 79.56 & 78.69 & 82.60 & 78.22 \\
\hline $\mathbf{1 9 9 7}$ & 85.69 & 87.53 & 85.84 & 85.38 & 81.09 & 81.35 & 79.39 & 79.19 & 83.72 & 80.87 & 75.43 & 81.21 & 82.19 \\
\hline $\mathbf{1 9 9 8}$ & 83.55 & 86.27 & 80.78 & 70.99 & 81.02 & 81.08 & 84.54 & 79.49 & 80.04 & 76.38 & 80.01 & 79.66 & 80.11 \\
\hline $\mathbf{1 9 9 9}$ & 78.68 & 71.86 & 78.63 & 75.66 & 81.29 & 80.10 & 78.74 & 85.46 & 82.41 & 88.24 & 79.97 & 79.51 & 80.12 \\
\hline $\mathbf{9 3 - 9 9}$ & 80.20 & 79.23 & 81.16 & 75.80 & 80.20 & 78.62 & 79.87 & 81.44 & 79.90 & 82.61 & 79.84 & 79.99 & 79.92 \\
\hline
\end{tabular}


Figura 5.12. Evolución horaria de la media e intervalo de confianza al 95\% de la humedad relativa (en \%) para cada año y para el conjunto de años (19951999) en la torre meteorológica Ayuntamiento.
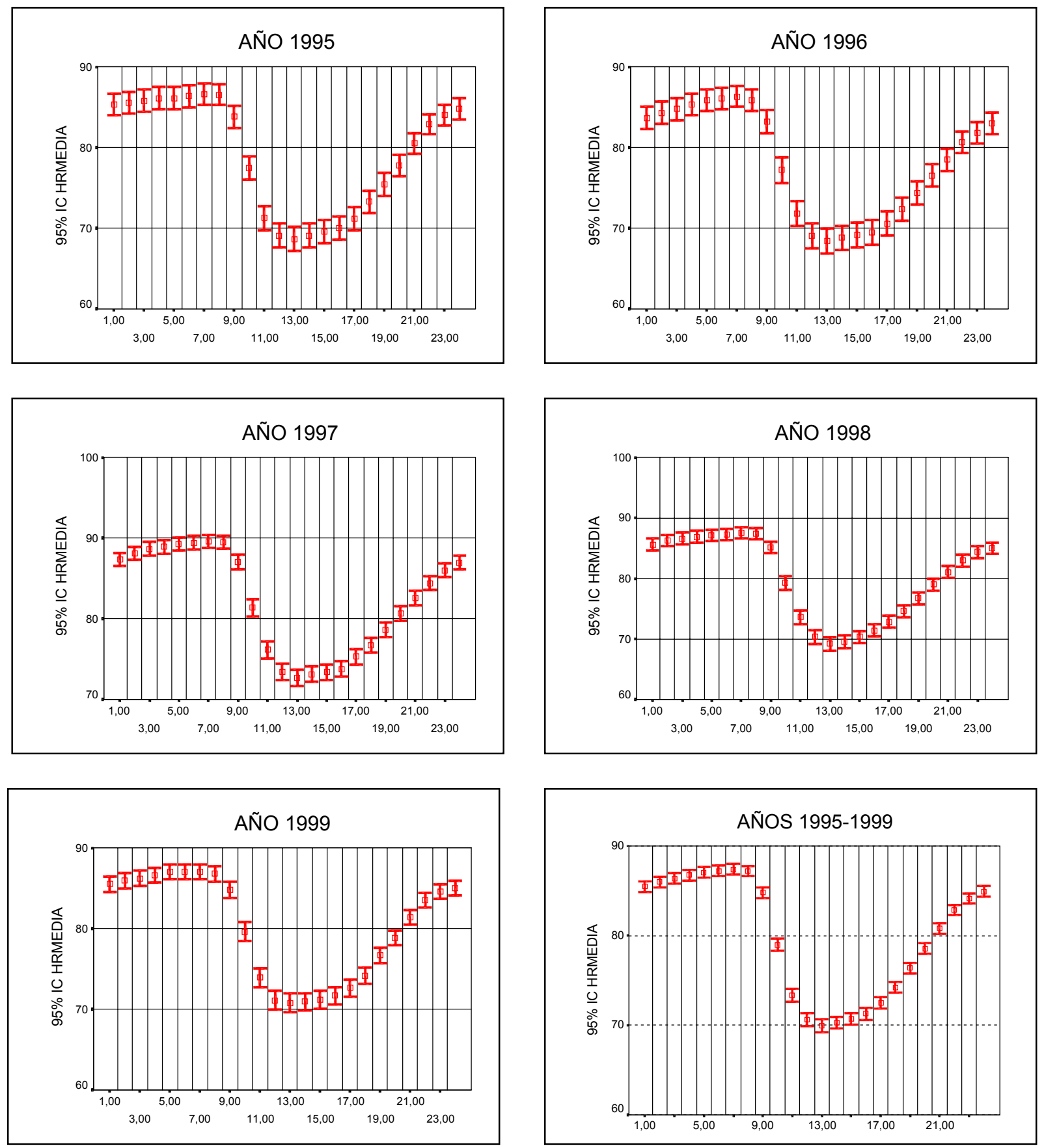
Figura 5.13. Resumen de la presión barométrica media mensual para los años 1993-1999, y para el conjunto 93-99 en la torre meteorológica Ayuntamiento en mb.
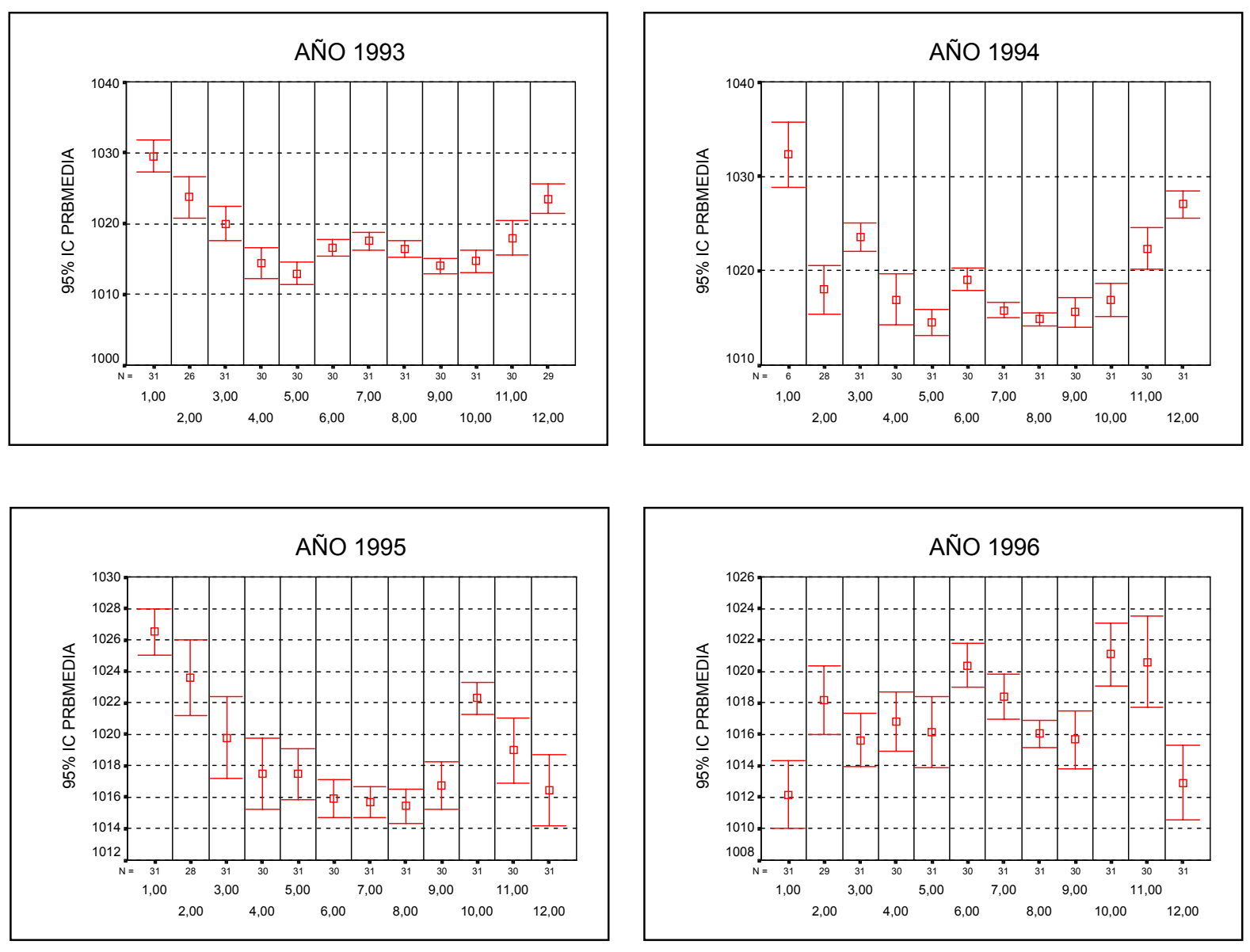
Figura 5.13 Continuación. Resumen de la presión barométrica media mensual para los años 1993-1999, y para el conjunto en la torre meteorológica Ayuntamiento en mb.
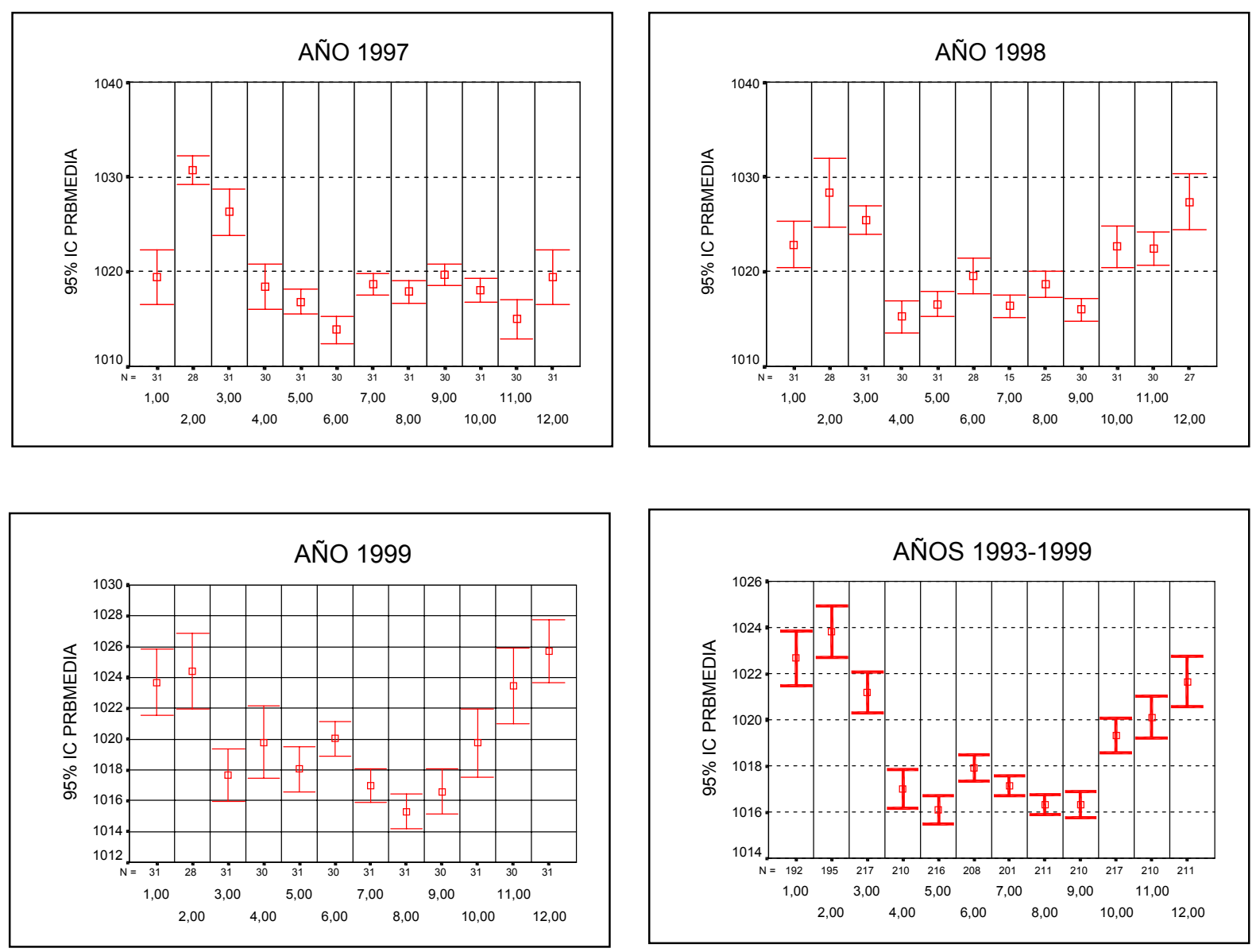
Tabla 5.11. Presión barométrica media mensual y anual para los años 1993-1999 y para el conjunto de los años en mb.

\begin{tabular}{|l|l|l|l|l|l|l|l|l|l|l|l|l|l|}
\hline $\mathbf{A n ̃ o}$ & Ene. & Feb. & Mar. & Abr. & May. & Jun. & Jul. & Ago. & Sept. & Oct. & Nov. & Dic. & Anual \\
\hline $\mathbf{1 9 9 3}$ & 1029 & 1024 & 1020 & 1014 & 1013 & 1017 & 1018 & 1017 & 1014 & 1015 & 1018 & 1023 & 1018 \\
\hline $\mathbf{1 9 9 4}$ & 1032 & 1018 & 1023 & 1017 & 1014 & 1019 & 1016 & 1015 & 1016 & 1017 & 1022 & 1027 & 1019 \\
\hline $\mathbf{1 9 9 5}$ & 1027 & 1024 & 1020 & 1017 & 1017 & 1016 & 1016 & 1015 & 1017 & 1022 & 1019 & 1016 & 1019 \\
\hline $\mathbf{1 9 9 6}$ & 1012 & 1018 & 1016 & 1017 & 1016 & 1020 & 1018 & 1016 & 1016 & 1021 & 1021 & 1013 & 1017 \\
\hline $\mathbf{1 9 9 7}$ & 1019 & 1031 & 1026 & 1018 & 1017 & 1014 & 1019 & 1018 & 1020 & 1018 & 1015 & 1019 & 1019 \\
\hline $\mathbf{1 9 9 8}$ & 1023 & 1028 & 1025 & 1015 & 1016 & 1019 & 1016 & 1019 & 1016 & 1023 & 1022 & 1027 & 1021 \\
\hline $\mathbf{1 9 9 9}$ & 1024 & 1024 & 1018 & 1020 & 1018 & 1020 & 1017 & 1015 & 1017 & 1020 & 1023 & 1026 & 1020 \\
\hline $\mathbf{9 3 - 9 9}$ & 1023 & 1024 & 1021 & 1017 & 1016 & 1018 & 1017 & 1016 & 1016 & 1019 & 1020 & 1022 & 1019 \\
\hline
\end{tabular}


Figura 5.14. Evolución diaria de la media e intervalo de confianza al $95 \%$ de la presión barométrica (en mb) para cada año y para el conjunto de años (1995-1999), en la torre meteorológica Ayuntamiento.
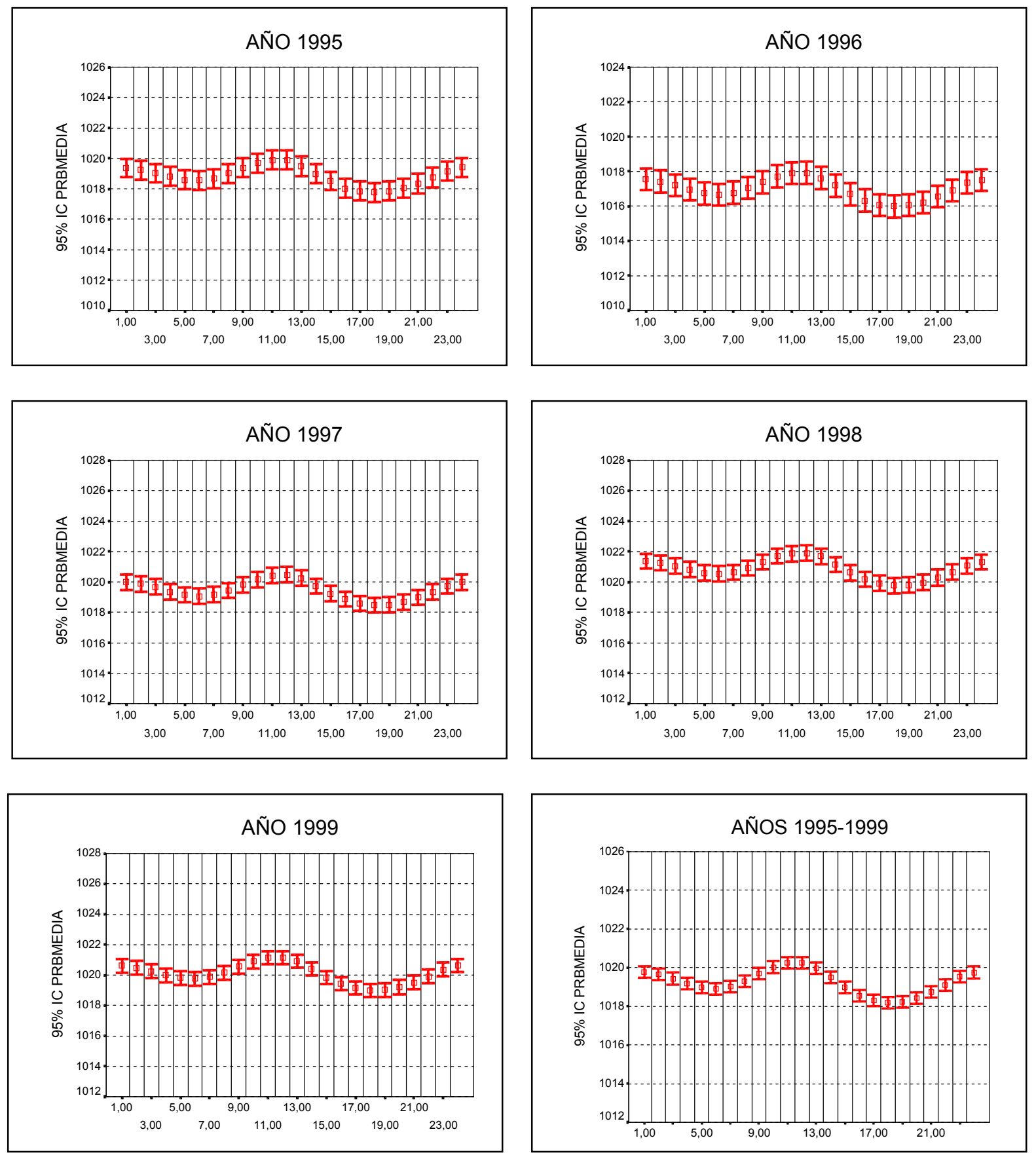
Figura 5.15. Resumen de la radiación solar media acumulada mensual para los años 1993-1999, y para el conjunto, en la torre meteorológica Ayuntamiento en $\mathrm{w} / \mathrm{m}^{2}$ día.
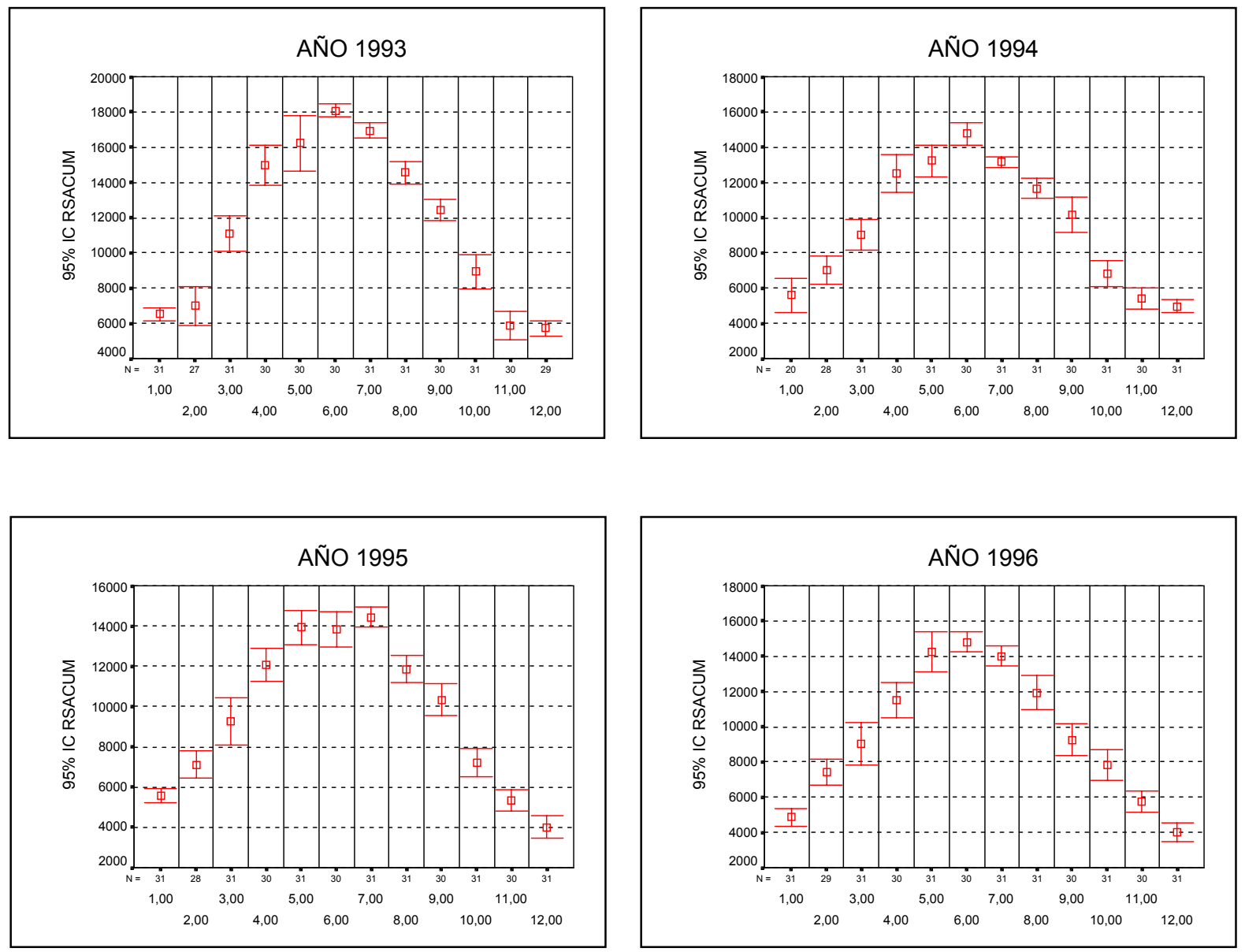
Figura 5.15. Continuación. Resumen de la radiación solar media acumulada mensual para los años 1993-1999, y para el conjunto en la torre meteorológica Ayuntamiento en $\mathrm{w} / \mathrm{m}^{2}$ día.
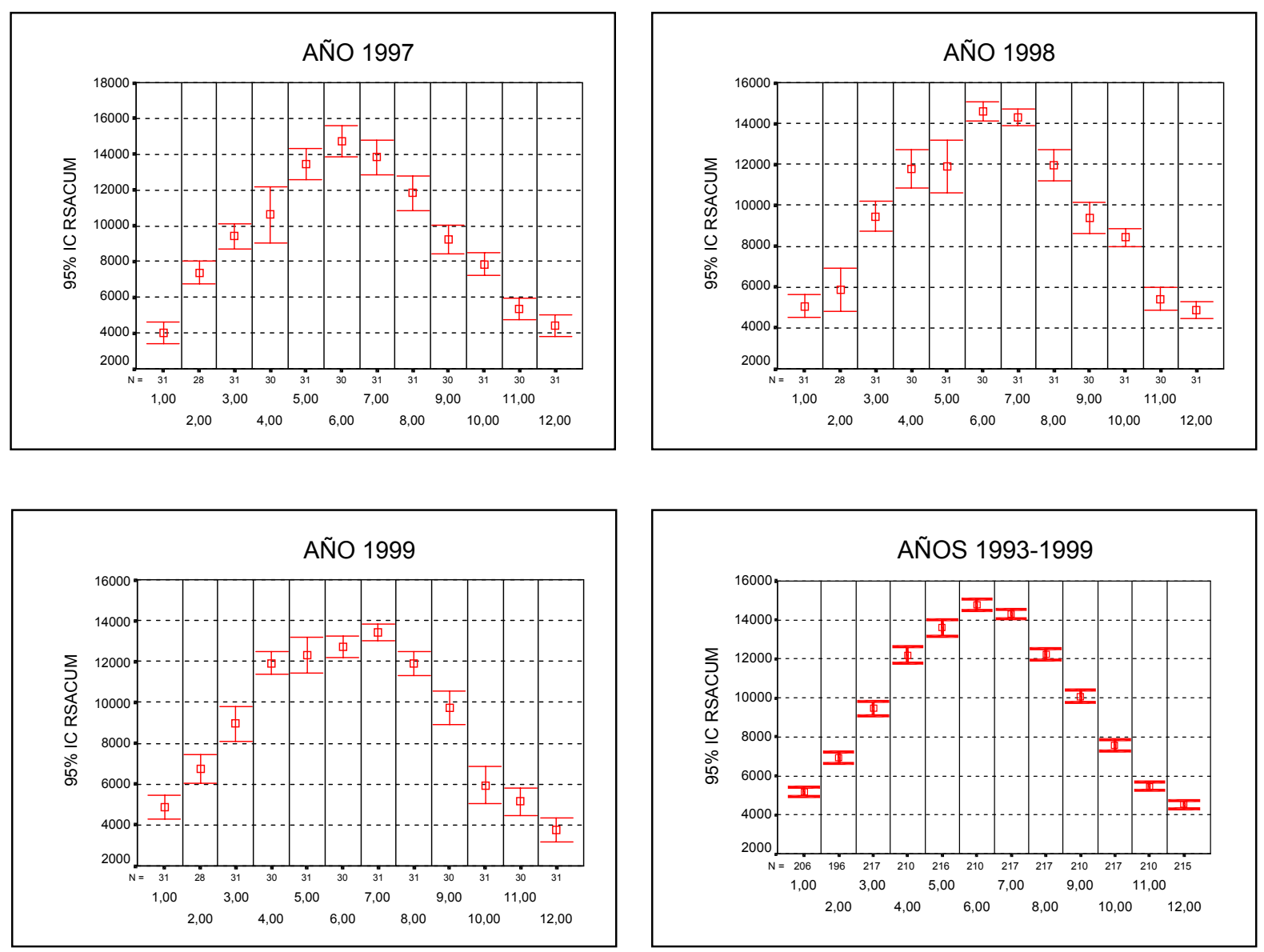
Tabla 5.12. Radiación solar media mensual y anual para los años 1993-1999 y para el conjunto de los años en $\mathrm{w} / \mathrm{m}^{2}$ día.

\begin{tabular}{|l|l|l|l|l|l|l|l|l|l|l|l|l|l|}
\hline Año & Ene. & Feb. & Mar. & Abr. & May. & Jun. & Jul. & Ago. & Sept. & Oct. & Nov. & Dic. & Anual \\
\hline $\mathbf{1 9 9 3}$ & 6530 & 7007 & 11097 & 14979 & 16220 & 18064 & 16950 & 14555 & 12440 & 8930 & 5886 & 5717 & 11586 \\
\hline $\mathbf{1 9 9 4}$ & 5592 & 7013 & 9048 & 12524 & 13231 & 14760 & 13166 & 11670 & 10182 & 6804 & 5386 & 4959 & 9658 \\
\hline $\mathbf{1 9 9 5}$ & 5581 & 7109 & 9251 & 12073 & 13929 & 13834 & 14429 & 11866 & 10346 & 7191 & 5336 & 4012 & 9591 \\
\hline $\mathbf{1 9 9 6}$ & 4850 & 7399 & 9036 & 11506 & 14251 & 14799 & 14015 & 11941 & 9241 & 7831 & 5742 & 4032 & 9557 \\
\hline $\mathbf{1 9 9 7}$ & 3393 & 7375 & 9398 & 10621 & 16455 & 14708 & 13816 & 11818 & 9228 & 7836 & 5338 & 4391 & 9341 \\
\hline $\mathbf{1 9 9 8}$ & 5063 & 5890 & 9464 & 11776 & 11910 & 14594 & 14293 & 11960 & 9398 & 8418 & 5419 & 4873 & 9440 \\
\hline $\mathbf{1 9 9 9}$ & 4874 & 6743 & 8944 & 11914 & 12313 & 12715 & 13417 & 11912 & 9724 & 5952 & 5143 & 3758 & 8958 \\
\hline $\mathbf{9 3 - 9 9}$ & 5191 & 6936 & 9463 & 12199 & 13603 & 14782 & 14298 & 12246 & 10080 & 7566 & 5464 & 4523 & 9730 \\
\hline
\end{tabular}


Figura 5.16a. Evolución diaria de la media e intervalo de confianza al 95\% de la radiación solar (en $\mathrm{w} / \mathrm{m}^{2}$ dia) para cada año y para el conjunto de años (1995-1999), en la torre meteorológica Ayuntamiento.
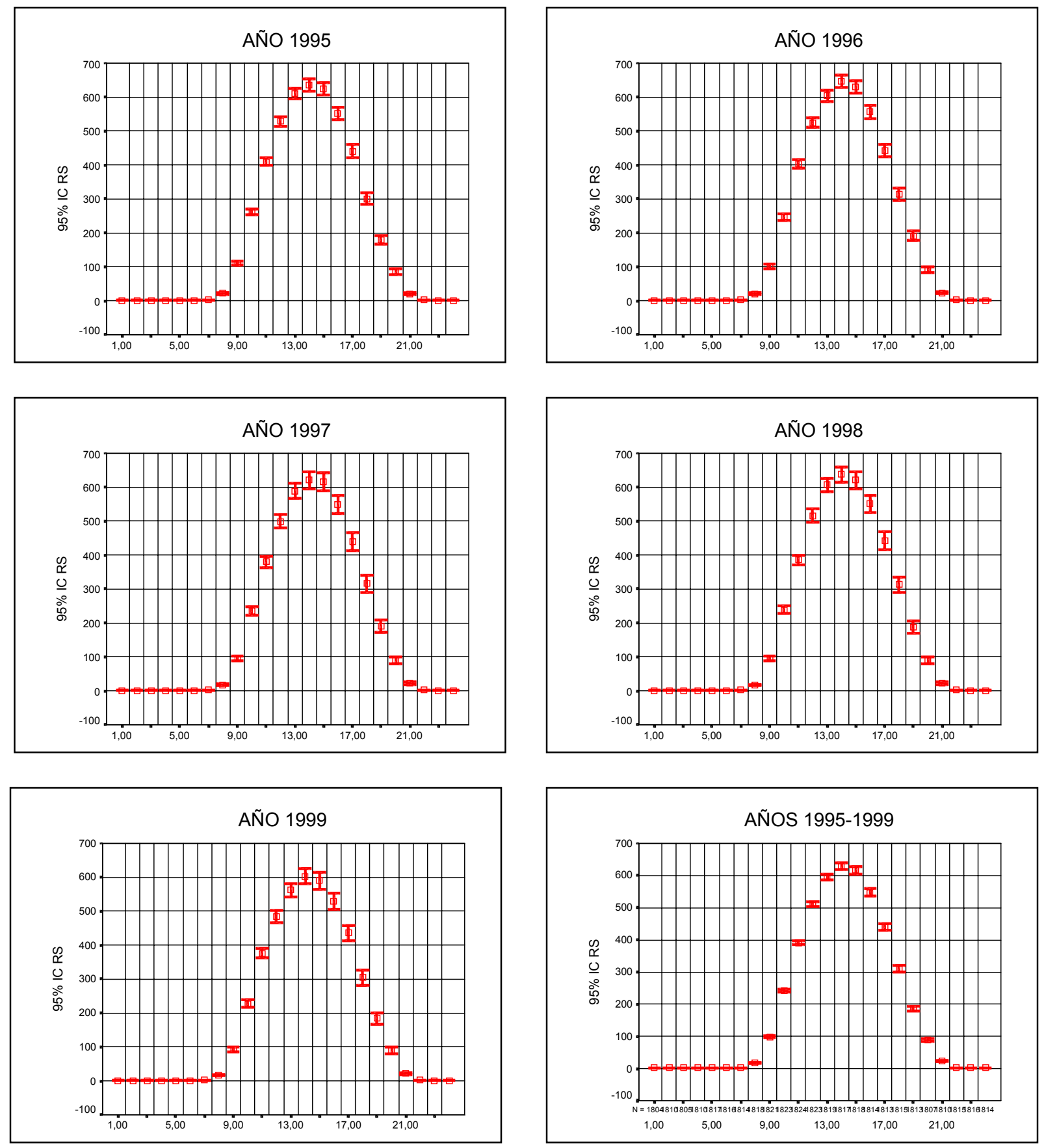
Figura 5.16b. Evolución diaria de la media e intervalo de confianza al 95\% de la velocidad media del viento (en $\mathrm{km} / \mathrm{hora}$ ) para cada año y para el conjunto de años (1995-1999), en la torre meteorológica Ayuntamiento.
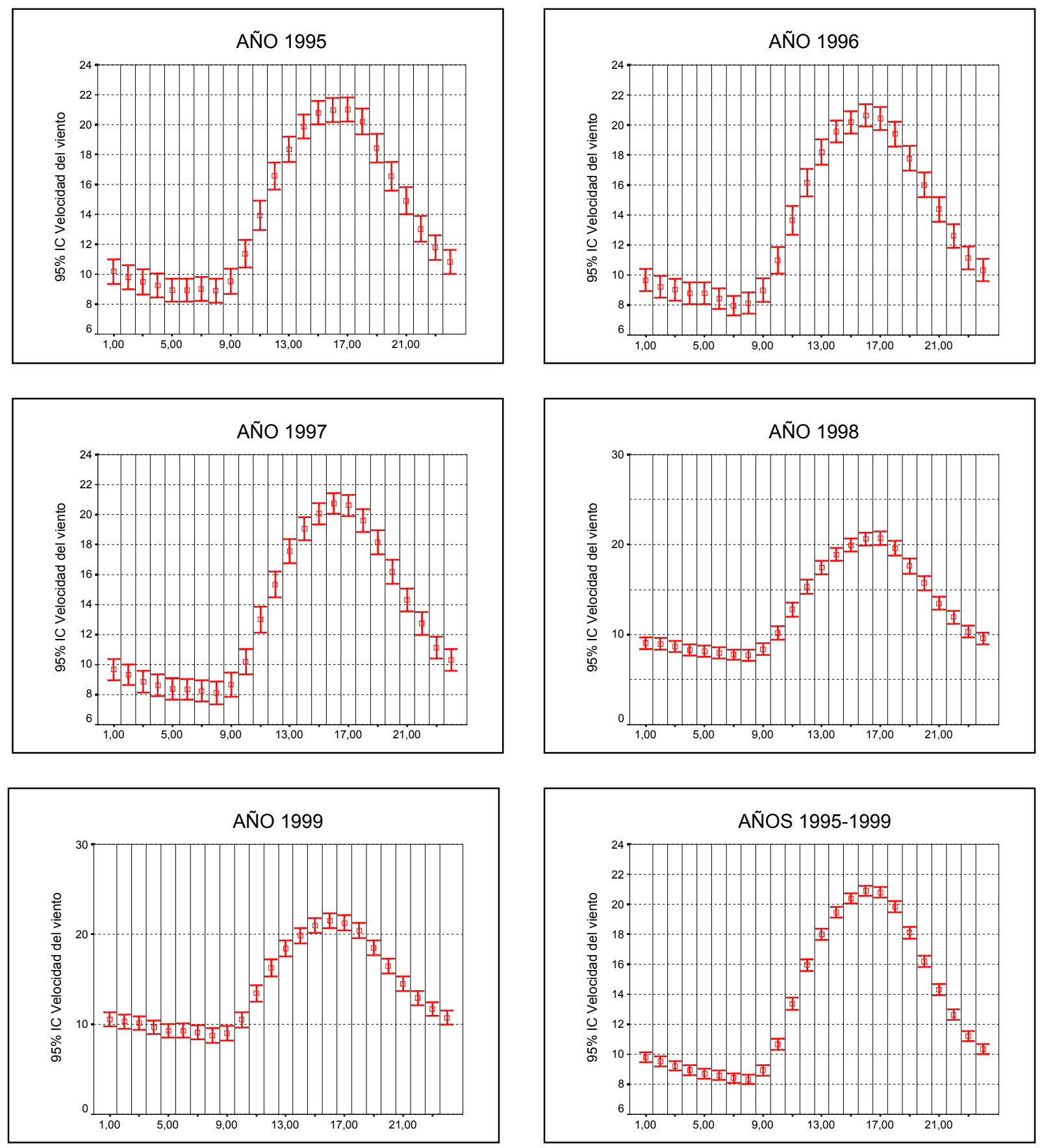
Figura 5.17. Resumen de la lluvia acumulada mensual para los años 1993-1999, y para el conjunto, en la torre meteorológica Cartagena-Ciudad en dl.
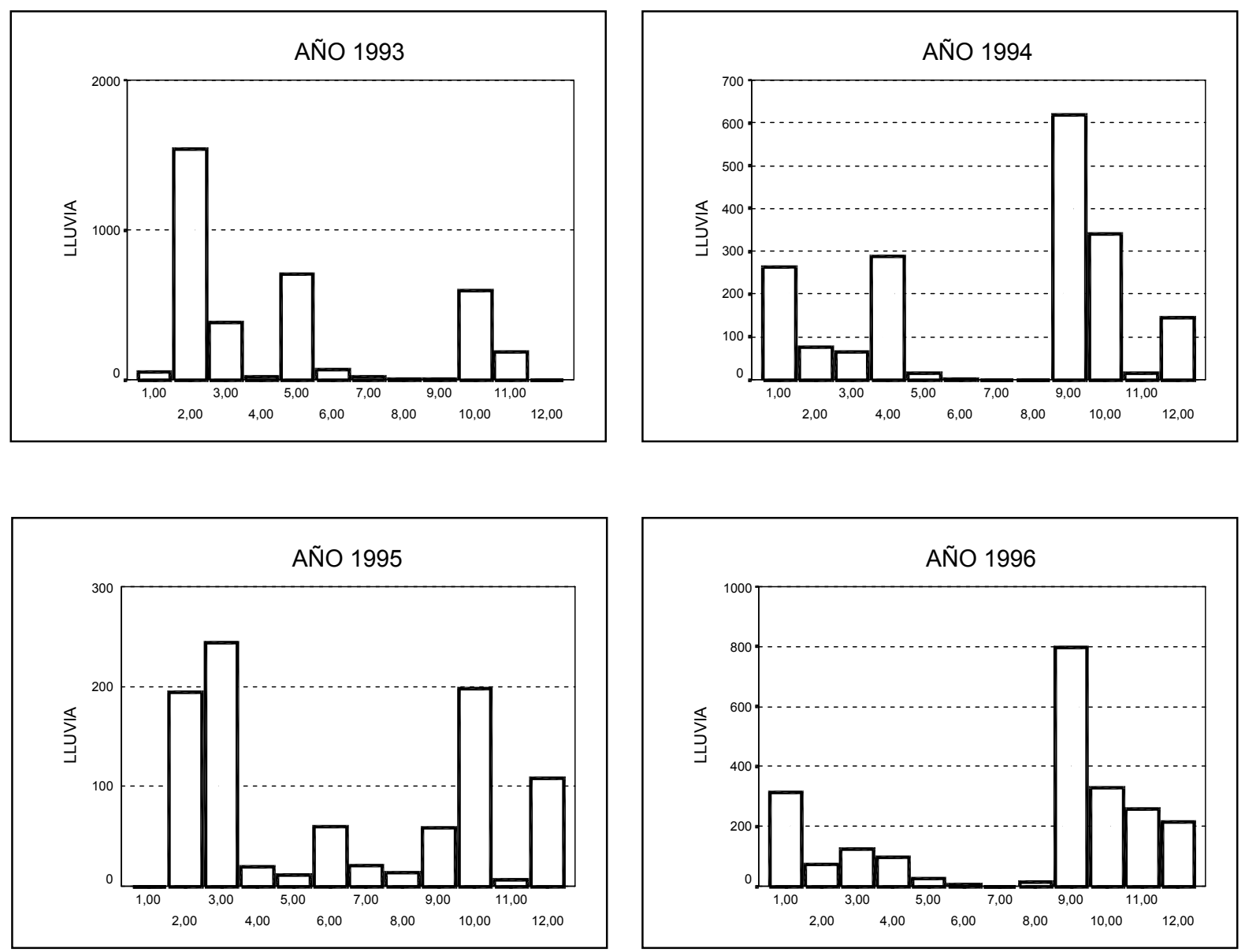
Figura 5.17. Continuación. Resumen de la lluvia acumulada mensual para los años 1993-1999, y para el conjunto en la torre meteorológica CartagenaCiudad en dl.
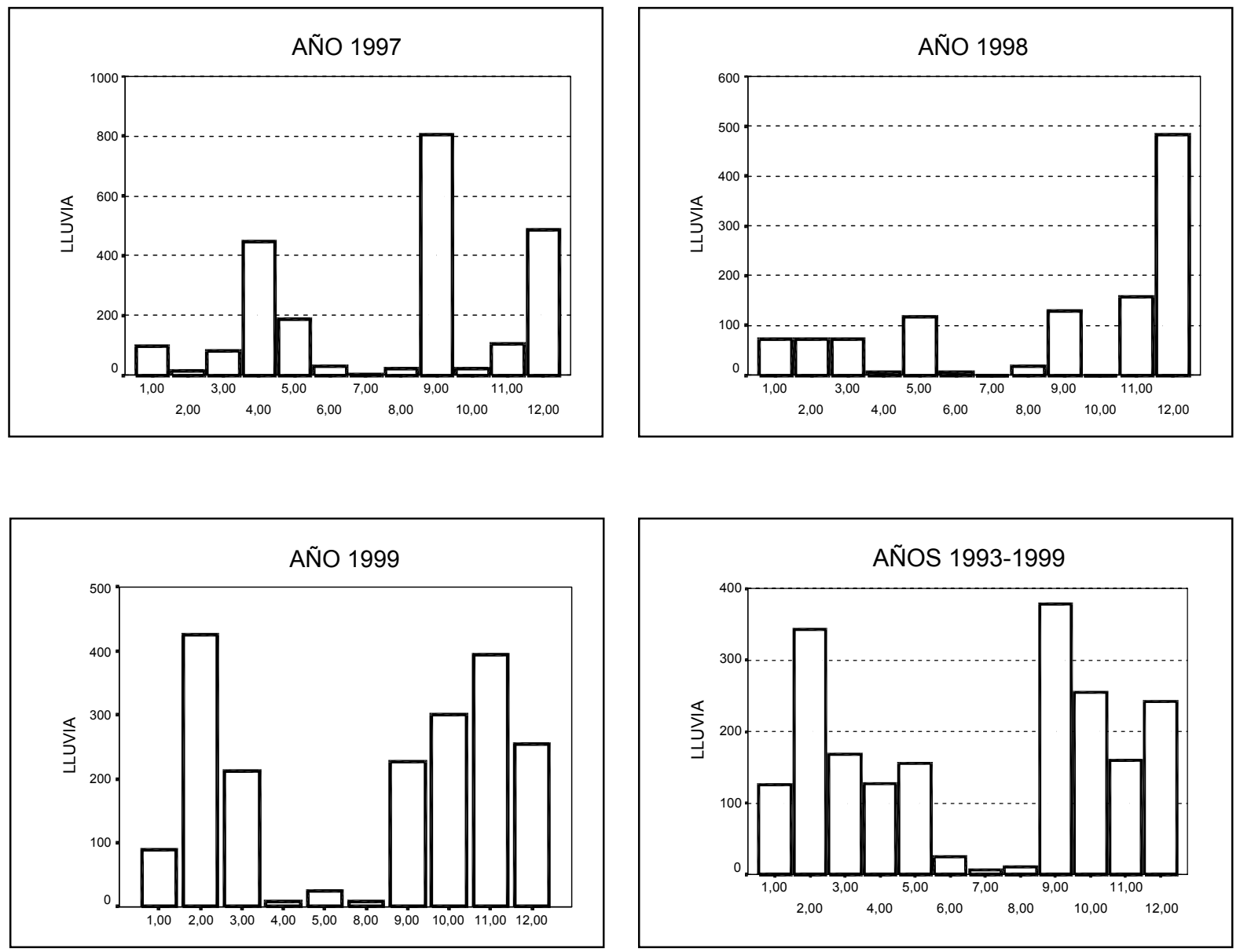
Tabla 5.13. Precipitación acumulada mensual y para los años 1993 a 1999 y media mensual y anual para el conjunto de los años en mm. Estación Cartagena-Ciudad.

\begin{tabular}{|c|c|c|c|c|c|c|c|c|c|c|c|c|c|}
\hline Año & Ene. & Feb. & Mar. & Abr. & May. & Jun. & Jul. & Ago. & Sept. & Oct. & Nov. & Dic. & Anual \\
\hline $\mathbf{1 9 9 3}$ & 4.8 & 153.8 & 38.4 & 2.0 & 70.5 & 6.9 & 2.2 & 0.5 & 0.5 & 59.6 & 18.8 & 0.0 & 358.0 \\
\hline $\mathbf{1 9 9 4}$ & 26.2 & 7.7 & 6.4 & 28.9 & 1.4 & 0.2 & 0.0 & 0.0 & 61.8 & 33.9 & 1.5 & 14.5 & 182.5 \\
\hline $\mathbf{1 9 9 5}$ & 0.0 & 19.4 & 24.4 & 2.0 & 1.1 & 6.0 & 2.1 & 1.3 & 5.9 & 19.8 & 0.6 & 10.8 & 93.4 \\
\hline $\mathbf{1 9 9 6}$ & 31.4 & 7.4 & 12.3 & 9.7 & 2.6 & 0.6 & 0.0 & 1.2 & 79.9 & 32.8 & 25.7 & 21.5 & 225.1 \\
\hline $\mathbf{1 9 9 7}$ & 9.5 & 1.4 & 7.9 & 44.7 & 18.8 & 2.9 & 0.1 & 2.0 & 80.7 & 2.3 & 10.3 & 48.7 & 229.3 \\
\hline $\mathbf{1 9 9 8}$ & 7.1 & 7.1 & 7.1 & 0.6 & 11.7 & 0.6 & 0.0 & 1.8 & 12.9 & 0.0 & 15.7 & 48.2 & 112.8 \\
\hline $\mathbf{1 9 9 9}$ & 9.0 & 42.5 & 21.3 & 0.8 & 2.5 & 0.0 & 0.0 & 0.9 & 22.7 & 30.0 & 39.5 & 25.5 & 194.7 \\
\hline $\mathbf{9 3 - 9 9}$ & 12.6 & 34.2 & 16.8 & 12.7 & 15.5 & 2.4 & 0.6 & 1.1 & 37.8 & 25.5 & 16.0 & 24.1 & 199.4 \\
\hline
\end{tabular}

Tabla 5.14. Precipitación media mensual para el periodo 1951-1990 y media anual de 30 años en mm. Estación Cartagena-Puerto.

\begin{tabular}{|l|l|l|l|l|l|l|l|l|l|l|l|l|l|}
\hline Años & Ene. & Feb. & Mar. & Abr. & May. & Jun. & Jul. & Ago. & Sept. & Oct. & Nov. & Dic. & Anual \\
\hline $\mathbf{5 1 - 9 0}$ & 42.6 & 23.1 & 27.7 & 42.1 & 28.4 & 11.2 & 3.7 & 7.3 & 14.2 & 64.5 & 42.6 & 43.1 & 350.5 \\
\hline
\end{tabular}


Figura 5.18. Rosa de los vientos y tabla de frecuencias de las direcciones del viento. Estación meteorológica Ayuntamiento. Año 1993.

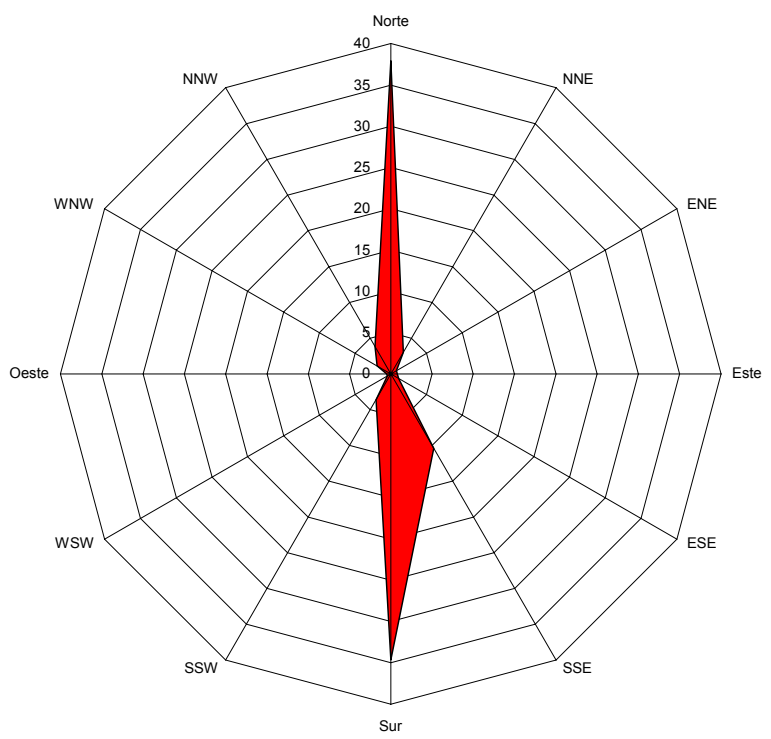

Frecuencias del viento año 1993. Estación Ayuntamiento

\begin{tabular}{|ll|r|r|r|r|}
\hline & & & & $\begin{array}{c}\text { Porcentaje } \\
\text { válido }\end{array}$ & $\begin{array}{r}\text { Porcentaje } \\
\text { acumulado }\end{array}$ \\
\hline Válidos & 1,00 & 138 & 37,9 & 38,2 & 38,2 \\
& 2,00 & 11 & 3,0 & 3,0 & 41,3 \\
& 3,00 & 3 &, 8 &, 8 & 42,1 \\
& 4,00 & 3 &, 8 &, 8 & 42,9 \\
& 5,00 & 4 & 1,1 & 1,1 & 44,0 \\
& 6,00 & 38 & 10,4 & 10,5 & 54,6 \\
& 7,00 & 126 & 34,6 & 34,9 & 89,5 \\
& 8,00 & 13 & 3,6 & 3,6 & 93,1 \\
& 9,00 & 2 &, 5 &, 6 & 93,6 \\
& 10,00 & 2 &, 5 &, 6 & 94,2 \\
& 11,00 & 7 & 1,9 & 1,9 & 96,1 \\
& 12,00 & 14 & 3,8 & 3,9 & 100,0 \\
& Total & 361 & 99,2 & 100,0 & \\
Perdidos & Sistem & 3 &, 8 & & \\
\cline { 2 - 2 } & Total & 364 & 100,0 & & \\
\hline
\end{tabular}


Figura 5.19. Frecuencias de los vientos por rangos de velocidad. Estación meteorológica Ayuntamiento. Año 1993 (Rango 1 = 0-4,9 km/h; rango 2 = $5-10,9 \mathrm{~km} / \mathrm{h}$; rango $4 \geq 15 \mathrm{~km} / \mathrm{h})$.

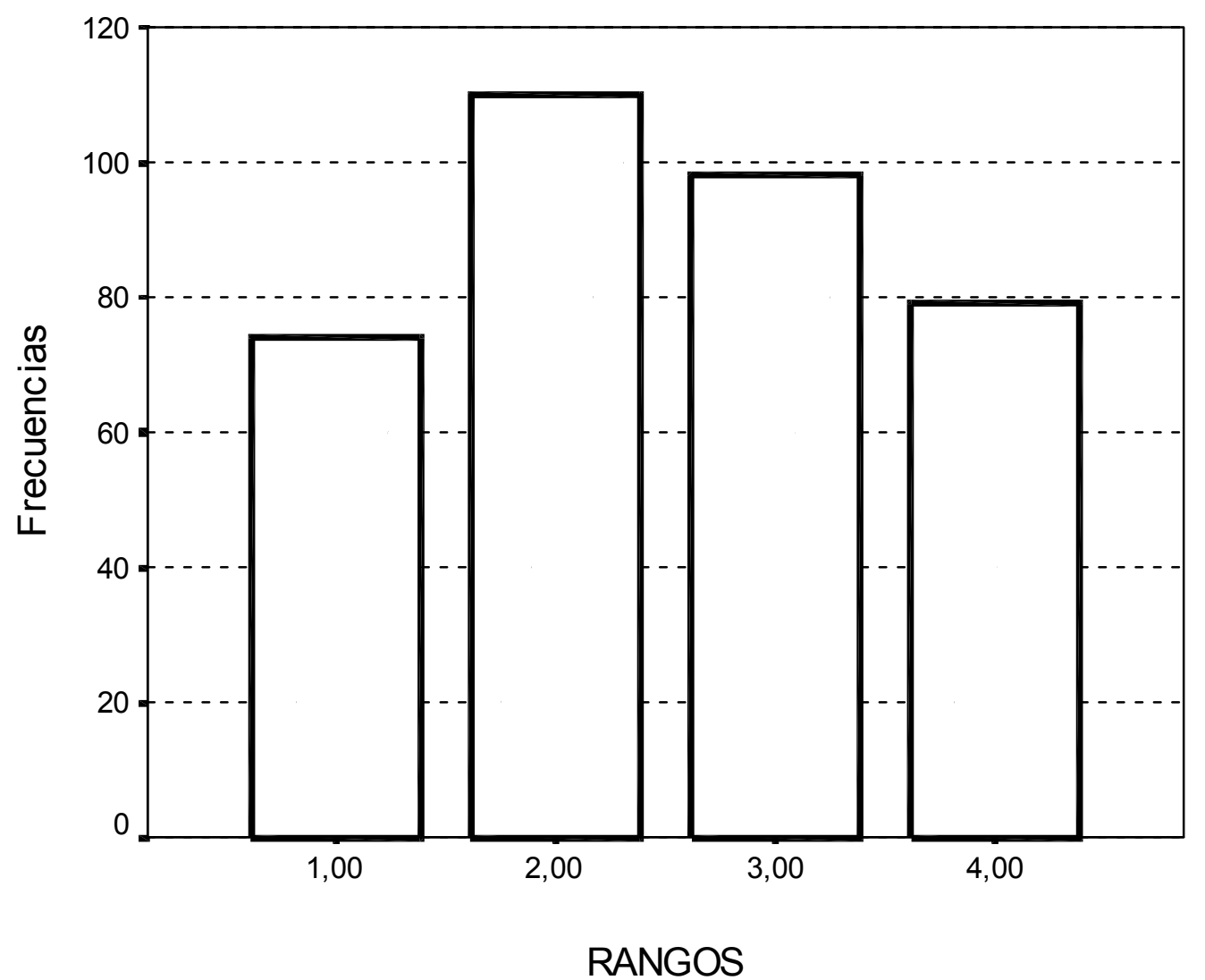

Tabla de frecuencias del viento por velocidades. Ayuntamiento 1993

\begin{tabular}{|ll|r|r|r|r|}
\hline & & Frecuencia & Porcentaje & $\begin{array}{c}\text { Porcentaje } \\
\text { válido }\end{array}$ & $\begin{array}{c}\text { Porcentaje } \\
\text { acumulado }\end{array}$ \\
\hline Válidos & 1,00 & 74 & 20,3 & 20,5 & 20,5 \\
& 2,00 & 110 & 30,2 & 30,5 & 51,0 \\
& 3,00 & 98 & 26,9 & 27,1 & 78,1 \\
& 4,00 & 79 & 21,7 & 21,9 & 100,0 \\
& Total & 361 & 99,2 & 100,0 & \\
Perdidos & Sistema & 3 &, 8 & & \\
Total & & 364 & 100,0 & & \\
\hline
\end{tabular}


Figura 5.20. Rosa de los vientos y tabla de frecuencias de las direcciones del viento. Estación meteorológica Ayuntamiento. Año 1994.

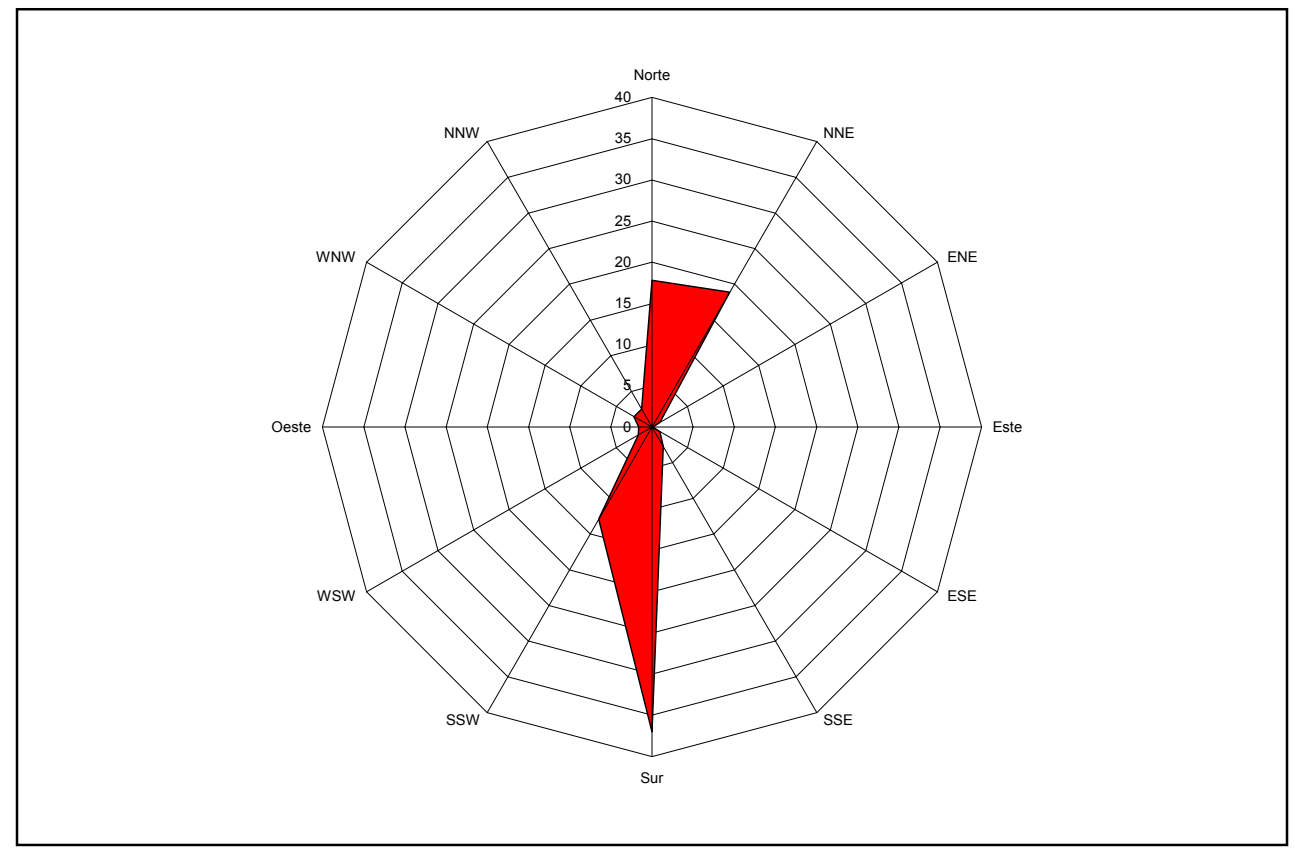

Frecuencias del viento año 1994. Estación ayuntamiento

\begin{tabular}{|ll|r|r|r|r|}
\hline & & Frecuencia & Porcentaje & $\begin{array}{c}\text { Porcentaje } \\
\text { válido }\end{array}$ & $\begin{array}{c}\text { Porcentaje } \\
\text { acumulado }\end{array}$ \\
\hline Válidos & 1,00 & 65 & 17,8 & 17,8 & 17,8 \\
& 2,00 & 69 & 18,9 & 18,9 & 36,7 \\
& 4,00 & 4 & 1,1 & 1,1 & 37,8 \\
5,00 & 4 & 1,1 & 1,1 & 38,9 \\
6,00 & 10 & 2,7 & 2,7 & 41,6 \\
7,00 & 135 & 37,0 & 37,0 & 78,6 \\
8,00 & 47 & 12,9 & 12,9 & 91,5 \\
9,00 & 7 & 1,9 & 1,9 & 93,4 \\
10,00 & 6 & 1,6 & 1,6 & 95,1 \\
11,00 & 9 & 2,5 & 2,5 & 97,5 \\
12,00 & 9 & 2,5 & 2,5 & 100,0 \\
Total & 365 & 100,0 & 100,0 & \\
\hline
\end{tabular}


Figura 5.21. Frecuencias de los vientos por rangos de velocidad. Estación meteorológica Ayuntamiento. Año 1994 (Rango 1 = 0-4,9 km/h; rango $2=$ $5-10,9 \mathrm{~km} / \mathrm{h}$; rango $4 \geq 15 \mathrm{~km} / \mathrm{h}$ ).

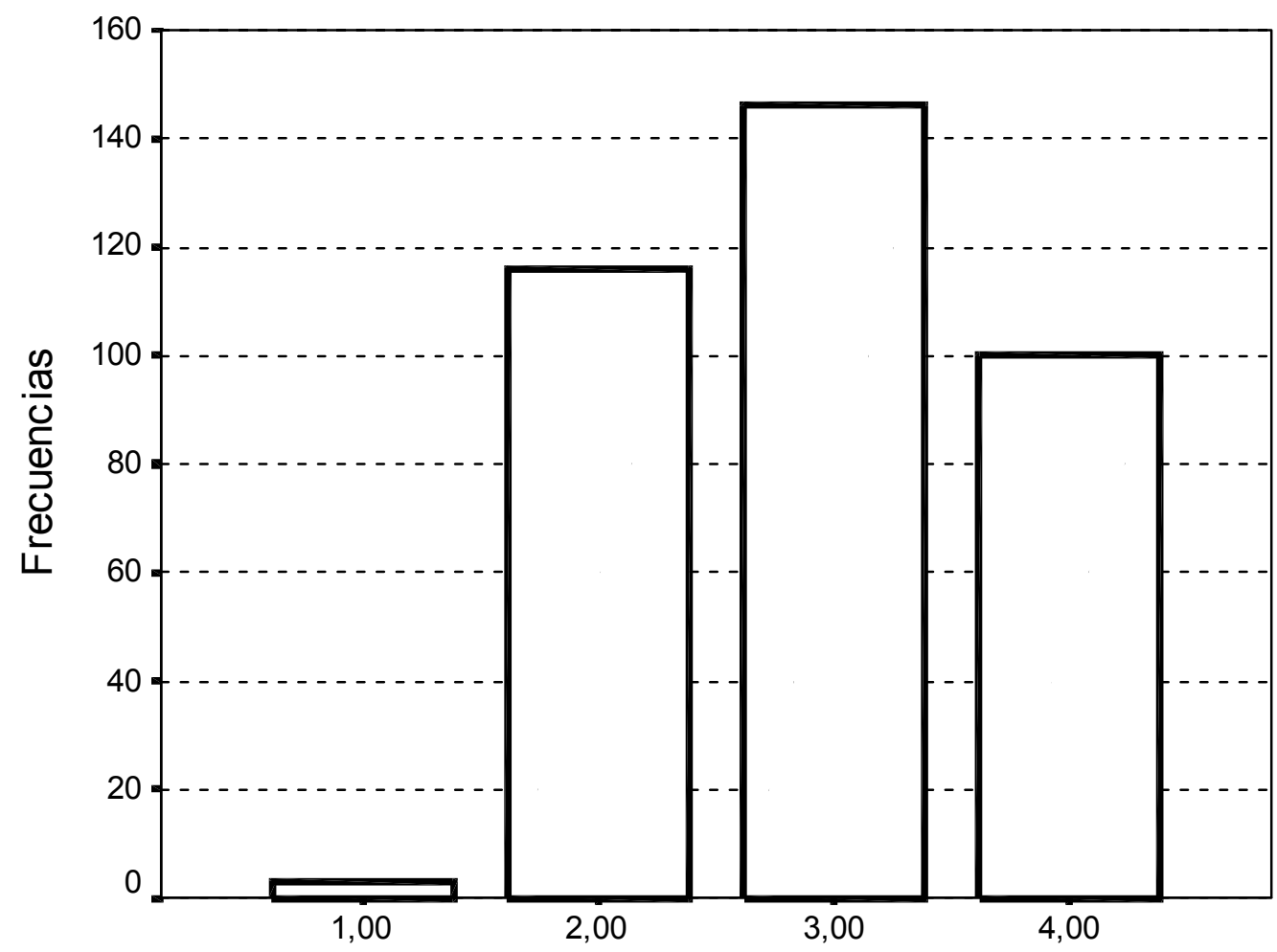

RANGOS

Tabla de frecuencias del viento por velocidades. Ayuntamiento 1994

\begin{tabular}{|rr|r|r|r|r|}
\hline & Frecuencia & Porcentaje & \multicolumn{1}{|c|}{$\begin{array}{c}\text { Porcentaje } \\
\text { válido }\end{array}$} & $\begin{array}{c}\text { Porcentaje } \\
\text { acumulado }\end{array}$ \\
\hline Válidos & 1,00 & 3 &, 8 &, 8 &, 8 \\
& 2,00 & 116 & 31,8 & 31,8 & 32,6 \\
3,00 & 146 & 40,0 & 40,0 & 72,6 \\
4,00 & 100 & 27,4 & 27,4 & 100,0 \\
& Total & 365 & 100,0 & 100,0 & \\
\hline
\end{tabular}


Figura 5.22. Rosa de los vientos y tabla de frecuencias de las direcciones del viento. Estación meteorológica Ayuntamiento. Año 1995.

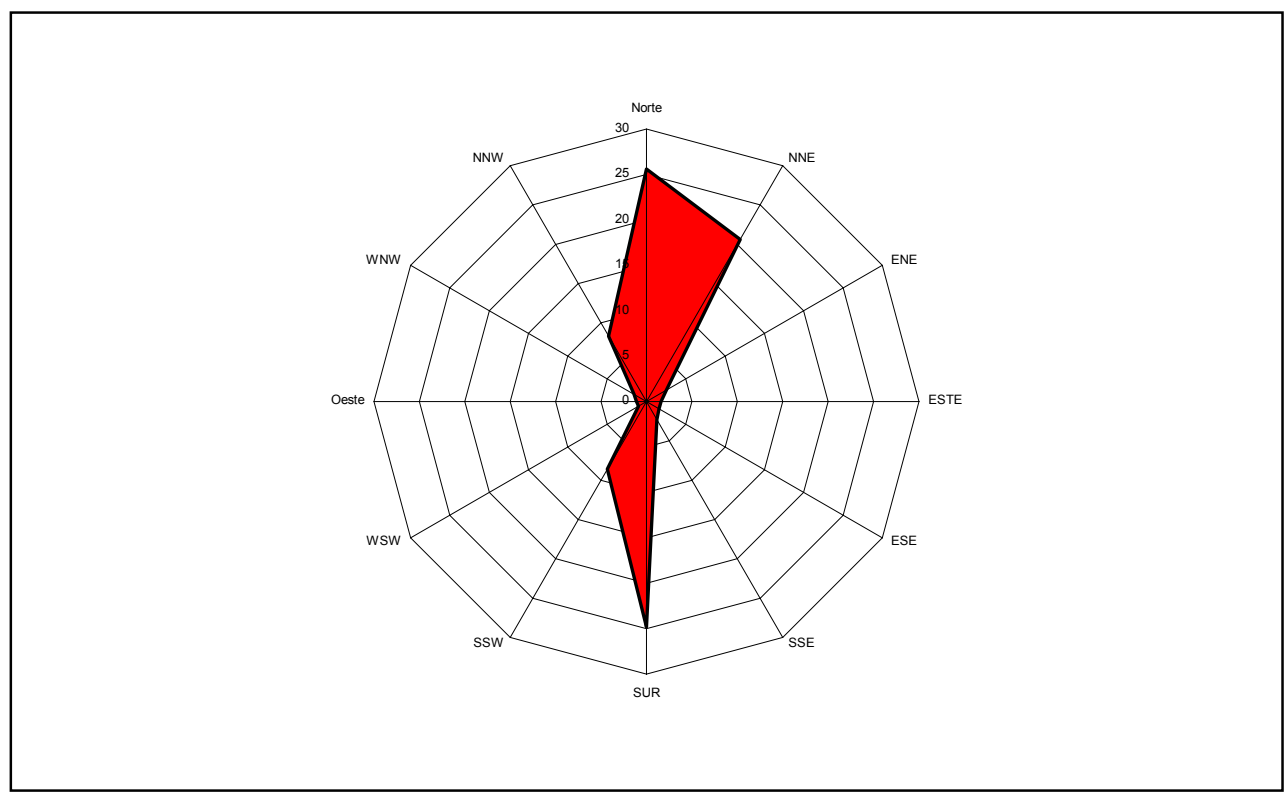

Frecuencias semihorarias del viento año 1995. Estación Ayuntamiento

\begin{tabular}{|ll|r|r|r|r|}
\hline & & Frecuencia & Porcentaje & $\begin{array}{c}\text { Porcentaje } \\
\text { válido }\end{array}$ & $\begin{array}{r}\text { Porcentaje } \\
\text { acumulado }\end{array}$ \\
\hline Válidos & 1,00 & 4482 & 25,6 & 25,7 & 25,7 \\
& 2,00 & 3608 & 20,6 & 20,7 & 46,3 \\
& 3,00 & 434 & 2,5 & 2,5 & 48,8 \\
& 4,00 & 275 & 1,6 & 1,6 & 50,4 \\
& 5,00 & 283 & 1,6 & 1,6 & 52,0 \\
& 6,00 & 402 & 2,3 & 2,3 & 54,3 \\
& 7,00 & 4347 & 24,8 & 24,9 & 79,2 \\
& 8,00 & 1514 & 8,6 & 8,7 & 87,9 \\
& 9,00 & 176 & 1,0 & 1,0 & 88,9 \\
& 10,00 & 199 & 1,1 & 1,1 & 90,0 \\
& 11,00 & 282 & 1,6 & 1,6 & 91,7 \\
& 12,00 & 1457 & 8,3 & 8,3 & 100,0 \\
Perdidos & Total & 17459 & 99,7 & 100,0 & \\
Total & Sistema & 61 &, 3 & & \\
\hline
\end{tabular}


Figura 5.23. Frecuencias de los vientos por rangos de velocidad. Estación meteorológica Ayuntamiento. Año 1995 (Rango 1 = 0-4,9 km/h; rango $2=$ $5-10,9 \mathrm{~km} / \mathrm{h}$; rango $4 \geq 15 \mathrm{~km} / \mathrm{h})$.

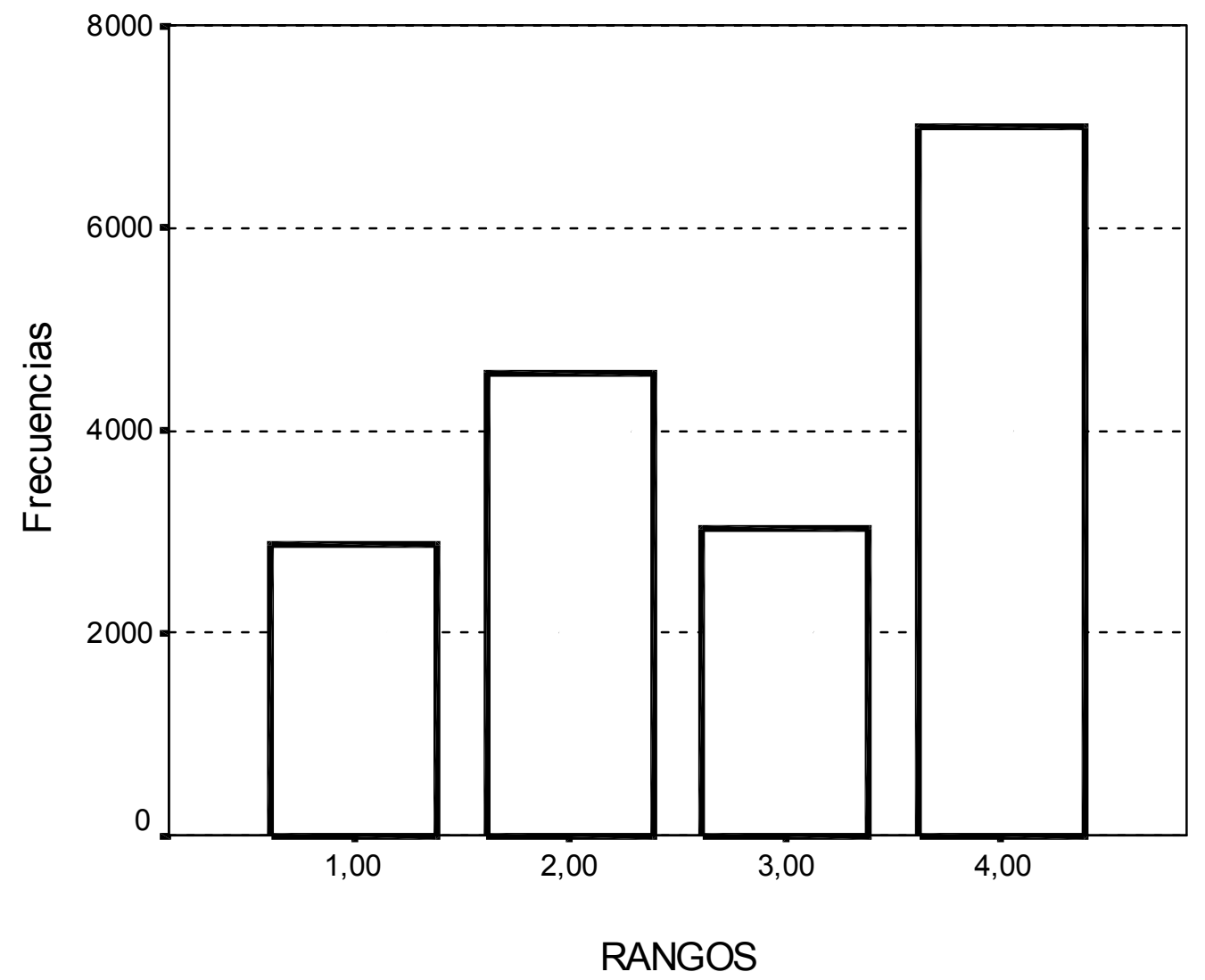

Tabla de frecuencias del viento por velocidades. Ayuntamiento 1995

\begin{tabular}{|ll|r|r|r|r|}
\hline & & Frecuencia & Porcentaje & $\begin{array}{c}\text { Porcentaje } \\
\text { válido }\end{array}$ & $\begin{array}{c}\text { Porcentaje } \\
\text { acumulado }\end{array}$ \\
\hline Válidos & 1,00 & 2864 & 16,3 & 16,4 & 16,4 \\
& 2,00 & 4569 & 26,1 & 26,2 & 42,6 \\
& 3,00 & 3030 & 17,3 & 17,4 & 59,9 \\
& 4,00 & 6995 & 39,9 & 40,1 & 100,0 \\
& Total & 17458 & 99,6 & 100,0 & \\
Perdidos & Sistema & 62 &, 4 & & \\
Total & & 17520 & 100,0 & & \\
\hline
\end{tabular}


Figura 5.24. Rosa de los vientos y tabla de frecuencias de las direcciones del viento. Estación meteorológica Ayuntamiento. Año 1996.

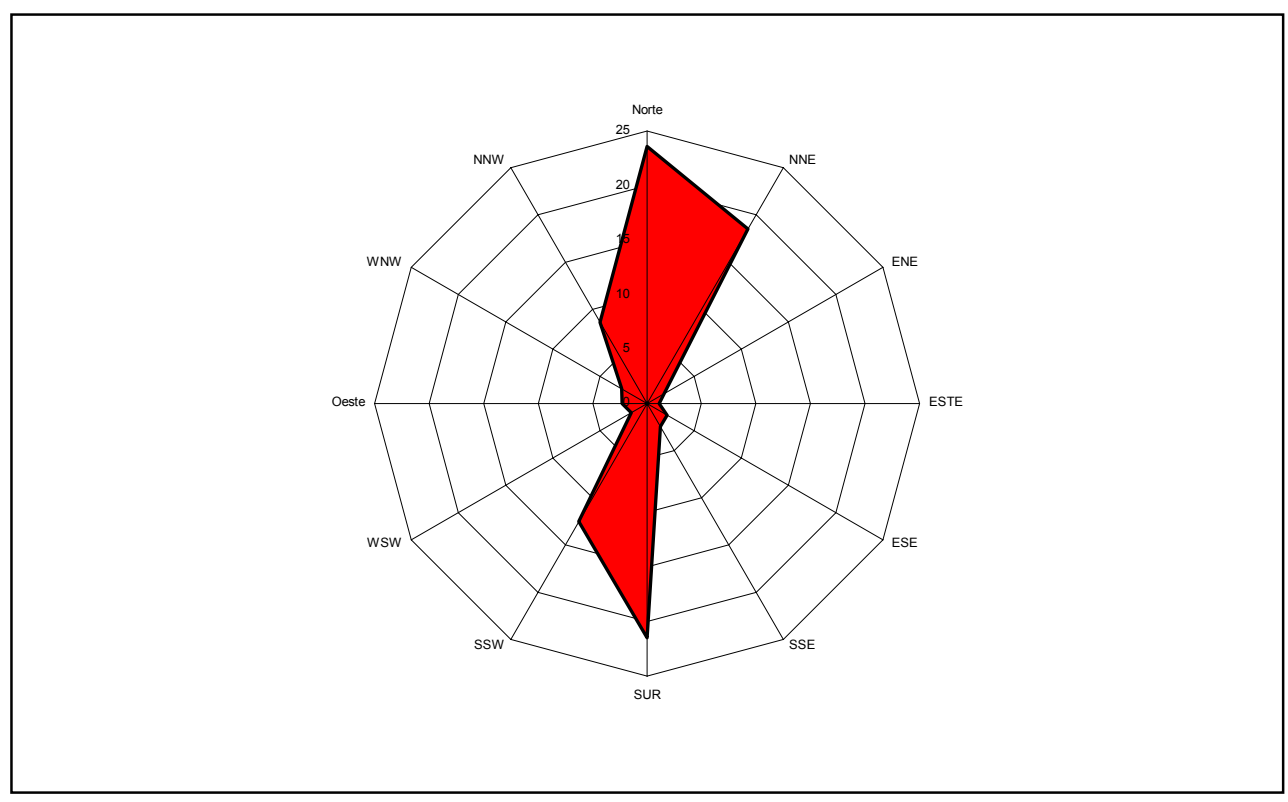

Frecuencias semihorarias del viento año 1996. Estación Ayuntamiento

\begin{tabular}{|ll|r|r|r|r|}
\hline & & Frecuencia & Porcentaje & $\begin{array}{c}\text { Porcentaje } \\
\text { válido }\end{array}$ & $\begin{array}{r}\text { Porcentaje } \\
\text { acumulado }\end{array}$ \\
\hline Válidos & 1,00 & 4149 & 23,6 & 23,9 & 23,9 \\
& 2,00 & 3247 & 18,5 & 18,7 & 42,6 \\
& 3,00 & 319 & 1,8 & 1,8 & 44,5 \\
& 4,00 & 189 & 1,1 & 1,1 & 45,6 \\
& 5,00 & 364 & 2,1 & 2,1 & 47,7 \\
& 6,00 & 423 & 2,4 & 2,4 & 50,1 \\
& 7,00 & 3769 & 21,5 & 21,7 & 71,8 \\
& 8,00 & 2203 & 12,5 & 12,7 & 84,5 \\
& 9,00 & 304 & 1,7 & 1,8 & 86,3 \\
& 10,00 & 399 & 2,3 & 2,3 & 88,6 \\
& 11,00 & 478 & 2,7 & 2,8 & 91,3 \\
& 12,00 & 1505 & 8,6 & 8,7 & 100,0 \\
Perdidos & Total & 17349 & 98,8 & 100,0 & \\
Total & Sistema & 219 & 1,2 & & \\
\hline
\end{tabular}


Figura 5.25. Frecuencias de los vientos por rangos de velocidad. Estación meteorológica Ayuntamiento. Año 1996 (Rango 1 = 0-4,9 km/h; rango 2 = $5-10,9 \mathrm{~km} / \mathrm{h}$; rango $4 \geq 15 \mathrm{~km} / \mathrm{h})$.

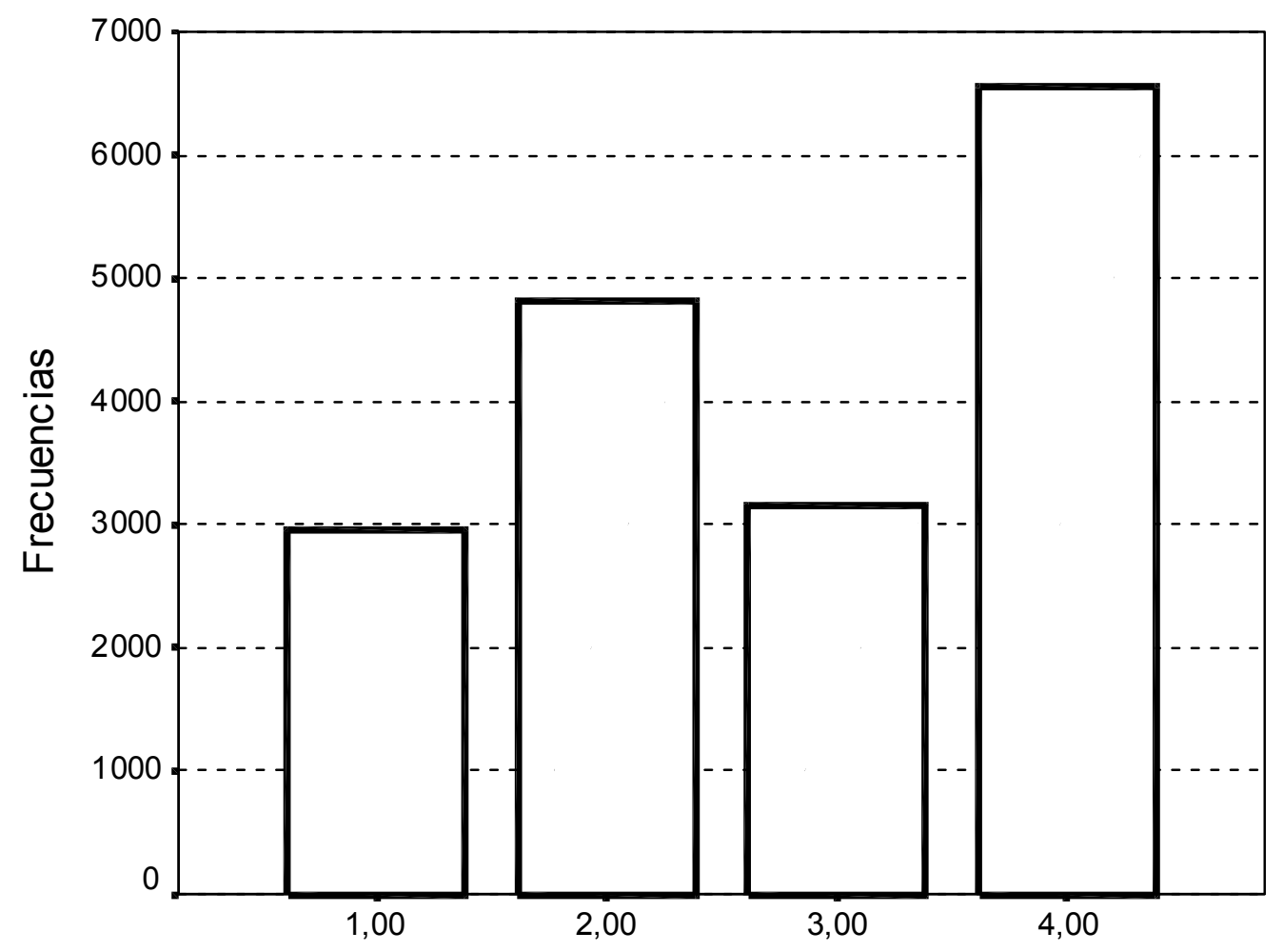

RANGOS

Tabla de frecuencias del viento por velocidades. Ayuntamiento 1996

\begin{tabular}{|ll|r|r|r|r|}
\hline & & & \multicolumn{1}{c|}{$\begin{array}{c}\text { Porcentaje } \\
\text { válido }\end{array}$} & $\begin{array}{r}\text { Porcentaje } \\
\text { acumulado }\end{array}$ \\
\hline Válidos & 1,00 & 2948 & 16,8 & 16,9 & 16,9 \\
& 2,00 & 4809 & 27,4 & 27,5 & 44,4 \\
& 3,00 & 3159 & 18,0 & 18,1 & 62,5 \\
& 4,00 & 6548 & 37,3 & 37,5 & 100,0 \\
& Total & 17464 & 99,4 & 100,0 & \\
Perdidos & Sistema & 104 &, 6 & & \\
Total & & 17568 & 100,0 & & \\
\hline
\end{tabular}


Figura 5.26. Rosa de los vientos y tabla de frecuencias de las direcciones del viento. Estación meteorológica Ayuntamiento. Año 1997.

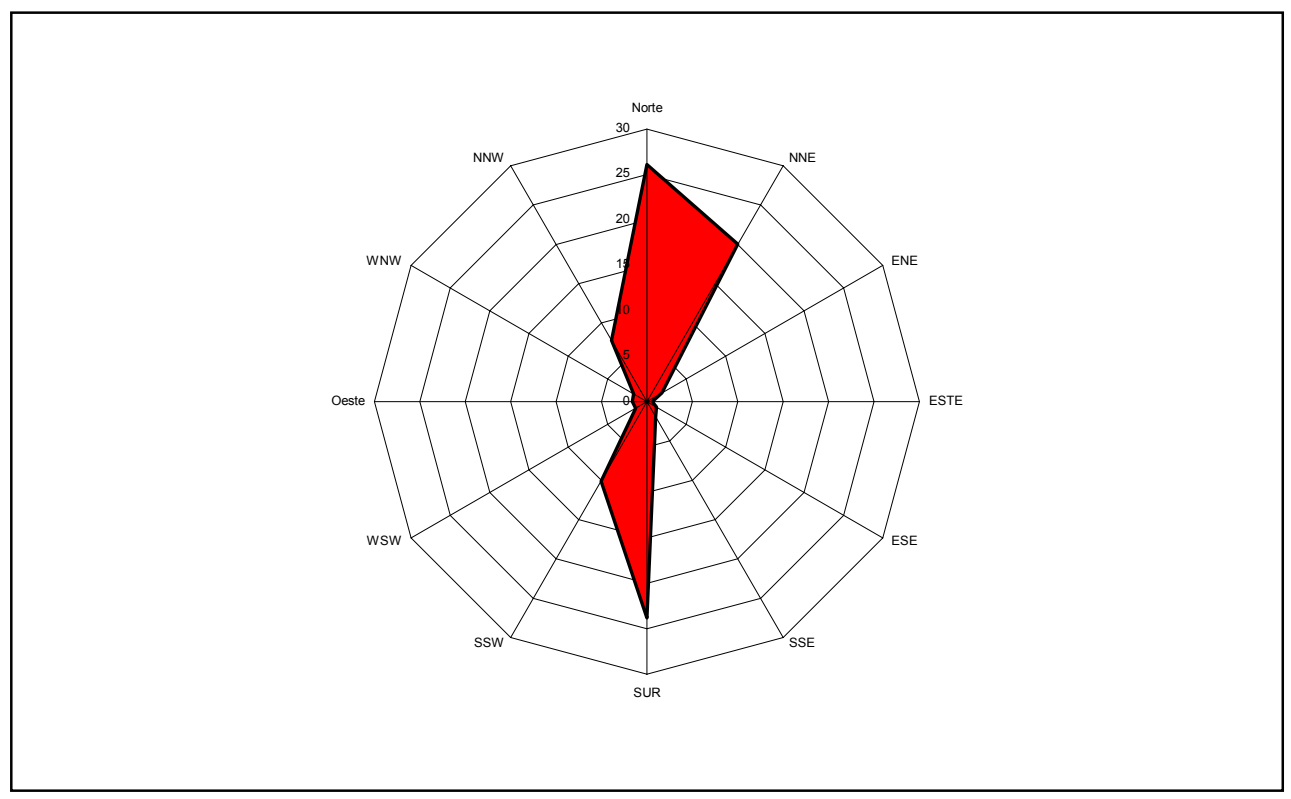

Frecuencias semihorarias del viento año 1997. Estación Ayuntamiento

\begin{tabular}{|ll|r|r|r|r|}
\hline & & Frecuencia & Porcentaje & $\begin{array}{c}\text { Porcentaje } \\
\text { válido }\end{array}$ & $\begin{array}{c}\text { Porcentaje } \\
\text { acumulado }\end{array}$ \\
\hline Válidos & 1,00 & 4572 & 26,1 & 26,6 & 26,6 \\
& 2,00 & 3502 & 20,0 & 20,4 & 47,0 \\
& 3,00 & 328 & 1,9 & 1,9 & 48,9 \\
& 4,00 & 105 &, 6 &, 6 & 49,5 \\
& 5,00 & 216 & 1,2 & 1,3 & 50,8 \\
& 6,00 & 338 & 1,9 & 2,0 & 52,7 \\
& 7,00 & 4165 & 23,8 & 24,2 & 77,0 \\
& 8,00 & 1771 & 10,1 & 10,3 & 87,3 \\
& 9,00 & 242 & 1,4 & 1,4 & 88,7 \\
& 10,00 & 279 & 1,6 & 1,6 & 90,3 \\
& 11,00 & 300 & 1,7 & 1,7 & 92,1 \\
& 12,00 & 1365 & 7,8 & 7,9 & 100,0 \\
Perdidos & Total & 17183 & 98,1 & 100,0 & \\
Total & Sistema & 337 & 1,9 & & \\
\hline
\end{tabular}


Figura 5.27. Frecuencias de los vientos por rangos de velocidad. Estación meteorológica Ayuntamiento. Año 1997 (Rango 1 = 0-4,9 km/h; rango $2=$ $5-10,9 \mathrm{~km} / \mathrm{h}$; rango $4 \geq 15 \mathrm{~km} / \mathrm{h})$.

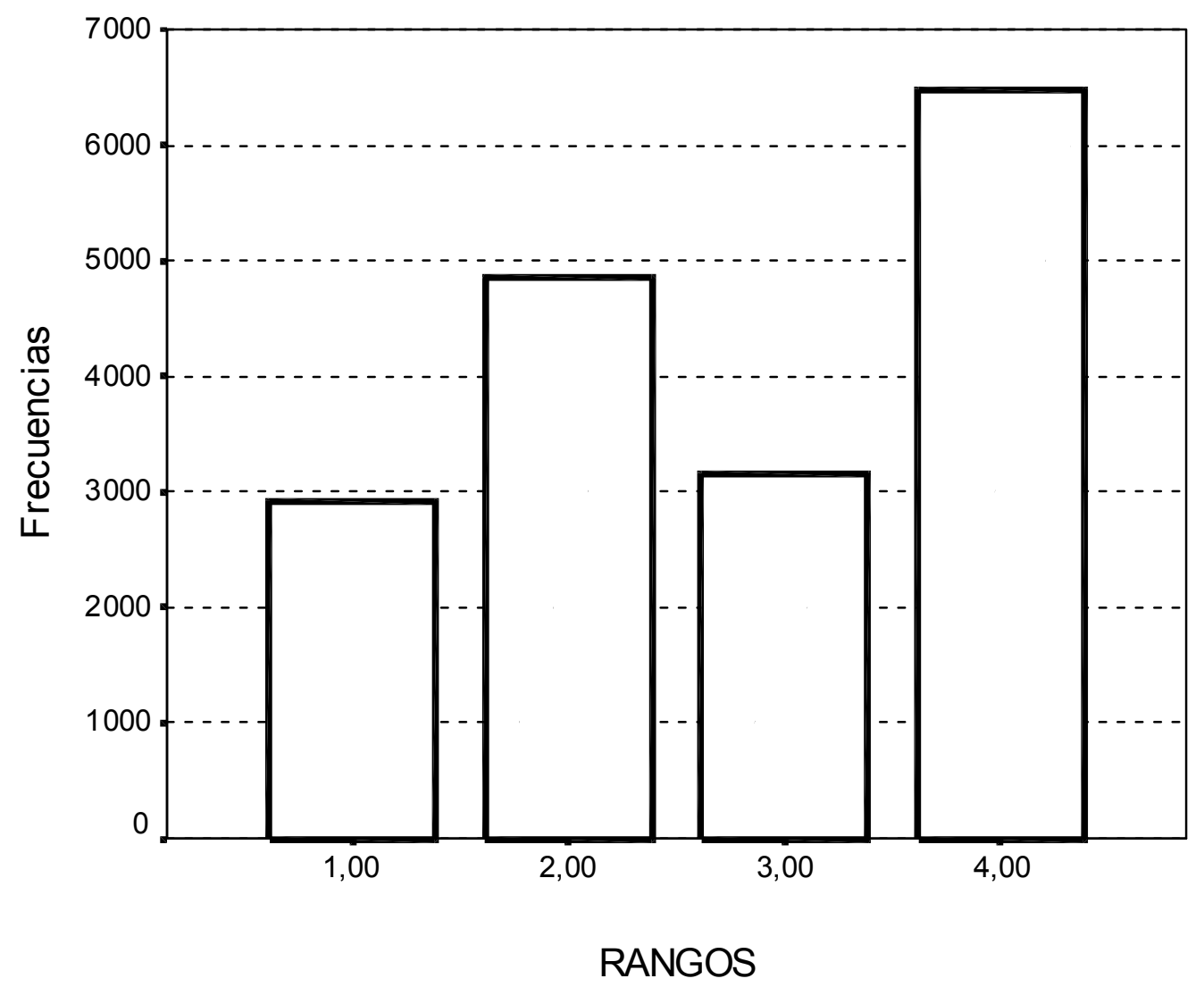

\begin{tabular}{|ll|r|r|r|r|}
\hline \multicolumn{6}{|c|}{ Tabla de frecuencias del viento por velocidades. Ayuntamiento 1997} \\
\hline & & Frecuencia & Porcentaje & $\begin{array}{c}\text { Porcentaje } \\
\text { válido }\end{array}$ & $\begin{array}{r}\text { Porcentaje } \\
\text { acumulado }\end{array}$ \\
\hline & & 2919 & 16,7 & 16,8 & 16,8 \\
& & 4846 & 27,7 & 27,8 & 44,6 \\
& 2,00 & 3156 & 18,0 & 18,1 & 62,7 \\
& 3,00 & 6483 & 37,0 & 37,3 & 100,0 \\
& 4,00 & 17404 & 99,3 & 100,0 & \\
Pélidos & 116 &, 7 & & \\
Total & Total & 17520 & 100,0 & & \\
\hline
\end{tabular}


Figura 5.28. Rosa de los vientos y tabla de frecuencias de las direcciones del viento. Estación meteorológica Ayuntamiento. Año 1998.

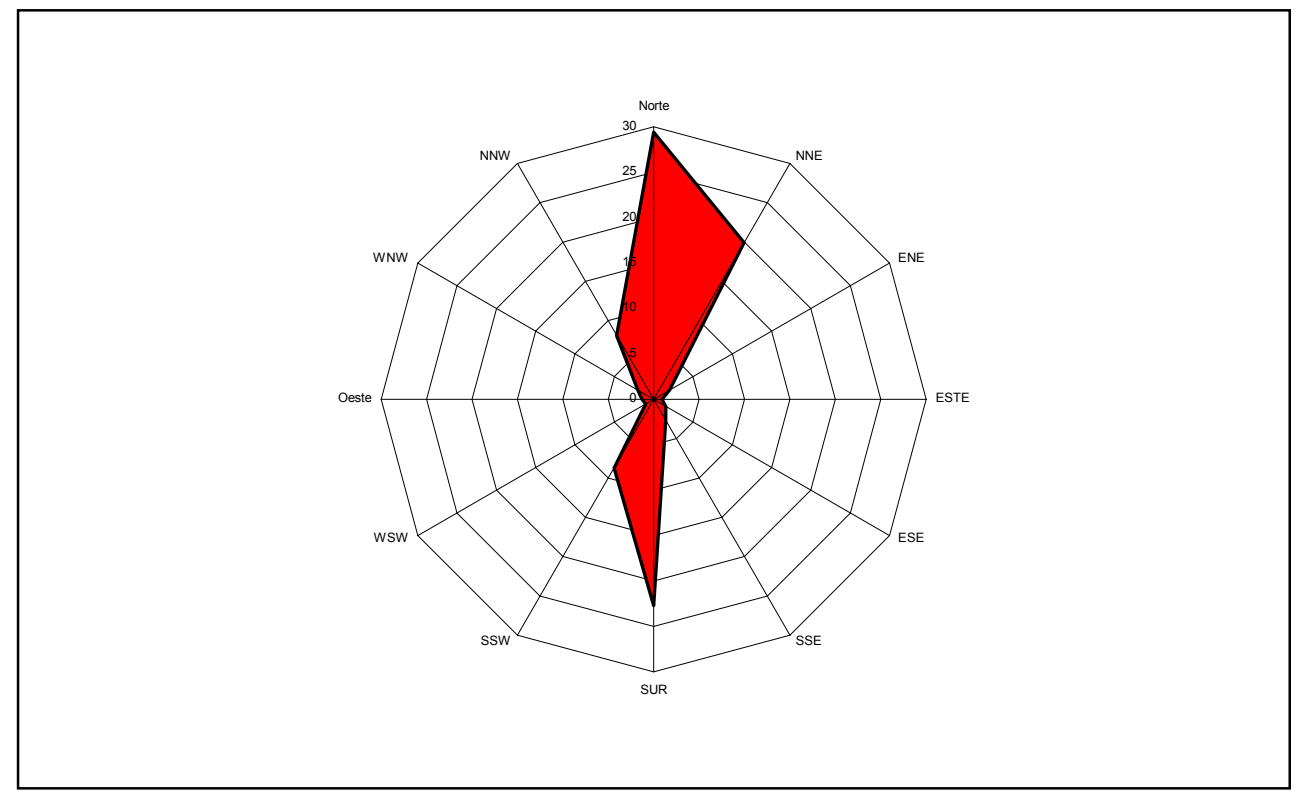

Frecuencias semihorarias del viento año 1998. Estación Ayuntamiento

\begin{tabular}{|rr|r|r|r|r|}
\hline & & Frecuencia & Porcentaje & $\begin{array}{c}\text { Porcentaje } \\
\text { válido }\end{array}$ & $\begin{array}{c}\text { Porcentaje } \\
\text { acumulado }\end{array}$ \\
\hline Válidos & 1,00 & 5147 & 29,4 & 29,4 & 29,4 \\
& 2,00 & 3485 & 19,9 & 19,9 & 49,3 \\
& 3,00 & 355 & 2,0 & 2,0 & 51,3 \\
4,00 & 156 &, 9 &, 9 & 52,2 \\
5,00 & 256 & 1,5 & 1,5 & 53,6 \\
6,00 & 455 & 2,6 & 2,6 & 56,2 \\
7,00 & 3975 & 22,7 & 22,7 & 78,9 \\
8,00 & 1529 & 8,7 & 8,7 & 87,7 \\
9,00 & 167 & 1,0 & 1,0 & 88,6 \\
10,00 & 223 & 1,3 & 1,3 & 89,9 \\
11,00 & 347 & 2,0 & 2,0 & 91,9 \\
12,00 & 1425 & 8,1 & 8,1 & 100,0 \\
Total & 17520 & 100,0 & 100,0 & \\
\hline
\end{tabular}


Figura 5.29. Frecuencias de los vientos por rangos de velocidad. Estación meteorológica Ayuntamiento. Año 1998 (Rango 1 = 0-4,9 km/h; rango $2=$ $5-10,9 \mathrm{~km} / \mathrm{h}$; rango $3=11-15,9$ y rango $4 \geq 16 \mathrm{~km} / \mathrm{h}$ ).

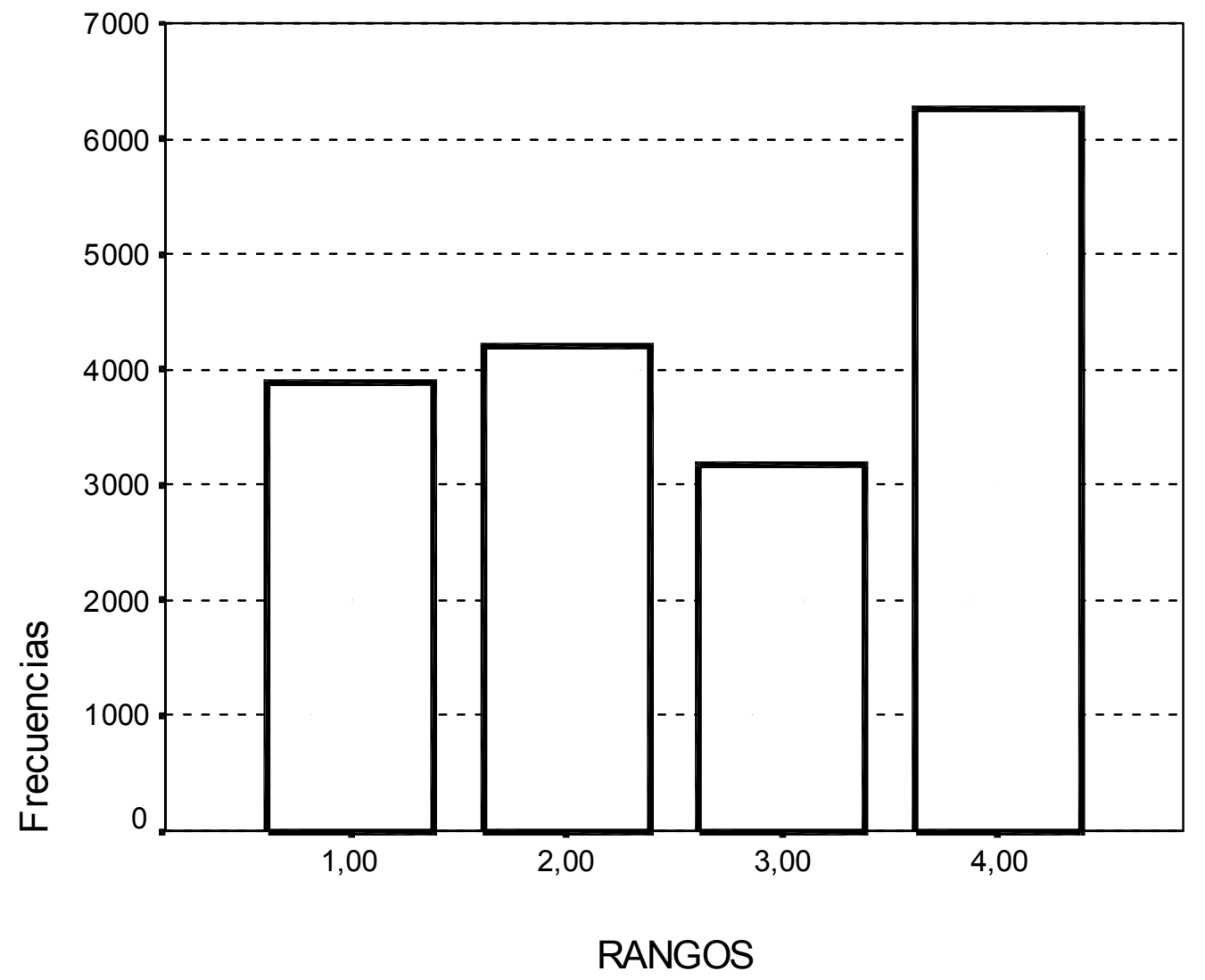

Tabla de frecuencias del viento por velocidades. Ayuntamiento 1998

\begin{tabular}{|rr|r|r|r|r|}
\hline & Frecuencia & Porcentaje & \multicolumn{1}{c|}{$\begin{array}{c}\text { Porcentaje } \\
\text { válido }\end{array}$} & $\begin{array}{r}\text { Porcentaje } \\
\text { acumulado }\end{array}$ \\
\hline Válidos & 1,00 & 3893 & 22,2 & 22,2 & 22,2 \\
& 2,00 & 4203 & 24,0 & 24,0 & 46,2 \\
& 3,00 & 3168 & 18,1 & 18,1 & 64,3 \\
& 4,00 & 6256 & 35,7 & 35,7 & 100,0 \\
& Total & 17520 & 100,0 & 100,0 & \\
\hline
\end{tabular}


Figura 5.30. Rosa de los vientos y tabla de frecuencias de las direcciones del viento. Estación meteorológica Ayuntamiento. Año 1999.

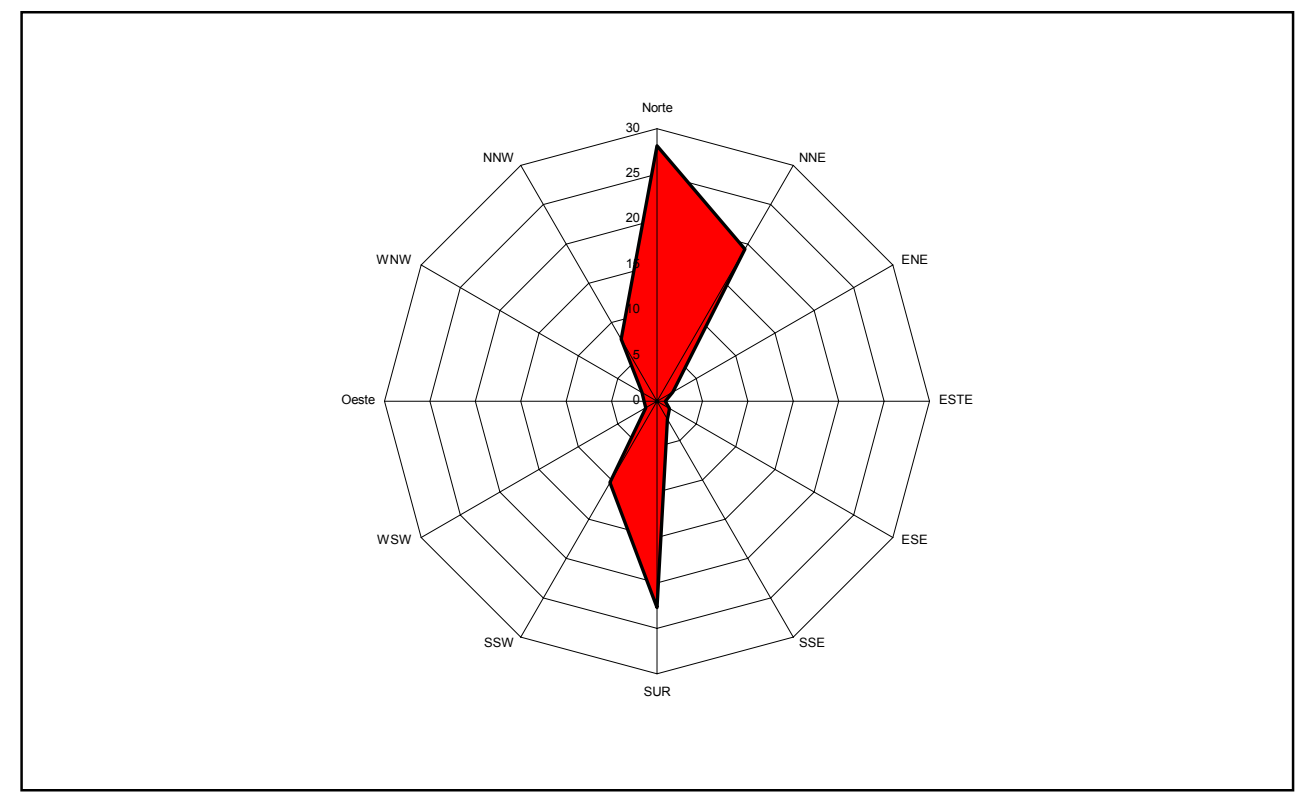

Frecuencias semihorarias del viento año 1999. Estación Ayuntamiento

\begin{tabular}{|ll|r|r|r|r|}
\hline & & Frecuencia & Porcentaje & $\begin{array}{c}\text { Porcentaje } \\
\text { válido }\end{array}$ & $\begin{array}{c}\text { Porcentaje } \\
\text { acumulado }\end{array}$ \\
\hline Válidos & 1,00 & 4931 & 28,1 & 28,2 & 28,2 \\
& 2,00 & 3390 & 19,3 & 19,4 & 47,6 \\
& 3,00 & 345 & 2,0 & 2,0 & 49,6 \\
& 4,00 & 153 &, 9 &, 9 & 50,5 \\
& 5,00 & 273 & 1,6 & 1,6 & 52,0 \\
& 6,00 & 407 & 2,3 & 2,3 & 54,3 \\
& 7,00 & 3980 & 22,7 & 22,8 & 77,1 \\
& 8,00 & 1797 & 10,3 & 10,3 & 87,4 \\
& 9,00 & 241 & 1,4 & 1,4 & 88,8 \\
& 10,00 & 248 & 1,4 & 1,4 & 90,2 \\
& 11,00 & 327 & 1,9 & 1,9 & 92,1 \\
& 12,00 & 1387 & 7,9 & 7,9 & 100,0 \\
Perdidos & Sistema & 4749 & 99,8 & 100,0 & \\
Total & 41 &, 2 & & \\
\hline
\end{tabular}


Figura 5.31. Frecuencias de los vientos por rangos de velocidad. Estación meteorológica Ayuntamiento. Año 1999 (Rango $1=0-4,9 \mathrm{~km} / \mathrm{h}$; rango $2=$ $5-10,9 \mathrm{~km} / \mathrm{h}$; rango $3=11-15,9$ y rango $4 \geq 16 \mathrm{~km} / \mathrm{h}$ ).

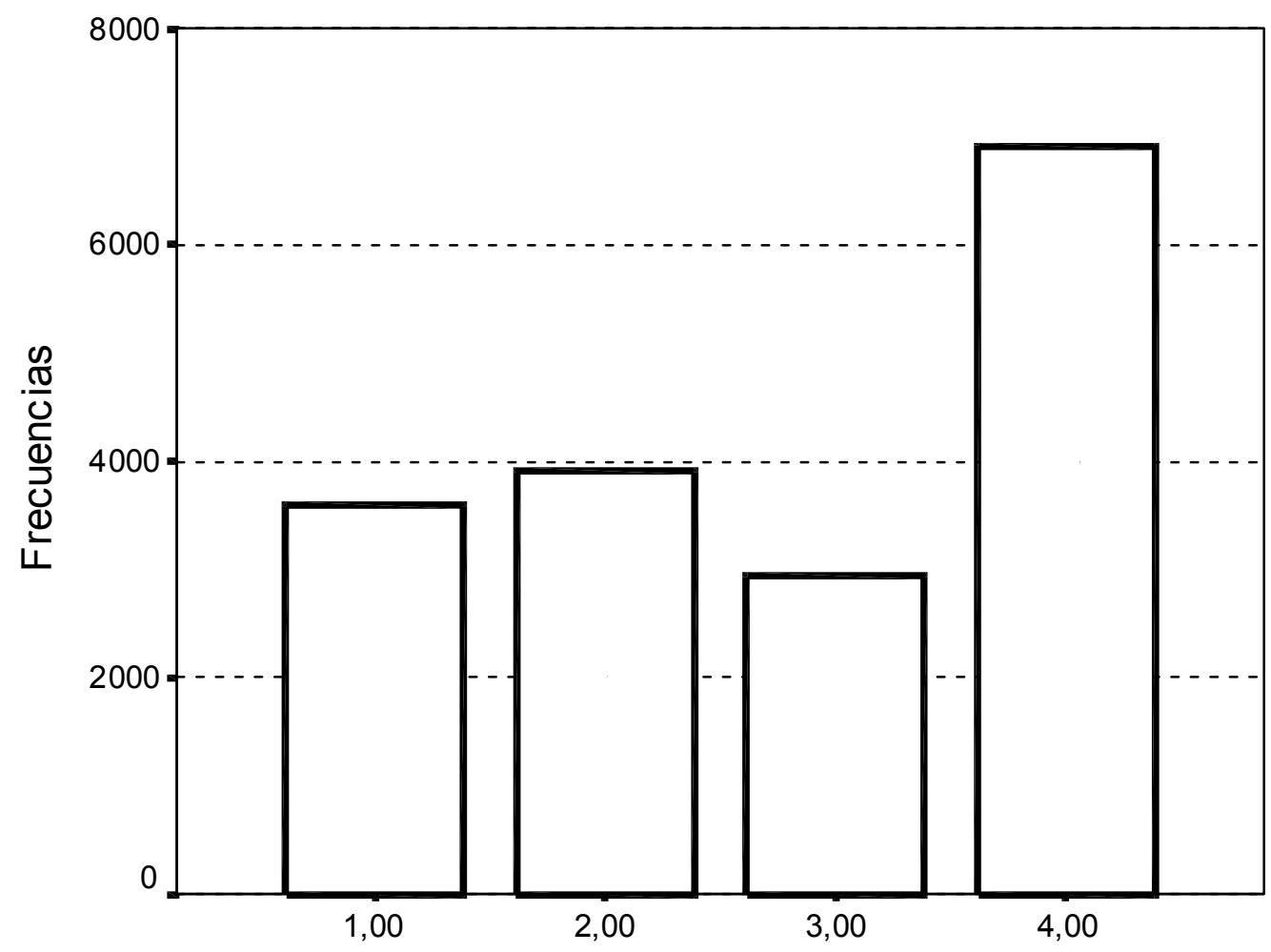

RANGOS

Tabla de frecuencias del viento por velocidades. Ayuntamiento 1999

\begin{tabular}{|ll|r|r|r|r|}
\hline & Frecuencia & Porcentaje & $\begin{array}{c}\text { Porcentaje } \\
\text { válido }\end{array}$ & $\begin{array}{r}\text { Porcentaje } \\
\text { acumulado }\end{array}$ \\
\hline Válidos & 1,00 & 3590 & 20,5 & 20,7 & 20,7 \\
& 2,00 & 3900 & 22,3 & 22,5 & 43,2 \\
& 3,00 & 2933 & 16,7 & 16,9 & 60,1 \\
& 4,00 & 6908 & 39,4 & 39,9 & 100,0 \\
& Total & 17331 & 98,9 & 100,0 & \\
Perdidos & Sistema & 189 & 1,1 & & \\
Total & & 17520 & 100,0 & & \\
\hline
\end{tabular}


Figura 5.32. Frecuencias de los vientos por direcciones. Estación meteorológica Ayuntamiento. Años 1995-1999.

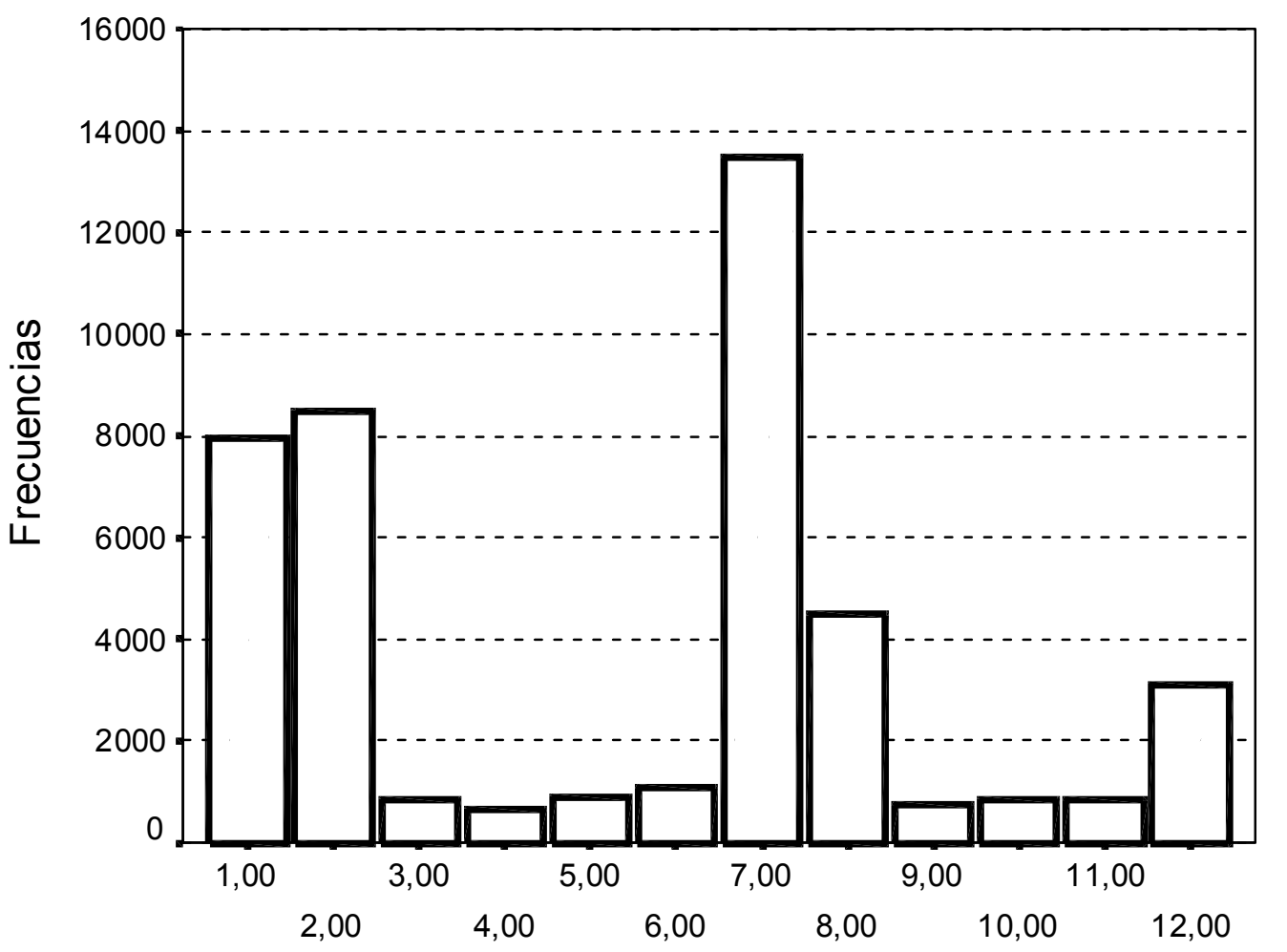

\section{RUMBOS}

\begin{tabular}{|c|c|c|c|c|c|}
\hline \multicolumn{6}{|c|}{ Direcciones del viento $1995-1999$} \\
\hline & & Frecuencia & Porcentaje & $\begin{array}{l}\text { Porcentaje } \\
\text { válido }\end{array}$ & $\begin{array}{l}\text { Porcentaje } \\
\text { acumulado }\end{array}$ \\
\hline \multirow[t]{13}{*}{ Válidos } & 1,00 & 7957 & 18,2 & 18,3 & 18,3 \\
\hline & 2,00 & 8491 & 19,4 & 19,6 & 37,9 \\
\hline & 3,00 & 851 & 1,9 & 2,0 & 39,8 \\
\hline & 4,00 & 649 & 1,5 & 1,5 & 41,3 \\
\hline & 5,00 & 909 & 2,1 & 2,1 & 43,4 \\
\hline & 6,00 & 1072 & 2,4 & 2,5 & 45,9 \\
\hline & 7,00 & 13475 & 30,7 & 31,0 & 76,9 \\
\hline & 8,00 & 4479 & 10,2 & 10,3 & 87,2 \\
\hline & 9,00 & 740 & 1,7 & 1,7 & 89,0 \\
\hline & 10,00 & 859 & 2,0 & 2,0 & 90,9 \\
\hline & 11,00 & 818 & 1,9 & 1,9 & 92,8 \\
\hline & 12,00 & 3119 & 7,1 & 7,2 & 100,0 \\
\hline & Total & 43419 & 99,1 & 100,0 & \\
\hline Perdidos & Sistema & 405 & ,9 & & \\
\hline Total & & 43824 & 100,0 & & \\
\hline
\end{tabular}


Figura 5.33. Frecuencias de los vientos por velocidades. Estación meteorológica Ayuntamiento. Años 1995-1999. Rangos determinados mediante análisis de frecuencias semihorarias diarias de la velocidad del viento (RANGOSMI).

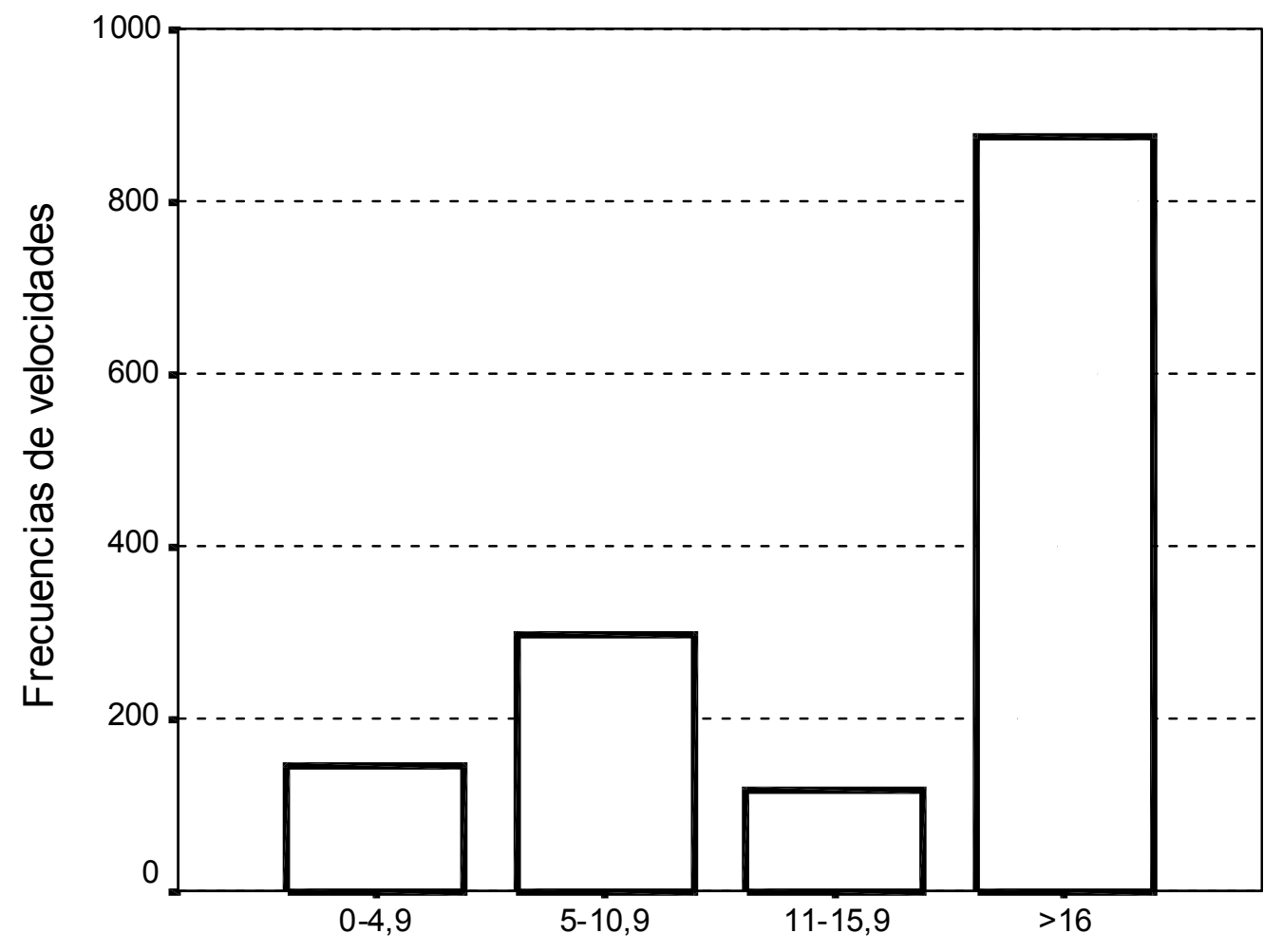

RANGOS

\begin{tabular}{|ll|r|r|r|r|}
\hline \multicolumn{7}{|c|}{ Velocidades del viento 1995-1999 } \\
\hline & & Frecuencia & Porcentaje & $\begin{array}{c}\text { Porcentaje } \\
\text { válido }\end{array}$ & $\begin{array}{r}\text { Porcentaje } \\
\text { acumulado }\end{array}$ \\
\hline Válidos & 1,00 & 145 & 7,9 & 10,1 & 10,1 \\
& 2,00 & 297 & 16,3 & 20,7 & 30,8 \\
& 3,00 & 117 & 6,4 & 8,2 & 39,0 \\
& 4,00 & 874 & 47,9 & 61,0 & 100,0 \\
Perdidos & Sistema & 393 & 78,5 & 100,0 & \\
Total & 1433 & 21,5 & & \\
\hline
\end{tabular}


Figura 5.34. Frecuencias de los vientos por velocidades. Estación meteorológica Ayuntamiento. Años 1995-1999. Rangos determinados mediante análisis de los valores de velocidad del viento medios diarios (RANGOS).

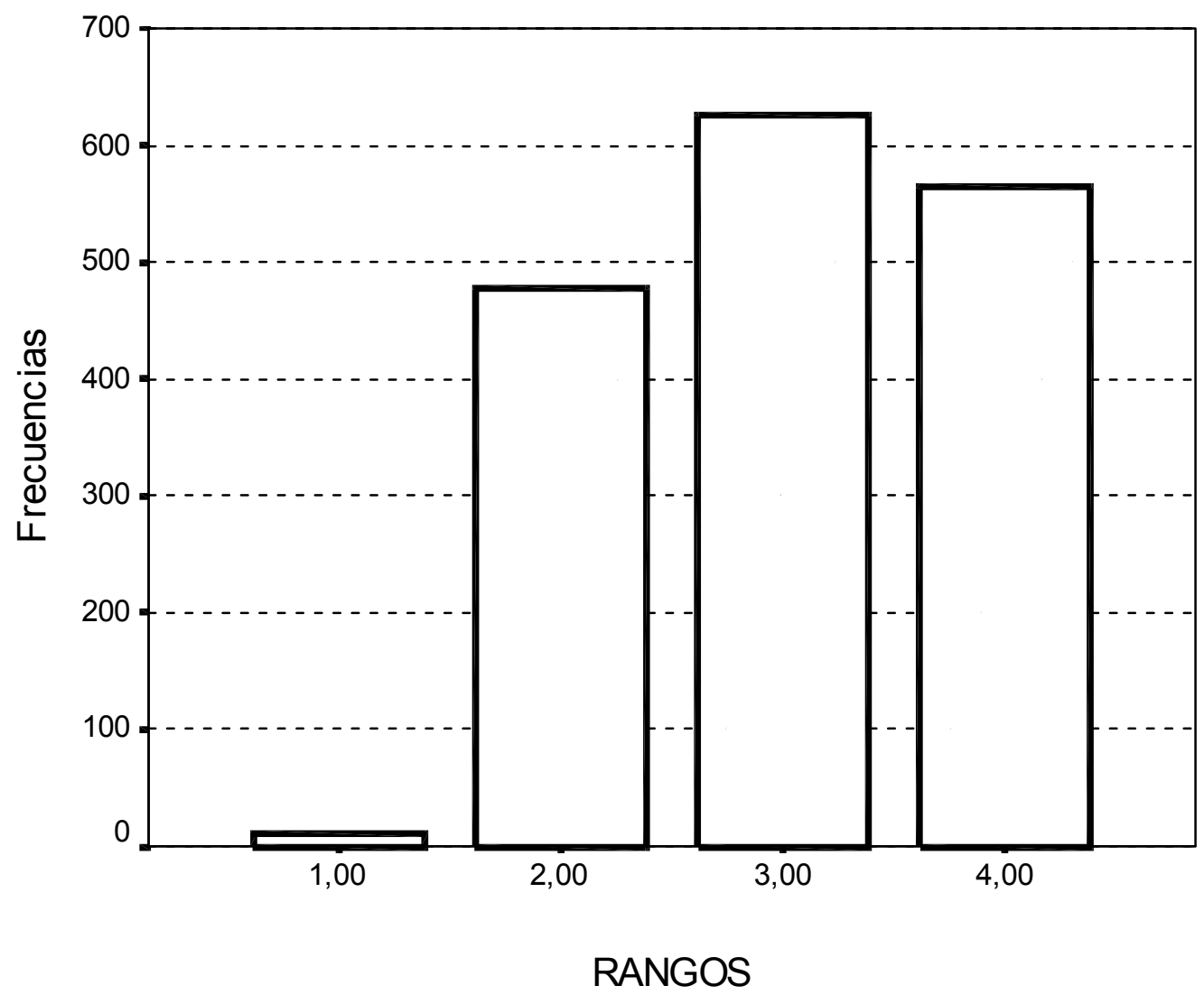

\begin{tabular}{|ll|r|r|r|r|}
\hline \multicolumn{7}{|c|}{ Velocidades del viento 1995-1999 } \\
\hline & & Frecuencia & Porcentaje & $\begin{array}{l}\text { Porcentaje } \\
\text { válido }\end{array}$ & $\begin{array}{c}\text { Porcentaje } \\
\text { acumulado }\end{array}$ \\
\hline Válidos & 1,00 & 11 &, 6 &, 7 &, 7 \\
& 2,00 & 477 & 26,1 & 28,4 & 29,1 \\
& 3,00 & 625 & 34,2 & 37,3 & 66,4 \\
& 4,00 & 564 & 30,9 & 33,6 & 100,0 \\
& Total & 1677 & 91,8 & 100,0 & \\
Perdidos & Sistema & 149 & 8,2 & & \\
Total & 1826 & 100,0 & & \\
\hline
\end{tabular}




\subsection{METEOROLOGÍA Y PÓLENES.}

\subsubsection{VARIABLES METEOROLÓGICAS Y CONCENTRACIONES POLÍNICAS TOTALES.}

En la tabla 5.15. se presentan los resultados del estudio de correlación de las distintas variables meteorológicas y las concentraciones polínicas totales diarias estandarizadas.

Tabla 5.15. Coeficientes de correlación lineal de pearson para la concentración polínica total diaria estandarizada y los distintos parámetros meteorológicos por años y para el periodo 1993-1999.

\begin{tabular}{|l|l|c|c|c|c|c|c|c|c|}
\hline & & $\mathbf{1 9 9 3}$ & $\mathbf{1 9 9 4}$ & $\mathbf{1 9 9 5}$ & $\mathbf{1 9 9 6}$ & $\mathbf{1 9 9 7}$ & $\mathbf{1 9 9 8}$ & $\mathbf{1 9 9 9}$ & $\mathbf{9 3 - 9 9}$ \\
\hline PRBMEDIA & C. Pearson & $\mathbf{- 0 . 1 7 * *}$ & $\mathbf{- 0 . 1 2 *}$ & $\mathbf{- 0 . 2 1 * *}$ & 0.003 & 0.03 & 0.03 & -0.11 & $\mathbf{- 0 . 0 7 * *}$ \\
& Sig. (bilateral) & 0.004 & 0.040 & 0.000 & 0.950 & 0.550 & 0.530 & 0.040 & 0.001 \\
& N & 282 & 295 & 330 & 338 & 349 & 337 & 350 & 2149 \\
\hline TMPMEDIA & C. Pearson & 0.01 & -0.10 & -0.08 & 0.08 & -0.02 & -0.04 & -0.06 & -0.04 \\
& Sig. (bilateral) & 0.870 & 0.060 & 0.150 & 0.120 & 0.770 & 0.500 & 0.280 & 0.080 \\
& N & 282 & 320 & 330 & 338 & 349 & 337 & 350 & 2174 \\
\hline HRMEDIA & C. Pearson & -0.03 & $\mathbf{- 0 . 1 7 * *}$ & $\mathbf{- 0 . 2 8 * *}$ & $\mathbf{- 0 . 1 1 *}$ & $\mathbf{- 0 . 1 6 * *}$ & $\mathbf{- 0 . 3 3 * *}$ & $\mathbf{- 0 . 2 4 * * *}$ & $\mathbf{- 0 . 1 7 * *}$ \\
& Sig. (bilateral) & 0.620 & 0.003 & 0.000 & 0.030 & 0.002 & 0.000 & 0.000 & 0.000 \\
& N & 282 & 320 & 330 & 338 & 349 & 337 & 350 & 2174 \\
\hline WMEDIA & C. Pearson & -0.035 & $\mathbf{0 . 2 4 * *}$ & $\mathbf{0 . 1 9 * *}$ & 0.05 & 0.09 & $\mathbf{0 . 2 3} * *$ & 0.09 & $\mathbf{0 . 1 3} * *$ \\
& Sig. (bilateral) & 0.560 & 0.000 & 0.001 & 0.370 & 0.070 & 0.000 & 0.082 & $\mathbf{0 . 0 0 0}$ \\
& N & 282 & 320 & 330 & 338 & 349 & 337 & 350 & $\mathbf{2 1 7 4}$ \\
\hline
\end{tabular}


Tabla 5.15. Continuación. Coeficientes de correlación lineal de Pearson para la concentración polínica total diaria estandarizada y los distintos parámetros meteorológicos por años y para el periodo 93-99.

\begin{tabular}{|l|l|c|c|c|c|c|c|c|c|}
\hline & & $\mathbf{1 9 9 3}$ & $\mathbf{1 9 9 4}$ & $\mathbf{1 9 9 5}$ & $\mathbf{1 9 9 6}$ & $\mathbf{1 9 9 7}$ & $\mathbf{1 9 9 8}$ & $\mathbf{1 9 9 9}$ & $\mathbf{9 3 - 9 9}$ \\
\hline RSACUM. & C. Pearson & $\mathbf{0 . 3 7 * *}$ & $\mathbf{0 . 2 3} * *$ & $\mathbf{0 . 3 5 * *}$ & $\mathbf{0 . 3 4} * *$ & $\mathbf{0 . 2 8} * *$ & $\mathbf{0 . 1 5}$ & $\mathbf{0} * \mathbf{0 . 1 7 * *}$ & $\mathbf{0 . 3 6 * *}$ \\
& Sig. (bilateral) & 0.000 & 0.000 & 0.000 & 0.000 & 0.000 & 0.005 & 0.002 & 0.000 \\
& N & 282 & 309 & 330 & 338 & 349 & 337 & 350 & 2163 \\
\hline LLUVIADIA & C. Pearson & -0.01 & -0.07 & -0.02 & -0.001 & -0.04 & -0.02 & -0.04 & -0.03 \\
& Sig. (bilateral) & 0.870 & 0.220 & 0.710 & 0.970 & 0.410 & 0.730 & 0.460 & 0.220 \\
& N & 285 & 320 & 330 & 338 & 349 & 337 & 350 & 2177 \\
\hline
\end{tabular}

\subsubsection{PRESIÓN Y CONCENTRACIÓN POLÍNICA TOTAL DIARIA ESTANDARIZADA.}

En las figuras 5.35. y 5.36. se muestra la media e intervalo de confianza al 95\% de la concentración polínica total estandarizada en función de las presiones atmosféricas registradas, considerando distintos rangos en cada caso. En el primer caso, figura 5.35. se han considerado dos rangos, bajas y altas presiones. En la figura 5.36., se han considerado tres rangos de presiones. También se presentan para ambos casos, las tablas resumen de los estadísticos del análisis de la varianza de las concentraciones polínicas totales estandarizadas por rangos de presión. 
Figura 5.35. Análisis de la varianza de la concentración polínica total estandarizada por rangos de presión (Bajas cuando la presión atmosférica es $\leq 1013 \mathrm{mb}$ y altas presiones cuando es $>1013 \mathrm{mb}$ ).

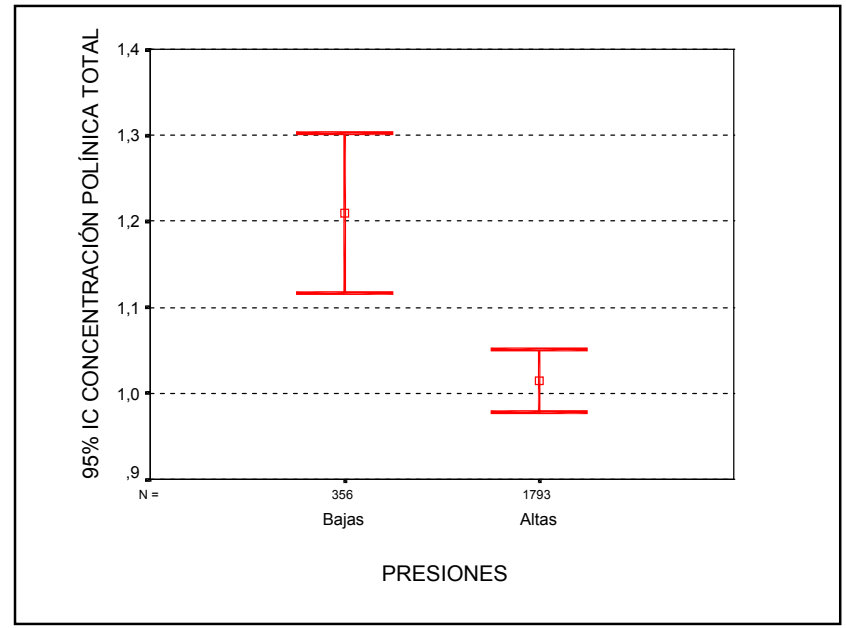

\begin{tabular}{|c|c|c|c|c|c|c|c|}
\hline & & \multicolumn{6}{|c|}{ ANÁLISIS DE LA VARIANZA DE POLENST POR RANGOS DE PRESIÓN } \\
\hline \multicolumn{8}{|c|}{ POLENST } \\
\hline & \multirow[b]{2}{*}{$\mathrm{N}$} & \multirow[b]{2}{*}{ Media } & \multirow[b]{2}{*}{$\begin{array}{l}\text { Desviación } \\
\text { típica }\end{array}$} & \multirow[b]{2}{*}{ Error típico } & \multicolumn{2}{|c|}{$\begin{array}{c}\text { Intervalo de confianza para } \\
\text { la media al } 95 \% \\
\end{array}$} & \multirow[b]{2}{*}{ Mínim } \\
\hline & & & & & Límite inferior & $\begin{array}{l}\text { Límite } \\
\text { superior }\end{array}$ & \\
\hline 1,00 & 356 & 1,2094 & ,8875 & $4,704 \mathrm{E}-02$ & 1,1169 & 1,3019 & \\
\hline 2,00 & 1793 & 1,0142 & ,7921 & 1,871E-02 & ,9775 & 1,0509 & \\
\hline Total & 2149 & 1,0465 & ,8117 & 1,751E-02 & 1,0122 & 1,0809 & \\
\hline \multicolumn{8}{|c|}{ ANOVA } \\
\hline \multicolumn{8}{|c|}{ POLENST } \\
\hline & & $\begin{array}{l}\text { Suma de } \\
\text { cuadrados }\end{array}$ & $\mathrm{gl}$ & $\begin{array}{c}\text { Media } \\
\text { cuadrática }\end{array}$ & $\mathrm{F}$ & Sig. & \\
\hline Inter- & pos & 11,319 & $\overline{1}$ & 11,319 & 17,310 &, 000 & \\
\hline Intra- & pos & 1403,976 & 2147 & ,654 & & & \\
\hline Total & & 1415,295 & 2148 & & & & \\
\hline
\end{tabular}


Figura 5.36. Análisis de la varianza de la concentración polínica total estandarizada por rangos de presión (1 cuando la presión atmosférica es $\leq$ $1005 \mathrm{mb} ; 2$ entre 1005 y $1015 \mathrm{mb}$ y 3 cuando es $\geq 1015 \mathrm{mb}$ ).
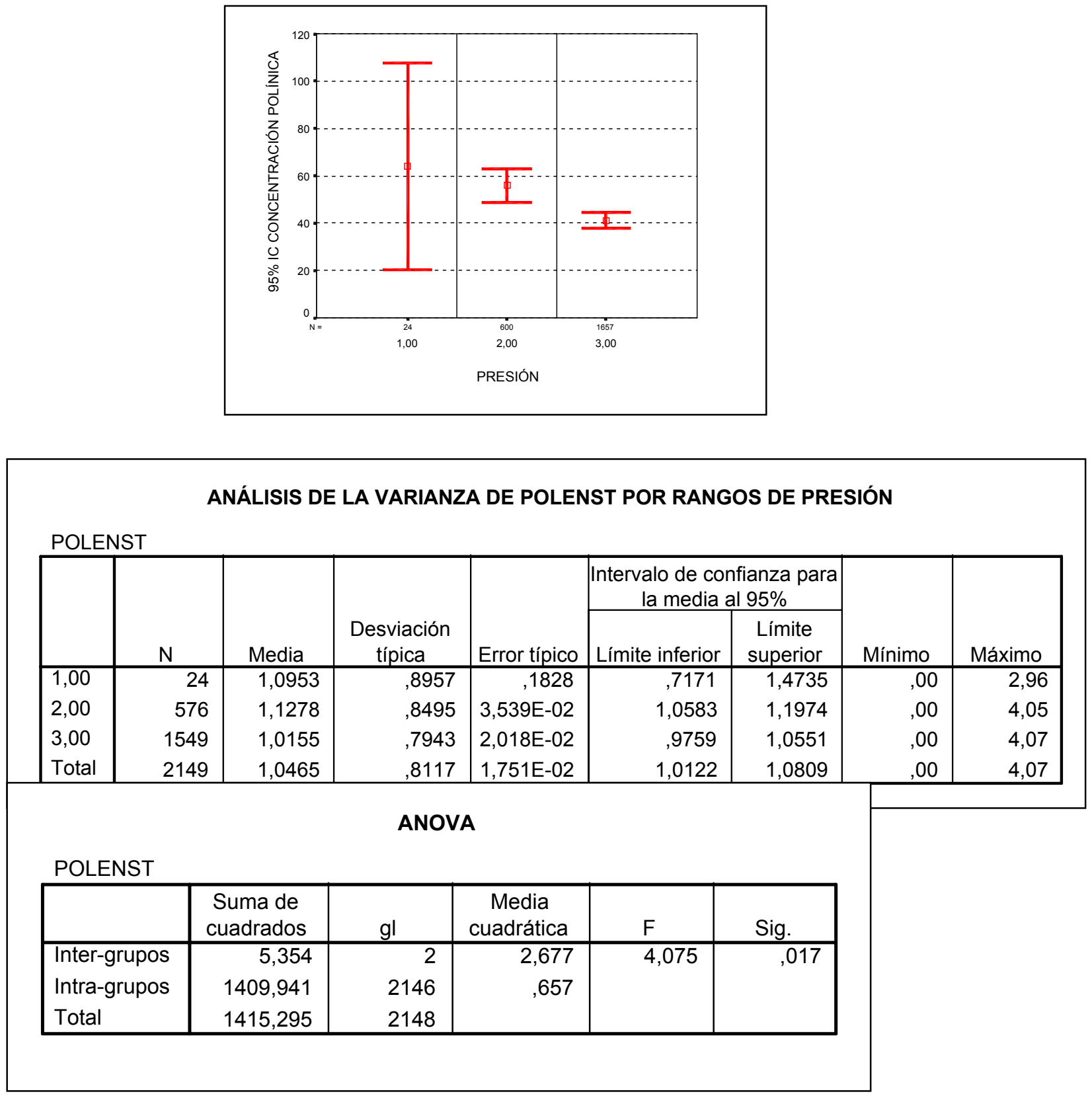


\subsubsection{VELOCIDAD DEL VIENTO Y CONCENTRACIÓN POLÍNICA TOTAL DIARIA ESTANDARIZADA.}

En este apartado se presentan los resultados del análisis de la varianza de la concentración polínica total para distintas velocidades del viento. Para ello, tal y como se ha explicado en el capítulo de materiales y métodos, los rangos se han calculado a partir de la velocidad media diaria del viento, mientras que la variable rangosmi se ha construido a partir del análisis de las frecuencias semihorarias de las velocidades del viento.

En primer lugar, en la figura 5.37. se muestran los resultados obtenidos para el periodo 1993-1999, considerando la variable RANGOS. En la figura 5.38., los resultados para el periodo 1995-1999 y también para la variable RANGOS. Finalmente, en la figura 5.20. se muestran los resultados para el periodo 19951999, pero en este caso considerando la variable RANGOSMI. 
Figura 5.37. Media e intervalo de confianza de la concentración polínica total estandarizada por rangos de velocidad del viento y ANOVA por rangos de velocidad para el periodo 1993-1999 (Rango $1=0-4,9 \mathrm{~km} / \mathrm{h}$; rango $2=5$ $10,9 \mathrm{~km} / \mathrm{h}$; rango $3=11-15,9$ y rango $4 \geq 16 \mathrm{~km} / \mathrm{h}$ ).

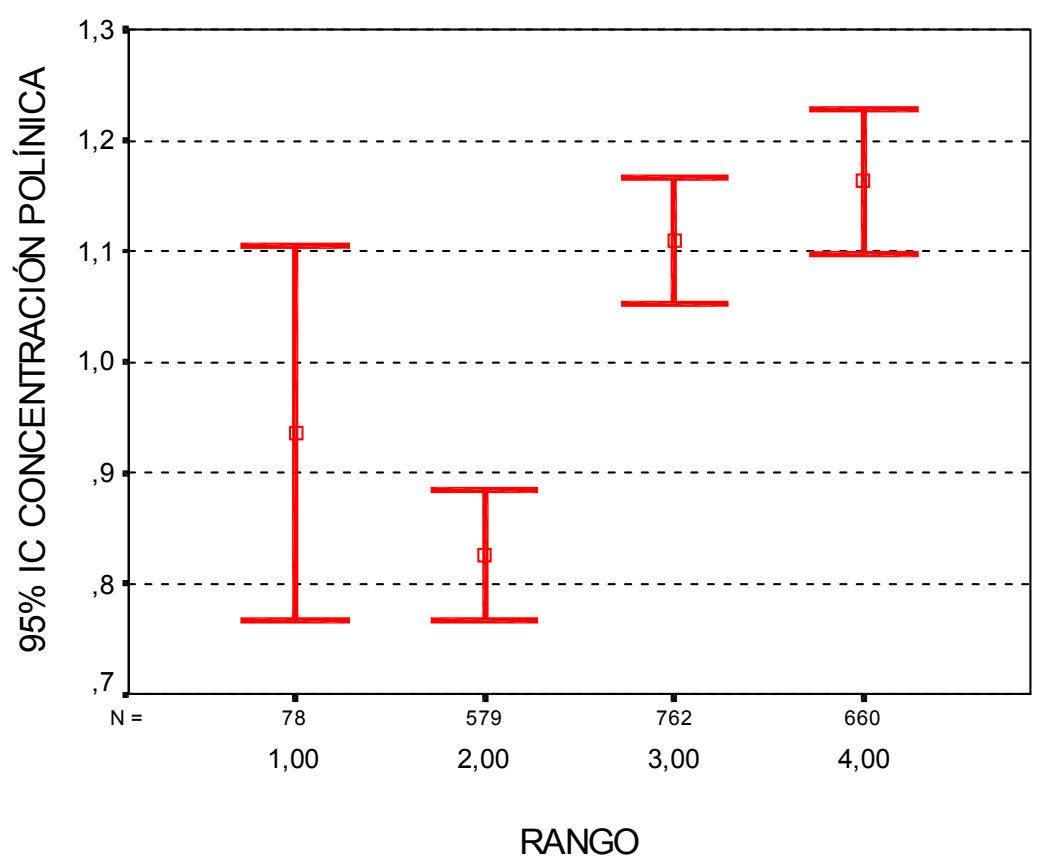

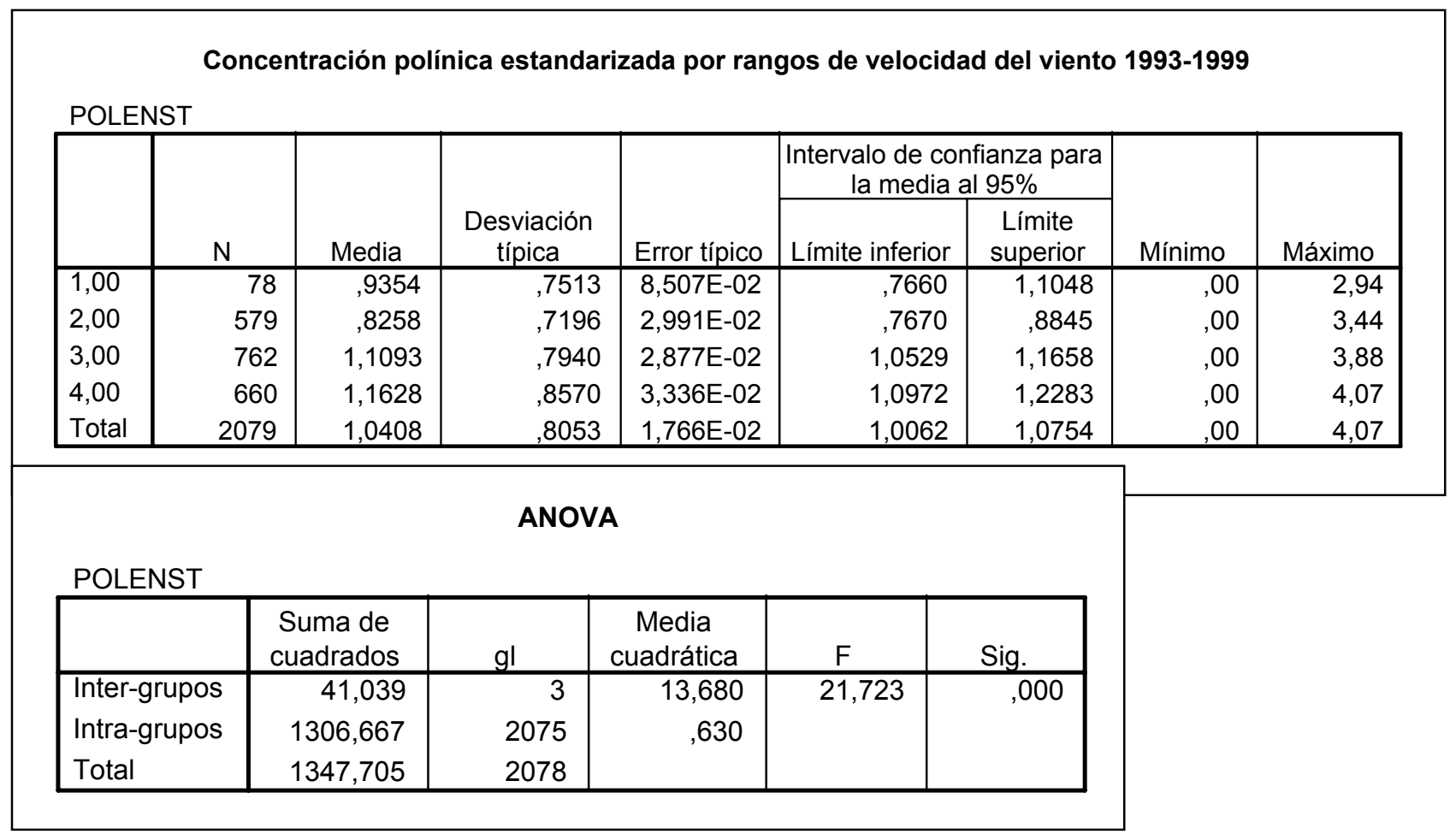


Figura 5.38. Media e intervalo de confianza de la concentración polínica total estandarizada por rangos de velocidad del viento y ANOVA por rangos de velocidad para el periodo 1995-1999, considerando la variable RANGOS (Rango $1=0-4,9 \mathrm{~km} / \mathrm{h}$; rango $2=5-10,9 \mathrm{~km} / \mathrm{h}$; rango $3=11-15,9 \mathrm{y}$ rango $4 \geq 16 \mathrm{~km} / \mathrm{h})$.

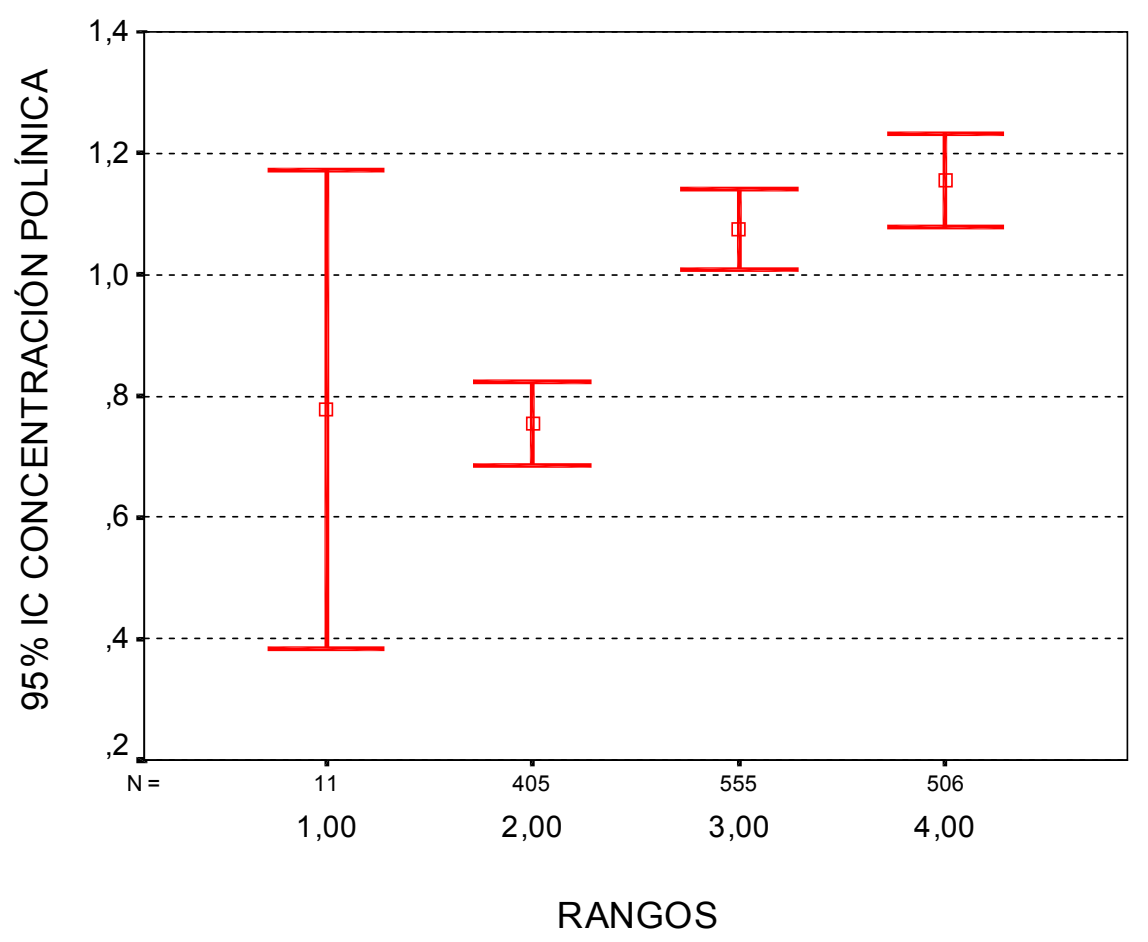

concentración polínica total estandarizada 1995-1999

POLENST

\begin{tabular}{|c|c|c|c|c|c|c|c|c|}
\hline & \multirow[b]{2}{*}{$\mathrm{N}$} & \multirow[b]{2}{*}{ Media } & \multirow[b]{2}{*}{$\begin{array}{l}\text { Desviación } \\
\text { típica }\end{array}$} & \multirow[b]{2}{*}{ Error típico } & \multicolumn{2}{|c|}{$\begin{array}{c}\text { ntervalo de confianza para } \\
\text { la media al } 95 \%\end{array}$} & \multirow[b]{2}{*}{ Mínimo } & \multirow[b]{2}{*}{ Máximo } \\
\hline & & & & & Límite inferior & $\begin{array}{l}\text { Límite } \\
\text { superior }\end{array}$ & & \\
\hline 1,00 & 11 & ,7786 & ,5877 & ,1772 & ,3838 & 1,1734 & ,00 & 1,49 \\
\hline 2,00 & 405 & ,7542 & 6961 & 3,459E-02 & ,6862 & ,8222 & ,00 & 2,91 \\
\hline 3,00 & 555 & 1,0744 & ,7930 & 3,366E-02 & 1,0083 & 1,1405 & ,00 & 3,88 \\
\hline 4,00 & 506 & 1,1553 & ,8854 & 3,936E-02 & 1,0779 & 1,2326 & ,00 & 4,07 \\
\hline Total & 1477 & 1,0121 & ,8163 & $2,124 \mathrm{E}-02$ & 9704 & 1,0538 & ,00 & 4,07 \\
\hline
\end{tabular}

ANOVA

POLENST

\begin{tabular}{|l|r|r|r|r|r|}
\hline & \multicolumn{1}{|c|}{$\begin{array}{c}\text { Suma de } \\
\text { cuadrados }\end{array}$} & gl & \multicolumn{1}{|c|}{$\begin{array}{c}\text { Media } \\
\text { cuadrática }\end{array}$} & \multicolumn{1}{c|}{ F } & \multicolumn{1}{c|}{ Sig. } \\
\hline Inter-grupos & 40,072 & 3 & 13,357 & 20,853 &, 000 \\
Intra-grupos & 943,531 & 1473 &, 641 & & \\
Total & 983,603 & 1476 & & & \\
\hline
\end{tabular}


Figura 5.39. Media e intervalo de confianza de la concentración polínica total estandarizada por rangos de velocidad del viento y ANOVA por rangos de velocidad para el periodo 1995-1999, considerando la variable RANGOSMI (Rango $1=0-4,9 \mathrm{~km} / \mathrm{h}$; rango $2=5-10,9 \mathrm{~km} / \mathrm{h}$; rango $3=$ $11-15,9$ y rango $4 \geq 16 \mathrm{~km} / \mathrm{h})$.

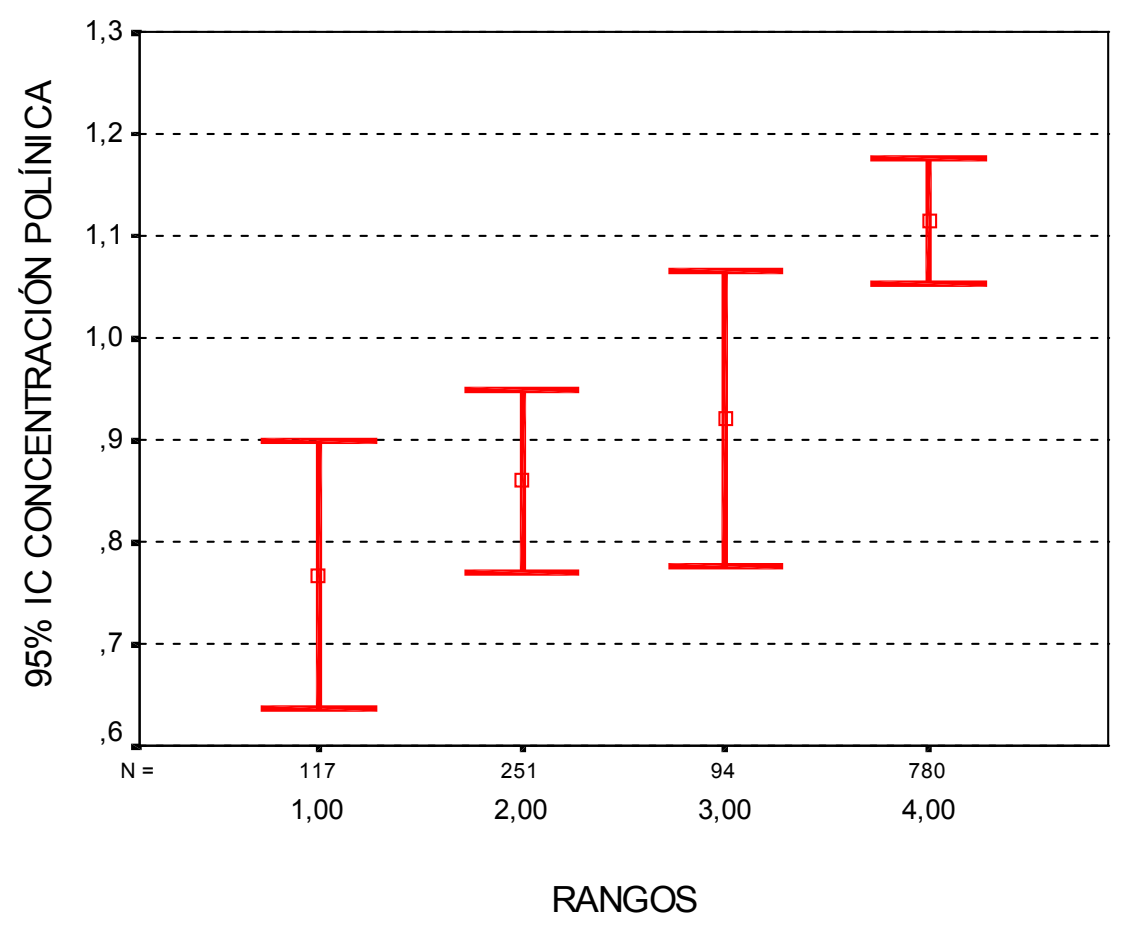

Concentración polínica estandarizada por rangos de velocidad del viento 1996-1999 POLENST

\begin{tabular}{|c|c|c|c|c|c|c|c|c|}
\hline & \multirow[b]{2}{*}{$\mathrm{N}$} & \multirow[b]{2}{*}{ Media } & \multirow[b]{2}{*}{$\begin{array}{l}\text { Desv. } \\
\text { típica }\end{array}$} & \multirow[b]{2}{*}{$\begin{array}{l}\text { Error } \\
\text { típico }\end{array}$} & \multicolumn{2}{|c|}{$\begin{array}{c}\text { Intervalo de } \\
\text { confianza para la } \\
\text { media al } 95 \%\end{array}$} & \multirow[b]{2}{*}{ Mínimo } & \multirow[b]{2}{*}{ Máximo } \\
\hline & & & & & $\begin{array}{l}\text { Límite } \\
\text { inferior }\end{array}$ & $\begin{array}{c}\text { Límite } \\
\text { superior }\end{array}$ & & \\
\hline 1,00 & 117 & ,7673 & ,7165 & 6,6E-02 & ,6361 & 8985 & ,00 & 3,88 \\
\hline 2,00 & 251 & ,8596 & ,7184 & 4,5E-02 & ,7703 & ,9490 & ,00 & 2,98 \\
\hline 3,00 & 94 & ,9206 & ,7064 & 7,3E-02 & ,7759 & 1,0653 & ,00 & 3,29 \\
\hline 4,00 & 780 & 1,1142 & ,8660 & 3,1E-02 & 1,0534 & 1,1751 & ,00 & 4,0 \\
\hline Total & 1242 & 1,0154 & ,8232 & 2,3E-02 &, 9696 & 1,0613 & ,00 & $4,0 i$ \\
\hline
\end{tabular}

ANOVA

POLENST

\begin{tabular}{|l|r|r|r|r|r|}
\hline & $\begin{array}{c}\text { Suma de } \\
\text { cuadrados }\end{array}$ & gl & \multicolumn{1}{c|}{$\begin{array}{c}\text { Media } \\
\text { cuadrática }\end{array}$} & \multicolumn{1}{c|}{ F } & Sig. \\
\hline Inter-grupos & 21,755 & 3 & 7,252 & 10,959 &, 000 \\
Intra-grupos & 819,217 & 1238 &, 662 & & \\
Total & 840,972 & 1241 & & \\
\hline
\end{tabular}




\subsubsection{DIRECCIÓN DEL VIENTO Y CONCENTRACIÓN POLÍNICA TOTAL DIARIA ESTANDARIZADA.}

En la figura 5.40. se presentan los resultados del ANOVA de la concentración polínica total diaria estandarizada para el periodo 1993-1999, considerando como dirección del viento la variable RUMBOS, obtenida a partir del análisis de las frecuencias del viento semihorarias para cada día.

En la figura 5.41., se muestra la media e intervalo de confianza al 95\% de la concentración polínica total estandarizada por cuadrantes y la tabla del ANOVA, también por cuadrantes, para los años 1993 a 1999. 
Figura 5.40. Media e intervalo de confianza al 95\% de la concentración polínica total estandarizada por rumbos del viento y ANOVA por rumbos para el periodo 1995-1999. Rosa de concentraciones por RUMBOS.

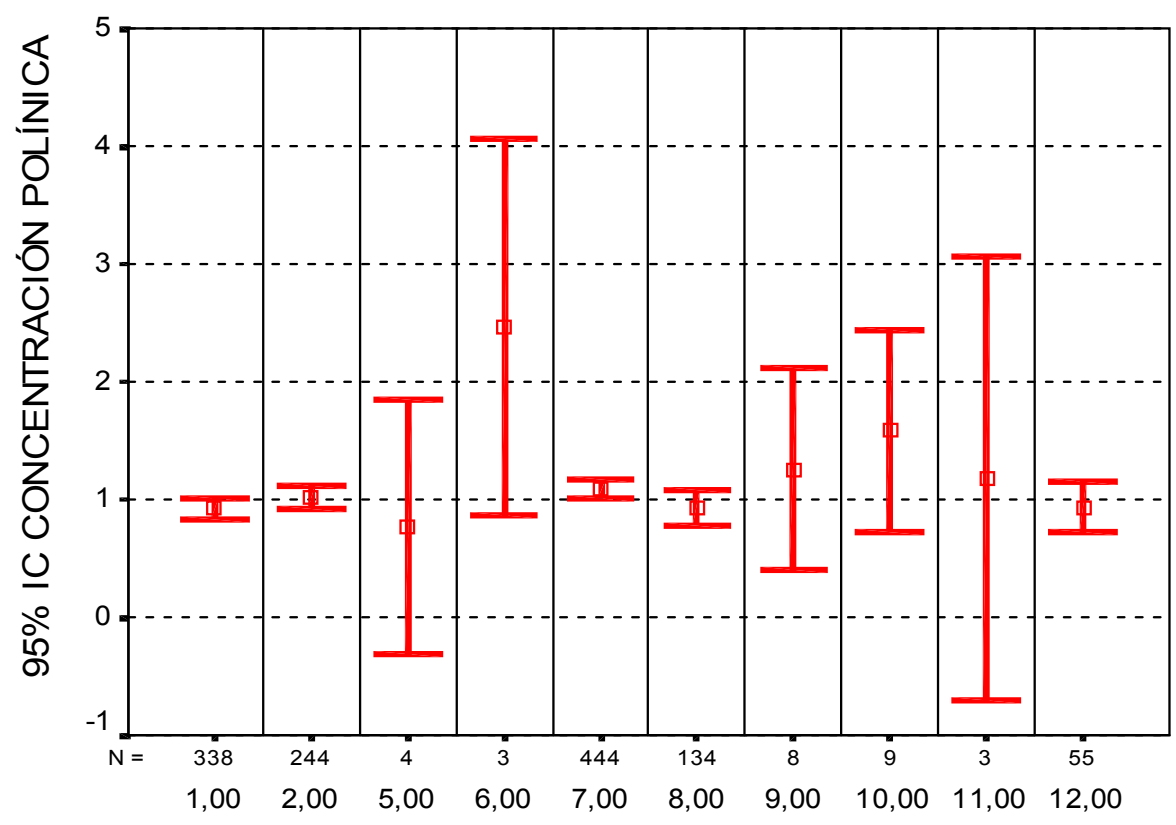

RUMBOS

\begin{tabular}{|l|l|l|r|r|r|r|r|}
\hline \multicolumn{2}{|c|}{ Concentración polínica estandarizada por rumbos del viento } \\
\hline
\end{tabular}


Figura 5.40. Continuación. Media e intervalo de confianza al $95 \%$ de la concentración polínica total estandarizada por rumbos del viento y ANOVA por rumbos para el periodo 1995-1999. Rosa de concentraciones por RUMBOS.

\begin{tabular}{|c|c|c|c|c|c|}
\hline \multicolumn{6}{|c|}{ ANOVA } \\
\hline & $\begin{array}{c}\text { Suma de } \\
\text { cuadrados }\end{array}$ & gl & $\begin{array}{c}\text { Media } \\
\text { cuadrática }\end{array}$ & $\mathrm{F}$ & Sig. \\
\hline Inter-grupos & 16,612 & 9 & 1,846 & 2,758 & ,003 \\
\hline Intra-grupos & 824,361 & 1232 & ,669 & & \\
\hline Total & 840,972 & 1241 & & & \\
\hline
\end{tabular}

Rosa de concentraciones polínicas totales estandarizadas por RUMBOS, para el periodo 1995-1999

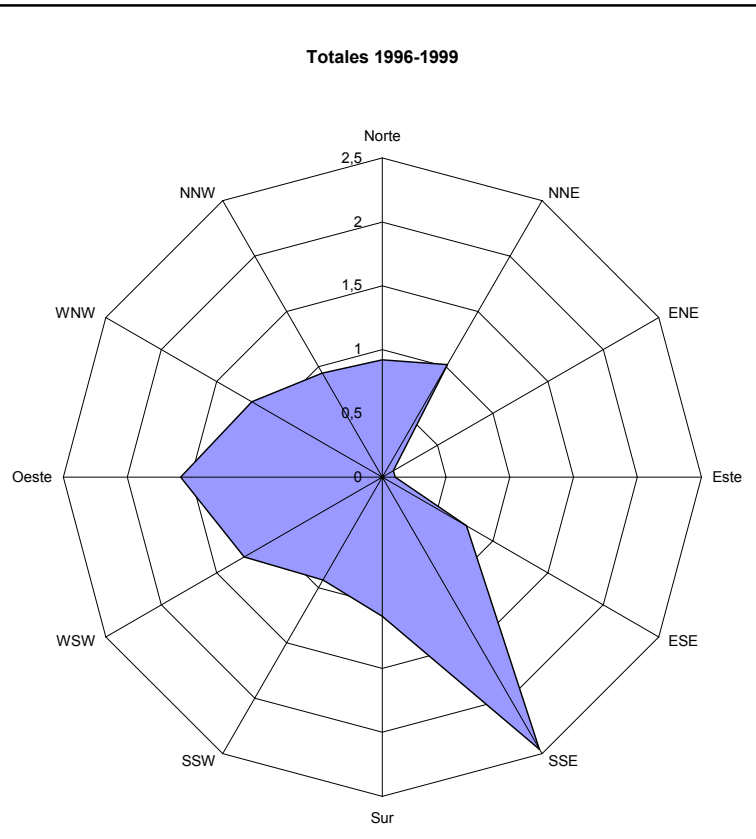

Figura 5.41. Media e intervalo de contianza al $95 \%$ de la concentración polinica

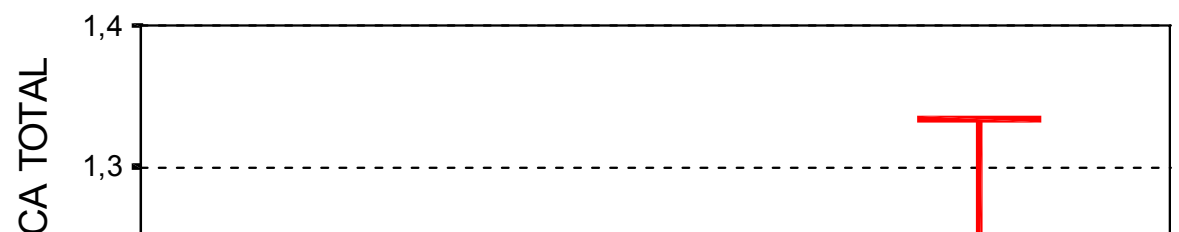


total estandarizada por cuadrantes de $90^{\circ}$ y ANOVA por cuadrantes para el periodo 1993-1999 ( $\left.\mathrm{N}=346-45^{\circ} ; \mathrm{E}=46-135 ; \mathrm{S}=136-230 ; \mathrm{E}=231-345\right)$.

\section{Concentración polínica total estandarizada por cuadrantes}

POLENST

\begin{tabular}{|c|c|c|c|c|c|c|c|c|}
\hline & \multirow[b]{2}{*}{$\mathrm{N}$} & \multirow[b]{2}{*}{ Media } & \multirow[b]{2}{*}{$\begin{array}{l}\text { Desviación } \\
\text { típica }\end{array}$} & \multirow[b]{2}{*}{ Error típico } & \multicolumn{2}{|c|}{$\begin{array}{c}\text { Intervalo de confianza para } \\
\text { la media al } 95 \%\end{array}$} & \multirow[b]{2}{*}{ Mínimo } & \multirow[b]{2}{*}{ Máximo } \\
\hline & & & & & Límite inferior & $\begin{array}{l}\text { Límite } \\
\text { superior }\end{array}$ & & \\
\hline $\bar{N}$ & 279 & 1,0408 & ,7297 & $4,368 \mathrm{E}-02$ & ,9549 & 1,1268 &, 00 & 3,13 \\
\hline$E$ & 415 & ,9888 & ,7691 & $3,775 \mathrm{E}-02$ & ,9146 & 1,0630 & ,00 & 3,65 \\
\hline$S$ & 1288 & 1,0385 & ,8037 & $2,240 \mathrm{E}-02$ & ,9945 & 1,0824 & , 00 & 3,88 \\
\hline W & 191 & 1,1900 & 1,0019 & $7,249 E-02$ & 1,0470 & 1,3330 & ,00 & 4,07 \\
\hline Total & 2173 & 1,0426 & 8087 & 1,735E-02 & 1,0086 & 1,0766 &, 00 & 4,07 \\
\hline
\end{tabular}

\section{ANOVA}

POLENST

\begin{tabular}{|l|r|r|r|r|r|}
\hline & \multicolumn{1}{|c|}{$\begin{array}{c}\text { Suma de } \\
\text { cuadrados }\end{array}$} & gl & $\begin{array}{c}\text { Media } \\
\text { cuadrática }\end{array}$ & \multicolumn{1}{l|}{ F } & \multicolumn{1}{c|}{ Sig. } \\
\hline Inter-grupos & 5,376 & 3 & 1,792 & 2,747 &, 042 \\
Intra-grupos & 1414,984 & 2169 &, 652 & & \\
Total & 1420,360 & 2172 & & & \\
\hline
\end{tabular}




\subsubsection{PRECIPITACIONES Y CONCENTRACIÓN POLÍNICA TOTAL DIARIA ESTANDARIZADA.}

En las figuras 5.42. y 5.43. se muestran los resultados del análisis de la varianza para la concentración polínica total estandarizada considerando dos grupos de lluvias (llueve y no llueve) y considerando cuatro grupos.

Por otro lado, se ha efectuado la correlación lineal entre las concentraciones polínicas acumuladas durante cada unos de los años estudiados (30 primeras semanas de cada año) y la lluvia total caída el año anterior, obteniéndose un coeficiente de correlación de 0,577 y una significación bilateral de 0,175 .

Figura 5.42. Media e intervalo de confianza al 95\% de la concentración polínica total estandarizada en presencia o ausencia de precipitación y ANOVA por las dos categorías (llueve y no llueve) para el periodo 1993-1999.

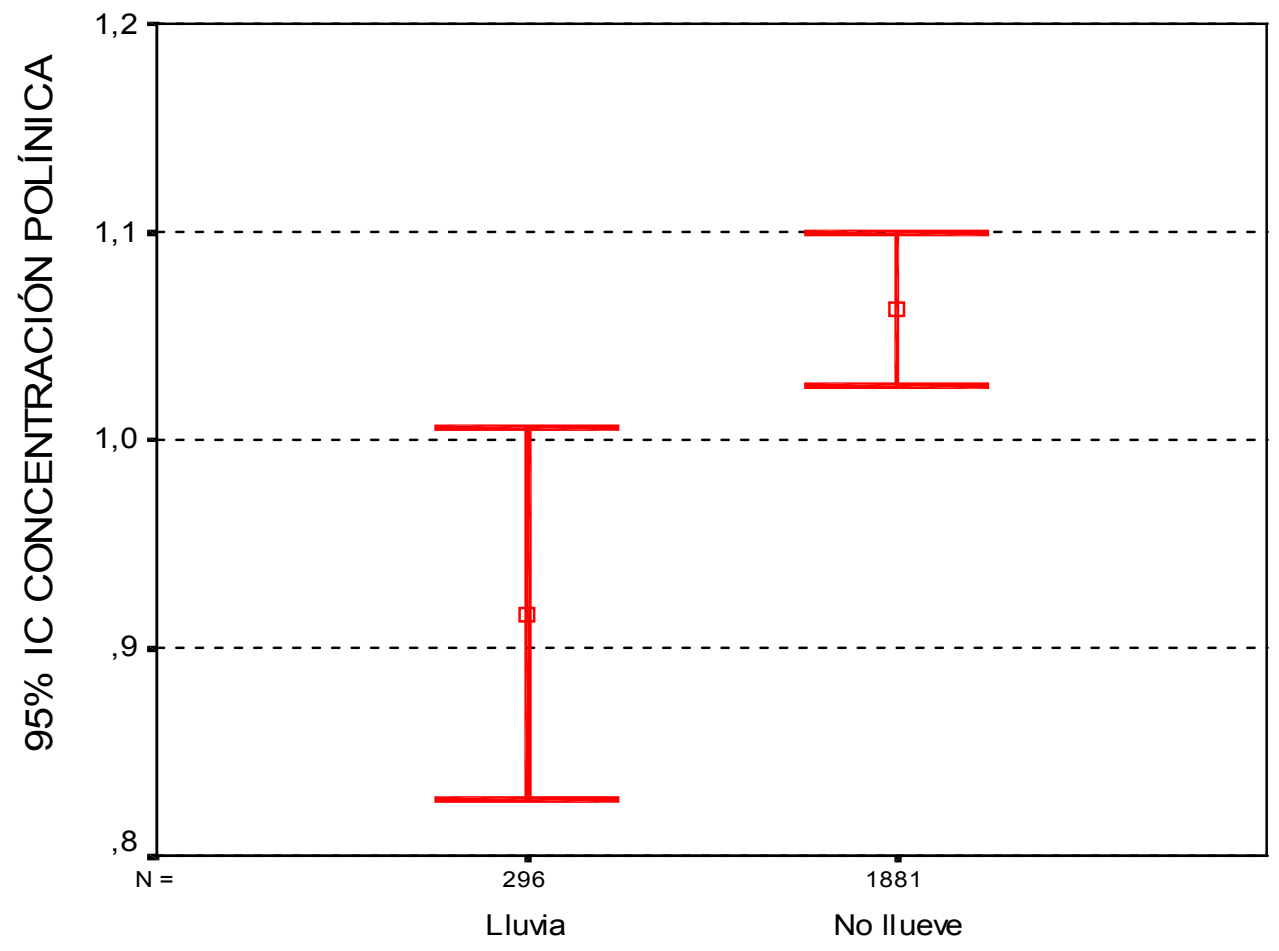


Figura 5.42. Continuación. Media e intervalo de confianza al 95\% de la concentración polínica total estandarizada en presencia o ausencia de precipitación y ANOVA por las dos categorías (llueve y no llueve) para el periodo 1993-1999.

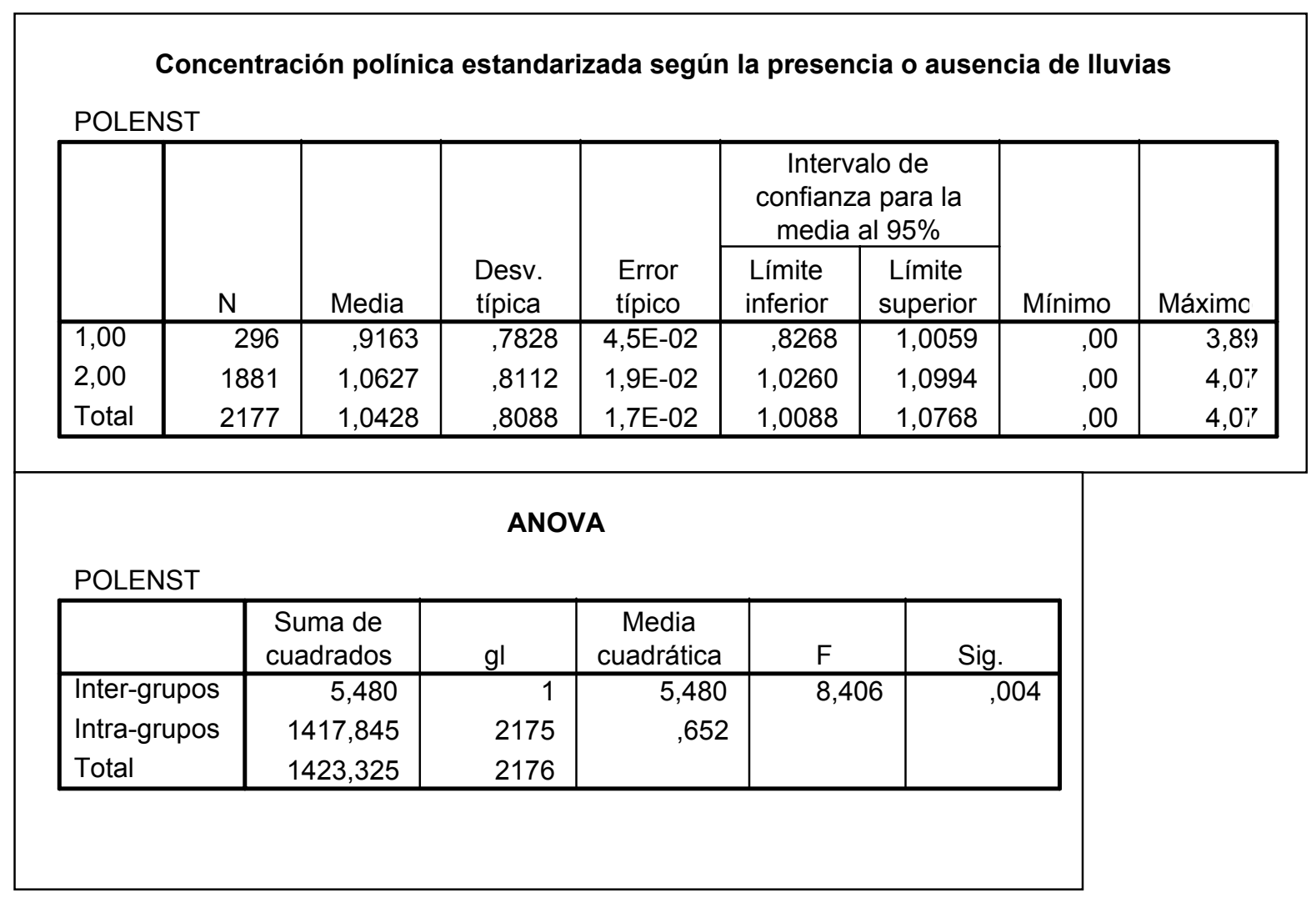


Figura 5.43. Media e intervalo de confianza al 95\% de la concentración polínica total estandarizada por rangos de lluvia ( 0 no ha llovido; de 0,1 a $4,91 / \mathrm{m}^{2}$; 5- $301 / \mathrm{m}^{2}$ y $>301 / \mathrm{m}^{2}$ ) para el periodo 1993-1999.

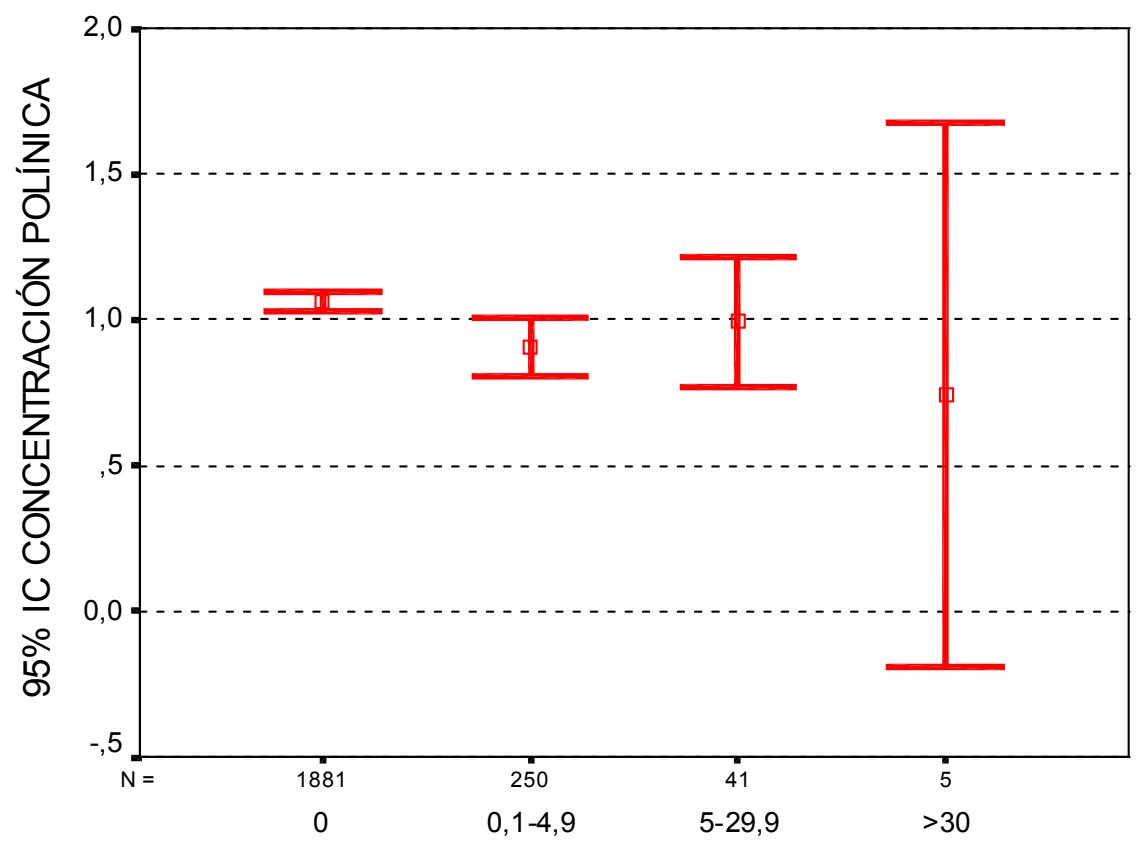

Lluvia

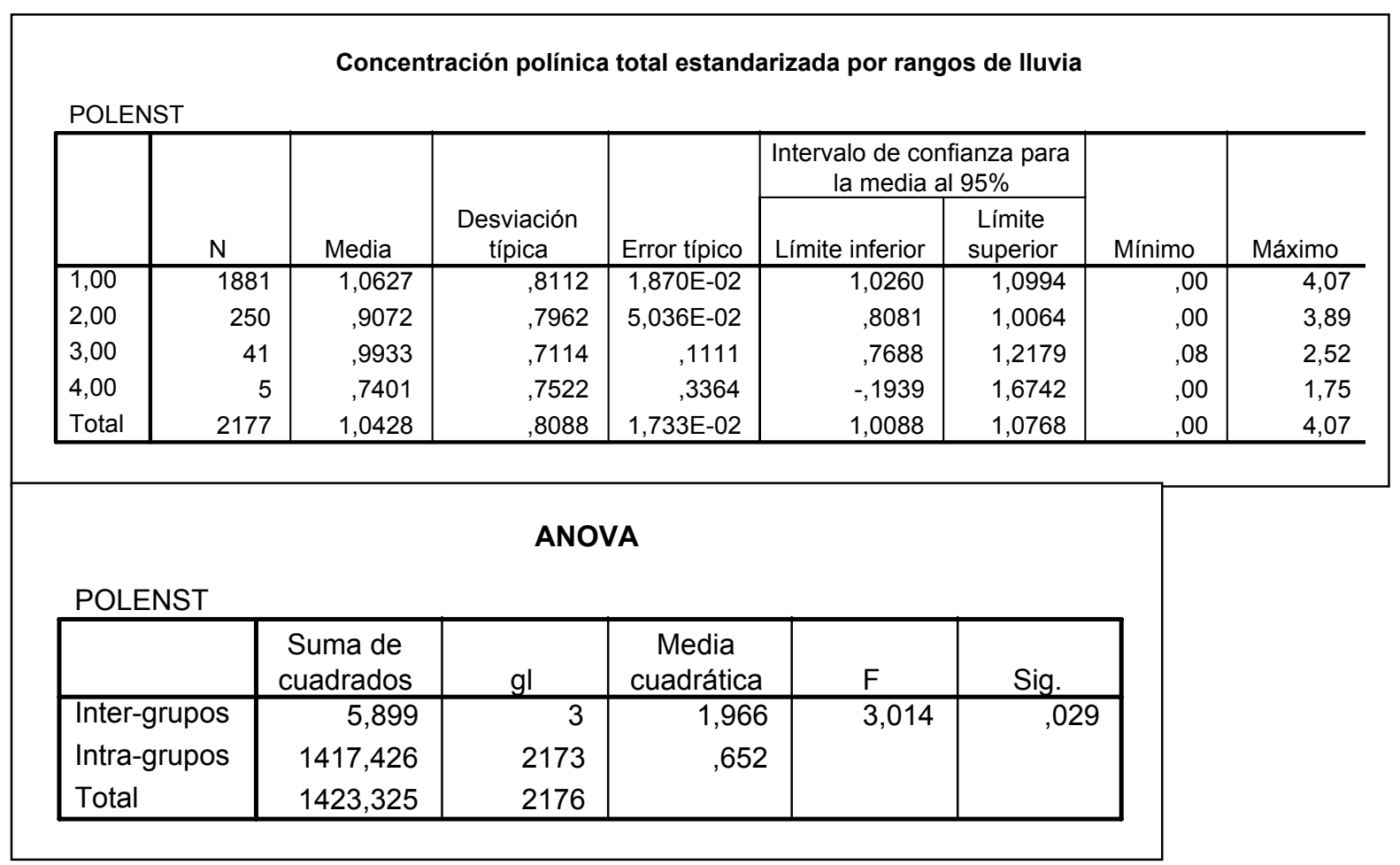




\subsubsection{VARIABLES METEOROLÓGICAS Y CONCENTRACIONES POLÍNICAS DE CHENOPODIACEAE-AMARANTHACEAE.}

En la tabla 5.16., se presentan las correlaciones lineales entre las distintas variables meteorológicas y las concentraciones polínicas de ChenopodiaceaeAmaranthaceae.

Tabla 5.16. Coeficientes de correlación lineal de Pearson para la concentración polínica de Chenopodiaceae-Amaranthaceae (las dos floraciones) y los distintos parámetros meteorológicos.

\begin{tabular}{|l|l|c|c|c|c|c|c|c|c|}
\hline \multicolumn{1}{|c|}{ AÑOS } & & $\mathbf{1 9 9 3}$ & $\mathbf{1 9 9 4}$ & $\mathbf{1 9 9 5}$ & $\mathbf{1 9 9 6}$ & $\mathbf{1 9 9 7}$ & $\mathbf{1 9 9 8}$ & $\mathbf{1 9 9 9}$ & $\mathbf{9 3 - 9 9}$ \\
\hline PRBMEDIA & C. Pearson & $\mathbf{- 0 . 3 3} * *$ & $\mathbf{- 0 . 1 7 * *}$ & $\mathbf{- 0 . 2 0 * *}$ & $\mathbf{- 0 . 1 4 * *}$ & -0.05 & $\mathbf{- 0 . 2 3 * *}$ & -0.10 & $\mathbf{- 0 . 2 3 * *}$ \\
& Sig. (bilateral) & 0.00 & 0.004 & 0.00 & 0.01 & 0.30 & 0.00 & 0.12 & 0.00 \\
& N & 277 & 301 & 332 & 351 & 357 & 304 & 262 & 1252 \\
\hline TMPMEDIA & C. Pearson & $\mathbf{0 . 2 2 * *}$ & $\mathbf{0 . 2 5 * *}$ & $\mathbf{0 . 2 3 * *}$ & $\mathbf{0 . 2 5 * *}$ & $\mathbf{0 . 1 7 * *}$ & $\mathbf{0 . 3 4} * *$ & $\mathbf{0 . 2 0 * *}$ & $\mathbf{0 . 2 8 * *}$ \\
& Sig. (bilateral) & 0.00 & 0.00 & 0.00 & 0.00 & 0.00 & 0.00 & 0.00 & 0.00 \\
& N & 277 & 326 & 332 & 351 & 357 & 304 & 262 & 1277 \\
\hline HRMEDIA & C. Pearson & -0.05 & -0.07 & -0.04 & 0.02 & -0.11 & -0.07 & 0.01 & $\mathbf{- 0 . 0 7 *}$ \\
& Sig. (bilateral) & 0.44 & 0.19 & 0.50 & 0.67 & 0.04 & 0.24 & 0.93 & 0.01 \\
& N & 277 & 326 & 332 & 351 & 357 & 304 & 262 & 1277 \\
\hline WMEDIA & C. Pearson & 0.05 & 0.08 & 0.07 & -0.04 & $\mathbf{0 . 1 1 *}$ & $\mathbf{0 . 2 7 * *}$ & 0.02 & $\mathbf{0 . 0 5 *}$ \\
& Sig. (bilateral) & 0.35 & 0.14 & 0.21 & 0.48 & 0.04 & 0.00 & 0.75 & 0.04 \\
& N & 277 & 326 & 332 & 351 & 357 & 304 & 262 & 1277 \\
\hline LLUVIADIA & C. Pearson & -0.04 & 0.04 & -0.01 & $\mathbf{0 . 2 4} * *$ & 0.02 & 0.06 & 0.09 & $\mathbf{0 . 0 8 * *}$ \\
& Sig. (bilateral) & 0.56 & 0.52 & 0.79 & 0.00 & 0.09 & 0.26 & 0.16 & 0.04 \\
& N & 277 & 326 & 332 & 351 & 357 & 304 & 262 & 1278 \\
\hline RSACUM. & C. Pearson & $\mathbf{0 . 2 6 *}$ & $\mathbf{0 . 2 0} * *$ & 0.19 & 0.04 & $\mathbf{0 . 1 9 * *}$ & 0.09 & 0.09 & $\mathbf{0 . 2 4 * *}$ \\
& Sig. (bilateral) & 0.00 & 0.00 & 0.00 & 0.50 & 0.00 & 0.10 & 0.16 & 0.00 \\
& N & 277 & 315 & 332 & 351 & 357 & 304 & 262 & 1266 \\
\hline
\end{tabular}


Tabla 5.17. Coeficientes de correlación lineal de Pearson para la concentración polínica de Chenopodiaceae-Amaranthaceae ( $2^{\mathrm{a}}$ floración) y los distintos parámetros meteorológicos.

\begin{tabular}{|l|l|c|c|c|c|c|c|c|c|}
\hline \multicolumn{1}{|c|}{ AÑOS } & & $\mathbf{1 9 9 3}$ & $\mathbf{1 9 9 4}$ & $\mathbf{1 9 9 5}$ & $\mathbf{1 9 9 6}$ & $\mathbf{1 9 9 7}$ & $\mathbf{1 9 9 8}$ & $\mathbf{1 9 9 9}$ & $\mathbf{9 3 - 9 9}$ \\
\hline PRBMEDIA & C. Pearson & $\mathbf{- 0 . 2 6 *}$ & 0.13 & $\mathbf{- 0 . 2 8 *}$ & $\mathbf{- 0 . 4 1 * *}$ & 0.22 & -0.18 & 0.10 & $\mathbf{- 0 . 1 5 * *}$ \\
& Sig. (bilateral) & 0.018 & 0.92 & 0.02 & 0.00 & 0.12 & 0.16 & 0.42 & 0.001 \\
& N & 84 & 61 & 63 & 91 & 48 & 57 & 62 & 466 \\
\hline TMPMEDIA & C. Pearson & 0.11 & 0.02 & $\mathbf{- 0 . 3 1 *}$ & 0.09 & -0.09 & 0.22 & 0.11 & 0.027 \\
& Sig. (bilateral) & 0.33 & 0.87 & 0.01 & 0.37 & 0.53 & 0.10 & 0.38 & 0.57 \\
& N & 84 & 61 & 63 & 91 & 48 & 57 & 62 & 466 \\
\hline HRMEDIA & C. Pearson & -0.006 & $\mathbf{- 0 . 2 9 *}$ & -0.10 & -0.04 & 0.12 & 0.05 & -0.15 & $\mathbf{- 0 . 1 2 *}$ \\
& Sig. (bilateral) & 0.65 & 0.025 & 0.43 & 0.71 & 0.39 & 0.69 & 0.24 & 0.014 \\
& N & 84 & 61 & 63 & 91 & 48 & 57 & 62 & 466 \\
\hline WMEDIA & C. Pearson & -0.082 & 0.008 & 0.03 & 0.08 & 0.10 & $\mathbf{0 . 3 0 *}$ & -0.05 & 0.07 \\
& Sig. (bilateral) & 0.45 & 0.94 & 0.81 & 0.45 & 0.48 & 0.02 & 0.69 & 0.16 \\
& N & 84 & 61 & 63 & 91 & 48 & 57 & 62 & 466 \\
\hline LLUVIADIA & C. Pearson & -0.06 & -0.07 & 0.06 & $\mathbf{0 . 2 7 * *}$ & -0.03 & $\mathbf{0 . 4 4 * * *}$ & 0.20 & 0.04 \\
& Sig. (bilateral) & 0.60 & 0.60 & 0.62 & 0.00 & 0.83 & 0.00 & 0.12 & 0.42 \\
\hline RSACUM. & N & 84 & 61 & 63 & 91 & 48 & 57 & 62 & 466 \\
\hline & Sig. (bilateral) & 0.12 & 0.029 & 0.40 & 0.009 & 0.84 & 0.84 & 0.52 & 0.83 \\
& N & 84 & 61 & 63 & 91 & 48 & 57 & 62 & 466 \\
\hline
\end{tabular}




\subsubsection{PRESIÓN Y CONCENTRACIÓN POLÍNICA DE CHENOPODIACEAE-AMARANTHACEAE (2 ${ }^{a}$ FLORACIÓN).}

En la figura 5.44. se presenta el ANOVA de la concentración polínica de la segunda floración de Chenopodiaceae-Amaranthaceae considerando dos grupos, altas y bajas presiones.

Figura 5.44. Análisis de la varianza de la concentración polínica de Chenopodiaceae-Amaranthaceae ( $2^{\mathrm{a}}$ floración) por rangos de presiones para los años 1995-1999 (Bajas cuando la presión atmosférica es $\leq 1013$ $\mathrm{mb}$ y altas presiones cuando es $>1013 \mathrm{mb}$ ).
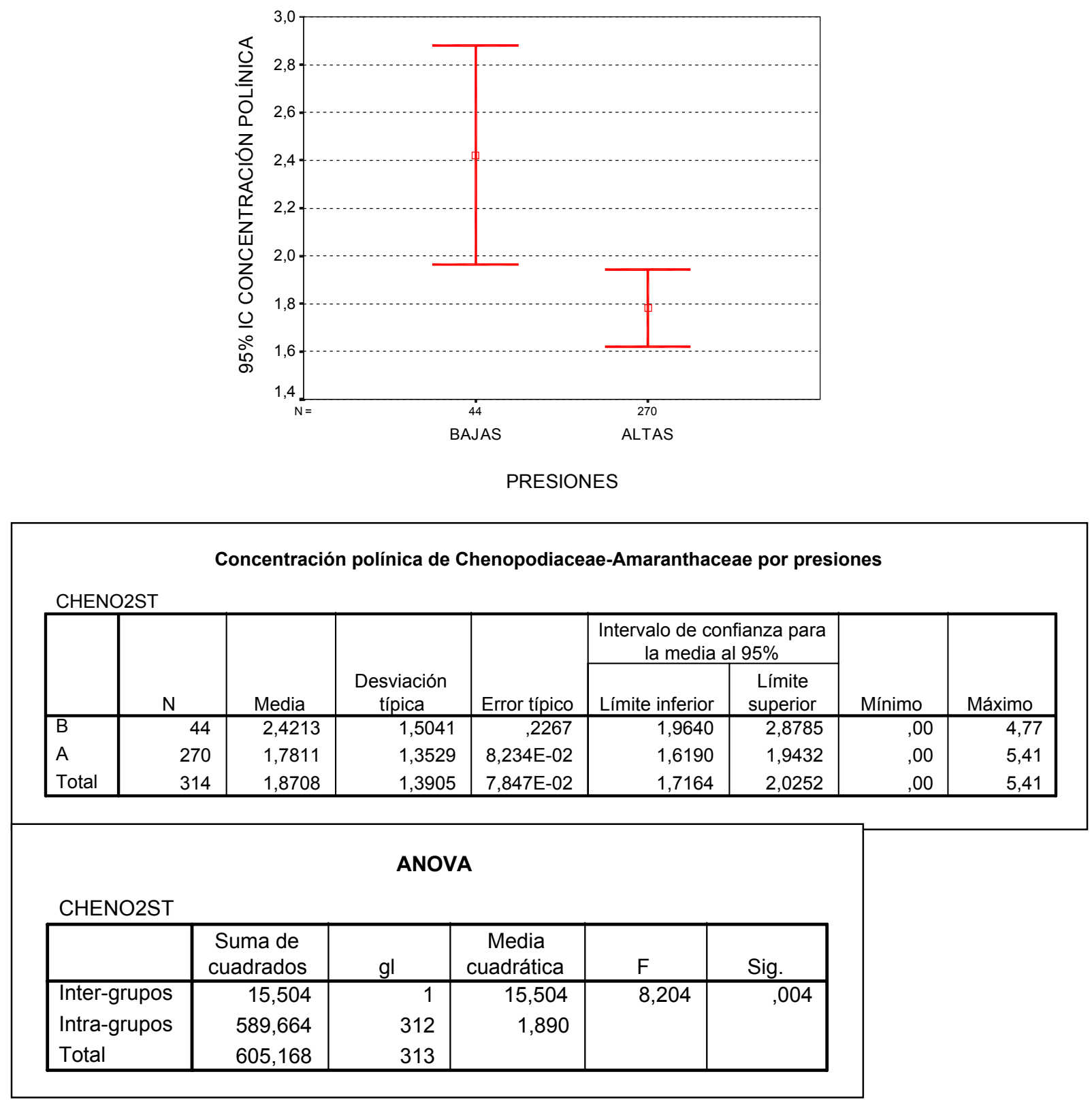


\subsubsection{VELOCIDAD DEL VIENTO Y CONCENTRACIÓN POLÍNICA DE CHENOPODIACEAE-AMARANTHACEAE $\left(^{\mathrm{a}}\right.$ FLORACIÓN).}

En las figuras 5.45. y 5.46. se muestran el ANOVA de la concentración polínica total diaria estandarizada para las variables RANGOSMI y RANGOS respectivamente.

Figura 5.45. Media e intervalo de confianza de la concentración polínica de Chenopodiaceae-Amaranthaceae ( $2^{\mathrm{a}}$ floración) por rangos de velocidad del viento y ANOVA por rangos de velocidad para el periodo 1995-1999 (Rango $1=0-4,9 \mathrm{~km} / \mathrm{h}$; rango $2=5-10,9 \mathrm{~km} / \mathrm{h}$; rango $3=11-15,9$ y rango $4 \geq 16 \mathrm{~km} / \mathrm{h})$ RANGOSMI.

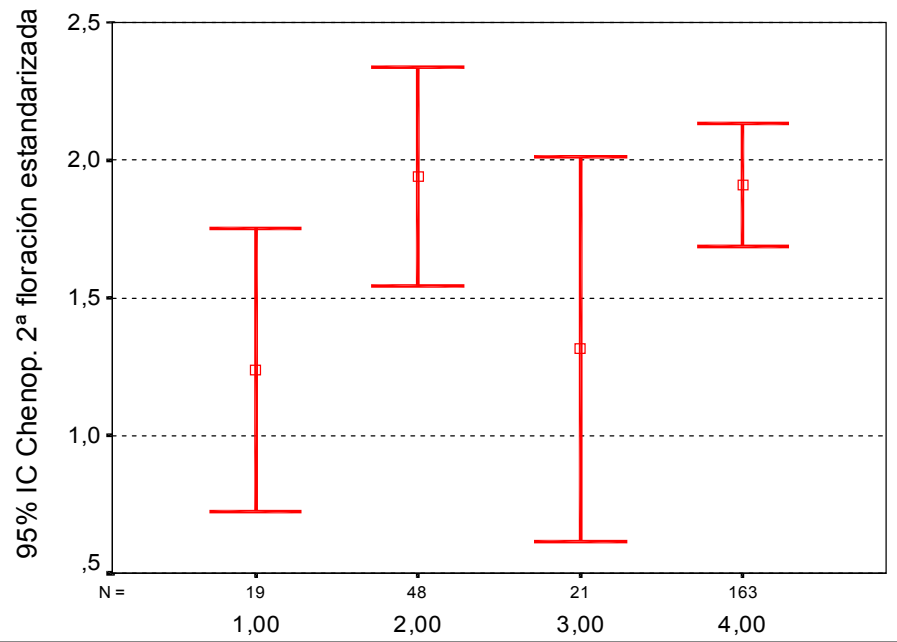

\begin{tabular}{|l|l|r|r|r|r|r|r|}
\hline \multicolumn{2}{|c|}{ Chenopodiaceae-Amaranthaceae 2 ${ }^{\text {a }}$ floración (1995-1999) } \\
\hline \\
\hline
\end{tabular}


Figura 5.46. Media e intervalo de confianza de la concentración polínica de Chenopodiaceae-Amaranthaceae ( $2^{\mathrm{a}}$ floración) por rangos de velocidad del viento y ANOVA por rangos de velocidad para el periodo 1995-1999 (Rango $1=0-4,9 \mathrm{~km} / \mathrm{h}$; rango $2=5-10,9 \mathrm{~km} / \mathrm{h}$; rango $3=11-15,9$ y rango $4 \geq 16 \mathrm{~km} / \mathrm{h}$ ) RANGOS.

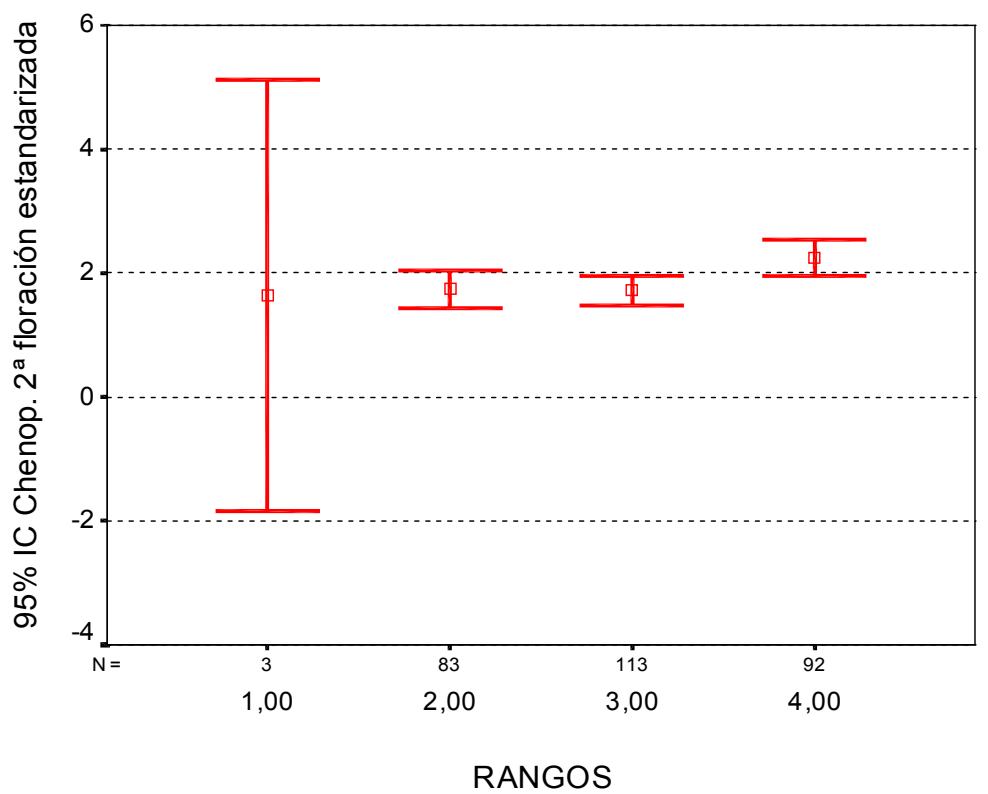

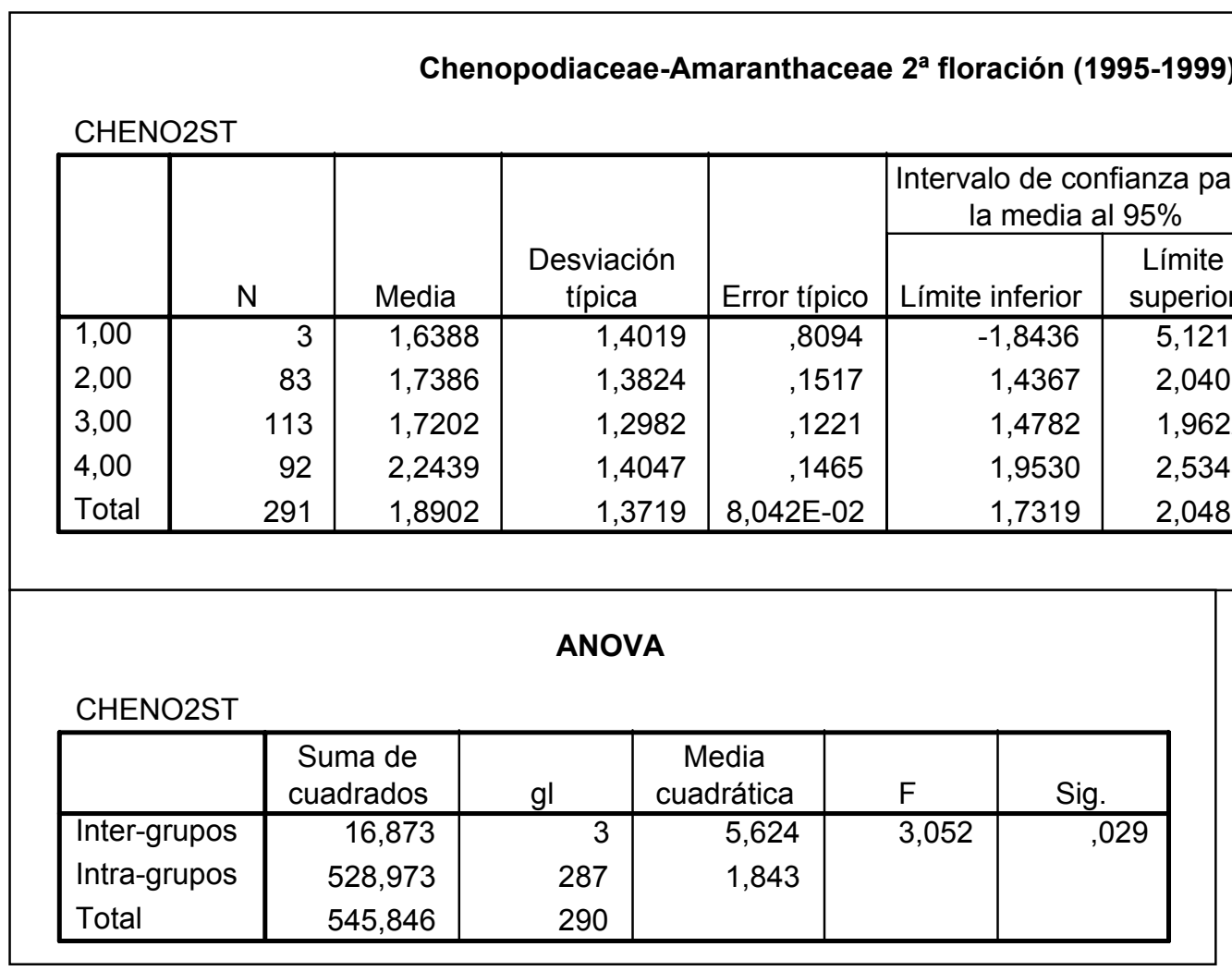




\subsubsection{DIRECCIÓN DEL VIENTO Y CONCENTRACIÓN POLÍNICA DE CHENOPODIACEAE-AMARANTHACEAE (2 FLORACIÓN).}

En la figura 5.47. se presentan los resultados del ANOVA de la concentración polínica total diaria estandarizada de ChenopodiaceaeAmaranthaceae ( $2^{\mathrm{a}}$ floración) para el periodo 1993-1999, considerando como dirección del viento la variable RUMBOS, obtenida a partir del análisis de las frecuencias semihorarias del viento para cada día, y la rosa de concentración para las distintas direcciones del viento (RUMBOS). 
Figura 5.47. Media e intervalo de confianza al 95\% de la concentración polínica de Chenopodiaceae-Amaranthaceae ( $2^{\mathrm{a}}$ floración) por rumbos del viento y ANOVA por rumbos para el periodo 1995-1999. Rosa de concentraciones por RUMBOS.

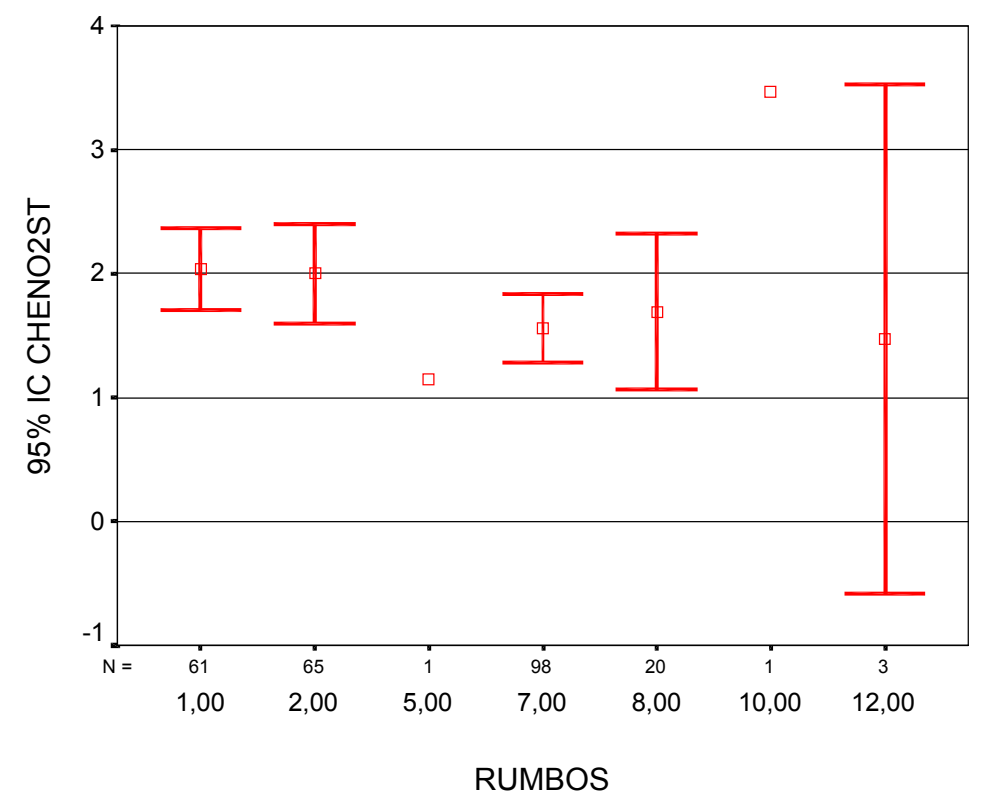

\begin{tabular}{|c|c|c|c|c|c|c|c|c|}
\hline \multicolumn{9}{|c|}{ Chenopodiaceae-Amaranthaceae $2^{\mathrm{a}}$ floración (1995-1999) } \\
\hline & \multirow[b]{2}{*}{$\mathrm{N}$} & \multirow[b]{2}{*}{ Media } & \multirow[b]{2}{*}{$\begin{array}{l}\text { Desviación } \\
\text { típica }\end{array}$} & \multirow[b]{2}{*}{ Error típico } & \multicolumn{2}{|c|}{$\begin{array}{c}\text { Intervalo de confianza para } \\
\text { la media al } 95 \%\end{array}$} & \multirow[b]{2}{*}{ Mínimo } & \multirow[b]{2}{*}{ Máximo } \\
\hline & & & & & Límite inferior & $\begin{array}{l}\text { Límite } \\
\text { superior }\end{array}$ & & \\
\hline $\mathrm{N}$ & 61 & 2,0376 & 1,2809 &, 1640 & 1,7096 & 2,3657 & ,00 & 4,61 \\
\hline NNE & 65 & 1,9992 & 1,6147 & ,2003 & 1,5991 & 2,3993 & 00 & 5,41 \\
\hline ESE & 1 & 1,1520 & & , & , & , & 1,15 & 1,15 \\
\hline S & 98 & 1,5605 & 1,3695 & ,1383 & 1,2859 & 1,8351 & ,00 & 4,82 \\
\hline SSW & 20 & 1,6950 & 1,3467 & ,3011 & 1,0647 & 2,3253 & ,00 & 4,19 \\
\hline W & 1 & 3,4686 & , & , & , & , & 3,47 & 3,47 \\
\hline WNW & 2 & 2,6652 & 1,8473 & 1,3062 & $-13,9319$ & 19,2624 & 1,36 & 3,97 \\
\hline NNW & 3 & 1,4737 & ,8278 & ,4779 &,- 5826 & 3,5301 & ,69 & 2,34 \\
\hline Total & 251 & 1,8145 & 1,4189 & 8,956E-02 & 1,6381 & 1,9909 & ,00 & 5,41 \\
\hline
\end{tabular}


Figura 5.47. Continuación. Media e intervalo de confianza al 95\% de la concentración polínica de Chenopodiaceae-Amaranthaceae ( $2^{a}$ floración) por rumbos del viento y ANOVA por rumbos para el periodo 1995-1999. Rosa de concentraciones por RUMBOS.

\begin{tabular}{|c|c|c|c|c|c|}
\hline \multicolumn{6}{|c|}{ ANOVA } \\
\hline & $\begin{array}{c}\text { Suma de } \\
\text { cuadrados }\end{array}$ & $\mathrm{gl}$ & $\begin{array}{c}\text { Media } \\
\text { cuadrática }\end{array}$ & $\mathrm{F}$ & Sig. \\
\hline Inter-grupos & 16,835 & 7 & 2,405 & 1,201 &, 303 \\
\hline Intra-grupos & 486,487 & 243 & 2,002 & & \\
\hline Total & 503,322 & 250 & & & \\
\hline
\end{tabular}

Rosa de concentraciones polínicas de Chenopodiaceae-Amaranthaceae $\left(2^{\mathrm{a}}\right.$ floración) por rumbos, para el periodo 1995-1999

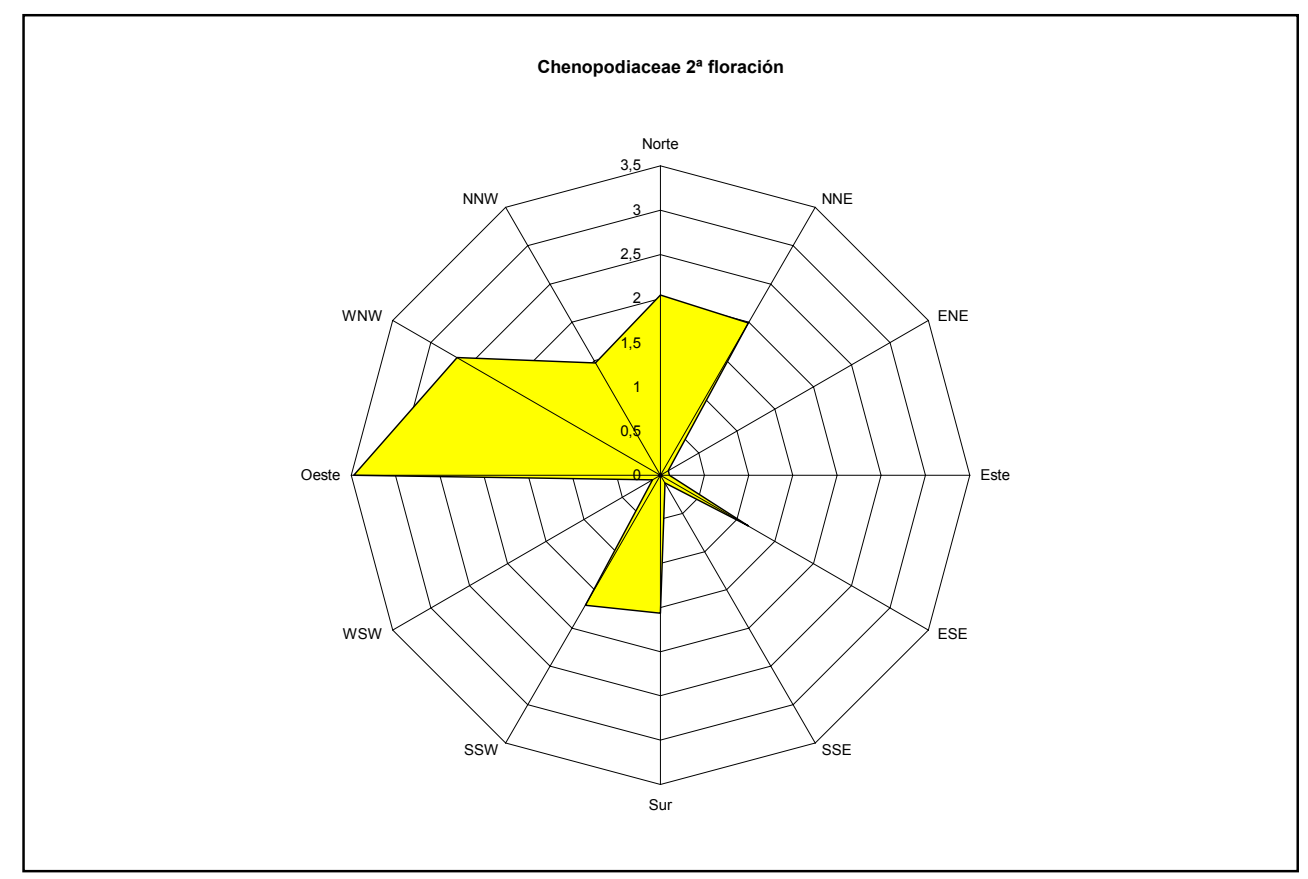




\subsubsection{PRECIPITACIONES Y CONCENTRACIÓN POLÍNICA DE CHENOPODIACEAE-AMARANTHACEAE (2 ${ }^{\mathrm{a}}$ FLORACIÓN).}

En las figuras 5.48. y 5.49. se muestran los resultados del análisis de la varianza para la concentración polínica total estandarizada considerando dos grupos de lluvias (llueve y no llueve) y considerando cuatro grupos.

Figura 5.48. Media e intervalo de confianza al $95 \%$ de la concentración polínica de Chenopodiaceae-Amaranthaceae ( $2^{\mathrm{a}}$ floración) en presencia o ausencia de precipitación y ANOVA por las dos categorías (llueve y no llueve) para el periodo 1995-1999.

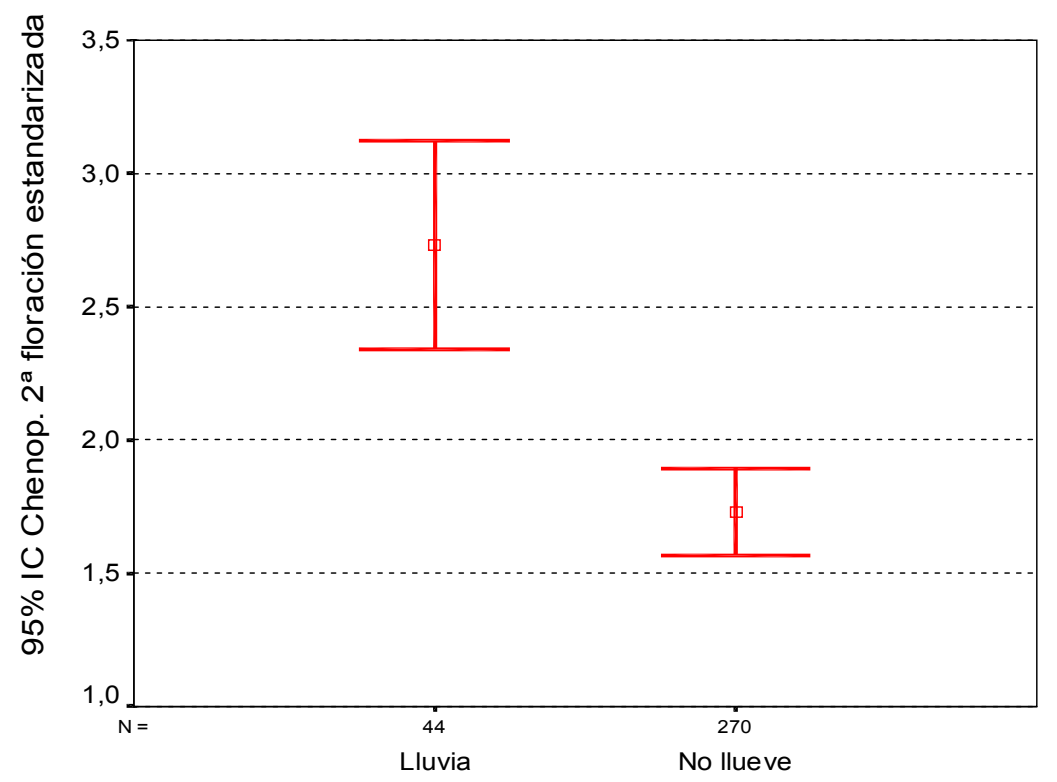

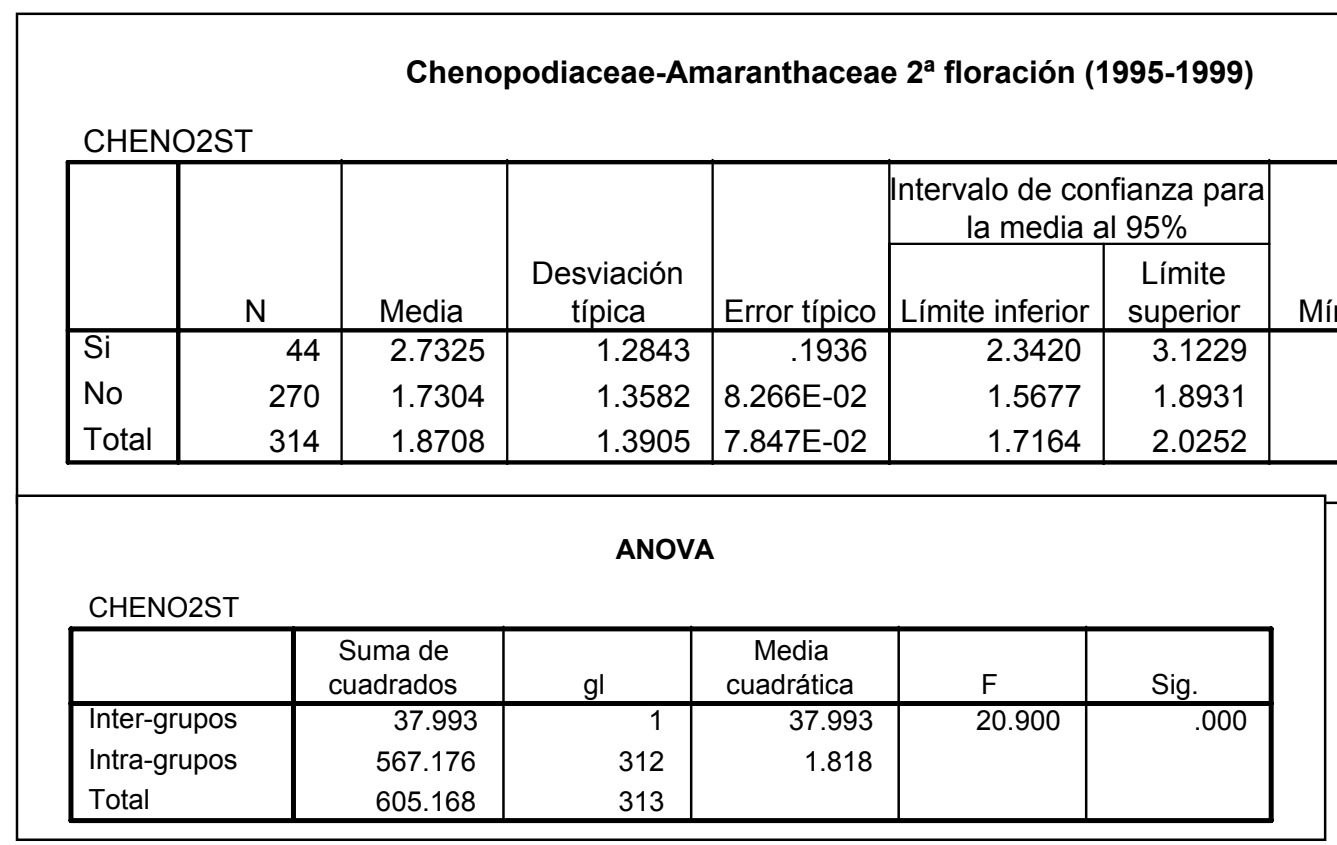


Figura 5.49. Media e intervalo de confianza al 95\% de la concentración polínica polínica de Chenopodiaceae-Amaranthaceae ( $2^{\mathrm{a}}$ floración) por rangos de lluvia ( 0 no ha llovido; de 0,1 a $4,91 / \mathrm{m}^{2} ; 5-301 / \mathrm{m}^{2}$ y $>301 / \mathrm{m}^{2}$ ) para el periodo 1995-1999.

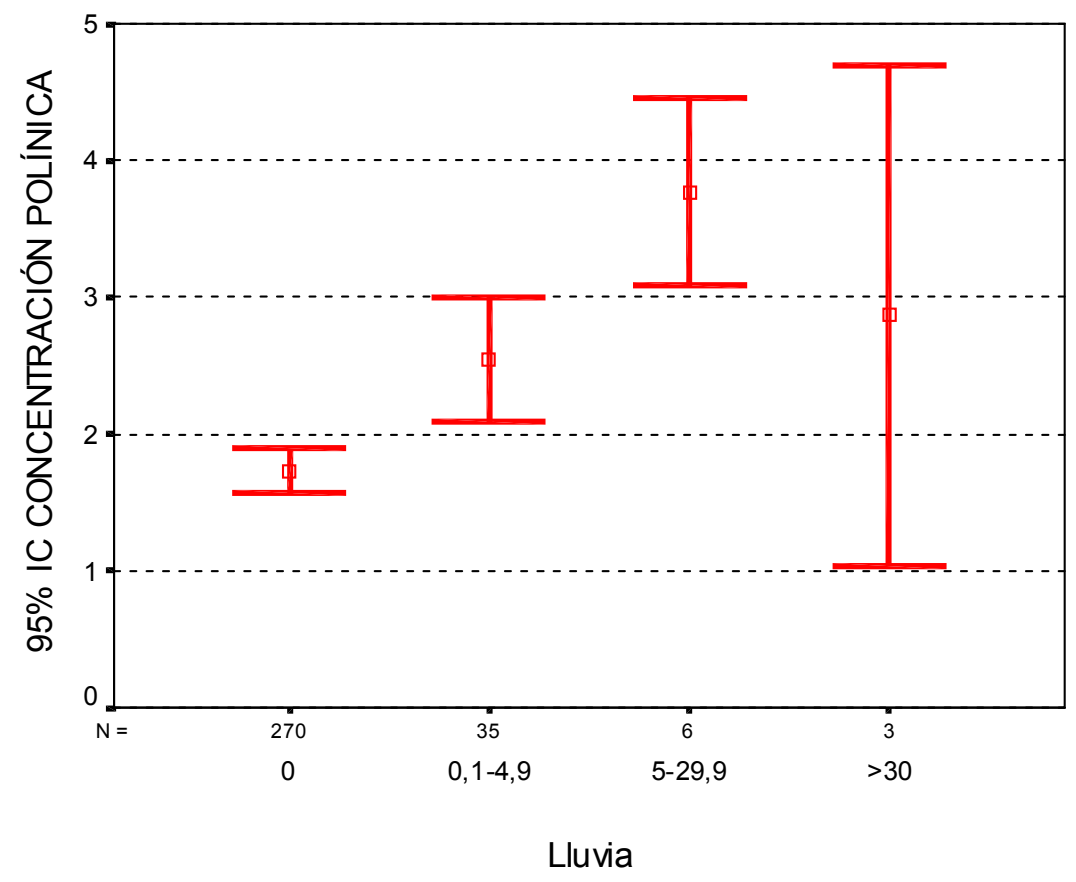

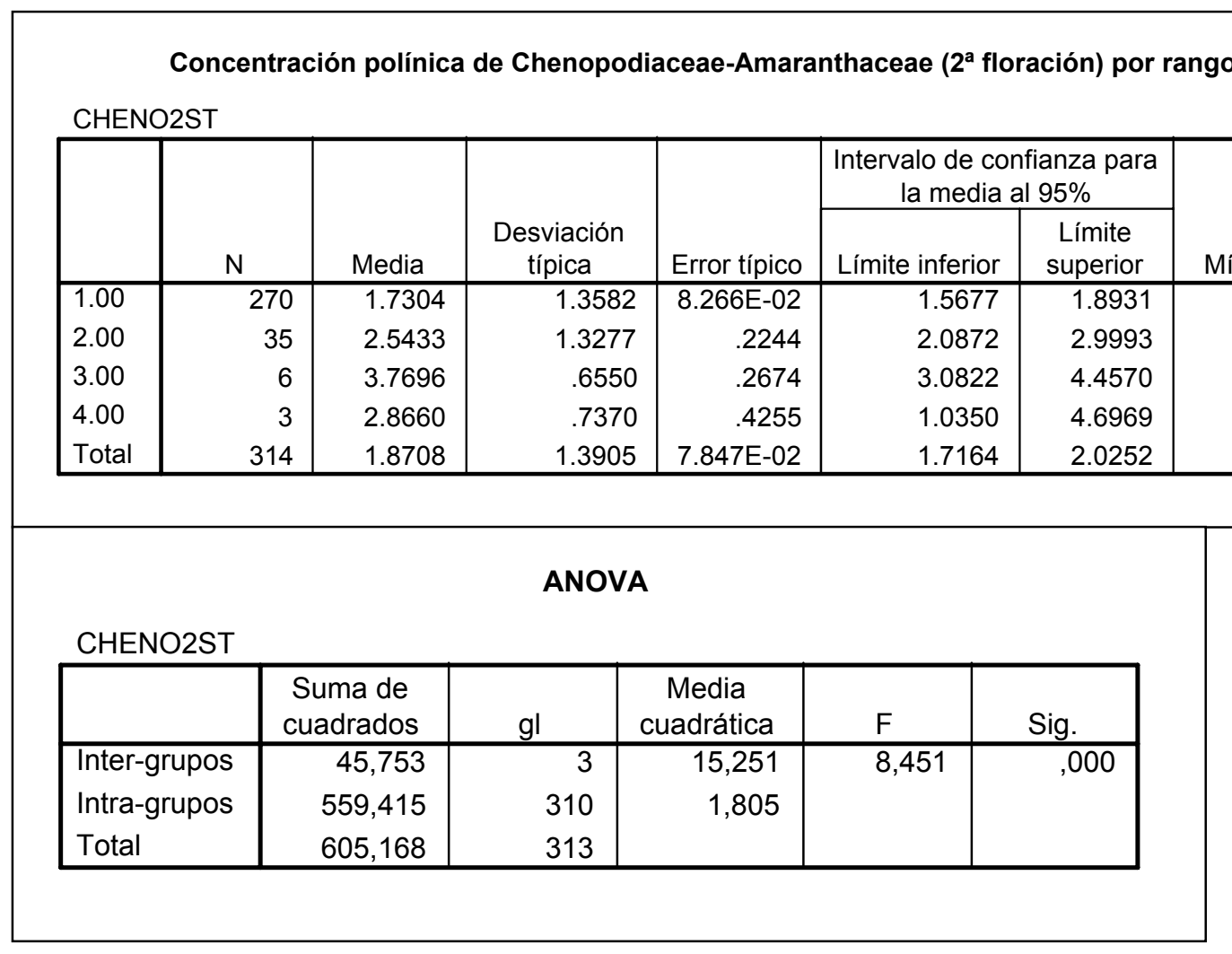




\subsection{RESULTADOS DE LA IDENTIFICACIÓN DE LOS FLUJOS DE VIENTO DOMINANTES EN LA CIUDAD DE CARTAGENA.}

Siguiendo el procedimiento descrito en el apartado de materiales y métodos, se han identificado los flujos de viento dominantes en la ciudad de Cartagena. Las tablas 5.18. y 5.19. recogen la matriz de componentes principales

y la matriz de coeficientes para el cálculo de las puntuaciones factoriales de cada caso y en cada uno de los factores extraídos. La figura 5.33, presenta el gráfico de sedimentación y la tabla resumen de la estadística para el análisis de componentes principales tras la extracción de 2 factores.

La tabla 5.20. recoge el número de casos que incluye cada uno de los clusters. La figura 5.51. muestra la media y los intervalos de confianza para la media al 95\% de los distintos parámetros meteorológicos medidos en las estaciones del Ayuntamiento, ETASA; Lo Campano y Escombreras para cada cluster, salvo para la lluvia que se recoge el valor acumulado para cada uno de los clusters. Las figuras 5.52., 5.53. y 5.54. muestran la media e intervalo de confianza de la media para la humedad relativa, presión y radiación solar en cada una de las horas consideradas y para cada uno de los clusters que finalmente se han establecido. Las figuras 5.55., 5.56., 5.57., 5.58. y 5.59. muestran las rosas de los vientos asociadas a cada uno de los clusters y en cada una de las estaciones meteorológicas. En las tablas 5.21. a 5.30., se recogen las frecuencias de las direcciones y velocidades del viento, para cada uno de los clusters identificados. 
Tabla 5.18.Matriz de componentes para el cálculo de las puntuaciones factoriales.

\begin{tabular}{|c|c|c|c|c|}
\hline \multicolumn{5}{|c|}{ Matriz de componentes } \\
\hline & \multicolumn{2}{|c|}{ Bruta } & \multicolumn{2}{|c|}{ Reescalada } \\
\hline & \multicolumn{2}{|c|}{ Componente } & \multicolumn{2}{|c|}{ Componente } \\
\hline & 1 & 2 & 1 & 2 \\
\hline$\overline{V X 1}$ & 13,372 & $-5,139$ &, 910 &,- 350 \\
\hline $\mathrm{VX2}$ & 8,103 & $-1,968$ &, 866 &,- 210 \\
\hline VX3 & 9,680 & $-4,146$ & ,885 &,- 379 \\
\hline VX4 & 16,614 & $-5,457$ & ,924 &,- 304 \\
\hline VY1 & 4,558 & 3,632 & ,702 &, 559 \\
\hline VY2 & 6,840 & 2,424 & ,797 & ,283 \\
\hline VY3 & 8,516 & 3,151 & 880 & ,326 \\
\hline VY4 & 14,349 & 10,837 & ,791 &, 597 \\
\hline \multicolumn{5}{|c|}{$\begin{array}{l}\text { Método de extracción: Análisis de } \\
\text { componentes principales. }\end{array}$} \\
\hline & compor & ntes extra & & \\
\hline
\end{tabular}

Tabla 5.19. Matriz de coeficientes para el cálculo de las puntuaciones en las componentes.

\begin{tabular}{|c|c|c|}
\hline & Com & nente \\
\hline & 1 & 2 \\
\hline $\mathrm{VX} 1$ & ,205 &,- 338 \\
\hline VX2 & ,079 &,- 082 \\
\hline VX3 & ,110 &,- 203 \\
\hline $\mathrm{VX} 4$ & ,311 &,- 438 \\
\hline VY1 & ,031 & , 105 \\
\hline VY2 & ,061 & 093, \\
\hline VY3 & ,086 & 136, \\
\hline VY4 & ,271 & ,879 \\
\hline \multicolumn{3}{|c|}{$\begin{array}{l}\text { Método de } \\
\text { extracción: Análisis } \\
\text { de componentes } \\
\text { principales. }\end{array}$} \\
\hline
\end{tabular}


Figura 5.50. Gráfico de sedimentación y tabla resumen de la estadística para el análisis de componentes principales tras la extracción de 2 factores.

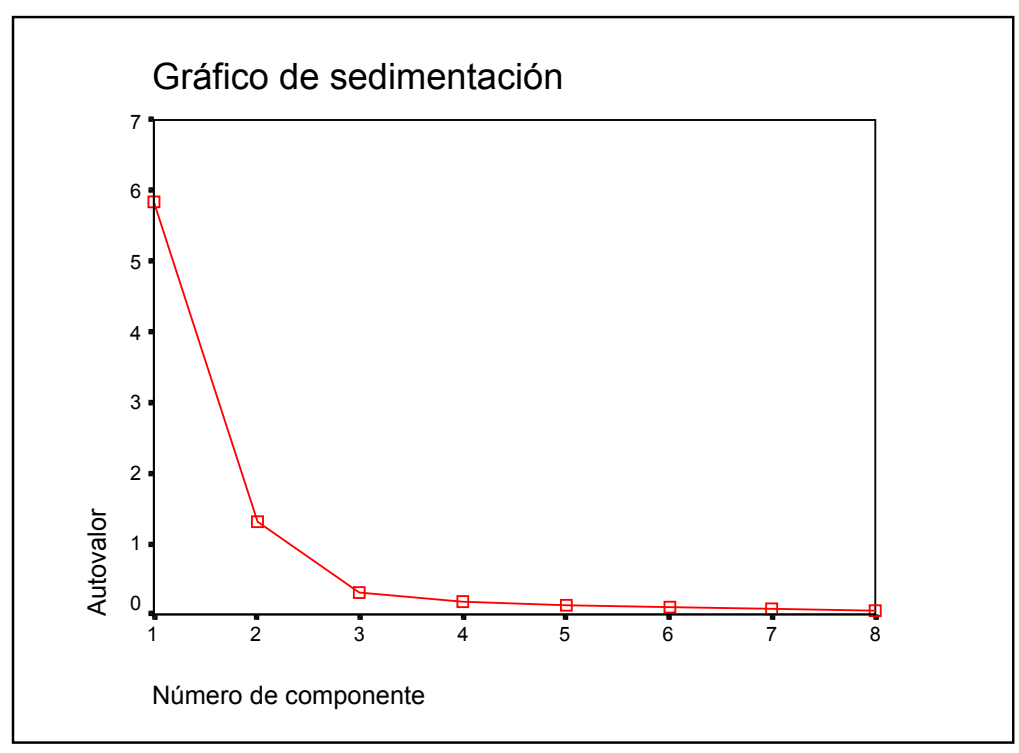

\begin{tabular}{|l|c|c|c|}
\hline \multirow{2}{*}{} & \multicolumn{3}{|c|}{$\begin{array}{c}\text { Sumas de las saturaciones al } \\
\text { cuadrado de la extracción }\end{array}$} \\
\cline { 2 - 4 } Componente & Total & $\begin{array}{c}\% \text { de la } \\
\text { varianza }\end{array}$ & $\begin{array}{c}\% \\
\text { acumulado }\end{array}$ \\
\hline 1 & 5,847 & 73,089 & 73,089 \\
\hline 2 & 1,304 & 16,300 & 89,389 \\
\hline
\end{tabular}


Tabla 5.20. Número de casos incluido en cada uno de los clusters.

Tabla de frecuencia Número inicial de casos

\begin{tabular}{|l|l|r|r|r|r|}
\hline \multicolumn{2}{|c|}{} & Frecuencia & Porcentaje & $\begin{array}{c}\text { Porcentaje } \\
\text { válido }\end{array}$ & $\begin{array}{r}\text { Porcentaje } \\
\text { acumulado }\end{array}$ \\
\hline \multirow{7}{*}{ Válidos } & 1 & 95 & 6,5 & 7,0 & 7,0 \\
\cline { 2 - 6 } & 2 & 361 & 24,7 & 26,6 & 33,7 \\
\cline { 2 - 6 } & 3 & 106 & 7,2 & 7,8 & 41,5 \\
\cline { 2 - 6 } & 4 & 213 & 14,5 & 15,7 & 57,2 \\
\cline { 2 - 6 } & 5 & 580 & 39,6 & 42,8 & 100,0 \\
\cline { 2 - 6 } & Total & 1355 & 92,6 & 100,0 & \\
\hline Perdidos & $\begin{array}{l}\text { Perdidos } \\
\text { del } \\
\end{array}$ & 109 & 7,4 & & \\
\cline { 2 - 6 } & sistema & & & & \\
\hline Total & & 109 & 7,4 & & \\
\hline
\end{tabular}


Figura 5.51. Media e intervalo de confianza al $95 \%$ de los distintos parámetros meteorológicos para cada cluster.
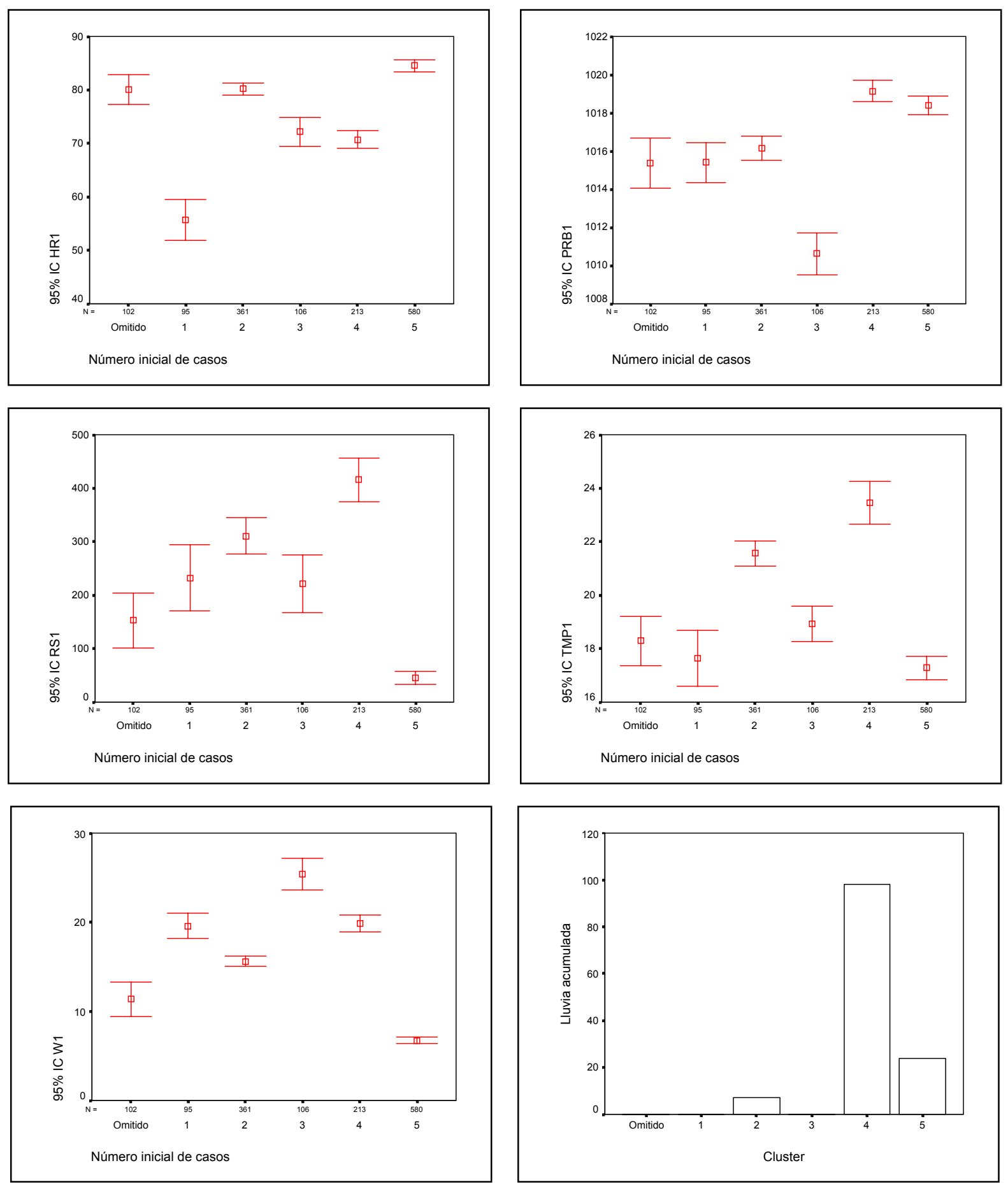
Figura 5.52. Media e intervalo de confianza al $95 \%$ de los valores horarios de humedad relativa media para cada cluster.
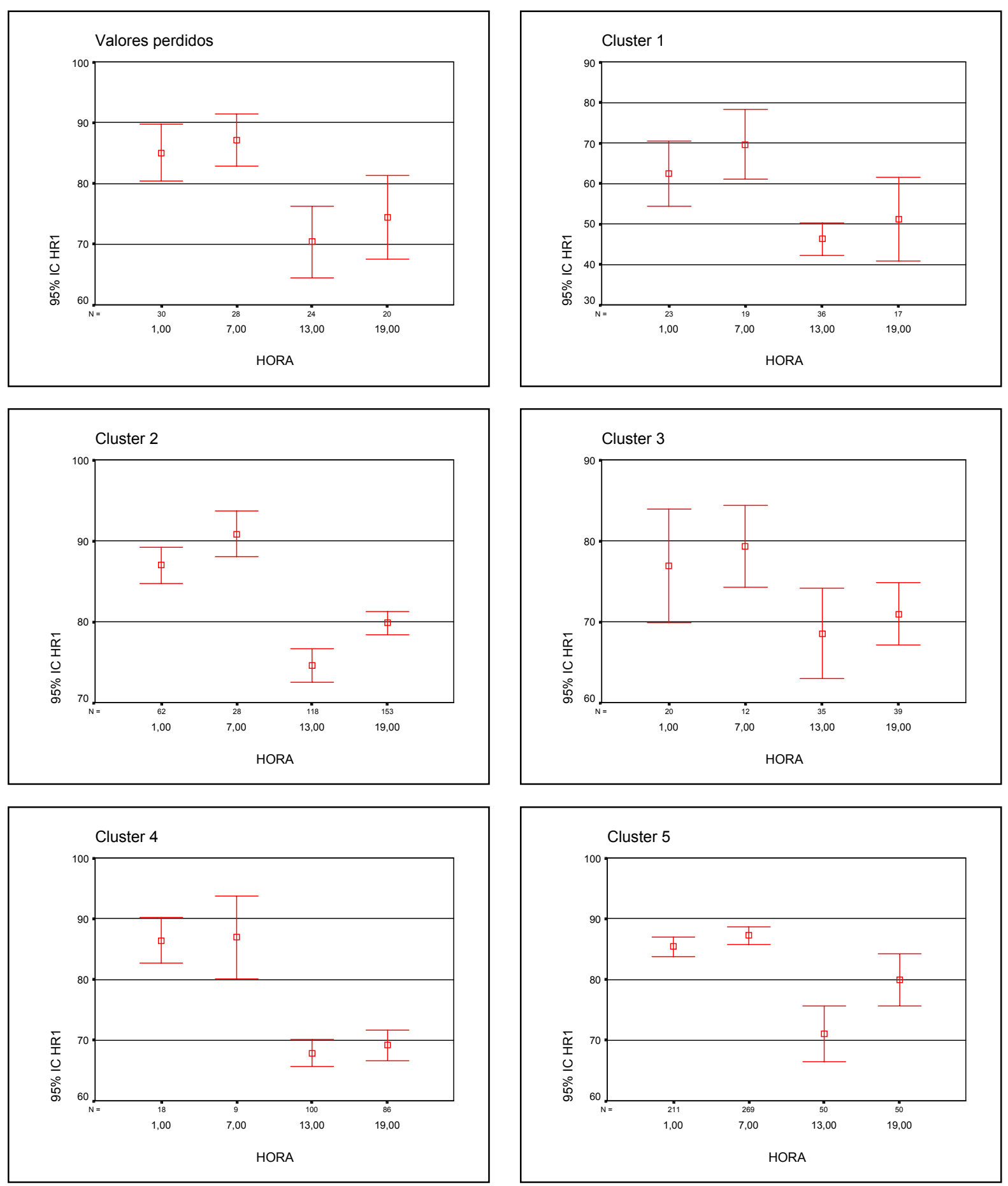
Figura 5.53. Media e intervalo de confianza al 95\% de los valores horarios de presión atmosférica para cada cluster.
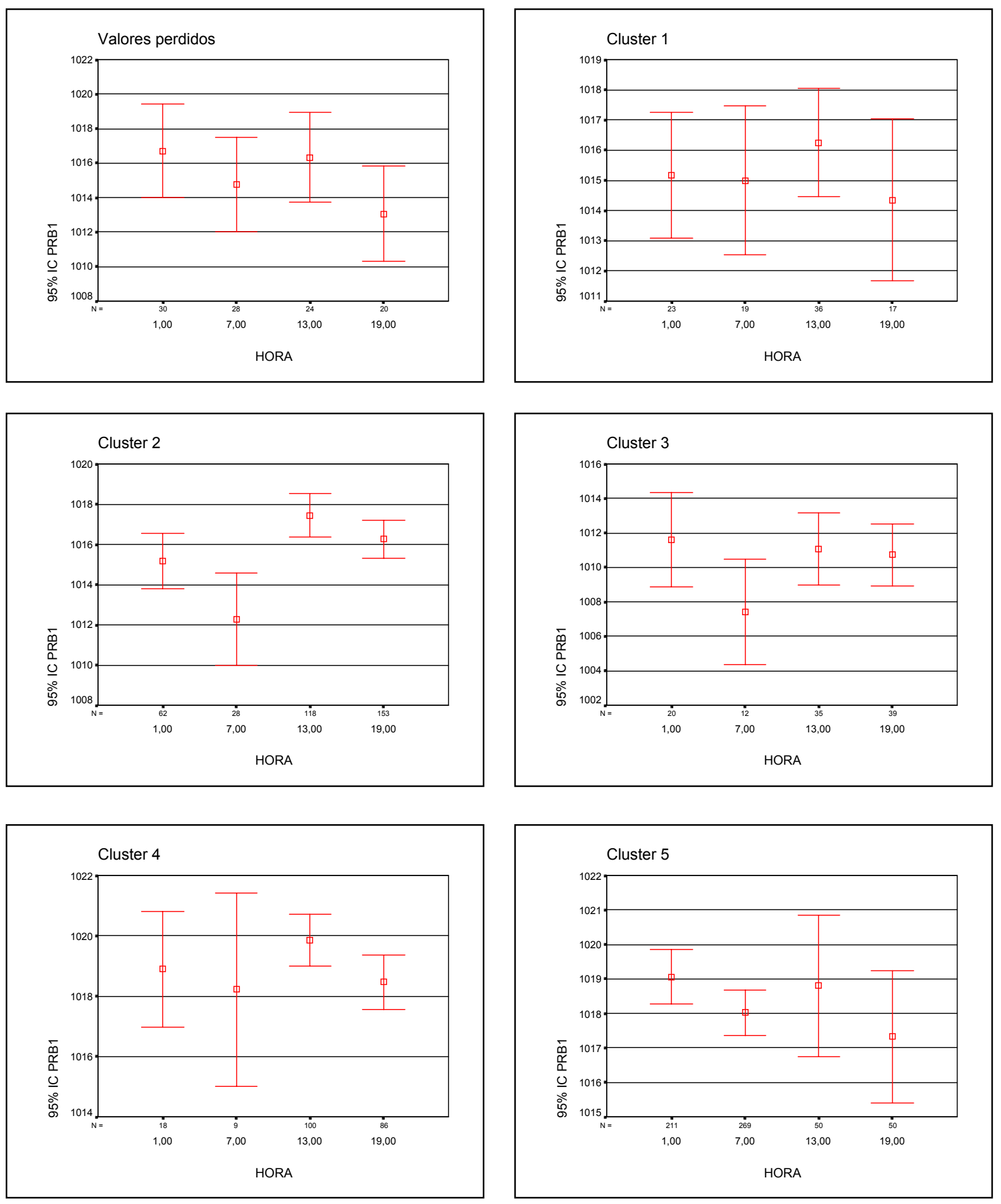
Figura 5.54. Media e intervalo de confianza al 95\% de los valores horarios de radiación solar para cada cluster.
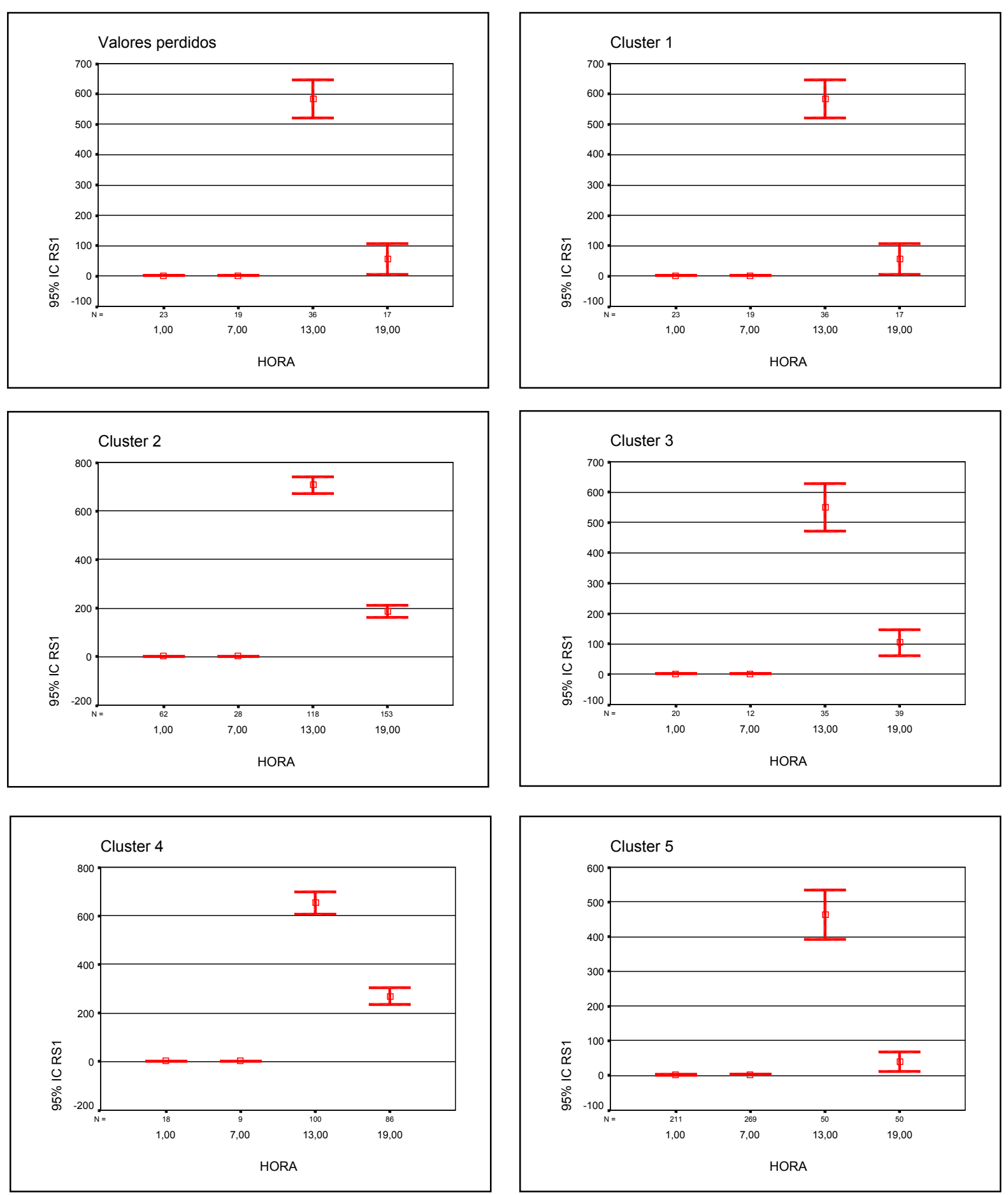
Figura 5.55. Rosa de los vientos en cada estación meteorológica para el cluster 1 .
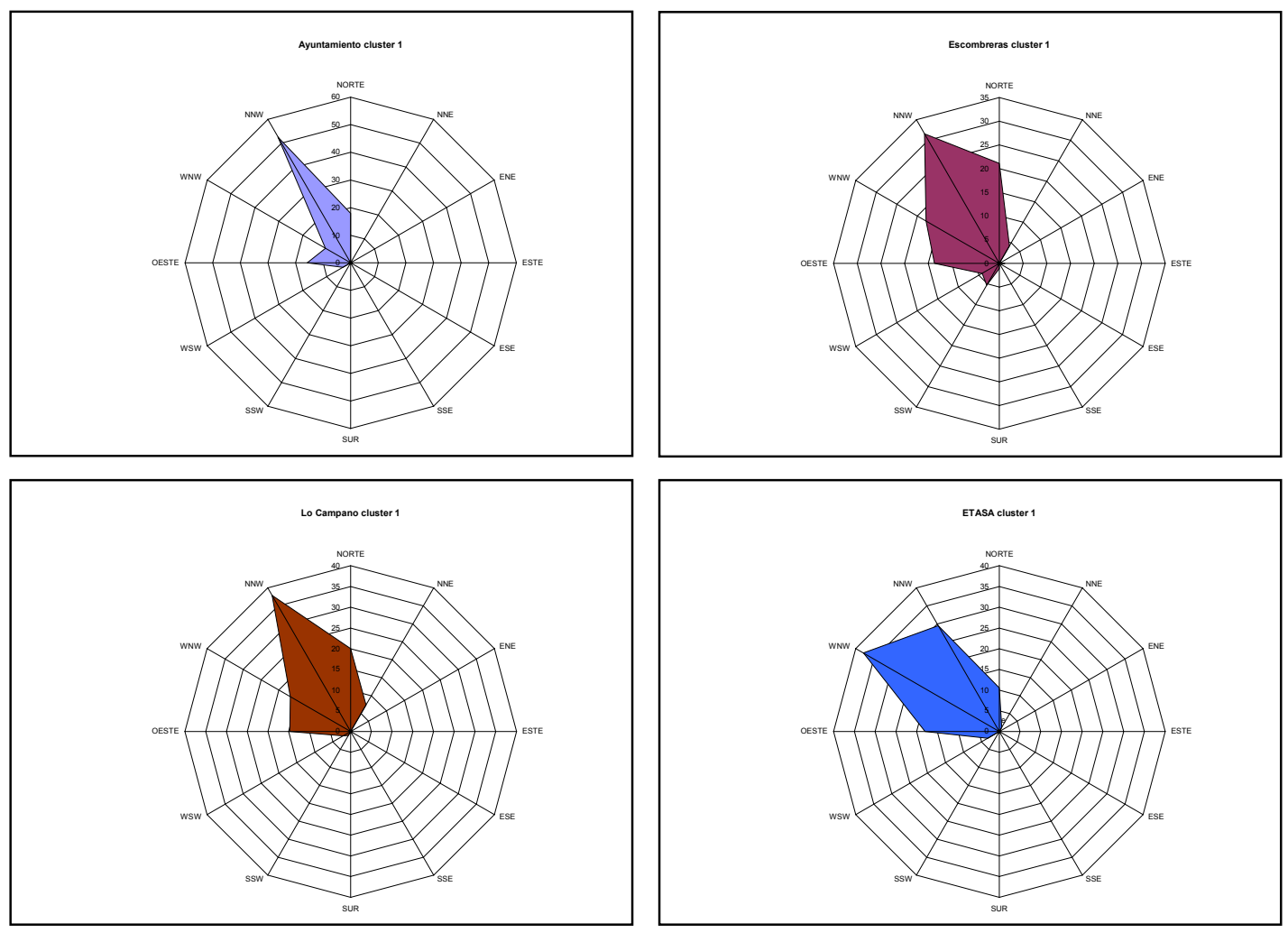

Tabla 5.21. Frecuencias de las direcciones del viento para el cluster $n^{o} 1$ en las distintas estaciones meteorológicas. Los resultados están expresados en porcentaje de casos para cada dirección.

\begin{tabular}{|l|c|c|c|c|c|c|c|c|c|c|c|c|}
\hline & N & NNE & ENE & E & ESE & SSE & S & SSW & WSW & W & WNW & NNW \\
\hline Ayuntamiento & 17.9 & 0 & 0 & 0 & 0 & 0 & 0 & 0 & 3.2 & 15.8 & 10.5 & 52.6 \\
\hline Escombreras & 21.1 & 4.2 & 0 & 1.1 & 0 & 0 & 1.1 & 5.3 & 4.2 & 13.7 & 17.9 & 31.6 \\
\hline Lo Campano & 20.0 & 7.4 & 0 & 0 & 0 & 0 & 0 & 1.1 & 2.1 & 14.7 & 16.8 & 37.9 \\
\hline Etasa & 10.5 & 1.1 & 0 & 0 & 0 & 0 & 0 & 0 & 3.2 & 17.9 & 37.9 & 29.5 \\
\hline
\end{tabular}

Tabla5.22. Frecuencias de las velocidades del viento para el cluster $n^{0} 1$ en las distintas estaciones meteorológicas. Los resultados están expresados en porcentaje de casos para cada rango de velocidad.

\begin{tabular}{|l|c|c|c|c|}
\hline & $\mathbf{0 - 4 . 9} \mathbf{~ k m} / \mathbf{h}$ & $\mathbf{5 - 1 0 . 9} \mathbf{~ k m} / \mathbf{h}$ & $\mathbf{1 1 - 1 5 . 9} \mathbf{~ k m} / \mathbf{h}$ & $\geq \mathbf{1 6 ~ k m} / \mathbf{h}$ \\
\hline Ayuntamiento & 0 & 8.4 & 23.2 & 68.4 \\
\hline Escombreras & 2.1 & 27.4 & 30.5 & 40.0 \\
\hline Lo Campano & 1.1 & 20.0 & 28.4 & 50.5 \\
\hline Etasa & 0 & 1.1 & 4.2 & 94.7 \\
\hline
\end{tabular}


Figura 5.56. Rosa de los vientos en cada estación meteorológica para el cluster 2.
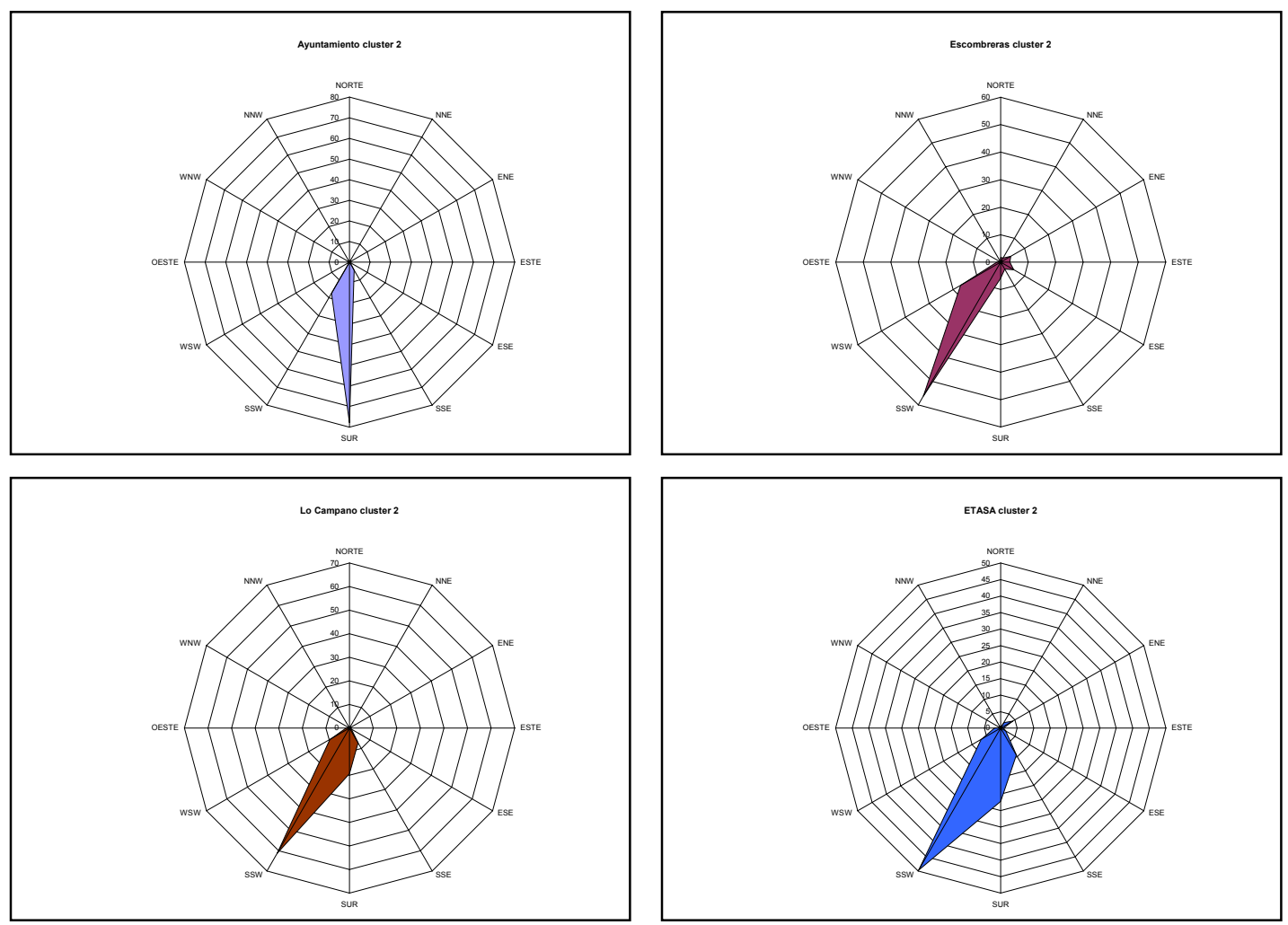

Tabla 5.23. Frecuencias de las direcciones del viento para el cluster $n^{\circ} 2$ en las distintas estaciones meteorológicas. Los resultados están expresados en porcentaje de casos para cada dirección.

\begin{tabular}{|l|c|c|c|c|c|c|c|c|c|c|c|c|}
\hline & N & NNE & ENE & E & ESE & SSE & S & SSW & WSW & W & WNW & $\begin{array}{c}\text { NN } \\
\text { W }\end{array}$ \\
\hline Ayuntamiento & 0 & 0 & 0 & 0 & 0.3 & 4.4 & 77.8 & 17.5 & 0 & 0 & 0 & 0 \\
\hline Escombreras & 1.7 & 1.7 & 4.2 & 3.3 & 5.5 & 2.8 & 5.8 & 56.2 & 16.9 & 1.4 & 0.3 & 0.3 \\
\hline Lo Campano & 0 & 0 & 0.3 & 0 & 0.8 & 7.2 & 19.4 & 61.2 & 9.7 & 1.4 & 0 & 0 \\
\hline Etasa & 0.3 & 1.9 & 4.2 & 0.8 & 1.7 & 9.4 & 22.2 & 49.6 & 6.9 & 1.9 & 0.3 & 0.6 \\
\hline
\end{tabular}

Tabla 5.24. Frecuencias de las velocidades del viento para el cluster $n^{0} 2$ en las distintas estaciones meteorológicas. Los resultados están expresados en porcentaje de casos para cada rango de velocidad.

\begin{tabular}{|l|c|c|c|c|}
\hline & $\mathbf{0 - 4 . 9} \mathbf{~ k m} / \mathbf{h}$ & $\mathbf{5 - 1 0 . 9} \mathbf{~ k m} / \mathbf{h}$ & $\mathbf{1 1 - 1 5 . 9} \mathbf{~ k m} / \mathbf{h}$ & $\geq \mathbf{1 6 ~ k m} / \mathbf{h}$ \\
\hline Ayuntamiento & 2.2 & 16.3 & 31.0 & 50.4 \\
\hline Escombreras & 9.1 & 51.0 & 26.6 & 13.3 \\
\hline Lo Campano & 3.9 & 22.4 & 30.5 & 43.2 \\
\hline Etasa & 2.5 & 11.4 & 18.8 & 67.3 \\
\hline
\end{tabular}


Figura 5.57. Rosa de los vientos en cada estación meteorológica para el cluster 3 .
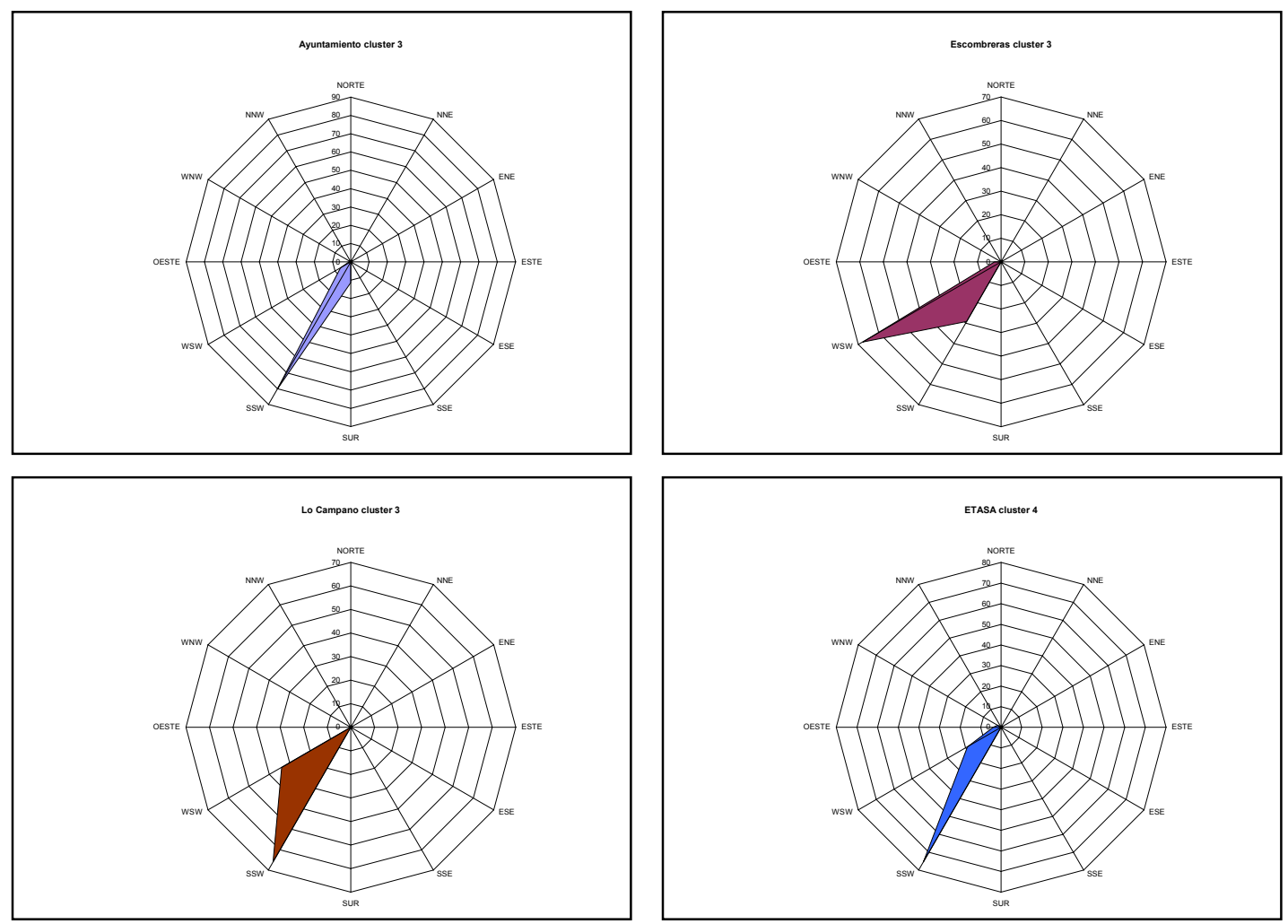

Tabla 5.25. Frecuencias de las direcciones del viento para el cluster $n^{\circ} 3$ en las distintas estaciones meteorológicas. Los resultados están expresados en porcentaje de casos para cada dirección.

\begin{tabular}{|l|c|c|c|c|c|c|c|c|c|c|c|c|}
\hline & N & NNE & ENE & E & ESE & SSE & S & SSW & WSW & W & WNW & $\begin{array}{c}\text { NN } \\
\text { W }\end{array}$ \\
\hline Ayuntamiento & 0 & 0 & 0 & 0 & 0 & 0 & 11.3 & 80.2 & 6.6 & 0.9 & 0.9 & 0 \\
\hline Escombreras & 0 & 0 & 0 & 0 & 0 & 0 & 0 & 29.2 & 67.9 & 2.8 & 0 & 0 \\
\hline Lo Campano & 0 & 0 & 0 & 0 & 0 & 0 & 0 & 66.0 & 34.0 & 0 & 0 & 0 \\
\hline Etasa & 0 & 0 & 0 & 0 & 0 & 0 & 0 & 75.5 & 18.9 & 3.8 & 1.9 & 0 \\
\hline
\end{tabular}

Tabla 5.26. Frecuencias de las velocidades del viento para el cluster $n^{0} 3$ en las distintas estaciones meteorológicas. Los resultados están expresados en porcentaje de casos para cada rango de velocidad.

\begin{tabular}{|c|c|c|c|c|}
\hline & $0-4.9 \mathrm{~km} / \mathrm{h}$ & $5-10.9 \mathrm{~km} / \mathrm{h}$ & $11-15.9 \mathrm{~km} / \mathrm{h}$ & $\geq 16 \mathrm{~km} / \mathrm{h}$ \\
\hline Ayuntamiento & 0 & 2.8 & 9.4 & 87.7 \\
\hline Escombreras & 0 & 1.9 & 14.2 & 84.0 \\
\hline Lo Campano & 0 & 0.9 & 10.4 & 88.7 \\
\hline Etasa & 0 & 1.9 & 1.9 & 96.2 \\
\hline
\end{tabular}


Figura 5.58. Rosa de los vientos en cada estación meteorológica para el cluster 4 .
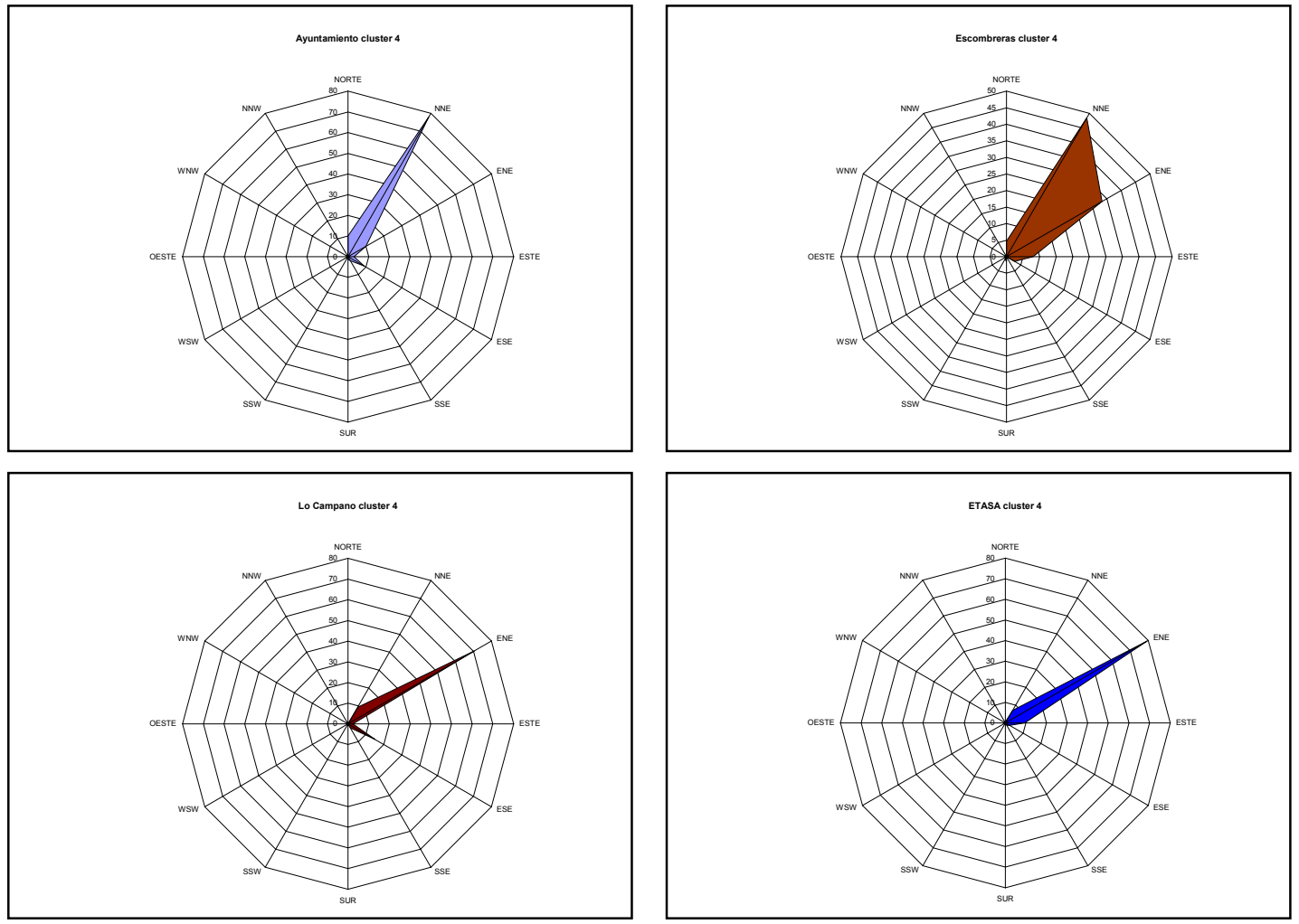

Tabla 5.27. Frecuencias de las direcciones del viento para el cluster $n^{\circ} 4$ en las distintas estaciones meteorológicas. Los resultados están expresados en porcentaje de casos para cada dirección.

\begin{tabular}{|l|c|c|c|c|c|c|c|c|c|c|c|c|}
\hline & N & NNE & ENE & E & ESE & SSE & S & SSW & WSW & W & WNW & NNW \\
\hline Ayuntamiento & 3.3 & 77.9 & 3.3 & 2.8 & 8.9 & 2.3 & 1.4 & 0 & 0 & 0 & 0 & 0 \\
\hline Escombreras & 4.7 & 48.4 & 33.3 & 8.0 & 2.8 & 1.4 & 0.9 & 0 & 0.5 & 0 & 0 & 0 \\
\hline Lo Campano & 0 & 9.4 & 70.4 & 2.3 & 15.0 & 2.3 & 0 & 0 & 0.5 & 0 & 0 & 0 \\
\hline Etasa & 0.5 & 7.0 & 79.3 & 9.4 & 2.3 & 1.4 & 0 & 0 & 0 & 0 & 0 & 0 \\
\hline
\end{tabular}

Tabla 5.28. Frecuencias de las velocidades del viento para el cluster $n^{0} 4$ en las distintas estaciones meteorológicas. Los resultados están expresados en porcentaje de casos para cada rango de velocidad.

\begin{tabular}{|l|c|c|c|c|}
\hline & $\mathbf{0 - 4 . 9} \mathbf{~ k m} / \mathbf{h}$ & $\mathbf{5 - 1 0 . 9} \mathbf{~ k m} / \mathbf{h}$ & $\mathbf{1 1 - 1 5 . 9} \mathbf{~ k m} / \mathbf{h}$ & $\geq \mathbf{1 6} \mathbf{~ k m} / \mathbf{h}$ \\
\hline Ayuntamiento & 0 & 8.5 & 19.2 & 71.8 \\
\hline Escombreras & 0.5 & 26.3 & 38.0 & 35.2 \\
\hline Lo Campano & 0 & 8.0 & 23.0 & 69.0 \\
\hline Etasa & 0 & 0 & 0.5 & 99.5 \\
\hline
\end{tabular}


Figura 5.59. Rosa de los vientos en cada estación meteorológica para el cluster 5 .
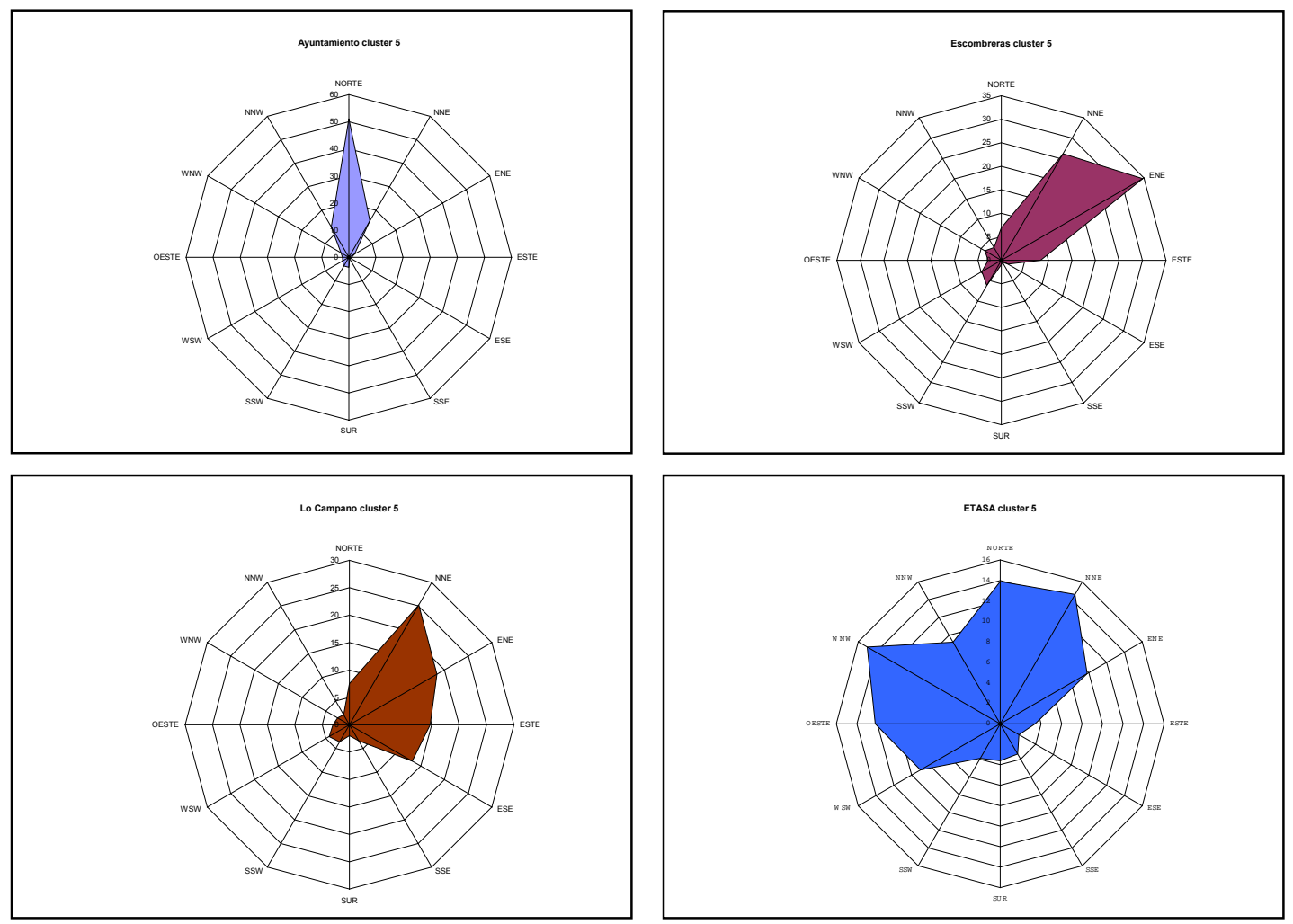

Tabla 5.29. Frecuencias de las direcciones del viento para el cluster $n^{0} 5$ en las distintas estaciones meteorológicas. Los resultados están expresados en porcentaje de casos para cada dirección.

\begin{tabular}{|l|c|c|c|c|c|c|c|c|c|c|c|c|}
\hline & $\mathbf{N}$ & $\mathbf{N N E}$ & $\mathbf{E N E}$ & E & ESE & SSE & S & SSW & WSW & W & WNW & NNW \\
\hline Ayuntamiento & 50.0 & 15.2 & 2.4 & 1.0 & 0.7 & 0.7 & 3.6 & 3.6 & 2.6 & 2.2 & 3.3 & 12.6 \\
\hline Escombreras & 6.9 & 26.2 & 34.7 & 8.3 & 1.6 & 0.5 & 0.9 & 6.2 & 4.8 & 2.8 & 4.1 & 3.1 \\
\hline Lo Campano & 7.2 & 24.3 & 17.8 & 14.1 & 12.8 & 3.3 & 1.9 & 3.4 & 4.1 & 2.9 & 2.4 & 2.1 \\
\hline Etasa & 12.8 & 13.4 & 9.0 & 3.1 & 1.9 & 3.1 & 3.3 & 3.6 & 8.3 & 11.2 & 13.8 & 8.4 \\
\hline
\end{tabular}

Tabla 5.30. Frecuencias de las velocidades del viento para el cluster $n^{\circ} 5$ en las distintas estaciones meteorológicas. Los resultados están expresados en porcentaje de casos para cada rango de velocidad.

\begin{tabular}{|c|c|c|c|c|}
\hline & $0-4.9 \mathrm{~km} / \mathrm{h}$ & $5-10.9 \mathrm{~km} / \mathrm{h}$ & $11-15.9 \mathrm{~km} / \mathrm{h}$ & $\geq 16 \mathrm{~km} / \mathrm{h}$ \\
\hline Ayuntamiento & 34.8 & 46.7 & 12.9 & 5.5 \\
\hline Escombreras & 31.2 & 50.2 & 14.5 & 4.1 \\
\hline Lo Campano & 55.5 & 36.6 & 6.2 & 1.7 \\
\hline Etasa & 32.4 & 32.2 & 15.0 & 20.3 \\
\hline
\end{tabular}




\subsection{RESULADOS DE CLASIFICAR LOS FLUJOS DE VIENTO DOMINANTES EN LA CIUDAD DE CARTAGENA PARA LOS AÑOS 1995-1997 EN 5 GRUPOS.}

Una vez identificados los distintos flujos de viento en la ciudad de Cartagena, tras la aplicación de la técnica clusters en dos pasos a los datos meteorológicos semihorarios de las 4 estaciones de medida, para el 1996, se ha procedido a forzar al algoritmo a clasificar los datos de viento en las 5 situaciones previamente identificadas.

Para ello se han utilizado los centros finales de los conglomerados del año 1996, como centros iniciales en este caso, llegando a una situación muy similar a la que se obtenía para el año 1996.

En la tabla 5.32. se recogen los centros finales de los conglomerados para el año 1996, e historial de iteraciones que se ha empleado para clasificar los años 1995-1997.

En la tabla 5.33., se muestran los conglomerados finales de los nuevos conglomerados obtenidos para los años 1995-1999.

La tabla 5.34., muestra el número de casos incluidos en cada conglomerado identificado, así como el número de casos perdidos.

En la figura 5.60. se presentan las principales características meteorológicas de cada uno de los cluster identificados.

Finalmente, en las figuras 5.61. a 5.65. se recogen las rosas de vientos asociadas a cada uno de los clusters y en cada una de las estaciones meteorológicas.

En las tablas 5.35. a 5.44., se recogen las frecuencias de las direcciones y velocidades del viento, para cada uno de los clusters identificados (1995-1997).

La figura 5.65., muestra la media e intervalo de confianza al 95\% de la concentración polínica total estandarizada para cada cluster. La tabla 5.45., recoge 
el análisis de la varianza de la concentración polínica total estandarizada por cluster, para los años 1995-1997. La figura 5.67., recoge la media e intervalo de confianza al 95\% de la concentración polínica total estandarizada para las distintas estaciones del año, para el periodo 1995-1999.

Tabla 5.32. Centros finales de los conglomerados para el año 1996 e historial de las iteraciones.

Centros iniciales de los conglomerados

\begin{tabular}{|l|c|c|c|c|c|}
\hline & \multicolumn{5}{|c|}{ Conglomerados } \\
\cline { 2 - 6 } & 1 & 2 & \multicolumn{1}{|c|}{3} & \multicolumn{1}{c|}{4} \\
\hline $\begin{array}{l}\text { REGR factor score } \\
\text { 1 for analysis 1 } \\
\begin{array}{l}\text { REGR factor score } \\
2 \text { for analysis 1 }\end{array}\end{array}$ & -04963 &,- 76457 & $-1,83995$ & 1,43408 &, 27736 \\
\hline
\end{tabular}

Historial de iteraciones ${ }^{a}$

\begin{tabular}{|l|r|c|c|c|c|}
\hline \multirow{2}{*}{ Iteración } & \multicolumn{5}{|c|}{ Cambio en los centros de los conglomerados } \\
\cline { 2 - 6 } & 1 & 2 & 3 & 4 & 5 \\
\hline 1 &, 164 & $5,05 \mathrm{E}-02$ & $7,14 \mathrm{E}-02$ &, 104 & $1,87 \mathrm{E}-02$ \\
3 & $9,82 \mathrm{E}-02$ & $2,93 \mathrm{E}-02$ & $6,04 \mathrm{E}-02$ & $2,44 \mathrm{E}-02$ & $1,35 \mathrm{E}-02$ \\
4 & $6,24 \mathrm{E}-02$ & $2,60 \mathrm{E}-02$ & $4,79 \mathrm{E}-02$ & $9,04 \mathrm{E}-03$ & $1,14 \mathrm{E}-02$ \\
5 & $3,36 \mathrm{E}-02$ & $2,05 \mathrm{E}-02$ & $3,34 \mathrm{E}-02$ & $9,73 \mathrm{E}-03$ & $8,13 \mathrm{E}-03$ \\
6 & $2,75 \mathrm{E}-02$ & $1,67 \mathrm{E}-02$ & $2,39 \mathrm{E}-02$ & $9,41 \mathrm{E}-03$ & $6,76 \mathrm{E}-03$ \\
7 & $1,32 \mathrm{E}-02$ & $8,12 \mathrm{E}-03$ & $1,15 \mathrm{E}-02$ & $4,43 \mathrm{E}-03$ & $2,87 \mathrm{E}-03$ \\
8 & $9,71 \mathrm{E}-03$ & $7,38 \mathrm{E}-03$ & $1,18 \mathrm{E}-02$ & $2,96 \mathrm{E}-03$ & $2,44 \mathrm{E}-03$ \\
9 & $5,57 \mathrm{E}-03$ & $5,54 \mathrm{E}-03$ & $9,84 \mathrm{E}-03$ & $3,17 \mathrm{E}-03$ & $1,96 \mathrm{E}-03$ \\
10 & $7,98 \mathrm{E}-03$ & $3,79 \mathrm{E}-03$ & $6,99 \mathrm{E}-03$ & $2,41 \mathrm{E}-03$ & $1,95 \mathrm{E}-03$ \\
& $1,01 \mathrm{E}-02$ & $3,23 \mathrm{E}-03$ & $4,38 \mathrm{E}-03$ & $2,57 \mathrm{E}-03$ & $2,40 \mathrm{E}-03$ \\
\hline
\end{tabular}

a. Las iteraciones se han detenido porque se ha llevado a cabo el número máximo de iteraciones. Las iteraciones no han convergido. La distancia máxima en la que han cambiado los centros es 7,442E-03. La iteración actual es 10. La distancia mínima entre los centros iniciales es 1,376. 
Tabla 5.33. Centros finales de los conglomerados para los años 1995-1997.

Centros de los conglomerados finales

\begin{tabular}{|l|c|r|r|r|r|}
\hline & \multicolumn{5}{|c|}{ Conglomerados } \\
\cline { 2 - 6 } & 1 & 2 & \multicolumn{1}{c|}{3} & \multicolumn{1}{c|}{5} \\
\hline $\begin{array}{l}\text { REGR factor score } \\
\text { 1 for analysis 1 }\end{array}$ &, 24518 &,- 60560 & $-1,68376$ & 1,43668 &, 27391 \\
$\begin{array}{l}\text { REGR factor score } \\
\text { 2 for analysis 1 }\end{array}$ & $-2,14090$ &, 73624 &, 04360 &, 95826 &,- 23992 \\
\hline
\end{tabular}

Tabla 5.34. Número de casos incluidos en cada cluster identificado para los años 19951997.

Número de casos en cada conglomerado

\begin{tabular}{|ll|r|}
\hline Conglomerado & 1 & 709,000 \\
& 2 & 1690,000 \\
& 3 & 929,000 \\
& 4 & 1059,000 \\
& 5 & 3258,000 \\
Válidos & & 7645,000 \\
Perdidos & & 1123,000 \\
\hline
\end{tabular}


Figura 5.60. Media e intervalo de confianza al $95 \%$ de los distintos parámetros meteorológicos para cada cluster, para el periodo 1995-1997.
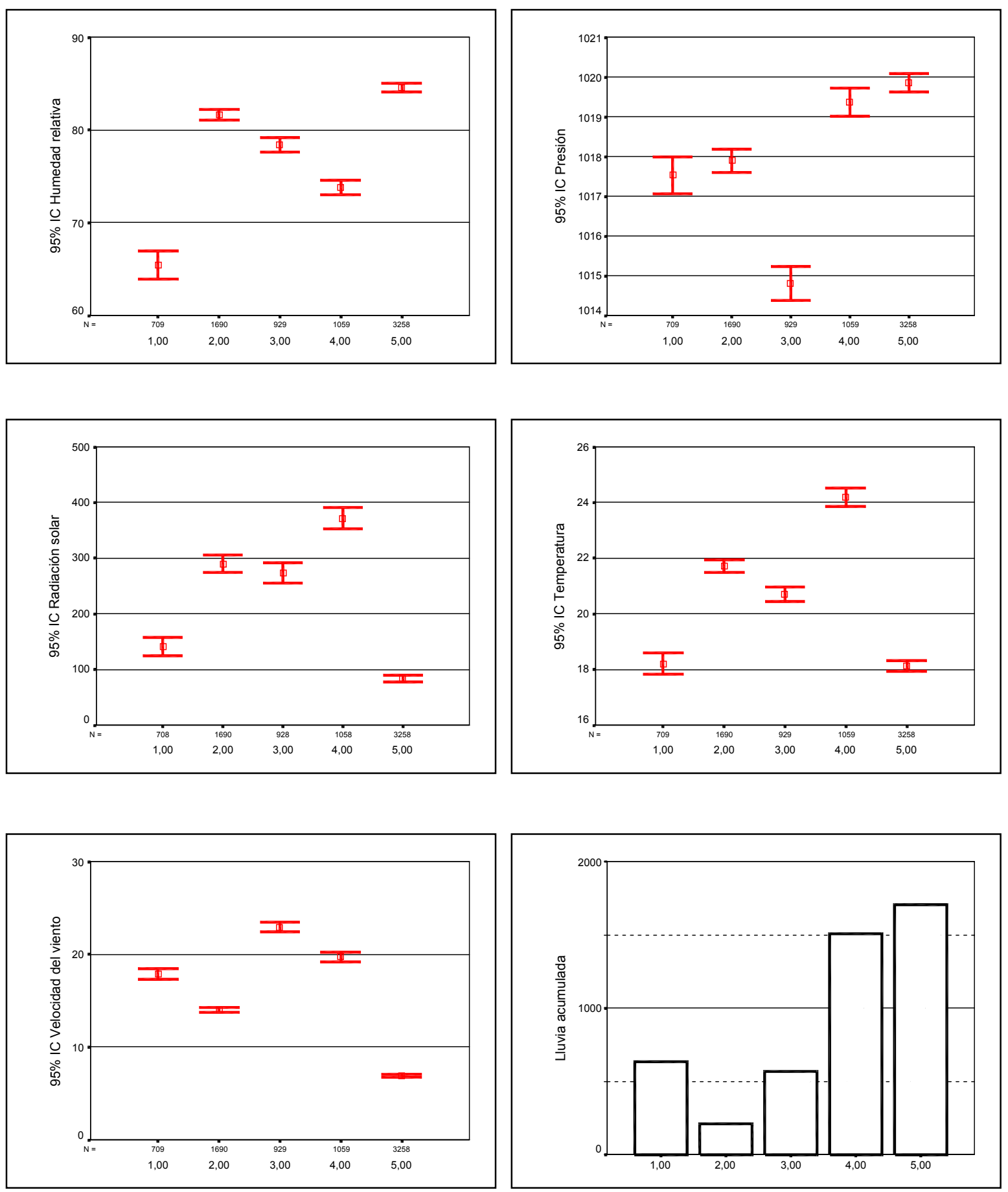
Figura 5.61. Rosa de los vientos en cada estación meteorológica para el cluster 1 .
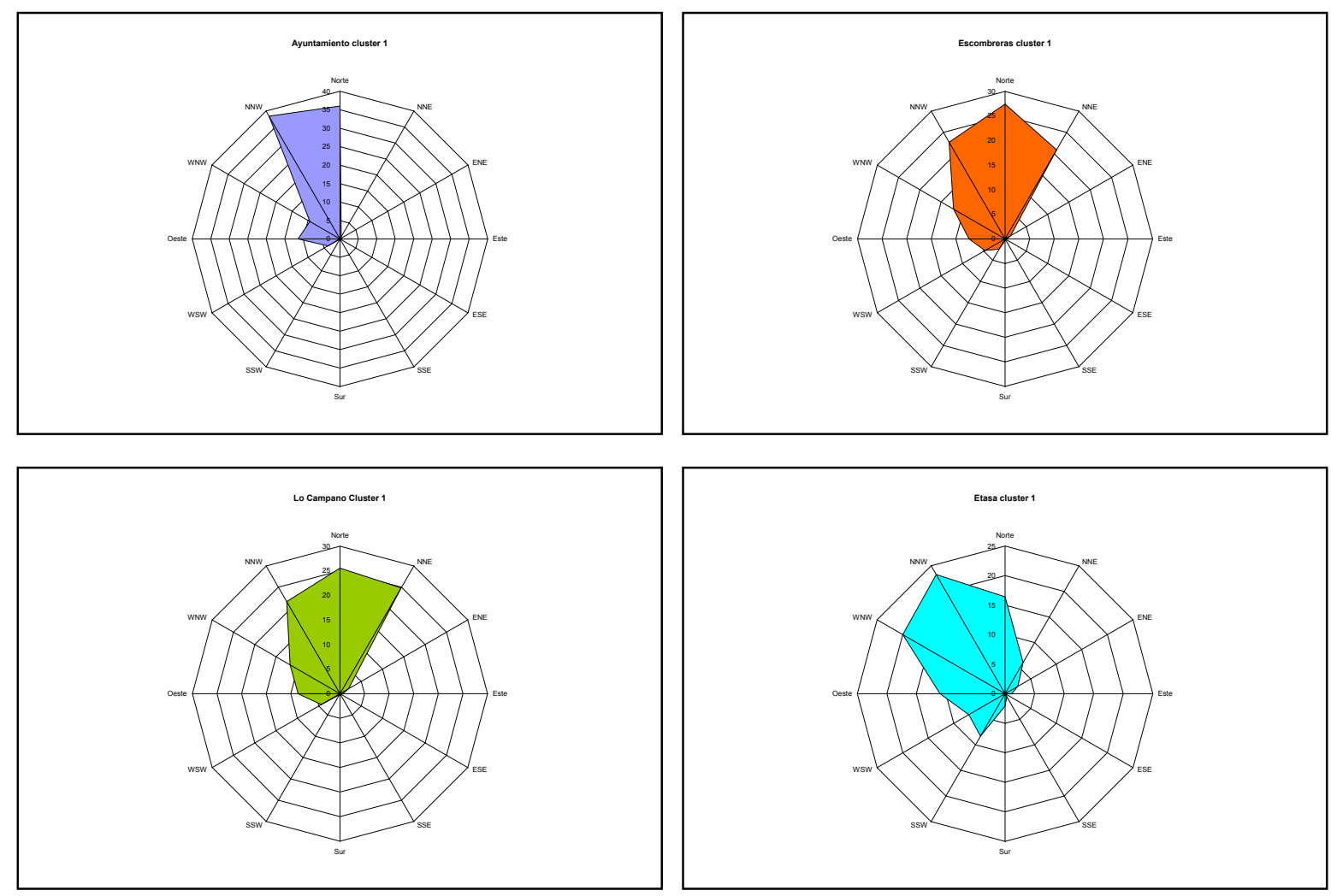

Tabla 5.35. Frecuencias de las direcciones del viento para el cluster $n^{\circ} 1$ en las distintas estaciones meteorológicas. Los resultados están expresados en porcentaje de casos para cada dirección.

\begin{tabular}{|l|c|c|c|c|c|c|c|c|c|c|c|c|}
\hline & N & NNE & ENE & E & ESE & SSE & S & SSW & WSW & W & WNW & NNW \\
\hline Ayuntamiento & 36.0 & 0.7 & 0.1 & 0 & 0.1 & 0 & 0 & 0.1 & 3.8 & 11.3 & 9.4 & 38.4 \\
\hline Escombreras & 27.5 & 20.9 & 1.3 & 0.4 & 0.1 & 0.1 & 0.4 & 2.4 & 4.7 & 7.3 & 12.1 & 22.7 \\
\hline Lo Campano & 25.5 & 24.8 & 2.0 & 0.6 & 0.3 & 0.3 & 0 & 0.3 & 4.4 & 8.5 & 11.7 & 21.6 \\
\hline Etasa & 16.4 & 6.1 & 2.5 & 1.1 & 0.1 & 0.6 & 2.1 & 8.3 & 7.1 & 11.0 & 20.0 & 23.3 \\
\hline
\end{tabular}

Tabla 5.36. Frecuencias de las velocidades del viento para el cluster $n^{\circ} 1$ en las distintas estaciones meteorológicas. Los resultados están expresados en porcentaje de casos para cada rango de velocidad.

\begin{tabular}{|l|c|c|c|c|}
\hline & $\mathbf{0 - 4 . 9} \mathbf{~ k m} / \mathbf{h}$ & $\mathbf{5 - 1 0 . 9} \mathbf{~ k m} / \mathbf{h}$ & $\mathbf{1 1 - 1 5 . 9} \mathbf{~ k m} / \mathbf{h}$ & $\geq \mathbf{1 6} \mathbf{~ k m} / \mathbf{h}$ \\
\hline Ayuntamiento & 4.4 & 12.0 & 23.7 & 59.9 \\
\hline Escombreras & 7.8 & 17.6 & 32.2 & 42.5 \\
\hline Lo Campano & 11.7 & 27.4 & 25.8 & 35.1 \\
\hline Etasa & 9.4 & 8.3 & 12.1 & 70.1 \\
\hline
\end{tabular}


Figura 5.62. Rosa de los vientos en cada estación meteorológica para el cluster 2 .
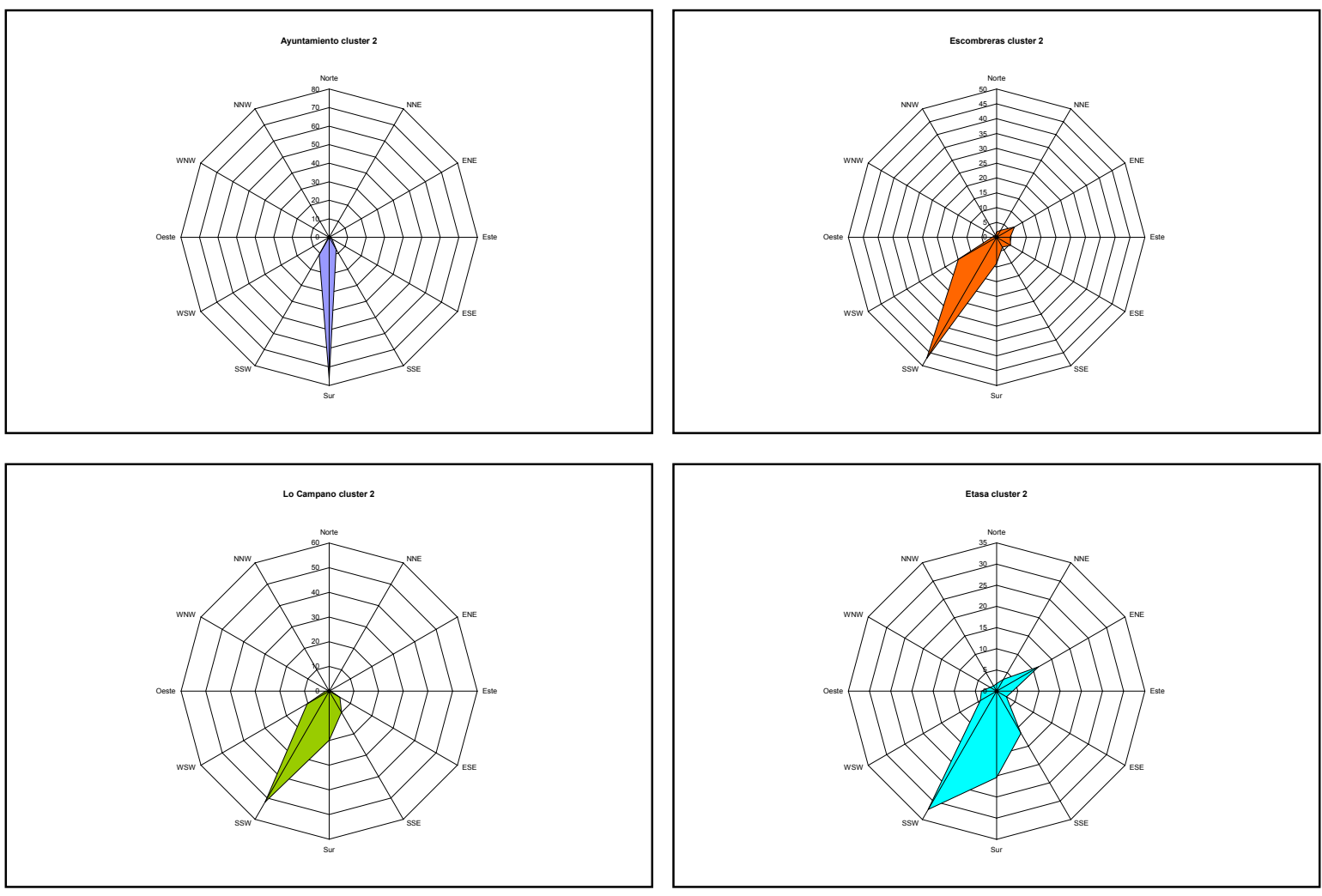

Tabla 5.37. Frecuencias de las direcciones del viento para el cluster $n^{\circ} 2$ en las distintas estaciones meteorológicas. Los resultados están expresados en porcentaje de casos para cada dirección.

\begin{tabular}{|l|c|c|c|c|c|c|c|c|c|c|c|c|}
\hline & N & NNE & ENE & E & ESE & SSE & S & SSW & WSW & W & WNW & NNW \\
\hline Ayuntamiento & 0.5 & 0.7 & 0.7 & 0.7 & 1.8 & 7.6 & 76.5 & 10.8 & 0.5 & 0.1 & 0 & 0.1 \\
\hline Escombreras & 1.8 & 2.7 & 7.0 & 4.6 & 5.4 & 3.8 & 8.8 & 47.2 & 14.9 & 1.5 & 0.9 & 0.8 \\
\hline Lo Campano & 0.1 & 0.2 & 0.5 & 0.7 & 5.1 & 9.9 & 19.9 & 51.8 & 10.2 & 1.4 & 0.2 & 0 \\
\hline Etasa & 1.8 & 3.2 & 11.4 & 3.8 & 2.7 & 11.5 & 20.4 & 32.3 & 4.4 & 3.6 & 1.8 & 1.4 \\
\hline
\end{tabular}

Tabla 5.38. Frecuencias de las velocidades del viento para el cluster $n^{0} 2$ en las distintas estaciones meteorológicas. Los resultados están expresados en porcentaje de casos para cada rango de velocidad.

\begin{tabular}{|l|c|c|c|c|}
\hline & $\mathbf{0 - 4 . 9} \mathbf{~ k m} / \mathbf{h}$ & $\mathbf{5 - 1 0 . 9} \mathbf{~ k m} / \mathbf{h}$ & $\mathbf{1 1 - 1 5 . 9} \mathbf{~ k m} / \mathbf{h}$ & $\geq \mathbf{1 6 ~ k m} / \mathbf{h}$ \\
\hline Ayuntamiento & 11.3 & 16.7 & 30.6 & 41.4 \\
\hline Escombreras & 27.3 & 45.0 & 22.7 & 5.0 \\
\hline Lo Campano & 15.0 & 25.6 & 28.4 & 30.9 \\
\hline Etasa & 12.5 & 14.7 & 18.1 & 54.6 \\
\hline
\end{tabular}


Figura 5.63. Rosa de los vientos en cada estación meteorológica para el cluster 3 .
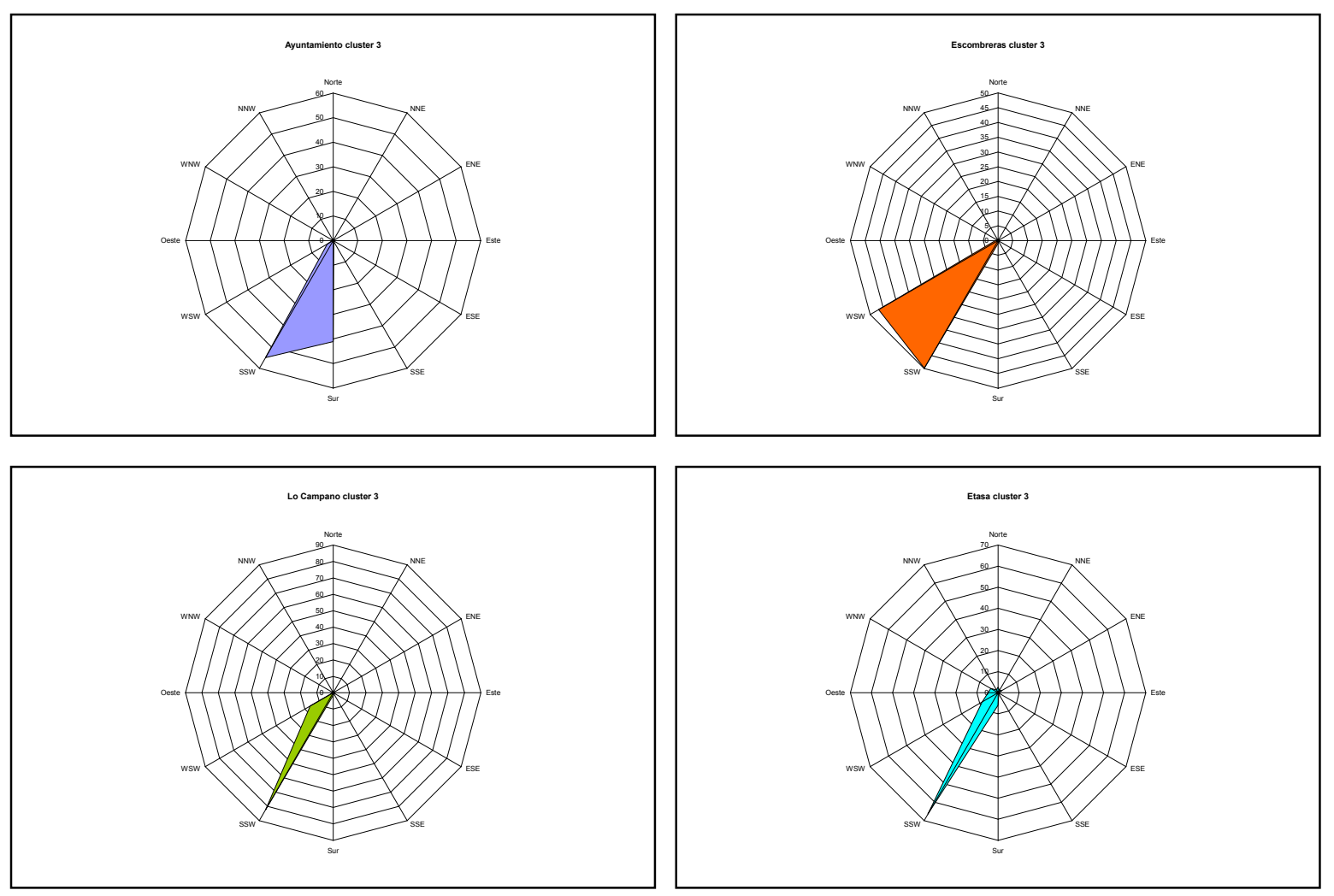

Tabla5.39. Frecuencias de las direcciones del viento para el cluster $n^{\circ} 3$ en las distintas estaciones meteorológicas. Los resultados están expresados en porcentaje de casos para cada dirección.

\begin{tabular}{|l|c|c|c|c|c|c|c|c|c|c|c|c|}
\hline & N & NNE & ENE & E & ESE & SSE & S & SSW & WSW & W & WNW & NNW \\
\hline Ayuntamiento & 0.1 & 0.1 & 0 & 0 & 0.1 & 0 & 41.1 & 55.0 & 2.9 & 0.4 & 0.1 & 0 \\
\hline Escombreras & 0 & 0.2 & 0.4 & 0.1 & 0 & 0.2 & 1.0 & 49.9 & 46.7 & 0.9 & 0.1 & 0.2 \\
\hline Lo Campano & 0 & 0 & 0 & 0 & 0 & 0.1 & 1.4 & 82.2 & 16.1 & 0 & 0 & 0 \\
\hline Etasa & 2.6 & 1.3 & 1.9 & 0.3 & 0.5 & 0.6 & 5.9 & 66.4 & 8.7 & 4.7 & 4.0 & 1.6 \\
\hline
\end{tabular}

Tabla 5.40. Frecuencias de las velocidades del viento para el cluster $n^{\circ} 3$ en las distintas estaciones meteorológicas. Los resultados están expresados en porcentaje de casos para cada rango de velocidad.

\begin{tabular}{|l|c|c|c|c|}
\hline & $\mathbf{0 - 4 . 9} \mathbf{~ k m} / \mathbf{h}$ & $\mathbf{5 - 1 0 . 9} \mathbf{~ k m} / \mathbf{h}$ & $\mathbf{1 1 - 1 5 . 9} \mathbf{~ k m} / \mathbf{h}$ & $\geq \mathbf{1 6} \mathbf{~ k m} / \mathbf{h}$ \\
\hline Ayuntamiento & 1.7 & 3.1 & 12.2 & 83.0 \\
\hline Escombreras & 3.4 & 10.4 & 27.7 & 58.4 \\
\hline Lo Campano & 0.3 & 2.3 & 10.3 & 87.1 \\
\hline Etasa & 6.8 & 6.7 & 5.2 & 81.4 \\
\hline
\end{tabular}


Figura 5.64. Rosa de los vientos en cada estación meteorológica para el cluster 4 .
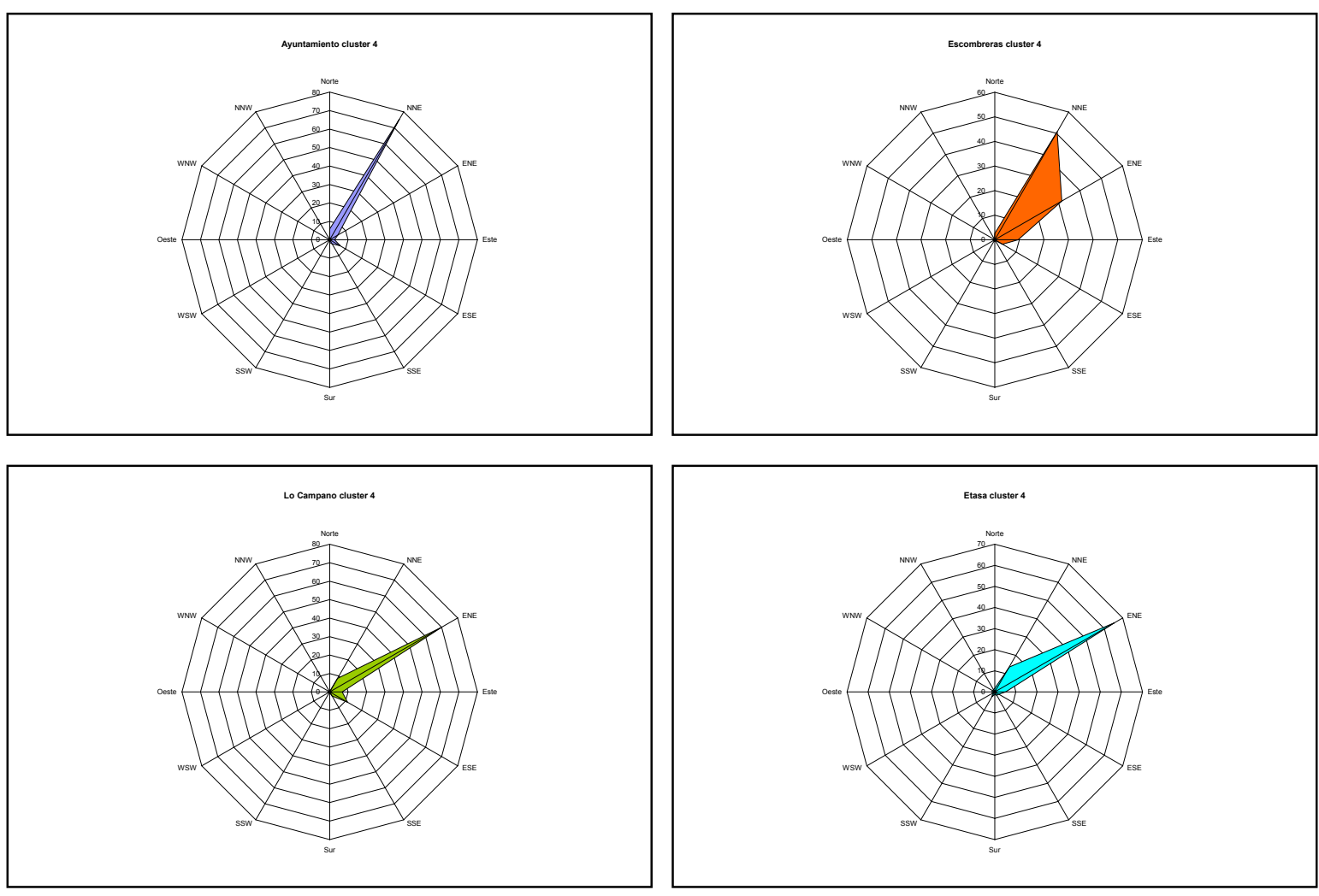

Tabla 5.41. Frecuencias de las direcciones del viento para el cluster $n^{\circ} 4$ en las distintas estaciones meteorológicas. Los resultados están expresados en porcentaje de casos para cada dirección.

\begin{tabular}{|l|c|c|c|c|c|c|c|c|c|c|c|c|}
\hline & N & NNE & ENE & E & ESE & SSE & S & SSW & WSW & W & WNW & NNW \\
\hline Ayuntamiento & 5.9 & 75.4 & 5.1 & 2.6 & 6.6 & 2.5 & 1.4 & 0.1 & 0 & 0 & 0 & 0.1 \\
\hline Escombreras & 2.6 & 50.7 & 31.4 & 9.5 & 3.6 & 0.3 & 0.7 & 0.5 & 0.3 & 0.1 & 0.1 & 0.2 \\
\hline Lo Campano & 0.2 & 8.4 & 70.2 & 6.8 & 11.1 & 2.5 & 0.4 & 0.1 & 0 & 0.1 & 0 & 0 \\
\hline Etasa & 1.7 & 13.7 & 65.5 & 5.2 & 2.2 & 1.8 & 1.3 & 2.6 & 1.2 & 1.5 & 1.0 & 1.3 \\
\hline
\end{tabular}

Tabla 5.42. Frecuencias de las velocidades del viento para el cluster $n^{\circ} 4$ en las distintas estaciones meteorológicas. Los resultados están expresados en porcentaje de casos para cada rango de velocidad.

\begin{tabular}{|l|c|c|c|c|}
\hline & $\mathbf{0 - 4 . 9} \mathbf{~ k m} / \mathbf{h}$ & $\mathbf{5 - 1 0 . 9} \mathbf{~ k m} / \mathbf{h}$ & $\mathbf{1 1 - 1 5 . 9} \mathbf{~ k m} / \mathbf{h}$ & $\geq \mathbf{1 6} \mathbf{~ k m} / \mathbf{h}$ \\
\hline Ayuntamiento & 5.8 & 8.1 & 17.2 & 68.8 \\
\hline Escombreras & 7.1 & 17.3 & 36.9 & 38.7 \\
\hline Lo Campano & 4.2 & 8.3 & 20.0 & 67.5 \\
\hline Etasa & 4.6 & 3.2 & 4.1 & 88.1 \\
\hline
\end{tabular}


Figura 5.65. Rosa de los vientos en cada estación meteorológica para el cluster 5 .
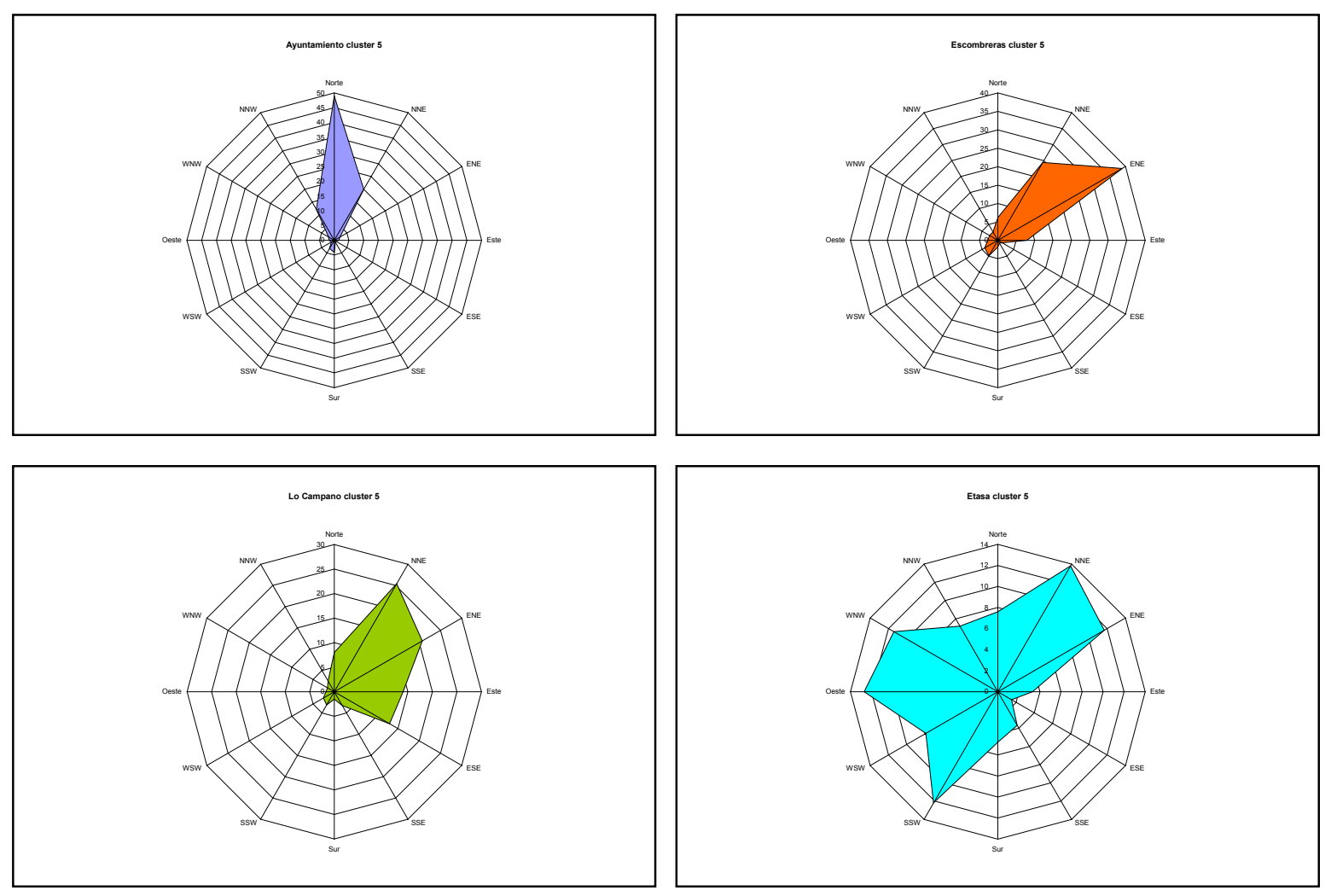

Tabla 5.43. Frecuencias de las direcciones del viento para el cluster $n^{0} 5$ en las distintas estaciones meteorológicas. Los resultados están expresados en porcentaje de casos para cada dirección.

\begin{tabular}{|l|c|c|c|c|c|c|c|c|c|c|c|c|}
\hline & N & NNE & ENE & E & ESE & SSE & S & SSW & WSW & W & WNW & NNW \\
\hline Ayuntamiento & 48.9 & 20.0 & 2.3 & 1.6 & 0.5 & 0.8 & 4.1 & 3.2 & 1.1 & 1.7 & 2.2 & 12.1 \\
\hline Escombreras & 6.2 & 24.4 & 39.0 & 7.9 & 1.3 & 0.9 & 1.8 & 4.8 & 4.1 & 2.7 & 2.6 & 2.6 \\
\hline Lo Campano & 8.0 & 25.4 & 20.7 & 14.0 & 13.0 & 3.2 & 1.5 & 3.1 & 2.5 & 1.7 & 1.6 & 2.5 \\
\hline Etasa & 7.6 & 13.8 & 11.7 & 3.3 & 1.5 & 3.7 & 4.8 & 12.2 & 7.9 & 12.7 & 11.4 & 7.2 \\
\hline
\end{tabular}

Tabla 5.44. Frecuencias de las velocidades del viento para el cluster $n^{\circ} 5$ en las distintas estaciones meteorológicas. Los resultados están expresados en porcentaje de casos para cada rango de velocidad.

\begin{tabular}{|l|c|c|c|c|}
\hline & $\mathbf{0 - 4 . 9} \mathbf{~ k m} / \mathbf{h}$ & $\mathbf{5 - 1 0 . 9} \mathbf{~ k m} / \mathbf{h}$ & $\mathbf{1 1 - 1 5 . 9} \mathbf{~ k m} / \mathbf{h}$ & $\geq \mathbf{1 6 ~ k m} / \mathbf{h}$ \\
\hline Ayuntamiento & 39.9 & 41.1 & 12.0 & 7.1 \\
\hline Escombreras & 41.2 & 38.2 & 15.7 & 4.9 \\
\hline Lo Campano & 58.8 & 30.4 & 6.7 & 4.0 \\
\hline Etasa & 30.8 & 25.4 & 12.9 & 31.0 \\
\hline
\end{tabular}


Figura 5.66. Concentración polínica media estandarizada e intervalo de confianza al 95\% para cada cluster de los años 1995-1999.

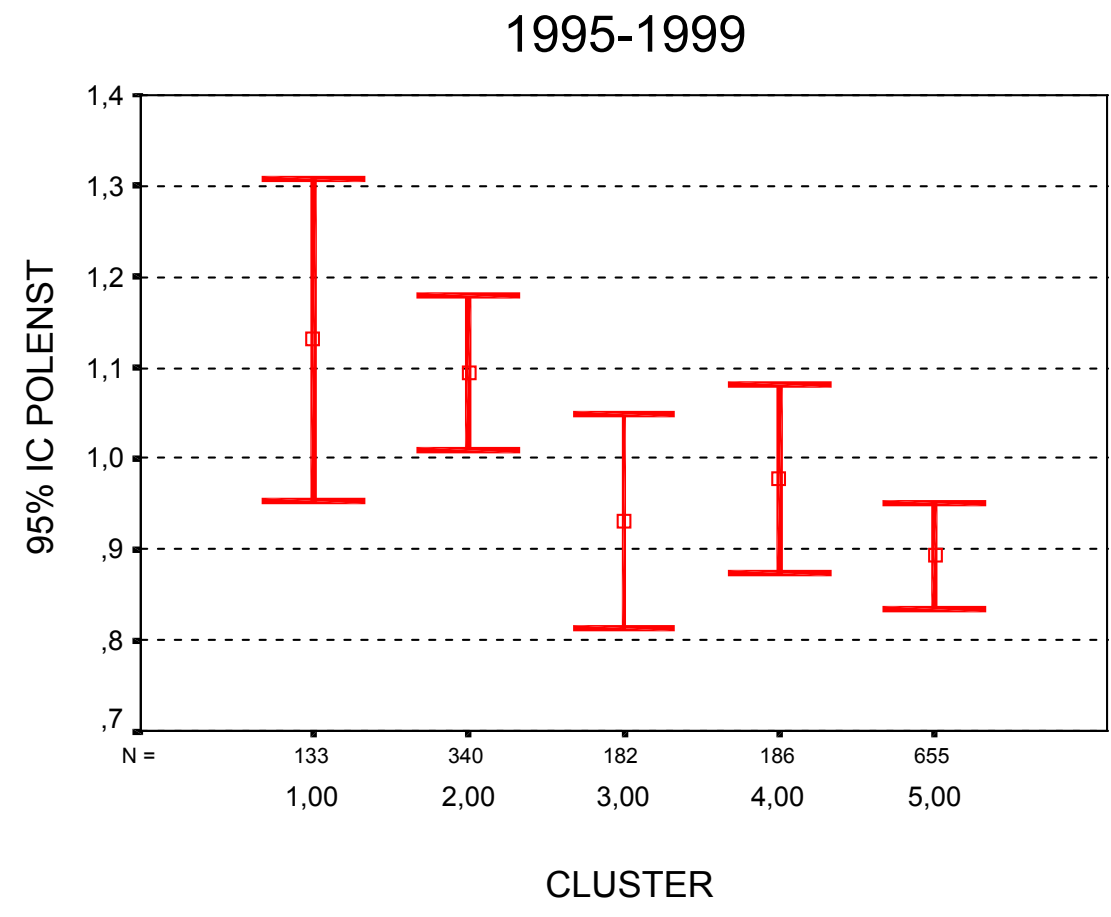

Tabla 5.45. Concentración polínica total estandarizada por clusters y ANOVA de los años 1995 a 1999.

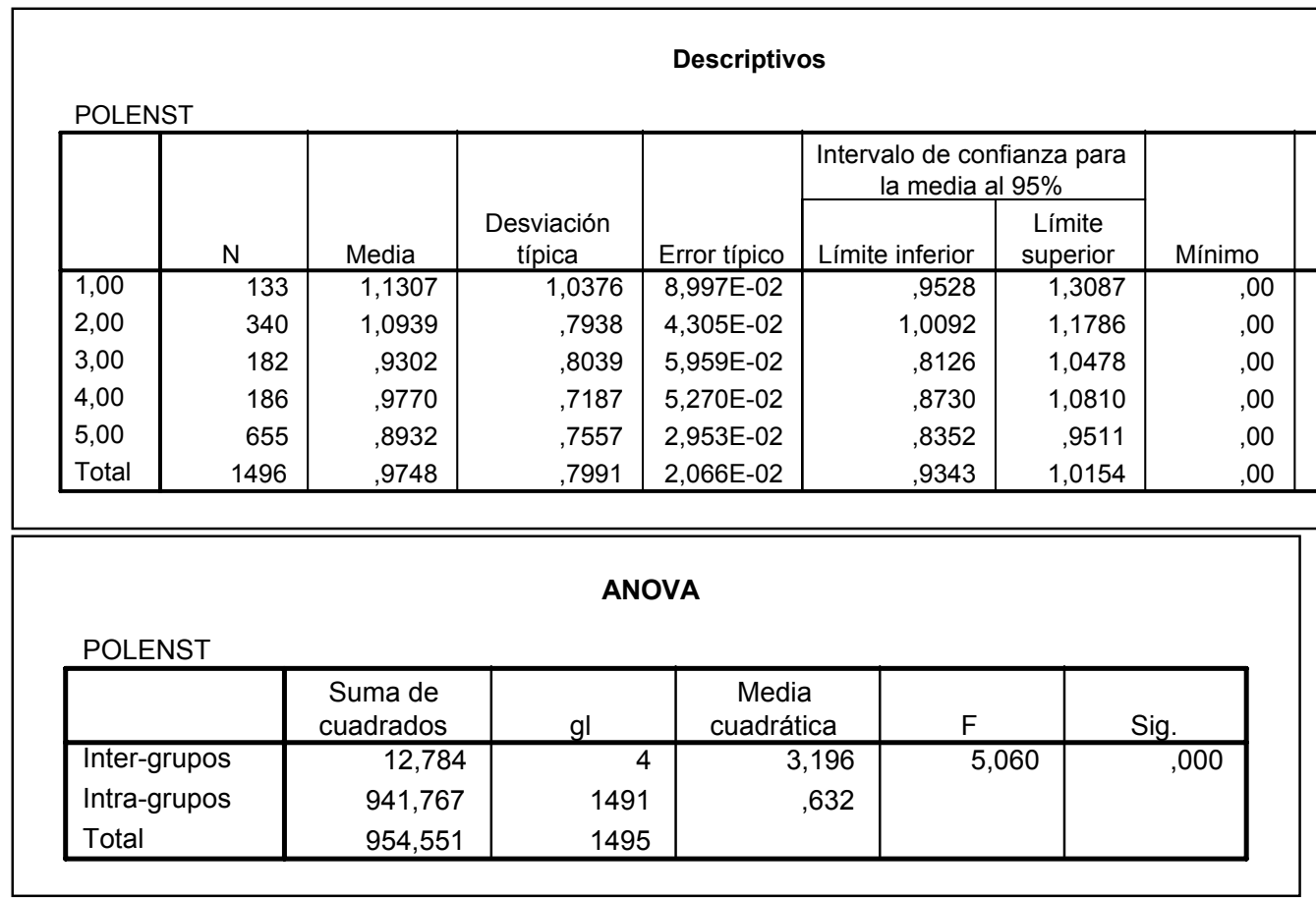


Figura 5.67. Concentración polínica media estandarizada e intervalo de confianza al 95\% para cada cluster y para cada estación de los años 1995-1999.
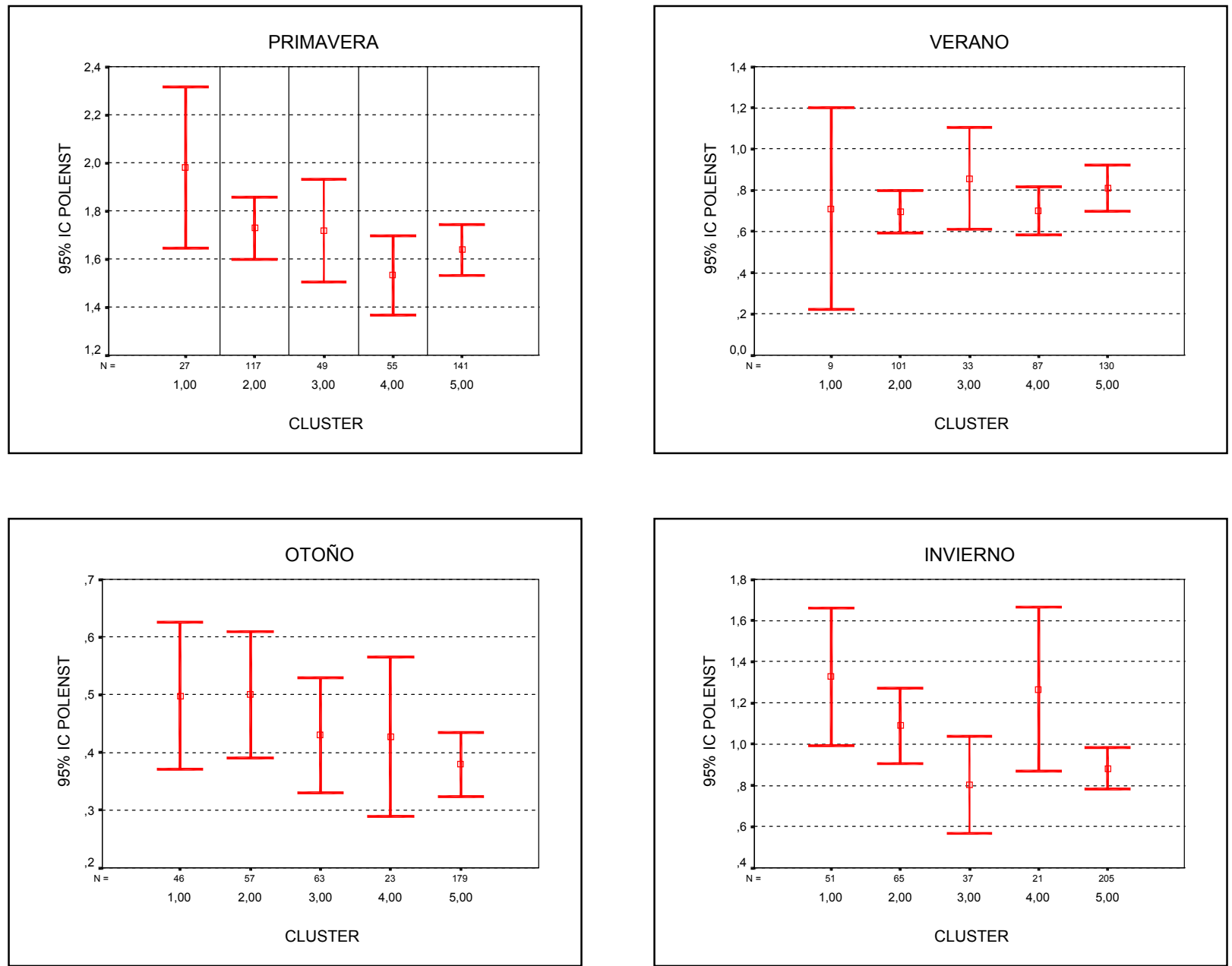


\subsection{MODELOS DE REGRESIÓN LINEAL MÚLTIPLE.}

\subsubsection{PÓLENES TOTALES.}

5.6.1.1. CORRELACIONES BIVARIADAS ENTRE LA CONCENTRACIÓN POLÍNICA TOTAL DIARIA ESTANDARIZADA Y LAS VARIABLES UTILIZADAS.

En la tabla 5.46. se presentan las correlaciones bivariadas entre la variable POLMODEL (concentración polínica total diaria estandarizada de las primeras 30 semanas de los años 1995-1999), y el resto de variables que se han creado para construir la base datos meteorológica y aerobiológica.

Tabla 5.46. Correlaciones bivariadas de Pearson entre la variable concentración polínica total diaria estandarizada para los años 1995-1999 y el resto de variables, nivel de significación y tamaño de la muestra en cada caso.

\begin{tabular}{|c|c|c|}
\hline & & POLMODEL \\
\hline CLUSTER & C. Pearson & $\mathbf{- 0 . 1 3 2 * *}$ \\
& Sig. (bilateral) & 0.000 \\
& $\mathbf{N}$ & 914 \\
\hline CLUSTER1 & C. Pearson & $\mathbf{0 . 1 2 * *}$ \\
& Sig. (bilateral) & 0.000 \\
\hline CLUSTER2 & N & 914 \\
& Cig. Pearson & 0.040 \\
& $\mathbf{N}$ & 0.232 \\
& C. Pearson & 914 \\
\hline CLUSTER3 & Sig. (bilateral) & 0.045 \\
& $\mathbf{N}$ & 0.179 \\
& & 914 \\
\hline
\end{tabular}


Tabla 5.46. Continuación. Correlaciones bivariadas de Pearson entre la variable concentración polínica total diaria estandarizada para los años 1995-1999 y el resto de variables, nivel de significación y tamaño de la muestra en cada caso.

\begin{tabular}{|c|c|c|}
\hline CLUSTER4 & $\begin{array}{c}\text { C. Pearson } \\
\text { Sig. (bilateral) } \\
\text { N }\end{array}$ & $\begin{array}{c}-0.032 \\
0.331 \\
914\end{array}$ \\
\hline CLUSTER5 & $\begin{array}{c}\text { C. Pearson } \\
\text { Sig. (bilateral) } \\
\text { N }\end{array}$ & $\begin{array}{c}\mathbf{- 0 . 1 4 1 * *} \\
0.000 \\
914\end{array}$ \\
\hline ESTACIÓN & $\begin{array}{c}\text { C. Pearson } \\
\text { Sig. (bilateral) } \\
\text { N }\end{array}$ & $\begin{array}{c}0.026 \\
0.423 \\
985\end{array}$ \\
\hline SEMANA & $\begin{array}{c}\text { C. Pearson } \\
\text { Sig. (bilateral) } \\
\text { N }\end{array}$ & $\begin{array}{c}\mathbf{0 . 1 4 1} * * \\
0.000 \\
985\end{array}$ \\
\hline PRBMEDIA & $\begin{array}{c}\text { C. Pearson } \\
\text { Sig. (bilateral) } \\
\text { N }\end{array}$ & $\begin{array}{c}\mathbf{- 0 . 0 7 8 *} \\
0.014 \\
985\end{array}$ \\
\hline TMPMEDIA & $\begin{array}{c}\text { C. Pearson } \\
\text { Sig. (bilateral) } \\
\text { N }\end{array}$ & $\begin{array}{c}\mathbf{0 . 0 7 9 *} \\
0.013 \\
985\end{array}$ \\
\hline HRMEDIA & $\begin{array}{c}\text { C. Pearson } \\
\text { Sig. (bilateral) } \\
\text { N }\end{array}$ & $\begin{array}{c}-\mathbf{0 . 2 1 7} * * \\
0.000 \\
985\end{array}$ \\
\hline
\end{tabular}


Tabla 5.46. Continuación. Correlaciones bivariadas de Pearson entre la variable concentración polínica total diaria estandarizada para los años 1995-1999 y el resto de variables, nivel de significación y tamaño de la muestra en cada caso.

\begin{tabular}{|c|c|c|}
\hline WMEDIA & $\begin{array}{c}\text { C. Pearson } \\
\text { Sig. (bilateral) } \\
\text { N }\end{array}$ & $\begin{array}{c}\mathbf{0 . 1 5 3 * *} \\
0.000 \\
985\end{array}$ \\
\hline DIRMEDIA & $\begin{array}{c}\text { C. Pearson } \\
\text { Sig. (bilateral) } \\
\text { N }\end{array}$ & $\begin{array}{c}\mathbf{0 . 0 8 2} * * \\
0.010 \\
985\end{array}$ \\
\hline RSACUM & $\begin{array}{c}\text { C. Pearson } \\
\text { Sig. (bilateral) } \\
\text { N }\end{array}$ & $\begin{array}{c}\mathbf{0 . 2 9 3} * * \\
0.000 \\
985\end{array}$ \\
\hline LLUVIADI & $\begin{array}{c}\text { C. Pearson } \\
\text { Sig. (bilateral) } \\
\text { N }\end{array}$ & $\begin{array}{c}-0.048 \\
0.134 \\
985\end{array}$ \\
\hline RUMBOS & $\begin{array}{c}\text { C. Pearson } \\
\text { Sig. (bilateral) } \\
\text { N }\end{array}$ & $\begin{array}{c}\mathbf{0 . 0 6 4 *} \\
0.046 \\
974\end{array}$ \\
\hline RANGO & $\begin{array}{c}\text { C. Pearson } \\
\text { Sig. (bilateral) } \\
\text { N }\end{array}$ & $\begin{array}{c}\mathbf{0 . 1 8 2} * * \\
0.000 \\
920\end{array}$ \\
\hline RUMBOS4 & $\begin{array}{c}\text { C. Pearson } \\
\text { Sig. (bilateral) } \\
\text { N }\end{array}$ & $\begin{array}{c}\mathbf{0 . 0 6 5 *} \\
0.043 \\
984\end{array}$ \\
\hline
\end{tabular}


Tabla 5.46. Continuación. Correlaciones bivariadas de Pearson entre la variable concentración polínica total diaria estandarizada para los años 1995-1999 y el resto de variables, nivel de significación y tamaño de la muestra en cada caso.

\begin{tabular}{|c|c|c|}
\hline TMIN & $\begin{array}{c}\text { C. Pearson } \\
\text { Sig. (bilateral) } \\
\text { N }\end{array}$ & $\begin{array}{c}\mathbf{0 . 0 7 4 *} \\
0.20 \\
985\end{array}$ \\
\hline TMAX & $\begin{array}{c}\text { C. Pearson } \\
\text { Sig. (bilateral) } \\
\text { N }\end{array}$ & $\begin{array}{c}\mathbf{0 . 0 8 6 *} \\
0.007 \\
985\end{array}$ \\
\hline HRMIN & $\begin{array}{c}\text { C. Pearson } \\
\text { Sig. (bilateral) } \\
\text { N }\end{array}$ & $\begin{array}{c}-\mathbf{0 . 2 2 5} * * \\
0.000 \\
985\end{array}$ \\
\hline HRMAX & $\begin{array}{c}\text { C. Pearson } \\
\text { Sig. (bilateral) } \\
\text { N }\end{array}$ & $\begin{array}{c}-\mathbf{0 . 1 1 8 * *} \\
0.000 \\
985\end{array}$ \\
\hline PRBMIN & $\begin{array}{c}\text { C. Pearson } \\
\text { Sig. (bilateral) } \\
\text { N }\end{array}$ & $\begin{array}{c}\mathbf{- 0 . 0 7 9 *} \\
0.013 \\
985\end{array}$ \\
\hline PRBMAX & $\begin{array}{c}\text { C. Pearson } \\
\text { Sig. (bilateral) } \\
\text { N }\end{array}$ & $\begin{array}{c}\mathbf{- 0 . 0 7 5 *} \\
0.019 \\
985\end{array}$ \\
\hline RSACU1 & $\begin{array}{c}\text { C. Pearson } \\
\text { Sig. (bilateral) } \\
\text { N }\end{array}$ & $\begin{array}{c}\mathbf{0 . 2 9 3} * * \\
0.000 \\
985\end{array}$ \\
\hline
\end{tabular}


Tabla 5.46. Continuación. Correlaciones bivariadas de Pearson entre la variable concentración polínica total diaria estandarizada para los años 1995-1999 y el resto de variables, nivel de significación y tamaño de la muestra en cada caso.

\begin{tabular}{|c|c|c|}
\hline$\Delta \mathbf{T}$ & $\begin{array}{c}\text { C. Pearson } \\
\text { Sig. (bilateral) } \\
\text { N }\end{array}$ & $\begin{array}{c}0.019 \\
0.547 \\
985\end{array}$ \\
\hline$\Delta \mathbf{H R}$ & $\begin{array}{c}\text { C. Pearson } \\
\text { Sig. (bilateral) } \\
\text { N }\end{array}$ & $\begin{array}{c}\mathbf{0 . 1 9 8}^{* * *} \\
0.000 \\
985\end{array}$ \\
\hline$\Delta \mathrm{PRB}$ & $\begin{array}{c}\text { C. Pearson } \\
\text { Sig. (bilateral) } \\
\text { N }\end{array}$ & $\begin{array}{c}0.029 \\
0.367 \\
985\end{array}$ \\
\hline$\Delta \mathrm{T} 1$ & $\begin{array}{c}\text { C. Pearson } \\
\text { Sig. (bilateral) } \\
\text { N }\end{array}$ & $\begin{array}{c}-0.042 \\
0.190 \\
985\end{array}$ \\
\hline$\Delta \mathrm{T} 2$ & $\begin{array}{c}\text { C. Pearson } \\
\text { Sig. (bilateral) } \\
\text { N }\end{array}$ & $\begin{array}{l}0.004 \\
0.911 \\
984\end{array}$ \\
\hline$\Delta \mathrm{T} 3$ & $\begin{array}{c}\text { C. Pearson } \\
\text { Sig. (bilateral) } \\
\text { N }\end{array}$ & $\begin{array}{c}0.024 \\
0.452 \\
983\end{array}$ \\
\hline$\Delta \mathrm{T} 4$ & $\begin{array}{c}\text { C. Pearson } \\
\text { Sig. (bilateral) } \\
\text { N }\end{array}$ & $\begin{array}{c}0.053 \\
0.098 \\
982\end{array}$ \\
\hline
\end{tabular}


Tabla 5.46. Continuación. Correlaciones bivariadas de Pearson entre la variable concentración polínica total diaria estandarizada para los años 1995-1999 y el resto de variables, nivel de significación y tamaño de la muestra en cada caso.

\begin{tabular}{|c|c|c|}
\hline$\Delta \mathrm{T} 5$ & $\begin{array}{c}\text { C. Pearson } \\
\text { Sig. (bilateral) } \\
\text { N }\end{array}$ & $\begin{array}{c}0.024 \\
0.451 \\
981\end{array}$ \\
\hline$\Delta \mathrm{T} 6$ & $\begin{array}{c}\text { C. Pearson } \\
\text { Sig. (bilateral) } \\
\text { N }\end{array}$ & $\begin{array}{c}-0.029 \\
0.358 \\
980\end{array}$ \\
\hline$\Delta$ HR1 & $\begin{array}{c}\text { C. Pearson } \\
\text { Sig. (bilateral) } \\
\text { N }\end{array}$ & $\begin{array}{c}\mathbf{0 . 0 8 4} * * \\
0.009 \\
985\end{array}$ \\
\hline$\Delta \mathrm{HR2}$ & $\begin{array}{c}\text { C. Pearson } \\
\text { Sig. (bilateral) } \\
\text { N }\end{array}$ & $\begin{array}{c}\mathbf{0 . 0 7 7 *} \\
0.015 \\
984\end{array}$ \\
\hline$\Delta \mathrm{HR3}$ & $\begin{array}{c}\text { C. Pearson } \\
\text { Sig. (bilateral) } \\
\text { N }\end{array}$ & $\begin{array}{c}0.053 \\
0.095 \\
983\end{array}$ \\
\hline$\Delta$ HR4 & $\begin{array}{c}\text { C. Pearson } \\
\text { Sig. (bilateral) } \\
\text { N }\end{array}$ & $\begin{array}{c}\mathbf{0 . 0 6 7 *} \\
0.036 \\
982\end{array}$ \\
\hline$\Delta \mathrm{HR5}$ & $\begin{array}{c}\text { C. Pearson } \\
\text { Sig. (bilateral) } \\
\text { N }\end{array}$ & $\begin{array}{c}0.038 \\
0.235 \\
981\end{array}$ \\
\hline
\end{tabular}


Tabla 5.46. Continuación. Correlaciones bivariadas de Pearson entre la variable concentración polínica total diaria estandarizada para los años 1995-1999 y el resto de variables, nivel de significación y tamaño de la muestra en cada caso.

\begin{tabular}{|c|c|c|}
\hline$\Delta$ HR6 & C. Pearson & 0.027 \\
& Sig. (bilateral) & 0.400 \\
& $\mathbf{N}$ & 980 \\
\hline P1MOD & C. Pearson & $\mathbf{0 . 7 2 * *}$ \\
& Sig. (bilateral) & 0.000 \\
& $\mathbf{N}$ & 969 \\
\hline P2MOD & C. Pearson & $\mathbf{0 . 5 8 * *}$ \\
& Sig. (bilateral) & 0.000 \\
& N & 958 \\
\hline P3MOD & C. Pearson & $\mathbf{0 . 4 9 * *}$ \\
& Sig. (bilateral) & 0.000 \\
& N & 947 \\
\hline
\end{tabular}




\subsubsection{MODELOS DE REGRESIÓN LINEAL MÚLTIPLE PARA LA CONCENTRACIÓN POLÍNICA TOTAL DIARIA ESTANDARIZADA 1995- 1998.}

- Modelos predictivos con sólo variables meteorológicas (temperatura, humedad relativa, radiación solar, presión, velocidad del viento).

En la tabla 5.47. se recoge el resumen de los mejores modelos obtenidos. En la tabla 5.48. el ANOVA de los modelos y en la tabla 5.49., las variables incluidas en cada modelo, así como los coeficientes de las distintas variables.

Tabla 5.47. Resumen de los modelos de regresión múltiple para la concentración polínica total diaria estandarizada y las distintas variables meteorológicas (19951998).

\begin{tabular}{|c|c|c|c|c|c|}
\hline \multicolumn{6}{|c|}{ Resumen del modelo $\mathrm{h}$} \\
\hline Modelo & $\mathrm{R}$ & R cuadrado & $\begin{array}{l}\text { R cuadrado } \\
\text { corregida }\end{array}$ & $\begin{array}{l}\text { Error típ. de la } \\
\text { estimación }\end{array}$ & $\begin{array}{l}\text { Durbin-W } \\
\text { atson }\end{array}$ \\
\hline 1 & $256^{\mathrm{a}}$ & 065 & 064 & ,8356 & \\
\hline 2 & $320^{\mathrm{b}}$ & 102 & 100 & 8195 & \\
\hline 3 & $352^{\mathrm{C}}$ & ,124 & ,121 & ,8100 & \\
\hline 4 &, $378^{d}$ & 143 & 139 & ,8017 & \\
\hline 5 & ,399e & 159 & 154 & ,7944 & \\
\hline 6 & $408^{f}$ & 166 & 160 & ,7916 & \\
\hline 7 & $414^{\mathrm{g}}$ & 171 & ,164 & ,7898 & 1,181 \\
\hline \multicolumn{6}{|c|}{ a. Variables predictoras: (Constante), RSACUM } \\
\hline \multicolumn{6}{|c|}{ b. Variables predictoras: (Constante), RSACUM, TMPMEDIA } \\
\hline \multicolumn{6}{|c|}{ c. Variables predictoras: (Constante), RSACUM, TMPMEDIA, HRMEDIA } \\
\hline \multicolumn{6}{|c|}{$\begin{array}{l}\text { d. Variables predictoras: (Constante), RSACUM, TMPMEDIA, HRMEDIA, } \\
\text { TMIN }\end{array}$} \\
\hline \multicolumn{6}{|c|}{$\begin{array}{l}\text { e. Variables predictoras: (Constante), RSACUM, TMPMEDIA, HRMEDIA, } \\
\text { TMIN, HRMAX }\end{array}$} \\
\hline \multicolumn{6}{|c|}{$\begin{array}{l}\text { f. Variables predictoras: (Constante), RSACUM, TMPMEDIA, HRMEDIA, } \\
\text { TMIN, HRMAX, WMEDIA }\end{array}$} \\
\hline \multicolumn{6}{|c|}{$\begin{array}{l}\text { g. Variables predictoras: (Constante), RSACUM, TMPMEDIA, HRMEDIA, } \\
\text { TMIN, HRMAX, WMEDIA, AT }\end{array}$} \\
\hline \multicolumn{6}{|c|}{ h. Variable dependiente: POLMODEL } \\
\hline
\end{tabular}


Tabla 5.48. ANOVA de los modelos resumen de regresión múltiple para la concentración polínica total diaria estandarizada y las distintas variables meteorológicas (1995-1998).

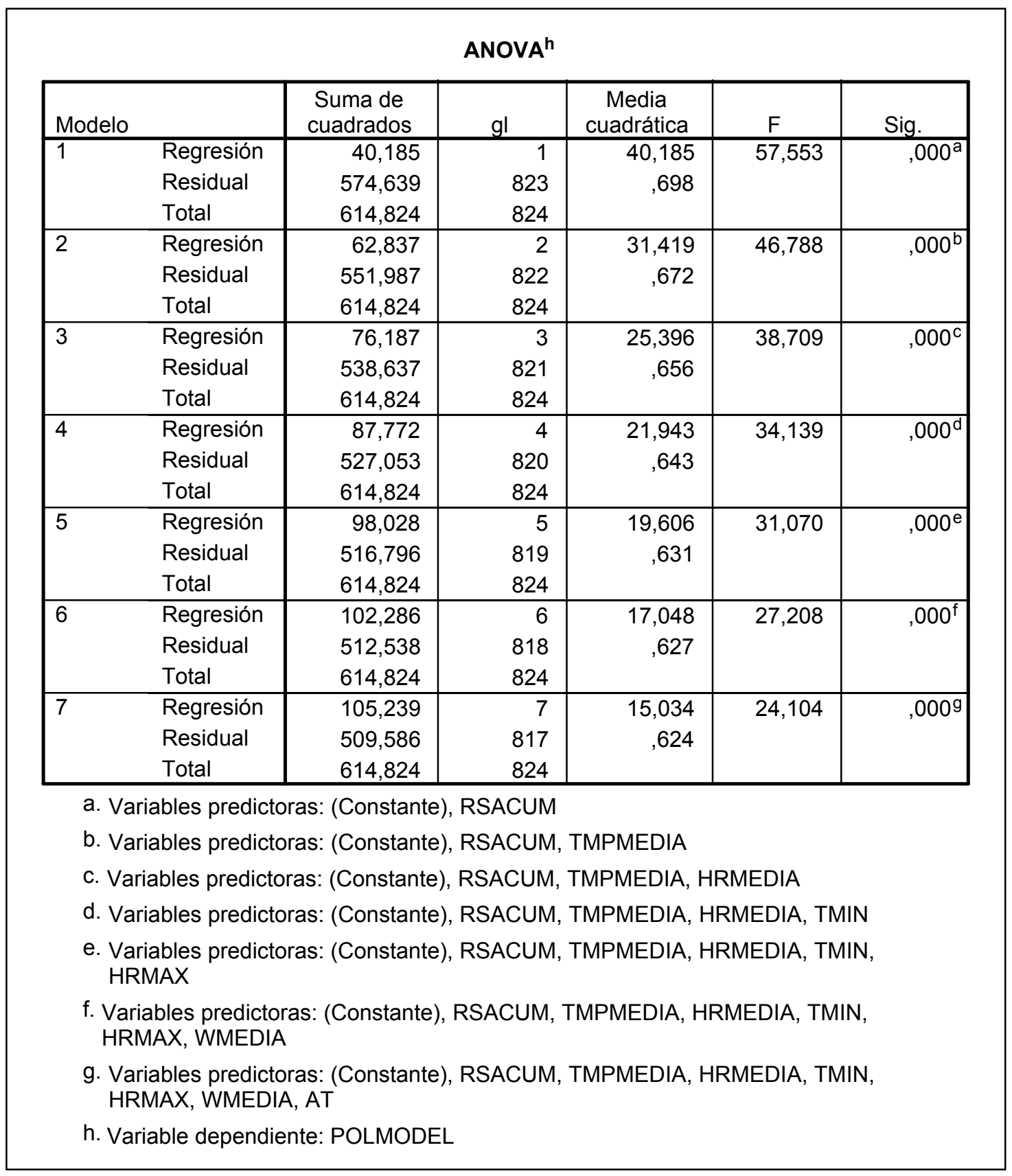


Tabla 5.49. Coeficientes de los modelos de regresión múltiple para la concentración polínica total diaria estandarizada y las distintas variables meteorológicas (19951998).

\begin{tabular}{|c|c|c|c|c|c|c|}
\hline \multicolumn{7}{|c|}{ Coeficientes $^{a}$} \\
\hline \multirow{2}{*}{\multicolumn{2}{|c|}{ Modelo }} & \multicolumn{2}{|c|}{$\begin{array}{l}\text { Coeficientes no } \\
\text { estandarizados }\end{array}$} & \multirow{2}{*}{$\begin{array}{c}\begin{array}{c}\text { Coeficien } \\
\text { tes } \\
\text { estandari } \\
\text { zados }\end{array} \\
\text { Beta }\end{array}$} & \multirow[b]{2}{*}{$t$} & \multirow[b]{2}{*}{ Sig. } \\
\hline & & B & Error típ. & & & \\
\hline \multirow[t]{2}{*}{1} & (Constante) &, 800 & , 078 & & 10,276 & 000 \\
\hline & RSACUM & $5,25 \mathrm{E}-05$ & ,000 & ,256 & 7,586 &, 000 \\
\hline \multirow[t]{3}{*}{2} & (Constante) & 1,313 & ,117 & & 11,245 & ,000 \\
\hline & RSACUM & $9,61 \mathrm{E}-05$ & ,000 & ,468 & 9,497 &, 000 \\
\hline & TMPMEDIA & $-5,2 \mathrm{E}-02$ & ,009 &,- 286 & $-5,808$ &, 000 \\
\hline \multirow[t]{4}{*}{3} & (Constante) & 2,219 & ,232 & & 9,578 & ,000 \\
\hline & RSACUM & 8,59E-05 & ,000 & ,418 & 8,379 & ,000 \\
\hline & TMPMEDIA & $-4,7 \mathrm{E}-02$ & ,009 &,- 257 & $-5,240$ & ,000 \\
\hline & HRMEDIA & $-1,1 \mathrm{E}-02$ & ,002 &,- 151 & $-4,511$ & ,000 \\
\hline \multirow[t]{5}{*}{4} & (Constante) & 2,820 & ,270 & & 10,464 & ,000 \\
\hline & RSACUM & $1,02 \mathrm{E}-04$ & ,000 & ,496 & 9,412 & ,000 \\
\hline & TMPMEDIA &,- 151 & 026 &,- 833 & $-5,783$ &, 000 \\
\hline & HRMEDIA & $-1,4 \mathrm{E}-02$ & ,003 &,- 184 & $-5,398$ &, 000 \\
\hline & TMIN & $9,30 \mathrm{E}-02$ & ,022 &, 538 & 4,245 &, 000 \\
\hline \multirow[t]{6}{*}{5} & (Constante) & 1,841 & ,361 & & 5,098 &, 000 \\
\hline & RSACUM & $1,05 E-04$ & 000 &, 512 & 9,788 &, 000 \\
\hline & TMPMEDIA &,- 180 & 027 &,- 998 & $-6,721$ &, 000 \\
\hline & HRMEDIA & $-3,0 \mathrm{E}-02$ & ,005 &,- 403 & $-6,299$ & ,000 \\
\hline & TMIN & ,116 & 022 & 674 & 5,179 &, 000 \\
\hline & HRMAX & 2,64E-02 & ,007 & ,250 & 4,032 &, 000 \\
\hline \multirow[t]{7}{*}{6} & (Constante) & 1,394 & ,399 & & 3,497 & ,000 \\
\hline & RSACUM & $1,06 \mathrm{E}-04$ & 000 &, 515 & 9,862 &, 000 \\
\hline & TMPMEDIA &,- 161 & ,028 &,- 887 & $-5,767$ & ,000 \\
\hline & HRMEDIA & $-2,9 \mathrm{E}-02$ & ,005 &,- 387 & $-6,036$ &, 000 \\
\hline & TMIN & $9,33 E-02$ & ,024 &, 540 & 3,876 &, 000 \\
\hline & HRMAX & $2,74 \mathrm{E}-02$ & ,007 & ,259 & 4,191 &, 000 \\
\hline & WMEDIA & 1,56E-02 &, 006 & 094 & 2,607 &, 009 \\
\hline \multirow[t]{8}{*}{7} & (Constante) & 1,242 & ,404 & & 3,076 &, 002 \\
\hline & RSACUM & 1,07E-04 & ,000 & ,522 & 10,003 & ,000 \\
\hline & TMPMEDIA &,- 231 & ,043 & $-1,275$ & $-5,420$ & ,000 \\
\hline & HRMEDIA & $-2,5 E-02$ & ,005 &,- 339 & $-5,001$ &, 000 \\
\hline & TMIN & ,163 & ,040 & ,943 & 4,074 & ,000 \\
\hline & HRMAX & 2,38E-02 & ,007 & ,225 & 3,530 &, 000 \\
\hline & WMEDIA & $2,07 \mathrm{E}-02$ &, 006 & ,124 & 3,223 &, 001 \\
\hline & AT & 4,87E-02 &, 022 & ,154 & 2,176 &, 030 \\
\hline
\end{tabular}

a. Variable dependiente: POLMODEL 
- Modelos predictivos con variables meteorológicas (temperatura, humedad relativa, radiación solar, presión, velocidad del viento), y con el resto de variables obtenidas a partir de éstas (variables de autocorrelación).

En la tabla 5.50. se recoge el resumen de los mejores modelos obtenidos. En la tabla 5.51. el ANOVA de los modelos y en la tabla 5.52., las variables incluidas en cada modelo, así como los coeficientes de las distintas variables.

Tabla 5.50. Resumen de los modelos de regresión múltiple para la concentración polínica total diaria estandarizada y las distintas variables meteorológicas y de autocorrelación (1995-1998).

\begin{tabular}{|c|c|c|c|c|c|}
\hline \multicolumn{6}{|c|}{ Resumen del modelo $h$} \\
\hline Modelo & $\mathrm{R}$ & $\mathrm{R}$ cuadrado & $\begin{array}{l}\text { R cuadrado } \\
\text { corregida }\end{array}$ & $\begin{array}{l}\text { Error típ. de la } \\
\text { estimación }\end{array}$ & $\begin{array}{l}\text { Durbin-W } \\
\text { atson }\end{array}$ \\
\hline 1 &, $705^{a}$ & ,497 & ,497 & ,6099 & \\
\hline 2 &, $714^{\mathrm{b}}$ &, 510 &, 509 & ,6024 & \\
\hline 3 &, $721^{\mathrm{c}}$ &, 520 & ,518 & ,5967 & \\
\hline 4 &, $726^{\mathrm{d}}$ &, 527 &, 525 &, 5925 & \\
\hline 5 &, $730^{\mathrm{e}}$ &, 532 &, 529 & ,5898 & \\
\hline 6 &, $731^{f}$ &, 535 &, 531 & ,5885 & \\
\hline 7 & ,7339 &, 537 &, 533 &, 5874 & 1,941 \\
\hline \multicolumn{6}{|c|}{ a. Variables predictoras: (Constante), P1MOD } \\
\hline \multicolumn{6}{|c|}{ b. Variables predictoras: (Constante), P1MOD, HRMIN } \\
\hline \multicolumn{6}{|c|}{ c. Variables predictoras: (Constante), P1MOD, HRMIN, AHR1 } \\
\hline \multicolumn{6}{|c|}{ d. Variables predictoras: (Constante), P1MOD, HRMIN, AHR1, P3MOD } \\
\hline \multicolumn{6}{|c|}{$\begin{array}{l}\text { e. Variables predictoras: (Constante), P1MOD, HRMIN, AHR1, P3MOD, } \\
\text { WMEDIA }\end{array}$} \\
\hline \multicolumn{6}{|c|}{$\begin{array}{l}\text { f. Variables predictoras: (Constante), P1MOD, HRMIN, AHR1, P3MOD, } \\
\text { WMEDIA, AT6 }\end{array}$} \\
\hline \multicolumn{6}{|c|}{$\begin{array}{l}\text { g. Variables predictoras: (Constante), P1MOD, HRMIN, AHR1, P3MOD, } \\
\text { WMEDIA, AT6, AT4 }\end{array}$} \\
\hline \multicolumn{6}{|c|}{ h. Variable dependiente: POLMODEL } \\
\hline
\end{tabular}


Tabla 5.51. ANOVA de los modelos resumen de regresión múltiple para la concentración polínica total diaria estandarizada y las distintas variables meteorológicas y de autocorrelación (1995-1998).

\begin{tabular}{|c|c|c|c|c|c|c|}
\hline \multicolumn{7}{|c|}{ ANOVA $^{\mathrm{h}}$} \\
\hline \multicolumn{2}{|c|}{ Modelo } & $\begin{array}{l}\text { Suma de } \\
\text { cuadrados }\end{array}$ & gl & $\begin{array}{c}\text { Media } \\
\text { cuadrática }\end{array}$ & $\mathrm{F}$ & Sig. \\
\hline 1 & $\begin{array}{l}\text { Regresión } \\
\text { Residual } \\
\text { Total } \\
\end{array}$ & $\begin{array}{l}290,340 \\
293,455 \\
583,795 \\
\end{array}$ & $\begin{array}{r}1 \\
789 \\
790 \\
\end{array}$ & $\begin{array}{r}290,340 \\
, 372\end{array}$ & 780,623 &, $000^{a}$ \\
\hline 2 & $\begin{array}{l}\text { Regresión } \\
\text { Residual } \\
\text { Total }\end{array}$ & $\begin{array}{l}297,843 \\
285,952 \\
583,795\end{array}$ & $\begin{array}{r}2 \\
788 \\
790 \\
\end{array}$ & $\begin{array}{r}148,921 \\
, 363\end{array}$ & 410,383 &, $000^{b}$ \\
\hline 3 & $\begin{array}{l}\text { Regresión } \\
\text { Residual } \\
\text { Total }\end{array}$ & $\begin{array}{l}303,545 \\
280,250 \\
583,795\end{array}$ & $\begin{array}{r}3 \\
787 \\
790\end{array}$ & $\begin{array}{r}101,182 \\
, 356\end{array}$ & 284,139 &, $000^{\mathrm{C}}$ \\
\hline 4 & $\begin{array}{l}\text { Regresión } \\
\text { Residual } \\
\text { Total }\end{array}$ & $\begin{array}{l}307,887 \\
275,908 \\
583,795\end{array}$ & $\begin{array}{r}4 \\
786 \\
790\end{array}$ & $\begin{array}{r}76,972 \\
, 351\end{array}$ & 219,275 &, $000^{d}$ \\
\hline 5 & $\begin{array}{l}\text { Regresión } \\
\text { Residual } \\
\text { Total } \\
\end{array}$ & $\begin{array}{l}310,757 \\
273,038 \\
583,795\end{array}$ & $\begin{array}{r}5 \\
785 \\
790 \\
\end{array}$ & $\begin{array}{r}62,151 \\
, 348\end{array}$ & 178,689 &, $000^{\mathrm{e}}$ \\
\hline 6 & $\begin{array}{l}\text { Regresión } \\
\text { Residual } \\
\text { Total } \\
\end{array}$ & $\begin{array}{l}312,231 \\
271,564 \\
583,795 \\
\end{array}$ & $\begin{array}{r}6 \\
784 \\
790 \\
\end{array}$ & $\begin{array}{r}52,039 \\
, 346\end{array}$ & 150,234 &, $000^{f}$ \\
\hline 7 & $\begin{array}{l}\text { Regresión } \\
\text { Residual } \\
\text { Total }\end{array}$ & $\begin{array}{l}313,627 \\
270,169 \\
583,795\end{array}$ & $\begin{array}{r}7 \\
783 \\
790 \\
\end{array}$ & $\begin{array}{r}44,804 \\
, 345\end{array}$ & 129,850 &, $000^{9}$ \\
\hline \multicolumn{7}{|c|}{ a. Variables predictoras: (Constante), P1MOD } \\
\hline \multicolumn{7}{|c|}{ b. Variables predictoras: (Constante), P1MOD, HRMIN } \\
\hline \multicolumn{7}{|c|}{ c. Variables predictoras: (Constante), P1MOD, HRMIN, AHR1 } \\
\hline \multicolumn{7}{|c|}{ d. Variables predictoras: (Constante), P1MOD, HRMIN, AHR1, P3MOD } \\
\hline \multicolumn{7}{|c|}{ e. Variables predictoras: (Constante), P1MOD, HRMIN, AHR1, P3MOD, WMEDIA } \\
\hline \multicolumn{7}{|c|}{$\begin{array}{l}\text { f. Variables predictoras: (Constante), P1MOD, HRMIN, AHR1, P3MOD, WMEDIA, } \\
\text { AT6 }\end{array}$} \\
\hline \multicolumn{7}{|c|}{$\begin{array}{l}\text { g. Variables predictoras: (Constante), P1MOD, HRMIN, AHR1, P3MOD, WMEDIA, } \\
\text { AT6, AT4 }\end{array}$} \\
\hline \multicolumn{7}{|c|}{ h. Variable dependiente: POLMODEL } \\
\hline
\end{tabular}


Tabla 5.52. Coeficientes de los modelos resumen de regresión múltiple para la concentración polínica total diaria estandarizada y las distintas variables meteorológicas y de autocorrelación (1995-1998).

\begin{tabular}{|c|c|c|c|c|c|c|}
\hline \multicolumn{7}{|c|}{ Coeficientes $^{a}$} \\
\hline \multirow{2}{*}{\multicolumn{2}{|c|}{ Modelo }} & \multicolumn{2}{|c|}{$\begin{array}{l}\text { Coeficientes no } \\
\text { estandarizados }\end{array}$} & \multirow[t]{2}{*}{ 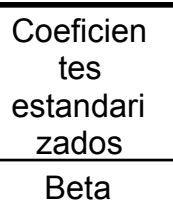 } & \multirow[b]{2}{*}{$t$} & \multirow[b]{2}{*}{ Sig. } \\
\hline & & $\mathrm{B}$ & Error típ. & & & \\
\hline \multirow[t]{2}{*}{1} & (Constante) & ,416 &, 041 & & 10,179 & 000 \\
\hline & P1MOD &, 703 &, 025 & ,705 & 27,940 & 000 \\
\hline \multirow[t]{3}{*}{2} & (Constante) & ,842 & ,102 & & 8,248 & ,000 \\
\hline & P1MOD & ,682 & 025 & 684 & 26,993 &, 000 \\
\hline & HRMIN & $-6,5 E-03$ & 001 &,- 115 & $-4,547$ &, 000 \\
\hline \multirow[t]{4}{*}{3} & (Constante) & 1,161 & ,129 & & 9,018 &, 000 \\
\hline & P1MOD & ,698 & ,025 & ,700 & 27,539 &, 000 \\
\hline & HRMIN & $-8,2 \mathrm{E}-03$ & 001 &,- 146 & $-5,553$ & , 000 \\
\hline & AHR1 & $-7,4 \mathrm{E}-03$ & ,002 &,- 105 & $-4,002$ & ,000 \\
\hline \multirow[t]{5}{*}{4} & (Constante) & 1,122 & ,128 & & 8,747 & ,000 \\
\hline & P1MOD & 640 & , 030 & ,641 & 21,185 &, 000 \\
\hline & HRMIN & $-8,5 \mathrm{E}-03$ & 001 &,- 149 & $-5,728$ &, 000 \\
\hline & AHR1 & -7,7E-03 & 002 &,- 110 & $-4,204$ &, 000 \\
\hline & P3MOD & ,104 & 030 & ,105 & 3,517 &, 000 \\
\hline \multirow[t]{6}{*}{5} & (Constante) & 966 & ,139 & & 6,963 & ,000 \\
\hline & P1MOD & ,635 &, 030 & ,637 & 21,094 &, 000 \\
\hline & HRMIN & $-8,5 \mathrm{E}-03$ & ,001 &,- 151 & $-5,817$ &, 000 \\
\hline & AHR1 & $-7,5 \mathrm{E}-03$ & ,002 &,- 108 & $-4,127$ &, 000 \\
\hline & P3MOD & 104 & 029 & ,104 & 3,516 &, 000 \\
\hline & WMEDIA & 1,16E-02 & ,004 &, 070 & 2,873 & ,004 \\
\hline \multirow[t]{7}{*}{6} & (Constante) & 1,089 & , 151 & & 7,225 &, 000 \\
\hline & P1MOD & 636 & , 030 & 637 & 21,161 & , 000 \\
\hline & HRMIN & $-8,5 \mathrm{E}-03$ & ,001 &,- 150 & $-5,809$ &, 000 \\
\hline & AHR1 & $-7,2 \mathrm{E}-03$ & ,002 &,- 103 & $-3,944$ &, 000 \\
\hline & P3MOD & , 104 & 029 & , 105 & 3,544 &, 000 \\
\hline & WMEDIA & $1,12 \mathrm{E}-02$ & ,004 & ,068 & 2,786 &, 005 \\
\hline & AT6 & -1,6E-02 & ,008 &,- 051 & $-2,063$ & ,039 \\
\hline \multirow[t]{8}{*}{7} & (Constante) & 972 & , 161 & & 6,023 & ,000 \\
\hline & P1MOD & ,634 & , 030 & ,636 & 21,139 & ,000 \\
\hline & HRMIN & $-8,3 E-03$ & 001 &,- 147 & $-5,681$ & ,000 \\
\hline & AHR1 & $-7,4 \mathrm{E}-03$ & ,002 &,- 106 & $-4,062$ & ,000 \\
\hline & P3MOD & ,108 & ,029 & ,108 & 3,660 & ,000 \\
\hline & WMEDIA & 1,13E-02 & ,004 &, 068 & 2,799 & ,005 \\
\hline & AT6 & $-1,8 \mathrm{E}-02$ & ,008 &,- 059 & $-2,373$ & ,018 \\
\hline & AT4 & $1,56 \mathrm{E}-02$ & ,008 &, 050 & 2,011 &, 045 \\
\hline
\end{tabular}

a. Variable dependiente: POLMODEL 
- Modelos predictivos con variables meteorológicas (temperatura, humedad relativa, radiación solar, presión, velocidad del viento), con variables obtenidas a partir de éstas (autocorrelación) y con las variables categóricas rumbosmi y rangosmi

En la tabla 5.53. se recoge el resumen de los mejores modelos obtenidos. En la tabla 5.54. el ANOVA de los modelos y en la tabla 5.55., las variables incluidas en cada modelo, así como los coeficientes de las distintas variables.

Tabla 5.53. Resumen de los modelos de regresión múltiple para la concentración polínica total diaria estandarizada y las distintas variables meteorológicas, de autocorrelación y variables categóricas rumbos (RUMI1-RIMI11) y rangosmi (RAMI1-RAMI3) (1995-1998)

\begin{tabular}{|c|c|c|c|c|c|}
\hline \multicolumn{6}{|c|}{ Resumen del modelo ${ }^{i}$} \\
\hline Modelo & $\mathrm{R}$ & R cuadrado & $\begin{array}{l}\text { R cuadrado } \\
\text { corregida }\end{array}$ & $\begin{array}{l}\text { Error típ. de la } \\
\text { estimación }\end{array}$ & $\begin{array}{l}\text { Durbin-W } \\
\text { atson }\end{array}$ \\
\hline 1 &, $705^{\mathrm{a}}$ & ,497 & 497 & 6099 & \\
\hline 2 &, $714^{\mathrm{b}}$ & ,510 & ,509 & 6024 & \\
\hline 3 &, $721^{\mathrm{c}}$ & ,520 & ,518 & ,5967 & \\
\hline 4 &, $726^{d}$ & ,527 & ,525 & ,5925 & \\
\hline 5 & ,730e & ,532 & ,529 & ,5898 & \\
\hline 6 &, $732^{f}$ &, 536 &, 532 &, 5879 & \\
\hline 7 &, $734 \mathrm{~g}$ & ,539 & ,534 & ,5866 & \\
\hline 8 &, $735^{\mathrm{h}}$ &, 541 &, 536 &, 5855 & 1,932 \\
\hline \multicolumn{6}{|c|}{ a. Variables predictoras: (Constante), P1MOD } \\
\hline \multicolumn{6}{|c|}{ b. Variables predictoras: (Constante), P1MOD, HRMIN } \\
\hline \multicolumn{6}{|c|}{ c. Variables predictoras: (Constante), P1MOD, HRMIN, AHR1 } \\
\hline \multicolumn{6}{|c|}{ d. Variables predictoras: (Constante), P1MOD, HRMIN, AHR1, P3MOD } \\
\hline \multicolumn{6}{|c|}{$\begin{array}{l}\text { e. Variables predictoras: (Constante), P1MOD, HRMIN, AHR1, P3MOD, } \\
\text { WMEDIA }\end{array}$} \\
\hline \multicolumn{6}{|c|}{$\begin{array}{l}\text { f. Variables predictoras: (Constante), P1MOD, HRMIN, AHR1, P3MOD, } \\
\text { WMEDIA, RUMI11 }\end{array}$} \\
\hline \multicolumn{6}{|c|}{$\begin{array}{l}\text { g. Variables predictoras: (Constante), P1MOD, HRMIN, AHR1, P3MOD, } \\
\text { WMEDIA, RUMI11, AT6 }\end{array}$} \\
\hline \multicolumn{6}{|c|}{$\begin{array}{l}\text { h. Variables predictoras: (Constante), P1MOD, HRMIN, AHR1, P3MOD, } \\
\text { WMEDIA, RUMI11, AT6, AT4 }\end{array}$} \\
\hline \multicolumn{6}{|c|}{ i. Variable dependiente: POLMODEL } \\
\hline
\end{tabular}


Tabla 5.54. ANOVA de los modelos de regresión múltiple para la concentración polínica total diaria estandarizada y las distintas variables meteorológicas, de autocorrelación y variables categóricas rumbos (RUMI1-RIMI11) y rangosmi (RAMI1-RAMI3) (1995-1998).

\begin{tabular}{|c|c|c|c|c|c|c|}
\hline \multicolumn{7}{|c|}{ ANOVA $^{i}$} \\
\hline \multicolumn{2}{|c|}{ Modelo } & $\begin{array}{l}\text { Suma de } \\
\text { cuadrados }\end{array}$ & gl & $\begin{array}{c}\text { Media } \\
\text { cuadrática }\end{array}$ & $\mathrm{F}$ & Sig. \\
\hline \multirow[t]{3}{*}{1} & Regresión & 290,340 & $\overline{1}$ & 290,340 & 780,623 &, $000^{a}$ \\
\hline & Residual & 293,455 & 789 & ,372 & & \\
\hline & Total & 583,795 & 790 & & & \\
\hline \multirow[t]{3}{*}{2} & Regresión & 297,843 & 2 & 148,921 & 410,383 &, $000^{b}$ \\
\hline & Residual & 285,952 & 788 & ,363 & & \\
\hline & Total & 583,795 & 790 & & & \\
\hline \multirow[t]{3}{*}{3} & Regresión & 303,545 & 3 & 101,182 & 284,139 &, $000^{c}$ \\
\hline & Residual & 280,250 & 787 & ,356 & & \\
\hline & Total & 583,795 & 790 & & & \\
\hline \multirow[t]{3}{*}{4} & Regresión & 307,887 & 4 & 76,972 & 219,275 &, $000^{d}$ \\
\hline & Residual & 275,908 & 786 & ,351 & & \\
\hline & Total & 583,795 & 790 & & & \\
\hline \multirow[t]{3}{*}{5} & Regresión & 310,757 & 5 & 62,151 & 178,689 &, $000^{e}$ \\
\hline & Residual & 273,038 & 785 & ,348 & & \\
\hline & Total & 583,795 & 790 & & & \\
\hline \multirow[t]{3}{*}{6} & Regresión & 312,784 & 6 & 52,131 & 150,807 &, $000^{f}$ \\
\hline & Residual & 271,012 & 784 & ,346 & & \\
\hline & Total & 583,795 & 790 & & & \\
\hline \multirow[t]{3}{*}{7} & Regresión & 314,395 & 7 & 44,914 & 130,540 & ,0009 \\
\hline & Residual & 269,400 & 783 & ,344 & & \\
\hline & Total & 583,795 & 790 & & & \\
\hline \multirow[t]{3}{*}{8} & Regresión & 315,762 & 8 & 39,470 & 115,157 &, $000^{h}$ \\
\hline & Residual & 268,033 & 782 & ,343 & & \\
\hline & Total & 583,795 & 790 & & & \\
\hline \multicolumn{7}{|c|}{ a. Variables predictoras: (Constante), P1MOD } \\
\hline \multicolumn{7}{|c|}{ b. Variables predictoras: (Constante), P1MOD, HRMIN } \\
\hline \multicolumn{7}{|c|}{ c. Variables predictoras: (Constante), P1MOD, HRMIN, AHR1 } \\
\hline \multicolumn{7}{|c|}{ d. Variables predictoras: (Constante), P1MOD, HRMIN, AHR1, P3MOD } \\
\hline \multicolumn{7}{|c|}{ e. Variables predictoras: (Constante), P1MOD, HRMIN, AHR1, P3MOD, WMEDIA } \\
\hline \multicolumn{7}{|c|}{$\begin{array}{l}\text { f. Variables predictoras: (Constante), P1MOD, HRMIN, AHR1, P3MOD, WMEDIA, } \\
\text { RUMI11 }\end{array}$} \\
\hline \multicolumn{7}{|c|}{$\begin{array}{l}\text { g. Variables predictoras: (Constante), P1MOD, HRMIN, AHR1, P3MOD, WMEDIA, } \\
\text { RUMI11, AT6 }\end{array}$} \\
\hline \multicolumn{7}{|c|}{$\begin{array}{l}\text { h. Variables predictoras: (Constante), P1MOD, HRMIN, AHR1, P3MOD, WMEDIA, } \\
\text { RUMI11, AT6, AT4 }\end{array}$} \\
\hline \multicolumn{7}{|c|}{ i. Variable dependiente: POLMODEL } \\
\hline
\end{tabular}


Tabla 5.55. Coeficientes de los modelos de regresión múltiple para la concentración polínica total diaria estandarizada y las distintas variables meteorológicas, autocorrelación y variables categóricas rumbos (RUMI1-RIMI11) y rangosmi (RAMI1-RAMI3) (1995-1998).

\begin{tabular}{|c|c|c|c|c|c|c|}
\hline \multicolumn{7}{|c|}{ Coeficientes $^{a}$} \\
\hline \multirow{2}{*}{\multicolumn{2}{|c|}{ Modelo }} & \multicolumn{2}{|c|}{$\begin{array}{l}\text { Coeficientes no } \\
\text { estandarizados }\end{array}$} & \multirow{2}{*}{$\begin{array}{c}\begin{array}{c}\text { Coeficien } \\
\text { tes }\end{array} \\
\text { estandari } \\
\text { zados } \\
\text { Beta }\end{array}$} & \multirow[b]{2}{*}{$t$} & \multirow[b]{2}{*}{ Sig. } \\
\hline & & B & Error típ. & & & \\
\hline \multirow[t]{2}{*}{1} & (Constante) & ,416 & ,041 & & 10,179 &, 000 \\
\hline & P1MOD & ,703 & ,025 & ,705 & 27,940 &, 000 \\
\hline \multirow[t]{3}{*}{2} & (Constante) & ,842 & ,102 & & 8,248 & ,000 \\
\hline & P1MOD & ,682 & ,025 & ,684 & 26,993 &, 000 \\
\hline & HRMIN & $-6,5 \mathrm{E}-03$ & ,001 &,- 115 & $-4,547$ & ,000 \\
\hline \multirow[t]{4}{*}{3} & (Constante) & 1,161 & ,129 & & 9,018 & ,000 \\
\hline & P1MOD & ,698 & ,025 & ,700 & 27,539 & ,000 \\
\hline & HRMIN & $-8,2 \mathrm{E}-03$ & ,001 &,- 146 & $-5,553$ & ,000 \\
\hline & AHR1 & $-7,4 \mathrm{E}-03$ & ,002 &,- 105 & $-4,002$ & ,000 \\
\hline \multirow[t]{5}{*}{4} & (Constante) & 1,122 & ,128 & & 8,747 &, 000 \\
\hline & P1MOD & ,640 & ,030 & ,641 & 21,185 & , 000 \\
\hline & HRMIN & $-8,5 E-03$ & 001 &,- 149 & $-5,728$ &, 000 \\
\hline & AHR1 & -7,7E-03 & ,002 &,- 110 & $-4,204$ & ,000 \\
\hline & P3MOD & ,104 &, 030 & ,105 & 3,517 &, 000 \\
\hline \multirow[t]{6}{*}{5} & (Constante) & ,966 & ,139 & & 6,963 &, 000 \\
\hline & P1MOD & ,635 & ,030 & ,637 & 21,094 & ,000 \\
\hline & HRMIN & $-8,5 \mathrm{E}-03$ & ,001 &,- 151 & $-5,817$ & ,000 \\
\hline & AHR1 & $-7,5 \mathrm{E}-03$ & ,002 &,- 108 & $-4,127$ & ,000 \\
\hline & P3MOD & 104 & ,029 & ,104 & 3,516 & ,000 \\
\hline & WMEDIA & 1,16E-02 & ,004 & ,070 & 2,873 & ,004 \\
\hline \multirow[t]{7}{*}{6} & (Constante) & ,982 & ,138 & & 7,089 &, 000 \\
\hline & P1MOD & ,634 & ,030 & ,636 & 21,148 & , 000 \\
\hline & HRMIN & $-8,8 \mathrm{E}-03$ & ,001 &,- 156 & $-6,001$ &, 000 \\
\hline & AHR1 & $-7,6 \mathrm{E}-03$ & ,002 &,- 109 & $-4,198$ & ,000 \\
\hline & P3MOD & 107 & ,029 & ,108 & 3,638 & ,000 \\
\hline & WMEDIA & 1,17E-02 & ,004 & 071 & 2,915 & ,004 \\
\hline & RUMI11 & $-1,431$ &, 591 &,- 059 & $-2,421$ &, 016 \\
\hline \multirow[t]{8}{*}{7} & (Constante) & 1,111 & ,150 & & 7,382 &, 000 \\
\hline & P1MOD & ,635 & ,030 & ,637 & 21,221 &, 000 \\
\hline & HRMIN & $-8,8 \mathrm{E}-03$ & ,001 &,- 155 & $-6,000$ & , 000 \\
\hline & AHR1 & $-7,3 \mathrm{E}-03$ & ,002 &,- 104 & $-4,010$ &, 000 \\
\hline & P3MOD & 108 & ,029 & ,108 & 3,673 & ,000 \\
\hline & WMEDIA & 1,13E-02 & ,004 & ,069 & 2,826 & ,005 \\
\hline & RUMI11 & $-1,480$ &, 590 &,- 061 & $-2,508$ & ,012 \\
\hline & AT6 & $-1,6 \mathrm{E}-02$ & ,008 &,- 053 & $-2,164$ & ,031 \\
\hline \multirow[t]{9}{*}{8} & (Constante) & ,995 & , 161 & & 6,175 &, 000 \\
\hline & P1MOD & 634 & ,030 & ,635 & 21,199 & ,000 \\
\hline & HRMIN & $-8,6 \mathrm{E}-03$ & ,001 &,- 152 & $-5,872$ & ,000 \\
\hline & AHR1 & $-7,5 \mathrm{E}-03$ & ,002 &,- 107 & $-4,127$ &, 000 \\
\hline & P3MOD & 111 & ,029 & ,112 & 3,787 & ,000 \\
\hline & WMEDIA & 1,14E-02 & ,004 & ,069 & 2,839 & ,005 \\
\hline & RUMI11 & $-1,470$ & ,589 &,- 061 & $-2,496$ &, 013 \\
\hline & AT6 & $-1,9 \mathrm{E}-02$ & ,008 &,- 061 & $-2,471$ & , 014 \\
\hline & AT4 & $1,55 \mathrm{E}-02$ &, 008 &, 049 & 1,997 &, 046 \\
\hline
\end{tabular}




\subsubsection{DESARROLLO DE MODELOS PREDICTIVOS DE REGRESIÓN LINEAL MÚLTIPLE PARA LOS CONGLOMERADOS QUE DEFINEN LOS FLUJOS DE VIENTO.}

- Modelos predictivos con variables meteorológicas (temperatura, humedad relativa, radiación solar, presión, velocidad del viento), con variables obtenidas a partir de éstas (autocorrelación) y con las variables categóricas rumbosmi y rangosmi, pero para cada flujo de viento (CLUSTER).

En la tabla 5.56. se recoge el resumen de los mejores modelos obtenidos. En la tabla 5.57. el ANOVA de los modelos y en la tabla 5.58., las variables incluidas en cada modelo, así como los coeficientes de las distintas variables.

Tabla 5.56. Resumen de los modelos de regresión múltiple para la concentración polínica total diaria estandarizada y las distintas variables meteorológicas, autocorrelación y variables categóricas rumbos (RUMI1-RIMI11) y rangosmi (RAMI1-RAMI3) 1995-1998. CLUSTER=1. $\mathrm{N}=79$.

\begin{tabular}{|l|r|r|r|r|r|}
\hline \multicolumn{7}{|c|}{ Resumen del modelo d,e } \\
\hline Modelo & $\mathrm{R}$ & R cuadrado & $\begin{array}{r}\text { R cuadrado } \\
\text { corregida }\end{array}$ & $\begin{array}{c}\text { Error típ. de la } \\
\text { estimación }\end{array}$ & $\begin{array}{c}\text { Durbin-W } \\
\text { atson }\end{array}$ \\
\hline 1 &, $792^{\mathrm{a}}$ &, 628 &, 623 &, 7296 & \\
2 &, $815^{\mathrm{b}}$ &, 664 &, 655 &, 6976 & \\
3 &, $828^{\mathrm{c}}$ &, 685 &, 672 &, 6797 & 2,326 \\
\hline
\end{tabular}


Tabla 5.57. ANOVA de los modelos de regresión múltiple para CLUSTER 1 (19951998).

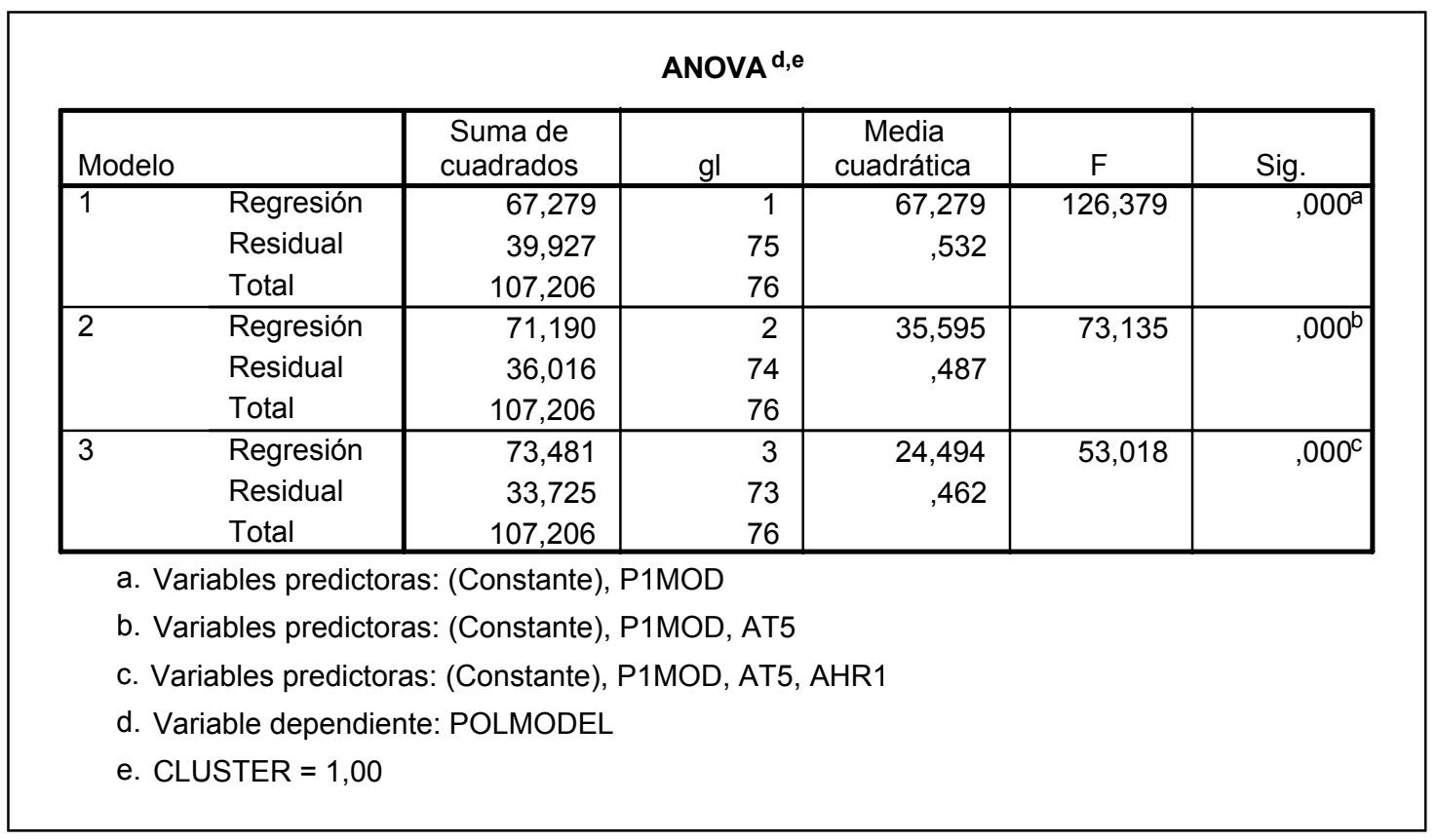

Tabla 5.58. Coeficientes de los modelos de regresión múltiple para CLUSTER 1 (19951998).

\begin{tabular}{|c|c|c|c|c|c|c|}
\hline \multicolumn{7}{|c|}{ Coeficientes $^{a, b}$} \\
\hline \multirow{2}{*}{\multicolumn{2}{|c|}{ Modelo }} & \multicolumn{2}{|c|}{$\begin{array}{l}\text { Coeficientes no } \\
\text { estandarizados }\end{array}$} & \multirow{2}{*}{$\begin{array}{c}\text { Coeficien } \\
\text { tes } \\
\text { estandari } \\
\text { zados }\end{array}$} & \multirow[b]{2}{*}{$\mathrm{t}$} & \multirow[b]{2}{*}{ Sig. } \\
\hline & & $\mathrm{B}$ & Error típ. & & & \\
\hline & (Constante) & ,418 & ,135 & & 3,098 &, 003 \\
\hline & P1MOD & ,853 & ,076 & ,792 & 11,242 & ,000 \\
\hline \multirow[t]{3}{*}{2} & (Constante) &,- 222 & ,260 & &,- 852 & ,397 \\
\hline & P1MOD & ,821 & ,073 & ,763 & 11,197 & ,000 \\
\hline & AT5 & 7,81E-02 & ,028 & , 193 & 2,835 & ,006 \\
\hline \multirow[t]{4}{*}{3} & (Constante) &,- 611 & ,308 & & $-1,984$ & ,051 \\
\hline & P1MOD & ,772 & ,075 & ,718 & 10,331 & ,000 \\
\hline & AT5 & 7,91E-02 & ,027 & , 195 & 2,943 & ,004 \\
\hline & AHR1 & 1,31E-02 &, 006 & ,153 & 2,227 &, 029 \\
\hline \multicolumn{7}{|c|}{ a. Variable dependiente: POLMODEL } \\
\hline \multicolumn{7}{|c|}{ b. CLUSTER = 1,00 } \\
\hline
\end{tabular}

En la tabla 5.59. se recoge el resumen de los mejores modelos obtenidos. En la 
tabla 5.60. el ANOVA de los modelos y en la tabla 5.61., las variables incluidas en cada modelo, así como los coeficientes de las distintas variables.

Tabla 5.59. Resumen de los modelos de regresión múltiple para CLUSTER 2 (19951998). $\mathrm{N}=229$.

\begin{tabular}{|c|c|c|c|c|c|}
\hline \multicolumn{6}{|c|}{ Resumen del modelo ${ }^{d, e}$} \\
\hline Modelo & $\mathrm{R}$ & R cuadrado & $\begin{array}{c}\text { R cuadrado } \\
\text { corregida }\end{array}$ & $\begin{array}{l}\text { Error típ. de la } \\
\text { estimación }\end{array}$ & $\begin{array}{l}\text { Durbin-W } \\
\text { atson }\end{array}$ \\
\hline 1 &, $701^{\mathrm{a}}$ & ,491 &, 488 & ,6162 & \\
\hline 2 &, $711^{\mathrm{b}}$ &, 506 &, 502 & ,6082 & \\
\hline 3 &, $721^{\mathrm{c}}$ &, 520 &, 514 & ,6008 & 2,100 \\
\hline \multicolumn{6}{|c|}{ a. Variables predictoras: (Constante), $\mathrm{P} 1 \mathrm{MOD}$} \\
\hline \multicolumn{6}{|c|}{ b. Variables predictoras: (Constante), P1MOD, AT6 } \\
\hline \multicolumn{6}{|c|}{ c. Variables predictoras: (Constante), P1MOD, AT6, P3MOD } \\
\hline \multicolumn{6}{|c|}{ d. Variable dependiente: POLMODEL } \\
\hline \multicolumn{6}{|c|}{ e. CLUSTER $=2,00$} \\
\hline
\end{tabular}

Tabla 5.60. ANOVA de los modelos de regresión múltiple para CLUSTER 2 (19951998).

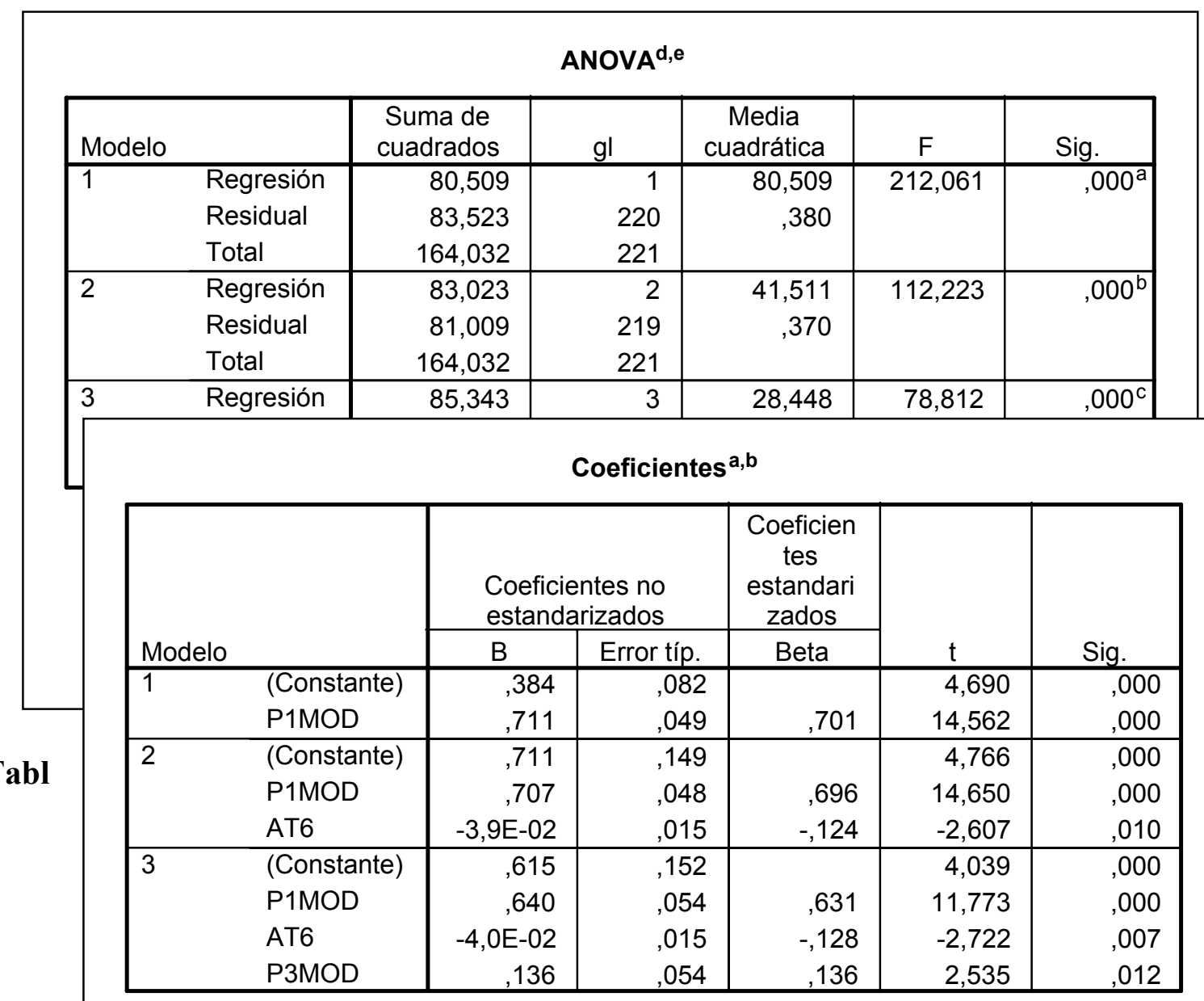

a. Variable dependiente: POLMODEL

b. CLUSTER $=2,00$ 
5.61. Coeficientes de los modelos de regresión múltiple para CLUSTER 2 (1995-1998). 
En la tabla 5.62. se recoge el resumen de los mejores modelos obtenidos. En la tabla 5.63. el ANOVA de los modelos y en la tabla 5.64., las variables incluidas en cada modelo, así como los coeficientes de las distintas variables.

Tabla 5.62. Resumen de los modelos de regresión múltiple para CLUSTER 3 (19951998). $\mathrm{N}=89$.

\begin{tabular}{|l|r|r|r|r|r|}
\hline \multicolumn{7}{|c|}{ Resumen del modelo e,f } \\
\hline Modelo & $\mathrm{R}$ & R cuadrado & $\begin{array}{r}\text { R cuadrado } \\
\text { corregida }\end{array}$ & $\begin{array}{c}\text { Error típ. de la } \\
\text { estimación }\end{array}$ & $\begin{array}{c}\text { Durbin-W } \\
\text { atson }\end{array}$ \\
\hline 1 &, $694^{\mathrm{a}}$ &, 481 &, 475 &, 6287 & \\
2 &, $734^{\mathrm{b}}$ &, 539 &, 527 &, 5965 & \\
3 &, $758^{\mathrm{c}}$ &, 575 &, 558 &, 5765 & \\
4 &, $774^{\mathrm{d}}$ &, 599 &, 578 &, 5636 & 1,892 \\
\hline
\end{tabular}

Tabla 5.63. ANOVA de los modelos de regresión múltiple para CLUSTER 3 (19951998).

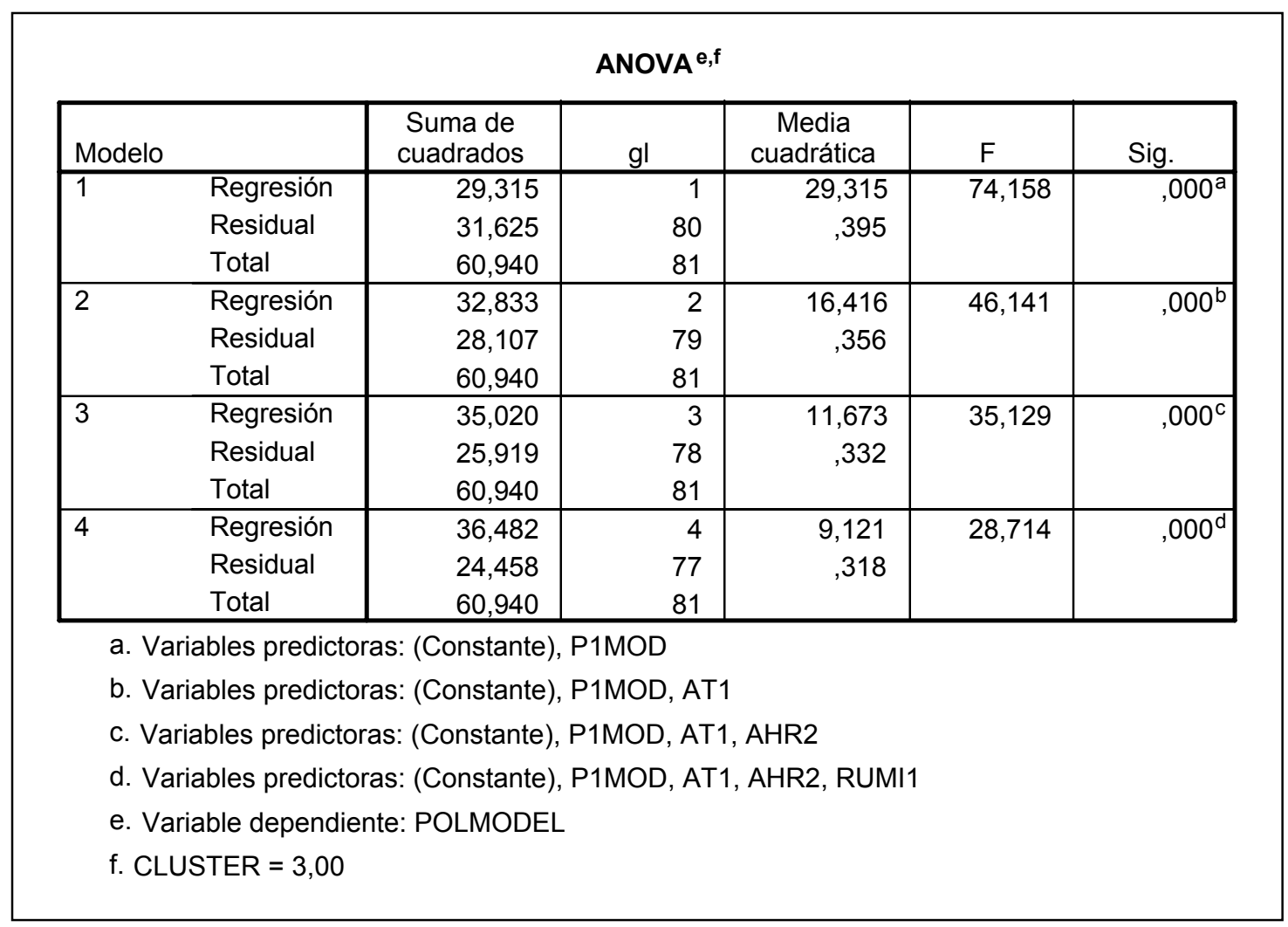


Tabla 5.64. Coeficientes de los modelos de regresión múltiple para CLUSTER 3 (19951998).

\begin{tabular}{|c|c|c|c|c|c|c|}
\hline \multicolumn{7}{|c|}{ Coeficientes $^{a, b}$} \\
\hline \multirow{2}{*}{\multicolumn{2}{|c|}{ Modelo }} & \multicolumn{2}{|c|}{$\begin{array}{l}\text { Coeficientes no } \\
\text { estandarizados }\end{array}$} & \multirow{2}{*}{$\begin{array}{c}\begin{array}{c}\text { Coeficien } \\
\text { tes } \\
\text { estandari } \\
\text { zados }\end{array} \\
\text { Beta } \\
\end{array}$} & \multirow[b]{2}{*}{$t$} & \multirow[b]{2}{*}{ Sig. } \\
\hline & & B & Error típ. & & & \\
\hline & (Constante) &, 531 & 1,133 & & 4,007 &, 000 \\
\hline & P1MOD & 678 & 079 & ,694 & 8,612 &, 000 \\
\hline \multirow[t]{3}{*}{2} & (Constante) & 1,186 & 243 & & 4,875 & 000 \\
\hline & P1MOD & 683 & ,075 & 698 & 9,132 & ,000 \\
\hline & AT1 & $-8,5 \mathrm{E}-02$ & ,027 &,- 240 & $-3,144$ & ,002 \\
\hline \multirow[t]{4}{*}{3} & (Constante) & ,856 & ,268 & & 3,195 & ,002 \\
\hline & P1MOD & 651 & ,073 & ,666 & 8,884 &, 000 \\
\hline & AT1 &,- 104 & ,027 &,- 292 & $-3,817$ &, 000 \\
\hline & AHR2 & $1,50 \mathrm{E}-02$ & ,006 & 199 & 2,566 & ,012 \\
\hline \multirow[t]{5}{*}{4} & (Constante) & ,746 & ,267 & & 2,794 & ,007 \\
\hline & P1MOD & 644 & ,072 & 658 & 8,976 & ,000 \\
\hline & AT1 & $-9,2 \mathrm{E}-02$ & ,027 &,- 260 & $-3,398$ & ,001 \\
\hline & AHR2 & 1,53E-02 & ,006 & 203 & 2,669 & ,009 \\
\hline & RUMI1 & ,887 & ,413 & 159 & 2,145 & ,035 \\
\hline \multicolumn{7}{|c|}{ a. Variable dependiente: POLMODEL } \\
\hline \multicolumn{7}{|c|}{ b. CLUSTER $=3,00$} \\
\hline
\end{tabular}


En la tabla 5.65. se recoge el resumen de los mejores modelos obtenidos. En la tabla 5.66. el ANOVA de los modelos y en la tabla 5.67., las variables incluidas en cada modelo, así como los coeficientes de las distintas variables.

Tabla 5.65. Resumen de los modelos de regresión múltiple para CLUSTER 4 (19951998). $\mathrm{N}=119$.

\begin{tabular}{|l|r|r|r|r|r|}
\hline \multicolumn{7}{|c|}{ Resumen del modelo } \\
\hline Modelo & $\mathrm{R}$ & R cuadrado & $\begin{array}{c}\text { R cuadrado } \\
\text { corregida }\end{array}$ & $\begin{array}{c}\text { Error típ. de la } \\
\text { estimación }\end{array}$ & $\begin{array}{c}\text { Durbin-W } \\
\text { atson }\end{array}$ \\
\hline 1 &, $616^{\mathrm{a}}$ &, 380 &, 374 &, 6116 & \\
2 &, $660^{\mathrm{b}}$ &, 435 &, 425 &, 5862 & \\
3 &, $678^{\mathrm{c}}$ &, 460 &, 445 &, 5758 & 1,918 \\
\hline
\end{tabular}

Tabla 5.66. ANOVA de los modelos de regresión múltiple para CLUSTER 4 (19951998).

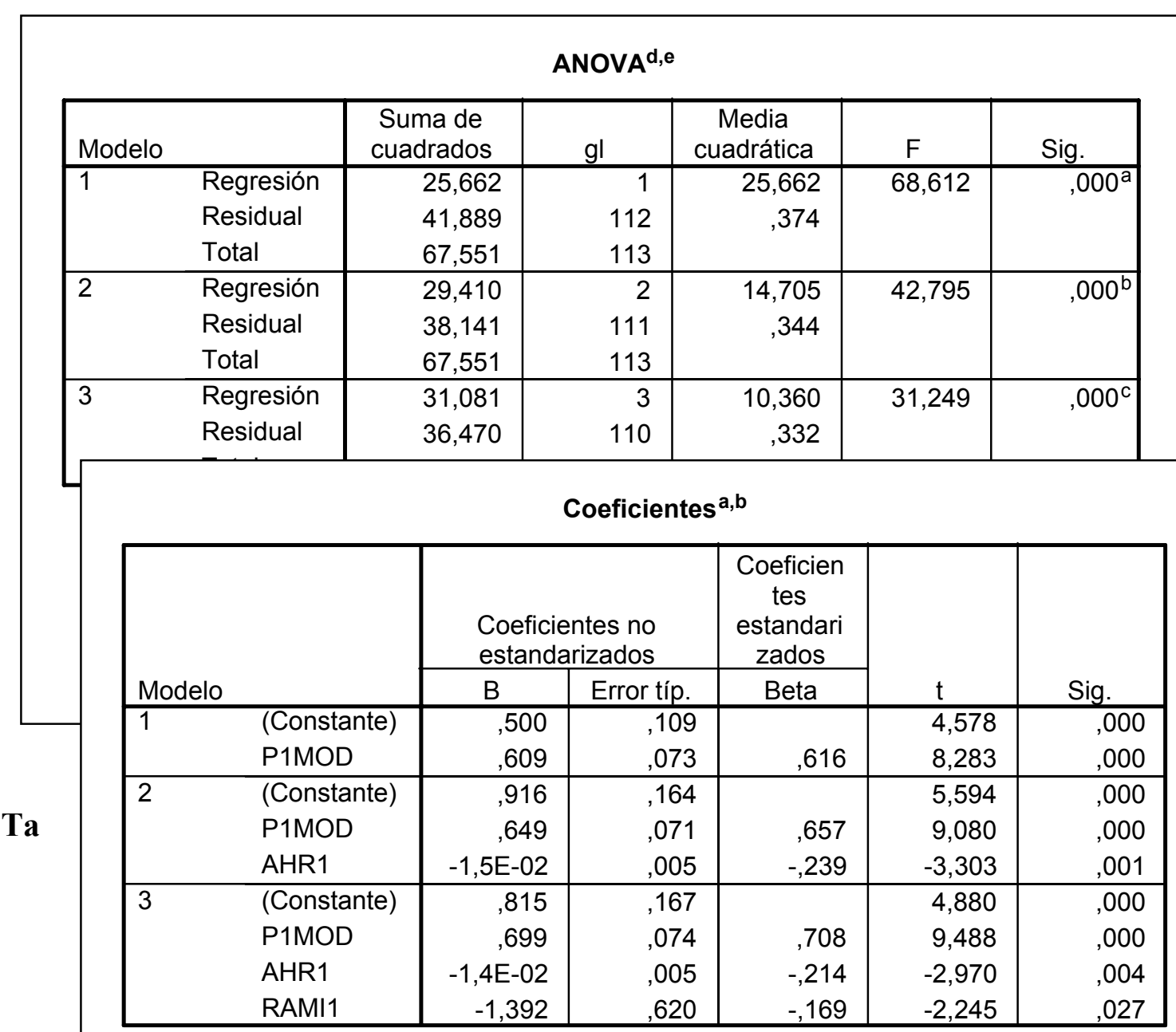

a. Variable dependiente: POLMODEL

b. CLUSTER $=4,00$ 
la 5.67. Coeficientes de los modelos de regresión múltiple para CLUSTER 4 (1995-1998). 
En la tabla 5.68. se recoge el resumen de los mejores modelos obtenidos. En la tabla 5.69. el ANOVA de los modelos y en la tabla 5.70., las variables incluidas en cada modelo, así como los coeficientes de las distintas variables.

Tabla 5.68. Resumen de los modelos de regresión múltiple para CLUSTER 5 (19951998). $\mathrm{N}=297$.

\begin{tabular}{|c|c|c|c|c|c|}
\hline \multicolumn{6}{|c|}{ Resumen del modelo $\mathrm{i}, \mathrm{j}$} \\
\hline Modelo & $\mathrm{R}$ & R cuadrado & $\begin{array}{l}\text { R cuadrado } \\
\text { corregida }\end{array}$ & $\begin{array}{l}\text { Error típ. de la } \\
\text { estimación }\end{array}$ & $\begin{array}{l}\text { Durbin-W } \\
\text { atson }\end{array}$ \\
\hline 1 & $704^{\mathrm{a}}$ & ,496 & .494 &, 5485 & \\
\hline 2 & $728^{\mathrm{b}}$ & 531 & 527 & 5302 & \\
\hline 3 &, $736^{c}$ & ,542 &, 537 &, 5245 & \\
\hline 4 &, $746^{d}$ &, 556 &, 550 &, 5173 & \\
\hline 5 &, $756^{\mathrm{e}}$ & 572 & 565 & 5089 & \\
\hline 6 & $766^{f}$ &, 586 &, 578 & ,5012 & \\
\hline 7 &, $772^{\mathrm{g}}$ & ,596 &, 586 & 4964 & \\
\hline 8 & $769^{h}$ & ,592 & ,583 & 4979 & 1,957 \\
\hline \multicolumn{6}{|c|}{ a. Variables predictoras: (Constante), $\mathrm{P} 1 \mathrm{MOD}$} \\
\hline \multicolumn{6}{|c|}{ b. Variables predictoras: (Constante), P1MOD, RSACUM } \\
\hline \multicolumn{6}{|c|}{ c. Variables predictoras: (Constante), P1MOD, RSACUM, AHR1 } \\
\hline \multicolumn{6}{|c|}{ d. Variables predictoras: (Constante), P1MOD, RSACUM, AHR1, AHR } \\
\hline \multicolumn{6}{|c|}{$\begin{array}{l}\text { e. Variables predictoras: (Constante), P1MOD, RSACUM, AHR1, AHR, } \\
\text { P3MOD }\end{array}$} \\
\hline \multicolumn{6}{|c|}{$\begin{array}{l}\text { f. Variables predictoras: (Constante), P1MOD, RSACUM, AHR1, AHR, } \\
\text { P3MOD, WMEDIA }\end{array}$} \\
\hline \multicolumn{6}{|c|}{$\begin{array}{l}\text { g. Variables predictoras: (Constante), P1MOD, RSACUM, AHR1, AHR, } \\
\text { P3MOD, WMEDIA, AT4 }\end{array}$} \\
\hline \multicolumn{6}{|c|}{$\begin{array}{l}\text { h. Variables predictoras: (Constante), P1MOD, AHR1, AHR, P3MOD, } \\
\text { WMEDIA, AT4 }\end{array}$} \\
\hline \multicolumn{6}{|c|}{ i. Variable dependiente: POLMODEL } \\
\hline \multicolumn{6}{|c|}{ j. CLUSTER $=5,00$} \\
\hline
\end{tabular}


Tabla 5.69. ANOVA de los modelos de regresión múltiple para CLUSTER 5 (19951998).

\begin{tabular}{|c|c|c|c|c|c|c|}
\hline \multicolumn{7}{|c|}{ ANOVA $^{\mathrm{i}, \mathrm{j}}$} \\
\hline \multicolumn{2}{|c|}{ Modelo } & $\begin{array}{l}\text { Suma de } \\
\text { cuadrados }\end{array}$ & gl & $\begin{array}{c}\text { Media } \\
\text { cuadrática }\end{array}$ & $\mathrm{F}$ & Sig. \\
\hline \multirow[t]{3}{*}{1} & Regresión & 86,997 & 1 & 86,997 & 289,123 &, $000^{a}$ \\
\hline & Residual & 88,464 & 294 & ,301 & & \\
\hline & Total & 175,461 & 295 & & & \\
\hline \multirow[t]{3}{*}{2} & Regresión & 93,101 & 2 & 46,551 & 165,606 &, $000^{b}$ \\
\hline & Residual & 82,360 & 293 & ,281 & & \\
\hline & Total & 175,461 & 295 & & & \\
\hline \multirow[t]{3}{*}{3} & Regresión & 95,128 & 3 & 31,709 & 115,260 &, $000^{c}$ \\
\hline & Residual & 80,333 & 292 & ,275 & & \\
\hline & Total & 175,461 & 295 & & & \\
\hline \multirow[t]{3}{*}{4} & Regresión & 97,602 & 4 & 24,400 & 91,197 &, $000^{d}$ \\
\hline & Residual & 77,859 & 291 & ,268 & & \\
\hline & Total & 175,461 & 295 & & & \\
\hline \multirow[t]{3}{*}{5} & Regresión & 100,362 & 5 & 20,072 & 77,511 &, $000^{\mathrm{e}}$ \\
\hline & Residual & 75,099 & 290 & ,259 & & \\
\hline & Total & 175,461 & 295 & & & \\
\hline \multirow[t]{3}{*}{6} & Regresión & 102,862 & 6 & 17,144 & 68,245 &, $000^{f}$ \\
\hline & Residual & 72,599 & 289 & ,251 & & \\
\hline & Total & 175,461 & 295 & & & \\
\hline \multirow[t]{3}{*}{7} & Regresión & 104,490 & 7 & 14,927 & 60,574 & ,0009 \\
\hline & Residual & 70,971 & 288 & ,246 & & \\
\hline & Total & 175,461 & 295 & & & \\
\hline \multirow[t]{3}{*}{8} & Regresión & 103,825 & 6 & 17,304 & 69,809 &, $000^{h}$ \\
\hline & Residual & 71,636 & 289 & ,248 & & \\
\hline & Total & 175,461 & 295 & & & \\
\hline \multicolumn{7}{|c|}{ a. Variables predictoras: (Constante), $\mathrm{P} 1 \mathrm{MOD}$} \\
\hline \multicolumn{7}{|c|}{ b. Variables predictoras: (Constante), P1MOD, RSACUM } \\
\hline \multicolumn{7}{|c|}{ c. Variables predictoras: (Constante), P1MOD, RSACUM, AHR1 } \\
\hline \multicolumn{7}{|c|}{ d. Variables predictoras: (Constante), P1MOD, RSACUM, AHR1, AHR } \\
\hline \multicolumn{7}{|c|}{ e. Variables predictoras: (Constante), P1MOD, RSACUM, AHR1, AHR, P3MOD } \\
\hline \multicolumn{7}{|c|}{$\begin{array}{l}\text { f. Variables predictoras: (Constante), P1MOD, RSACUM, AHR1, AHR, P3MOD, } \\
\text { WMEDIA }\end{array}$} \\
\hline \multicolumn{7}{|c|}{$\begin{array}{l}\text { g. Variables predictoras: (Constante), P1MOD, RSACUM, AHR1, AHR, P3MOD, } \\
\text { WMEDIA, AT4 }\end{array}$} \\
\hline \multicolumn{7}{|c|}{ h. Variables predictoras: (Constante), P1MOD, AHR1, AHR, P3MOD, WMEDIA, AT4 } \\
\hline \multicolumn{7}{|c|}{ i. Variable dependiente: POLMODEL } \\
\hline \multicolumn{7}{|c|}{ j. CLUSTER $=5,00$} \\
\hline
\end{tabular}


Tabla 5.70. Coeficientes de los modelos de regresión múltiple para CLUSTER 5 (19951998).

\begin{tabular}{|c|c|c|c|c|c|c|}
\hline \multicolumn{7}{|c|}{ Coeficientes $a, b$} \\
\hline \multirow[b]{2}{*}{ Modelo } & & \multicolumn{2}{|c|}{$\begin{array}{l}\text { Coeficientes no } \\
\text { estandarizados }\end{array}$} & \multirow{2}{*}{$\begin{array}{l}\text { Coeficien } \\
\text { tes } \\
\text { estandari } \\
\text { zados } \\
\text { Beta }\end{array}$} & \multirow[b]{2}{*}{$t$} & \multirow[b]{2}{*}{ Sig. } \\
\hline & & B & Error típ. & & & \\
\hline \multirow[t]{2}{*}{1} & (Constante) & ,424 & ,061 & & 6,944 &, 000 \\
\hline & P1MOD & ,661 & ,039 & ,704 & 17,004 &, 000 \\
\hline \multirow[t]{3}{*}{2} & (Constante) & 189 & ,078 & & 2,437 & ,015 \\
\hline & P1MOD &, 560 & ,043 & ,597 & 12,951 & ,000 \\
\hline & RSACUM & 3,89E-05 & ,000 & ,215 & 4,660 &, 000 \\
\hline \multirow[t]{4}{*}{3} & (Constante) & ,367 & ,101 & & 3,636 &, 000 \\
\hline & P1MOD &, 576 & ,043 & ,614 & 13,339 &, 000 \\
\hline & RSACUM & $4,25 \mathrm{E}-05$ & ,000 & ,235 & 5,087 &, 000 \\
\hline & AHR1 & $-7,3 \mathrm{E}-03$ &, 003 &,- 112 & $-2,715$ &, 007 \\
\hline \multirow[t]{5}{*}{4} & (Constante) & ,207 & ,113 & & 1,835 & ,068 \\
\hline & P1MOD &, 582 & ,043 & ,620 & 13,637 & ,000 \\
\hline & RSACUM & $3,30 \mathrm{E}-05$ & ,000 & ,182 & 3,739 & 000 \\
\hline & AHR1 & $-9,0 \mathrm{E}-03$ & ,003 &,- 138 & $-3,314$ & ,001 \\
\hline & AHR & 8,87E-03 & ,003 & ,134 & 3,040 &, 003 \\
\hline \multirow[t]{6}{*}{5} & (Constante) & ,163 & ,112 & & 1,459 & ,146 \\
\hline & P1MOD &, 526 & ,045 &, 561 & 11,619 &, 000 \\
\hline & RSACUM & $2,50 \mathrm{E}-05$ & ,000 & 138 & 2,769 & ,006 \\
\hline & AHR1 & $-9,9 \mathrm{E}-03$ & ,003 &,- 152 & $-3,681$ & ,000 \\
\hline & AHR & 9,91E-03 & ,003 & 150 & 3,432 & ,001 \\
\hline & P3MOD & 143 & ,044 & ,154 & 3,265 & ,001 \\
\hline \multirow[t]{7}{*}{6} & (Constante) &,- 151 & ,148 & & $-1,016$ & 310 \\
\hline & P1MOD &, 520 & ,045 & ,555 & 11,662 &, 000 \\
\hline & RSACUM & 1,56E-05 & ,000 & ,087 & 1,671 & ,096 \\
\hline & AHR1 & $-9,1 E-03$ & ,003 &,- 139 & $-3,405$ & ,001 \\
\hline & AHR & 1,17E-02 & ,003 & 176 & 4,034 &, 000 \\
\hline & P3MOD & , 148 & ,043 & 160 & 3,428 & ,001 \\
\hline & WMEDIA & 2,78E-02 & ,009 & 129 & 3,155 & ,002 \\
\hline \multirow[t]{8}{*}{7} & (Constante) &,- 361 & ,168 & & $-2,147$ &, 033 \\
\hline & P1MOD &, 508 & ,044 & ,541 & 11,414 &, 000 \\
\hline & RSACUM & 1,52E-05 & ,000 & ,084 & 1,643 & 102 \\
\hline & AHR1 & $-9,9 \mathrm{E}-03$ & ,003 &,- 152 & $-3,730$ &, 000 \\
\hline & AHR & 1,14E-02 & ,003 & ,172 & 3,975 &, 000 \\
\hline & P3MOD & ,160 & ,043 & 173 & 3,725 &, 000 \\
\hline & WMEDIA & 2,93E-02 & ,009 & 136 & 3,356 & ,001 \\
\hline & AT4 & $2,71 \mathrm{E}-02$ & 011 & ,099 & 2,570 & 011 \\
\hline \multirow[t]{7}{*}{8} & (Constante) &,- 395 & 167 & & $-2,365$ &, 019 \\
\hline & P1MOD &, 527 & ,043 & ,562 & 12,253 &, 000 \\
\hline & AHR1 & $-9,6 \mathrm{E}-03$ & ,003 &,- 147 & $-3,612$ &, 000 \\
\hline & AHR & 1,33E-02 & ,003 & 201 & 5,062 &, 000 \\
\hline & P3MOD & 179 & 041 & 194 & 4,316 &, 000 \\
\hline & WMEDIA & $3,39 \mathrm{E}-02$ & ,008 & 157 & 4,073 &, 000 \\
\hline & AT4 & $2,74 \mathrm{E}-02$ &, 011 &, 100 & 2,591 &, 010 \\
\hline \multicolumn{7}{|c|}{ a. Variable dependiente: POLMODEL } \\
\hline b. $\mathrm{Cl}$ & STER $=5,00$ & & & & & \\
\hline
\end{tabular}




\subsubsection{VALIDACIÓN DEL MODELO DE REGRESIÓN LINEAL MÚLTIPLE PARA LA CONCENTRACIÓN POLÍNICA TOTAL DIARIA ESTANDARIZADA 1995-1998.}

La ecuación 5.1. recoge el modelo de regresión lineal múltiple para la concentración polínica total diaria estandarizada (1995-1998). La figura 5.68. muestra el gráfico de dispersión de los valores predichos por el modelo para el año 1999 y las concentraciones reales de este año. En la tabla 5.72,se recogen los coeficientes de correlación y determinación para los datos predichos por el modelo y reales para el año 1999. La figura 5.69, recoge el gráfico P-P normal de regresión para los residuos tipificados del modelo (1995-1998).

Ecuación 5.1. Modelo de regresión múltiple para el modelo. Nivel de significación de todas las variables incluidas en el modelo $\leq 0,05 . R^{2}=0,54$.

$$
\begin{gathered}
\text { POPRED1999 }=0.995+0.634 * \text { POLMODEL }-0.008605 * \text { HRMIN }-0.00749 * \\
\Delta \mathrm{HR} 1+0.111 * \mathrm{P} 3 \mathrm{MOD}+0.01137 * \text { WMEDIA }-1.47 * \text { RUMI } 11-0.01886 * \Delta \mathrm{T} 6+ \\
0.01548 * \Delta \mathrm{T} 4
\end{gathered}
$$

Figura 5.68. Gráfico de dispersión para las predicciones del año 1999.

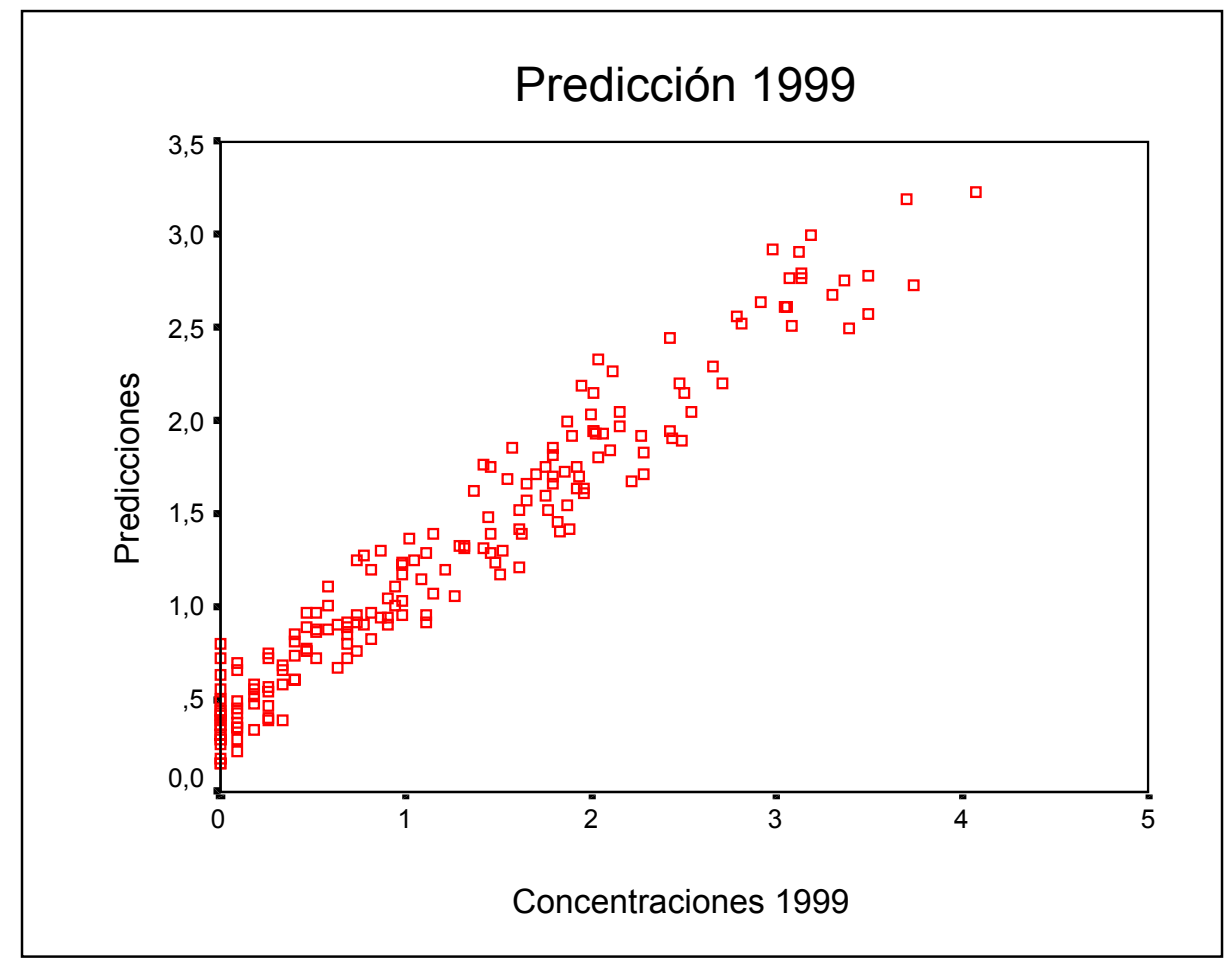


Tabla 5.72. Coeficientes de correlación y determinación entre los datos predichos por el modelo y los datos reales para el año 1999. Valores calculados y críticos $(\alpha=$ $0,05)$ de los contrastes de diferencias entre varianzas $(F)$ y entre medias $(t)$.

\begin{tabular}{|c|c||}
\hline $\mathbf{r}$ & $0,97^{* *}$ \\
\hline $\mathbf{r}^{2}$ & 0,94 \\
\hline F calculado & 0,53 \\
\hline F crítico & 1,00 \\
\hline t calculado & 0,36 \\
\hline t crítico & 1,65 \\
\hline
\end{tabular}

${ }^{* *}$ Nivel de significación al $99 \%$

Figura 5.69. Gráfico P-P normal de regresión para los residuos tipificados del modelo general 1995-1998.

Gráfico P-P normal de regresión Residuo tip.

Variable dependiente: POLMODEL

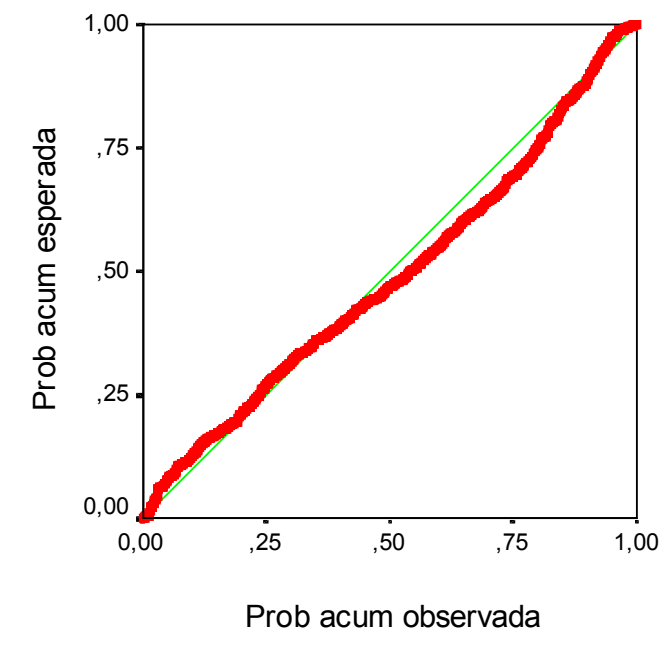




\subsubsection{VALIDACIÓN DE LOS MODELOS DE REGRESIÓN LINEAL MÚLTIPLE PARA LA CONCENTRACIÓN POLÍNICA TOTAL DIARIA ESTANDARIZADA PARA CADA CLUSTER IDENTIFICADO.}

\section{- VALIDACIÓN DEL MODELO OBTENIDO PARA EL CLUSTER 1.}

La ecuación 5.2. recoge el modelo de regresión lineal múltiple para la concentración polínica total diaria estandarizada (1995-1998), para el cluster 1. La figura 5.70. muestra el gráfico de dispersión de los valores predichos por el modelo para el año 1999 y las concentraciones reales de este año. En la tabla 5.73., se recogen los coeficientes de correlación y determinación para los datos predichos por el modelo y reales para el año 1999. La figura 5.71, recoge el gráfico P-P normal de regresión para los residuos tipificados del modelo (1995-1998).

Ecuación 5.2. Modelo de regresión múltiple para el cluster 1. Nivel de significación de todas las variables incluidas en el modelo $\leq 0,05 . R^{2}=0,68$.

$$
\text { POPREDC1 }=-0.611+0.772 * \mathrm{P} 1 \mathrm{MOD}+0.07905 * \Delta \mathrm{T} 5+0.01313 * \Delta \mathrm{HR} 1
$$

Figura 5.70. Gráfico de dispersión para las predicciones del cluster1 (año 1999).

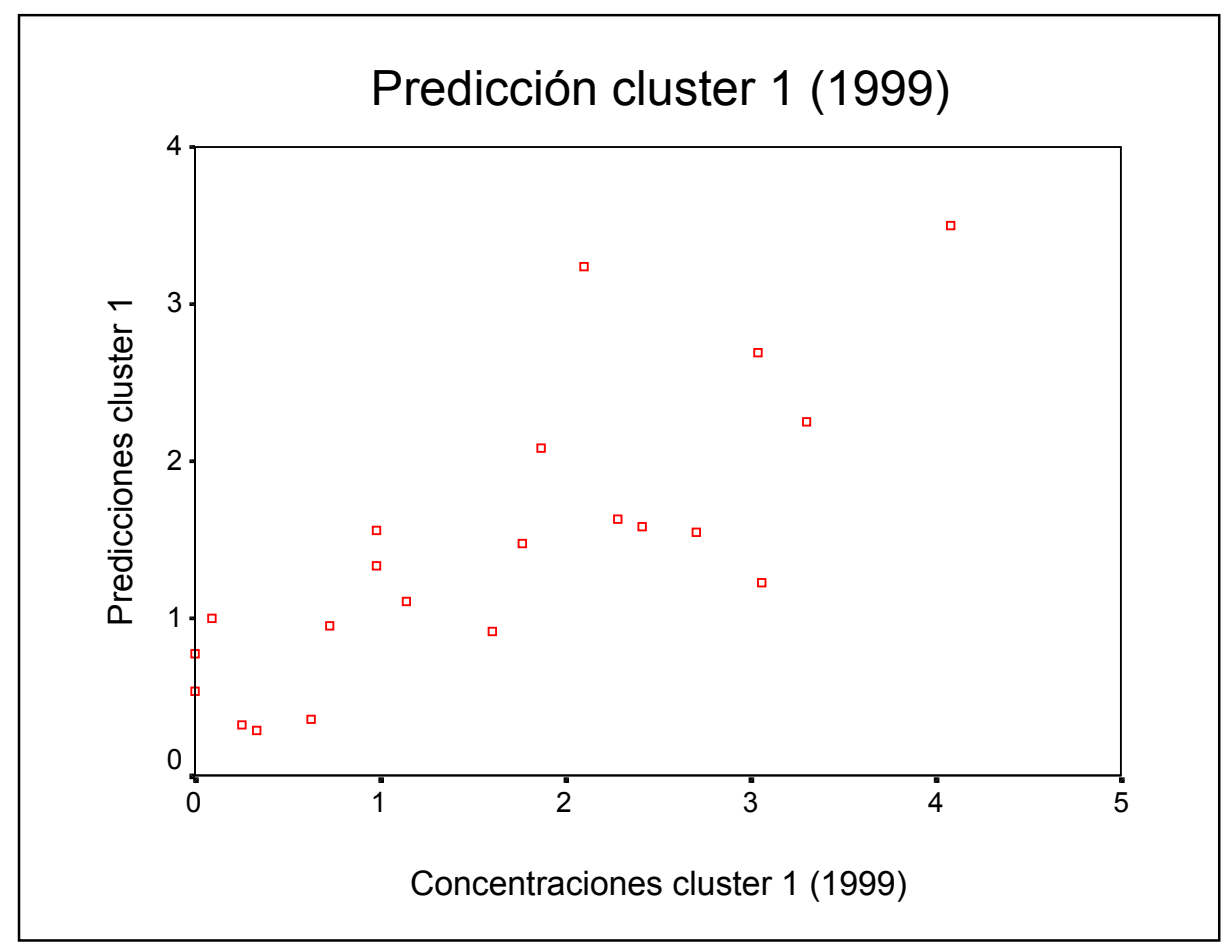


Tabla 5.73. Coeficientes de correlación y determinación entre los datos predichos por el modelo y los datos reales para el año 1999. Valores calculados y críticos $(\alpha=$ $0,05)$ de los contrastes de diferencias entre varianzas $(F)$ y entre medias $(t)$.

\begin{tabular}{|c|c||}
\hline $\mathrm{r}$ & $0,81^{* *}$ \\
\hline $\mathrm{r}^{2}$ & 0,66 \\
\hline F calculado & 0,59 \\
\hline F crítico & 2,03 \\
\hline $\mathrm{t}$ calculado & 0,45 \\
\hline $\mathrm{t}$ crítico & 1,65 \\
\hline \hline
\end{tabular}

Nivel de significación al 99\%

Figura 5.71.Gráfico P-P normal de regresión para los residuos tipificados del modelo del cluster 1, para los años 1995-1998.

Gráfico P-P normal de regresión Residuo tip.

Variable dependiente: POLMODEL

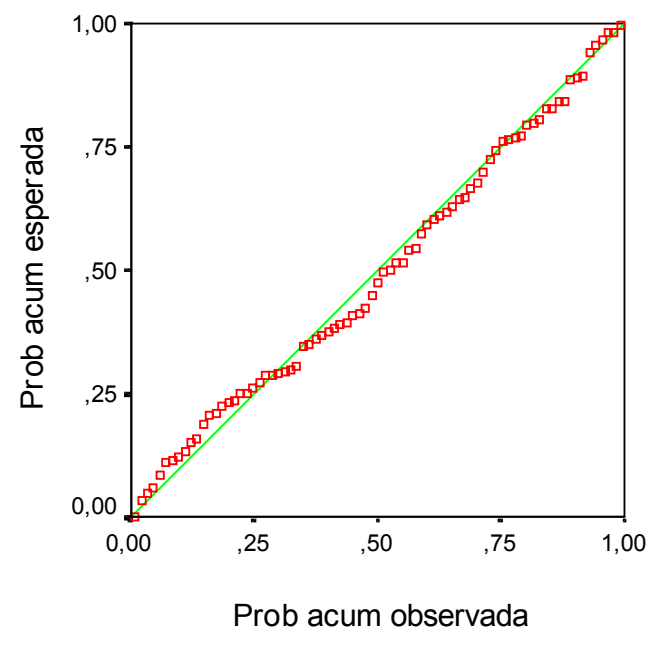


- VALIDACIÓN DEL MODELO OBTENIDO PARA EL CLUSTER 2

La ecuación 5.3. recoge el modelo de regresión lineal múltiple para la concentración polínica total diaria estandarizada (1995-1998), para el cluster 2. La figura 5.72. muestra el gráfico de dispersión de los valores predichos por el modelo para el año 1999 y las concentraciones reales de este año. En la tabla 5.74., se recogen los coeficientes de correlación y determinación para los datos predichos por el modelo y reales para el año 1999. La figura 5.73., recoge el gráfico P-P normal de regresión para los residuos tipificados del modelo (1995-1998).

Ecuación 5.3. Modelo de regresión múltiple para el cluster 2. Nivel de significación de todas las variables incluidas en el modelo $\leq 0,05 . \mathrm{R}^{2}=0,52$.

POPREDC2 $=0.615+0.640 * \mathrm{P} 1 \mathrm{MOD}-0.0399 * \Delta \mathrm{T} 6+0.136 * \mathrm{P} 3 \mathrm{MOD}$

Figura 5.72. Gráfico de dispersión para las predicciones del cluster 2 (año 1999).

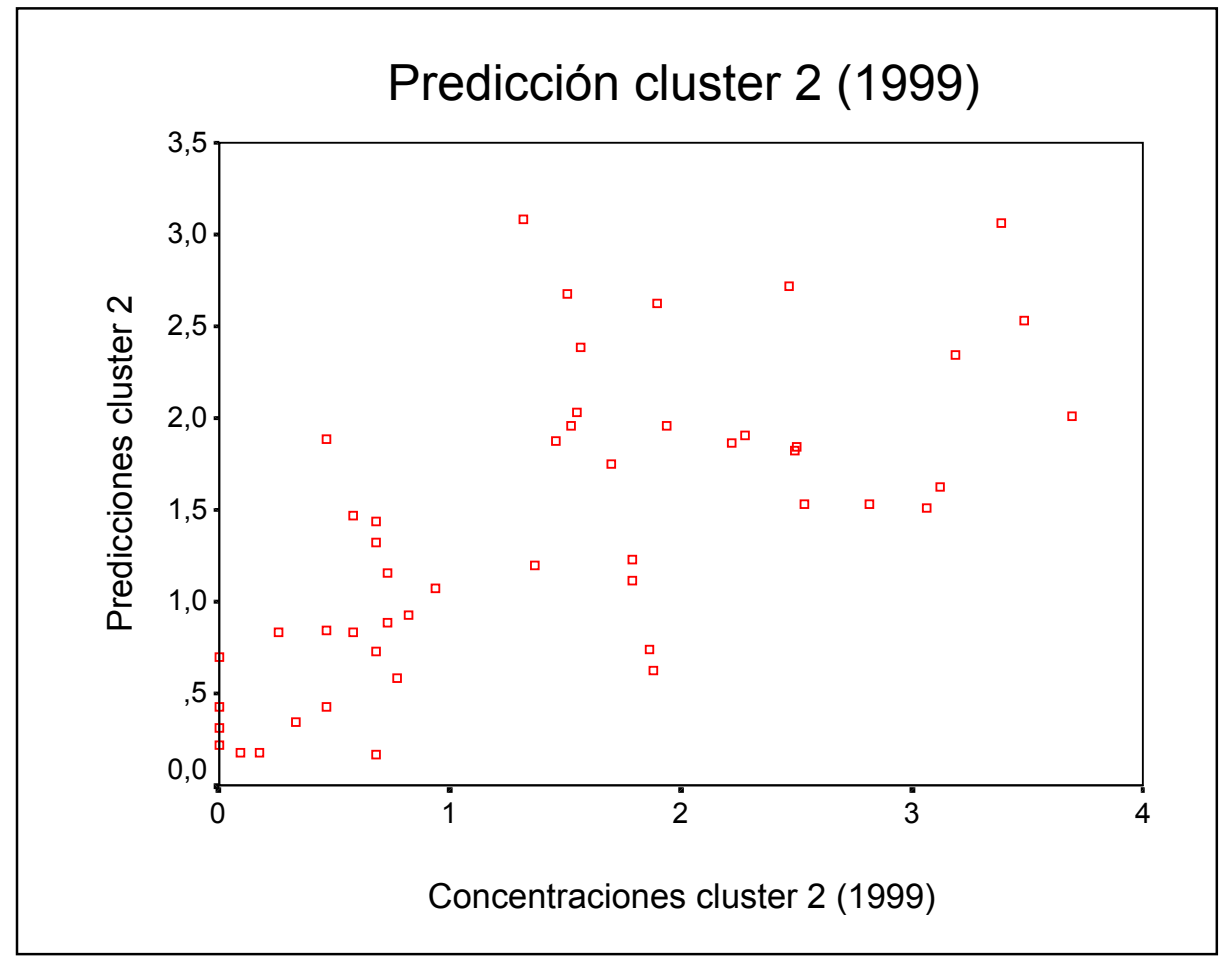


Tabla 5.74. Coeficientes de correlación y determinación entre los datos predichos por el modelo y los datos reales para el año 1999. Valores calculados y críticos $(\alpha=$ $0,05)$ de los contrastes de diferencias entre varianzas $(F)$ y entre medias $(t)$.

\begin{tabular}{|c|c||}
\hline $\mathbf{r}$ & $0,69^{* *}$ \\
\hline $\mathbf{r}^{2}$ & 0,47 \\
\hline F calculado & 0,58 \\
\hline F crítico & 2,05 \\
\hline t calculado & 0,05 \\
\hline t crítico & 1,65 \\
\hline \hline
\end{tabular}

"Nivel de significación al 99\%

Figura 5.73.Gráfico P-P normal de regresión para los residuos tipificados del modelo del cluster 2, para los años 1995-1998.

Gráfico P-P normal de regresión Residuo tip.

Variable dependiente: POLMODEL

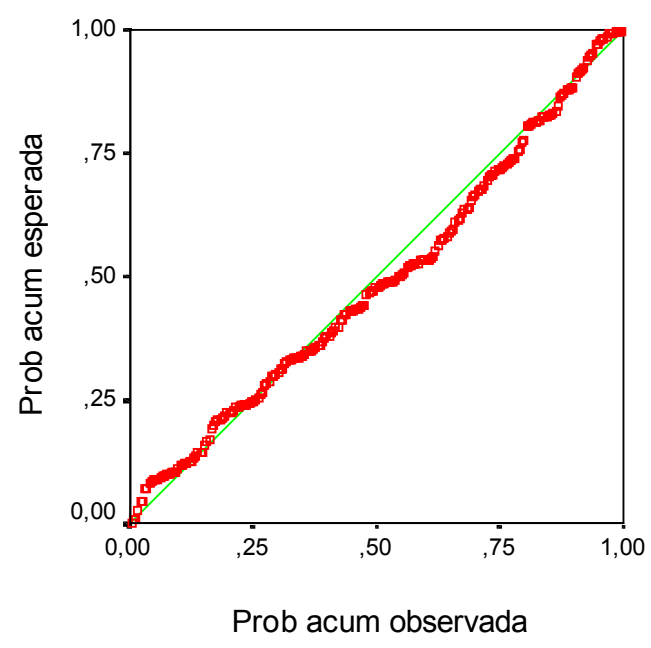


- VALIDACIÓN DEL MODELO OBTENIDO PARA EL CLUSTER 3

La ecuación 5.4. recoge el modelo de regresión lineal múltiple para la concentración polínica total diaria estandarizada (1995-1998), para el cluster 3. La figura 5.74. muestra el gráfico de dispersión de los valores predichos por el modelo para el año 1999 y las concentraciones reales de este año. En la tabla 5.75., se recogen los coeficientes de correlación y determinación para los datos predichos por el modelo y reales para el año 1999. La figura 5.75., recoge el gráfico P-P normal de regresión para los residuos tipificados del modelo (1995-1998).

Ecuación 5.4. Modelo de regresión múltiple para el cluster 3. Nivel de significación de todas las variables incluidas en el modelo $\leq 0,05 . \mathrm{R}^{2}=0,60$.

POPREDC3 $=0.746+0.644 * \mathrm{P} 1 \mathrm{MOD}-0.09227 * \Delta \mathrm{T} 11+0.01531 * \Delta \mathrm{HR} 2+0.887$

* RUMI1

Figura 5.74. Gráfico de dispersión para las predicciones del cluster 3 (año 1999).

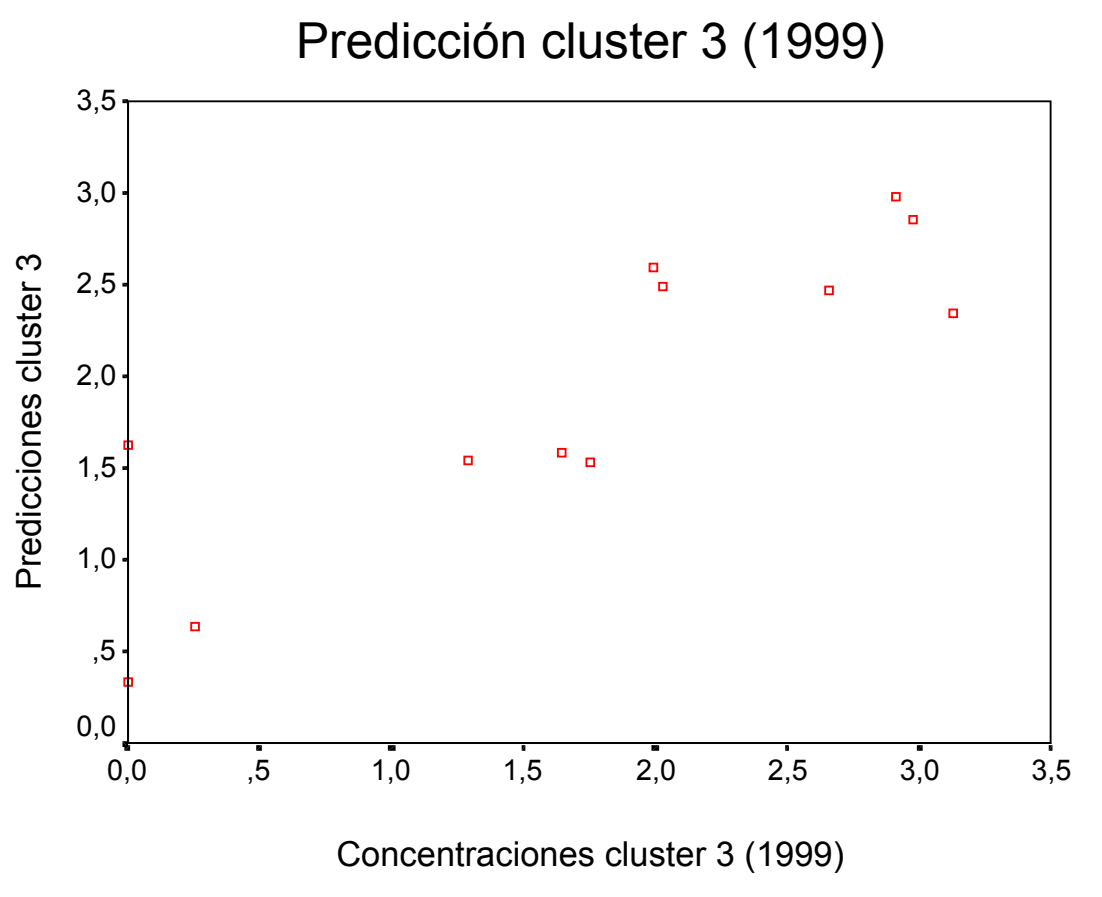


Tabla 5.75. Coeficientes de correlación y determinación entre los datos predichos por el modelo y los datos reales para el año 1999. Valores calculados y críticos $(\alpha=$ $0,05)$ de los contrastes de diferencias entre varianzas $(F)$ y entre medias $(t)$.

\begin{tabular}{|c|c||}
\hline $\mathrm{r}$ & $0,87^{* *}$ \\
\hline $\mathrm{r}^{2}$ & 0,75 \\
\hline F calculado & 1,80 \\
\hline F crítico & 4,45 \\
\hline $\mathrm{t}$ calculado & 0,47 \\
\hline $\mathrm{t}$ crítico & 1,71 \\
\hline \hline
\end{tabular}

"Nivel de significación al 99\%

Figura 5.75.Gráfico P-P normal de regresión para los residuos tipificados del modelo del cluster 3, para los años 1995-1998.

Gráfico P-P normal de regresión Residuo tip.

Variable dependiente: POLMODEL

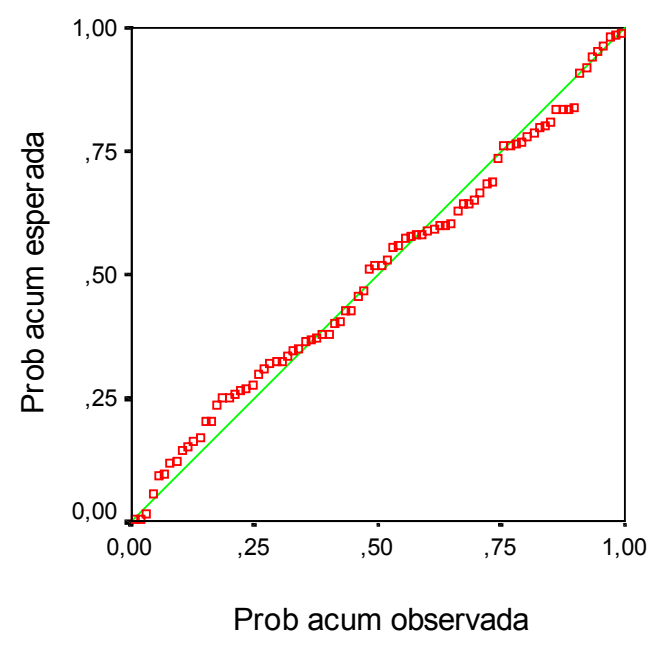




\section{VALIDACIÓN DEL MODELO OBTENIDO PARA EL CLUSTER 4}

La ecuación 5.5. recoge el modelo de regresión lineal múltiple para la concentración polínica total diaria estandarizada (1995-1998), para el cluster 4. La figura 5.76. muestra el gráfico de dispersión de los valores predichos por el modelo para el año 1999 y las concentraciones reales de este año. En la tabla 5.76., se recogen los coeficientes de correlación y determinación para los datos predichos por el modelo y reales para el año 1999. La figura 5.77., recoge el gráfico P-P normal de regresión para los residuos tipificados del modelo (1995-1998).

Ecuación 5.5. Modelo de regresión múltiple para el cluster 4. Nivel de significación de todas las variables incluidas en el modelo $\leq 0,05 . \mathrm{R}^{2}=0,46$.

POPREDC4 $=0.815+0.699 *$ P1MOD $-0.01375 * \Delta$ HR $1-1.392 *$ RAMI 1

Figura 5.76. Gráfico de dispersión para las predicciones del cluster 4 (año 1999).

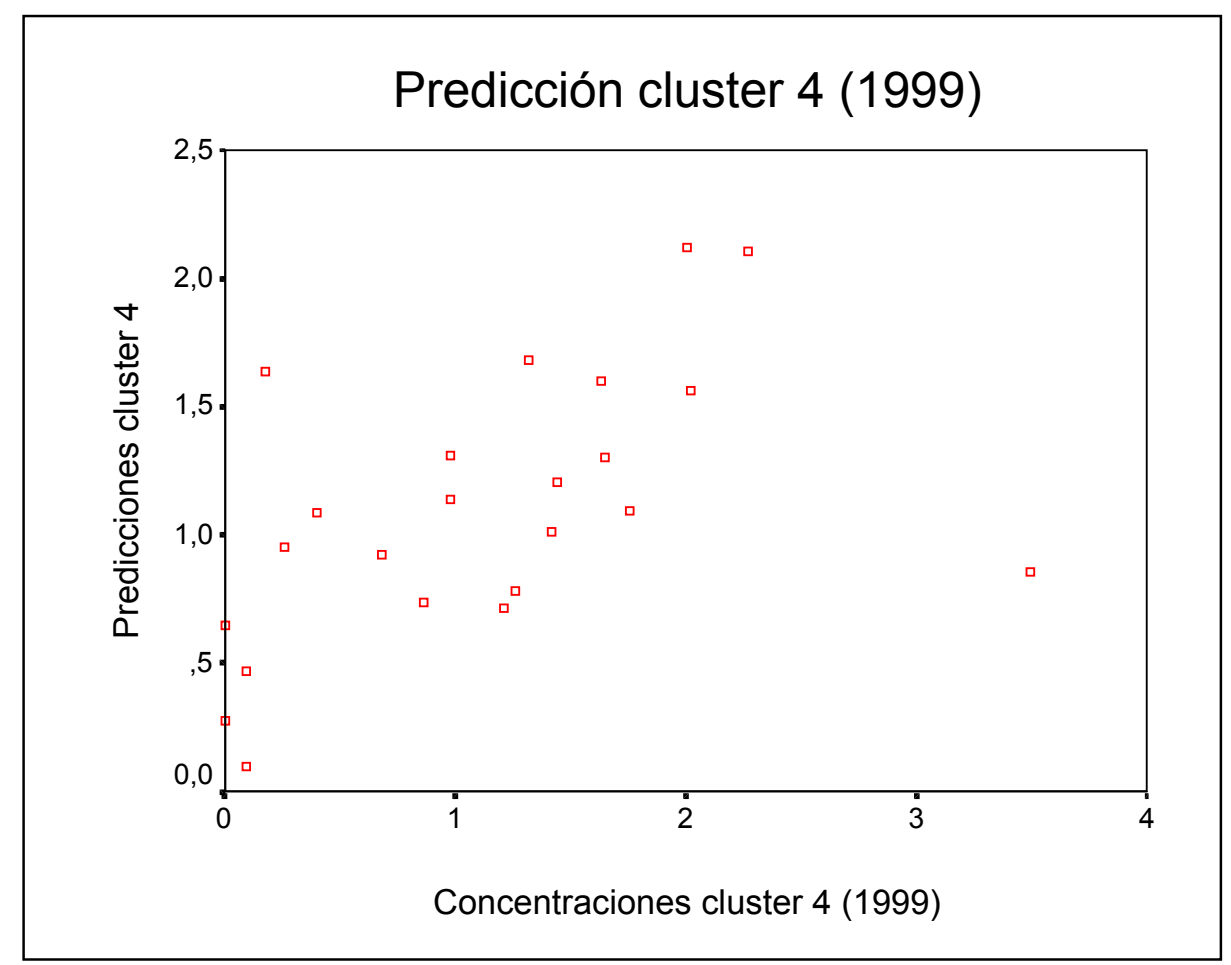


Tabla 5.76. Coeficientes de correlación y determinación entre los datos predichos por el modelo y los datos reales para el año 1999. Valores calculados y críticos $(\alpha=$ $0,05)$ de los contrastes de diferencias entre varianzas $(F)$ y entre medias $(t)$.

\begin{tabular}{|c|c||}
\hline $\mathrm{r}$ & $0,51^{*}$ \\
\hline $\mathrm{r}^{2}$ & 0,26 \\
\hline F calculado & 2,84 \\
\hline F crítico & 2,65 \\
\hline $\mathrm{t}$ calculado & 0,24 \\
\hline $\mathrm{t}$ crítico & 1,70 \\
\hline
\end{tabular}

${ }^{*}$ Nivel de significación al 95\%

Figura 5.77.Gráfico P-P normal de regresión para los residuos tipificados del modelo del cluster 4, para los años 1995-1998.

Gráfico P-P normal de regresión Residuo tip.

Variable dependiente: POLMODEL

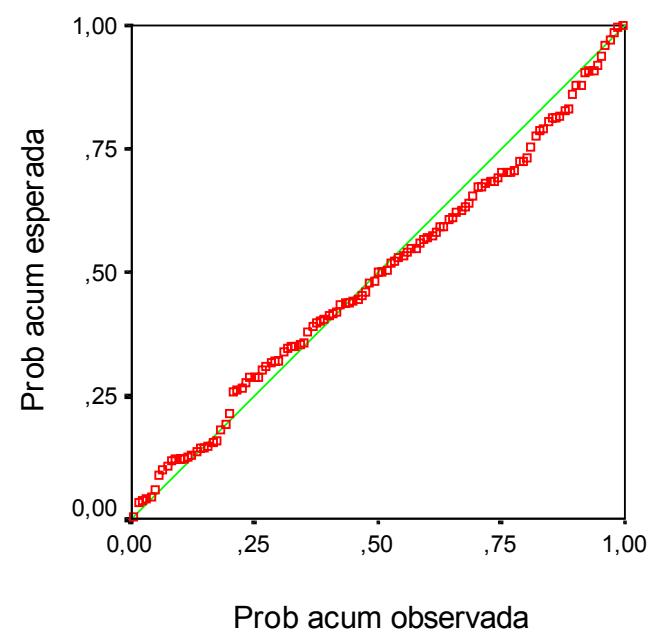




\section{- VALIDACIÓN DEL MODELO OBTENIDO PARA EL CLUSTER 5}

La ecuación 5.6. recoge el modelo de regresión lineal múltiple para la concentración polínica total diaria estandarizada (1995-1998), para el cluster 3. La figura 5.78. muestra el gráfico de dispersión de los valores predichos por el modelo para el año 1999 y las concentraciones reales de este año. En la tabla 5.77., se recogen los coeficientes de correlación y determinación para los datos predichos por el modelo y reales para el año 1999. La figura 5.79., recoge el gráfico P-P normal de regresión para los residuos tipificados del modelo (19951998).

Ecuación 5.6. Modelo de regresión múltiple para el cluster 5. Nivel de significación de todas las variables incluidas en el modelo $\leq 0,05 . \mathrm{R}^{2}=$ 0,59 .

POPREDC5 $=-0.395+0.527 * \mathrm{P} 1 \mathrm{MOD}-0.009606 * \Delta \mathrm{HR} 1+0.01334 * \Delta \mathrm{HR}+$ $0.179 * \mathrm{P} 3 \mathrm{MOD}+0.03385 * \mathrm{WMEDIA}+0.02739 * \Delta \mathrm{T} 4$

Figura 5.78. Gráfico de dispersión para las predicciones del cluster 5 (año 1999).

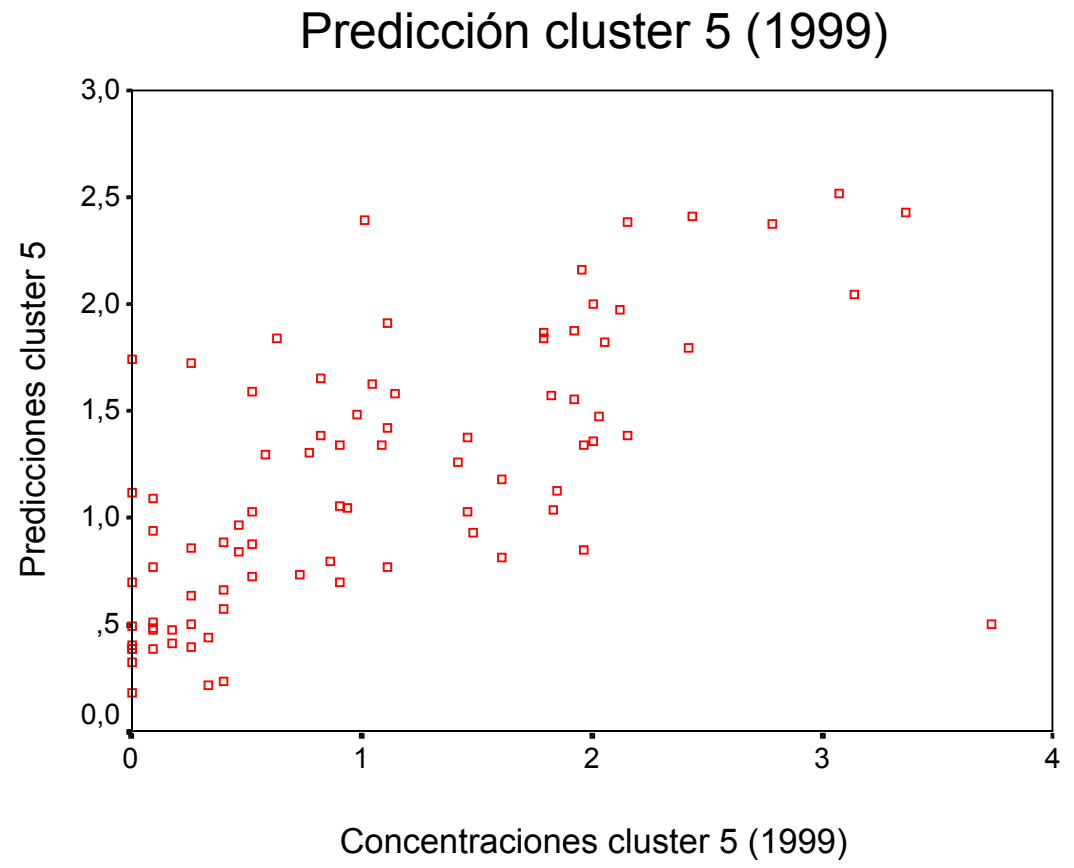


Tabla 5.77. Coeficientes de correlación y determinación entre los datos predichos por el modelo y los datos reales para el año 1999. Valores calculados y críticos $(\alpha=0,05)$ de los contrastes de diferencias entre varianzas $(F)$ y entre medias $(\mathrm{t})$.

\begin{tabular}{|c|c|}
\hline $\mathrm{r}$ & $0,67^{* *}$ \\
\hline $\mathrm{r}^{2}$ & 0,45 \\
\hline F calculado & 0,47 \\
\hline F crítico & 1,60 \\
\hline $\mathrm{t}$ calculado & 1,35 \\
\hline $\mathrm{t}$ crítico & 1,65 \\
\hline
\end{tabular}

Nivel de significación al 99\%

Figura 5.79.Gráfico P-P normal de regresión para los residuos tipificados del modelo del cluster 5, para los años 1995-1998.

Gráfico P-P normal de regresión Residuo tip.

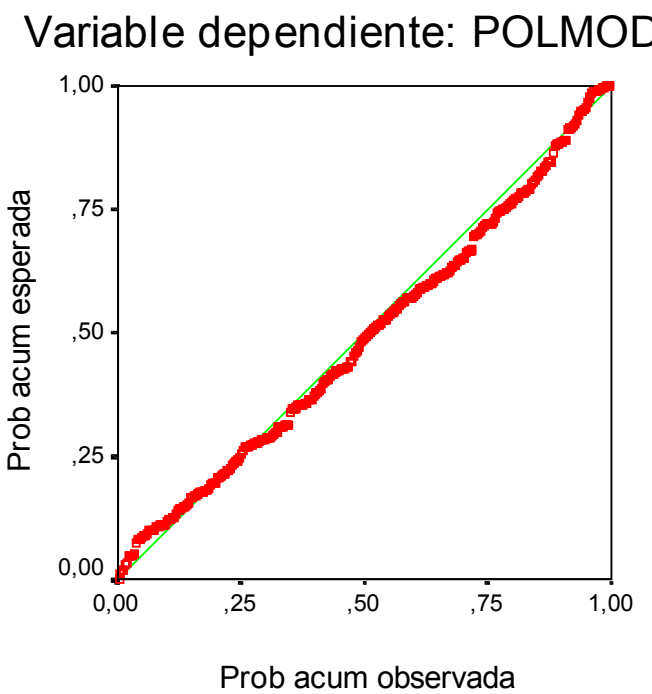




\subsubsection{CONCENTRACIONES POLÍNICAS DE CHENOPODIACEAE- AMARANTHACEAE.}

\subsubsection{CORRELACIONES BIVARIADAS ENTRE LAS CONCENTRACIONES POLÍNICAS DE CHENOPODIACEAE-AMARANTHACEAE Y EL RESTO DE VARIABLES.}

En la tabla 5.78. se presentan las correlaciones bivariadas entre la variable CHENO2ST (concentración polínica total diaria estandarizada de la segunda floración de Chenopodiaceae-Amaranthaceae de los años 1995-1999), y el resto de variables que se han utilizado para construir la base datos meteorológica y aerobiológica.

Tabla 5.78. Correlaciones bivariadas de Pearson entre la variable concentración polínica total diaria de Chenopodiaceae-Amaranthaceae $2^{\mathrm{a}}$ floración estandarizada para los años 1995-1999 y el resto de variables, nivel de significación y tamaño de la muestra en cada caso.

\begin{tabular}{|c|c|c|}
\hline & & CHENO2ST \\
\hline CLUSTER & C. Pearson & 0.015 \\
& Sig. (bilateral) & 0.801 \\
& $\mathbf{N}$ & 295 \\
\hline CLUSTER1 & C. Pearson & 0.064 \\
& Sig. (bilateral) & 0.274 \\
& $\mathbf{N}$ & 295 \\
\hline \multirow{2}{*}{ CLUSTER2 } & C. Pearson & -0.018 \\
& Sig. (bilateral) & 0.763 \\
& $\mathbf{N}$ & 295 \\
\hline
\end{tabular}


Tabla 5.78. Continuación. Correlaciones bivariadas de Pearson entre la variable concentración polínica total diaria estandarizada para los años 1995-1999 y el resto de variables, nivel de significación y tamaño de la muestra en cada caso.

\begin{tabular}{|c|c|c|}
\hline CLUSTER3 & $\begin{array}{c}\text { C. Pearson } \\
\text { Sig. (bilateral) } \\
\text { N }\end{array}$ & $\begin{array}{c}0.035 \\
0.549 \\
295\end{array}$ \\
\hline CLUSTER4 & $\begin{array}{c}\text { C. Pearson } \\
\text { Sig. (bilateral) } \\
\text { N }\end{array}$ & $\begin{array}{c}0.066 \\
0.259 \\
295\end{array}$ \\
\hline CLUSTER5 & $\begin{array}{c}\text { C. Pearson } \\
\text { Sig. (bilateral) } \\
\text { N }\end{array}$ & $\begin{array}{c}-0.125^{*} \\
0.031 \\
295\end{array}$ \\
\hline ESTACIÓN & $\begin{array}{c}\text { C. Pearson } \\
\text { Sig. (bilateral) } \\
\text { N }\end{array}$ & $\begin{array}{c}-0.281 * * \\
0.000 \\
295\end{array}$ \\
\hline SEMANA & $\begin{array}{c}\text { C. Pearson } \\
\text { Sig. (bilateral) } \\
\text { N }\end{array}$ & $\begin{array}{c}0.058 \\
0.317 \\
295\end{array}$ \\
\hline PRBMEDIA & $\begin{array}{c}\text { C. Pearson } \\
\text { Sig. (bilateral) } \\
\text { N }\end{array}$ & $\begin{array}{c}-0.177 * * \\
0.002 \\
295\end{array}$ \\
\hline TMPMEDIA & $\begin{array}{c}\text { C. Pearson } \\
\text { Sig. (bilateral) } \\
\text { N }\end{array}$ & $\begin{array}{c}-0.051 \\
0.378 \\
295\end{array}$ \\
\hline
\end{tabular}


Tabla 5.78. Continuación. Correlaciones bivariadas de Pearson entre la variable concentración polínica total diaria estandarizada para los años 1995-1999 y el resto de variables, nivel de significación y tamaño de la muestra en cada caso.

\begin{tabular}{|c|c|c|}
\hline HRMEDIA & $\begin{array}{c}\text { C. Pearson } \\
\text { Sig. (bilateral) } \\
\text { N }\end{array}$ & $\begin{array}{c}-0.087 \\
0.138 \\
295\end{array}$ \\
\hline DIRMEDIA & $\begin{array}{c}\text { C. Pearson } \\
\text { Sig. (bilateral) } \\
\text { N }\end{array}$ & $\begin{array}{l}0.051 \\
0.379 \\
295\end{array}$ \\
\hline WMEDIA & $\begin{array}{c}\text { C. Pearson } \\
\text { Sig. (bilateral) } \\
\text { N }\end{array}$ & $\begin{array}{c}0.152^{* *} \\
0.009 \\
295\end{array}$ \\
\hline RSACUM & $\begin{array}{c}\text { C. Pearson } \\
\text { Sig. (bilateral) } \\
\text { N }\end{array}$ & $\begin{array}{c}-0.0119 * \\
0.040 \\
295\end{array}$ \\
\hline LLUVIADI & $\begin{array}{c}\text { C. Pearson } \\
\text { Sig. (bilateral) } \\
\text { N }\end{array}$ & $\begin{array}{c}0.155^{* *} \\
0.008 \\
295\end{array}$ \\
\hline RUMBOS & $\begin{array}{c}\text { C. Pearson } \\
\text { Sig. (bilateral) } \\
\text { N }\end{array}$ & $\begin{array}{l}0.046 \\
0.436 \\
293\end{array}$ \\
\hline RANGO & $\begin{array}{c}\text { C. Pearson } \\
\text { Sig. (bilateral) } \\
\text { N }\end{array}$ & $\begin{array}{c}0.135^{*} \\
0.025 \\
276\end{array}$ \\
\hline
\end{tabular}


Tabla 5.78. Continuación. Correlaciones bivariadas de Pearson entre la variable concentración polínica total diaria estandarizada para los años 1995-1999 y el resto de variables, nivel de significación y tamaño de la muestra en cada caso.

\begin{tabular}{|c|c|c|}
\hline RUMBOS4 & $\begin{array}{c}\text { C. Pearson } \\
\text { Sig. (bilateral) } \\
\text { N }\end{array}$ & $\begin{array}{c}0.043 \\
0.458 \\
295\end{array}$ \\
\hline TMIN & $\begin{array}{c}\text { C. Pearson } \\
\text { Sig. (bilateral) } \\
\text { N }\end{array}$ & $\begin{array}{l}-0.26 \\
0.660 \\
295\end{array}$ \\
\hline TMAX & $\begin{array}{c}\text { C. Pearson } \\
\text { Sig. (bilateral) } \\
\text { N }\end{array}$ & $\begin{array}{c}-0.101 \\
0.082 \\
295\end{array}$ \\
\hline HRMIN & $\begin{array}{c}\text { C. Pearson } \\
\text { Sig. (bilateral) } \\
\text { N }\end{array}$ & $\begin{array}{c}-0.091 \\
0.121 \\
295\end{array}$ \\
\hline HRMAX & $\begin{array}{c}\text { C. Pearson } \\
\text { Sig. (bilateral) } \\
\text { N }\end{array}$ & $\begin{array}{c}-0.051 \\
0.382 \\
295\end{array}$ \\
\hline PRBMIN & $\begin{array}{c}\text { C. Pearson } \\
\text { Sig. (bilateral) } \\
\text { N }\end{array}$ & $\begin{array}{c}-0.142 * \\
0.015 \\
295\end{array}$ \\
\hline PRBMAX & $\begin{array}{c}\text { C. Pearson } \\
\text { Sig. (bilateral) } \\
\text { N }\end{array}$ & $\begin{array}{c}-0.173 * * \\
0.003 \\
295\end{array}$ \\
\hline
\end{tabular}


Tabla 5.78. Continuación. Correlaciones bivariadas de Pearson entre la variable concentración polínica total diaria estandarizada para los años 1995-1999 y el resto de variables, nivel de significación y tamaño de la muestra en cada caso.

\begin{tabular}{|c|c|c|}
\hline RSACU1 & $\begin{array}{c}\text { C. Pearson } \\
\text { Sig. (bilateral) } \\
\text { N }\end{array}$ & $\begin{array}{c}-0.119^{*} \\
0.040 \\
295\end{array}$ \\
\hline$\Delta \mathbf{T}$ & $\begin{array}{c}\text { C. Pearson } \\
\text { Sig. (bilateral) } \\
\text { N }\end{array}$ & $\begin{array}{c}-0.098 \\
0.094 \\
295\end{array}$ \\
\hline$\Delta \mathbf{H R}$ & $\begin{array}{c}\text { C. Pearson } \\
\text { Sig. (bilateral) } \\
\text { N }\end{array}$ & $\begin{array}{l}0.082 \\
0.160 \\
295\end{array}$ \\
\hline$\Delta \mathbf{P R B}$ & $\begin{array}{c}\text { C. Pearson } \\
\text { Sig. (bilateral) } \\
\text { N }\end{array}$ & $\begin{array}{l}0.009 \\
0.875 \\
295\end{array}$ \\
\hline$\Delta \mathrm{T} 1$ & $\begin{array}{c}\text { C. Pearson } \\
\text { Sig. (bilateral) } \\
\text { N }\end{array}$ & $\begin{array}{c}-0.071 \\
0.223 \\
295\end{array}$ \\
\hline$\Delta \mathrm{T} 2$ & $\begin{array}{c}\text { C. Pearson } \\
\text { Sig. (bilateral) } \\
\text { N }\end{array}$ & $\begin{array}{c}-0.053 \\
0.362 \\
295\end{array}$ \\
\hline$\Delta \mathrm{T3}$ & $\begin{array}{c}\text { C. Pearson } \\
\text { Sig. (bilateral) } \\
\text { N }\end{array}$ & $\begin{array}{c}-0.061 \\
0.295 \\
295\end{array}$ \\
\hline
\end{tabular}


Tabla 5.78. Continuación. Correlaciones bivariadas de Pearson entre la variable concentración polínica total diaria estandarizada para los años 1995-1999 y el resto de variables, nivel de significación y tamaño de la muestra en cada caso.

\begin{tabular}{|c|c|c|}
\hline$\Delta \mathrm{T} 4$ & $\begin{array}{c}\text { C. Pearson } \\
\text { Sig. (bilateral) } \\
\text { N }\end{array}$ & $\begin{array}{c}-0.028 \\
0.633 \\
295\end{array}$ \\
\hline$\Delta \mathrm{T} 5$ & $\begin{array}{c}\text { C. Pearson } \\
\text { Sig. (bilateral) } \\
\text { N }\end{array}$ & $\begin{array}{c}-0.083 \\
0.156 \\
295\end{array}$ \\
\hline$\Delta \mathrm{T6}$ & $\begin{array}{c}\text { C. Pearson } \\
\text { Sig. (bilateral) } \\
\text { N }\end{array}$ & $\begin{array}{c}-0.046 \\
0.436 \\
295\end{array}$ \\
\hline$\Delta \mathrm{HR} 1$ & $\begin{array}{c}\text { C. Pearson } \\
\text { Sig. (bilateral) } \\
\text { N }\end{array}$ & $\begin{array}{c}0.049 \\
0.405 \\
295\end{array}$ \\
\hline$\Delta$ HR2 & $\begin{array}{c}\text { C. Pearson } \\
\text { Sig. (bilateral) } \\
\text { N }\end{array}$ & $\begin{array}{c}0.078 \\
0.179 \\
295\end{array}$ \\
\hline$\Delta$ HR3 & $\begin{array}{c}\text { C. Pearson } \\
\text { Sig. (bilateral) } \\
\text { N }\end{array}$ & $\begin{array}{c}0.089 \\
0.127 \\
295\end{array}$ \\
\hline$\Delta \mathrm{HR} 4$ & $\begin{array}{c}\text { C. Pearson } \\
\text { Sig. (bilateral) } \\
\text { N }\end{array}$ & $\begin{array}{c}0.130^{*} \\
0.026 \\
295\end{array}$ \\
\hline
\end{tabular}


Tabla 5.78. Continuación. Correlaciones bivariadas de Pearson entre la variable concentración polínica total diaria estandarizada para los años 1995-1999 y el resto de variables, nivel de significación y tamaño de la muestra en cada caso.

\begin{tabular}{|c|c|c|}
\hline$\Delta \mathrm{HR5}$ & $\begin{array}{c}\text { C. Pearson } \\
\text { Sig. (bilateral) } \\
\text { N }\end{array}$ & $\begin{array}{l}0.091 \\
0.120 \\
295\end{array}$ \\
\hline$\Delta$ HR6 & $\begin{array}{c}\text { C. Pearson } \\
\text { Sig. (bilateral) } \\
\text { N }\end{array}$ & $\begin{array}{l}0.110 \\
0.058 \\
295\end{array}$ \\
\hline CH2ST1 & $\begin{array}{c}\text { C. Pearson } \\
\text { Sig. (bilateral) } \\
\text { N }\end{array}$ & $\begin{array}{c}0.769^{* *} \\
0.000 \\
287\end{array}$ \\
\hline CH2ST2 & $\begin{array}{c}\text { C. Pearson } \\
\text { Sig. (bilateral) } \\
\text { N }\end{array}$ & $\begin{array}{c}0.664^{* *} \\
0.000 \\
280\end{array}$ \\
\hline CH2ST3 & $\begin{array}{c}\text { C. Pearson } \\
\text { Sig. (bilateral) } \\
\text { N }\end{array}$ & $\begin{array}{c}0.608^{* *} \\
0.000 \\
273\end{array}$ \\
\hline
\end{tabular}




\subsubsection{MODELOS PREDICTIVOS DE REGRESIÓN LINEAL MÚLTIPLE PARA LA SEGUNDA FLORACIÓN DE LA CONCENTRACIÓN POLÍNICA ESTANDARIZADA DE CHENOPODIACEAE-AMARANTHACEAE (1995-1998).}

- Modelos predictivos con sólo variables meteorológicas (temperatura, humedad relativa, radiación solar, presión y velocidad del viento).

En la tabla 5.79., se recoge el resumen de los mejores modelos obtenidos. En la tabla 5.80. el ANOVA de los modelos y en la tabla 5.81., las variables incluidas en cada modelo, así como los coeficientes de las distintas variables.

Tabla 5.79. Resumen de los modelos de regresión múltiple para la concentración polínica total diaria de Chenopodiaceae-Amaranthaceae $2^{\mathrm{a}}$ floración estandarizada y las distintas variables meteorológicas (1995-1998).

\begin{tabular}{|l|r|r|r|r|r|}
\hline \multicolumn{7}{|c|}{ Resumen del modelod } \\
\hline Modelo & $\mathrm{R}$ & R cuadrado & $\begin{array}{c}\text { R cuadrado } \\
\text { corregida }\end{array}$ & $\begin{array}{c}\text { Error típ. de la } \\
\text { estimación }\end{array}$ & $\begin{array}{c}\text { Durbin-W } \\
\text { atson }\end{array}$ \\
\hline 1 &, $177^{\mathrm{a}}$ &, 031 &, 028 & 1,3281 & \\
2 &, $217^{\mathrm{b}}$ &, 047 &, 040 & 1,3195 & \\
3 &, $244^{\mathrm{c}}$ &, 060 &, 050 & 1,3130 &, 488 \\
\hline
\end{tabular}


Tabla 5.80. ANOVA de los modelos de regresión múltiple para la concentración polínica total diaria de Chenopodiaceae-Amaranthaceae $2^{\mathrm{a}}$ floración estandarizada y las distintas variables meteorológicas (1995-1998).

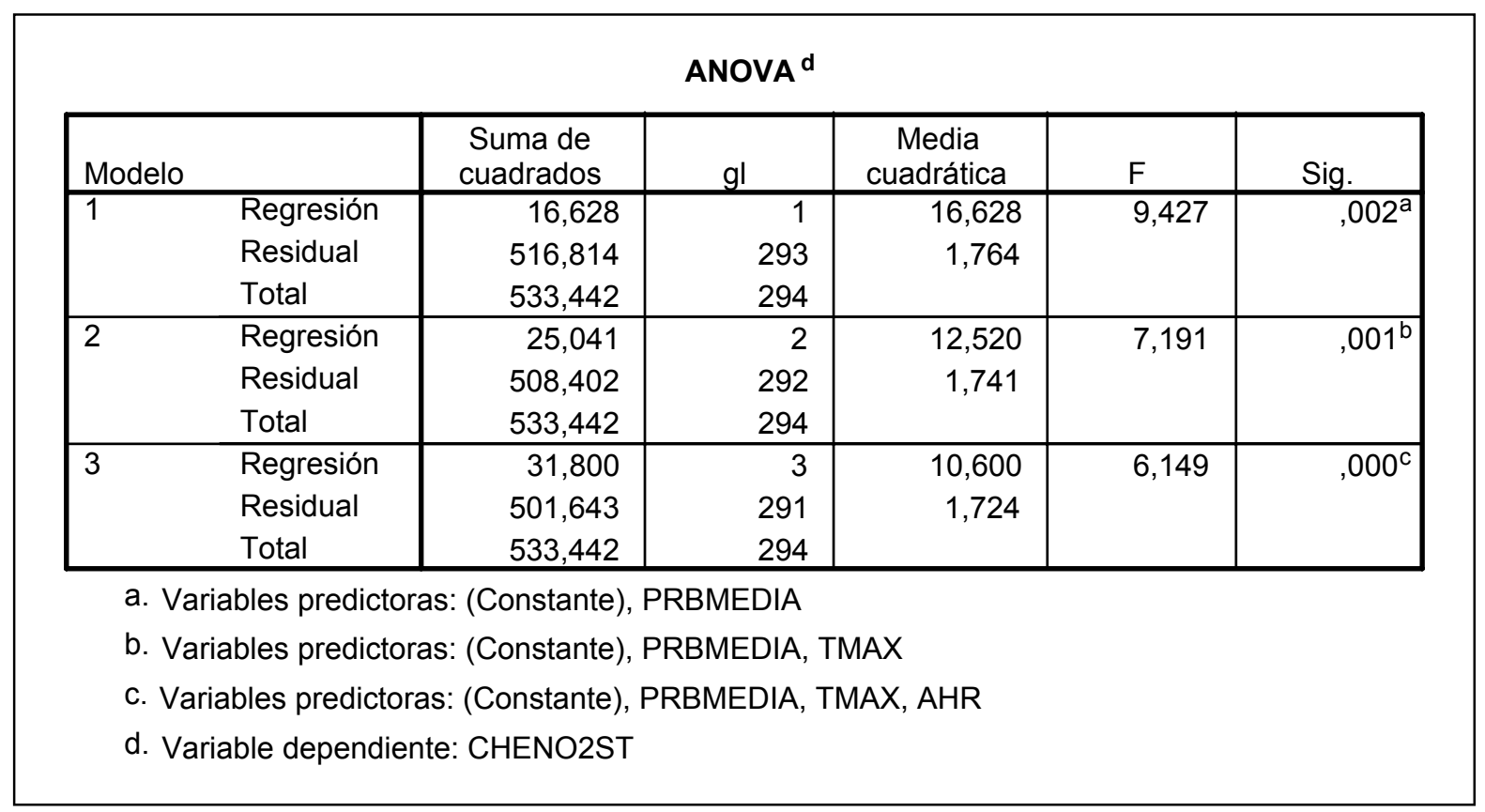

Tabla 5.81. Coeficientes de los modelos de regresión múltiple para la concentración polínica total diaria de Chenopodiaceae-Amaranthaceae $2^{\mathrm{a}}$ floración estandarizada y las distintas variables meteorológicas (19951998).

\begin{tabular}{|c|c|c|c|c|c|c|}
\hline \multicolumn{7}{|c|}{ Coeficientes $^{a}$} \\
\hline \multirow{2}{*}{\multicolumn{2}{|c|}{ Modelo }} & \multicolumn{2}{|c|}{$\begin{array}{l}\text { Coeficientes no } \\
\text { estandarizados }\end{array}$} & \multirow[t]{2}{*}{$\begin{array}{c}\text { Coeficien } \\
\text { tes } \\
\text { estandari } \\
\text { zados } \\
\text { Beta } \\
\end{array}$} & \multirow[b]{2}{*}{$t$} & \multirow[b]{2}{*}{ Sig. } \\
\hline & & B & Error típ. & & & \\
\hline & (Constante) & 61,265 & 19,353 & & 3,166 &, 002 \\
\hline & PRBMEDIA & $-5,8 \mathrm{E}-02$ &, 019 &,- 177 & $-3,070$ &, 002 \\
\hline \multirow[t]{3}{*}{2} & (Constante) & 68,459 & 19,504 & & 3,510 &, 001 \\
\hline & PRBMEDIA & $-6,4 \mathrm{E}-02$ & ,019 &,- 193 & $-3,351$ & 001 \\
\hline & TMAX & $-5,5 \mathrm{E}-02$ &, 025 &,- 127 & $-2,198$ & ,029 \\
\hline \multirow[t]{4}{*}{3} & (Constante) & 67,620 & 19,412 & & 3,483 &, 001 \\
\hline & PRBMEDIA & $-6,3 \mathrm{E}-02$ & ,019 &,- 191 & $-3,325$ & 001 \\
\hline & TMAX & $-7,0 \mathrm{E}-02$ & ,026 &,- 161 & $-2,684$ & ,008 \\
\hline & $\mathrm{AHR}$ & $1,53 \mathrm{E}-02$ &, 008 &, 118 & 1,980 &, 049 \\
\hline
\end{tabular}

a. Variable dependiente: CHENO2ST 
- Modelos predictivos con variables meteorológicas (temperatura, humedad relativa, radiación solar, presión, velocidad del viento), y con el resto de variables obtenidas a partir de éstas (autocorrelación).

En la tabla 5.82., se recoge el resumen de los mejores modelos obtenidos. En la tabla 5.83. el ANOVA de los modelos y en la tabla 5.84., las variables incluidas en cada modelo, así como los coeficientes de las distintas variables.

Tabla 5.82. Resumen de los modelos de regresión múltiple para la concentración polínica total diaria de Chenopodiaceae-Amaranthaceae $2^{\mathrm{a}}$ floración estandarizada y las distintas variables meteorológicas y de autocorrelación (1995-1998).

\begin{tabular}{|c|c|c|c|c|c|}
\hline \multicolumn{6}{|c|}{ Resumen del modelo } \\
\hline Modelo & $\mathrm{R}$ & $\mathrm{R}$ cuadrado & $\begin{array}{l}\text { R cuadrado } \\
\text { corregida }\end{array}$ & $\begin{array}{c}\text { Error típ. de la } \\
\text { estimación }\end{array}$ & $\begin{array}{l}\text { Durbin-W } \\
\text { atson }\end{array}$ \\
\hline 1 &, $764^{a}$ &, 584 &, 583 & ,8677 & \\
\hline 2 &, $777^{\mathrm{b}}$ & ,603 & 600 & ,8494 & \\
\hline 3 &, $782^{\mathrm{C}}$ & 611 & 607 & ,8421 & 2,100 \\
\hline \multicolumn{6}{|c|}{ a. Variables predictoras: (Constante), $\mathrm{CH} 2 \mathrm{ST} 1$} \\
\hline \multicolumn{6}{|c|}{ b. Variables predictoras: (Constante), $\mathrm{CH} 2 \mathrm{ST} 1, \mathrm{CH} 2 \mathrm{ST} 3$} \\
\hline \multicolumn{6}{|c|}{ c. Variables predictoras: (Constante), $\mathrm{CH} 2 \mathrm{ST} 1, \mathrm{CH} 2 \mathrm{ST} 3, \mathrm{PRBMAX}$} \\
\hline \multicolumn{6}{|c|}{ d. Variable dependiente. CHENO2ST } \\
\hline
\end{tabular}

Tabla 5.83. ANOVA de los modelos de regresión múltiple para la concentración polínica total diaria de Chenopodiaceae-Amaranthaceae $2^{\mathrm{a}}$ floración estandarizada y las distintas variables meteorológicas y de autocorrelación.(1995-1998).

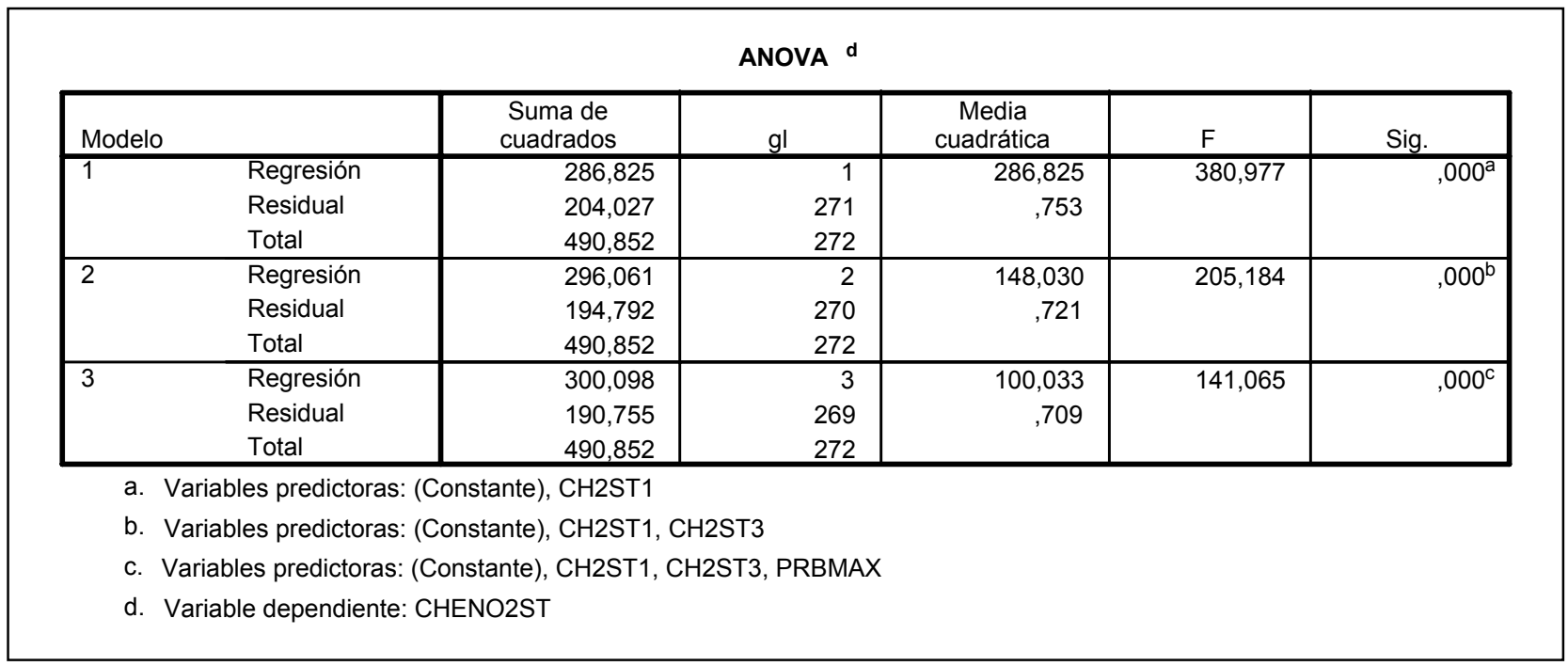


Tabla 5.84. Coeficientes de los modelos de regresión múltiple para la concentración polínica total diaria de Chenopodiaceae-Amaranthaceae $2^{\mathrm{a}}$ floración estandarizada y las distintas variables meteorológicas y de autocorrelación (1995-1998).

\begin{tabular}{|c|c|c|c|c|c|c|}
\hline \multicolumn{7}{|c|}{ Coeficientes $^{a}$} \\
\hline \multirow{2}{*}{\multicolumn{2}{|c|}{ Modelo }} & \multicolumn{2}{|c|}{$\begin{array}{l}\text { Coeficientes no } \\
\text { estandarizados }\end{array}$} & \multirow{2}{*}{$\begin{array}{l}\text { Coeficien } \\
\text { tes } \\
\text { estandari } \\
\text { zados } \\
\text { Beta }\end{array}$} & \multirow[b]{2}{*}{$\mathrm{t}$} & \multirow[b]{2}{*}{ Sig. } \\
\hline & & B & Error típ. & & & \\
\hline & (Constante) & ,428 & ,092 & & 4,666 & ,000 \\
\hline & CH2ST1 & ,773 & ,040 & ,764 & 19,519 &, 000 \\
\hline \multirow[t]{3}{*}{2} & (Constante) & ,315 & ,095 & & 3,305 & 001 \\
\hline & CH2ST1 & 651 & ,052 & 644 & 12,593 & ,000 \\
\hline & CH2ST3 & ,183 & ,051 & ,183 & 3,578 &, 000 \\
\hline \multirow[t]{4}{*}{3} & (Constante) & 32,116 & 13,329 & & 2,410 & 017 \\
\hline & CH2ST1 & 639 & ,051 & 632 & 12,416 & 000 \\
\hline & CH2ST3 & , 178 & ,051 & , 178 & 3,508 & ,001 \\
\hline & PRBMAX & $-3,1 \mathrm{E}-02$ & ,013 &,- 092 & $-2,386$ & ,018 \\
\hline
\end{tabular}


- Modelos predictivos con variables meteorológicas (temperatura, humedad relativa, radiación solar, presión, velocidad del viento), con variables obtenidas a partir de éstas (autocorrelación) y con las variables categóricas rumbos y rangosmi.

En la tabla 5.85., se recoge el resumen de los mejores modelos obtenidos. En la tabla 5.86. el ANOVA de los modelos y en la tabla 5.87., las variables incluidas en cada modelo, así como los coeficientes de las distintas variables.

Tabla 5.85. Resumen de los modelos de regresión múltiple para la concentración polínica total diaria de Chenopodiaceae-Amaranthaceae $2^{\mathrm{a}}$ floración estandarizada y las distintas variables meteorológicas, de autocorrelación y las variables categóricas rumbos y rangosmi (1995-1998).

\begin{tabular}{|l|r|r|r|r|r|}
\hline \multicolumn{7}{|c|}{ Resumen del modelo c } \\
\hline Modelo & $\mathrm{R}$ & $\mathrm{R}$ cuadrado & $\begin{array}{c}\text { R cuadrado } \\
\text { corregida }\end{array}$ & $\begin{array}{c}\text { Error típ. de la } \\
\text { estimación }\end{array}$ & $\begin{array}{c}\text { Durbin-W } \\
\text { atson }\end{array}$ \\
\hline 1 &, $754^{\mathrm{a}}$ &, 568 &, 566 &, 8989 & \\
2 &, $764^{\mathrm{b}}$ &, 583 &, 579 &, 8848 & 2,115 \\
\hline
\end{tabular}

Tabla 5.86. ANOVA de los modelos de regresión múltiple para la concentración polínica total diaria de Chenopodiaceae-Amaranthaceae $2^{\mathrm{a}}$ floración estandarizada y las distintas variables meteorológicas, de autocorrelación y las variables categóricas rumbos y rangosmi (1995-1998).

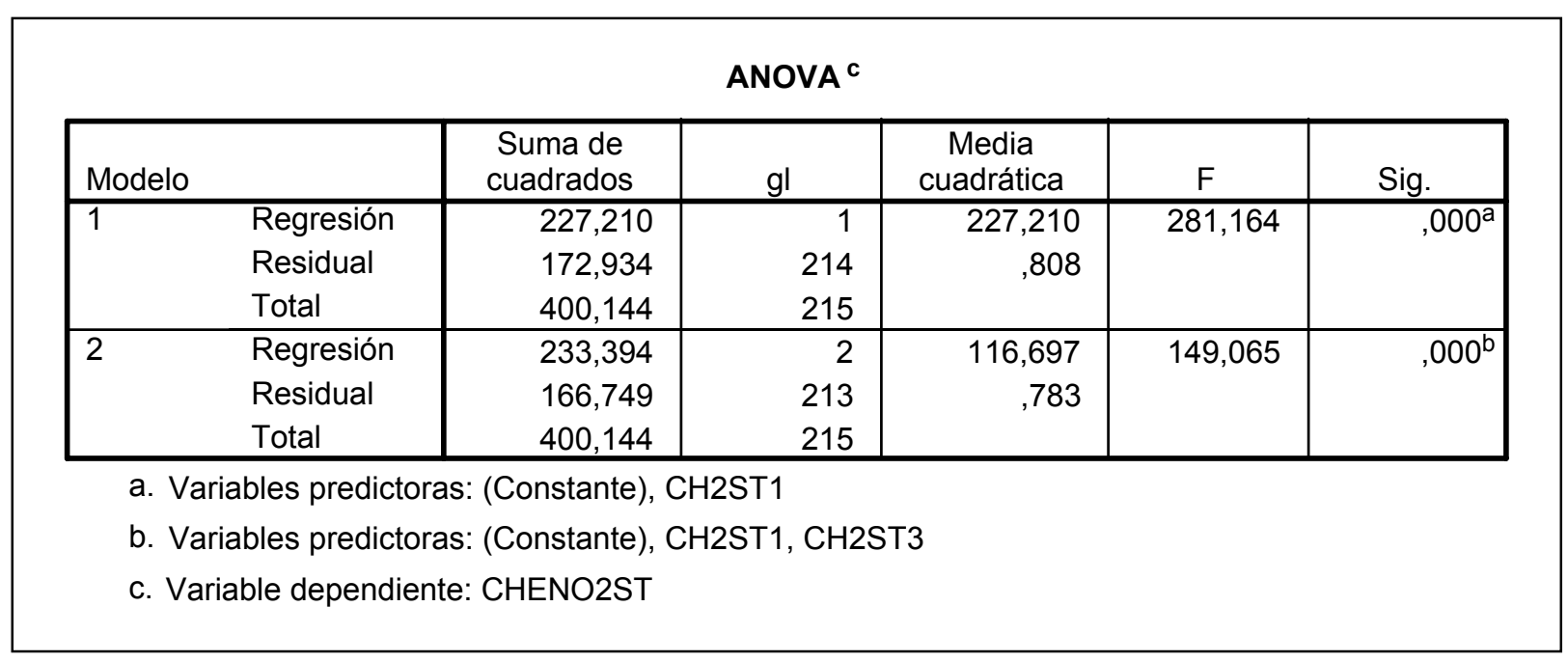


Tabla 5.87. Coeficientes de los modelos de regresión múltiple para la concentración polínica total diaria de Chenopodiaceae-Amaranthaceae $2^{\mathrm{a}}$ floración estandarizada y las distintas variables meteorológicas, de autocorrelación y las variables categóricas rumbos y rangosmi (19951998).

\begin{tabular}{|c|c|c|c|c|c|c|}
\hline \multicolumn{7}{|c|}{ Coeficientes $^{a}$} \\
\hline \multirow{2}{*}{\multicolumn{2}{|c|}{ Modelo }} & \multicolumn{2}{|c|}{$\begin{array}{l}\text { Coeficientes no } \\
\text { estandarizados }\end{array}$} & \multirow{2}{*}{$\begin{array}{l}\text { Coeficien } \\
\text { tes } \\
\text { estandari } \\
\text { zados } \\
\text { Beta }\end{array}$} & \multirow[b]{2}{*}{$\mathrm{t}$} & \multirow[b]{2}{*}{ Sig. } \\
\hline & & $B$ & Error típ. & & & \\
\hline & (Constante) & 4,415 &, 103 & & 4,029 &, 000 \\
\hline & $\mathrm{CH} 2 \mathrm{ST} 1$ & ,767 & ,046 & ,754 & 16,768 &, 000 \\
\hline \multirow[t]{3}{*}{2} & (Constante) & ,309 & ,108 & & 2,864 &, 005 \\
\hline & $\mathrm{CH} 2 \mathrm{ST} 1$ & 662 & 058 & ,650 & 11,321 &, 000 \\
\hline & $\mathrm{CH} 2 \mathrm{ST} 3$ &, 163 & ,058 & 161 & 2,811 &, 005 \\
\hline
\end{tabular}


5.6.2.3. DESARROLLO DE MODELOS PREDICTIVOS DE REGRESIÓN LINEAL MÚLTIPLE PARA LA SEGUNDA FLORACIÓN DE LA CONCENTRACIÓN POLÍNICA ESTANDARIZADA DE CHENOPODIACEAE-AMARANTHACEAE PARA LOS CONGLOMERADOS QUE DEFINEN LOS FLUJOS DE VIENTO.

A continuación se presentan los resultados de los modelos predictivos con variables meteorológicas, de autocorrelación y categóricas (rumbos y rangosmi), para cada cluster.

En la tabla 5.88. se recoge el resumen de los mejores modelos obtenidos. En la tabla 5.89. el ANOVA de los modelos, y en la tabla 5.90., las variables incluidas en cada modelo, así como los coeficientes de las distintas variables, para el cluster 1 .

Tabla 5.88. . Resumen de los modelos de regresión lineal múltiple para el CLUSTER 1 (1995-1998).

\begin{tabular}{|c|c|c|c|c|c|}
\hline \multicolumn{6}{|c|}{ Resumen del modelo b,c } \\
\hline Modelo & $\mathrm{R}$ & $\mathrm{R}$ cuadrado & $\begin{array}{l}\text { R cuadrado } \\
\text { corregida }\end{array}$ & $\begin{array}{c}\text { Error típ. de la } \\
\text { estimación }\end{array}$ & $\begin{array}{l}\text { Durbin-W } \\
\text { atson }\end{array}$ \\
\hline 1 &, $633^{a}$ & ,401 & ,341 & ,7965 & 2,120 \\
\hline
\end{tabular}


Tabla 5.89. ANOVA de los modelos de regresión múltiple para el CLUSTER 1 (1995-1998).

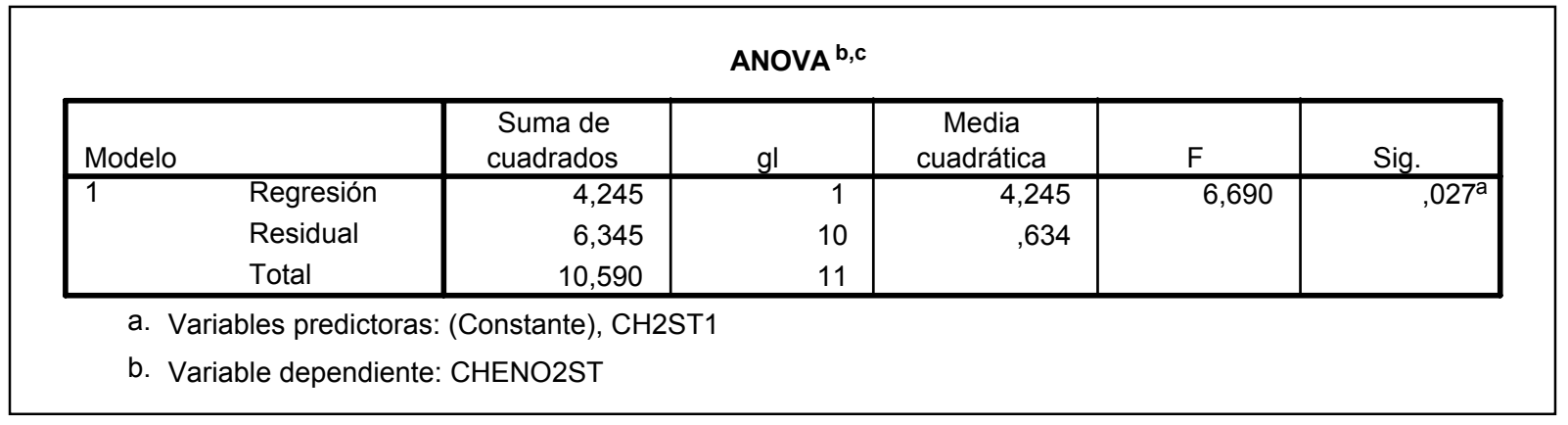

Tabla 5.90. Coeficientes de los modelos de regresión múltiple para el CLUSTER 1 (1995-1998).

\begin{tabular}{|c|c|c|c|c|c|}
\hline \multicolumn{6}{|c|}{ Coeficientes ${ }^{a, b}$} \\
\hline \multirow[b]{2}{*}{ Modelo } & \multicolumn{2}{|c|}{$\begin{array}{l}\text { Coeficientes no } \\
\text { estandarizados }\end{array}$} & \multirow{2}{*}{$\begin{array}{l}\text { Coeficient } \\
\text { es } \\
\text { estandari } \\
\text { zados } \\
\text { Beta }\end{array}$} & \multirow[b]{2}{*}{$\mathrm{t}$} & \multirow[b]{2}{*}{ Sig. } \\
\hline & B & Error típ. & & & \\
\hline (Constante) & 946 & ,402 & & 2,351 & 041 \\
\hline CH2ST1 & ,459 & 177 & ,633 & 2,586 &, 027 \\
\hline \multicolumn{6}{|c|}{ a. Variable dependiente: CHENO2ST } \\
\hline b. CLUSTER $=1,00$ & & & & & \\
\hline
\end{tabular}


En la tabla 5.91. se recoge el resumen de los mejores modelos obtenidos. En la tabla 5.92. el ANOVA de los modelos, y en la tabla 5.93. las variables incluidas en cada modelo, así como los coeficientes de las distintas variables, para el cluster 2 .

Tabla 5.91. Resumen de los modelos de regresión lineal múltiple para el CLUSTER 2 (1995-1998).

\begin{tabular}{|l|r|r|r|r|r|}
\hline \multicolumn{7}{|c|}{ Resumen del modelo d,e } \\
\hline Modelo & $\mathrm{R}$ & R cuadrado & $\begin{array}{r}\text { R cuadrado } \\
\text { corregida }\end{array}$ & $\begin{array}{r}\text { Error típ. de la } \\
\text { estimación }\end{array}$ & $\begin{array}{c}\text { Durbin-W } \\
\text { atson }\end{array}$ \\
\hline 1 &, $793^{\mathrm{a}}$ &, 629 &, 623 &, 8302 & \\
2 &, $813^{\mathrm{b}}$ &, 661 &, 650 &, 8005 & \\
3 &, $826^{\mathrm{c}}$ &, 682 &, 667 &, 7808 & 1,938 \\
\hline \multicolumn{6}{|c|}{ a. Variables predictoras: (Constante), CH2ST1 } \\
b. Variables predictoras: (Constante), CH2ST1, LLUVIADI \\
c. Variables predictoras: (Constante), CH2ST1, LLUVIADI, CH2ST2 \\
d. Variable dependiente: CHENO2ST \\
e. CLUSTER = 2,00
\end{tabular}

Tabla 5.92. ANOVA de los modelos de regresión múltiple para el CLUSTER 2 (1995-1998).

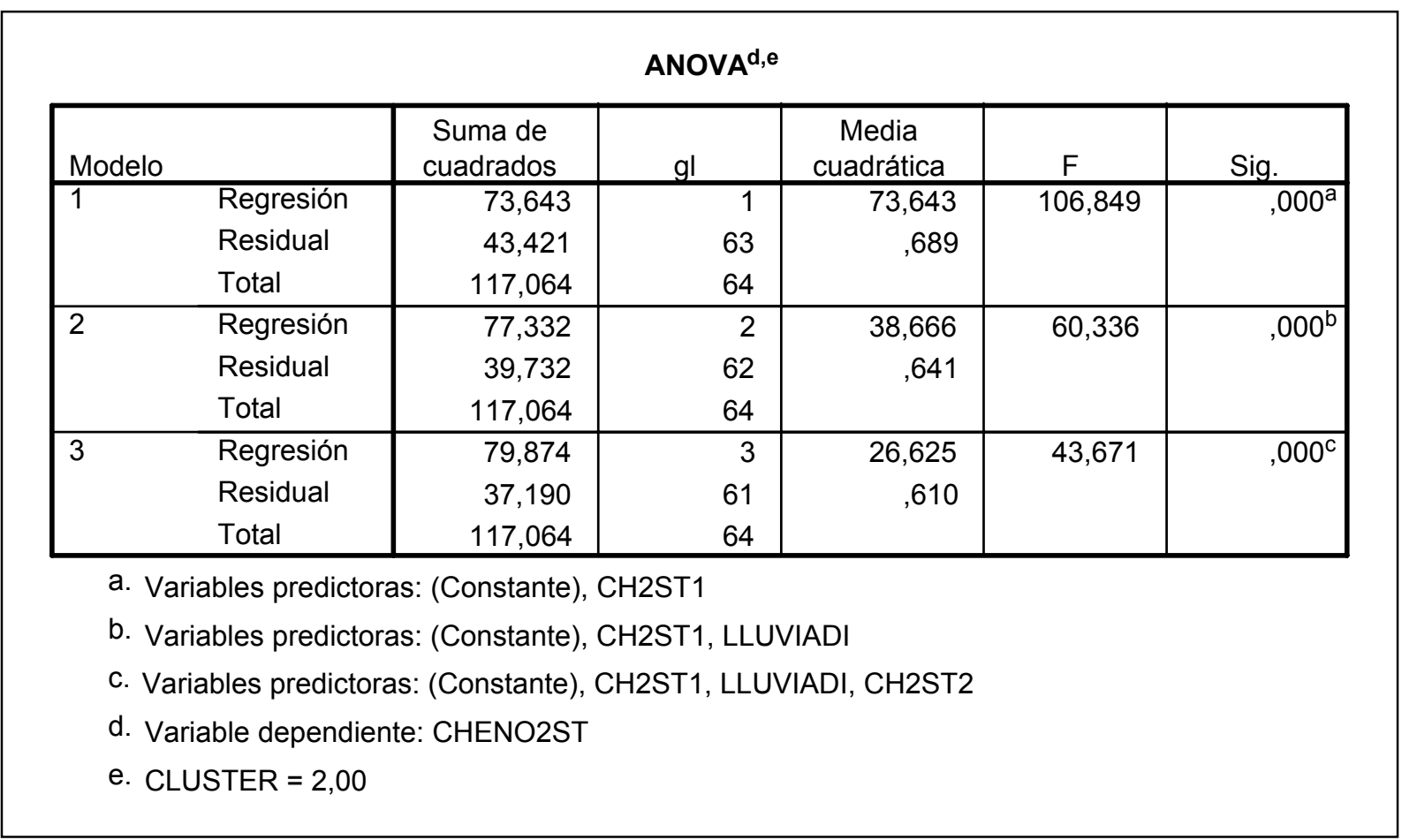


Tabla 5.93. Coeficientes de los modelos de regresión múltiple para el CLUSTER 2 (1995-1998).

\begin{tabular}{|c|c|c|c|c|c|c|}
\hline \multicolumn{7}{|c|}{ Coeficientes $^{a, b}$} \\
\hline \multirow{2}{*}{\multicolumn{2}{|c|}{ Modelo }} & \multicolumn{2}{|c|}{$\begin{array}{l}\text { Coeficientes no } \\
\text { estandarizados }\end{array}$} & \multirow{2}{*}{$\begin{array}{l}\text { Coeficient } \\
\text { es } \\
\text { estandari } \\
\text { zados } \\
\text { Beta }\end{array}$} & \multirow[b]{2}{*}{$t$} & \multirow[b]{2}{*}{ Sig. } \\
\hline & & $B$ & Error típ. & & & \\
\hline & (Constante) & ,324 & 166 & & $\overline{1,956}$ &, 055 \\
\hline & $\mathrm{CH} 2 \mathrm{ST} 1$ & 834 & 081 & ,793 & 10,337 &, 000 \\
\hline \multirow[t]{3}{*}{2} & (Constante) & ,267 & ,162 & & 1,652 & , 104 \\
\hline & $\mathrm{CH} 2 \mathrm{ST} 1$ & 835 & ,078 & ,794 & 10,726 &, 000 \\
\hline & LLUVIADI & ,334 & ,139 & ,178 & 2,399 & 019 \\
\hline \multirow[t]{4}{*}{3} & (Constante) & ,144 & ,169 & & ,855 & ,396 \\
\hline & CH2ST1 & ,658 & ,115 & 625 & 5,713 &, 000 \\
\hline & LLUVIADI & ,354 & ,136 & 188 & 2,605 &, 012 \\
\hline & $\mathrm{CH} 2 \mathrm{ST} 2$ & ,228 & ,112 & ,224 & 2,042 & ,045 \\
\hline \multicolumn{7}{|c|}{ a. Variable dependiente: $\mathrm{CHENO2ST}$} \\
\hline \multicolumn{7}{|c|}{ b. CLUSTER = 2,00 } \\
\hline
\end{tabular}


En la tabla 5.94. se recoge el resumen de los mejores modelos obtenidos. En la tabla 5.95. ANOVA de los modelos, y en la tabla 5.96. las variables incluidas en cada modelo, así como los coeficientes de las distintas variables, para el cluster 3.

Tabla 5.94. Resumen de los modelos de regresión múltiple para el CLUSTER 3 (1995-1998).

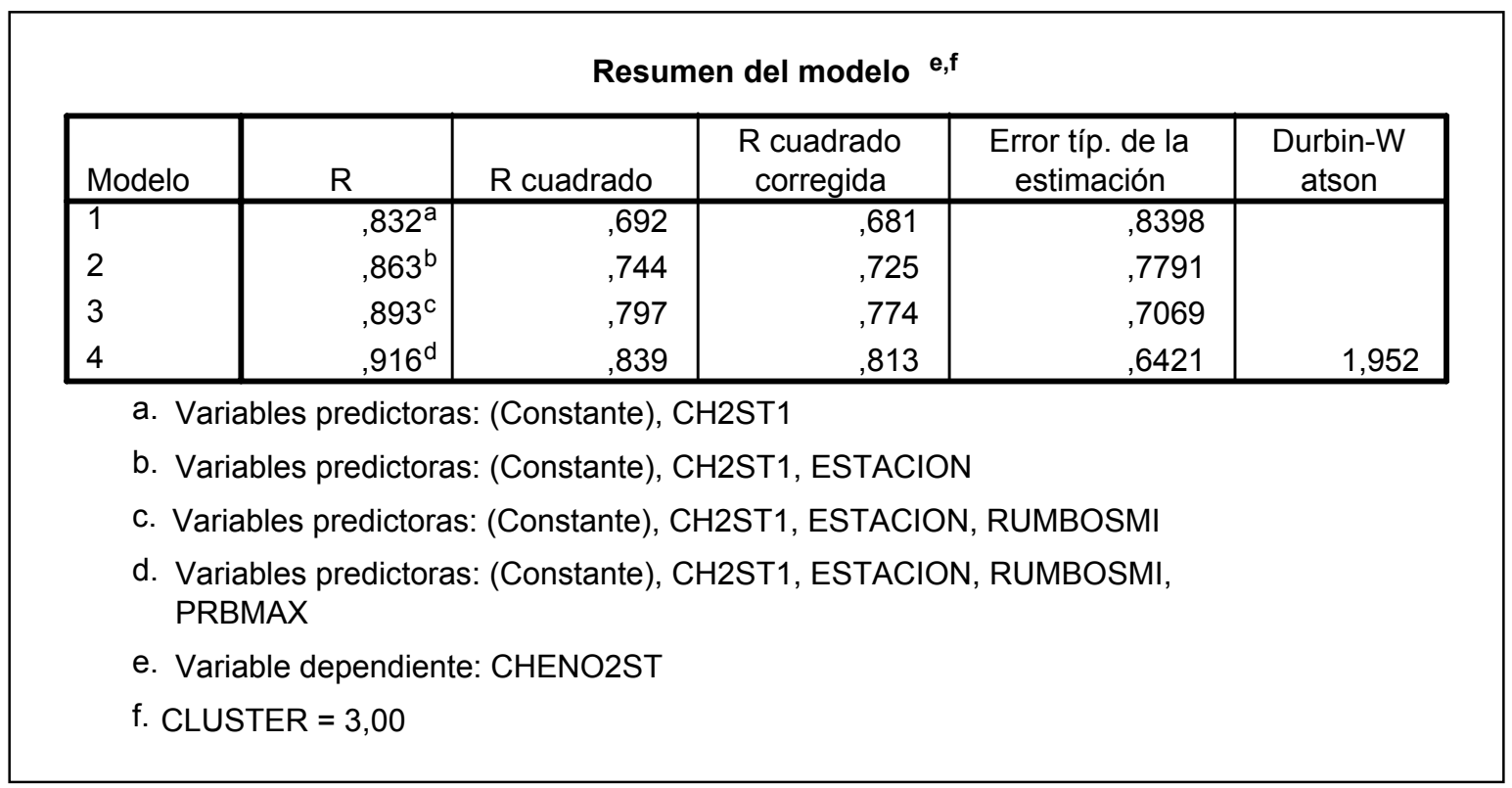


Tabla 5.95. ANOVA de los modelos de regresión múltiple para el CLUSTER 3

(1995-1998).

\begin{tabular}{|c|c|c|c|c|c|c|}
\hline \multicolumn{7}{|c|}{ ANOVA $^{e, f}$} \\
\hline Modelo & & $\begin{array}{c}\text { Suma de } \\
\text { cuadrados }\end{array}$ & gl & $\begin{array}{c}\text { Media } \\
\text { cuadrática }\end{array}$ & $F$ & Sig. \\
\hline 1 & $\begin{array}{l}\text { Regresión } \\
\text { Residual } \\
\text { Total }\end{array}$ & $\begin{array}{r}44,355 \\
19,746 \\
64,101\end{array}$ & $\begin{array}{r}1 \\
28 \\
29\end{array}$ & $\begin{array}{r}44,355 \\
, 705\end{array}$ & 62,895 &, $000^{\mathrm{a}}$ \\
\hline 2 & $\begin{array}{l}\text { Regresión } \\
\text { Residual } \\
\text { Total }\end{array}$ & $\begin{array}{l}47,712 \\
16,389 \\
64,101 \\
\end{array}$ & $\begin{array}{r}2 \\
27 \\
29\end{array}$ & $\begin{array}{r}23,856 \\
, 607\end{array}$ & 39,302 &, $000^{b}$ \\
\hline 3 & $\begin{array}{l}\text { Regresión } \\
\text { Residual } \\
\text { Total }\end{array}$ & $\begin{array}{l}51,109 \\
12,992 \\
64,101\end{array}$ & $\begin{array}{r}3 \\
26 \\
29\end{array}$ & $\begin{array}{r}17,036 \\
, 500\end{array}$ & 34,093 &, $000^{\mathrm{C}}$ \\
\hline 4 & $\begin{array}{l}\text { Regresión } \\
\text { Residual } \\
\text { Total }\end{array}$ & $\begin{array}{l}53,795 \\
10,306 \\
64,101\end{array}$ & $\begin{array}{r}4 \\
25 \\
29\end{array}$ & $\begin{array}{r}13,449 \\
, 412\end{array}$ & 32,623 &, $000^{d}$ \\
\hline
\end{tabular}

a. Variables predictoras: (Constante), $\mathrm{CH} 2 \mathrm{ST} 1$

b. Variables predictoras: (Constante), CH2ST1, ESTACION

c. Variables predictoras: (Constante), CH2ST1, ESTACION, RUMBOSMI

d. Variables predictoras: (Constante), CH2ST1, ESTACION, RUMBOSMI, PRBMAX

e. Variable dependiente: CHENO2ST

f. CLUSTER $=3,00$

Tabla 5.96. Coeficientes de los modelos de regresión múltiple para el CLUSTER 3(1995-1998).

\begin{tabular}{|c|c|c|c|c|c|c|}
\hline \multicolumn{7}{|c|}{ Coeficientes a,b } \\
\hline \multirow{2}{*}{\multicolumn{2}{|c|}{ Modelo }} & \multicolumn{2}{|c|}{$\begin{array}{l}\text { Coeficientes no } \\
\text { estandarizados }\end{array}$} & $\begin{array}{l}\text { Coeficient } \\
\text { es } \\
\text { estandari } \\
\text { zados }\end{array}$ & \multirow[b]{2}{*}{$t$} & \multirow[b]{2}{*}{ Sig. } \\
\hline & & B & Error típ. & Beta & & \\
\hline \multirow[t]{2}{*}{1} & (Constante) &,- 226 & ,310 & &,- 730 & ,471 \\
\hline & $\mathrm{CH} 2 \mathrm{ST} 1$ & ,970 & ,122 & ,832 & 7,931 & ,000 \\
\hline \multirow[t]{3}{*}{2} & (Constante) & 2,681 & 1,269 & & 2,113 &, 044 \\
\hline & $\mathrm{CH} 2 \mathrm{ST} 1$ & ,833 & ,128 & ,714 & 6,530 &, 000 \\
\hline & ESTACION &,- 759 & ,323 &,- 257 & $-2,352$ & ,026 \\
\hline \multirow[t]{4}{*}{3} & (Constante) & 1,156 & 1,291 & & 895 & ,379 \\
\hline & $\mathrm{CH} 2 \mathrm{ST} 1$ & ,889 & , 118 & ,762 & 7,550 & ,000 \\
\hline & ESTACION &,- 970 & ,304 &,- 329 & $-3,194$ & ,004 \\
\hline & RUMBOSMI & ,297 & ,114 & ,252 & 2,607 & ,015 \\
\hline \multirow[t]{5}{*}{4} & (Constante) & 92,971 & 35,990 & & 2,583 & ,016 \\
\hline & CH2ST1 & ,828 & , 110 & ,710 & 7,553 & ,000 \\
\hline & ESTACION &,- 961 & ,276 &,- 326 & $-3,483$ & ,002 \\
\hline & RUMBOSMI & ,332 & 104 & ,282 & 3,183 & ,004 \\
\hline & PRBMAX & $-9,05 E-02$ & ,035 &,- 216 & $-2,552$ &, 017 \\
\hline
\end{tabular}


En la tabla 5.97. se recoge el resumen de los mejores modelos obtenidos. En la tabla 5.98. ANOVA de los modelos, y en la tabla 5.99.,las variables incluidas en cada modelo, así como los coeficientes de las distintas variables, para el cluster 4 .

Tabla 5.97. Resumen de los modelos de regresión múltiple para el CLUSTER 4 (1995-1998).

\begin{tabular}{|l|r|r|r|r|r|}
\hline \multicolumn{7}{|c|}{ Resumen del modelo ${ }^{\text {b,c }}$} \\
\hline Modelo & $\mathrm{R}$ & $\mathrm{R}$ cuadrado & $\begin{array}{c}\text { R cuadrado } \\
\text { corregida }\end{array}$ & $\begin{array}{c}\text { Error típ. de la } \\
\text { estimación }\end{array}$ & $\begin{array}{c}\text { Durbin-W } \\
\text { atson }\end{array}$ \\
\hline 1 &, $744^{\mathrm{a}}$ &, 554 &, 542 &, 9793 & 1,921 \\
\hline
\end{tabular}

Tabla 5.98. ANOVA de los modelos de regresión múltiple para el CLUSTER 4 (1995-1998).

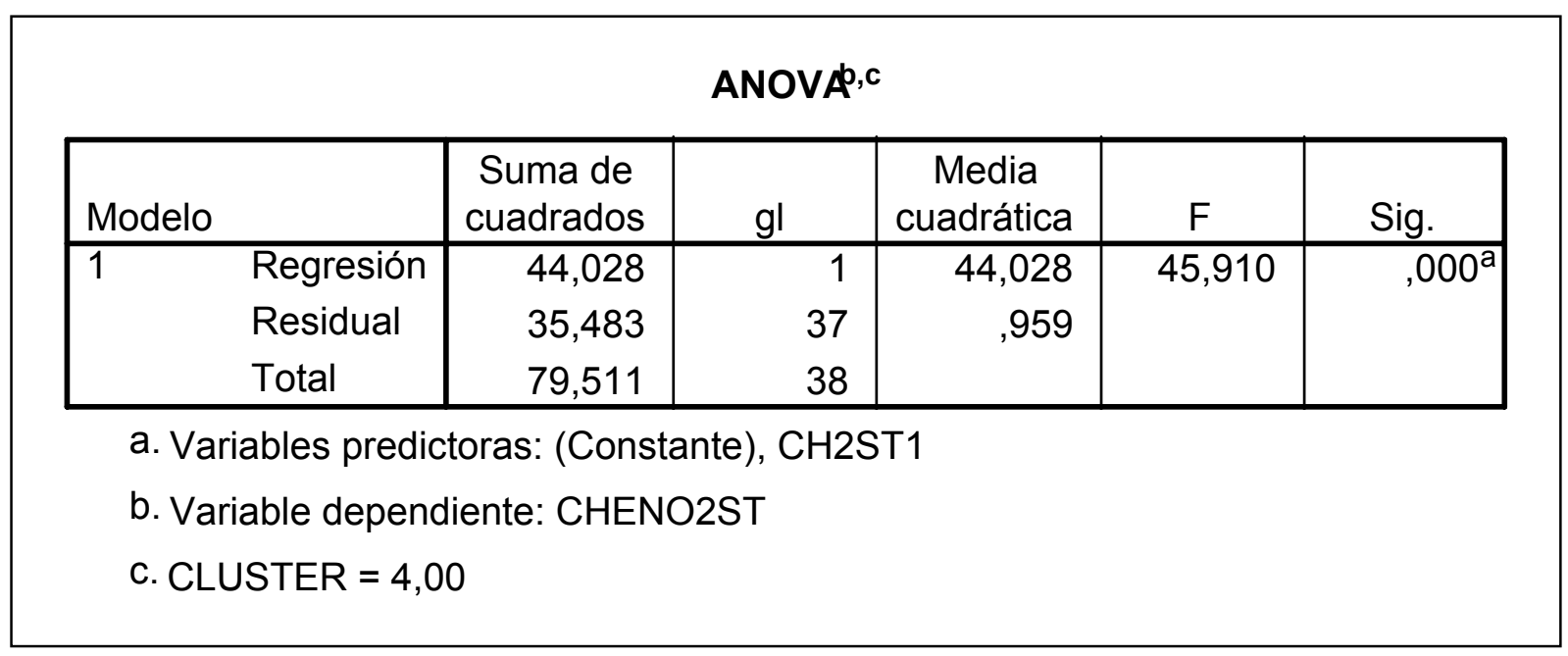


Tabla 5.99. Coeficientes de los modelos de regresión múltiple para el CLUSTER 4 (1995-1998).

\begin{tabular}{|c|c|c|c|c|c|}
\hline \multicolumn{6}{|c|}{ Coeficientes,b } \\
\hline \multirow[b]{2}{*}{ Modelo } & \multicolumn{2}{|c|}{$\begin{array}{l}\text { Coeficientes no } \\
\text { estandarizados }\end{array}$} & \multirow{2}{*}{$\begin{array}{l}\text { Coeficient } \\
\text { es } \\
\text { estandari } \\
\text { zados } \\
\text { Beta }\end{array}$} & \multirow[b]{2}{*}{$\mathrm{t}$} & \multirow[b]{2}{*}{ Sig. } \\
\hline & B & Error típ. & & & \\
\hline (Constante) & ,753 & ,266 & & 2,827 & ,008 \\
\hline CH2ST1 & ,719 & 106 &, 744 & 6,776 & ,000 \\
\hline \multicolumn{6}{|c|}{ a. Variable dependiente: CHENO2ST } \\
\hline \multicolumn{6}{|l|}{ b. CLUSTER = 4,00 } \\
\hline
\end{tabular}


En la tabla 5.100. se recoge el resumen de los mejores modelos obtenidos. En la tabla 5.101. el ANOVA de los modelos, y en la tabla 5.102., las variables incluidas en cada modelo, así como los coeficientes de las distintas variables, para el cluster 5 .

Tabla 5.100. Resumen de los modelos de regresión múltiple para el CLUSTER 5 (1995-1998).

\section{Resumen del model6}

\begin{tabular}{|l|r|r|r|r|c|}
\hline Modelo & \multicolumn{1}{|c|}{$\mathrm{R}$} & R cuadrado & $\begin{array}{c}\text { R cuadrado } \\
\text { corregida }\end{array}$ & $\begin{array}{c}\text { Error típ. de la } \\
\text { estimación }\end{array}$ & $\begin{array}{c}\text { Durbin-W } \\
\text { atson }\end{array}$ \\
\hline 1 &, $709^{\mathrm{a}}$ &, 503 &, 495 &, 9342 & \\
2 &, $731^{\mathrm{b}}$ &, 535 &, 521 &, 9103 & 1,962 \\
\hline
\end{tabular}

a. Variables predictoras: (Constante), CH2ST1

b. Variables predictoras: (Constante), CH2ST1, CH2ST3

c. Variable dependiente: CHENO2ST

d. CLUSTER $=5,00$

Tabla 5.101. ANOVA de los modelos de regresión múltiple para el CLUSTER 5 (1995-1998).

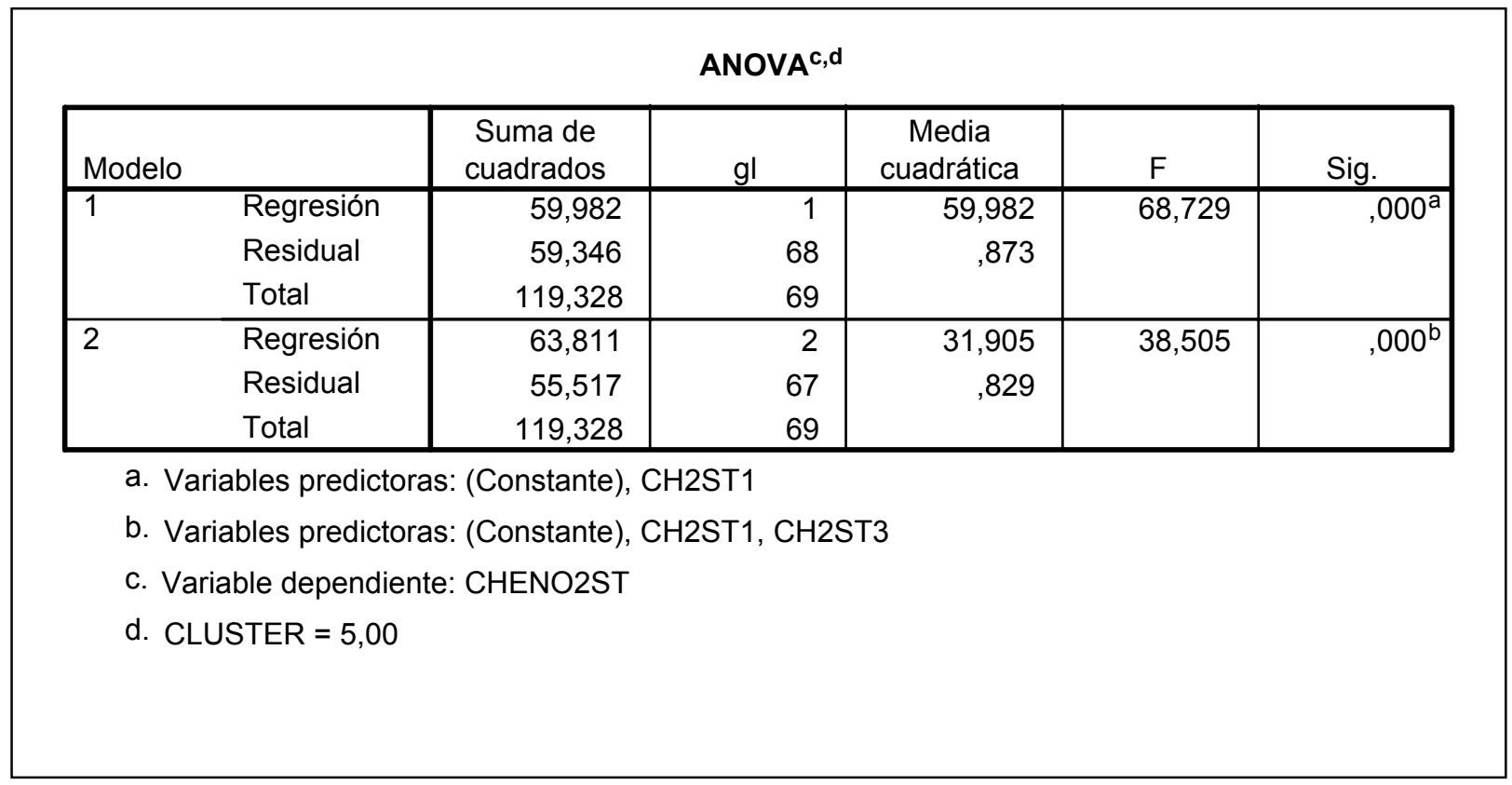


Tabla 5.102. Coeficientes de los modelos de regresión múltiple para el CLUSTER 5 (1995-1998).

\begin{tabular}{|c|c|c|c|c|c|}
\hline \multicolumn{6}{|c|}{ Coeficientes, } \\
\hline \multirow[b]{2}{*}{ Modelo } & \multicolumn{2}{|c|}{$\begin{array}{l}\text { Coeficientes no } \\
\text { estandarizados }\end{array}$} & \multirow{2}{*}{$\begin{array}{c}\text { Coeficient } \\
\text { es } \\
\text { estandari } \\
\text { zados } \\
\text { Beta }\end{array}$} & \multirow[b]{2}{*}{$t$} & \multirow[b]{2}{*}{ Sig. } \\
\hline & B & Error típ. & & & \\
\hline (Constante) & ,446 & 184 & & 2,428 & 018 \\
\hline CH2ST1 & ,712 & ,086 & ,709 & 8,290 & ,000 \\
\hline (Constante) & ,322 & ,188 & & 1,714 & ,091 \\
\hline CH2ST1 &, 534 & ,118 &, 532 & 4,537 & ,000 \\
\hline CH2ST3 & ,235 & 109 & ,252 & 2,150 & 035 \\
\hline \multicolumn{6}{|c|}{ a. Variable dependiente: CHENO2ST } \\
\hline \multicolumn{6}{|l|}{ b. CLUSTER $=5,00$} \\
\hline
\end{tabular}




\subsubsection{VALIDACIÓN DEL MODELO LINEAL DE REGRESIÓN MÚLTIPLE PARA LA SEGUNDA FLORACIÓN DE LAS CONCENTRACIONES POLÍNICAS DE CHENOPODIACEAE- AMARANTHACEAE CON LOS DATOS DEL AÑO 1999.}

La ecuación 5.7. recoge el modelo de regresión lineal múltiple para la concentración polínica total diaria estandarizada de la segunda floración de Chenopodiaceae-Amaranthaceae (1995-1998). La figura 5.80., muestra el gráfico de dispersión de los valores predichos por el modelo para el año 1999 y las concentraciones reales de este año. En la tabla 5.103., se recogen los coeficientes de correlación y determinación para los datos predichos por el modelo y reales para el año 1999. La figura 5.81., recoge el gráfico P-P normal de regresión para los residuos tipificados del modelo (1995-1998).

Ecuación 5.7. Modelo de regresión múltiple para el modelo. Nivel de significación de todas las variables incluidas en el modelo $\leq 0,05 . \mathrm{R}^{2}=$ 0,61 .

$\mathrm{CH} 2 \mathrm{PRED}=32.116+0.639 * \mathrm{CH} 2 \mathrm{ST} 1+0.178 * \mathrm{CH} 2 \mathrm{ST} 3-0.031 * \mathrm{PRBMAX}$

Figura 5.80. Gráfico de dispersión para las predicciones del año 1999.

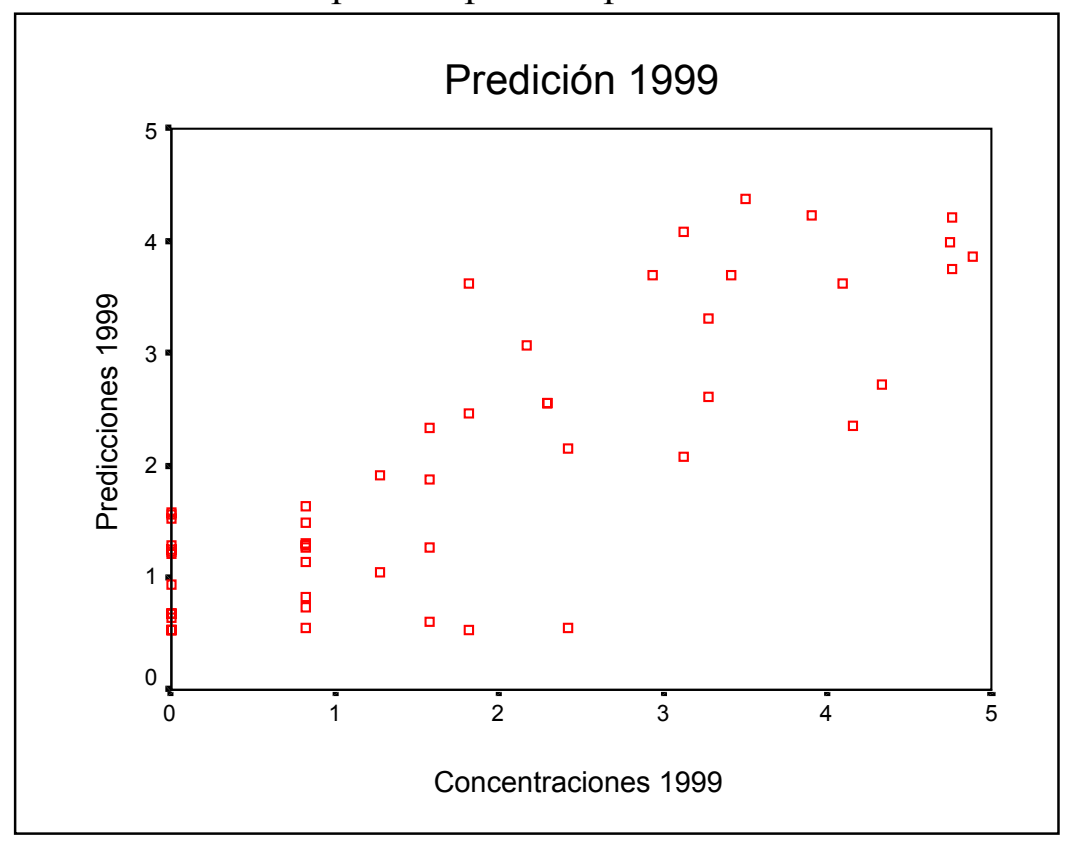


Tabla.5.103. Coeficientes de correlación y determinación entre los datos predichos por el modelo y los datos reales para el año 1999. Valores calculados y críticos $(\alpha=0,05)$ de los contrastes de diferencias entre varianzas $(\mathrm{F})$ y entre medias $(\mathrm{t})$.

\begin{tabular}{||l|c||}
\hline $\mathbf{r}$ & $0,83^{* *}$ \\
\hline $\mathbf{r}^{2}$ & 0,68 \\
\hline F calculado & 1,62 \\
\hline F crítico & 1,90 \\
\hline t calculado & 0,99 \\
\hline t crítico & 1,65 \\
\hline
\end{tabular}

${ }^{* *}$ Nivel de significación al 99\%

Figura 5.81. Gráfico P-P normal de regresión para los residuos tipificados del modelo general 1995-1998.

Gráfico P-P normal de regresión Residuo tip.

Variable dependiente: CHENO2ST

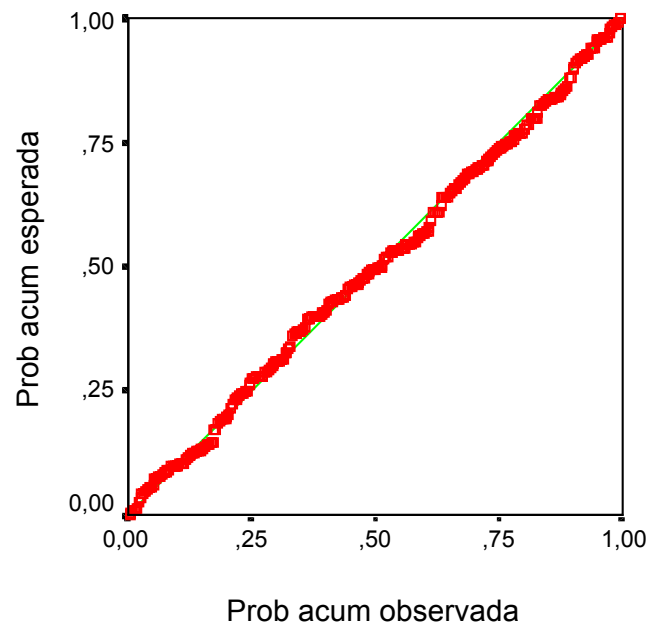




\subsection{MODELOS DE REGRESIÓN LOGÍSTICA.}

\subsubsection{MODELOS DE REGRESIÓN LOGÍSTICA PARA LA CONCENTRACIÓN POLÍNICA TOTAL ESTANDARIZADA (52 SEMANAS), DE 1995 A 1998.}

A continuación se presentan los resultados de los mejores modelos de regresión logística obtenidos para las concentraciones polínicas totales estandarizadas registradas durante los años 1995 a 1998.

La tabla 5.104, recoge el número de casos que han sido incluidos en el desarrollo de los modelos de regresión logística para el conjunto de años 1995 a 1998, puesto que el año 1999 se ha utilizado para la validación del mejor modelo obtenido. La tabla 5.105, muestra la codificación de la variable dependiente (media de la concentración polínica total estandarizada).

La tabla 5.106. recoge las pruebas omnibus sobre los coeficientes del modelo en los distintos pasos. La tabla 5.107, muestra los coeficientes de los distintos estadísticos utilizados para evaluar la bondad del ajuste de los distintos modelos.

La tabla 5.108, muestra el resumen del proceso de clasificación seguido, así como el porcentaje de casos clasificados correctamente en cada paso. La tabla 5.109, recoge las variables englobadas en el modelo de regresión logística seleccionado para el conjunto de los años 1995-1998. 
Tabla 5.104. Resumen del número de casos introducidos en los modelos de regresión logística para los años 1995-1998.

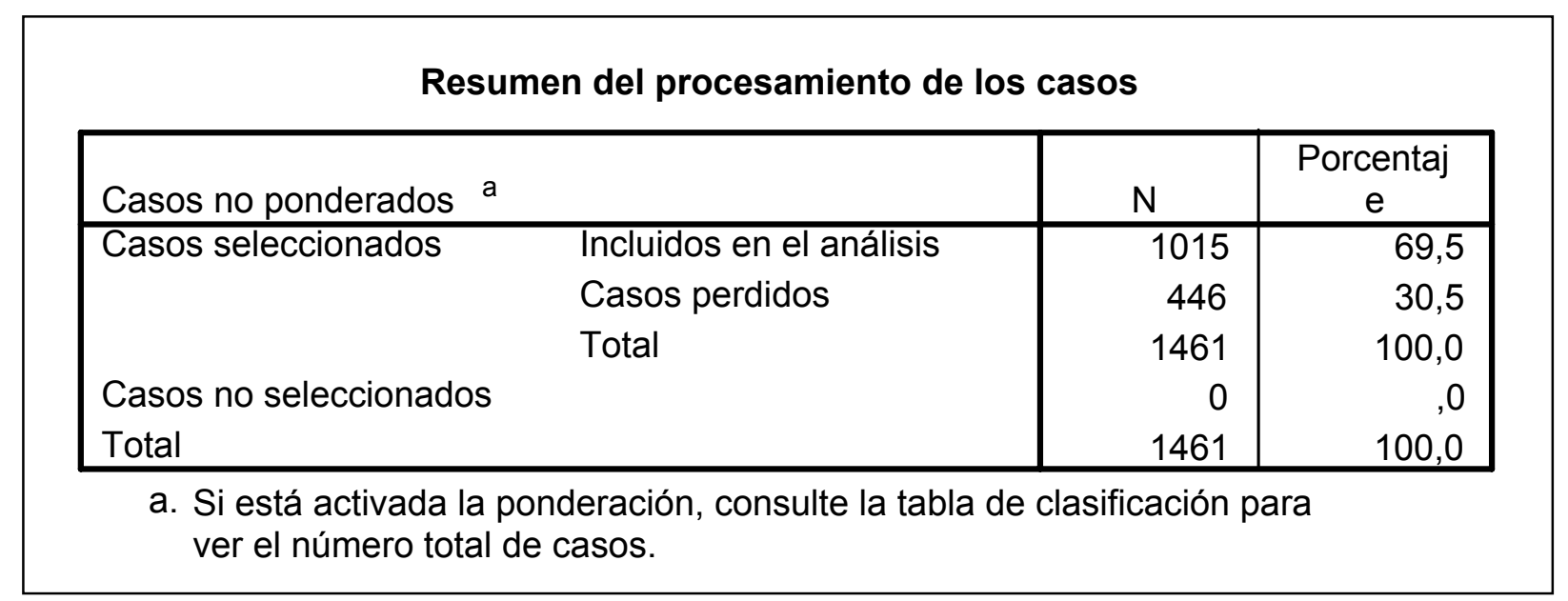

Tabla 5.105. Codificación de la variable dependiente concentración polínica total estandarizada, (0) menor o igual a la media y (1) mayor que la media, para los años 1995-1998.

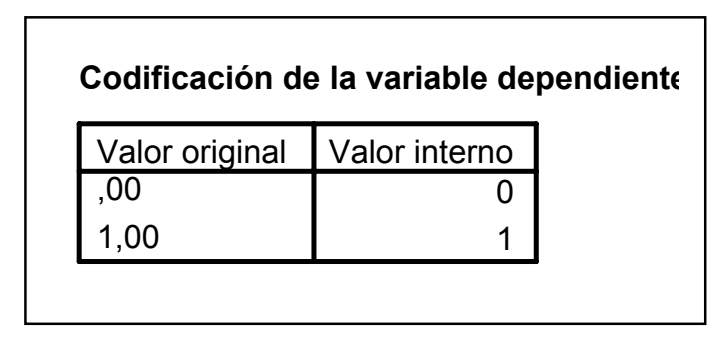


Tabla 5.106. Pruebas omnibus sobre los coeficientes del modelo.

\begin{tabular}{|c|c|c|c|c|}
\hline \multicolumn{5}{|c|}{ Pruebas omnibus sobre los coeficientes del modelo } \\
\hline & & Chi-cuadrado & $\mathrm{gl}$ & Sig. \\
\hline \multirow[t]{3}{*}{ Paso 1} & Paso & 469,783 & 11 &, 000 \\
\hline & Bloque & 469,783 & 11 & ,000 \\
\hline & Modelo & 469,783 & 11 &, 000 \\
\hline \multirow[t]{3}{*}{ Paso 2} & Paso & 157,460 & 51 &, 000 \\
\hline & Bloque & 627,243 & 62 &, 000 \\
\hline & Modelo & 627,243 & 62 &, 000 \\
\hline \multirow[t]{3}{*}{ Paso $3^{a}$} & Paso & $-22,335$ & 11 & ,022 \\
\hline & Bloque & 604,908 & 51 &, 000 \\
\hline & Modelo & 604,908 & 51 &, 000 \\
\hline \multirow[t]{3}{*}{ Paso 4} & Paso & 11,538 & 1 &, 001 \\
\hline & Bloque & 616,446 & 52 & ,000 \\
\hline & Modelo & 616,446 & 52 & ,000 \\
\hline \multirow[t]{3}{*}{ Paso 5} & Paso & 10,566 & 1 & ,001 \\
\hline & Bloque & 627,012 & 53 & ,000 \\
\hline & Modelo & 627,012 & 53 & ,000 \\
\hline \multirow[t]{3}{*}{ Paso 6} & Paso & 24,888 & 11 & ,009 \\
\hline & Bloque & 651,900 & 64 & ,000 \\
\hline & Modelo & 651,900 & 64 & ,000 \\
\hline \multirow[t]{3}{*}{ Paso 7} & Paso & 6,454 & 1 &, 011 \\
\hline & Bloque & 658,354 & 65 & ,000 \\
\hline & Modelo & 658,354 & 65 &, 000 \\
\hline \multirow[t]{3}{*}{ Paso $8^{a}$} & Paso & $-25,205$ & 11 & ,009 \\
\hline & Bloque & 633,149 & 54 & ,000 \\
\hline & Modelo & 633,149 & 54 &, 000 \\
\hline \multicolumn{5}{|c|}{$\begin{array}{l}\text { a. Un valor de chi-cuadrado negativo indica que ha } \\
\text { disminuido el valor de chi-cuadrado con respecto al } \\
\text { paso anterior. }\end{array}$} \\
\hline
\end{tabular}


Tabla.5.107. Coeficientes de los estadísticos para contrastar los distintos modelos obtenidos parar cuantificar la bondad del ajuste.

\begin{tabular}{|l|r|r|r|}
\hline \multicolumn{4}{|c|}{ Resumen de los modelos } \\
\hline & -2 log de la & \multicolumn{2}{|c|}{$\begin{array}{c}\text { R cuadrado } \\
\text { de Cox y } \\
\text { Snell }\end{array}$} \\
$\begin{array}{c}\text { R cuadrado } \\
\text { de } \\
\text { Nagelkerke }\end{array}$ \\
\hline 1 & 893,961 &, 371 &, 501 \\
2 & 736,501 &, 461 &, 624 \\
3 & 758,836 &, 449 &, 607 \\
4 & 747,297 &, 455 &, 616 \\
5 & 736,732 &, 461 &, 624 \\
6 & 711,843 &, 474 &, 641 \\
7 & 705,389 &, 477 &, 646 \\
8 & 730,595 &, 464 &, 628 \\
\hline
\end{tabular}


Tabla 5.108. Tabla resumen del proceso de clasificación para cada paso seguido en la construcción de los distintos modelos obtenidos.

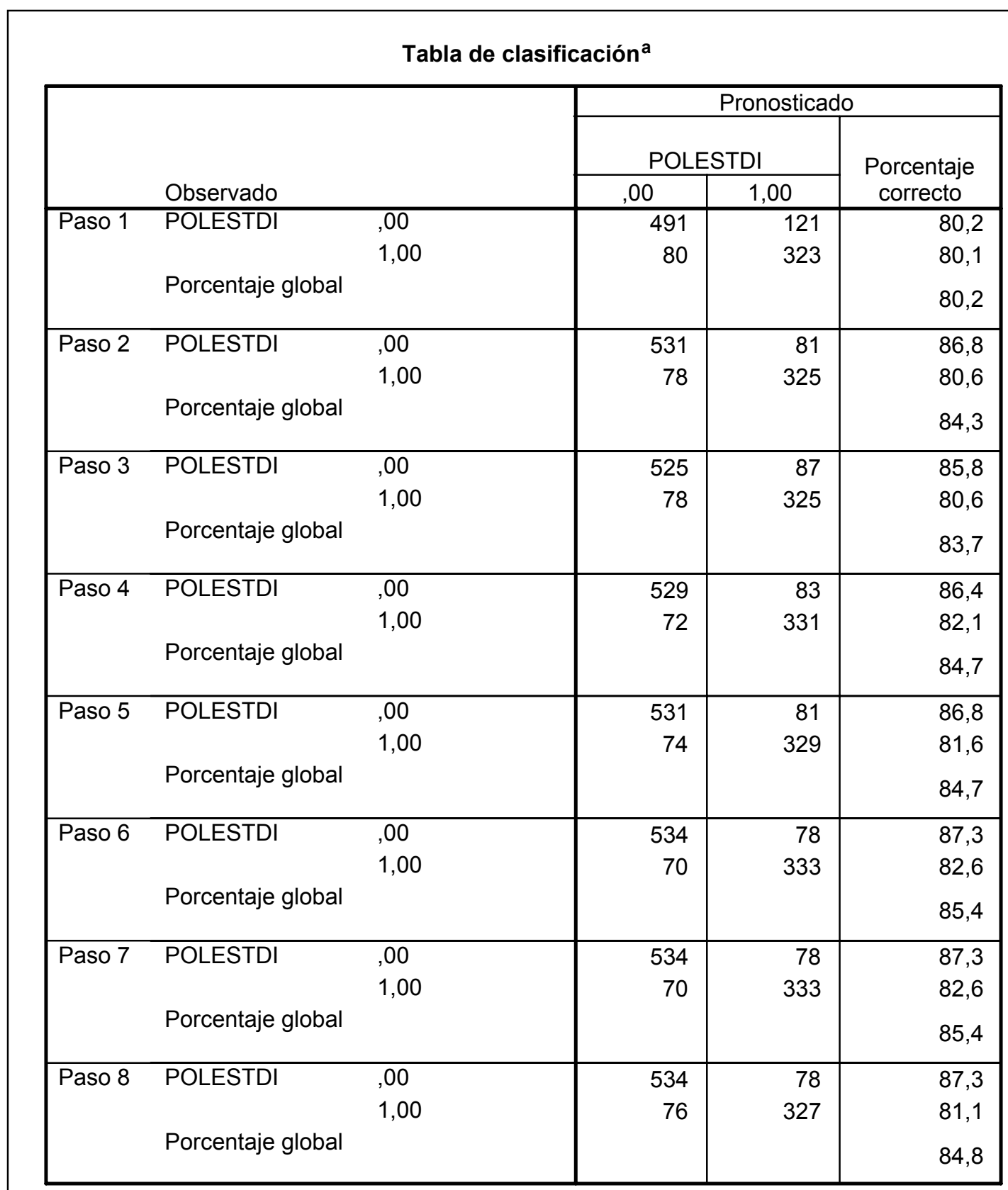

a. El valor de corte es ,500

a Variable(s) introducida(s) en el paso 1: MES.

b Variable(s) introducida(s) en el paso 2: SEMANA.

c Variable(s) introducida(s) en el paso 4: TMAX.

d Variable(s) introducida(s) en el paso 5: AT5.

e Variable(s) introducida(s) en el paso 6: MES.

$\mathrm{f}$ Variable(s) introducida(s) en el paso 7: AT3. 
Tabla 5.109. Variables introducidas en el modelo de regresión logística seleccionado para el conjunto de los años 1995-1998.

\begin{tabular}{|c|c|c|c|c|c|c|c|}
\hline & & B & E.T. & WALD & GL & SIG & EXP(B) \\
\hline PASO 5 & SEMANA & & & 267,167 & 51 & 000 & \\
\hline & SEMANA(1) & $-6,526$ & 25,266 & ,067 & & 796 & 001 \\
\hline & SEMANA(2) & 681 & 1,286 & 280 & & ,597 & 1,976 \\
\hline & SEMANA(3) & 1,110 & 1,215 & ,835 & & 361 & 3,034 \\
\hline & SEMANA(4) & 1,126 & 1,217 &, 856 & 1 & 355 & 3,085 \\
\hline & SEMANA(5) &,- 161 & 1,461 &, 012 & 1 & 912 & 851 \\
\hline & SEMANA(6) & 1,001 & 1,215 & ,678 & 1 & 410 & 2,720 \\
\hline & SEMANA(7) & 2,553 & 1,133 & 5,075 & 1 & 024 & 12,852 \\
\hline & SEMANA(8) & 2,810 & 1,135 & 6,134 & 1 & 013 & 16,612 \\
\hline & SEMANA(9) & 2,874 & 1,132 & 6,443 & 1 & 011 & 17,708 \\
\hline & SEMANA(10) & 3,426 & 1,156 & 8,790 & 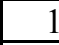 & ,003 & 30,764 \\
\hline & SEMANA(11) & 4,213 & 1,189 & 12,565 & 1 & 000 & 67,582 \\
\hline & SEMANA(12) & 3,848 & 1,181 & 10,612 & 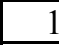 & ,001 & 46,895 \\
\hline & SEMANA(13) & 2,506 & 1,130 & 4,924 & & 026 & 12,261 \\
\hline & SEMANA(14) & 4,384 & 1,217 & 12,983 & & 000 & 80,118 \\
\hline & SEMANA(15) & 3,812 & 1,160 & 10,792 & & ,001 & 45,228 \\
\hline & SEMANA(16) & 3,886 & 1,185 & 10,757 & & 001 & 48,703 \\
\hline & SEMANA(17) & 4,699 & 1,285 & 13,377 & & 000 & 109,854 \\
\hline & SEMANA(18) & 4,042 & 1,224 & 10,907 & & ,001 & 56,945 \\
\hline & SEMANA(19) & 5,376 & 1,467 & 13,436 & & , 000 & 216,255 \\
\hline & SEMANA(20) & 3,707 & 1,192 & 9,664 & & ,002 & 40,715 \\
\hline & SEMANA(21) & 5,003 & 1,477 & 11,474 & & 001 & 148,806 \\
\hline & SEMANA(22) & 3,427 & 1,205 & 8,090 & & ,004 & 30,785 \\
\hline & SEMANA(23) & 4,146 & 1,310 & 10,017 & & 002 & 63,189 \\
\hline & SEMANA(24) & 4,677 & 1,506 & 9,646 & & 002 & 107,435 \\
\hline & SEMANA(25) & 1,801 & 1,193 & 2,277 & & ,131 & 6,055 \\
\hline & SEMANA(26) & 254 & 1,223 & ,043 & & 835 & 1,290 \\
\hline & SEMANA(27) & ,945 & 1,238 & ,583 & & ,445 & 2,573 \\
\hline & SEMANA(28) & ,915 & 1,226 & ,557 & & ,455 & 2,497 \\
\hline & SEMANA(29) &,- 817 & 1,546 & ,279 & & ,597 & ,442 \\
\hline & SEMANA(30) & $-8,174$ & 23,287 &, 123 & &, 726 & 000 \\
\hline & SEMANA(31) & $-8,220$ & 25,463 &, 104 & &, 747 &, 000 \\
\hline & SEMANA(32) & $-1,868$ & 1,543 & 1,466 & & 226 &, 154 \\
\hline & SEMANA(33) & $-8,098$ & 26,426 & ,094 & &, 759 & 000 \\
\hline & SEMANA(34) & $-8,235$ & 22,146 & ,138 & &, 710 & 000 \\
\hline & SEMANA(35) &,- 684 & 1,301 & 277 & & ,599 & 504 \\
\hline & SEMANA(36) & 2,012 & 1,227 & 2,689 & & ,101 & 7,479 \\
\hline & SEMANA(37) & 4,162 & 1,515 & 7,550 & & ,006 & 64,185 \\
\hline & SEMANA(38) & 2,260 & 1,190 & 3,609 & & ,057 & 9,585 \\
\hline & SEMANA(39) &,- 052 & 1,260 & ,002 & & ,967 & ,950 \\
\hline & SEMANA(40) & ,488 & 1,225 & , 159 & & (690 & 1,629 \\
\hline & SEMANA(41) &,- 706 & 1,332 & 280 & & ,596 & ,494 \\
\hline & SEMANA(42) & 233 & 1,209 & ,037 & & 847 & 1,263 \\
\hline & SEMANA(43) &,- 612 & 1,312 & ,218 & & ,641 &, 542 \\
\hline & SEMANA(44) &,- 967 & 1,473 & ,432 & & ,511 & ,380 \\
\hline & SEMANA(45) &,- 920 & 1,473 & , 390 & & ,532 & ,398 \\
\hline & SEMANA(46) & $-6,809$ & 23,658 & ,083 & & ,773 & 001 \\
\hline & SEMANA(47) &,- 669 & 1,466 & ,208 & & ,648 &, 512 \\
\hline & SEMANA(48) & ,956 & 1,186 & ,650 & & ,420 & 2,602 \\
\hline
\end{tabular}


Tabla 5.109.Continuación. Variables introducidas en el modelo de regresión logística seleccionado para el conjunto de los años 1995-1999.

\begin{tabular}{|r|r|r|r|r|r|r|r||}
\hline \hline & & \multicolumn{1}{c|}{ B } & \multicolumn{1}{|c|}{ E.T. } & WALD & GL & SIG & EXP(B) \\
\hline & SEMANA(49) & $-6,553$ & 26,230 &, 062 & 1 &, 803 &, 001 \\
\hline & SEMANA(50) &, 643 & 1,221 &, 277 & 1 &, 599 & 1,902 \\
\hline & SEMANA(51) & $-6,748$ & 21,320 &, 100 & 1 &, 752 &, 001 \\
\hline & TMAX &, 129 &, 040 & 10,376 & 1 &, 001 & 1,138 \\
\hline & AT5 &, 116 &, 036 & 10,259 & 1 &, 001 & 1,123 \\
\hline & Constante & $-6,175$ & 1,331 & 21,518 & 1 &, 000 &, 002 \\
\hline
\end{tabular}




\subsubsection{VALIDACIÓN DEL MODELO DE REGRESIÓN LOGÍSTICA CON LOS DATOS DEL AÑO 1999.}

A continuación se presentan los resultados de la clasificación obtenida cuando se ha aplicado el modelo anteriormente presentado a los datos del año 1999.

La tabla 5.110, recoge el número de casos pertenecientes al año 1999 que han sido utilizados en la validación del modelo anteriormente. La tabla 5.111, muestra la codificación de la variable dependiente (media de la concentración polínica total estandarizada para el año 1999).

La tabla 5.112. recoge las pruebas omnibus sobre los coeficientes del modelo. La tabla 5.113, muestra los coeficientes de los distintos estadísticos utilizados para evaluar la bondad del ajuste del modelo con los datos del año 1999.

La tabla 5.114, muestra el resumen del proceso de clasificación seguido, así como el porcentaje de casos del año 1999, que han sido clasificados correctamente. La tabla 5.109, recoge las variables englobadas en el modelo de regresión logística utilizado, así como los nuevos coeficientes calculados para los datos del año 1999.

Tabla 5.110. Resumen del número de casos introducidos en el modelo de regresión logística para el año 1999.

\begin{tabular}{|l|r|r|}
\hline \multicolumn{3}{|c|}{ Resumen del procesamiento de los casos } \\
\begin{tabular}{|ll|r|r|}
\hline Casos no ponderados ${ }^{\text {a }}$ & $\mathrm{N}$ & Porcentaje \\
\hline Casos seleccionados & Incluidos en el análisis & 350 & 95,9 \\
& Casos perdidos & 15 & 4,1 \\
& Total & 365 & 100,0 \\
Casos no seleccionados & & 0 &, 0 \\
Total & & 365 & 100,0 \\
\hline a. Si está activada la ponderación, consulte la tabla de clasificación para \\
ver el número total de casos.
\end{tabular} \\
\hline
\end{tabular}


Tabla 5.111. Codificación de la variable dependiente (concentración polínica total estandarizada, (0) menor o igual que la media y (1) mayor que la media), para el año 1999.

\begin{tabular}{|l|r|}
\hline \multicolumn{2}{|c|}{ Codificación de la variable dependiente } \\
\begin{tabular}{|l|r|}
\hline Valor original & Valor interno \\
\hline, 00 & 0 \\
1,00 & 1 \\
\hline
\end{tabular} \\
\hline
\end{tabular}

Tabla.5.112. Pruebas omnibus sobre los coeficientes del modelo de regresión logística para los datos del año 1999.

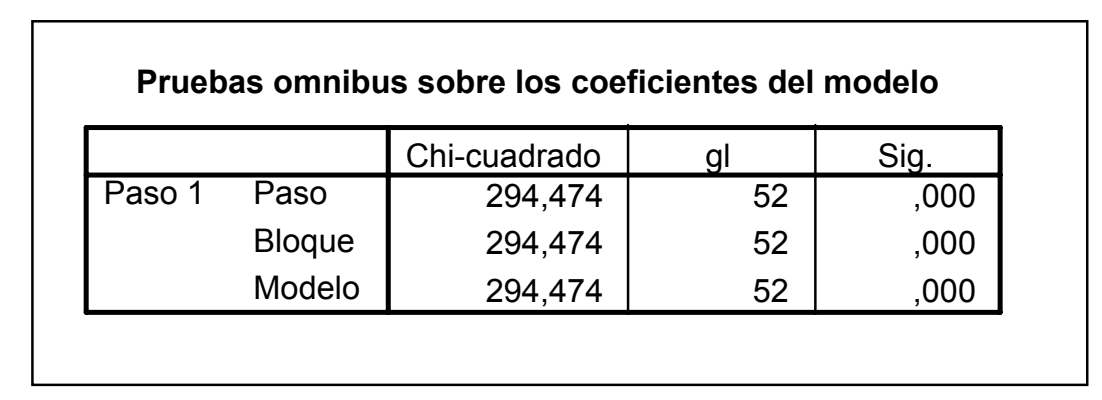

Tabla 5.113. Coeficientes de los estadísticos para cuantificar la bondad del ajuste del modelo para los datos del año 1999.

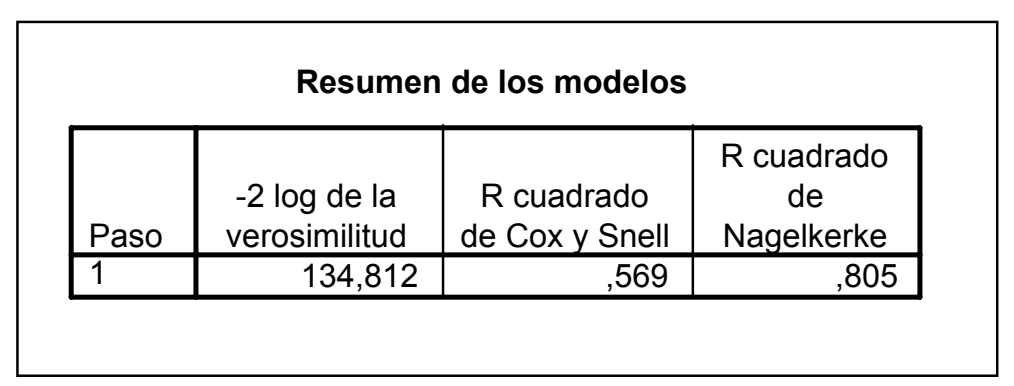


Tabla 5.114. Resumen del proceso de clasificación para el ajuste del mejor modelo.

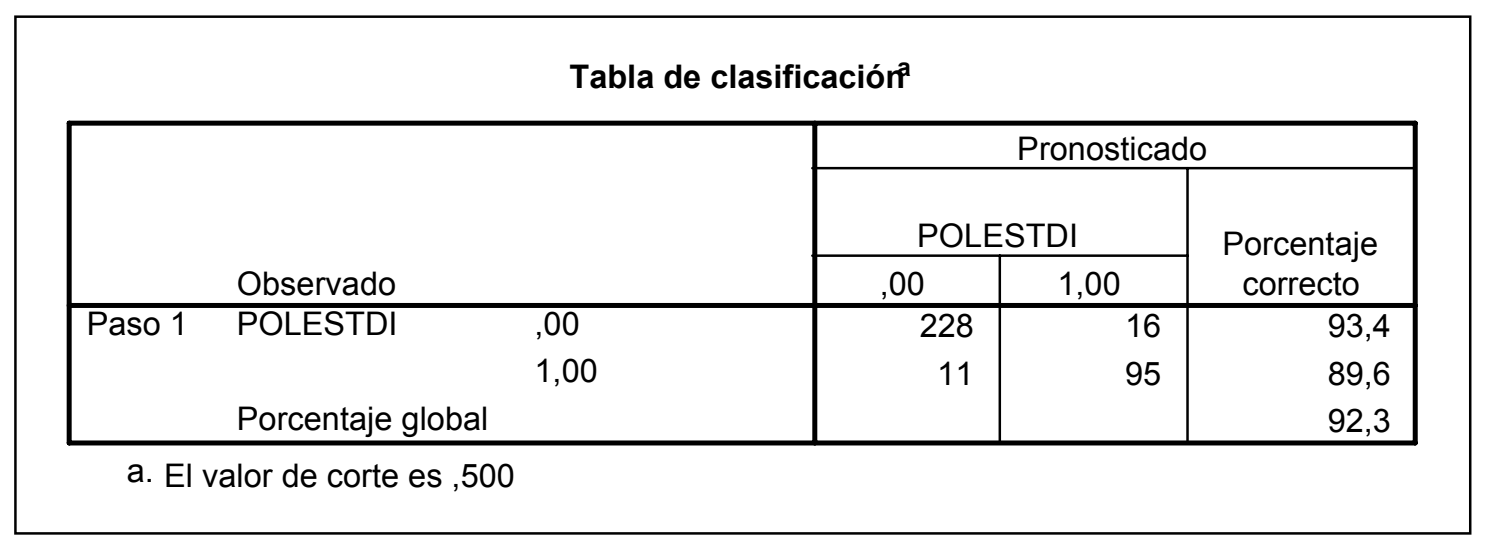

Tabla 5.115. Variables introducidas en la ecuación obtenida para el modelo.

\begin{tabular}{|c|c|c|c|c|c|c|}
\hline & B & E.T. & WALD & GL & SIG. & EXP(B) \\
\hline SEMANA & & & 30,972 & 50 & ,984 & \\
\hline SEMANA(1) & ,703 & 183,512 & , 000 & 1 & ,997 & 2,019 \\
\hline SEMANA(2) &, 602 & 140,029 &, 000 & 1 & ,997 & 1,826 \\
\hline SEMANA(3) & ,809 & 138,909 &, 000 & 1 & ,995 & 2,245 \\
\hline SEMANA(4) &, 163 & 140,793 &, 000 & 1 & ,999 & 1,177 \\
\hline SEMANA(5) &, 058 & 139,008 &, 000 & 1 & 1,000 & 1,060 \\
\hline SEMANA(6) & 9,637 & 98,833 & ,010 & 1 & ,922 & 15323,771 \\
\hline SEMANA(7) & 13,779 & 98,833 &, 019 & 1 & ,889 & 964025,953 \\
\hline SEMANA(8) & 12,155 & 98,831 &, 015 & 1 & ,902 & 190012,927 \\
\hline SEMANA(9) & 13,938 & 98,834 &, 020 & 1 & ,888 & 1130640,749 \\
\hline SEMANA(10) & 11,177 & 98,830 &, 013 & 1 & ,910 & 71491,113 \\
\hline SEMANA(11) & 11,046 & 98,830 & ,012 & 1 & ,911 & 62685,787 \\
\hline SEMANA(12) & 11,473 & 98,831 &, 013 & 1 & ,908 & 96078,134 \\
\hline SEMANA(13) & 22,485 & 141,161 &, 025 & 1 &, 873 & 5825263110,512 \\
\hline SEMANA(14) & 10,814 & 98,831 &, 012 & 1 & ,913 & 49734,713 \\
\hline SEMANA(15) & 11,597 & 98,833 &, 014 & 1 & ,907 & 108784,071 \\
\hline SEMANA(16) & 9,699 & 98,831 & ,010 & 1 & ,922 & 16307,802 \\
\hline SEMANA(17) & 21,925 & 140,623 & ,024 & 1 & ,876 & 3326768975,922 \\
\hline SEMANA(18) & 21,309 & 140,413 &, 023 & 1 & ,879 & 1796875714,437 \\
\hline SEMANA(19) & 20,551 & 139,686 &, 022 & 1 &, 883 & 842111899,486 \\
\hline SEMANA(20) & 11,752 & 98,833 & ,014 & 1 & ,905 & 126953,490 \\
\hline SEMANA(21) & 20,493 & 140,099 & ,021 & 1 & ,884 & 794650376,846 \\
\hline SEMANA(22) & 9,668 & 98,832 & ,010 & 1 & ,922 & 15803,430 \\
\hline SEMANA(23) & 8,206 & 98,833 & ,007 & 1 & ,934 & 3663,854 \\
\hline SEMANA(24) & 6,757 & 98,836 & ,005 & 1 & ,945 & 859,958 \\
\hline SEMANA(25) & 8,106 & 98,834 &, 007 & 1 & ,935 & 3312,642 \\
\hline
\end{tabular}


Tabla 5.115.Continuación. Variables introducidas en la ecuación obtenida para el modelo.

\begin{tabular}{|c|c|c|c|c|c|c|}
\hline & B & E.T. & WALD & GL & SIG. & EXP(B) \\
\hline SEMANA(26) & $-2,382$ & 154,693 &, 000 & 1 & ,988 & ,092 \\
\hline SEMANA(27) & 6,223 & 98,839 & ,004 & 1 & ,950 & 504,160 \\
\hline SEMANA(28) & $-3,761$ & 140,189 &, 001 & 1 & ,979 &, 023 \\
\hline SEMANA(29) & $-3,808$ & 141,985 & ,001 & 1 & ,979 &, 022 \\
\hline SEMANA(30) & $-3,785$ & 140,946 & ,001 & 1 & ,979 &, 023 \\
\hline SEMANA(31) & $-3,328$ & 141,679 & ,001 & 1 & ,981 &, 036 \\
\hline SEMANA(32) & $-4,202$ & 141,386 & ,001 & 1 & ,976 &, 015 \\
\hline SEMANA(33) & $-3,924$ & 139,055 &, 001 & 1 & ,977 &, 020 \\
\hline SEMANA(34) & $-3,987$ & 140,452 & ,001 & 1 & ,977 & ,019 \\
\hline SEMANA(35) & $-4,006$ & 141,443 & ,001 & 1 & ,977 &, 018 \\
\hline SEMANA(36) & 9,413 & 98,839 &, 009 & 1 & ,924 & 12248,519 \\
\hline SEMANA(37) & 8,911 & 98,835 &, 008 & 1 & ,928 & 7413,081 \\
\hline SEMANA(38) & $-2,420$ & 137,552 &, 000 & 1 & ,986 & ,089 \\
\hline SEMANA(39) & $-2,580$ & 140,147 &, 000 & 1 & ,985 &, 076 \\
\hline SEMANA(40) & $-1,610$ & 141,393 & ,000 & 1 & ,991 & 200 \\
\hline SEMANA(41) & $-2,114$ & 140,864 &, 000 & 1 & ,988 &, 121 \\
\hline SEMANA(42) & $-1,655$ & 141,093 & ,000 & 1 & ,991 & , 191 \\
\hline SEMANA(43) & $-2,166$ & 139,452 &, 000 & 1 & ,988 &, 115 \\
\hline SEMANA(44) & 7,463 & 98,835 & ,006 & 1 & ,940 & 1741,897 \\
\hline SEMANA(45) &,- 550 & 137,687 &, 000 & 1 & ,997 & ,577 \\
\hline SEMANA(46) & ,121 & 142,800 &, 000 & 1 & 1,000 & 1,128 \\
\hline SEMANA(47) & ,476 & 140,468 &, 000 & 1 & ,997 & 1,610 \\
\hline SEMANA(48) &,- 018 & 140,135 &, 000 & 1 & 1,000 & ,982 \\
\hline SEMANA(49) &,- 095 & 141,338 &, 000 & 1 & 1,000 & ,910 \\
\hline SEMANA(50) &, 555 & 138,741 & ,000 & 1 & ,997 & 1,741 \\
\hline AT5 &,- 168 & , 101 & 2,779 & 1 & ,096 & ,845 \\
\hline TMAX & ,301 & ,105 & 8,199 & 1 & ,004 & 1,351 \\
\hline Constante & $-15,728$ & 98,852 &, 025 & 1 & ,874 &, 000 \\
\hline
\end{tabular}

Variable(s) introducida(s) en el paso 1: SEMANA, AT5, TMAX. 


\subsection{MODELIZACIÓN DE LA CONCENTRACIÓN POLÍNICA MEDIA SEMANAL 1994 A 1999 MEDIANTE ANÁLISIS DE SERIES TEMPORALES DE BOX-JENKINS (MODELOS ARIMA).}

A continuación se presentan los resultados obtenidos para un modelo de series temporales (ARIMA), para las concentraciones medias semanales durante el periodo 1994 a 1999.

La figura 5.82, recoge la evolución de la media de la concentración polínica total semanal durante los años 1994 a 1999. Las figuras 5.83. y 5.84., muestran los gráficos de autocorrelación y autocorrelación parcial de la serie inicial, respectivamente.

La figura 5.85, recoge la secuencia de la serie transformada, después de haber efectuado una diferenciación de orden 1. Las figuras 5.86 y 5.87, muestran los gráficos de autocorrelación y autocorrelación parcial de la serie transformada, repectivamente, tras la diferenciación de orden 1.

La figura 5.88, recoge la secuencia de la serie transformada, después de haber efectuado una diferenciación de orden 52, sobre la serie anterior. Las figuras 5.89. y 5.90, muestran los gráficos de autocorrelación y autocorrelación parcial de la serie transformada, repectivamente, tras la diferenciación de orden 52.

La ecuación 5.8, recoge la ecuación del modelo ARIMA, obtenido para las concentraciones polínicas medias semanales de los años 1994 a 1999, tras realizar dos diferenciaciones sucesivas (una de orden uno y otra de orden 52).

Las figuras 5.91. y 5.92, muestran los gráficos de autocorrelación y autocorrelación parcial de los residuales que proporciona el modelo, respectivamente. 
Figura 5.82. Evolución de las concentraciones polínicas medias semanales (granos $/ \mathrm{m}^{3}$ de aire), durante los años 1994-1999.

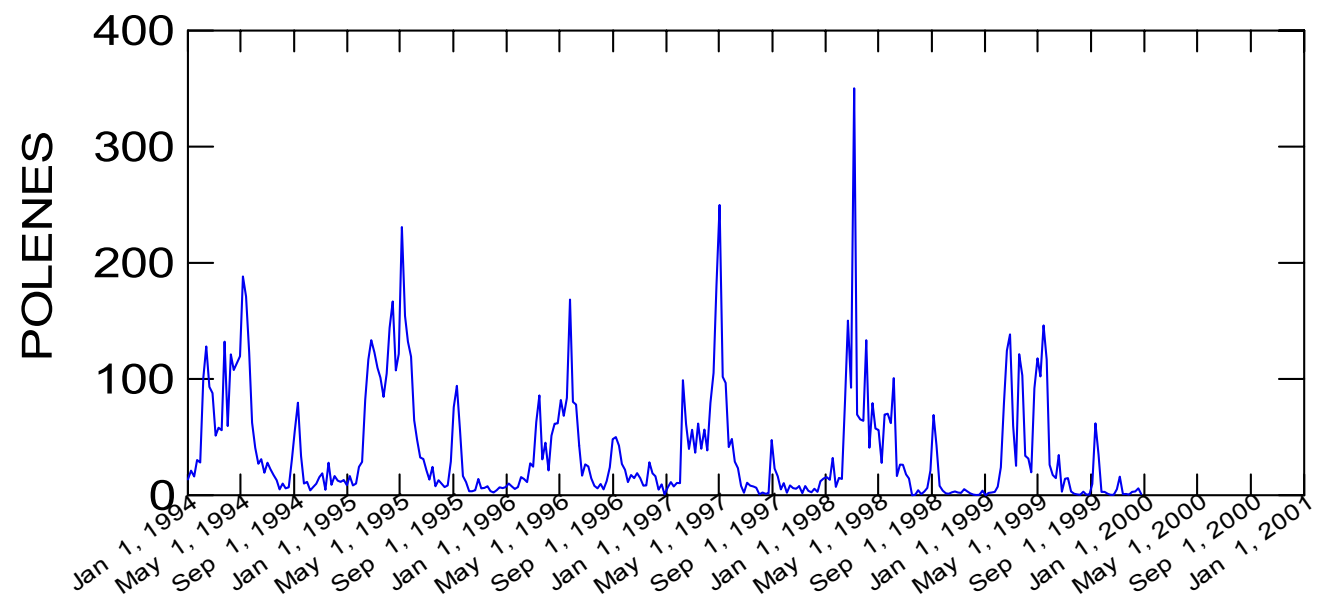

Fecha

Figura 5.83. Autocorrelación de la serie inicial concentración polínica media semanal 1994-1999 sin transformar.

\section{Autocorrelation Plot}

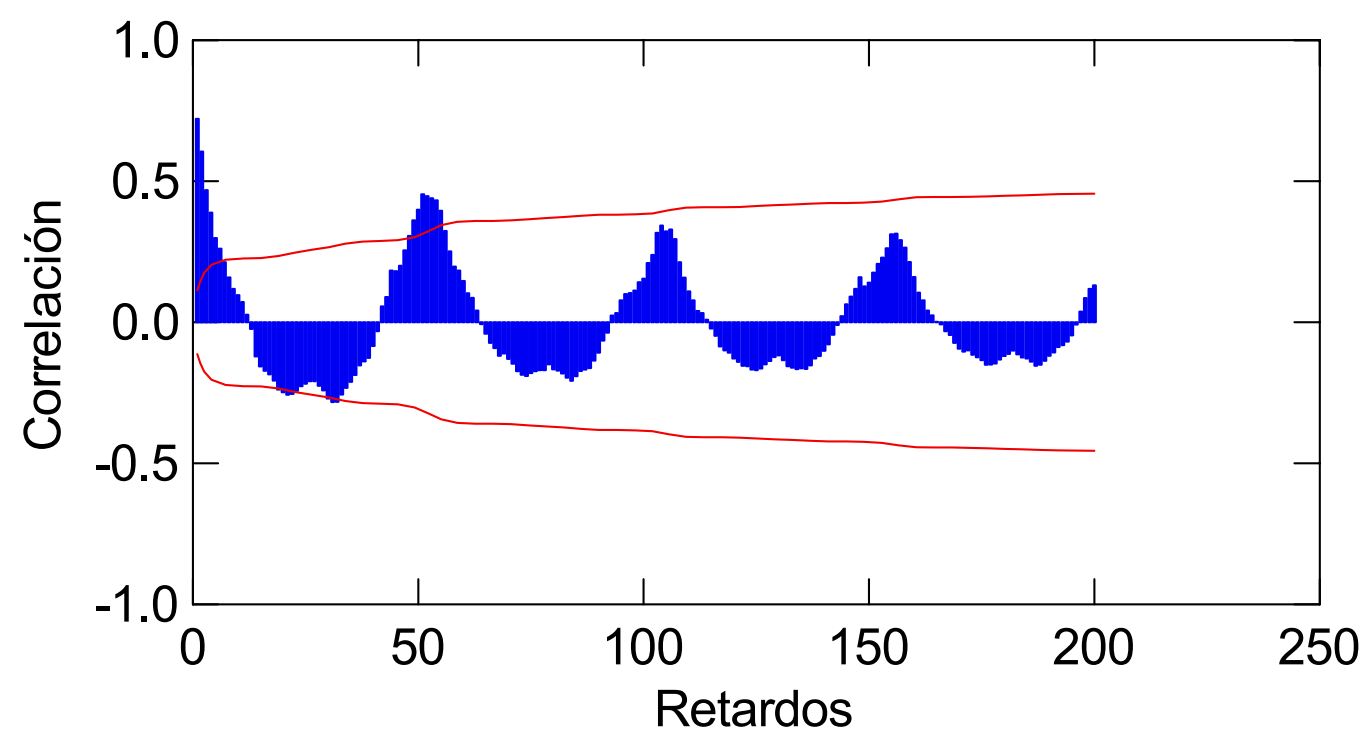


Figura 5.84. Autocorrelación parcial de la serie inicial (concentración polínica media semanal, 1994-1999).

\section{Partial Autocorrelation Plot}

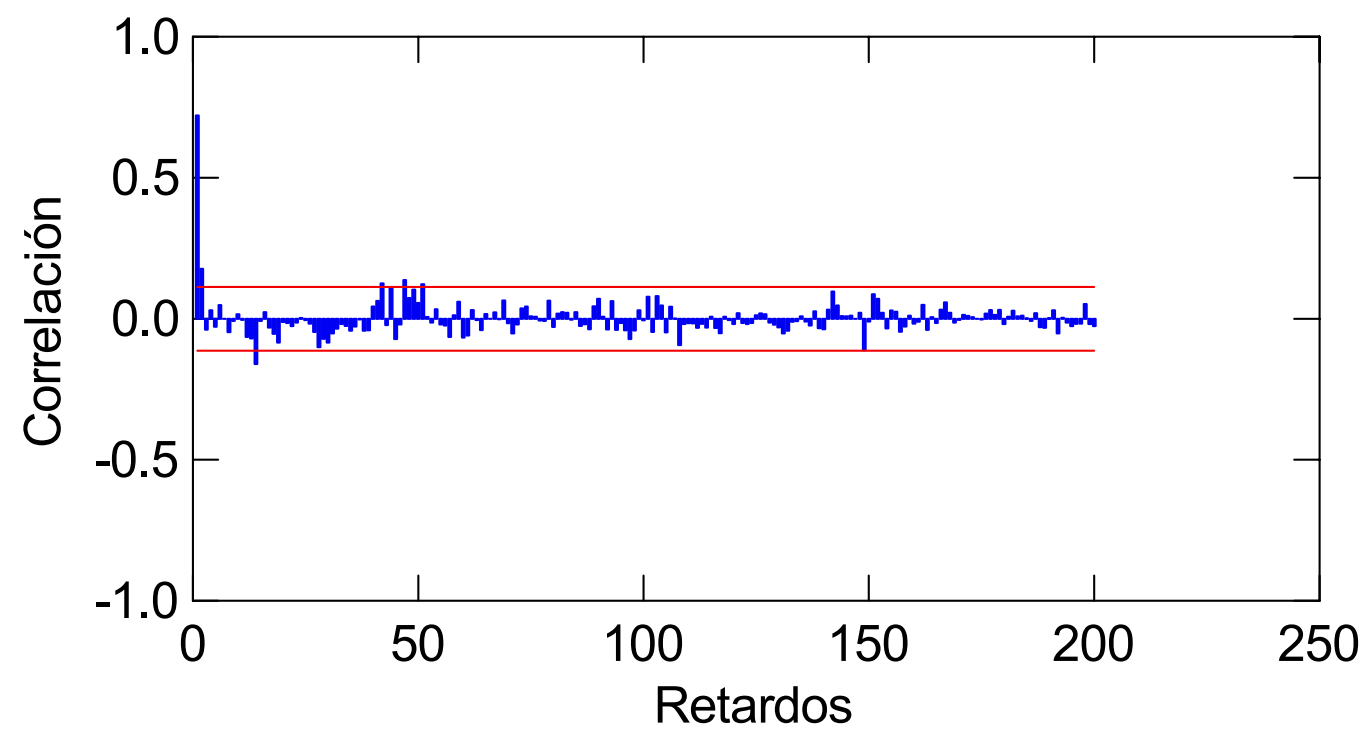

Figura 5.85. Secuencia de la serie transformada, tras realizar una diferenciación de orden uno.

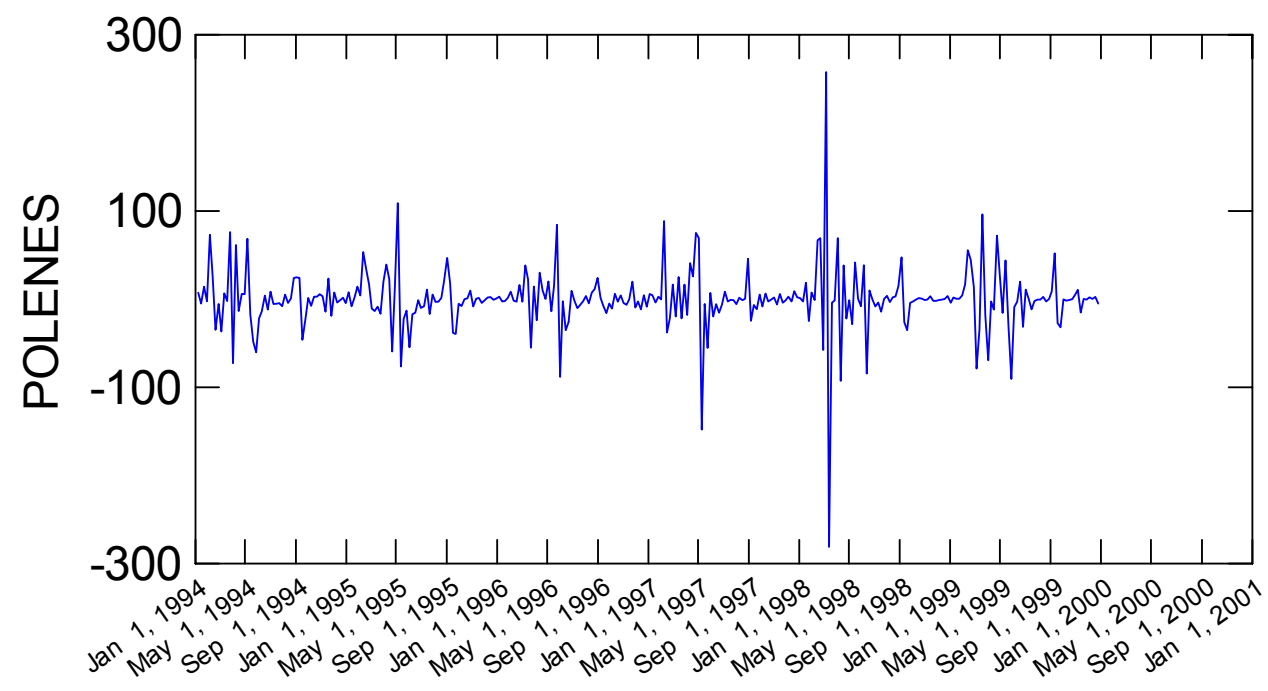

Fecha 
Figura 5.86. Autocorrelación de la serie tras realizar una diferenciación de orden 1.

\section{Autocorrelation Plot}

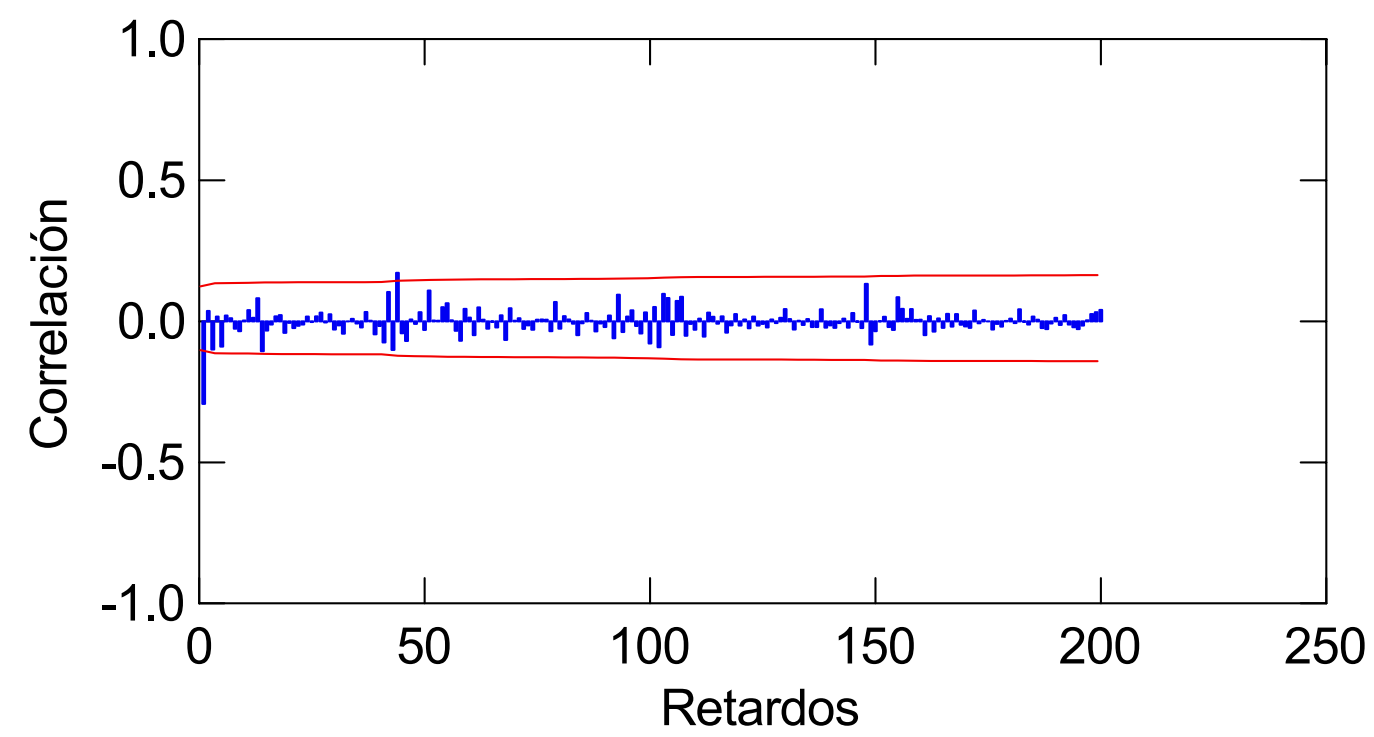

Figura 5.87. Autocorrelación parcial de la serie tras realizar una diferenciación de orden 1.

\section{Partial Autocorrelation Plot}

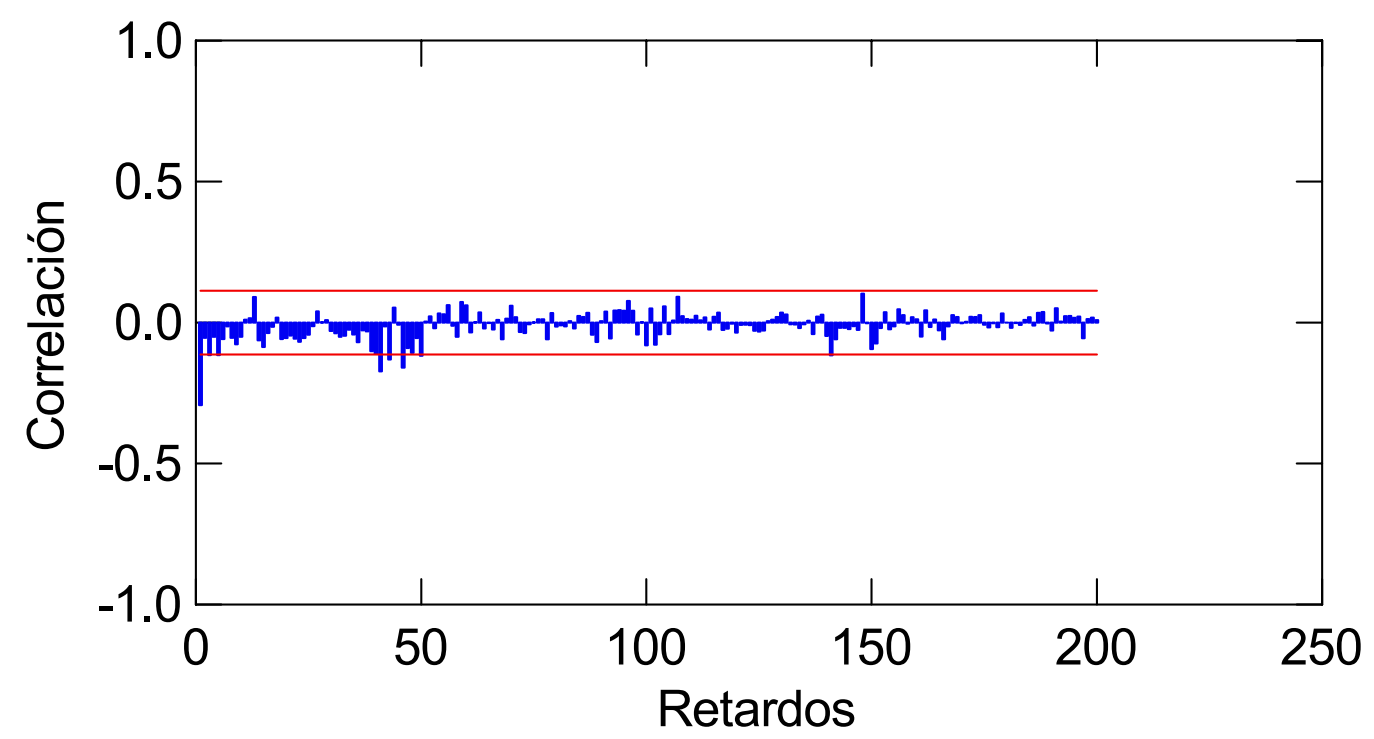


Figura 5.88. Secuencia de la serie transformada, tras realizar una diferenciación de orden 52 .

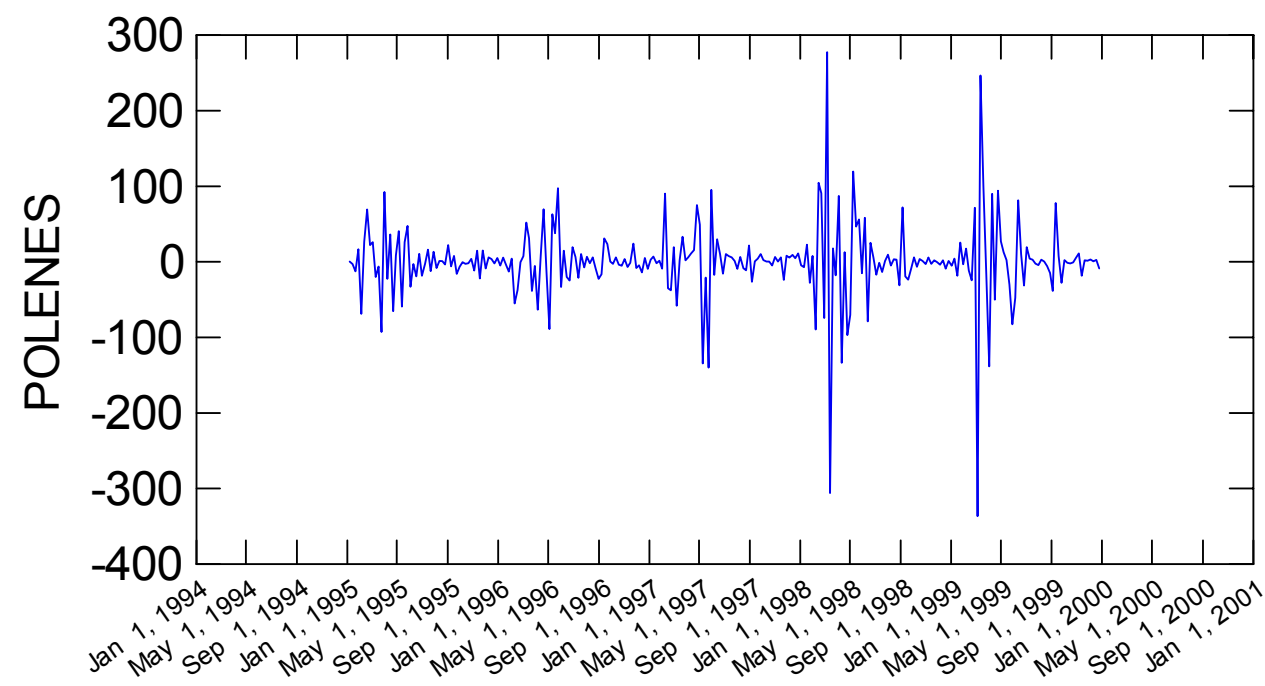

Fecha

Figura.5.89. Autocorrelación de la serie tras realizar una diferenciación de orden 52.

\section{Autocorrelation Plot}

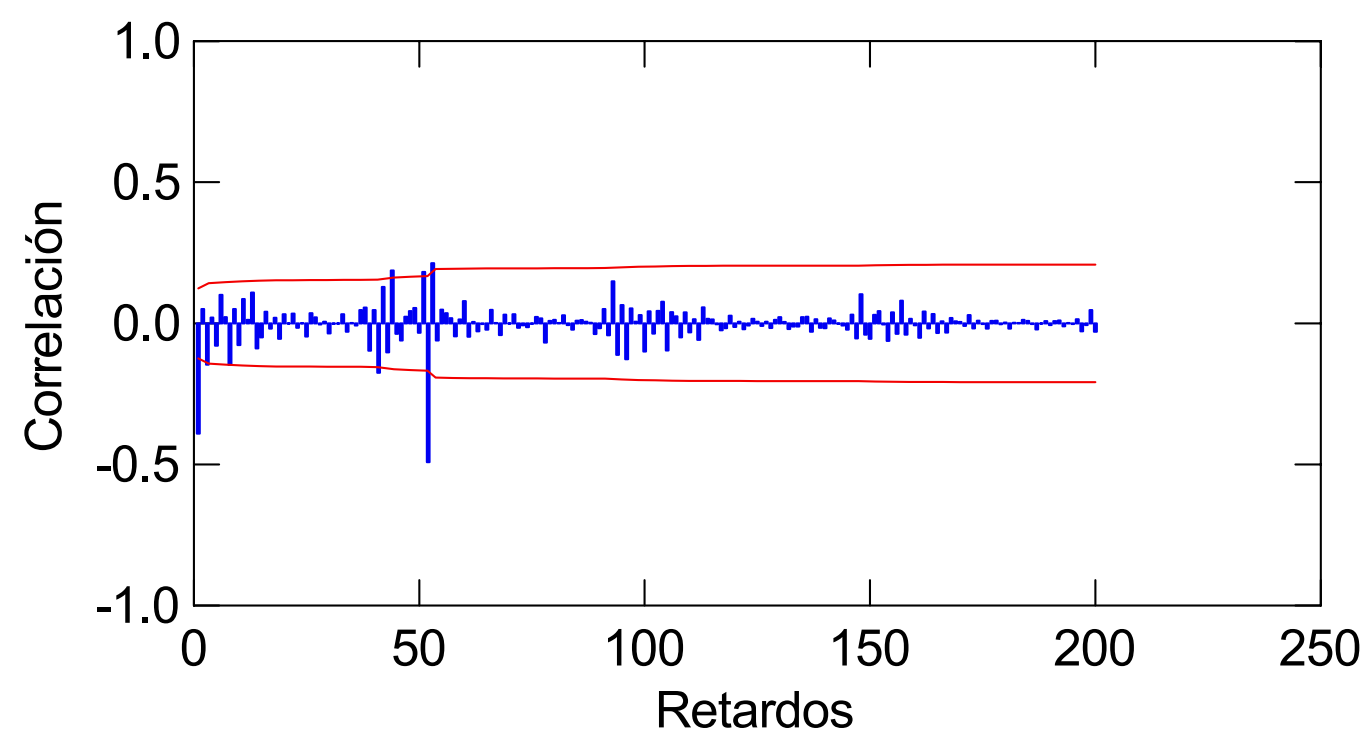


Figura 5.90. Autocorrelación parcial de la serie tras realizar una diferenciación de orden 52.

\section{Partial Autocorrelation Plot}

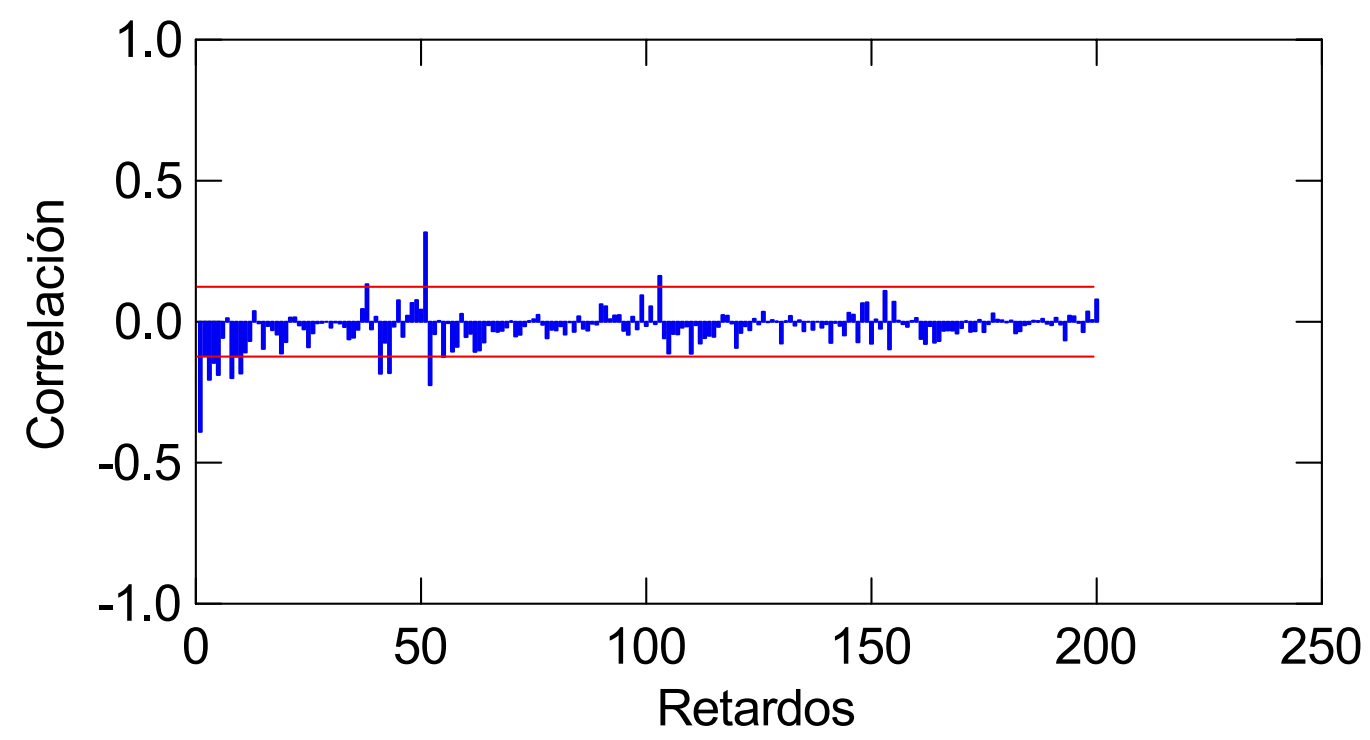

Ecuación 5.8. Modelo ARIMA obtenido para los años 1994-1999.

$$
(1-B)\left(1-B^{52}\right)_{Y t}=(1-0,783 B)\left(1-0,709 B^{52}\right) \Delta t
$$


Figura 5.91. Autocorrelación de los residuales.

\section{Autocorrelation Plot}

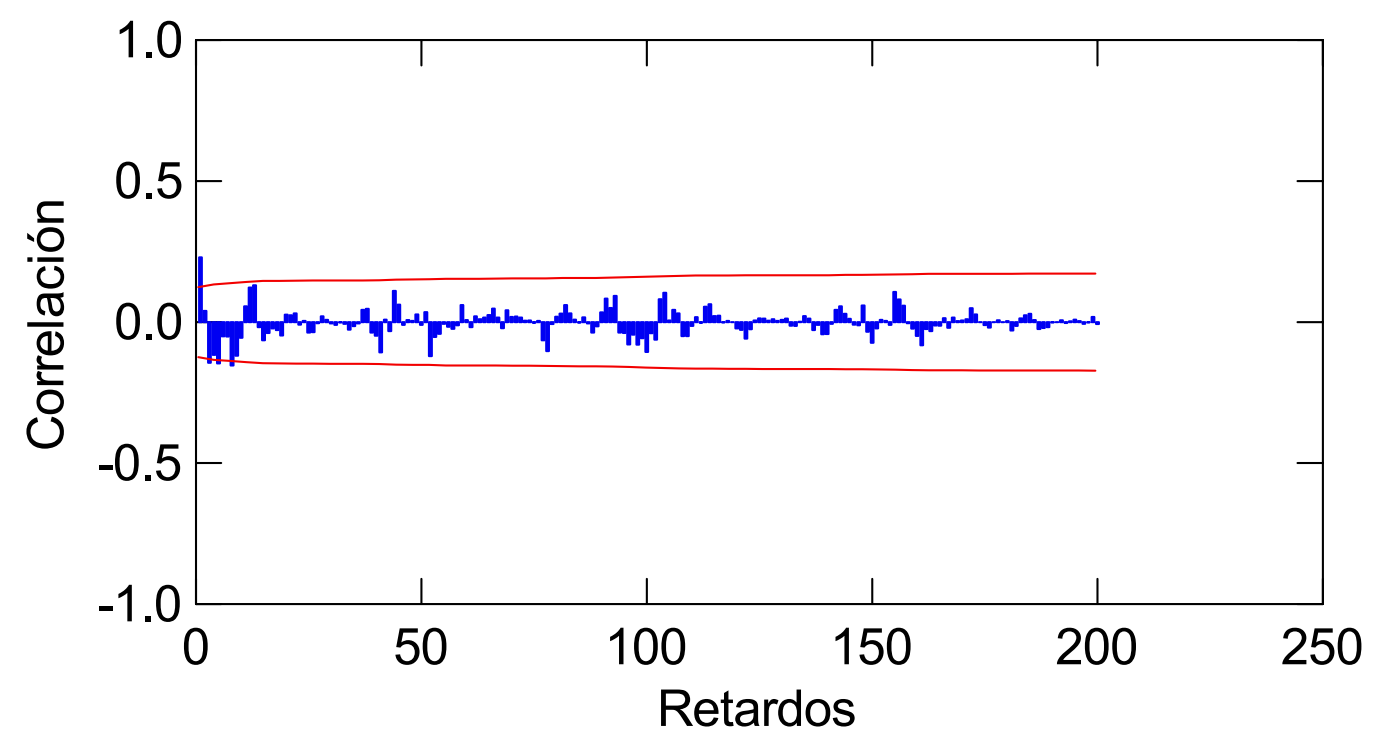

Figura 5.92. Autocorrelación parcial de los residuales

\section{Partial Autocorrelation Plot}

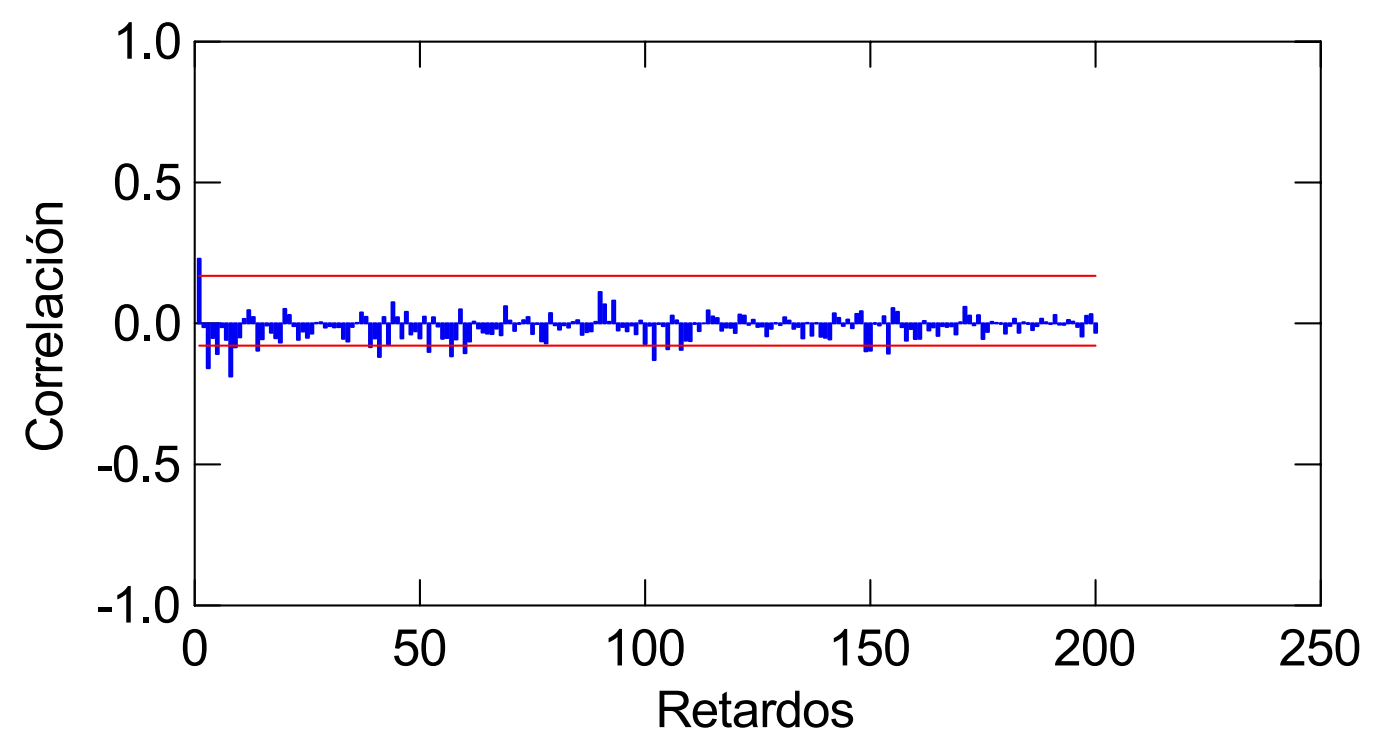




\subsubsection{PREDICCIÓN Y VALIDACIÓN DEL MODELO ARIMA PARA EL AÑO 2000.}

En la tabla 5.116, se presentan las predicciones realizadas con el modelo ARIMA anterior para el año 2000, con el valor medio esperado para cada semana, así como los límites inferior y superior del intervalo de confianza al 95\% de confianza.

En la figura 5.93., se recoge la secuencia de las concentraciones polínicas medias semanales para el periodo 1994 a 1999 y las predicciones efectuadas para el año 2000, con su intervalo de confianza al 95\%.

La figura 5.94, muestra la secuencia real de las concentraciones polínicas medias semanales del año 2000, y los valores predichos por el modelo. En la figura 5.95, se recoge el gráfico de dispersión para las predicciones efectuadas por el modelo y los valores reales del año 2000 .

En la tabla 5.117. se presentan los coeficientes de correlación y determinación entre los datos predichos por el modelo y los datos reales para el año 2000, y los valores calculados y críticos de los contrastes de diferencia entre varianzas y entre medias.

En la tabla 5.118, se recogen los estadísticos de las concentraciones polínicas reales de los años 1994 a 1999, de la predicciones realizadas con el modelo ARIMA (1994-2000) y de los residuales de la predicción. 
Tabla 5.116. Predicciones realizadas con el modelo ARIMA obtenido, para el año 2000, con el intervalo de confianza al 95\%.

\begin{tabular}{||l|l|l|l|l|l||}
\hline & & & \multicolumn{2}{|c|}{ MEDIA E INTERVALO CONFIANZA 95\% } \\
\hline MES & DíA & AÑO & $\begin{array}{c}\text { INFERIOR } \\
\mathbf{9 5 \%}\end{array}$ & PREDICCIÓN & $\begin{array}{c}\text { SUPRIOR } \\
\mathbf{9 5 \%}\end{array}$ \\
\hline Enero & 1 & 2000 & -67.426 & 5.000 & 77.426 \\
\hline Enero & 8 & 2000 & -70.068 & 4.047 & 78.162 \\
\hline Enero & 15 & 2000 & -65.816 & 9.950 & 85.716 \\
\hline Enero & 22 & 2000 & -71.189 & 6.193 & 83.576 \\
\hline Enero & 29 & 2000 & -55.763 & 23.202 & 102.167 \\
\hline Febrero & 5 & 2000 & -31.059 & 49.458 & 129.975 \\
\hline Febrero & 12 & 2000 & -11.993 & 70.046 & 152.086 \\
\hline Febrero & 19 & 2000 & 12.798 & 96.331 & 179.865 \\
\hline Febrero & 26 & 2000 & -1.717 & 83.285 & 168.288 \\
\hline Marzo & 4 & 2000 & 28.722 & 115.167 & 201.613 \\
\hline Marzo & 11 & 2000 & -35.973 & 51.893 & 139.758 \\
\hline Marzo & 18 & 2000 & -6.818 & 82.444 & 171.707 \\
\hline Marzo & 25 & 2000 & -21.255 & 69.383 & 160.021 \\
\hline Abril & 1 & 2000 & -19.716 & 72.278 & 164.271 \\
\hline Abril & 8 & 2000 & -32.541 & 60.787 & 154.116 \\
\hline Abril & 15 & 2000 & -27.777 & 66.869 & 161.514 \\
\hline Abril & 22 & 2000 & 0.570 & 96.514 & 192.458 \\
\hline Abril & 29 & 2000 & 39.007 & 136.232 & 233.457 \\
\hline Mayo & 6 & 2000 & -4.450 & 94.039 & 192.529 \\
\hline Mayo & 13 & 2000 & 6.404 & 106.142 & 205.879 \\
\hline Mayo & 20 & 2000 & -14.247 & 86.724 & 187.694 \\
\hline Mayo & 27 & 2000 & -59.412 & 42.777 & 144.966 \\
\hline Junio & 3 & 2000 & -61.954 & 41.438 & 144.831 \\
\hline Junio & 10 & 2000 & -86.337 & 18.246 & 122.828 \\
\hline Junio & 17 & 2000 & -86.703 & 19.056 & 124.815 \\
\hline Junio & 24 & 2000 & -96.182 & 10.741 & 117.663 \\
\hline Julio & 1 & 2000 & -96.294 & 11.780 & 119.853 \\
\hline Julio & 8 & 2000 & -99.574 & 9.639 & 118.851 \\
\hline Julio & 15 & 2000 & -109.784 & 0.556 & 110.896 \\
\hline Julio & 22 & 2000 & -112.820 & -1.364 & 110.091 \\
\hline Julio & 29 & 2000 & -113.017 & -0.457 & 112.104 \\
\hline Agosto & 5 & 2000 & -116.114 & -2.460 & 111.194 \\
\hline Agosto & 12 & 2000 & -115.096 & -0.358 & 114.380 \\
\hline Agosto & 19 & 2000 & -109.224 & 6.587 & 122.398 \\
\hline Agosto & 26 & 2000 & -90.055 & 26.820 & 143.694 \\
\hline Septiembre & 2 & 2000 & -76.425 & 41.504 & 159.433 \\
\hline Septiembre & 9 & 2000 & -80.310 & 38.663 & 157.637 \\
\hline Septiembre & 16 & 2000 & -106.834 & 13.175 & 133.184 \\
\hline Septiembre & 23 & 2000 & -117.881 & 3.155 & 124.190 \\
\hline Septiembre & 30 & 2000 & -123.648 & -1.595 & 120.459 \\
\hline \hline & & & & & \\
\hline
\end{tabular}


Tabla 5.116. Continuación. Predicciones realizadas con el modelo ARIMA obtenido, para el año 2000, con el intervalo de confianza al 95\%.

\begin{tabular}{||l|l|l|l|l|l||}
\hline & & & \multicolumn{3}{|c||}{ MEDIA E INTERVALO CONFIANZA 95\% } \\
\hline MES & DÍA & AÑO & $\begin{array}{c}\text { INFRIOR } \\
\mathbf{9 5 \%}\end{array}$ & PREDICCIÓN & $\begin{array}{c}\text { SUPERIOR } \\
\mathbf{9 5 \%}\end{array}$ \\
\hline Octubre & 7 & 2000 & -123.087 & -0.024 & 123.039 \\
\hline Octubre & 14 & 2000 & -124.155 & -0.091 & 123.974 \\
\hline Octubre & 21 & 2000 & -122.876 & 2.182 & 127.240 \\
\hline Octubre & 28 & 2000 & -122.806 & 3.237 & 129.281 \\
\hline Noviembre & 4 & 2000 & -124.751 & 2.270 & 129.292 \\
\hline Noviembre & 11 & 2000 & -124.290 & 3.702 & 131.694 \\
\hline Noviembre & 18 & 2000 & -127.778 & 1.177 & 130.132 \\
\hline Noviembre & 25 & 2000 & -129.182 & 0.729 & 130.640 \\
\hline Diciembre & 2 & 2000 & -129.992 & 0.868 & 131.728 \\
\hline Diciembre & 9 & 2000 & -132.534 & -0.731 & 131.071 \\
\hline Diciembre & 16 & 2000 & -130.609 & 2.129 & 134.867 \\
\hline Diciembre & 23 & 2000 & -133.520 & 0.146 & 133.813 \\
\hline \hline
\end{tabular}


Figura 5.93. Secuencia de las concentraciones polínicas mensuales para el periodo 1994-1999 y predicciones con el intervalo de confianza al 95\% para el año 2000.

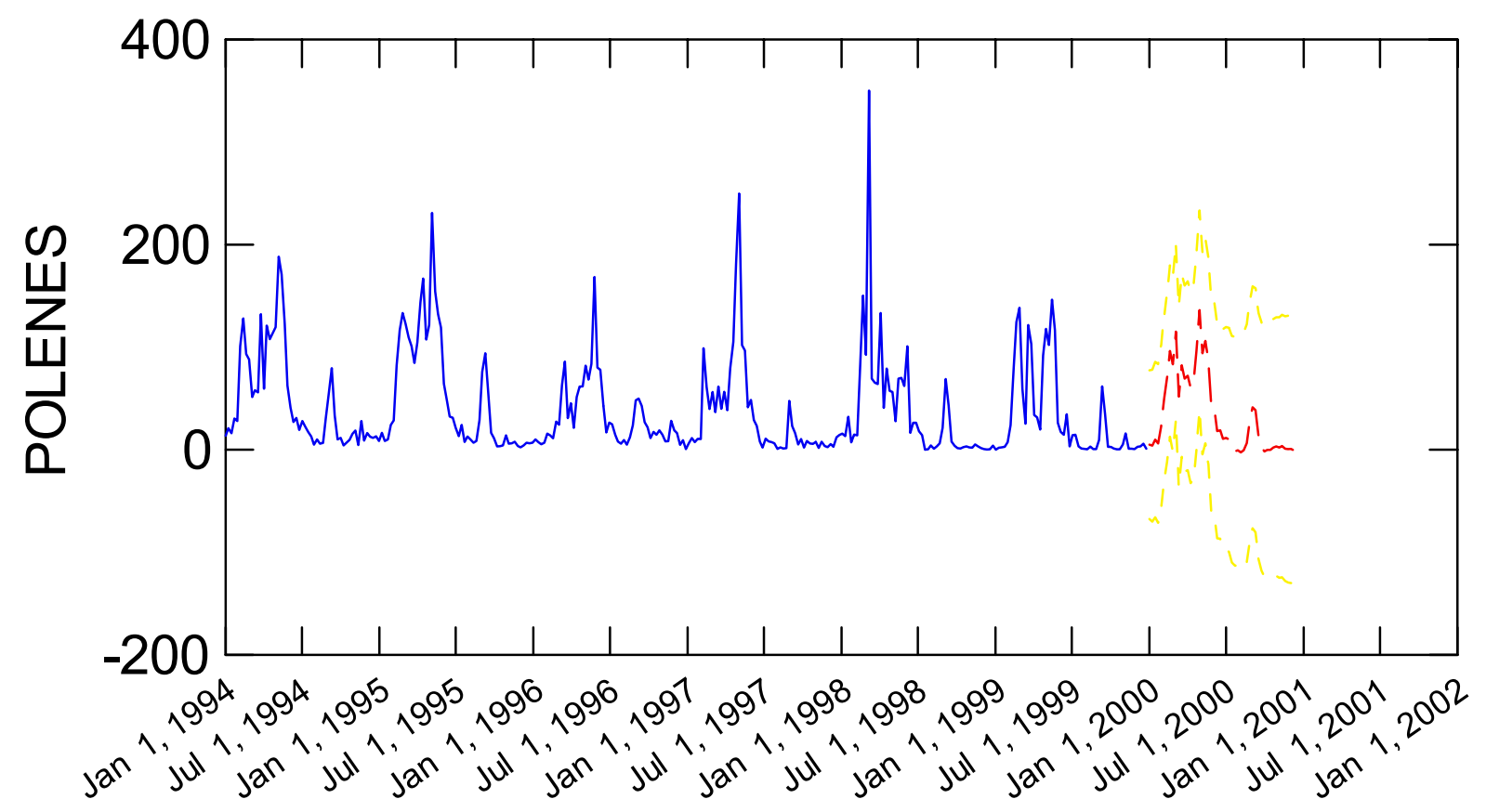

Fecha

Figura 5.94. Secuencia de las concentraciones polínicas medias mensuales predichas para el año 2000 y las reales.

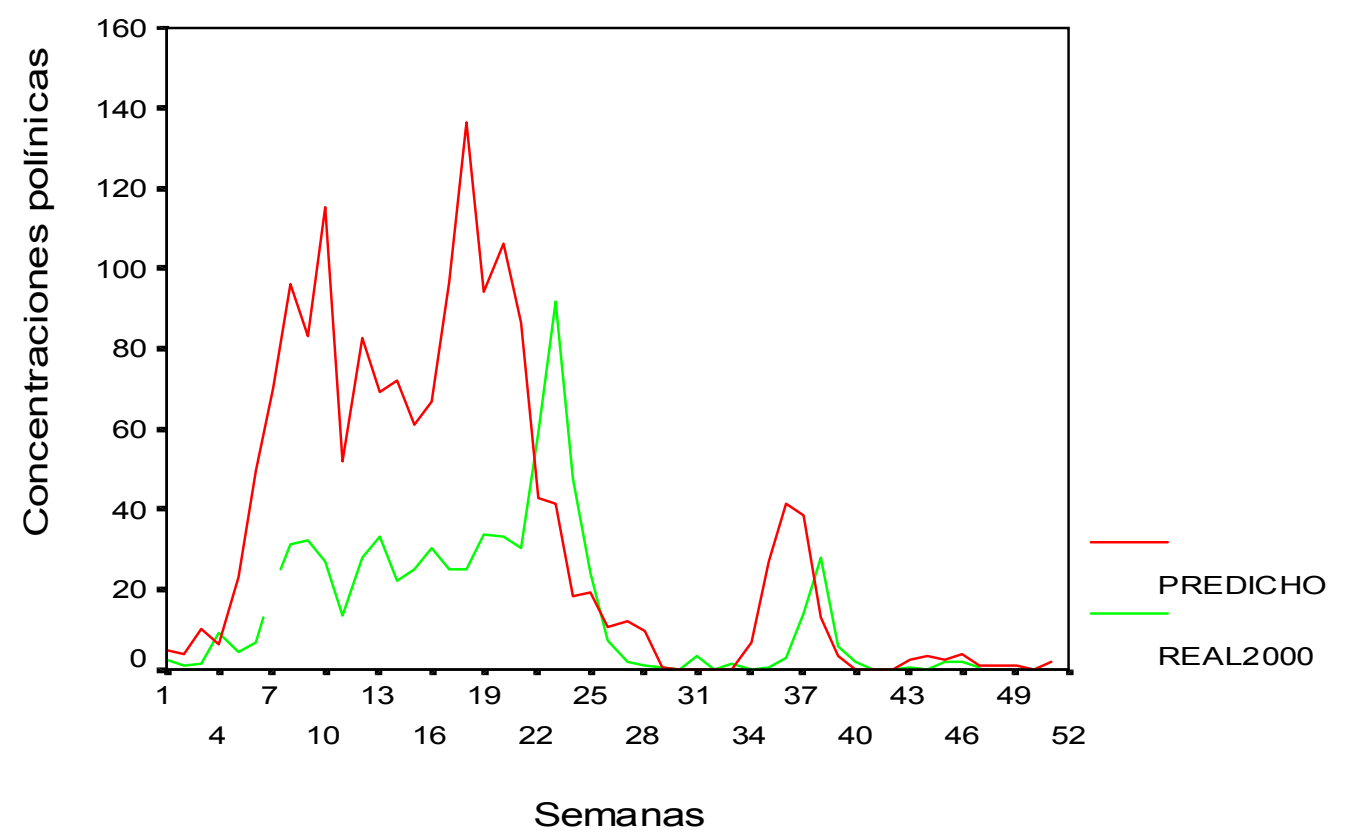


Figura 5.95. Gráfico de dispersión para las predicciones del modelo ARIMA para el año 2000.

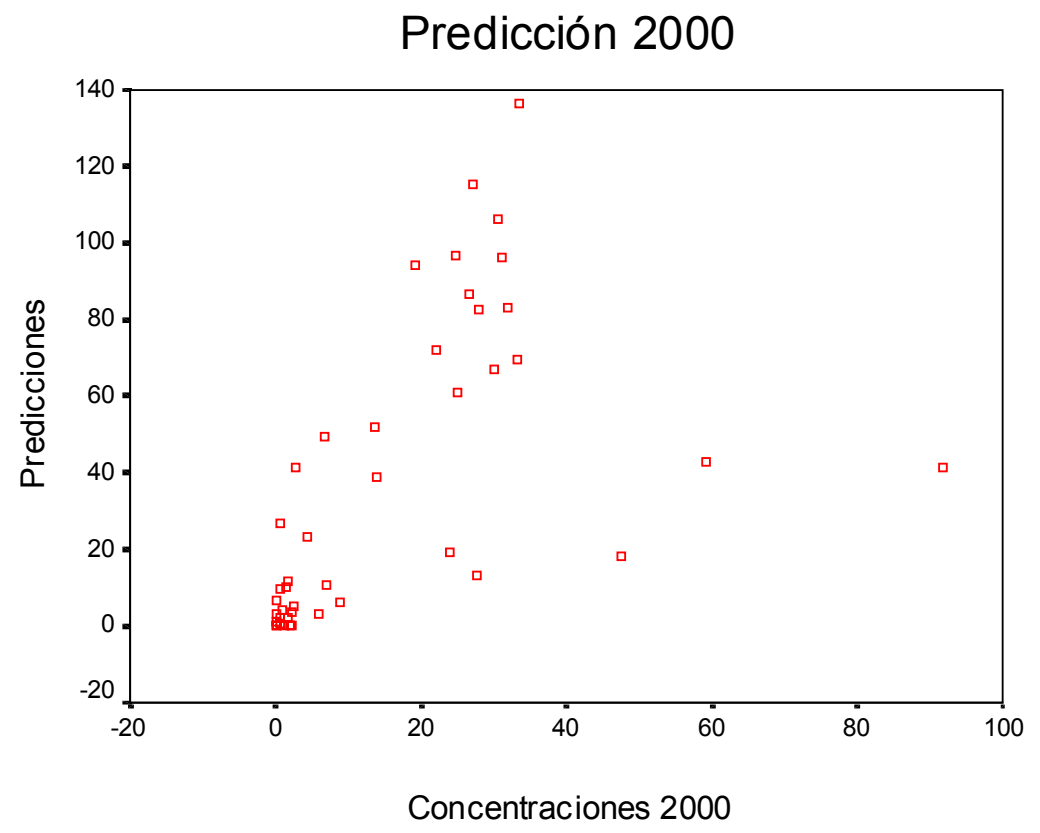

Tabla. 5.117. Coeficientes de correlación y determinación entre los datos predichos por el modelo y los datos reales para el año 2000. Valores calculados y críticos $(\alpha=0,05)$ de los contrastes de diferencia entre varianzas $(F)$ y entre medias $(t)$.

\begin{tabular}{|c|c||}
\hline \hline $\mathrm{r}$ & $0,55^{* *}$ \\
\hline $\mathrm{r}^{2}$ & 0,30 \\
\hline F calculado & 0,25 \\
\hline F crítico & 1,66 \\
\hline $\mathrm{t}$ calculado & 2,83 \\
\hline $\mathrm{t}$ crítico & 2,58 \\
\hline \multicolumn{2}{|c|}{$*$ Significación al 99\% }
\end{tabular}


Tabla 5.118. Estadísticos de las concentraciones polínicas reales de los años 1994 a 1999, de las predicciones del modelo ARIMA 1994-2000 y de los residuales de la predicción.

\begin{tabular}{||l|c|c|c|c||}
\hline \hline & $\begin{array}{c}\text { PÓLENES } \\
\mathbf{1 9 9 4 - 1 9 9 9}\end{array}$ & $\begin{array}{c}\text { PÓLENES } \\
\mathbf{1 9 9 4 - 2 0 0 0}\end{array}$ & PREDICCIONES & RESIDUALES \\
\hline $\mathbf{N}$ & 303 & 347 & 365 & 260 \\
\hline Media & 38,64 & 35,74 & 38,14 & 0,172 \\
\hline Mínimo & 0 & 0 & $-2,46$ & $-126,67$ \\
\hline Máximo & 350,29 & 350,29 & 350,29 & 277,56 \\
\hline Desviación típica & 48,39 & 46,33 & 47,09 & 36,88 \\
\hline
\end{tabular}


6. DISCUSIÓN

\section{CApÍtulo 6 DISCUSIÓN}




\section{CAPÍTULO 6. DISCUSIÓN}

A lo largo del presente capítulo vamos a discutir el conjunto de los resultados que se han presentado en el capítulo anterior. El orden en la presentación de los resultados y, por lo tanto, en el desarrollo del presente capítulo se corresponde con la secuencia lógica establecida hasta llegar a lo que constituye el fin último de este trabajo, es decir, el desarrollo de modelos predictivos que permitan definir la intensidad a lo largo de un periodo de tiempo de las concentraciones que se alcanzan en la atmósfera de uno o todos los tipos polínicos presentes.

Para poder realizar modelos predictivos es necesario contar con las bases de datos adecuadas que contengan la información relevante para el problema específico a tratar. Para ello, hemos partido de las bases de datos aeropalinológicas generadas por nuestro grupo de trabajo, y que combinan la información aerobiológica con la información meteorológica de la ciudad de Cartagena, un análisis profundo del contenido aerobiológico en las bases de datos desde marzo de 1993 hasta marzo de 1999, se encuentra en Elvira-Rendueles (2001).

En el presente trabajo, hemos analizado distintos métodos estadísticos de predicción, pero como paso previo ha sido necesario plantearnos tanto el comportamiento de las concentraciones polínicas, como analizar la dependencia que ésta tiene de otros parámetros. Como nuestro estudio se centra en las concentraciones de polen en el aire, hemos considerado la influencia que la meteorología va a tener sobre estos valores.

Dentro de los datos meteorológicos es el campo de vientos, uno de los parámetros que va a jugar un mayor papel en las concentraciones finales que se van a encontrar en el aire para un determinado agente, en un determinado lugar y tiempo. Una revisión bibliográfica intensa relacionada con este aspecto, nos llevó a utilizar el análisis de cluster como herramienta para obtener nuevas variables que permitieran introducir la información contenida en el vector viento dentro de los modelos de predicción.

En el desarrollo de los modelos predictivos inicialmente incluimos únicamente variables meteorológicas, sin embargo, los bajos coeficientes de determinación que se alcanzan, nos aconsejaron ampliar la perspectiva hacia el estudio de las 
autocorrelaciones, por los que se generaron nuevas variables piernas o de retardo que fueron incluidas en las predicciones, mejorando considerablemente los coeficientes de determinación obtenidos en los modelos seleccionados.

Los resultados que encontramos tras los análisis de regresión lineal nos hicieron abordar dos nuevos enfoques. En primer lugar, como desde el punto de vista de la adopción de medidas preventivas por parte de la población sensible puede ser interesante conocer cuándo se supera determinado umbral de concentración, nos planteamos el desarrollo de modelos de regresión logística que permitan predecir cuando se van a producir valores por encima de un límite umbral establecido.

En segundo lugar, la mejora obtenida en los coeficientes de determinación en los modelos de regresión lineal, en los que se incorpora la concentración polínica del día anterior, nos llevó a plantearnos como alternativa una estrategia predictiva basada en los modelos ARIMA, de análisis de series temporales.

Estas han sido las distintas fases en el trabajo, que pasamos a discutir de modo detallado para cada uno de los apartados que ha sido necesario abordar para el desarrollo completo de los objetivos planteados en el capítulo 2.

\subsection{CONCENTRACIONES POLÍNICAS DE LA CIUDAD DE CARTAGENA DURANTE LOS AÑOS 1993-1999.}

El estudio de la fracción biótica del aerosol atmosférico de la ciudad de Cartagena se viene realizando, con la metodología Hirst, desde marzo de 1993 hasta la actualidad, habiéndose indentificado hasta el momento un total de 44 tipos polínicos agrupados en 36 familias como señala Elvira-Rendueles (2001).

En el presente estudio se han analizado las concentraciones polínicas registradas hasta diciembre de 1999, observándose a la vista de los resultados mostrados en la tabla 5.1a. un descenso del 47,3\% en la concentración polínica total desde el año 1993 hasta el año 1999.

Durante este periodo de tiempo se ha producido un desplazamiento en la abundancia relativa de las especies herbáceas frente a especies arbóreas, tabla 5.1b., así 
por ejemplo se ha pasado de más de un 30\% de Urticaceae en el año 1993 a menos de un $20 \%$ en el año 1999, mientras que el tipo polínico Cupressaceae ha pasado de algo más de un 10\% en 1993 a más del 30\% en 1999, hecho que puede atribuirse por un lado a la intensificación de la agricultura y la urbanización, así como a la intensa sequía que se ha padecido en la zona durante este periodo (Elvira-Rendueles, 2001).

A la vista de las figuras 5.1. y 5.2. podemos hablar de un comportamiento estacional en la evolución de la concentración polínica total a lo largo del año, observándose para cada ciclo anual dos periodos. El primero, más complejo, en el que aparecen varios picos sucesivos y que son el resultado de las diferentes aportaciones de cada tipo polínico que florece en esta época del año. El segundo pico, se presenta a finales del verano y otoño, correspondiéndose de modo claro con la segunda floración de Chenopodiaceae-Amaranthaceae, como puede observarse en la figura 5.6.

El análisis de la tabla 5.2. nos permite profundizar en algunos de los aspectos que hemos señalado anteriormente. Así puede observarse que, en general, el mes de mayo es el que presenta la mayor media mensual, seguido de abril y de marzo, repitiéndose otro pico relativo en el mes de septiembre.

Sin embargo, en el año 1998 el comportamiento es distinto, encontrando en mayo valores menores que en meses precedentes, hecho que atribuimos a la importante disminución en este año de los contenidos polínicos de determinados taxones como Urticaceae y Oleaceae, dándose para ambos, recuentos muy inferiores a los valores medios para el total de los años estudiados, mientras que para Cupressaceae y Pinaceae, especies arbóreas de floración pre-primaveral, ocurre lo contrario, aumentado los valores totales recontados para este año, tabla 5.1b.

Con objeto de conocer la distribución de frecuencias de las concentraciones polínicas encontradas durante los años 1993 a 1999 en la ciudad de Cartagena, en la figura 5.3a. se ha representado el histograma de frecuencias de los datos de concentración polínica total estandarizada.

El punto de partida para la interpretación de un conjunto importante de datos, es conocer la función de distribución de probabilidad de referencia a la que se ajustan. Generalmente, con datos biológicos se asumen modelos de distribución normal (Comtois, 2000), para datos de concentraciones de contaminantes en el aire se utilizan 
distribuciones Lognormales, Weibul y Gamma (Georgopoulos y Seinfeld, 1982) y para datos aerobiológicos se usa frecuentemente la distribución Lognormal (Stark et al., 1997), aunque describe de modo deficiente los valores bajos cercanos a los límites de detección (Comtois, 2000).

Comtois (2000), indica que la distribución Gamma sólo toma valores positivos y es muy útil en el análisis bayesiano, además, las mayores frecuencias se dan para los valores menores que la media y presenta una larga cola hacia la derecha. Todos estos aspectos se presentan en los datos aerobiológicos, encontrando también este comportamiento en nuestro caso, tal como puede observarse en la figura 5.3a. La distribución Gamma es representativa de un proceso de dilución aleatoria sucesiva, típico de la Aerobiología donde los granos de polen son introducidos en un medio transportador, en ausencia de nuevas aportaciones son diluidos por el movimiento de la atmósfera y resulta tras la liberación, completamente mezclada en cortos periodos de tiempo por mecanismos de turbulencia.

Así, se han realizado ajustes de los datos experimentales a las distintas distribuciones mediante gráficos P-P, resultando el más adecuado para la distribución Gamma, tal como se recoge en la figura 5.3b., aunque el perfil de la serie temporal de nuestros datos aerobiológicos tiene una forma que podría asimilarse a una distribución normal, lo que constituiría una buena aproximación a un patrón ideal aerobiológico (Comtois, 2000).

La figura 5.4. muestra la evolución de las concentraciones polínicas máximas semanales en los años estudiados, encontrando una estructura en dientes de sierra, cuya intensidad varía de año en año. Centrándonos en el primer periodo de cada año, caracterizamos cinco picos diferenciados entre las semanas séptima y la número 27. Aunque resulta difícil la asociación de cada pico con un tipo polínico, podemos afirmar que el primer pico que aparece se corresponde casi en su totalidad con la floración de Cupressaceae, mientras que el principal responsable de la forma del segundo pico es Pinaceae (Moreno-Grau et al., 1998).

A los picos tercero, cuarto y quinto, resulta todavía más difícil asignar un tipo polínico concreto, puesto que se trata del periodo principal de floración para la mayoría de las especies presentes en la zona, de manera que se producen aportes muy variados, 
aunque principalmente son Quercus, Oleaceae, Urticaceae y la primera floración de Chenopodiaceae-Amaranthaceae, por este orden, los principales responsables de estos picos (Elvira-Rendueles, 2001).

En la tabla 5.4. se presentan las concentraciones medias mensuales de la familia Chenopodiaceae-Amaranthaceae durante los años 1993-1999, observándose dos máximos relativos para cada año y que coinciden con los dos periodos principales de floración, uno en primavera y otro que ocurre a finales del verano y principios del otoño. El resto del año se registran valores de concentración muy bajos y que podrían atribuirse al desfase que existe en la floración de las distintas especies, a la variabilidad espacial, así como a los factores que inciden en la resuspensión de algunos granos que con anterioridad habían sido depositados sobre las distintas superficies. Como señala Elvira-Rendueles (2001) se trata del tercer taxón en abundancia por detrás de Urticaceae y Cupressaceae, para la ciudad de Cartagena para el periodo 1993-1999.

El primer máximo relativo señalado anteriormente, salvo para los años 1998 y 1999 en los que parece que tuvo lugar un adelanto en la floración, se produce durante el mes de mayo. En cambio, el segundo máximo relativo coincide bastante bien para todos los años estudiados, como puede deducirse del análisis de la figura 5.5., siendo la semana número 37 cuando se alcanzan los valores máximos.

En la figura 5.6. se presentan las evoluciones conjuntas de las concentraciones polínicas totales y de Chenopodiaceae-Amaranthaceae para los años estudiados, observándose como hemos comentado anteriormente un primer periodo durante finales de invierno y principios de primavera en el que se registran las mayores concentraciones, con una forma en dientes de sierra y que se corresponde con lo que podríamos denominar periodo principal de polinización.

A la vista de la gráfica, se aprecia un segundo máximo a finales de verano y principios de otoño, que prácticamente en su totalidad se debe a la segunda floración de Chenopodiaceae-Amaranthaceae, hecho que nos ha servido para plantear la construcción de los modelos predictivos de regresión múltiple desde una doble perspectiva. Por un lado, hemos considerado las concentraciones polínicas totales registradas durante las primeras 30 semanas de cada año y por otro, las concentraciones polínicas de la segunda floración de Chenopodiaceae-Amaranthaceae. 
6. DISCUSIÓN

\subsection{METEOROLOGÍA DE LA CIUDAD DE CARTAGENA DURANTE LOS} AÑOS 1993-1999.

Los distintos parámetros meteorológicos están íntimamente relacionados con la producción y dispersión de pólenes en la atmósfera, como han puesto de manifiesto numerosos autores (Davies y Smith, 1973; Spieksma, 1980; Moseholm et al., 1987; Galán et al., 1995; Norris-Hill, 1995; Díaz De La Guardia et al., 1998; Moreno-Grau et al., 1998; Galán et al., 2000). Por ello, en el apartado 5.2., se recoge un resumen de los aspectos meteorológicos más relevantes para la ciudad de Cartagena durante el periodo estudiado.

Como señala Capel Molina (1986), Cartagena es la capital de la comarca denominada Campo de Cartagena que constituye un gran plano inclinado con dirección Noroeste-Sureste, limitado al Norte y Noroeste por las sierras Pre-Litorales (Carrascoy, El Puerto, Los Villares, Columbrares y Escalona), y por el Sur y Suroeste por las sierras Litorales (El Algarrobo, La Muela, Pelayo, Gorda, La Fausilla y Minera, con sus últimas estribaciones en Cabo de Palos). La climatología de la zona está condicionada por su latitud norte, aproximadamente entre los $38^{\circ}$ y $37^{\circ} 40^{\prime}$. Además, la proximidad del cinturón de altas presiones subtropicales hace que durante extensos periodos del año la zona se vea afectada por el mismo, condicionando en definitiva el clima de la zona.

En relación con las temperaturas medias, como se puede apreciar en la figura 5.7. y en la tabla 5.5., Cartagena se caracteriza por poseer temperaturas medias suaves a lo largo de todo el año, que en la mayoría de los años están por encima de $\operatorname{los} 10^{\circ} \mathrm{C}$. En cuanto al comportamiento mensual, es en enero cuando se alcanzan los valores menores, mientras que las medias mensuales más altas corresponden al mes de agosto. La temperatura media anual del conjunto de años estudiados (1993-1999) se sitúa en torno a $\operatorname{los} 20^{\circ} \mathrm{C}$.

También parece que existen diferencias de temperaturas significativas cuando se estudian en distintos puntos de la ciudad, atribuyéndose tal efecto a la mayor o menor proximidad al mar, quedando reflejado el efecto termorregulador de éste, así como a las diferentes características y propiedades que presentan las superficies en la ciudad y en el campo (Pérez-Tornell, 1997). 
Cuando se estudia el patrón horario de las temperaturas medias para los distintos años, como queda recogido en la figura 5.8., se aprecia que el incremento térmico diario se inicia a primeras horas de la mañana hasta alcanzar el máximo sobre las 13 horas. Este comportamiento es inverso al que presenta la humedad relativa como puede observarse en la figura 5.12., alcanzándose los máximos valores durante la noche y primeras horas de la mañana, mientras que los mínimos ocurren al mediodía.

El comportamiento encontrado es similar al encontrado en la ciudad de Mérida (México) y además, es importante resaltar la combinación del comportamiento de estos dos parámetros en cualquier estudio ambiental (Veleva et al., 1997). Así, en nuestro caso, van a resultar decisivos en el comportamiento que va a tener el grano de polen en la atmósfera.

Aunque usualmente los parámetros temperatura y humedad relativa se presentan como valores medios mensuales o anuales, resulta muy interesante en algunos casos conocer los máximos o mínimos absolutos de un periodo de tiempo, para comprender mejor ciertos fenómenos (Veleva et al., 1997).

En las figuras 5.9. y 5.10. y tablas 5.6. y 5.7. se muestran las evoluciones mensuales de la media e intervalo de confianza al 95\% para las temperaturas mínimas y máximas respectivamente durante cada año estudiado y durante el conjunto de años, observando una ausencia de temperaturas bajo cero y temperaturas máximas que en el mes de agosto superan $\operatorname{los} 30^{\circ} \mathrm{C}$.

Otro parámetro que resulta fundamental en el estudio de la fracción biótica del aerosol atmosférico es la humedad relativa, y más concretamente las fluctuaciones de ésta a lo largo del día. Así, el grano de polen posee una propiedad denominada harmometangia, que consiste en la capacidad que éste posee para adaptarse a las condiciones de mayor o menor humedad del ambiente en donde se encuentra (Blackmore y Barnes, 1986; Suárez-Cervera y Márquez-Pereira, 1990). A la vista de la figura 5.11. y tabla 5.10., se observan valores medios mensuales elevados, por encima todos ellos del 50\%, hecho que podríamos atribuir a la proximidad al mar. Es de destacar, que los valores menores se registran para la mayoría de los años en el mes de abril, hecho que queda reflejado cuando se estudia la evolución para el conjunto de años. Como hemos comentado anteriormente, en la figura 5.12. se recoge la evolución 
horaria de la humedad relativa, apreciando un comportamiento contrario al de la temperatura, puesto que la disminución de la temperatura del aire conlleva una menor capacidad de almacenar vapor de agua.

La evolución de la presión media mensual para los distintos años se recoge en la figura 5.13. y tabla 5.11., observándose en general unas presiones más altas durante los meses de invierno y otoño, mientras que los menores valores se corresponden con los meses de primavera y verano, que es cuando se van a registrar las mayores concentraciones polínicas. Este comportamiento, nos obliga a interpretar con cierta cautela los coeficientes de correlación obtenidos para la concentración polínica total diaria con la presión barométrica.

En cuanto a la evolución diaria, en la figura 5.14. se puede apreciar un comportamiento semejante para todos los años y para el conjunto, observándose a su vez dos máximos diarios. Uno que se presenta durante el día, a las horas centrales (11$13 \mathrm{~h}$ ), y otro que ocurre de madrugada (23-2 h), como consecuencia de la desigual densidad del aire según la temperatura (Wark y Warner, 1990), la relación de estas variables con el contenido de humedad (De Nevers, 1997) y los patrones de circulación del aire sobre la zona, tanto a nivel local (brisas) como dentro del sistema de la baja térmica de la península ibérica (Millán et al., 1992).

En la figura 5.15. y tabla 5.12. se presenta el resumen del comportamiento de la radiación solar media acumulada mensual para cada uno de los años y para el conjunto, apreciándose unos valores máximos para los meses de primavera y verano, siendo concretamente el mes de junio cuando se alcanzan los máximos valores, por tratarse del mes en el que los días presentan una mayor duración y la inclinación de los rayos solares incidentes es más perpendicular. En cuanto al valor medio anual todos resultan similares, excepto para el año 1993 en el que se alcanzaron valores un poco por encima de la media del periodo.

Si estudiamos la evolución horaria de la radiación solar diaria, observamos un comportamiento bastante parecido al que presenta la temperatura, aunque en el caso de la radiación los valores máximos están desplazados hacia las horas centrales del día, como queda reflejado en la figura 5.16., debido a su mayor dependencia con la presencia del sol, mientras que en el caso de la temperatura, el incremento y descenso 
diario es más suave. Este comportamiento también es muy parecido al de la velocidad del viento, puesto que el calentamiento de las masas de aire provoca una serie de movimientos que se traducen en mayores velocidades del viento (figura 5.16b.). Así, cuando el sol calienta la superficie de la tierra se producen fenómenos convectivos, que determinan que los vientos en superficie tiendan a constituirse como los de altura, igualando a éstos en dirección y velocidad (Estrela y Millán, 1994).

En cuanto a las precipitaciones acumuladas mensuales, que se presentan en la figura 5.17. y tabla 5.13., tenemos que afirmar que los valores registrados en los últimos años están muy por debajo de la media mensual de 30 años, que se presentan en la tabla 5.14. Este hecho tiene una influencia negativa en los registros polínicos totales de los últimos años. Además esta disminución de las precipitaciones puede tener otro efecto negativo sobre la contaminación en general, puesto que esa mayor aridez se puede traducir en mayores concentraciones de polvo en la atmósfera.

Aunque en la ciudad de Cartagena se dispone de cuatro torres meteorológicas, y datos de todas ellas se han utilizado en algunas fases de este estudio, la mayoría de los datos meteorológicos utilizados han sido registrados en la torre ubicada en el edificio del Ayuntamiento. Aunque las diferencias en cuanto al vector viento son pequeñas por su proximidad, la compleja orografía de la zona hace que en algunos casos se obtengan diferencias significativas.

Así, en las figuras 5.18. a 5.32. se recoge el comportamiento del vector viento en la torre ubicada en el ayuntamiento. Para ello se han elaborado rosas de frecuencias de las direcciones del viento, dividiendo los $360^{\circ}$ sexagesimales en doce rumbos. También se presentan las frecuencias de las velocidades del viento, para lo que hemos considerado 4 rangos. Para todos los años estudiados, encontramos un comportamiento del viento caracterizado por el predominio de los vientos del primer y tercer cuadrante, con la particularidad de que la dirección sur presenta frecuencias muy elevadas, hecho que atribuimos al efecto barrera que suponen las sierras litorales para el viento a lo largo de toda la costa, obligando a que los vientos adopten una dirección SSW ó WSW. Sin embargo, cuando estos vientos llegan a la bocana del puerto que mira a Sur, hace que éste no encuentre obstáculo alguno para su paso, y por consiguiente adoptan esta dirección predominante. Este efecto explicado en los antecedentes bibliográficos, es conocido como efecto chimenea. 
Cuando se estudia el comportamiento de las direcciones del viento en el resto de estaciones, se observa que es muy similar, con la única salvedad que la dirección Sur, predominante en la estación del Ayuntamiento, se traduce para el resto de estaciones en dirección SSW o WSW.

Con respecto a las velocidades del viento, se han estudiado generando dos variables: los rangos obtenidos mediante un análisis, para cada día, de las frecuencias de la velocidad del viento semihoraria (RANGOSMI) y otra segunda variable, en la que se ha calculado previamente la velocidad media diaria y se ha categorizado por rango de intensidad (RANGOS).

Como puede verse en las figuras 5.33. y 5.34., se encuentran diferencias apreciables entre ambas clasificaciones, ya que el segundo de los procedimientos lleva a obtener frecuencias muy altas para los valores intermedios de la velocidad del viento, desapareciendo prácticamente, las calmas. En cambio, el primer procedimiento proporciona un número muy elevado de días (prácticamente 50\%) que presentan vientos con velocidades superiores a $16 \mathrm{~km} /$ hora y una distribución del resto de los días, en la que un $16 \%$ corresponde al grupo 2 , un $8 \%$ al grupo 1 y el resto al grupo 3 .

Consideramos que los resultados que se obtienen con la variable RANGOSMI, recogen mejor el comportamiento del viento en la zona, en la que abundan las situaciones de brisas intensas, junto con una serie de días en los que prácticamente dominan las calmas.

\subsection{METEOROLOGÍA Y PÓLENES.}

\subsubsection{VARIABLES METEOROLÓGICAS Y CONCENTRACIONES POLÍNICAS TOTALES.}

Como paso previo al desarrollo de modelos predictivos son varios los autores que aconsejan un detallado análisis de las correlaciones existentes entre las variables que a priori se consideran relacionadas con la variable dependiente (Bisquerra, 1989; Galán et al., 1995; Norris Hill, 1995; Díaz de la Guardia et al., 1996; Galán et al., 2000), para incluir exclusivamente en el estudio de regresión las variables relevantes en ese problema específico. En la tabla 5.15., se presentan los coeficientes de correlación 
bivariada de Pearson para las concentraciones polínicas totales diarias estandarizadas y los distintos parámetros meteorológicos inicialmente considerados, habiendo obtenido significación estadística para la presión media, humedad relativa media, velocidad media del viento y radiación solar acumulada, para el conjunto de los datos. El análisis año a año indica que para la presión media no existe correlación con significación estadística para los años 1996, 1997 y 1998, mientras que para la humedad relativa no es significativa en el año 1993 y para la velocidad del viento no existe esta correlación estadísticamente significativa en los años 1993, 1996, 1997 y 1999.

Para facilitar la discusión, la centraremos en los resultados obtenidos con el conjunto de los datos. Así, para la presión atmosférica aunque obtenemos un coeficiente de correlación bajo, ésta es negativa con alta significación. Esto quiere decir que un aumento de presión atmosférica se traduce en una disminución de las concentraciones de pólenes aerovagantes. Existe poca documentación con respecto a este punto, aunque Glassheim et al. (1995), referencian una correlación positiva y significativa para los pólenes procedentes de arbustos, aunque nosotros para nuestro resultado, hemos planteado la posibilidad de que el asentamiento que se produce en las masas de aire como consecuencia de las altas presiones, disminuyan la capacidad de flotación de los granos de polen, que en definitiva son partículas grandes, mayores de $10 \mu \mathrm{m}$ (ElviraRendueles, 2001).

La humedad relativa muestra una correlación negativa y significativa con las concentraciones totales de polen. Este comportamiento ha sido ya definido en la atmósfera de Palencia (Herrero y Fraile, 1997), y se justifica en la capacidad del grano de polen de variar su forma y tamaño en función del grado de hidratación (Blackmore y Barnes, 1986), propiedad denominada harmometangia, así como en los mecanismos de eliminación de partículas de la atmósfera (Nicholson, 1995; Seinfeld y Pandis, 1998).

En cuanto a la velocidad del viento se ha encontrado una correlación positiva con significación estadística, lo que indica que hay un aumento en las concentraciones de polen en el aire conforme aumenta la velocidad del viento. Finalmente, con la radiación solar se ha encontrado una correlación positiva que está totalmente acorde con la influencia que ésta tiene sobre los procesos de formación y liberación del grano de polen (Akers et al., 1979), aunque únicamente hemos encontrado referencia a este 
parámetro meteorológico en los trabajos de Bringfelt et al. (1982) y Glassheim et al. (1995), con análogos resultados a los nuestros.

Con el fin de profundizar en las relaciones existentes entre las variables meteorológicas y las concentraciones polínicas, hemos efectuado análisis de la varianza para determinados parámetros meteorológicos. Así, para las presiones atmosféricas hemos realizado dos análisis distintos. En el primero de ellos, presentado en la figura 5.35., clasificando las presiones en dos grupos, menores o iguales a 1013 milibares y mayores a este valor, viéndose claramente la disminución en la concentración polínica que se da en situación de altas presiones, siendo las diferencias entre grupos en el ANOVA estadísticamente significativas.

Cuando el ANOVA se repite para tres rangos de presiones, figura 5.36., observamos que presiones por debajo de $1005 \mathrm{mb}$ se dan con muy baja frecuencia en la zona, 24 días de un total de 2149 días analizados y este grupo de datos presenta un amplio intervalo de confianza para la media, constituyendo un grupo homogéneo con los otros dos grupos de datos, entre los que sí se establece diferencias con significación estadística, en el mismo sentido antes comentado.

Las torres meteorológicas, de las que hemos tomado los datos para este estudio, se complementan con un sistema informático que ha ido sufriendo actualizaciones a lo largo de los años estudiados. Así los datos de los años 1993 y 1994 se almacenaban como media diaria obtenida mediante un software incorporado en el sistema. El aumento de la potencia informática permitió a partir del año 1994, almacenar la información en formato semihorario y medias diarias.

Por eso, hemos generado dos variables distintas para los rangos del viento. Para los rangos del viento se ha generado una primera variable que contiene las medias diarias que se obtienen con el software del sistema, que comprende los años 1993 a 1999 y que hemos denominado rangos, y otra segunda variable que contiene la información de la media semihoraria de cada día, para la velocidad del viento en el periodo 1995 a 1999, y que hemos denominado rangosmi.

La diferencia fundamental entre los resultados por el software que incorpora el sistema y los valores contenidos en la variable rangosmi, es que para la construcción de ésta, se ha efectuado un análisis tanto de los valores de la variable a lo largo del día 
como de su frecuencia, por lo que el dato diario recoge para cada uno de los subgrupos establecidos el que ha aparecido cada día con mayor frecuencia.

Las figuras 5.38. y 5.39. recogen el análisis de la varianza de la concentración polínica total estandarizada diaria por rangos de la velocidad del viento para el periodo 93-99 y 95-99, respectivamente. El comportamiento en ambos casos en similar, aunque algo más pronunciado para el periodo completo, produciéndose un aumento en las concentraciones polínicas entre el rango dos y los rangos tres y cuatro, constituyendo este rango dos un grupo homogéneo con el rango uno. Observamos en la figura 5.38. como, aunque no se alcancen diferencias con significación estadística, se da una disminución en el valor medio desde el rango uno hasta el rango dos, diferencia cuando el periodo analizado es el 95-99.

En la figura 5.39., se presenta el ANOVA efectuado para la variable rangosmi, en este caso puede verse como se produce un paulatino aumento de las concentraciones de polen con los distintos rangos de la velocidad del viento, siendo las velocidades mayores a $16 \mathrm{~km} /$ hora las que dan lugar a mayor concentración de polen.

Como han señalado Faegri e Iversen (1989), en el límite de velocidad de 5 $\mathrm{km} /$ hora separa los componentes locales y de gravedad en la dispersión del polen, por lo que el rango uno es el que se ve más afectado por este carácter local, mientras que en el resto de los rangos se aprecia la creciente contribución de la flora más alejada del captador, aunque también habría que analizar con mayor profundidad el efecto que rachas intensas de viento puedan tener sobre la liberación de granos de polen de las anteras, resuspensión de granos de polen depositados sobre las superficies, etc.

Estudios realizados en la ciudad de Granada (Díaz de la Guardia et al., 1998) y en Extremadura (Muñoz et al., 2000), para pólenes de algunos tipos de plantas herbáceas indican correlaciones negativas con la velocidad del viento (en el segundo de los trabajos con la distancia recorrida por el viento). Sin embargo, Fornaciari et al. (1992), encuentran para periodos de cuatro horas correlaciones positivas entre la velocidad del viento y los valores de polen de Urticaceae, salvo para los días de lluvia en el mes de junio. Consideramos que esta disparidad en los comportamientos pueda estar relacionada con la abundancia de flora cercana al captador. En nuestro caso, no existen masas vegetales abundantes en las proximidades del mismo, por lo que nos 
parece razonable el resultado que obtenemos, con un aumento de las concentraciones polínicas con la velocidad del viento al permitir la llegada al captador de masas de aire que contienen los pólenes liberados por las masas vegetales ubicadas fuera de la ciudad.

La figura 5.40. muestra el ANOVA efectuado para la variable rumbo del viento. Las diferencias entre grupos son estadísticamente significativas, es decir, no existe igualdad de medias. Complementando el análisis de la varianza con el test de comparaciones múltiples de Bonferroni, no se han encontrado diferencias con significación estadística entre ninguno de los grupos, lo que indicaría una contribución homogénea desde los distintos puntos al captador, y por lo tanto, la correcta ubicación del captador sin que existan obstáculos al flujo que impidan la llegada de los granos de polen (Moreno-Grau et al., 1998; Elvira-Rendueles, 2001). El valor medio más alto corresponde al rumbo (SSE) en el que sólo se han clasificado tres de los días estudiados, por lo que el intervalo de confianza para la media en este punto es muy grande, no pudiéndose establecer con claridad la existencia de direcciones predominantes. Este mismo resultado se obtiene cuando se efectúa el ANOVA por cuadrantes, como se puede apreciar en la figura 5.41. Conforme aumenta el número de datos de la base estadística podremos profundizar en la influencia de la dirección del viento sobre la concentración polínica total, y comprobar si se obtienen diferencias estadísticamente significativas entre los distintos grupos.

La lluvia juega un doble papel sobre las concentraciones polínicas, por un lado, ha sido abundantemente referenciado el efecto de lavado de la atmósfera que juega la lluvia (McDonald, 1980; Suárez-Cervera y Márquez-Pereira, 1990 y Norris-Hill y Emberlin, 1993), aunque por otro lado, también se puede encontrar bien documentado el efecto positivo que la lluvia previa a la floración tiene sobre el desarrollo de las plantas (Márquez-Pereira, 1996; Trigo, 1998 y Muñoz et al., 2000), efecto que aunque no presente significación estadística puede apreciarse en la correlación positiva encontrada entre las lluvias acumuladas del año anterior y los pólenes totales de las 30 primeras semanas del año siguiente.

En las correlaciones bivariadas entre las lluvias diarias y las concentraciones polínicas, recogidas en la tabla 5.15., no hemos encontrado coeficientes con significación estadística. Por ello, hemos codificado los datos de lluvia diaria como variable dicotómica (llueve o no llueve), efectuando un análisis de la varianza, 
utilizando como factor esta nueva variable, encontrando diferencias con significación estadística para los valores medios de cada uno de los grupos, así la media de la concentración polínica en los días de lluvia es de 0,9 frente a 1,1 (valores estandarizados) los días que no llueve, figura 5.42 .

En un intento de ver el efecto de la intensidad de la lluvia sobre los valores de concentración de polen, se recodificó la variable lluvia en cuatro rangos, figura 5.43., encontrando diferencias con significación estadística entre el primer grupo cuando no llueve y el grupo uno (lluvias de menos de $5 \operatorname{litros} / \mathrm{m}^{2}$ y dia). Se produce un ligero aumento sin significación estadística para el grupo tres (lluvias de 5 a 29,9 litros $/ \mathrm{m}^{2}$ y día), y una posterior disminución en el valor medio para las lluvias mayores de 30 litros $/ \mathrm{m}^{2}$ y día, aunque el escaso valor de $\mathrm{N}$ en este grupo, hace que obtengamos un amplísimo intervalo de confianza para la media.

Norris-Hill y Emberlin (1993), señalan que en cuatro años de estudios aerobiológicos en Londres, encuentran días en los que los recuentos polínicos aumentan durante las lluvias, explicando este comportamiento como un efecto del aporte de polen desde las masas de aire enriquecidas, que se produce durante los primeros periodos del episodio, como consecuencia del arrastre de los granos de polen por las gotas de agua. El aumento correspondiente al grupo tercero ya comentado, de la figura 5.43., podría tener relación con los resultados aportados en este trabajo. Ha sido ya señalado que (Fornaciari et al., 1992) las concentraciones de polen se ven afectadas por los parámetros climáticos sólo en los días secos, registrándose un patrón de comportamiento anómalo en los días de lluvia.

\subsubsection{VARIABLES METEOROLÓGICAS Y CONCENTRACIONES POLÍNICAS DE CHENOPODIACEAE-AMARANTHACEAE.}

Los resultados que se obtienen para los coeficientes de correlación para las dos floraciones de este grupo, tabla 5.16., son similares a los que ya hemos comentado de los pólenes totales. En este caso, alcanza significación estadística la correlación positiva existente entre la temperatura media diaria y la concentración de polen. Cuando este análisis se ha repetido para las concentraciones de la segunda floración, tabla 5.17., sólo mantienen significación estadística las correlaciones entre la presión media y la 
humedad relativa, desapareciendo las que encontrábamos para los pólenes totales con la velocidad del viento y con la radiación solar acumulada, debiéndose esta pérdida de relación con la radiación solar acumulada a que nos encontramos en el mes de septiembre en el que se va a producir una disminución paulatina de la radiación solar a lo largo del mismo, mientras que va a tener lugar el aumento de las concentraciones de este polen en la primera quincena del mes y su posterior disminución.

Resultados similares a los encontrados por nosotros, para la temperatura media y la humedad relativa han sido referenciados por Muñoz et al., (2000a) para este tipo polínico en las ciudades de Badajoz, Mérida y Cáceres.

En la tabla 5.44. presentamos el ANOVA realizado para presiones atmosféricas menores o iguales a $1013 \mathrm{mb}$ o mayores, encontrando diferencias con significación estadística, correspondiendo los mayores valores a los días que tienen medias de presión por debajo de 1013. Este es el mismo resultado que hemos encontrado para los pólenes totales, y nuevamente consideramos que la situación de estabilidad atmosférica dificulta una buena dispersión de los granos de polen. Sólo en el trabajo de Glassheim et al. (1995), hemos encontrado referenciado la correlación bivariada entre la presión atmosférica y la concentración de quenopodiaceas, indicando un coeficiente de correlación de 0,08 sin significación estadística, resultando difícil contrastar la hipótesis que se plantea.

Las figuras 5.45. y 5.46. presentan el ANOVA efectuado para las variables RANGOSMI (obtenida a partir del análisis de las frecuencias con las que se dan las distintas velocidades a lo largo de cada día) y RANGOS (obtenida a partir de la velocidad media diaria). Aunque se observan diferencias para los diagramas de barras en los dos casos, en el primero de ellos el análisis de la varianza no da diferencia entre los grupos con significación estadística, en el segundo caso, existe diferencias entre grupos al 95\% de significación, encontrando los mayores valores de concentración para el rango 4, es decir, los días de mayores velocidades del viento.

En cuanto al ANOVA efectuado por rumbos del viento, no se han encontrado diferencias con significación estadística, entre los grupos, figura 5.47.

En el análisis de la varianza efectuado para la lluvia, cuando consideramos dos grupos, figura 5.48., encontramos un resultado opuesto al referenciado para los pólenes 
totales. Para la segunda floración de Chenopodiaceae-Amaranthaceae, los días de lluvia se obtienen mayores concentraciones medias de polen que para el conjunto de los días en que no llueve.

En la figura 5.49. se ha presentado el mismo análisis, dividiendo la lluvia en cuatro grupos, también obtenemos un ANOVA con diferencias entre grupos con significación estadística, observando un aumento en los valores medios conforme aumenta la cantidad de lluvia y un disminución en este valor para el rango cuarto, aunque el escaso número de veces en que se dan estos valores, originan un amplio intervalo de confianza. Para poder interpretar adecuadamente estos resultados, se requiere un análisis pormenorizado de las lluvias, y seguramente disponer de datos horarios de las concentraciones polínicas.

En general, el parámetro meteorológico más correlacionado con los niveles de polen en el aire es la temperatura (Fernández-González et al., 1993; Stark et al., 1997), otros parámetros meteorológicos relacionados con los niveles de polen son la humedad, la precipitación, el viento (Galán et al., 1995) y la radiación solar (Bringfelt et al., 1982). Son muchos los trabajos en los que se estudian en diferentes localidades las relaciones existentes entre los niveles de polen en el aire, bien en conjunto (Antépara et al., 1995; Trigo et al., 1997; Moreno-Grau et al., 1998) o por tipos polínicos (McDonald, 1980; Bringfelt et al., 1982; Galán et al., 1995; Herrero y Fraile, 1997; Díaz de la Guardia et al., 1998; Muñoz Rodríguez et al., 2000a), y la meteorología, encontrando variaciones entre años y entre distintas localizaciones. Las variaciones interanuales han sido atribuidas a situaciones meteorológicas diferentes (Mc Donald, 1980; Díaz de la Guardia et al., 1998; Muñoz Rodríguez et al., 2000a y b), aunque también se señalan como causas para estas variaciones las actividades humanas, que pueden modular las condiciones meteorológicas, en zonas cultivadas con irrigación (Muñoz Rodríguez et al., 2000b), modificar los patrones de crecimiento de las especies vegetales, incremento del uso de determinadas plantas ornamentales o disminuir las especies herbáceas silvestres, por un intenso desarrollo urbanístico (Elvira-Rendueles, 2001). 


\subsection{IDENTIFICACIÓN DE LOS FLUJOS DE VIENTO DOMINANTES EN LA CIUDAD DE CARTAGENA.}

Uno de los parámetros meteorológicos básicos para comprender la dispersión de los granos de polen en la atmósfera es el vector viento. Sin embargo, es muy difícil asignar correctamente un único dato de dirección y velocidad del viento a un día concreto, sobre todo en zonas de orografía compleja, próximas a masas de agua, en las que la meteorología local domina el campo de vientos y por lo tanto, son las brisas las que prevalecen frente a los patrones de circulación general, existiendo direcciones predominantes en dos cuadrantes opuestos, lo que se conoce como flujos y reflujos.

Uno de los elementos principales que debe ser incluido en la evaluación del impacto ambiental de la entrada de contaminantes en la atmósfera es la comprensión de las características climatológicas de la circulación sobre el área que rodea el punto de emisión, es decir, la descripción espacial y temporal del campo de advección que mueve los contaminantes. La clasificación de los campos del viento, nos permite describir los patrones de circulación bidimensionales sobre un cierto área, conocer su frecuencia y asociar cada situación local en una clase previamente identificada (Desiato, 1997).

Para este propósito, una herramienta válida es el análisis de cluster. Esta metodología ha sido utilizada previamente por varios autores, tanto para clasificación de situaciones meteorológicas (Crutcher et al., 1986; Stooksbury y Michaels, 1991), como para el estudio de la influencia de la meteorología en la contaminación atmosférica (Ibarra et al.,1993; Eder et al., 1994).

Las posibilidades que presenta la clasificación de los datos climatológicos para una mejor comprensión de los fenómenos atmosféricos, han convertido en los últimos años al análisis de clusters, con todas sus variantes, en una herramienta muy valiosa para evaluar la influencia del clima en una amplia serie de problemas medioambientales, relacionados fundamentalmente con la contaminación atmosférica, ya sea ésta de origen natural o antropogénico.

Así, uno de los objetivos de esta clasificación es la identificación de masas de aire homogéneas o ciertas situaciones meteorológicas tipo en una determinada zona, que pudieran servir para dar una mejor explicación del comportamiento o de los niveles de concentración de ciertos contaminantes en la atmósfera (Kalkstein y Corrigan, 1986). 
Los estudios de la variación temporal de los niveles de concentración atmosférica y su relación con la meteorología, han sido uno de los aspectos sobre los que más se ha investigado en los últimos años. Numerosos resultados han puesto de manifiesto que las emisiones, transporte, y difusión de algunos contaminantes del aire, están relacionados con algunos parámetros meteorológicos, tales como la temperatura, humedad, flujo de vientos dominantes, etc. (Eder et al., 1994).

En principio, cabe esperar que cada una de estas situaciones tipo va a llevar asociada un campo de concentraciones variable para los distintos contaminantes, siendo estas variaciones, dentro de cada situación tipo, mucho más pequeñas que las correspondientes a las de las condiciones de las fuentes emisoras, puesto que en los niveles de concentración registrados van a influir numerosas variables, como pueden ser los distintos regímenes de emisión, día de la semana, época del año, ubicación de las fuentes emisoras, abandono o implantación de nuevas plantaciones, etc.(Ibarra et al., 1993).

En el caso concreto de algunos contaminantes secundarios, que son el resultado de una serie de reacciones fotoquímicas, en las que también influyen los niveles de otros compuestos, la frecuencia e intensidad con que se producen las reacciones fotoquímicas, depende en gran medida de las condiciones meteorológicas reinantes durante un corto periodo de tiempo. De hecho, son numerosos los estudios que han puesto de manifiesto la dependencia de las concentraciones de ozono con determinadas condiciones meteorológicas que se presentan en un determinado periodo (Millán et al.,1986.; Pryor et al., 1995).

Algunos investigadores han puesto de manifiesto la dependencia de los niveles de algunos contaminantes en la atmósfera con la meteorología, pero en muchos de los casos, la clasificación de las condiciones climáticas, la han hecho basándose en criterios subjetivos, como son el análisis de los patrones de circulación general o tipos de masas de aire (Kelly et al., 1982; Comrie y Yarnd, 1992; Kassomenos et al., 1995).

Otros autores han analizado pormenorizadamente los datos meteorológicos correspondientes a una determinada zona y clasifican e interpretan los patrones dispersivos característicos para el área bajo estudio, como es el caso del Bajo Nervión, (Alonso et al., 1989, Millán et al., 1986), mediante el análisis diario de cada periodo de 
medidas de acuerdo con el comportamiento y la evolución de las masas de aire en la zona. Estableciendo la relación entre los tipos de información disponible y los efectos locales observados, de los que se desprende que para el área estudiada existe una discrepancia casi sistemática entre las condiciones meteorológicas sinópticas y las locales.

Otros autores (Albizuri et al., 1991) aplican la misma metodología para definir seis situaciones tipo en Cartagena, dos bajo vientos del suroeste, dos bajo vientos del noreste y los flujos locales de brisas tierra mar y viceversa.

Estudios más recientes, y con el fin de llegar a conocer lo mejor posible la relación existente entre meteorología y calidad del aire, y reducir así la varianza inexplicada a través de esquemas de clasificación subjetivos, han eliminado esa subjetividad empleada por el investigador en la clasificación de las condiciones meteorológicas, mediante el empleo de una técnica estadística de análisis multivariante, denominada análisis de cluster (Kalkstein et al., 1987; Eder et al., 1994 y Zelenka, 1997).

Son numerosos los trabajos en los que se ha utilizado esta técnica de cluster para clasificar determinadas condiciones meteorológicas o para la clasificación espacial de una amplia zona en regiones homogéneas desde el punto de vista climático, utilizando varias técnicas de clustering, como el método de Ward, Centroide y Promedio entre grupos, fundamentalmente, (Kalkstein y Corrigan, 1986; Kalkstein et al., 1987; Stooksbury y Michaels, 1991; Dorling et al., 1992; Dorling y Davies, 1995; Brankov et al., 1998).

Una técnica de clustering en dos pasos, ha sido empleada para este fin, con el objetivo de conseguir una mayor homogeneidad en los grupos finalmente obtenidos (Davis y Kalkstein, 1990a y b), de manera que el objetivo perseguido es conseguir una gran homogeneidad de las características dentro de cada uno de los grupos y las diferencias entre los distintos grupos sea la mayor posible.

En general, se efectúa un procedimiento de cluster en dos pasos, usando una técnica jerárquica, que permite decidir el número de cluster a extraer, seguida de una no jerárquica. Los métodos más comunes de agrupación jerárquica son muy numerosos, como se ha expuesto en el capítulo de antecedentes. Estas técnicas difieren en cómo se 
calculan las distancias entre las entradas y en cómo se definen las dos entradas más próximas. En función de la técnica seleccionada el número de cluster que finalmente se extrae difiere (Stooksbury y Michaels, 1991).

La elección de las variables que se introducen en el análisis es otro de los problemas que se plantean a la hora de aplicar estas metodologías. Stooksbury y Michaels (1991), utilizan 72 variables de los datos de superficie de las que las seis categorías de mayor importancia son: media de la temperatura máxima diaria para cada mes, media de la temperatura mínima diaria para cada mes, rango de la media de la temperatura diaria por mes, precipitación total cada mes, media mensual del número de días con precipitación significativa y un término del balance mensual hídrico.

En otros estudios, además de introducir datos meteorológicos tanto de superficie como de altura (Kalsktein et al., 1987; Eder et al., 1994 y Zelenka, 1997), y se efectúa antes del cluster en dos pasos un análisis de los componentes principales, generando como nuevas variables las puntuaciones factoriales de los casos, que constituyen las variables de entrada en el análisis de cluster, (Bisquerra, 1989).

El objetivo perseguido en este apartado, es la aplicación de esta técnica de clustering en dos pasos, a los datos del vector viento obtenidos en las distintas estaciones de la red meteorológica de la ciudad de Cartagena del año 1996, y perteneciente al Excmo. Ayuntamiento Cartagena, para identificar los distintos flujos de viento predominantes en la ciudad, que nos pudieran facilitar la comprensión de los niveles registrados para algunos contaminantes, así como su dinámica en la atmósfera, tal como se ha expuesto en el capítulo de materiales y métodos. Por otro lado, se pretende con la aplicación de esta técnica la identificación de los principales flujos de vientos dominantes en la zona, de forma que podamos crear nuevas variables que puedan ser valiosas en la construcción de los modelos predictivos, así como la construcción de modelos para cada una de las situaciones identificadas.

Nosotros hemos utilizado la metodología de análisis de cluster en dos pasos para clasificar los datos semihorarios del vector viento registrados en el año 1996 en las cuatro torres meteorológicas de medida ubicadas en la ciudad y su entorno, para la clasificación de éstos y así poder definir los flujos de viento característicos de la ciudad de Cartagena, que presenta una topografía bastante compleja. 
Como se ha comentado anteriormente, a partir del fichero inicial de datos semihorarios, registrados en cada una de las estaciones de medida, se ha construido un nuevo fichero que contiene como variables las coordenadas $V_{\mathrm{x}} \mathrm{y} \mathrm{V}_{\mathrm{y}}$ del viento en cada de las estaciones ( 8 variables), que constituyen las columnas. Como filas se han utilizado los registros de los datos a las horas 01, 07, 13 y 19, para cada uno de los días considerados, con lo cual al final se disponía de una total de 1464 filas, como queda reflejado en la tabla 5.20. De esta manera, cada uno de los valores de viento a cada una de estas horas y en cada una de las estaciones, constituía una situación independiente del resto. Se ha optado por abordar el problema de esta manera, por considerar que a lo largo de un mismo día pueden presentarse situaciones que pertenezcan a clusters distintos.

Sobre este fichero que se ha generado, se ha efectuado un análisis factorial, utilizando como método de extracción el de componentes principales. El criterio de extracción de factores ha sido gráfico, de manera que del análisis de sedimentación se ha decidido extraer 2 factores, que explican el 89,38 \% de la varianza total, como queda reflejado en la figura 5.20., valor éste que es bastante bueno si lo comparamos con otros encontrados en la bibliografía (Eder et al., 1994).

A partir de la matriz factorial, tabla 5.18., se han calculado las puntuaciones factoriales de todos los casos, sobre las que se ha realizado el análisis factorial en dos pasos. No se ha procedido a la tipificación de los valores, por considerar que como sólo se estaba trabajando con valores del vector viento, no era necesario.

Del análisis de cluster jerárquico por el método de vinculación promedio intragrupo (average linkage), se ha optado por elegir 5 clusters, siendo la distancia de combinación de 14. Una vez establecido el número final de clusters a retener por el método jerárquico, se ha aplicado un método no jerárquico (K-means) en el que los 1464 casos iniciales han quedado asignados como se muestra en la tabla 5.20. El 7,4\% de los datos iniciales han sido perdidos por el sistema, bien por falta de datos en alguna de las estaciones de medida o en otros casos por tratarse de datos no validados, tabla 5.20 .

Una vez establecidos los 5 clusters en base única y exclusivamente a los valores del vector viento en las cuatro torres de medida, se han combinado con el fichero que 
contenía el resto de parámetros meteorológicos registrados a esas mismas horas, con el fin de poder definir mejor las características de los clusters finalmente obtenidos, quedando todo ello recogido en las figuras 5.51. a 5.54.

También se ha procedido a la elaboración de rosas de vientos en cada punto de medida y para los datos de dirección del viento obtenidos en cada punto, dividiendo para ello las distintas direcciones en 12 rumbos, cada uno de ellos de una amplitud de $30^{\circ}$, así como las tablas de frecuencias de las direcciones y velocidades del viento para cada clusters, presentado todo en las figuras 5.55. a 5.59. y tablas 5.21. a 5.30.

Del análisis de los casos pertenecientes a cada uno de los 5 clusters finalmente establecidos, de los valores medios de algunos parámetros meteorológicos y de las rosas de los vientos obtenidos para cada uno, se deduce que:

- El cluster 1 agrupa un total de 95 casos (6,5\% de los casos analizados). Recoge fundamentalmente situaciones de altas presiones $(71,6 \%)$, con humedad relativa media (55-66\%), elevada radiación solar, sin precipitaciones y temperaturas medias moderadas $\left(17,65{ }^{\circ} \mathrm{C}\right)$. Por los valores de temperatura registrados, así como los valores de radiación solar, parece presentarse durante el otoño e invierno principalmente. Las velocidades del viento son intermedias y los casos corresponden a situaciones que se repiten casi con la misma frecuencia durante el día que durante la noche. De las rosas de vientos de la figura 5.55., se observa que las direcciones predominantes son NNW y Norte en todas las estaciones.

- En el cluster 2, se recogen un total de 361 casos $(24,7 \%$ del total). Se presentan fundamentalmente bajo situaciones anticiclónicas, con una elevada humedad relativa media $(80 \%)$, lluvias muy escasas, temperatura media elevada $\left(21,56^{\circ} \mathrm{C}\right) \mathrm{y}$ elevada radiación solar. Podría presentarse fundamentalmente durante los meses de otoño y primavera por los valores registrados de los parámetros meteorológicos más importantes. Estos casos se presentan fundamentalmente durante el día. De las rosas de vientos de la figura 5.56., se deduce que en este cluster las direcciones predominantes del viento son SSW y Sur.

- En el cluster 3, se incluyen 106 casos (7,2\% del total). Son situaciones de bajas presiones que se presentan conjuntamente con las máximas velocidades del viento registradas en la ciudad. Ausencia de lluvias, humedad relativa media (72-81\%), 
radiación solar media y temperaturas medias relativamente moderadas $\left(18,93{ }^{\circ} \mathrm{C}\right)$. Estos casos se presentan durante el día y la noche, aunque con una mayor frecuencia durante el día. Las direcciones del viento que aparecen en la figura 5.57., muestran que la dirección predominante es SSW.

- En el cluster 4 se recogen 213 casos (14,5\% del total). Predominan las situaciones de altas presiones, aunque es este cluster el que recoge fundamentalmente las precipitaciones caídas durante este año en Cartagena, fenómeno que puede deberse a lluvias torrenciales, puesto que este cluster viene acompañado de las máximas temperaturas y radiación solar registradas a lo largo del año, por lo que parece que se presenta fundamental durante la estación veraniega. La humedad relativa media es bastante elevada. La dirección del viento predominante en este cluster es la de Norte y NNE, lo que justificaría que estas masas de aire proveniente del Levante, y obligadas por la topografía a adoptar estas direcciones, fueran las causantes de las lluvias registradas durante estas situaciones, figura 5.58.

- En el cluster 5, se han registrado 580 casos (39,6\% del total). Se corresponden con las menores velocidades del viento, que podríamos denominar calmas y en las que podríamos englobar las brisas mar-tierra y viceversa, así como ciertas situaciones que podríamos denominar de transición. Se presentan las mayores humedades relativas medias (84-91\%), lluvias escasas y situaciones de altas presiones fundamentalmente. Esta situación se da fundamentalmente durante la noche y para ser más exactos durante las últimas horas de la noche y primeras de la mañana, de manera que la radiación solar registrada en estos casos es la menor de todos los clusters obtenidos. La dirección del viento predominante en este cluster, al ser el de más bajas velocidades, no queda definida tan claramente como en los casos anteriores, puesto que en estos casos la topografía juega un papel condicionante para los flujos del viento, figura 5.59.

\subsection{IDENTIFICACIÓN DE LOS FLUJOS DE VIENTO DOMINANTES EN LA CIUDAD DE CARTAGENA PARA LOS AÑOS 1995-1997.}

Mediante el análisis del cluster en dos pasos se han clasificado 5 situaciones meteorológicas diferenciadas, a las que se asocian comportamientos 
específicos de los vientos, similares para cada una de las estaciones incluidas en el estudio.

A la vista de los resultados obtenidos, que concuerdan bastante bien con los obtenidos por otros autores para la ciudad de Cartagena (Enviroment and Systems, 1989; Moreno-Grau, 1998), aunque en este caso sólo se haya trabajado con datos de viento para efectuar tal clasificación, consideramos correcta la clasificación obtenida, siendo los centros finales de los conglomerados obtenidos para el año 1996, tabla 5.32., los que se han utilizado como centros iniciales para los conglomerados finales. En la tabla 5.33. aparecen los valores de los centros de los conglomerados que se han utilizado para la clasificación del conjunto de los datos, la tabla 5.34. recoge los casos incluidos en cada cluster.

En el fichero de los datos de viento semihorarios seleccionados para la obtención de los clusters, se ha generado una nueva variable que asigna cada dato a un tipo de cluster. A partir del análisis de las frecuencias con que cada cluster aparece en un determinado día, se han generado nuevas variables, la primera llamada cluster, asigna uno de los cinco conglomerados encontrados a un día. De modo paralelo, se han generado cinco variables denominadas C1 a C5 que recogen el porcentaje de pertenencia de cada día a cada cluster.

En las figuras 5.60. a 5.65. se recogen para cada uno de los clusters el comportamiento de los datos meteorológicos, que nos ha permitido verificar los resultados de la primera clasificación, anteriormente comentados.

En la figura 5.66. se recoge la concentración polínica total media estandarizada para cada cluster y el intervalo de confianza al 95\% y en la tabla 5.45., el análisis de la varianza por la variable cluster, observándose diferencias con significación estadística entre grupos, lo que indica que los clusters recogen campos de concentraciones distintos. La figura 5.67., recoge los valores medios con el intervalo de confianza al $95 \%$ de la concentración polínica total estandarizada en el conjunto de los años 1995-1999, para cada cluster, en cada una de las estaciones del año.

Consideramos que la variable cluster recoge la influencia del campo de vientos y puede ser aplicada en los estudios de las concentraciones polínicas y es una variable más fácil de manejar en estudios estadísticos o en la modelización predictiva que la variable dirección del viento. Por lo que, como luego veremos, la hemos utilizado en el desarrollo de los modelos lineales predictivos. 


\subsection{MODELOS PREDICTIVOS: MODELOS DE REGRESIÓN MÚLTIPLE.}

Como hemos podido observar anteriormente, las concentraciones diarias de polen varían de día en día de acuerdo con los ritmos de floración de las plantas y la influencia de la meteorología. Una adecuada predicción de estas variaciones permitiría a las personas sensibles poner en marcha las acciones preventivas para evitar los síntomas de la polinosis (Bringfelt et al., 1982; Antépara et al., 1995; Norris-Hill, 1995; Dahl y Strandhede, 1996) o predecir el crecimiento futuro de especies de interés económico, usando la cantidad de polen emitida a la atmósfera (Fornaciari et al., 1998). Los distintos grupos de aerobiólogos, realizan esfuerzos notables por construir modelos predictivos que puedan ser utilizados como herramienta en los distintos campos en los que esta disciplina tiene aplicación.

Esta línea de trabajo, no sólo se produce en los estudios aerobiológicos, sino que en los últimos años la calidad del aire ha sido señalada como uno de los factores que de modo más importante contribuyen a la calidad de vida en las áreas urbanas, especialmente en las zonas densamente pobladas y en áreas industrializadas (Kolehmainen et al., 2001), zonas para las que se ha indicado un aumento de la sintomatología alérgica (Schäppi et al., 1996; D’Amato et al., 2000), habiéndose producido un incremento notable de la modelización estadística de los datos de calidad del aire, frente a los modelos determinísticos tradicionales (Kolehmainen et al., 2001).

Una primera forma de acercarse a este problema es el desarrollo de modelos de regresión lineal, en el que intervengan las variables meteorológicas más relacionadas con la concentración de polen (Emberlin et al., 1993; Stark et al., 1997; Galán et al., 1995 y 2000). En este estudio, hemos desarrollado modelos predictivos basados en la regresión lineal de los datos diarios estandarizados de polen total de las primeras 30 semanas del año y de los datos diarios estandarizados de la segunda floración del tipo ChenopodiaceaeAmaranthaceae, con los datos de 1995 a 1998, separando los datos del año 1999, para la validación de los modelos obtenidos.

Hemos decidido realizar el estudio por separado de estos dos subgrupos, ya que de esta manera para el primero de los casos, abordamos la modelización 
de un comportamiento complejo por darse en estas primeras 30 semanas del año, de modo conjunto, las floraciones de la mayor parte de los diferentes tipos polínicos que se han identificado en la atmósfera de Cartagena. El segundo subgrupo, por el contrario, permite desarrollar modelos predictivos sobre un tipo polínico concreto, cuyo periodo de polinización es muy homogéneo, y que es el responsable en un porcentaje muy importante, de la concentración polínica total registrada en ese periodo.

Nuestros primeros modelos de regresión lineal múltiple, se centraron en la selección de las variables meteorológicas con una mayor correlación con las concentraciones polínicas, y con los datos de los años 1994 a 1996, obtuvimos el mejor modelo que consideraba la lluvia, la humedad relativa y la radiación solar, con un coeficiente de determinación de 0,22 (Moreno-Grau et al., 1998).

Cuando se repite este planteamiento para el conjunto de los datos 19951998, centrándonos en las 30 primeras semanas del año, el mejor modelo, recogido en la tabla 5.47., sólo alcanza un coeficiente de determinación de 0,17 $(\mathrm{R}=0,41)$. El porcentaje de la varianza inexplicado es muy alto, y aunque coeficientes de correlación de este orden de magnitud se encuentran en la bibliografía (Bringfelt et al., 1982; Galán et al., 1995), consideramos que es necesario profundizar en la selección de las variables para explicar mayores porcentajes de la varianza total.

Parece lógico admitir que la concentración polínica en un determinado día también tendrá una gran relación con la concentración existente el día anterior, al igual que la temperatura de un día estará muy correlacionada con la temperatura del día anterior, etc. Este enfoque nos llevó a generar variables de retardo tanto de las concentraciones polínicas como de las variables meteorológicas e introducirlas en los modelos lineales múltiples.

Como fase previa se incorporó la correlación existente de estas nuevas variables y la variable dependiente, introduciendo como variables predictivas aquellas que arrojaron correlaciones estadísticamente significativas. Como se ha indicado en el capítulo de materiales y métodos, el procedimiento fue de pasos sucesivos, y cuando se introducen las variables que hemos denominado de autocorrelación, aumentan de modo importante los coeficientes de determinación obtenidos $\left(\mathrm{R}=0,73 \mathrm{y} \mathrm{R}^{2}=0,54\right)$, siendo las variables seleccionadas para el mejor de los modelos el polen del día anterior, la humedad 
relativa mínima, la humedad relativa del día anterior, el polen de tres días antes, la velocidad media del viento, la diferencia de temperatura máxima y mínima de seis días antes y la de cuatro días antes. Los resultados de estos modelos de regresión se presentan en las tablas 5.50. a 5.52.

Hasta el momento no habíamos incorporado en los modelos la dirección del viento, por lo que el paso siguiente fue la introducción en los modelos de la información relativa a los vientos, como variables categóricas, tanto de velocidad (RANGOS) como de dirección (RUMBOS). Aunque una de estas nuevas variables es introducida en los modelos (tablas 5.53. a 5.55.), no genera una mejora sustantiva en el coeficiente de determinación $\left(\mathrm{R}=0,74 \mathrm{y}^{2}=0,54\right)$.

El siguiente paso, fue realizar los modelos de regresión múltiple para la concentración polínica total estandarizada subdividiendo los datos de partida, en función del cluster al que habíamos asignado cada día. Los resultados se encuentran en las tablas 5.56. a 5.70. Podemos observar que para los conglomerados uno, tres y cinco, se obtienen mejoras en la varianza explicada por los modelos, así para el cluster 1 obtenemos valores de $\mathrm{R}=0,83$ y de $\mathrm{R}^{2}=$ 0,69 . Para el cluster $3, \mathrm{R}=0,77$ y $\mathrm{R}^{2}=0,60$, y para el cluster $5, \mathrm{R}=0,77$ y $\mathrm{R}^{2}=$ 0,60 , mientras que para el cluster 2 , obtenemos $\mathrm{R}=0,72$ y $\mathrm{R}^{2}=0,52$ y en el cluster 4 , se obtienen peores resultados con un $\mathrm{R}=0,68$ y $\mathrm{R}^{2}=0,46$.

Otro aspecto a destacar de la división por la variable cluster, es que salvo para el modelo correspondiente al cluster 5 , se produce una disminución importante en el número de variables predictoras, así par el cluster 1, 2 y 4 tenemos tres variables, para el cluster 3, 4 variables y para el cluster 5, 7 variables.

Con el fin de validar los modelos predictivos obtenidos, se predijeron los datos del año 1999, tanto en su conjunto como separados por conglomerados. Las figuras 5.68. y 5.69. y la tabla 5.72., muestran el resultado de esta validación. En la primera de ellas, se muestran las predicciones frente a las concentraciones reales, obteniendo un buen ajuste, tal como puede verse en la tabla 5.72., el coeficiente de correlación entre ambas variables es de 0,97 con una significación del $99 \%\left(\mathrm{R}^{2}=0,95\right)$, se han calculado los estadísticos $\mathrm{F}$ y $\mathrm{t}$ para el test de diferencias de varianzas y de medias, no pudiendo rechazar la hipótesis nula de igualdad en ninguno de los dos casos. El análisis del gráfico P-P (figura 5.69.), indica también la bondad del ajuste. 
Cuando se predicen los valores de la variable dividida por los valores de los conglomerados a los que pertenece el día, se obtienen buenas predicciones con coeficientes de correlación que en ningún caso alcanzan el valor encontrado para el conjunto de los datos, pero también significativas al 99\% para los cinco conglomerados, encontrando la principal ventaja de esta división en el menor número de variables predictivas que hay que utilizar, salvo para el cluster 5. Las pruebas de diferencias de medias y de varianzas no permiten rechazar la hipótesis nula de igualdad de las mismas, salvo en el cluster 4, donde se rechaza para la diferencia de varianzas. Los gráficos P-P, de regresión de los residuos tipificados, muestran un adecuado ajuste para todos los conglomerados.

A la vista del conjunto de los modelos de regresión múltiple lineal elaborados, consideramos suficiente la introducción de las variables meteorológicas y las de autocorrelación, aunque puede mejorar el análisis, en algunos casos, con la introducción en los modelos de variables categóricas, como los rangos y rumbos del viento o la clasificación de los días en función de los flujos de viento.

Hemos repetido el mismo procedimiento para el segundo pico del tipo polínico Chenopodiaceae-Amaranthaceae. En la tabla 5.78. se presentan las correlaciones bivariadas de Pearson entre los datos de esta segunda floración y las variables meteorológicas y las relacionadas, con las que se ha trabajado. Sólo las variables que muestran una correlación significativa con la variable dependiente han sido utilizadas en los modelos de regresión múltiple.

La tabla 5.79. recoge el resumen de los modelos de regresión múltiple, siendo las variables independientes directamente las variables meteorológicas. El mejor de los modelos alcanza un coeficiente de correlación de 0,24. Al introducir las variables de autocorrelación, aumenta el coeficiente de correlación hasta 0,78 (tabla 5.82.), y el coeficiente de determinación 0,61. El mejor de estos modelos, incluye la concentración de este grupo estandarizada del día anterior y de tres días antes, además de la presión atmosférica máxima para ese día. Para el segundo pico de las quenopodiáceas, el introducir variables categóricas que expresen el comportamiento de los vientos, tabla 5.85., no supone una mejoría en cuanto a los parámetros del modelo, cabe destacar que en este caso el mejor modelo no incluye ninguna variable meteorológica, requiriéndose únicamente las concentraciones estandarizadas del polen del día anterior y de tres días antes. 
Cuando se hacen los modelos de regresión múltiple para cada uno de los conglomerados en los que se han clasificado los días, se obtienen mejores ajustes para los clusters dos $\left(\mathrm{R}=0,83\right.$ y $\left.\mathrm{R}^{2}=0,68\right)$ y tres $\left(\mathrm{R}=0,92\right.$ y $\left.\mathrm{R}^{2}=0,84\right)$, los conglomerados uno $\left(\mathrm{R}=0,63\right.$ y $\left.\mathrm{R}^{2}=0,40\right)$, cuatro $\left(\mathrm{R}=0,74\right.$ y $\left.\mathrm{R}^{2}=0,55\right)$ y cinco $\left(\mathrm{R}=0,73\right.$ y $\left.\mathrm{R}^{2}=0,54\right)$, ofrecen ecuaciones predictivas que explican un porcentaje de la varianza similar al obtenido con el conjunto de los datos.

La validación con los datos del año 1999, sólo se ha efectuado para el modelo de regresión general, cuya fórmula se recoge en la ecuación 5.7., presentando los resultados en los gráficos 5.80. y 5.81. y la tabla 5.103., dado el bajo valor del número de datos para alguno de los conglomerados. El gráfico de dispersión muestra el ajuste de los datos, para el que se obtiene un coeficiente de correlación de Pearson de 0,83 , con significación al $99 \%\left(\mathrm{R}^{2}=0,68\right)$, el gráfico P-P de los residuales contribuye a probar la validez del ajuste.

Una parte importante de los trabajos en los que se aplican modelos de regresión lineal están encaminados a predecir el inicio de la estación polínica para algún tipo en concreto (Frenguelli et al., 1989; Driessen et al., 1990; Forniaciari et al., 1998). En este tipo de modelos, la temperatura en el aire en el periodo que precede el inicio de la polinización, es de gran importancia, así en polen de olivo el mejor modelo para predecir el inicio de la floración en Perugia y Ascoli Piceno es la media de las temperaturas máximas diarias del mes de mayo (Frenguelli et al., 1989). En el suroeste de España (Huelva), el mejor modelo se obtiene con la media de la temperatura de febrero y marzo (GonzálezMinero et al., 1996). En Perugia (Forniciari et al., 1998), encuentran un modelo predictivo para el retardo en la polinización que depende de un índice de polen, de la temperatura media del mes de febrero y de la lluvia total en mayo.

Estos mismos modelos efectuados para Poaceae, introducen la media de la temperatura máxima diaria de los meses de marzo y abril, en las ciudades de Perugia y Ascoli Piceno (Frenguelli et al., 1989), o el valor de la temperatura media acumulada desde el uno de marzo hasta el 30 de mayo, por encima de $9^{\circ} \mathrm{C}$ en un estudio realizado en Bilbao en los años 1987 a 1989 (Antépara et al., 1995).

Otros investigadores, centran su interés en conocer la duración y severidad de la polinización. La duración de la estación se define como el periodo de tiempo en el que se recoge el $98 \%$ del total de polen (Emberlin et al., 
1993). En estos trabajos, además de la importancia de la temperatura, aparece como variable predictiva la lluvia acumulada en determinados periodos, así en Bilbao (Antépara et al., 1995), la lluvia acumulada al principio y durante la polinización son dos variables de influencia junto con la temperatura acumulada. En Londres, la precipitación total de junio se incluye en los modelos de duración de la estación, junto con la temperatura acumulada de junio y las temperaturas acumuladas del uno de enero al 30 de abril y la de mayo, junto con el día en el que se alcanza el 75\% de los pólenes de la estación (Galán et al., 1995).

Un tercer grupo de modelos de regresión, pretenden conocer la evolución diaria de las concentraciones polínicas. Un gran número de los trabajos se centran se centran en tipos polínicos concretos, así Emberlín et al., (1993), predicen el total acumulado de Poaceae, a partir del día en el que se alcanza el $75 \%$ del total y las temperaturas acumuladas de marzo, abril, mayo y junio, y la lluvia de junio, explicando el 66,3\% de la varianza de los datos.

En un estudio comparativo de las variaciones diarias de gramíneas en las ciudades de Córdoba y Londres (Galán et al., 1995), se presentan modelos que para la ciudad de Londres comprenden los años 1987 a 1991, alcanzando para esta ciudad con los totales coeficientes de correlación de 0,27 , siendo las variables independientes la temperatura media y la radiación solar. Con los datos de pólenes de gramíneas, de la ciudad de Córdoba de los años 1982 a 1986, se consigue un modelo de regresión lineal con un coeficiente de correlación de 0,13 y las variables independientes temperatura máxima diaria y radiación solar. Cuando se repite este estudio centrando el análisis en el periodo hasta que se alcanza el máximo, los modelos obtenidos en ambas ciudades para el total de los años estudiados presentan coeficientes de correlación de 0,40 para Londres, con la temperatura máxima como variable independiente, y de 0,38 para Córdoba, siendo en este caso las variables independientes la temperatura mínima, la radiación solar y la humedad relativa.

Recio et al. (1996), desarrollan un modelo predictivo para el polen de olivo en Málaga con datos de 1992 a 1994, mediante una ecuación de regresión simple, en el que la variable independiente es la temperatura media acumulada desde la aparición de las yemas florales, obteniendo un $\mathrm{R}^{2}$ de 0,61 .

En el trabajo de Dahl y Strandhede (1996), se presentan modelos predictivos de la intensidad de la estación del polen de Betula, encontrando para 
la ciudad de Malmö modelos que explican hasta el 78,5\% de la varianza del polen acumulado, introduciendo como variables independientes dos sumas de temperaturas y la suma total de polen durante el año precedente. En este sentido, el efecto de autocorrelación presente en los datos de polen e inherente a las variables temporales (Comtois, 2000), debe ser tenido en cuenta en el desarrollo de modelos predictivos. Este planteamiento se ha abordado en otros estudios de contaminantes atmosféricos, cuando se plantea el análisis de series temporales para datos ambientales (Scheff, 2000).

Así, Galán et al., (2000), desarrollan modelos predictivos para las concentraciones polínicas diarias de Urticaceae en el sureste de España con datos de los años 1996 y 1997. Es de resaltar que el mejor de los modelos que obtienen sólo para el año 1997, con un coeficiente de determinación de 0,60, considera como variables independientes la temperatura media diaria y la concentración polínica del día anterior, sobre todo para aquellos días en los que la lluvia no es muy elevada. Ya ha sido indicado que la concentración de polen se ve afectada por todos los parámetros climáticos sólo durante los días secos, un patrón anómalo se observa durante los días de lluvia (Forniaciari et al., 1992).

Como ya hemos indicado, nuestros modelos mejoran sensiblemente cuando se introducen variables de retardo de los datos polínicos y meteorológicos, siendo la variable de la concentración polínica del día anterior la que se encuentra más fuertemente correlacionada con la variable dependiente, influyendo poco en el análisis de regresión las variables construidas en este estudio para introducir el efecto de los vientos sobre la concentración polínica.

En los resultados presentados, no se ven diferencias importantes entre estudiar el comportamiento de los pólenes totales y un tipo polínico específico. Por ello, en los distintos modelos estadísticos que se han desarrollado a partir de este punto, hemos considerado sólo la concentración polínica total para el periodo estudiado.

Otro aspecto a destacar aquí, es el poco margen temporal en las predicciones efectuadas por estos modelos, ya que requieren datos del día anterior para definir la concentración de un día, por lo que los beneficios mayores de la modelización, que se encuentran ligados a conocer con antelación suficiente un determinado fenómeno, lo que permite adoptar las acciones oportunas, bien la toma de medidas profilácticas, el inicio de la medicación, 
ordenar determinadas prácticas agrícolas, tratamientos fitosanitarios, o bien medidas relacionadas con la gestión ambiental, no se van a conseguir.

\subsection{MODELOS DE REGRESIÓN LOGÍSTICA.}

Los problemas comentados al finalizar el punto anterior, nos han llevado a plantear otra perspectiva dentro de los modelos estadísticos. Partiendo de estudios epidemiológicos en los que a partir de los años 60 se generalizó el uso de los modelos logísticos, que resultan útiles para los casos en los que se desee predecir la presencia o ausencia de una característica o resultado, a partir de un conjunto de variables de predicción, numéricas o categóricas (Bayo, 1998; Cooper-Arnold et al., 1999; Bortkiewicz et al., 2001).

Los modelos de regresión logística se han abordado para las concentraciones polínicas totales registradas a lo largo de todo el año, para el periodo de 1995 a 1998, y nos ha permitido estimar la probabilidad de que en un día del año se alcancen concentraciones polínicas por encima o por debajo de un valor inicialmente fijado por nosotros (variable dependiente dicotómica), a partir de los valores numéricos o categóricos de las diferentes variables introducidas en el modelo (variables dependientes).

Este planteamiento puede ser especialmente útil en el caso de las concentraciones polínicas, ya que se han señalado en la bibliografía diferentes valores umbrales a partir de los cuales aparece sintomatología polínica (Rantio-Lentimaki et al., 1991; Antépara et al., 1995; Subiza et al., 1995; Ong et al., 1995).

Un inconveniente con el que nos hemos encontrado en el desarrollo de este tipo de modelos, ha sido la falta de un criterio unánime, por parte de los investigadores que trabajan en este campo, que nos permitiera definir con precisión el valor de concentración polínica a partir del cual, los pacientes sensibles pudieran manifestar algún síntoma. Así, Ong et al.(1995), afirman que el número de granos de polen en el aire para que se manifiesten los síntomas se sitúan entre 10 y 50; Rantio-Lehtimaki et al.(1991), comentan que al principio de la estación polínica, valores de por encima 30 granos $/ \mathrm{m}^{3}$, son suficientes para aparición de síntomas nasales; mientras que Antépara et al. (1995), afirman que concentraciones polínicas superiores a 37 granos $/ \mathrm{m}^{3}$ son 
suficientes para producir síntomas moderados o severos en la totalidad de los pacientes sensibles.

La Asociación Española de Alergia e Inmunología (2001), indica que para el caso de Poaceae, el $100 \%$ de los pacientes clínicamente sensibles presenta sintomatología por encima de los 50 granos $/ \mathrm{m}^{3}$, cifra que también indican Subiza et al.(1995).

Frankland (1996), indica que cuando las concentraciones medias diarias que obtenía en Londres con su spore-trap, eran $>50$ gramíneas $/ \mathrm{m}^{3}$, todos los pacientes clínicamente sensibles a las gramíneas, y residentes en ese área, presentaban síntomas, considerando a esta cifra como alta (no como umbral, ya que muchos pacientes experimentaban síntomas con $<20$ ).

Por todo ello, hemos decidido utilizar como valor de corte de la variable dicotómica la media aritmética de las concentraciones polínicas totales estandarizadas, que expresado como granos de polen por metro cúbico de aire, es una cifra entorno a 40 granos $/ \mathrm{m}^{3}$, valor que consideramos adecuado con lo referenciado en la bibliografía consultada.

Aunque no hemos encontrado en la bibliografía modelos logísticos aplicados a la predicción en Aerobiología, nos ha parecido una herramienta útil, ya que nos van a permitir determinar la probabilidad de que un día concreto se encuentre por encima o por debajo de un valor umbral fijado como desencadenante de los síntomas, a partir de variables predictoras a las que se asocia un factor de protección o de riesgo determinado.

Los modelos de regresión logística han sido utilizados para predecir la presencia o ausencia de especies en un determinado lugar, en relación con variables de hábitat o ambientales. Así, se han utilizado ampliamente para predecir la presencia y el uso del hábitat por especies de vertebrados en peligro y plantas vasculares, para examinar las respuestas de las especies ante perturbaciones ambientales, etc. (Pearce y Ferrier, 2000).

También han sido utilizados en estudios epidemilógicos, tanto en población general, como en estudios aplicados en Higiene Industrial. Aplicando esta metodología se han analizado los factores de riesgo implicados en la caries de dientes (Domínguez 
Rojas et al., 1993) y enfermedades peridontales (Sterne et al., 1990). Análisis de regresión logística han permitido ajustar por edad y hábito tabáquico los síntomas entre población trabajadora de la madera (Udeni Alwis et al., 1999).

En un estudio comparativo de los métodos de predicción: regresión lineal múltiple, regresión logística y el método de regresión de Cox (Walter et al., 1990), señalan que no se presenta ninguna superioridad remarcable para los distintos métodos examinados, por lo menos, con respecto a la selección de las variables de pronóstico más relevantes. En cambio, si encuentran notables diferencias en el orden en el que se seleccionan las variables y los coeficientes estimados.

Nosotros hemos utilizado el método del paso hacia delante. En la tabla 5.104., se presenta el resumen de los casos introducidos en el modelo de regresión logística a partir de los datos de concentraciones polínicas estandarizadas de los años 1995 a 1998, categorizadas tal y como se presenta en la tabla 5. 105.

En la tabla 5.106., se presenta la prueba omnibus sobre los coeficientes del modelo, en los que podemos destacar que el p-valor asociado al estadístico Chicuadrado, es menor que 0,05 para cada uno de los pasos, por lo que se rechaza la hipótesis nula de que la mejora no es significativa. Por otro lado, el p-valor asociado al estadístico Chi-cuadrado para cada uno de los modelos es también menor a 0,05 , por lo que se rechaza la hipótesis nula de que los parámetros asociados a las variables generadas a partir de los valores iniciales sean nulas, (Ferrán-Aranaz, 2001).

Los coeficientes de los estadísticos presentados en la tabla 5.107., $\mathrm{R}$ cuadrado de Cox y Snell y R cuadrado de Nagelkerke, juegan un papel similar al de los coeficientes de determinación en el modelo de regresión lineal, y tratan de cuantificar mediante un valor entre cero y uno, la bondad del ajuste. El primero de ellos, se basa en la comparación de la verosimilitud del modelo final con la del modelo inicial, que sólo incluye la constante, presentando el inconveniente de que no alcanza la cota superior del uno. El segundo, consiste en una corrección del anterior, tal que dicha cota pueda ser alcanzada (Ferrán-Aranaz, 2001). En nuestro caso, el valor obtenido en el paso 5, para la R cuadrado de Nagelkerke es de 0,624 , por lo que podría interpretarse como que el modelo de regresión logística explica el comportamiento de la variable dependiente POLESTDI al 62,4\%. 
La clasificación de los individuos en uno u otro grupo, se realiza a partir de la probabilidad estimada de pertenecer al segundo grupo. Si, para un determinado individuo la probabilidad de pertenecer a la segunda subpoblación es mayor o igual que 0,5 , será clasificado en dicha subpoblación. En caso contrario, quedaría clasificado en la primera. El porcentaje de casos correctamente clasificados será un índice de la efectividad del modelo.

En la tabla 5.108., se presenta la tabla resumen del proceso de clasificación seguido para la construcción de los modelos. Podemos observar como mejora el porcentaje de casos correctamente clasificados, hasta alcanzar aproximadamente un $85 \%$ de clasificaciones correctas. Con el fin de seleccionar un modelo de fácil aplicación y que no incluya variables redundantes, hemos seleccionado el modelo número 5, que incluye la semana del año, la temperatura máxima diaria, diferencia entre la temperatura máxima y mínima de cinco días antes, que clasifica correctamente el $84,7 \%$ de los casos.

En el análisis de la tabla 5.109., la columna EXP (B), puede interpretarse como los factores de protección o de riesgo, de tal manera que un valor de este coeficiente menor a la unidad indicará el carácter protector de esta variable, mientras que un valor mayor a la unidad indicará un factor de riesgo. Así, la semana 19, presenta un alto factor de riesgo, para conseguir valores de pólenes por encima del valor de corte que hemos utilizado. Hay que destacar que las variables TMAX Y AT5, también constituyen factores de riesgo sobre las concentraciones polínicas que podamos encontrar.

Este modelo, permite conociendo la semana del año en la que nos encontramos y con las previsiones de temperatura máxima y mínima, definir la probabilidad de estar por encima o por debajo del valor de corte establecido, y por lo tanto, la de pertenecer a una de las dos subpoblaciones. Consideramos, que la aplicación de este tipo de modelos a los datos polínicos puede ser útil, y constituir una alternativa valiosa a otro tipo de modelos predictivos.

Una vez comprobado que, mediante la función estimada a partir de los valores de las variables SEMANA, TMAX y AT3, el porcentaje de casos perfectamente clasificados es elevado, cabe esperar que la función también proporcione buenos resultados a la hora de predecir la pertenencia a una de las dos subpoblaciones de la 
variable dependiente. Para ello, hemos utilizado los datos de las variables dependientes del año 1999, seleccionadas en el modelo anteriormente comentado, se han estimado nuevamente los coeficientes de la función y se han pronosticado las probabilidades y el grupo de pertenencia de cada uno de los casos, para este año 1999.

En las tablas 5.110. a 5.115., se presentan los resultados de esta predicción, alcanzando un porcentaje correcto de clasificación del 92,3\% (tabla 5.114.), explicando el $80,5 \%$ de la variabilidad de las concentraciones polínicas del año 1999, como refleja el estadístico R cuadrado de Nagelkerke (tabla 5.113.).

\subsection{MODELOS ARIMA PARA LAS CONCENTRACIONES POLÍNICAS MEDIAS SEMANALES 1993 A 1998.}

Aunque el procedimiento más generalizado para realizar programas de predicción de concentraciones de polen aerovagante es el análisis de regresión, al estar autocorrelacionadas las concentraciones diarias de polen, no sólo está indicado emplear análisis de regresión, sino también probar las técnicas de modelización de series temporales en este campo (Moseholm et al., 1987).

Cuando una secuencia de observaciones es tomada en una unidad experimental, un determinado lugar en un determinado tiempo, la suposición de independencia, espacial y temporal, se viola frecuentemente. La elección del intervalo de muestreo y el tiempo de promedio de la muestra es muy importante (Scheff, 2000). Los componentes de una serie temporal son las observaciones ordenadas, tendencias, patrones estacionales o cíclicos y fluctuaciones aleatorias. La tendencia es un cambio de la media a largo plazo; el patrón estacional o cíclico son oscilaciones en la tendencia, debidas a causas periódicas y las fluctuaciones aleatorias, son las oscilaciones debidas al azar, también denominadas ruido blanco. Las series temporales que se mantienen en el mismo nivel se denominan estacionarias (Bizquerra, 1989).

Las variaciones cíclicas a veces se superponen a una tendencia, las series temporales con tendencia y variaciones cíclicas o estacionales, pueden representarse mediante modelos ARIMA $(p, d, q)(\mathrm{P}, \mathrm{D}, \mathrm{Q})$, siglas de los modelos autorregresivos integrados de medias móviles, que permite describir un valor como una función lineal 
de datos anteriores y errores debidos al azar (Bizquerra, 1989). El primer paréntesis se refiere a la tendencia o parte regular, el segundo a las variaciones estacionales o parte cíclica.

En las figuras 5.82. a 5.91. y tablas 5.116. a 5.117., se han presentado los resultados del modelo ARIMA desarrollado para las medias semanales de las concentraciones polínicas de los años 1993 a 1998. El primer paso en el análisis de series temporales, es la visualización gráfica de la misma, figura 5.82. En ella, podemos observar un comportamiento cíclico para todos los años estudiados. En la figura 5.83. se presenta la función de autocorrelación $(\mathrm{ACF})$ de la serie inicial y en la figura 5.84., la función de autocorrelación parcial (PACF). En la primera de ellas, podemos observar una periodicidad clara de orden 52 , además de una alta correlación con los datos anteriores. La segunda, muestra, claramente, la gran influencia del valor anterior.

Como la identificación del modelo es un proceso exploratorio, la forma de proceder es un modelo tentativo, que se va modelando de forma iterativa e interactiva (Bizquerra, 1989). Así, con el fin de eliminar la autocorrelación con el dato anterior, se efectuó una diferenciación de 1. La figura 5.85., muestra la secuencia de la serie transformada, tras la diferenciación. En las figuras 5.86. y 5.87., se muestran los gráficos de autocorrelación y autocorrelación parcial de la serie transformada. Se ensayaron distintos modelos con estas series transformadas, pero los resultados no eran los adecuados, por lo que se procedió a considerar la ciclicidad de la serie, realizando una segunda diferenciación de orden 52. La figura 5.88., muestra la secuencia de la nueva serie transformada, y las figuras 5.89. y 5.90., las funciones de autocorrelación y autocorrelación parcial de esta nueva serie.

De los distintos modelos ensayados con la nueva serie, el que mejor resultado nos dio fue para los coeficientes $\mathrm{p}=0$ y $q=1 ; \mathrm{P}=0$ y $\mathrm{Q}=1$. Recordamos, que las diferencias aplicadas a la serie fueron, primero uno y después 52, obteniendo finalmente el modelo que se presenta en la tabla 5.116.

El hecho de que el modelo identificado sea adecuado, no debe hacer descartar la posibilidad, de que otro modelo algo más complejo pueda ajustarse mejor a la serie observada, por ello probamos modelos de órdenes superior al modelo original, obteniendo peores resultados que con el modelo presentado. 
El análisis de los residuales, es la pieza clave para efectuar un dianóstico del modelo, para ello, se analiza tanto los gráficos de autocorrelación como autocorrelación parcial de los residuales, así como sus estadísticos (Tabla 5.119.). Como puede observarse en las figuras 5.91. y 5.92., sólo los primeros retardos exceden el intervalo de confianza, y salvo el primero con valores bajos, para luego estar dentro en todos los valores dentro del intervalo señalado. Bisquerra (1989) acepta desviaciones de este tipo en los ejemplos que propone. Otra condición de los residuales es que la media sea cero, obteniendo en nuestro caso un valor de 0,17 . El conjunto de los resultados, nos han hecho considerar el modelo adecuado.

Finalmente, con el modelo obtenido se realizaron las predicciones semanales para el año 2000, presentando los resultados en la tabla 5.117., donde se muestra para cada fecha la media e intervalo de confianza al 95\% de las predicciones. Al construir un modelo predictivo, es conveniente dividir la serie en un modelo histórico o de estimación y un periodo de validación (Ferrán-Aranaz, 2001). Por ello, se construyó el modelo con los datos de los años 1994 a 1999, y se han comparado los resultados obtenidos con los datos reales del año 2000. La figura 5.93. muestra la representación gráfica de las concentraciones polínicas medias semanales registradas durante los años 1994 a 1999 y las predicciones realizadas para el año 2000, con el intervalo de confianza al 95\%.

La predicción presentada en la figura 5.93., parece adecuada, dando lugar a unos valores pronosticados, cuyos intervalos de confianza con un aspecto similar al de la serie. Sin embargo, en otros de los modelos que hemos ensayado hasta seleccionar este, los intervalos de confianza presentaban un comportamiento incompatible con el comportamiento teórico de la evolución de los pólenes. La silueta y los valores de los intervalos de predicción aportan información sobre los modelos ARIMA, dichos intervalos varían de modo notable de series estacionarias a no estacionarias. Uno de los mayores beneficios de los intervalos de confianza es su uso para decidir cuando un modelo está teóricamente, intuitivamente y prácticamente validado. Cuando el comportamiento de los intervalos es incosistente con nuestro conocimiento de la serie, el modelo debe ser reevaluado (DeLurgio, 1988).

En la figura 5.94. se han representado los valores reales del año 2000 y los valores pronosticados por el modelo. En la figura 5.95. se recoge el gráfico de 
dispersión de los valores pronosticados frente a los reales para el año 2000. En la tabla 5.118. se muestran los coeficientes de regresión y de determinación entre estas dos variables y los resultados de los test de diferencias de varianzas y medias realizados.

Cuando comparamos los datos reales del año 2000, con los datos predichos por el modelo, observamos que el modelo sobre estima los valores de polen (figura 5.94.), aunque reproduce los diferentes máximos de la serie con cierto adelanto. En el gráfico de dispersión, figura 5.95., se aprecia esta sobre estimación de las predicciones. En cuanto a los contrastes de diferencia de varianzas y de medias, no existen diferencias con significación estadística $(\alpha=0,05)$ entre las varianzas pero sí para los valores medios de los datos reales y de los predichos por el modelo. En cuanto a la correlación entre las dos variables encontramos un coeficiente de correlación de Pearson de 0,55, con significación al 99\%, y un coeficiente de determinación de 0,30, tabla 5.118.

En la tabla 5.119., se recogen los estadísticos descriptivos de las concentraciones de polen de los años 1994 a 1999, 1994 a 2000, las predicciones (1994-2000) y la de los residuales (1995-1999). La diferencia en el número de datos en cada caso, es debida a que el fichero de trabajo contiene como datos la media semanal, las concentraciones medias semanales de 1994 a 1999, hemos eliminado los datos del año 1993, ya que comenzaban en marzo. Las predicciones contienen 52 datos más que el fichero de partida, ya que incluye los valores del año $2000 \mathrm{y}$ los datos perdidos por el sistema son interpolados. Los residuales contienen 260 datos, correspondientes a los años 1995 a 1999, ya que se pierden los datos del primer año, al realizar la diferenciación de orden 52 y tampoco tenemos datos de residuales para el año 2000 , puesto que se trata de la predicción.

Podemos observar en la tabla 5.119., que los valores de la media para los pólenes 1994-1999 y las predicciones 1994-2000, son muy aproximados, mientras que para los datos reales 1994-2000, el valor medio disminuye, ya que al parecer se ha producido durante el año 2000 un recuento polínico mucho menor que en los años precedentes, también recordamos que el valor medio de los residuales se encuentra próximo a cero, dato que hemos tenido en cuenta a la hora de seleccionar el modelo.

Consideramos que la desviación del modelo es consecuencia de que estamos incluyendo en el mismo únicamente los valores de polen, que hemos podido comprobar 
a lo largo de este trabajo se encuentran fuertemente correlacionados con los parámetros meteorológicos. Hay sistemas en los que una o más variables independientes no estacionarias, variables de entrada, están relacionadas con una variable dependiente, llamada de salida. Estos modelos llamados MARIMA combinan los modelos ARIMA y los modelos de regresión múltiple (DeLurgio, 1998). Por ello, una de nuestras futuras líneas de trabajo se centrará en el desarrollo de modelos MARIMA, y de la posible mejora del modelo ARIMA propuesto mediante el análisis de intervención, introduciendo una variable independiente categórica, que puede producir una variación en la serie temporal (Bizquerra, 1989).

La modelización ambiental implica el uso de gran variedad de técnicas, que posiblemente en combinación, permitan elegir la más apropiada en cada caso, dependiendo de la complejidad del problema planteado y del grado de conocimiento que se tenga sobre el mismo. Cuando se tiene una adecuada fuente de datos, suficiente capacidad de computación, junto con un fuerte conocimiento teórico del problema, se estará en condiciones de desarrollar modelos numéricos (Gardner y Dorling, 1998). Sin embargo, en general, conforme la complejidad de un problema aumenta, nuestro conocimiento teórico disminuye y se hacen necesarios planteamientos estadísticos, que como hemos indicado se usan cada vez más frente a los modelos numéricos (Kolehmainen et al. 2001).

A lo largo de este trabajo hemos propuesto tres aproximaciones estadísticas al desarrollo de predicciones de las concentraciones de pólenes aerovagantes en la ciudad de Cartagena. La dispersión del polen es un acontecimiento natural de gran significación biológica (Comtois y Sherknies, 1991), con repercusión en la agricultura, en la evaluación ambiental y en medicina (Herrero y Fraile, 1997). Su modelización permitirá, además, alcanzar un mayor conocimiento de los principios y los procesos que la gobiernan (Comtois y Sherknies, 1991).

El comportamiento del polen aerovagante es un fenómeno complejo, así, cuando se estudia su variación a diferentes altitudes se encuentra que hasta los $200 \mathrm{~m}$ es la relación de mezcla el factor más importante, mientras que por encima de esta altitud la temperatura del aire gobierna las concentraciones de polen, sólo a las mayores altitudes la velocidad del viento tiene una clara influencia (Comtois et al., 2000). Cuando los estudios se centran a nivel de superficie, ya hemos indicado que el parámetro 
meteorológico más correlacionado es la temperatura, hecho que se confirma en nuestros modelos, ya que tanto en los modelos de regresión lineal múltiple, para los pólenes totales, como en los de regresión logística variables relacionadas con la temperatura quedan incorporadas, tan sólo en el modelo para el cluster 4 no aparece una variable predictora relacionada con la temperatura.

Es interesante destacar que, cuando en los modelos de regresión lineal múltiple se introducen variables de retardo y categóricas, pierde relevancia la temperatura media diaria apareciendo como variables predictoras las diferencias de temperatura máxima y mínima con un determinado retardo. Insistimos que la variable más correlacionada es la concentración de polen del día anterior, para el modelo de pólenes totales.

En los modelos de regresión lineal desarrollados para la segunda floración de las Chenopodiaceae-Amarnathaceae, la inclusión de las variables de retardo y categóricas, también comporta la pérdida de significación de la variable temperatura (en este caso máxima diaria), permaneciendo en el modelo únicamente variables de retardo de las concentraciones polínicas, salvo para los modelos por conglomerados en los que aparece la lluvia diaria para el cluster 2, y la presión máxima, los rumbos y la estación en el cluster 3 .

El modelo de regresión logística selecciona como variables predictoras la semana del año, variable categórica, y las variables numéricas temperatura máxima y diferencia entre la máxima y la mínima de cinco días antes. Estos modelos han dado un buen resultado, clasificando de un modo eficiente los días que se encuentran por debajo o por encima de un valor umbral, en nuestro caso la media aritmética de la distribución de polen estandarizada. En este estudio se han clasificado correctamente el 92,3\% de los datos del año 1999, que no han sido utilizados en el desarrollo del modelo.

En todos estos modelos es interesante encontrar un buen ajuste con poco número de variables de entrada, o predictoras (Soja y Soja, 1999), en nuestro trabajo, podemos observar como la aplicación de la clasificación por flujos de viento permite, en casi todos los casos, disminuir de modo importante el número de variables utilizadas en la predicción, para los modelos de regresión lineal múltiple, tanto en los desarrollados para los pólenes totales como para el segundo pico de Chenopodiaceae-Amaranthaceae. El 
modelo de regresión logística propuesto también incluye pocas variables predictoras, requiriendo únicamente estimaciones de las temperaturas en la zona.

Finalmente, el desarrollo de modelos basados en el análisis de series temporales implica la identificación de los componentes de tendencia y cíclicos (Salcedo et al., 1999). Componentes periódicos de alta frecuencia, los días anteriores, y un patrón anual, han sido puestos de manifiesto en nuestra serie. Sin embargo, los efectos de otras variables predictoras no han sido tenidos en cuenta, por lo que, al hacer predicciones, el modelo se aparta de la realidad.

Por todo ello, consideramos que en el estado actual de desarrollo de los modelos predictivos de las concentraciones de polen en la atmósfera de Cartagena, la herramienta más útil que podemos brindar a las autoridades sanitarias y medioambientales es el modelo de regresión logística, que incorporado a los sistemas de gestión permitiría alertar a la población sensible de los días en los que se producirán valores de concentración por encima del umbral desencadenante de sintomatología. 


\section{Capítulo 7 CONCLUSIONES}




\section{CAPÍTULO 7. CONCLUSIONES}

Del presente estudio realizado para la ciudad de Cartagena, en el periodo de 1993 a 1999, podemos destacar las siguientes conclusiones:

1.-Para el desarrollo de los modelos predictivos de la concentración polínica en la atmósfera de la ciudad de Cartagena se han creado, en soporte informático, bases de datos que combinan la información aeropalinológica con la información meteorológica de los años 1993 a 1999 (ambos inclusive), y se han generado las variables necesarias, tanto por transformación de los datos como variables de retardo.

2.-Se han descrito las principales características estacionales y horarias de las variables meteorológicas recogidas por la red de vigilancia de la contaminación atmosférica de la ciudad de Cartagena, combinadas con los datos de lluvia obtenidos de la estación Cartagena-Ciudad del Instituto Nacional de Meteorología, destacando en el periodo estudiado la baja pluviometría registrada, y cómo el efecto de barrera de las sierras litorales, condiciona la presencia de los flujos de viento del primer y tercer cuadrante, y el efecto chimenea, que supone la bocana del puerto a los vientos del sur y del norte, permitiendo en la torre meteorológica ubicada en el edificio administrativo del Ayuntamiento, registrar estas direcciones con la máxima frecuencia. Con relación a las velocidades del viento, cabe destacar el predominio de las brisas en la meteorología local.

3.- Aunque existe variabilidad en el estudio de las correlaciones lineales entre las concentraciones de pólenes totales y el tipo Chenopodiaceae-Amaranthaceae y las variables meteorológicas, para el conjunto de los datos, se ha encontrado que para los pólenes totales los coeficientes de correlación han sido significativos y negativos, con la presión media y humedad relativa media, y positivos y significativos, con la velocidad media del viento y la radiación solar acumulada. Para el conjunto del grupo 
Chenopodiaceae-Amaranthaceae, se han encontrado coeficientes de correlación positivos y significativos con la temperatura media, velocidad del viento, radiación solar acumulada, lluvia diaria, y negativa y significativa con la presión media y la humedad relativa. Repetido este análisis para el segundo pico de este grupo, se han encontrado coeficientes de correlación negativos y significativos con la presión media y con la humedad relativa.

4.- Se han realizado análisis de la varianza utilizando como factor distintas variables relacionadas con los parámetros meteorológicos, destacando el efecto de lavado de la lluvia encontrado para los pólenes totales, y el aumento de la concentración polínica total y del tipo Chenopodiaceae-Amaranthaceae con la disminución de la presión atmosférica, mientras que se ha encontrado un efecto contrario de la lluvia para este tipo polínico.

5.- Se han identificado cinco patrones de comportamiento de los flujos de viento mediante análisis de conglomerados en dos pasos. El primero recoge el 6,5\% de los casos y las direcciones predominantes son NNW y Norte. En el segundo, con un 24,7\% de los casos, predominan las direcciones SSW y Sur. El tercero, incluye el 7,2\% de los casos, siendo la dirección SSW la más frecuente. El cuarto, con un 14,5\% de los casos, recoge principalmente las direcciones Norte y NNE. El quinto conglomerado agrupa el $39,65 \%$ de los casos, destacando las bajas velocidades del viento y siendo las direcciones predominantes más difíciles de definir.

6.- Se han desarrollado modelos predictivos de las concentraciones polínicas de la atmósfera de Cartagena por regresión lineal múltiple sobre el total de los datos del periodo 1995 a 1998. A la vista del conjunto de los modelos desarrollados, consideramos suficiente la introducción de las variables meteorológicas y las de autocorrelación, aunque puede mejorar el análisis con la introducción de variables categóricas o la clasificación de los días por métodos estadísticos como el análisis de conglomerados. 
7.- El mejor modelo de regresión lineal múltiple, para la concentración polínica total, explica el $54 \%$ de la varianza total e incluye como variables predictoras la concentración de polen del día anterior, la humedad relativa mínima, el rango de la humedad relativa del día anterior, la concentración polínica de tres días antes, la velocidad media del viento, las diferencias de temperatura seis y cuatro días antes y la variable categórica rumbo del viento NNE. Cuando se repite este análisis para cada cluster, llegamos a explicar el $69 \%$ de la varianza total para el mejor ajuste, que corresponde al cluster 1 , y el $46 \%$ en el peor ajuste, que corresponde al cluster 4, destacando el menor número de variables predictoras que obtenemos para cuatro de los conglomerados.

8.- Repetido el mismo tratamiento para el segundo pico del tipo ChenopodiaceaeAmaranthaceae, en el mejor modelo general se explica el $61 \%$ de la varianza total, siendo las variables predictoras, las concentraciones de este tipo polínico el día anterior y tres días antes y la presión atmosférica máxima. Los modelos desarrollados para cada uno de los conglomerados, explican en el mejor de los casos el $84 \%$ de la varianza para el cluster 3 y en el peor el 40\%, para el cluster 1 .

9.- La validación de los modelos anteriores se ha efectuado con los datos del año 1999, comparando los valores predichos con los valores registrados en ese periodo, obteniendo en todos los casos buenos ajustes y estadísticos $\mathrm{F}$ y $\mathrm{t}$ que permiten aceptar la hipótesis nula de igualdad de varianzas y medias, respectivamente. Se ha omitido la validación para los modelos del tipo Chenopodiaceae-Amaranthaceae por conglomerados, dado el bajo número de datos en alguno de ellos.

10.- La aplicación de modelos de regresión logística, que permiten estimar la probabilidad de que la concentración polínica se encuentre cada día por debajo o por encima de un determinado valor (en nuestro caso, la media aritmética de la concentración polínica total estandarizada), ha dado buenos resultados, seleccionando, como más adecuado, el modelo que incluye como variables predictoras, la semana del 
año, la temperatura máxima diaria y la diferencia entre la temperatura máxima y mínima de cinco días antes, que clasifica correctamente el $84,7 \%$ de los casos. Las tres variables incluidas en el modelo constituyen factores de riesgo.

11.- Para la validación del modelo logístico, se ha aplicado el modelo para los días del año 1999, y comparado con los datos reales, siendo coincidentes en el 92,3\% de los casos, explicando el $80,5 \%$ de la variabilidad de las concentraciones polínicas del año 1999.

12. Mediante análisis de series temporales se ha desarrollado un modelo ARIMA $(0,1,1)$ $(0,1,1)_{52}$ para predecir las medias semanales de las concentraciones polínicas, utilizando como variable de entrada las medias semanales del periodo 1994 a 1999. La predicción obtenida para el año 2000, parece adecuada, reproduciendo el comportamiento en dientes de sierra típicos del primer periodo de polinización en nuestra ciudad y el segundo pico aislado, principalmente de Chenopodiaceae-Amaranthaceae.

13.- La validación del modelo ARIMA efectuada con los datos reales de las medias semanales de las lecturas del año 2000, indica una sobreestimación de los valores polínicos por parte del modelo y un pequeño adelanto de la estimación, existiendo diferencia estadísticamente significativa entre las medias de los valores predichos y reales.

14.- Del conjunto de modelos estadísticos desarrollados en la presente memoria, consideramos que la herramienta más útil que podemos brindar a las autoridades sanitarias y medioambientales es el modelo de regresión logística, que incorporado a los sistemas de gestión de la calidad del aire permitiría alertar a la población sensible de los días en los que se producirán valores de concentración por encima del umbral desencadenante de sintomatología polínica. 


\section{Capítulo 8 BIBLIOGRAFÍA}




\section{CAPÍTULO 8. BIBLIOGRAFÍA}

Aira, M.J; Dopazo, A; Jato, M.V. y Rodriguez, F.J. 1998. Aerobiología en Galicia: estación de Santiago de Compostela. Boletín de la REA 4: 107-110.

Akers, T. G.; Edmonds, R. L.; Kramer, C. L.; Lighthart, B.; McManus, M. L.; Schichting, H. E.; Solomon, Jr. A. M. y Spendlove, J. C. 1979. Modeling of Aerobiological Systems. En: Aerobiology: The Ecological Systems Approach. Ed. R. L. Edmonds. Dowden, Hutchingon \& Ross Inc. Pennsylvania: 11-84 .

Alba, M. F. 1996. Caracterización polínica de la atmósfera de Granada: relación con las variables meteorológicas y modelos predictivos de los taxones más alergogenos. Universidad de Granada. Departamento de Biología Vegetal. En: TESEO. Resúmenes de tesis doctorales. Ministerio de Educación y Ciencia.

Albizuri Churruca, A.; Navazo Muñoz, M.; Gutierrez-Cañas M. C.; Alonso Alonso, L. y Hierro Santacoloma, J. (1989). Cartagena: diseño y optimización de una red de vigilancia, e integración de emisiones industriales, para aplicación al diagnóstico y control de calidad del aire. En: Actas del I Congreso de Ingeniería Ambiental. Bilbao. 10 pp.

Alcázar, P; Galán, P; Cariñanos; P y Domínguez, E. 1998. Aerobiologia en Andalucía: estación de Priego de Córdoba (1995-1996). Boletín de la REA 3: 17-20.

Alergológica 1995. Factores epidemiológicos, clínicos y socioeconómicos de las enfermedades alérgicas en España. Sociedad Española de Alergología e Inmunología Clínica. Abelló S.A. Madrid. 358 pp.

Alergológica 2001. Asociación Española de Alergología e Inmunología Clínica.

Alloway, B. J. (1995) Soil Processes ant the behaviour of heavy metals. En: Heavy Metals in Soils. Ed. Alloway. Blackie Academic y Professional. London, 11-37.

Alonso, L.; Navazo Muñoz, M.; Albizuri Churruca, A.;Hierro Santacoloma, J. y M. Millán, (1989). Determinación experimental de áreas fuente y receptoras de contaminación atmosférica en función de sus patrones dispersivos característicos. En: Actas del I Congreso de Ingeniería Ambiental. Bilbao. 7 pp. 
Andersen, S. Th. 1974. Wind conditions and pollen deposition in a mixed deciduous forest I and II. Grana 14: 57-63.

Andersen, A. 1985. New sampler for the collection, sizing, and enumeration of viable airborne particles. J. Bact. 76: 471-484.

Andersen, T. B. 1991. A model to predict the beginning of the pollen season. Grana 30: 269-275.

Antépara, I.; Fernández, J. C.; Gamboa, P.; Jauregui, I. y Miguel, F. 1995. Pollen allergy in the Bilbao area (European Atlantic seaboard climate): pollination forecasting methods. Clinical and Experimental Allergy 25: 133-140.

Ariño, X. y Saiz-Jiménez, C. 1996. Colonization and deterioration processes in Roman mortars by cyanobacteria, algae and lichens. Aerobiología 12: 9-18.

Balling, R. C. 1984. Classification in climatology. Spatial Statistics and Models, G. L. Gaile and C. J. Willmot, Eds., Reidel, 81-108.

Bayo, J., 1998. Estudio de plomo, cadmio y cinc en dientes de leche de niños del municipio de Cartagena: desarrollo de modelos predictivos. Tesis Doctoral. Universidad de Murcia. Departamento de Ingeniería Química Cartagena. 352 pp.

Belchí-Hernández, J. 1998. Alergenicidad de Zygophyllum fabago L. Estudio aerobiológico, Clínico e Inmunológico. Tesis Doctoral. Universidad de Murcia. $233 \mathrm{pp}$.

Belmonte, J. y Roure, J.M. 1991. Characteristics of the aeropollen dynamics at several localities in Spain. Grana 30: 364-372.

Belmonte, J.; Roure, J.M.; Colás, C.; Duce, F. y Portillo, J.R. 1995(a). Aerobiología de Aragón: Zaragoza. Boletín de la REA 1: 51-55.

Belmonte, J.; Roure, J.M.; Botey, J. y Cadahía, A. 1995(b). Aerobiología en Catalunya: Pont de Suert, Girona, Bellaterra, Barcelona, Tarragona, Roquetes (Tortosa) y Lleida. Boletín de la REA 1: 87-102.

Belmonte, J.; Roure, J.M.; Cobo, R. y García, J. 1995 (c). Aerobiología en Cáceres. Boletín de la REA 1: 103-106. 
Bermejo, D.; García, A.M.; Sancho, P. y Valero, C. 1998. Aerobiología en Aragon: estación de Zaragoza. Boletín de la REA 4: 53-56.

Bisquerra, R. 1989. Introducción al análisis multivariante. Promociones y Publicaciones Universitarias. Barcelona. Vol. I: 397 pp. y Vol. II. 808 pp.

Blackmore, S. y Barnes S.H. 1986. Harmomegathic mechanisms in pollen grains. En: Pollen and Spores. Form and Function. S. Balckmore e I.K. Ferguson. Academic Press. London. 137-149.

Bortkiewicz, A.; Gadzicka, E. y Szymczak, W. 2001. Cardiovascular Disturbances in Workers Exposed to Carbon Disulfide. Applied Occupational and Environmental Hygiene 16(4): 455-463.

Brankov, E.; Trivikrama Rao, S. y Steven Porter, P. (1998). A trajectory-clustering correlation methodology for examining the long-range transport of air pollutants. Atmospheric Environment, 32(9): 1525-1534.

Bringfelt, B. 1979. Estudies of pollen concentration in Stockholm and weather data. En: Int. Conf. Aerobiol. Umweltbundesamt, Berichte. 5-79.

Bringfelt, B.; Engström, I. y Nilsson, S. 1982. An evaluation of some models to predict airborne pollen concentration from meteorological conditions in Stockholm, Sweden. Grana 21: 59-64.

Burleigh, J. R.; Edmonds, R. L.; Harrington, J. B.; Lighthart, Jr. B.; McCoy, R. E.; Mason, C. J.; Quentin, G. H.; Solomon, A. M. y Wallin, J. R. 1979. Modeling of Aerobiological Systems. En: Aerobiology: The Ecological Systems Approach. Ed. R. L. Edmonds. Dowden, Hutchingon \& Ross Inc. Pennsylvania. 279-371.

Cabezudo, B.; Recio, M.; Sánchez-Laulhé, J. M.; Trigo, M.; Toro, F. J. y Polvorinos, F., 1997. Atmospheric transportation of marihuana pollen from north Africa to the southwest of Europe. Atmospheric Environment 31: 3323-3328.

Cacho, J. y Sainz, M. J. 1989. La Antártida. El agujero de ozono. Tabapress. 250 pp.

Capel Molina, J. J. 1986. El clima del territorio de Cartagena. En: Historia de Cartagena. Tomo I. Murcia. Ediciones Mediterráneo. 170-192.

Cariñanos, P.; Alcázar, P.; Galán, C. y Domínguez, E. 1998. Aerobiología en 
Andalucia: estación de Chirivel (Almería). Boletín de la REA 4: 17-20.

Castells i Soler, T. 2000. Localització immunocitoquímica de les proteins al lergéniques en grans de pol.len de Zygophyllum fabago L. Tesis Doctoral. Universitat de Barcelona. 388 pp.

Cirillio, M. C.; Clerici, G. y Manzi, D. 1990. Atmospheric transport of sulphur dioxide on a local scale: a case study. En: Modelling in Ecotoxicology. Developments in Environmental. Modelling 16. Elsevier. Amsterdam. 173-195 pp.

Cole, E. C.; Foarde, K. K.; Leese, K. E.; Franke, D. L. y Berry, M. A. 1993. Biocontaminants in carpeted environments. Proceedings of Indoor Air 1993; 4: 351-256.

Comrie., A.C. y Yarnd, B. (1992). Relatinships between synoptic scale and atmospheric circulation and ozone concentrations in metropolitan Pittsburgh, Pennsylvania. Atmospheric Environment, 26B: 301-312.

Comtois, P. 1982. Histoire holocène du climat et de la végétation à Lanoraie (Québec). Can. J. Earth Sci. 19 (10): 1938-1952.

Comtois, P. 1997. Pollen dispersal and long distance transport: the case of thermophilic pollen in subarctic Canada. Aerobiología 13: 37-42.

Comtois, P. 1999. Spatial aerobiology. En: Libro Homenaje al Profesor Dr. Joaquín Moreno Clavel. Universidad de Murcia: Cartagena, 397-403.

Comtois, P. 2000. The gamma distribution as the true aerobiological probability density function (PDF). Aerobiologia 16: 171-176.

Comtois, P. y Schemenauer, R. S. 1991. Tree pollen viability in areas subject to high pollutant deposition. Aerobiología 7: 144-151.

Comtois, P. y Mandrioli, P. 1997. The aerobiological results from the 1994 cruise of the Urania (cnr) on the Adriatic. I. Pollen and spore counts on the Mediterranean sea as compared to mainland Italia. Aerobiología 12: 167-172.

Comtois, P. y Sherknies, D. 1991. Pollen Curves Typology. Grana 30: 184-189.

Comtois, P; Fernández-González, D.; Valencia-Barrera, R.M.; Sánchez, J.L.; Fraile, R. y Rodier, S. 2000. Pollen Content Study of the Lower Atmosphere in León 
(Spain) by use of a Tethered Ballon. Aerobiologia 16: 187-191.

Cooper-Arnold, K.; Moree, T.; Hodgson, M.; Pettigrew, C.; Wallace, R.; Clive, J. y Gasecki, J. 1999. Occupational Tuberculosis Among Deputy Sheriffs in Connecticut: A Risk Model of Transmission. Applied Occupational and Environmental Hygiene 14(11): 768-776.

Cost Action 615, 1995. Database, monitoring and modelling of urban air pollution. European Commision. Ed.: Schatzmann y Arend. Luxembourg. 10 pp.

Cour, P. y Villemour, P. 1985. Fluctuaciones des émissions polliniques atmosphériques et previtions des récoltes des fruits. 5éme colloque sur les recherches frutiéres, Bourdeaux, pp. 5-20.

Cristofolini, F. y Gottardini, E. 2000. Concentration of airborne pollen of Vitis vinifera L. and yield forecast: a case study at S. Michele all'Adige, Trento, Italy. Aerobiologia 16: 125-129.

Crutcher, H. L.; Rhodes, M. E.; Graves, M. E.; Fairbarn, B. y Nelson, A. L. 1986. Application of cluster analysis to aerometric data. J. Air Pollut. Control Assoc., 36: 1116-1122.

Currie, L., 1992. Source Apportionment of Atmospheric Particles. En: Environmental Particles. Volume 1. Jacques Buffle \& Herman P. Van Leeuwen (ed.). Boca Raton. 3-74.

D’Amato, G.; Liccardi, G.; Russo, M. y D’Amato, M. 2000. On the Interrelationship between Outdoor Air Pollution and Respiratory Allergy. Aerobiologia 16: 1-6.

Dahl, A. y Strandhede, S. 1996. Predicting the intensity of the birch pollen season. Aerobiologia 12: 97-106.

Davies, R. R. y Smith, L. P. 1973. Forecasting the start and severity of the hay fever season. Clinical Allergy, 3: 263-267.

Davis, R. E. y Kalkstein, L. S. 1990a. Development of an automated spatial synoptic climatological classification. International Journal of Climatology, 10: 769-794.

Davis, R. E. y Kalkstein, L. S. 1990b. Using a spatial synoptic climatological classification to assess changes in atmospheric pollution concentrations. 
Physical Geography, 11: 320-342.

DeLurgio, S. A., 1998. Forecasting principles and applications. Ed. McGraw-Hill. Boston. 802 pp.

De Nevers, N. 1998. Ingeniería de Control de la Contaminación del Aire. McGraw Hill. México. 546 pp.

Desiato, F. 1997. Classification of Air Pollutant Advections Fields through Cluster Analysis. En: Air Pollution V: Modeling, Monitoring and Management. Ed. H. Power, T. Tirabassi y C.A. Brebbia. Computational Mechanics Publications. Southampton, 433-442.

Díaz de la Guardia, C. y Blanca, G. 1994. Flora Ornamental de Granada: Polen e Incidencia en las Alergias. Universidad de Granada. Granada. 284 pp.

Díaz de la Guardia, C.; Alonso, R., Alba, F. y Valle, F. 1995. Airborne grass pollen in Granada (Spain). Aerobiologia 11. 47-50.

Díaz de la Guardia, C. y Alba, F. 1998. Aerobiología en Andalucía: estación de Granada. Boletín de la REA 4: 29-32.

Díaz de la Guardia, C.; Alba, F.; Girón, F. y Sabariego, S. 1998. An aerobiological study of Urticaceae pollen in the city of Granada (S. Spain): correlation with meteorological parameters. Grana 37: 298-304.

Di-Giovanni, F., Beckett, P. M. y Flenley, I. R. 1989. Modelling of dispersion and deposition of tree pollen within a forest canopy. Grana 28: 129-139.

Di-Giovanni, F. y Becket, P. M. 1990. On the mathematical modeling of pollen dispersal and deposition. Journal of Applied Meteorology 29: 1352-1357.

Domínguez-Rojas, V.; Astasio-Arbiza, P.; Ortega-Molina, P.; Gordillo-Florencio, E.; García-Núñez, J. A. y Bascones-Martínez, A. 1993. Analysis of several risks factors involved in dental caries through multiple logistic regression. International Dental Journal, 43: 149-156.

Domínguez Vilches, E. 1995. La Red Española de Aerobiología. Boletín de la REA 1: 37.

Domínguez-Vilches, E.; Cariñanos, P.; Galán, C.; Guerra, F.; Infante, F. y Villamandos, 
F. 1995. Airborne pollen concentrations, solid particle content in the air and allergy symptoms in Córdoba, Spain. Aerobiologia 11: 129-135.

Dorling, S. R. y Davis, T. D. y Pierce, C. E. 1992. Cluster analysis: A technique for estimating the synoptic meteorological controls on air and precipitation chemistry method and applications. Atmospheric Environmental, 26: 2575-2581.

Dorlin, S. R. y Davies, T. D. 1995. Extending cluster analysis synoptic meteorology links to characterise chemical climates at six northwest european monitoring stations. Atmospheric Environment, 29: 145-167.

Driessen, M. N. B. M.; Van Herpen, R.M.A. y Smithuis, L.O.M.J. 1990. Prediction of the start of the grass pollen season for the sourthern part of the Netherlands. Grana 29: 79-86.

Dutkiewicz, J.; Krysinska-Traczyk, E.; Skírska, C.; Sitkowska, J.; Prazmo, Z. y Urbanowick, B. 2000. Exposure of agricultural workers to airborne microorganisms and endotoxin during handling of various vegetable products. Aerobiologia 16: 193-198.

Eder, B. K., Davis, J. M. y Bloomfield, P. 1994. An automated classification scheme designed to better elucidate the dependence of ozone on meteorology. Journal of Applied Meteorology, 33: 1182-1199.

Edmonds, R.L. 1979. Introduction. En: Aerobiology: The Ecological Systems Approach. Ed. R. L. Edmonds. Dowden, Hutchingon \& Ross Inc. Pennsylvania, 1-10.

Elvira-Rendueles, B. 2001. Caracterización aeropalinológica del bioaerosol atmosférico de la ciudad de Cartagena. Tesis Doctoral. Universidad Politécnica de Cartagena. Departamento de Ingeniería Química y Ambiental. 421 pp.

Elvira Rendueles, B.; Moreno-Grau, S.; Angosto, J.M.; Bayo, J.; Moreno, J.M. у Moreno-Clavel, J., 1999. Variación anual de las esporas fúngicas del bioaerosol de Cartagena, año 1997. En: Libro Homenaje al Profesor Dr. Joaquín Moreno Clavel. Universidad de Murcia: Cartagena, 841-862.

Elvira-Rendueles, B.; Moreno-Grau, S.; Angosto, J.M.; Bayo-Bernal, J.; Moreno, J.M.y Moreno-Clavel, J. 2000. Evolución de los taxones Urticaceae, Cupressaceae, 
Chenopodiaceae-Amaranthaceae, Olea, Poaceae y Zygophylum en 6 años de muestreo aerobiológico en Cartagena (España) 1993/99. En: XIII Simposio de la APLE. Universidad Politécnica de Cartagena: Cartagena, pág. 43.

Emberlin, J. 1994. The effects of patterns in climate and pollen abundance on allergy. Allergy 49: 15-20.

Emberlin, J.; Savage, M. y Jones, S. 1993. Annual variations in grass pollen seasons in London 1961-1990: trends and forecast models. Clinical and Experimental Allergy 23: 911-918.

Emberlin, J. y Norris-Hill, J. 1996. The influence of wind speed on the ambient concentrations of pollen from gramineae, platanus, and betula in the air of London, England. En: Aerobiology : 27-38.

Environment y Systems, 1989. Estudio de dispersión de contaminantes atmosféricos, emisiones industriales y medidas correctoras a aplicar en la ciudad de Cartagena. Bilbao. 45 pp.

Estrela, M. J. y Millán, M. M. 1994. Manual Práctico de Introducción a la Meteorología. Centro de Estudios Ambientales del Mediterráneo. Valencia. pp.

Faegri, K. e Iversen, J. 1989. Textbook of pollen analysis. $4^{\mathrm{a}}$ ed. John Wiley \& Sons: Chichester. 328 pp.

Fairley, D. y Batchelder, G. L. 1986. A study of oak-pollen production and phenology in northern California: Prediction of annual variation in pollen counts based on geographic and meteorologic factors. J. Allergy Clin. Immunol. 78: 300-7.

Fernández González, D. 1990. Estudio del contenido de polen y esporas en la atmósfera de la ciudad de León. Tesis Doctoral. Universidad de León. León. 315 pp.

Fernández-González, D.; Suárez-Cervera, M.; Díaz-González, T. y Valencia-Barrera, R. M. 1993. Airborne pollen and spores of León (Spain). Int. J. Biometeorol.. 37: 89-95.

Ferranz-Aranaz, M. 2001. SPSS para Windows. Análisis estadístico. McGraw-Hill. Madrid. $421 \mathrm{pp}$.

Font Tullot, I. 1991. El hombre y su ambiente atmosférico. Instituto Nacional de 
Meteorología. Madrid.

Fornaciari, M.; Bricchi, E.; Greco, F.; Fascini, D.; Giannoni, C.; Frenguelli, G.; Romano, B. 1992. Daily variations of Urticaceae pollen count and influence of meteoclimatic parameters in East Perugia during 1989. Aerobilogia 8:407-413.

Fornaciari, M.; Pieroni, L.; Ciuchi, P. y Romano, B., 1998. A regression model for the start of the pollen season in Olea europaea. Grana 37: 110-113.

Foster, S. y Franz, Ch.R. 1995. Assessing Process Re-enguneering Impacts through Baselining. Benchmarking for Quality Management and Technology 2(3): 4-19.

Frankland, A. W. 1996. Aerobiology and allergy. An autobiography. Aerobiologia 12: 55-61.

Frenguelli, G.; Bricchi, E.; Romano, B.; Mincigrucci, G. y Spieksma, F. Th., 1989. A predictive study on the beginning of the pollen season for Gramineae and Olea europaea L. Aerobiologia 5: 64-70.

Galán, C. 1998. Introducción: La Red Española de Aerobiologia. Boletín de la REA 3: 5-6.

Galán, C.; Emberlin, J.; Domínguez, E., Bryant, R. H. y Villamandos, F. 1995. A comparative analysis of daily variations in the Gramineae pollen counts at Córdoba, Spain and London, UK. Grana 34: 189-198.

Galán, C.; Cariñanos, P.; Alcázar, P.; Infante, F.; Castro, A. y Domínguez, E. 1998. Aerobiología en Andalucía: estación de Córdoba. Boletín de la REA 4: 21-24.

Galán, C.; Alcázar, P.; Cariñanos, P.; García, H.; Domínguez-Vilches, E. 2000. Meteorological factors affecting daily Urticaceae pollen counts in southwest Spain. International Journal Biometeorology 43: 191-195.

Gardner, M. W. y R. Dorling, 1998. Artificial neural networks (the multilayer perceptron). A review of applications in the atmospheric sciences. Atmospheric Environment, 32: 2627-2636.

Georgopoulos, P. G. y Seinfeld, J. H. 1982. Statistical distributions of air pollutant concentrations. Environ. Sci. Technol. 7: 401-416.

Gil, F.; Facio, F.; Villanueva, E.; Pérez, M. L.; Tojo, R. y Gil, A. 1996. The association 
of tooth lead content with dental health factors. The Science of the Total Environment 192: 183-191.

Giostra, U., Mandrioli, P., Tampieri, F. y Trombetti, F. 1991. Model for pollen inmission and transport in the evolving convective boundary layer. Grana 30: 210-214.

Glassheim, J. W.; Ledoux, R. A. y Vaughan, T. R. 1995. Analysis of meteorologic variables and seasonal aeroallergen pollen counts in Denver, Colorado. Ann. Allergy, Asthma Immunol. 75:149-156.

Goldberg, C., Buch, H.; Moseholm, L. y Weeke, E. R. 1988. Airborne pollen records in Denmark, 1977-1986. Grana 27: 209-217.

González-Minero, F.J.; Candau, P. y González Romano, M.L. 1993. Variación estacional de esporas fúngicas en el aire de Huelva de abril de 1989 a abril de 1991. An. Asoc. Palinol. Leng. Esp. 6: 5-15.

González-Minero, F. J.; Candau, P.; Tomas, C. y Morales, J. 1997. Variación anual y estacional del polen de Urticaceae en el aire de Sevilla y su relación con los factores meteorológicos. Polen 8: 69-77.

González-Minero, G.; Candau, P.; Morales, J. y Tomas, C. 1998. Forecasting olive crop production based on ten consecutive years of monitoring airborne pollen in Andalucia (southern Spain). Agriculture, Ecosystems and Environment 69: 201215.

Grant Smith, E. 1990. Sampling and identifying allergenic pollen and molds. Vol. 11. Blewston Press: San Antonio (Texas). 196 pp.

Gregory, P. H. 1973. Microbiology of the atmosphere. $2^{\text {a }}$ Ed. Leonard Hill. U. K. 377 pp.

Hernández López, M. 1998. Técnicas de Clasificación: Medidas de Proximidad, Métodos de Agrupamiento y Validación de una Solución Cluster. Facultad de Ciencias Económicas y Empresariales. Universidad de la Laguna. 156 pp.

Herrero, B.; Fombella Blanco, M.A.; Fernández González, D. y Valencia Barrera, R.M. 1996(a). Aerobiological study of fungal spores from Palencia (Spain). 
Aerobiologia 12: 27-35.

Herrero, B.; Fombella-Blanco, M.A.; Fernández-González, D. y Valencia-Barrera, R.M. 1996(b). The role of meteorological factors in determining the annual variation of Alternaria and Cladosporium spores in the atmosphere of Palencia, 19901992. Int. J. Biometeorol. 39: 139-142.

Herrero, B. y Fraile, C. 1997. Annual Variation of Airborne Pollen in the City of Palencia, Spain, 1990-1992. Grana 36: 358-365.

Hies, T. ; Treffeisen, R.; Sebald, L. y Reimer, E. 2000. Spectral analysis of air pollutants. Part 1: elemental carbon time series. Atmospheric Environment (34): 3495-3502.

Hirst, J. M. 1952. An automatic volumetric spore trap. Ann. Appl. Biology 39: 257-265.

Hirst, J.M. 1994. Aerobiology at Rothamsted. Grana, 33: 66-70.

Hogrefe, C.; Rao, S. T. y Zurbenko, I. G. 1997. Detecting trends and biases in time series of ozonesonde data. Atmospheric Environment 32; 2569-2586.

Hopke, P. K. 1992. Factor and correlation analysis of multivariable environmental data. En : Methods of Environmental Data Analysis. C. N. Hewitt ed. Elsevier Applied Science. London. 139-180.

Hyde, H. A. y Adams, K. F. 1960. Airborne allegens at Cardiff, 1942-1959. Acta Allergol. 15 (7): 159-169.

Ibarra, G. I.; Alonso, L. y Navazo, M. 1993. Aplicación de la técnica "clustering" a datos de redes meteorológicas y de calidad de aire de superficie para la identificación de patrones dispersivos. Actas del III Congreso de Ingeniería Ambiental 1993. Bilbao. pp 67-78.

Iglesias, I.; Méndez, J. y Seijo, C. 1998. Aerobiología en Galicia: estación de Ourense. Boletín de la REA 4: 111-114.

Ip, W.H.; Fung, R. y Keung, K.W. 1999. An Investigation of Stochastic Analysis of Flexible Manufacturing Systems Simulation. Int. J. Adv. Manuf. Technol. 15: 244-250. 
Iribarne, J. V. y Godson, W. L. 1981. Atmospheric Termodinamic. Reidel Publishing Cia. Amsterdam.

Jäger, S., Nilsson, S., Berggren, B., Pessi, A.-M., Helander, M. y Ramfjord, H. 1996. Trends of some airborne tree pollen in the Nordic countries and Austria, 19801993. A comparison between Stockholm, Trondheim, Turku and Vienna. Grana $35: 171-178$.

Jørgensen, S. E., 1990. Modelling in Ecotoxicology. Developments in Environmental. Modelling 16. Elsevier. Amsterdam. 353 pp.

Jørgensen, S. E., 1991. Modelling in Environmental Chemistry. Developments in Environmental Modelling 17. Elsevier. Amsterdam. 505 pp.

Jørgensen, S. E., 1999. Environmental modelling at the edge of the third millennium. En: En: Libro Homenaje al Profesor Dr. Joaquín Moreno Clavel. Universidad de Murcia: Cartagena, 405-438.

Jørgensen, S. E. 2000. 25 Years of ecological modelling by Ecological Modelling. Ecological Modelling 126: 95-99.

Kaiser, R. y Maravall, A. 1999. Estimation of the Business Cycle: A Modified HodrickPescott Filter. Spanish Economic Review 1: 175-206.

Kalabokas, P. K. y Bartzis, J. G. 1998. Photochemical air pollution characteristics at the station on the NCSR-Dmokritos, during the MEDCAPHOT-Trace camping in Athens, Greece (20 august-20 september). Atmospheric Environment, 32 (12): 2123-2140.

Kalkstein, L. S. y Corrigan, P. 1986. A synoptic climatological approach for geographical analysis: Assesment of sulfur dioxide concentrations. Ann. Assoc. Amer. Geogr., 76: 381-395.

Kalkstein, T., G. T. y Skindlov, J. A. 1987. An evaluation of three clustering procedures for use in synoptic climatological classification. American Meteorological Society, 26: 717-730.

Kassomenos, P, Cortón, V. y Kallos, G. 1995. Analysis of the climatological and air quality observations from the greater Athens area. Atmospheric Environment, 
29: 3671-3688.

Kawashima, S. y Takahashi, Y. 1995. Modelling and simulation of mesoscale dispersion processes for airborne cedar pollen. Grana 34: 142-150.

Kelly, N.A., Wolff, G. T. y Ferman, M. A. 1982. Background pollutant measurements in air masses affecting the eastern half of the United States.- $i$ air masses arriving from the northwest. Atmospheric Environment, 16: 1077-1088.

Kiely, G. 1999. Ingeniería Ambiental: Fundamentos, Entornos, Tecnologías y Sistemas de Gestión. Mc Graw-Hill. Madrid. 1331 pp.

Kleeman, M. J. y Cass, G. R., 1999. Identifying the effect of individual emissions sources on particulate air quality within a photochemical aerosol processes trajectory model. Atmospheric Environment 33: 4597-4613.

Kolehmainen, M.; Martikainen, H. y Ruuskanen, J. 2001. Neural Networks and Periodic Components used in Air Quality Forecasting. Atmospheric Environment 35: 815-825.

Koutsoyiannis, D. 2000. A Generalized Mathematical Framework for Stochastic Simulation and Forecast of Hydrologic Time Series. Water Resources Research 36(6): 1519-1533.

Krimmel, J.T. y Mele, M. 1998. Investigating Stolen Vehicle Dump Sites. An Interrupted Time Series Quasi-experiment. Policing: An International Journal $f$ Police Strategies and Management 21(3): 479-489.

Lankford, P. M. y Semple, R. K. 1973. Classification by statistical methods. J. Appl. Meteor., 2: 56-65.

Larese, F.; Rizzi, L.; Sauli, M. L.; De Zotti, R. y Fiorito, A. 1992. The relationships between the concentrations of airborne pollen and allergic symptoms in Trieste (Northen Italy) in 1989. Aerobiología 8: 345-348.

Levetin, E. 1995. Fungi. En: Bioaerosols. Burge, H.A. (ed.) Indoor Air Research Series. Lewis Publishers. Boca Raton. 87-120.

Levetin, E.; Shaughnessy, R.; Fisher, E.; Ligman, B.; Harrison, J. y Brennan, T. 1997. Indoor air quality in schools: Exposure to fungal allergens. Aerobiologia 11: 27- 
34.

Lewis WH, V.P. 1979. North American pollinosis due to insect-pollinated plants. Ann. Allergy. 42: 309-319.

Lewis. W.H., V. P. y Zenger, V.E. 1983. Airborne and allergenic pollen of North America. The Johns Hopkins University Press. Baltimore. 254 pp.

Libro blanco: La asistencia alergológica en España, 1986. Sociedad Española de Alergia e Inmunologia Clínica. Madrid. 110 pp.

Márquez-Pereira, J. 1996. Estudio del componente palinológico de la atmósfera de Vitoria y su incidencia en la Salud Pública. Tesis Doctoral. Universidad de Barcelona. Barcelona. 358 pp.

Masters, G. M. 1991. Introduction to Environmental Engineering and Science. Prentice Hall. Englewood Cliffs. 460 pp.

McCartney, H. A. 1994. Physical factors in the dispersal of aerobiological particles. $5^{\text {th }}$ International Conference, Bangalore, 1994. Aerobiology. Editor : S. N. Agashe. pp. 439-450.

McCartney, H. A. y Fitt, B. D. L. 1985. Construction of dispersal models. In: Advances in Plant Pathology, Vol. 3: Mathematical Modelling of Crop Diseases. C. A. Gilligan (ed.), Academic Press, London. 107-143.

McDonald, M. S. 1980. Correlation of air-borne grass pollen levels with meteorological data. Grana 19:53-56.

McGough, T. y Tsolacos, S. 1995. Forecasting Commercial Rental Values Using ARIMA Models. Journal of Property Valuation and Investment 13(5): 6-22.

McQueen, J. T. And R. R. Draxler, 1994. Evaluation of model back trajectories of the Kuwait oil fires smoke plume using digital satellite data. Atmospheric Environment. 28: 2159-2174.

Melas, D.; Ziomas, I.; Klemm, O. y Jzerefos, C. S. 1998. Flow dynamics in Athens area under moderate large-scales winds. Atmospheric Environment, 32 (12): 22092222.

Milford, J. B. y Russell, A. G. 1993. Atmospheric models: atmospheric pollutant 
dynamics, meteorology and climate. En: . Environmental Modeling Vol. 1. Computer Methods and Software for Simulating Environmental Pollution and its Adverse Effects. Ed. P. Zannetti. Computational Mechanics Publications. Southampton. 11-74.

Millán, M. M.; Alonso, L. y Legarreta, J. A. 1986. Dispersión de contaminantes en la atmósfera: parte I. Energía, Julio-Agosto: 89-101.

Millán, M.; Artiñano, B.; Alonso, L.; Castro, M.; Fernández-Patier, R. y Goberna, J. 1992. Mesometeorological Cycles of Air Pollution in the Iberian Peninsula. Comission of the European Communities. Bruselas. 219 pp.

Monte, M. y Ferrari, R. 1993. Biodeterioration in subterranean environments. Aerobiología 9: 141-148.

Moore, P.; Webb, J. A. y Collinson, M. E. 1991. Pollen analysis. $2^{\text {a }}$ ed. Blackwell Scientific Publications. Oxford. 216 pp.

Morán, F. 1984. Apuntes de termodinámica de la atmósfera. Instituto Nacional de Meteorología. Madrid.

Moreno-Grau, J. M. 1998. Estudio de contaminantes fotoquímicos y sus precursores en la atmósfera de Cartagena. Tesis Doctoral. Universidad de Murcia. Departamento de Ingeniería Química y Ambiental. 475 pp.

Moreno-Grau, S.; García-Sánchez, A.; Moreno-Clavel, J.; Serrano-Aniorte; J. y Moreno-Grau, M. D. 1996. A mathematical model for waste water stabilization ponds with macrophytes and microphytes. Ecological Modelling 91: 77-103.

Moreno-Grau, S.; Bayo, J.; Elvira-Renduales, B.; Angosto, J. M.; Moreno, J. M. y Moreno-Clavel, J. 1998. Statistical evaluation of three years of pollen sampling in Cartagena, Spain. Grana 37: 41-47.

Moseholm, L., Weeke, E. R. y Petersen, B. N. 1987. Forecast of pollen concentrations of poaceae (Grasses) in the air by time series analysis. Pollen et Spores 29 (2-3): 305-322.

Muñoz, A.; Silva, I. y Tormo, R. 2000a. The relationships between Poaceae pollination levels and cereal yields. Aerobiologia 16: 281-286. 
Muñoz, A. F.; Silva, I.; Tormo, R.; Moreno, A. y Tavira, J. 2000b. Dispersal of Amaranthaceae and Chenopodiaceae pollen in the atmosphere of Extremadura (SW Spain). Grana 39: 56-62.

Nicholson, K. W. 1995. Physical aspects of bioaerosols sampling and deposition. En: Bioaerosols Handbook. C. S. Cox y C. M. Wathes. CRC Press. Boca Raton. 2753.

Norris-Hill, J. 1995. The modelling of daily Poaceae pollen concentrations. Grana 34: 182-188.

Norris-Hill, J. y Emberlin, J. 1993. The incidence of increased pollen concentrations during rainfall in the air of London. Aerobiología 9: 27-32.

O'Rourke, M. K. 1988. Relationships between airborne pollen concentrations and weather parameters in an arid environment. Editor. P. Comtois. Symposium, Aerobiology, 1888: 55-76.

Odgen, E.; Odgen, C.; Raynor, G. S.; Hayes, J. V.; Lewis, M. D. y Haines, J. H. 1974. Manual for sampling pollen. MacMillen, C. $325 \mathrm{pp}$

Oke, T. R. 1973. City size and the urban heat island. Atmospheric Environment 7: 769779.

Ong E.K., Singh, M.B. y Knox, R.B. 1995. Seasonal ditribution of pollen in the atmosphere of Melbourne: an airborne pollen callendar. Aerobiologia, 11: 51-55.

Östermark, R. 2000. The Forecasting Performance of Cartesian ARIMA Search and a Vector-valued State Space Model. Kybernetes 29(1): 83-103.

Pearce, J. y Ferrier, S. 2000. An evaluation of alternative algorithms for fitting species distribution models using logistic regression. Ecological Modelling, 128: 127147.

Pérez-Tornell, A. 1997. El aerosol atmosférico de Cartagena: Contenido en partículas totales en suspensión, plomo, cinc, cobre y cadmio, (1990-1994). Tesis Doctoral. Departamento de Ingeniería Química Cartagena. Universidad de Murcia. 313 pp.

Pryor, S. C., I. G. McKendry y D. G. Steyn, 1995. Synoptic-Scale meteorological variability and surface ozone concentrations in Vancouver, British Columbia. 
Journal of Applied Meteorology, 34: 1824-1833.

Rantio-Lehtimäki, A. 1995. Aerobiology of pollen and pollen antigens. En: Bioaerosols Handbook. Edited by: Cristopher S. Cox y Cristopher M. Wathes. Tokyo. 621 pp.

Rantio-Lehtimäki, A.; Linnea Helander, M. y Pesi, A. M. 1991. Circadiam periodicity of airborne pollen and spores significance of sampling height. Aerobiologia 7: 129-135.

Raynor, G. S. y Hayes, J. V. 1970. Experimental prediction of daily ragweed concentration. Annals of Allergy 28: 580-585.

Recio, M.; Cabezudo, B.; Trigo, M.M. y Toro, F.J. 1996. Olea europaea pollen in the atmosphere of Málaga (S. Spain) and its relationship with meteorological parameters. Grana 35: 308-313.

Regal, P. J. 1982. Pollination by wind and animals: Ecology of geographic patterns. Ann. Rev. Ecol. Syst. 13: 497-594.

Reible, D. D. 1998. Fundamentals of Environmental Engineering. Springer. Lewis Publishers. Boca Raton. 526 pp.

Reiss, N. M. y Kostic, S. R. 1976. Pollen season severity and meteorologic parameters in central New Jersey. J. Allergy Clin. Immunol. 6: 609-614.

Roscoe, B. A.; Hopke, P. K.; Dattner, S. L. y Jenks, J. M. 1982. The use of principal component factor analysis to interpret particulate compositional data sets. J. Air Pollut. Control Assoc. 32 (6): 637-642.

Roure, J. M. y Belmonte, J. 1988. Primeros resultados para el estudio de las relaciones entre la producción polínica y la producción de biomasa en las comunidades forestales. VI Simposio de Palinología A.P.L.E. Salamanca, pp. 205-209.

Sabariego, S.: Díaz de la Guardia, C.; Mota, J.F. y Alba, F. 2001. Principales tipos polínicos herbáceos en la atmósfera de Almería. En: Libro de textos completos del XIII Simposio de la APLE. Universidad Politécnica de Cartagena. Cartagena. 8 pp.(En prensa).

Sáenz-Laín, C. y Gómez-Ferreras, C. 2000. Mieles Españolas: Características e 
identificación mediante el análisis del polen. Ediciones Mundi-Prensa. Madrid. $163 \mathrm{pp}$.

Salcedo, R.L.R.; Alvim Ferraz, M.C.M.; Alves, C.A. y Martins, F.G. 1999. Time-series Analysis of Air Pollution Data. Atmospheric Environment 33: 2361-2372.

Schäppi, G.F.; Monn, Ch.; Wüthrich, B. y Wanner, H.U. 1996. Analysis of Allergens in Ambient Aerosols: Comparison of Areas Subjected to Different Levels of Air Pollution. Aerobiologia 12: 185-190.

Scheff, P. 2000. Time-Series analysis for environmental data. VI Curso Internacional de Modelización Aplicada al Medio Ambiente. 24 pp.

Sebald, L.; Renate, T.; Reimer, E. y Hies, T. 2000. Spectral analysis of air pollutants. Part 2: ozone times series. Atmospheric Environment 34: 3503-3509.

Seinfeld, J. H. y Pandis, S. N. 1998. Atmospheric Chemistry and Physics. From Air Pollution to Climate Change. John Wiley y Sons. New York.1326 pp.

Seoane-Camba, J. y Suárez-Cervera, M. 1986. On the ontogeny of the oncus in the pollen grain of Parietria officinalis L. (Urticaceae). Canadian Journal of Botany-Revue Canadienne de Botanique. 64(2): 3155-3167.

Sinclair, C. G. 1991. Cinética de los procesos microbianos. En: Biotecnología Básica. Editorial Acribia. S. A. Zagaroza. 75-127 pp.

Smart, I. J., Tuddenham, W. G. y Knox, B. 1979. Aerobiology of grass pollen in the city atmosphere of Melbourne: Effects of weather parameters and pollen sources. Aust. J. Bot., 27: 333-42.

Snowdon, A. L. 1990. A colour atlas of post-harvest. Diseases and disordes of fruits and vegetables. Vol 1: General introduction and fruits. Wolfe Scientific Ltd. Barcelona. 302 pp.

Snowdon, A. L. 1990. A colour atlas of post-harvest. Diseases anddisordes of fruits and vegetables. Vol. 2: Vegetables. Wolfe Scientific Ltd. Barcelona. 328 pp.

Soja, G y Soja, A.M. 1999. Ozone Indices Based on Simple Meteorological Parameters: Potentials and Limitations of Regression and Neural Networks Models. Atmospheric Environment 33: 4299-4307. 
Solomon, A. M. y Hayes, H. D. 1972. Desert pollen production I. Qualitative influence of moisture. J. Ariz. Acad. Sci. 7: 52-74.

Spedding, T.A. y Chan, K.K. 2000. Forecasting Demand and Inventory Management using Bayesian Time Series. Integrated Mnufacturing Systems 11(5): 331-339.

Spieksma, F. Th. M. 1992. Allergological aerobiology. Aerobiología, 8: 5-8.

Spieksma, F.Th. M. 1994. Calendars of fifteen airborne pollen types in twenty-one European Regions. En : Allergy Service Guide in Europe. De Nilsson and Spieksma. pp.: 56-94.

Spieksma, F. Th. M., Emberlin, J. C., Hjelmroos, M., Jäger, S. y Leuschner, R. M. 1995. Atmospheric birch (Betula) pollen in Europe: Trends and fluctuations in annual quantities and the starting dates of the seasons. Grana 34: 51-57

Stark, P. C., Ryan, L. M., McDonald, J. L. y Burge, H. A. 1997. Using meteorologic data to predict daily ragweed pollen levels. Aerobiología 13: 177-184.

Stephen, A. H. 1998. Atmospheric transport of freshwater algae Pediastrum in the American Southwest. Grana 37: 374-375.

Sterne, J. A. C.; Curtis, M. A.; Gillett, I. R.; Griffiths, G. S.; Maiden, M. F.; Eilton, J. M. y Johnson, N. W. 1990. Statistical models for data from periodontal research. J. Clin. Periodontal, 17: 129-137.

Steyaert, L. T. 1993. Environmental simulation modeling. En: Environmental Modeling with GIS. Ed. M. F. Goodchild. Oxford University Press. New York. 105-107.

Sthephen, A. H. 1998. Atmospheric transport of freshwater algae Pediastrum in the American Southwest. Grana 37: 374-375

Stooksbury, D. E. y P. J. Michaels, 1991. Cluster analysis of Southeastern U.S. climate stations. Theoretical and Applied Climatology, 44: 143-150.

Suárez-Cervera, M. 1996. Aerobiología. En: Atlas del polen de Galicia. Diputación de Orense: Ourense, 13-16.

Suárez-Cervera, M. y Márquez Pereira, J. 1990. El polen y las esporas en el ambiente. En: Manual de aerobiologia del País Vasco. Departamento de Productos Naturales, Biología Vegetal y Sanitaria y Edafología. Universidad de Barcelona. 
$148 \mathrm{pp}$.

Suárez-Cervera, M. y Seoane-Camba, J. 1983. Study of pollen content in the atmosphere of Barcelona according to a new filtration device. Collectanea Botanica 14: 587-615.

Suárez-Cervera, M.; Márquez-Pereira, J.; Martín, J.; Molero, J. y Seoane-Camba, J. 1995a. Structure of the apertural sporoderm of pollen grains in Euphorbia and Chamaesyce (Euphorbiaceae). Pl. Syst. Evol. 197: 111-122.

Suárez-Cervera, M.; Márquez-Pereira, J. y Seoane-Camba, J. 1995b. Pollen grain and Ubisch body development in Platanus acerifolia. Rev. Palaeobot. Palynol. 85: 63-84.

Suárez-Cervera, M.; Le Thomas, A.; Goldblatt, P.; Márquez-Pereira, J. y SeoaneCamba, J. 2000. The channelled intine of Aristea major: ultrastructural modifications during development, activation and germination. En: Pollen and Spores: morphology and biology (eds. M. Harley, C. M. Morton \& S. Blackmore). Royal Bot. Gard. Kew. En prensa.

Subiza, F. J.; Jerez, M.; Jiménez, J. A.; Narganes, M. J.; Cabrera, M.; Varela, S. y Subiza, E. 1995. Allergenic pollen and pollinosis in Madrid. J. Allergy Clin. Immunol. 96: 15-23.

Sutra, J. P. 1992. Climat et prevention des pollinoses: La prevision statistique de la date initiale de pollinisation du bouleau en France. Climat et Sante, 7: 53-84.

Thanikaimoni, G. 1986. Pollen apertures: form and function. En: Blackmore, S., I. K. Ferguson, (ed). Pollen and Spores: Form and Function. Academic Press, London. 119-136 pp.

Trigo, M. M. 1998. Incidencia del polen en España, resumen del año 1997. Boletín de la REA 4: 11-12.

Trigo, M.M.; Recio, M.; Toro, F. J. y Cabezudo, B. 1996. Intradiurnal fluctuations in airborne pollen in Málaga (S. Spain): A quantitative method. Grana 36: 39-43

Tse, R.Y.C. 1997. An Application of the ARIMA mmodel to real-estate prices in Hong Kong. Journal of Property Finance 8(2): 152-163. 
Turner, D. B. 1994. Atmospheric Dispersion Estimates. An introduction to dispersion modeling. Lewis Publishers. Boca Raton.

Udeni Alwis, K; Mandryk, J. y Hocking, A. D. 1999. Exposure to biohazards in wood dust: Bacteria, fungi, endotoxins and (1-3)- $\beta$-D-Glucans. Applied Occupational and Environmental Hygiene, 14 (9): 598-608.

Veleva, L.; Pérez, G. y Acosta, M. 1997. Statistical análisis of the temperature-humidity complex and time of wetness of a tropical climate in the Yucatán peninsula in México. Atmospheric Environment, 31 (59): 773-776.

Vinacua, B. 1997. Análisis estadístico con SPSS para Windows. Estadística básica. Madrid: McGraw-Hill. 304 pp.

Walter, S. D.; Feinstein, A. R. y Wells, C. K. 1990. A comparison of multivariable mathematical methods for predicting survival-II. Statistical Selection of prognostic variables. Journal Clinical Epidemiology 43: 349-359.

Wark, K. y Warner, C. F. 1990. Contaminación del Aire: Origen y Control. Limusa Noriega. México. 650 pp.

Watson, J.G. 1979. Chemical element balance receptor model methodology for assessing the sources of fine and total suspended matter in Porland, Oregon. Michigan. 428 pp.

Wayne, R. P. 1991. Chemistry of the atmospheres. Second Edition. Oxford Science Publications. Claredon Press. Oxford. 447 pp.

Willmott, C. J. y Vernon, M. T., 1980. Solar climates of the conterminous United States: A preliminary investigation. Sol. Energy, 24: 295-303.

Zannetti, P. 1993. Environmental Modeling Vol. 1. Computer Methods and Software for Simulating Environmental Pollution and its Adverse Effects. Computational Mechanics Publications. Southampton. 532 pp.

Zelenka, M. P. 1997. An analysis of the meteorological parameters afecting ambient concentrations of acid aerosols in uniontown, Pennsylvania. Atmospheric Environment, 31 (6): 869-878. 